\title{
Discovery of Novel Complex Metal Hydrides for Hydrogen Storage through Molecular Modeling and Combinatorial Methods
}

Gregory J. Lewis* (primary author), David A. Lesch*, J.W. Adriaan Sachtler*, John J. Low*, Craig M. Jensen, Vidvuds Ozolins, Don Siegel, and Laurel Harmon

UOP LLC, a Honeywell Company*

25 E. Algonquin Road

Des Plaines, IL 60017-5016

Phone: 847-912-9237; Fax: 408-980-1430; E-mail: gregory.lewis@uop.com

DOE Technology Development Manager: Carole Read

Phone: (202) 586-3152; Fax: (202) 586-9811; E-mail: Carole.Read@ee.doe.gov

DOE Project Officer: Jesse Adams

Phone: (303) 275-4954; Fax: (303) 275-4753; E-mail: Jesse.Adams@go.doe.gov

Subcontractors:

Laurel Harmon, Striatus Incorporated, Dexter, MI

Craig Jensen, Hawaii Hydrogen Carriers, Honolulu, HI

Vidvuds Ozolins, UCLA, Los Angeles, CA

Don Siegel, Ford Motor Co, Dearborn, MI

Contract Number: DE-FC36-04G014013

Project Start Date:

Project End Date:

Final Technical Report Date: $\quad 28$ February 2011
1 May 2004

30 June 2009 


\section{CONTENTS}

1. EXECUTIVE SUMMARY ..............................................

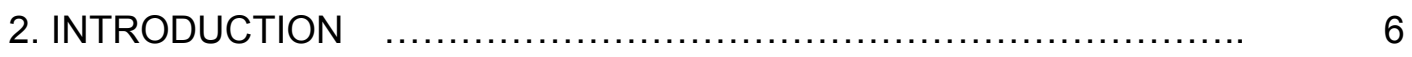

3. PROJECT OVERVIEW and SCOPE ................................. 9

4. ACCOMPLISHMENTS versus MILESTONES ...................... 13

5. EXPERIMENTAL and THEORETICAL METHODS and INFORMATICS 15

6. RESULTS AND DISCUSSION........................................ 17

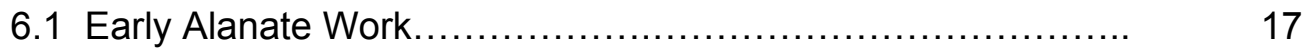

6.2 Beyond Alanates.......................................... 27

6.3 Alkali/Alkaline Earth Single Metallohydride plus Single Metal

Hydride Systems................................................ $\quad 40$

6.4 Binary Alanate and Amide plus Single Hydride Systems........ 50

6.5 Binary Metal Borohydride-Amide Systems................... 57

6.6 Ternary Amide-Alanate-Borohydride Systems.................. 62

6.7 Destabilization Reactions........................................ 65

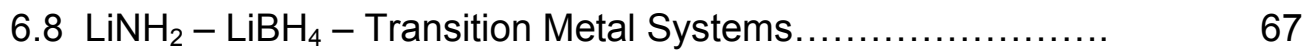

$6.9 \mathrm{LiNH}_{2}-\mathrm{LiBH}_{4}-$ Transition Metal Oxide Systems................. 79

6.10 High Throughput Synthesis of Hydrogen Storage Materials... 84

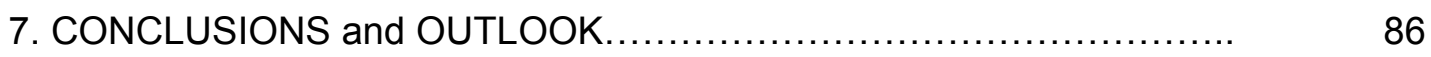

8. AWARD PRODUCTS GENERATED ............................... 90

9. VHTS COMPUTER MODELING SUMMARY ........................ 93

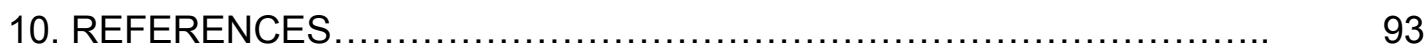

APPENDIX A - Medium and High Throughput Testing Equipment.......... 96

APPENDIX B - VHTS Details .............................................. 157

APPENDIX C - Informatics Details ..................................... 178

APPENDIX D - Synthesis and Hydrogen Storage Assay Data Tables....... 182

APPENDIX E - Detailed study of $2 \mathrm{LiNH}_{2}-\mathrm{MgH}_{2}-\mathrm{LiBH}_{4}$ System:

A Self-Catalyzing Hydrogen-Storage Material

APPENDIX F - First-principles determination of multicomponent hydride phase diagrams: Application to the Li-Mg-N-H system ....

APPENDIX G - Thermodynamic guidelines to the prediction of hydrogen storage reactions and their application to destabilized hydride mixtures. 


\section{EXECUTIVE SUMMARY}

UOP LLC, a Honeywell Company, Ford Motor Company, and Striatus, Inc., collaborated with Professor Craig Jensen of the University of Hawaii and Professor Vidvuds Ozolins of University of California, Los Angeles on a multi-year cost-shared program to discover novel complex metal hydrides for hydrogen storage. This innovative program combined sophisticated molecular modeling with high throughput combinatorial experiments to maximize the probability of identifying commercially relevant, economical hydrogen storage materials with broad application.

Metal hydrides for hydrogen storage.

A set of tools was developed to pursue the medium throughput (MT) and high throughput (HT) combinatorial exploratory investigation of novel complex metal hydrides for hydrogen storage. Before this project, the rate limiting step in the discovery of new hydrogen storage materials was the evaluation of the hydrogen storage capacity in a PCT (Pressure-Composition-Temperature) apparatus run at equilibrium, a test that takes a week. We developed two dynamic, non-equilibrium assays for hydrogen capacity that could evaluate either 8 (MT) or 48 (HT) samples in parallel in $2-4$ days, with the objective of quickly identifying promising materials for further detailed study. The apparatus was capable of hydrogenation ("hydriding") and dehydrogenation (via desorption) of samples up to $350{ }^{\circ} \mathrm{C}(\mathrm{HT})$.

The assay programs consisted of monitoring hydrogen evolution as a function of temperature. The desorption cycle proceeds from room temperature in a $2{ }^{\circ} \mathrm{C} / \mathrm{min}$ ramp to a maximum desorption temperature of $100-350{ }^{\circ} \mathrm{C}$, depending on the material. This was followed by a hydrogenation step to replenish the material (12 hr, the slow part), carried out at $100{ }^{\circ} \mathrm{C}-350{ }^{\circ} \mathrm{C}$, at hydrogen pressures of $87-120$ bar, again depending on the material. Typically two to four desorption/hydriding cycles would be carried out on each set of samples. Subject to the conditions employed, this apparatus made it possible to identify reversible hydrogen storage materials and distinguish them from materials that undergo slow continuous desorption. Information gleaned from the capacity tests were supplemented with structural information collected on the assynthesized materials and the spent materials recovered from the assay via HT powder XRD. This helped explain much of the observed chemistry (such as verifying hydrogen releases during synthesis and testing, lack of reactivity, ion-exchange reactions, etc.) and identified active species in hydrogen storage reactions. Tools for facilitating parallel sample handling were also developed for processing samples (e.g., loading reactors, milling). All of these tools were developed to handle the air and water sensitive materials that are innate to this project.

This project also incorporated theoretical methods to help select candidate materials families for testing. The Virtual High Throughput Screening served as a virtual laboratory, calculating structures and their properties. First Principles calculations were applied to various systems to examine hydrogen storage reaction pathways and the associated thermodynamics. The first system studied experimentally was the $\mathrm{NaAlH}_{4}$ $\mathrm{LiAlH}_{4}-\mathrm{Mg}\left(\mathrm{AlH}_{4}\right)_{2}$ phase diagram, which was used in part to validate the MT and HT hydrogen capacity assays. The VHTS study on this system showed that two mixed alanates were more stable than the individual alanates, but each of these were unstable with respect to losing hydrogen at room temperature. This was consistent with the experimental results as no new mixed alanates were observed.

First principles calculations were applied to the $\mathrm{Li}-\mathrm{Mg}-\mathrm{N}-\mathrm{H}$ phase diagram as several of the components, including $\mathrm{Li}_{2} \mathrm{Mg}(\mathrm{NH})_{2}$ and $\mathrm{Mg}\left(\mathrm{NH}_{2}\right)_{2}$ were found to be the functioning hydrogen storage materials in the $\mathrm{LiNH}_{2}-\mathrm{LiBH}_{4}-\mathrm{MgH}_{2}$ system studied 
experimentally. The calculations were able to reproduce all of the known structures in this well-studied system and calculate the various hydrogen storage reactions that occur between these species. First Principles calculations were also applied to the realm of "destabilized reactions," in which two different hydrogen storage materials are driven to release hydrogen more efficiently together than by themselves via the formation of an inter-species compound, for example, $2 \mathrm{LiBH}_{4}+\mathrm{MgH}_{2} \leftrightarrow \mathrm{MgB}_{2}+2 \mathrm{LiH}+3 \mathrm{H}_{2}$. In this case, the formation of $\mathrm{MgB}_{2}$ destabilizes both $\mathrm{LiBH}_{4}$ and $\mathrm{MgH}_{2}$, enhancing $\mathrm{H}_{2}$ desorption. First Principles calculations identified several destabilization reactions, such as $2 \mathrm{LiBH}_{4}$ $+\mathrm{Cr} \leftrightarrow \mathrm{CrB}_{2}+2 \mathrm{LiH}+3 \mathrm{H}_{2}$ and $2 \mathrm{LiBH}_{4}+\mathrm{TiH}_{2} \leftrightarrow \mathrm{TiB}_{2}+2 \mathrm{LiH}+4 \mathrm{H}_{2}$ as thermodynamically favorable reactions. These were tested in the MT assay, but didn't give the desired products, because the kinetics of the reaction were too sluggish under our test conditions. This indicates a situation where a catalyst would have to be found to enable the hydrogen storage reactions under more favorable conditions.

The experimental program began with the validation of the MT assay tool with $\mathrm{NaAlH}_{4} / 0.02$ mole Ti, the state of the art hydrogen storage system given by reaction $\mathrm{A}$ :

$$
\mathrm{NaAlH}_{4} \leftrightarrow \mathrm{NaH}+\mathrm{Al}+3 / 2 \mathrm{H}_{2}
$$

The MT assay consisted of two desorptions to $240{ }^{\circ} \mathrm{C}$, with a hydriding step in between $\left(125^{\circ} \mathrm{C}, 87\right.$ bar $\left.\mathrm{H}_{2}\right)$. Once certified, a combinatorial 21-point study of the $\mathrm{NaAlH}_{4}-\mathrm{LiAlH}_{4}$ $-\mathrm{Mg}\left(\mathrm{AlH}_{4}\right)_{2}$ phase diagram was investigated with the MT assay. Since both $\mathrm{LiAlH}_{4}(8.0$ $\%)$ and $\mathrm{Mg}\left(\mathrm{AlH}_{4}\right)_{2}(7.0 \%)$ have higher hydrogen contents and are less stable than $\mathrm{NaAlH}_{4}$ (5.6 wt. \%), a hydrogen storage material based on a Na-Li-Mg mixed alanate would be an improvement over $\mathrm{NaAlH}_{4}$ and could possibly meet the DOE target of 6.5 wt. $\% \mathrm{H}_{2}$. Stability proved to be a problem as many of the materials decomposed during synthesis, altering the expected assay results. This resulted in repeating the entire experiment with a mild milling approach, which only temporarily increased capacity. $\mathrm{NaAlH}_{4}$ was the best performer in both studies and no new mixed alanates were observed, a result consistent with the VHTS. Powder XRD suggested that the reverse reaction, the regeneration of the alanate from alkali hydride, $\mathrm{Al}$ and hydrogen, was hampering reversibility. The reverse reaction was then studied for the same phase diagram, starting with $\mathrm{LiH}, \mathrm{NaH}$, and $\mathrm{MgH}_{2}$, and $\mathrm{Al}$. The study was extended to phase diagrams including $\mathrm{KH}$ and $\mathrm{CaH}_{2}$ as well. A strong cation effect was revealed in which the lower the charge density of the alkali/alkaline earth cation, the easier the reverse or rehydriding reaction, hence $\mathrm{K}^{+}>\mathrm{Na}^{+}>>\mathrm{Ca}^{2+}, \mathrm{Li}^{+}$, and $\mathrm{Mg}^{2+}$. This is just the opposite of the trend in the desorption reaction, where $\mathrm{KAlH}_{4}$, while easily formed during hydriding, barely desorbs hydrogen even up to $350{ }^{\circ} \mathrm{C}$. Like the mixed alanate study, no new mixed alanates were found in the reverse reaction study. Both forward and reverse alanate reaction studies revealed a number of aluminum hexahydrides, including $\mathrm{Li}_{3} \mathrm{AlH}_{6}$, $\mathrm{Na}_{3} A l H_{6}, \mathrm{LiNa}_{2} \mathrm{AlH}_{6}, \mathrm{~K}_{2} \mathrm{NaAlH}_{6}$, and $\mathrm{K}_{3} A \mathrm{AlH}_{6}$, of which only $\mathrm{Na}_{3} \mathrm{AlH}_{6}$ and $\mathrm{LiNa}_{2} \mathrm{AlH}_{6}$ were reversible. Alkaline earths $\mathrm{Mg}$ and $\mathrm{Ca}$ never participated in the formation of $\mathrm{Al}$ hexahydrides. The observed hydrogen storage capacity in the Al hexahydrides was less than $4 \mathrm{wt}$ \%, well short of DOE targets.

The HT assay came on line and after certification with studies on $\mathrm{NaAlH}_{4}$, was first applied to the $\mathrm{LiNH}_{2}-\mathrm{LiBH}_{4}-\mathrm{MgH}_{2}$ phase diagram. Selected compositions within the three binary subsystems had been studied: $2 \mathrm{LiNH}_{2}-\mathrm{MgH}_{2}{ }^{1,2}, 2 \mathrm{LiBH}_{4}-\mathrm{MgH}_{2}{ }^{3}$ and $2 \mathrm{LiNH}_{2}-\mathrm{LiBH}_{4}{ }^{4}$ The 60 -point study elucidated trends within the system locating an optimum material of $0.6 \mathrm{LiNH}_{2}-0.3 \mathrm{MgH}_{2}-0.1 \mathrm{LiBH}_{4}$ that stored about 4 wt. \% $\mathrm{H}_{2}$ reversibly and operated below $220^{\circ} \mathrm{C}$. Powder x-ray diffraction showed that the operating hydrogen storage reaction in this system was that observed in the $2 \mathrm{LiNH}_{2}+$ $\mathrm{MgH}_{2}$ system: 


$$
2 \mathrm{LiH}+\mathrm{Mg}\left(\mathrm{NH}_{2}\right)_{2} \leftrightarrow \mathrm{Li}_{2} \mathrm{Mg}(\mathrm{NH})_{2}+2 \mathrm{H}_{2}
$$

Also present was the phase $\mathrm{Li}_{4}\left(\mathrm{NH}_{2}\right)_{3} \mathrm{BH}_{4}$, which had been discovered in the $\mathrm{LiNH}_{2}$ $\mathrm{LiBH}_{4}$ system. ${ }^{4,5}$ This new ternary formulation performed much better than the wellknown $2 \mathrm{LiNH}_{2}-\mathrm{MgH}_{2}$ system by $50{ }^{\circ} \mathrm{C}$ in the $\mathrm{HT}$ assay. The $\mathrm{Li}_{4}\left(\mathrm{NH}_{2}\right)_{3} \mathrm{BH}_{4}$ is a low melting ionic liquid under our test conditions and facilitates the phase transformations required in the hydrogen storage reaction, which no longer relies on a higher energy solid state reaction pathway. Further study showed that the $0.6 \mathrm{LiNH}_{2}-0.3 \mathrm{MgH}_{2}-0.1$ $\mathrm{LiBH}_{4}$ formulation was very stable with respect to ammonia and diborane desorption, the observed desorption was from hydrogen. This result could not have been anticipated and was made possible by the efficiency of HT combinatorial methods.

Investigation of the analogous $\mathrm{LiNH}_{2}-\mathrm{LiBH}_{4}-\mathrm{CaH}_{2}$ phase diagram revealed new reversible hydrogen storage materials $0.625 \mathrm{LiBH}_{4}+0.375 \mathrm{CaH}_{2}$ and $0.375 \mathrm{LiNH}_{2}+$ $0.25 \mathrm{LiBH}_{4}+0.375 \mathrm{CaH}_{2}$ operating at 1 wt. \% reversible hydrogen below $175^{\circ} \mathrm{C}$.

Powder $\mathrm{x}$-ray diffraction revealed a new structure for the spent materials which had not been previously observed. While the storage capacity was not impressive, an important aspect is that it boron appears to participate in a low temperature reversible reaction.

The motivation to activate B-based materials is due to the high gravimetric capacity associated with $\mathrm{LiBH}_{4}\left(18.5 \mathrm{wt} . \% \mathrm{H}_{2}\right)$. While alkali borohydrides release hydrogen at high temperatures $\left(>300^{\circ} \mathrm{C}\right)$, transition metal borohydrides are comparatively unstable, sometimes evolving hydrogen below room temperature. An effort was made to make mixed alkali-transition metal borohydrides via the reaction:

$$
\begin{array}{r}
\mathrm{MCl}_{\mathrm{x}}+(\mathrm{X}+\mathrm{Y}) \mathrm{M}^{\prime} \mathrm{BH}_{4} \underset{\mathrm{M}}{\longrightarrow}=\text { transition metal, } \mathrm{M}^{\prime}=\text { Group I metal } \\
\mathrm{M}^{\prime} \mathrm{M}^{\prime}\left(\mathrm{BH}_{4}\right)_{\mathrm{x}+\mathrm{y}}+\mathrm{MCl}
\end{array}
$$

Transition metals investigated included $\mathrm{Zn}, \mathrm{Co}, \mathrm{Fe}, \mathrm{Cr}, \mathrm{Cu}, \mathrm{Ni}, \mathrm{Sc}, \mathrm{V}$ and Ti. The chemistry was still problematic as many of the transition metal borohydrides were not stabilized and decomposed during milling, evolving hydrogen. A key result was a new material of composition $4 \mathrm{LiBH}_{4}+\mathrm{CuCl}_{2}$ was found to reversibly store about $1.5 \mathrm{wt}$. \% $\mathrm{H}_{2}$, operating up to $150{ }^{\circ} \mathrm{C}$. While the storage capacity is again very short of DOE targets; the results imply that $B$ had been activated in a low temperature reversible material.

The last major area of study also focused on activating boron-based materials in order to exploit the tremendous gravimetric capacity of $\mathrm{LiBH}_{4}$. A number of $\mathrm{LiNH}_{2}-$ $\mathrm{LiBH}_{4}$ - transition metal (TM) systems were investigated for the following reasons:

- Excellent gravimetric capacity of $\mathrm{LiNH}_{2}$ (8.8 wt. \%) and $\mathrm{LiBH}_{4}(18.5$ wt. \%)

- Ability of $\mathrm{LiNH}_{2}-\mathrm{LiBH}_{4}$ mixtures to form ionic liquids, which can lower the temperature of hydrogen storage reactions

- Ability of $\mathrm{LiNH}_{2}-\mathrm{LiBH}_{4}$ to form mixed salts, such as $\mathrm{Li}_{4}\left(\mathrm{NH}_{2}\right)_{3} \mathrm{BH}$ that might extend to other metals besides $\mathrm{Li}$ and provide a matrix to help stabilize TM borohydrides

The study included a variety of transition metals introduced as chlorides and in some cases as oxides. While $\mathrm{Co}$ and $\mathrm{Ni}$ showed good desorption properties $\left(>5 \mathrm{wt} . \% \mathrm{H}_{2}\right)$, the materials were not reversible. The same was true for $\mathrm{V}_{2} \mathrm{O}_{5}$. Many materials, such as those based on $\mathrm{Zn}, \mathrm{Mn}$ and $\mathrm{Zr}$ were still too reactive, evolving hydrogen during synthesis.

Another major project activity was the assembly of a high throughput synthesis system. The automated synthesizer was set up in a glovebox and was capable of 
handling liquids and powders and carrying out sealed block syntheses up to $250{ }^{\circ} \mathrm{C}$. Unfortunately, the synthesizer could not handle the delivery of the fine powders required fro hydrogen storage applications. Although the powder delivery system was overhauled and redesigned several times, this problem was never remedied.

Technical effectiveness and economic viability. The high throughput combinatorial approach did not in this instance deliver a new hydrogen storage material that meets DOE targets. However, there is no question of the value of this approach:

- Fast and effective, can cover much more ground than in conventional methods, by up to a factor of 50 in the case of this study

- Wealth of information, can better elucidate trends in the chemistry because more points can be studied

- Experimental freedom to explore beyond one's biases and to include extra experiments due to the experimental efficiency - a case in point is our study of the $\mathrm{LiNH}_{2}-\mathrm{LiBH}_{4}-\mathrm{MgH}_{2}$ phase diagram. The 60 point study is impossible by conventional methods, but accessible by $\mathrm{HT}$ methods and allowed us to discover the unanticipated role of the $\mathrm{Li}_{4}\left(\mathrm{NH}_{2}\right)_{3} \mathrm{BH}_{4}$ ionic liquid in the $\mathrm{Mg}\left(\mathrm{NH}_{2}\right)_{2}+$ $2 \mathrm{LiH} \leftrightarrow \mathrm{Li}_{2} \mathrm{Mg}(\mathrm{NH})_{2}+2 \mathrm{H}_{2}$ reaction

- The leads uncovered by HT combinatorial methods can then be studied in detail by conventional methods

For the expenditure of research dollars, the HT approach is the most efficient way to investigate a problem if it can be implemented.

Theory also works well with HT combinatorial processes because the HT approach provides a wealth of data to test the theory. A feedback loop that can enhance both theory and experimentation can be the result.

Public benefit. The key objective of this program was to drive toward hydrogen storage systems which meet or exceed the stated DOE performance targets and therefore have the potential to both improve U.S. energy security through reduced dependence on foreign energy sources and to diminish environmental impacts from greenhouse gases.

\section{INTRODUCTION}

A major difficulty in the utilization of hydrogen as a transportation fuel is onboard hydrogen storage. This has prompted an extensive effort to develop solid hydrogen storage systems for vehicular application. Intermetallic hydrides long have been investigated as hydrogen carriers. However, despite decades of research no member of this class of hydride was found that had the combination of a high gravimetric hydrogen density, adequate hydrogen dissociation energetics, and low cost required for commercial vehicular application. ${ }^{6,7}$ In 1995, Bogdanovic discovered that mixing the solid sodium alanate $\left(\mathrm{NaAlH}_{4}\right)$ with a few mole percent of selected transition metal complexes accelerates and renders reversible the elimination of hydrogen under moderate conditions. ${ }^{8}$ This was a revolutionary discovery as the reversible elimination of hydrogen at moderate temperatures was unprecedented for saline hydrides. The hydrogen cycling performance of doped $\mathrm{NaAlH}_{4}$ has since been the subject of intensive investigation. $9,10,11,12,13,14,15,16,17,18,19,20$ These studies have led to considerable practical 
improvements and it now appears that titanium doped $\mathrm{NaAlH}_{4}$ approaches the threshold requirements of a practically viable means for the onboard storage of hydrogen. ${ }^{11,12,15,17,18}$

Immediately following Bogdanovic's disclosure of his discovery, it was anticipated that alternative dopants and counter ions for the $\left[\mathrm{AlH}_{4}{ }^{-}\right]$complex could be identified that would further improve dehydriding kinetics and thermodynamic properties. In 1998, Zidan and Jensen discovered that mechanical doping of $\mathrm{NaAlH}_{4}$ improves dehydriding kinetics such that the onset of rapid dehydrogenation occurs at $100{ }^{\circ} \mathrm{C}$ (vs. $150{ }^{\circ} \mathrm{C}$ ) and stabilizes a 4.2 weight $\%$ hydrogen cycling capacity. ${ }^{10}$ They also found that kinetic enhancement of the two step dehydriding process and its reverse is achieved with $\mathrm{Ti} / \mathrm{Zr}$ "dual doped" hydride. ${ }^{11}$ Despite these improvements and others that have been made in engineering a practical hydrogen storage system based on titanium doped $\mathrm{NaAlH}_{4}{ }^{18}$ no dopant precursors have been found to date that result in kinetic enhancement beyond those cataloged in Bogdanovic's original 1995 patent. $^{8}$ Similarly, no aluminum tetrahydride other than the sodium salt has been found to undergo largely reversible dehydriding under moderate conditions upon doping. Three aluminum hexahydrides containing $\mathrm{Na}$ and $\mathrm{Li}\left(\mathrm{Na}_{3} \mathrm{AlH} \mathrm{H}_{6}, \mathrm{Na}_{2} \mathrm{LiAlH}_{6}\right.$ and $\left.\mathrm{Li}_{3} A \mathrm{AlH}_{6}\right)$ have been found to be reversible. Unfortunately these hydrides contain less or equal reversible hydrogen than $\mathrm{NaAlH}_{4}$.

This lack of progress is surprising in view of the recent "gold rush" flurry of activity that has been direct towards the development of alanates as practical onboard hydrogen carries. Clearly, these efforts have been handicapped by the dearth in the understanding of the nature and mechanism of action of the dopants. This situation has recently changed as X-ray diffraction, ${ }^{21}$ nuclear magnetic resonance, ${ }^{22}$ and electron spin resonance studies ${ }^{23}$ and ${ }^{57} \mathrm{Fe}$ Moessbauer ${ }^{9}$ have began to elucidate the structural changes that occur upon doping. The results of these studies clearly indicate that, contrary to prior speculation, ${ }^{9,13,16,19}$ the dopants are not segregated, surface localized species but are instead substituted into $\mathrm{Na}^{+}$sites throughout the bulk hydride lattice. The introduction of $\mathrm{M}^{3+}$ cations necessitates the creation of two $\mathrm{Na}^{+}$vacancies in the hydride in order to maintain charge neutrality. Detailed characterization examining different methods of dopant introduction will further elucidate the exact nature of the site modification for the $\mathrm{Al}, \mathrm{H}, \mathrm{Na}$ and dopant. Thus, in addition to the remarkable enhancement of dehydrogenation kinetics that arise upon doping $\mathrm{NaAlH}_{4}$, the bulk substitution of sodium in the hydride should have a very significant effect on the thermodynamic properties of the hydride as well.

In light of this new model of the doped hydrides, we proposed a renewed search for complex hydrides and other saline hydrides with improved hydrogen storage properties. "The complex hydrides are a large group of compounds in which hydrogen is combined in fixed proportions with two other constituents, generally metallic elements. These compounds have the general formula $\mathrm{M}\left(\mathrm{M}^{\prime} \mathrm{H}_{4}\right)_{n}$, where $n$ is the valence of $\mathrm{M}$ and $\mathrm{M}^{\prime}$ ' is a trivalent Group 3 (IIIA) element, such as boron, aluminum, or gallium." ${ }^{24}$ For the purposes of this work, we extended the definition of complex hydrides to include the hexahydrides $\left[\mathrm{M}\left(\mathrm{M}^{\prime} \mathrm{H}_{6}\right)_{\mathrm{n} / 3}\right]$. The thermodynamics for hydrogen desorption from $\mathrm{NaAlH}_{4}$ is outside the target range of this work. The decomposition of $\mathrm{NaAlH}_{4}$ is a two step process:

$$
\begin{aligned}
& 3 \mathrm{NaAlH}_{4} \leftrightarrow \mathrm{Na}_{3} \mathrm{AlH}_{6}+2 \mathrm{Al}+3 \mathrm{H}_{2} \\
& \mathrm{Na}_{3} \mathrm{AlH}_{6} \leftrightarrow 3 \mathrm{NaH}+\mathrm{Al}+3 / 2 \mathrm{H}_{2}
\end{aligned}
$$


The first step has an equilibrium pressure of 1 bar at $33^{\circ} \mathrm{C}$. The second step has a equilibrium hydrogen pressure of $1 \mathrm{bar}$ at $110^{\circ} \mathrm{C}$. Although the temperature for the first reaction is inside the DOE target range, the temperature of the second step is above the temperature range. The reversible hydrogen content for pure $\mathrm{NaAlH}_{4}$ under these conditions is $5.5 \%$. These results imply that a less stable complex hydride may be a practical sorbent for hydrogen storage.

Fortunately, several less stable complex hydrides are already known. The enthalpies for the desorption of hydrogen from complex hydrides from published calorimetric data are reported in Table 1. ${ }^{25,26}$ Complex hydrides can be mixed to get new compounds with different thermodynamics. ${ }^{12}$ Unfortunately, $\mathrm{Mg}$ and $\mathrm{Li}$ alanates could have acceptable hydrogen capacity but appear to be too unstable. We thought that a mixture of $\mathrm{Na}, \mathrm{Li}$ and $\mathrm{Mg}$ alanates might yield a compound with acceptable stability and hydrogen capacity.

Table 1. Example Hydride Decomposition Reactions.

$\begin{array}{llll} & \begin{array}{l}\Delta \mathbf{H} \\ \text { (kcal/mol) }\end{array} & \Delta \mathbf{H} / \mathbf{H}_{\mathbf{2}} & \mathbf{H} \mathbf{w t} \% \\ \mathrm{Mg}\left(\mathrm{AlH}_{4}\right)_{2} \leftrightarrow \mathrm{MgH}_{2}+2 \mathrm{Al}+3 \mathrm{H}_{2} & 1.0 & 0.3 & 7.0 \\ 3 \mathrm{Li}\left(\mathrm{AlH}_{4}\right) \leftrightarrow \mathrm{Li}_{3} \mathrm{AlH} \\ 6\end{array}$

Note that $\mathrm{Na}$ and $\mathrm{Mg}$ forms a ternary hydride $\mathrm{NaMgH}_{3}$, so it is possible that an equimolar mixture of $\mathrm{NaAlH}_{4}$ and $\mathrm{Mg}\left(\mathrm{AlH}_{4}\right)_{2}$ could react to form $\mathrm{NaMgH}_{3}, \mathrm{Al}$ and $\mathrm{H}_{2}$. The formation of multinary saline hydrides during hydrogen desorption could result in novel phases that improve the thermodynamics of desorption. This is another possible advantage of mixtures of complex hydrides that we wanted to pursue.

Further, we reasoned that a less stable complex hydride would require a new catalyst to operate effectively at lower temperatures. Pure hydrides tend to have sluggish sorption kinetics. Recently it has been shown that $\mathrm{MgH}_{2}$ promoted with $\mathrm{Fe}_{3} \mathrm{O}_{4}$ and $\mathrm{Cr}_{2} \mathrm{O}_{3}$ are reversible hydrogen storage materials. ${ }^{9}$ These results show that oxides can catalyze hydrogen desorption from complex hydrides. Bogdanovic has tested a wide range of transition metals and rare earths as catalysts for $\mathrm{NaAlH}_{4}{ }^{9}$ Although most of these catalysts did not perform as well as $\mathrm{Ti}$ and $\mathrm{Zr}$ above $100^{\circ} \mathrm{C}$, their relative performance could change below $100{ }^{\circ} \mathrm{C}$ on less stable hydrides. High-energy ball-milling to yield nanocrystalline particles has been also shown to improve the rate of sorption. ${ }^{27} \mathrm{~A}$ combinatorial approach will allow us to scan many combinations of candidate catalysts and preparation procedures. 


\section{PROJECT OVERVIEW and SCOPE}

\subsection{Molecular Modeling of Complex Metal Hydrides}

Virtual High Throughput Screening (VHTS). The key to VHTS is the selection of a model which captures the essential physics of the material and is computationally efficient. A successful VHTS effort requires a model to accurately predict structure and another model that can predict properties that correlate with experiment.

Our first task was to predict structures of complex hydrides. Note that the structures of these hydrides resemble oxides and halides. They are composed of arrays of anions (e.g., $\mathrm{AlH}_{4}{ }^{-}$or $\mathrm{AlH}_{6}{ }^{-3}$ ) with cations occupying interstitial sites. The lowest energy cation distribution in supercells of close packed, body centered, and other arrays of $\mathrm{AlH}_{4}{ }^{-}$ anions will be found with combinatorial minimization. ${ }^{28}$ The second step involved lattice energy minimization of several of the lowest cation distributions. Simulated annealing was used to ensure that the structure had not converged to a local minimum. A relatively simple force-field was usually adequate to scan for the lowest energy geometries. Atomic charges for the electrostatic interactions were derived from band structure calculations on reference compounds. Finally, we defined bond stretching terms and bond bending terms for the Al-H bonds in the $\mathrm{AlH}_{4}^{-}$tetrahedra and $\mathrm{AlH}_{6}{ }^{-3}$ octahedra derived from experimental IR spectra and first principle calculations. The nonbonding interatomic potentials were derived by fitting to properties predicted from band structure calculations. The software tools utilized for this task were derived from software used to predict the cation distribution of low silica zeolites in UOP VHTS of zeolites. ${ }^{29}$ This molecular mechanics approach allowed for the prediction of the structure of a dozen different hydride phases per day after scanning millions of possible structures for each composition.

The second step utilized a more sophisticated molecular mechanics method to predict phonon bands and estimate the enthalpy, entropy of the novel complex hydrides. This method was very similar to the approach taken by Catlow, et al. in modeling oxides. ${ }^{30}$ The parameters for these calculations were derived from the results of band structure calculations and experimental data on reference compounds. The program GULP written by Julian Gale was used to predict thermodynamics. ${ }^{31}$ We found it was possible to predict the thermodynamics of a dozen phases per day. Only the phases predicted to desorb hydrogen in or near the target conditions of this solicitation were considered in the next phase of the modeling work.

Thermodynamics of complex hydrides from first principles. The team also utilized firstprinciples atomistic modeling to evaluate important thermodynamic quantities like enthalpies and entropies of hydrogen desorption for reference compounds and the most interesting novel phases. Due to dramatic advances in methodology and available computing power, these methods were used as a versatile, practical, and quantitatively predictive tool for understanding the properties and phase transformations for our materials of interest. These methods were used to provide properties for parameterization of the semi-empirical methods in the VHTS effort described above. Further, the methods were used to estimate reaction enthalpies accurate to $2 \mathrm{kcal} / \mathrm{mol}$. In other words, this provides equilibrium hydrogen pressures accurate to an order of magnitude, and allows the ranking of activity of complex hydrides for hydrogen storage. The Vienna Ab-Initio Simulation Package (VASP) was used to perform full structural optimization of many different alloy structures with respect to the atomic positions, 
volumes and unit-cell shapes. The VASP code is widely used by groups throughout the world since it offers unsurpassed speed, capabilities and numerical accuracy. Due to a very high degree of automation and stability, the VASP code requires minimal human intervention when performing common tasks such as structural optimization and calculation of the total energies and electronic band structures. Since the calculation of vibrational and rotational effects is quite time-consuming, it was only done in the latter stages of theoretical refinement for particularly promising compounds. Early on, the estimates of entropy from the semi-empirical methods were used to estimate equilibrium pressures.

\subsection{High Throughput Materials Screening and Optimization}

The materials and chemical industries have increasingly adopted combinatorial chemistry. Advances in automation, robotics, analysis and miniaturization have enabled development of rapid assays that measure material properties over a range of operating conditions, validated against conventional tests and molecular models. Advances in data management, pattern recognition, and empirical data modeling have enabled researchers to extract response surfaces and structure-property relationships from the wealth of data such tests provide.

Combinatorial materials synthesis is linked to conventional laboratory procedures through synthesis and characterization of known and novel materials. Combinatorial screening assays are then linked to more realistic conventional laboratory tests on scaled-up samples. Finally, laboratory-scale studies are linked to commercial testing procedures. The discovery process is focused by systematic experiment planning which makes full use of feedback among the different levels of testing, and of molecular and empirical models of material properties that are refined throughout the experimentation process.

Typical complex hydride development is characterized by sequential, iterative examination of candidate materials within a limited range of possibilities. Since a wide variety of materials are known to catalyze desorption of hydrogen, work often proceeds in parallel with several materials with no easy way to pick winners early in the development cycle. In short, the typical approach to developing these materials for hydrogen storage application is painstaking and slow due to the equipment and the methodologies employed. In contrast, combinatorial materials discovery is an efficient way to evaluate large numbers of new materials under a variety of conditions. Hydrogen storage by complex hydrides is a very challenging application for combinatorial methods due to the air sensitivity of the hydrides, the requirement of a relatively high hydrogen capacity, and low temperatures. Key technical hurdles required creation of a link between the combinatorial scale and commercial reality, maintenance of a proper balance between empirical and phenomenological methodologies, and analysis and visualization of large quantities of data.

The systematic multi-scale approach outlined here was able to accelerate novel metal hydride experiments by a factor of 50 . The coupling of the combinatorial experiments with molecular modeling increased the effectiveness of the search for new hydrogen storage materials by an even greater factor. 
This project advanced the state of the art in the combinatorial synthesis and testing of air sensitive materials. The capabilities before and after execution of this project are shown in Table 2. As shown here, before Project capabilities allowed for the preparation and testing at the rate of a sample a day. Work in the Project allowed up to a 48-fold increase in that, with considerably more information becoming available and integrated about each material under investigation.

Table 2. Experimental Capabilities for Complex Metal Hydride Studies Before and After Project Completion

\begin{tabular}{|c|c|c|}
\hline & Before Project Capabilities & After Project Capabilities \\
\hline \multicolumn{3}{|c|}{ Sample Preparation } \\
\hline Throughput & 1 sample/day & 8-16 samples/day \\
\hline $\begin{array}{l}\text { Range of } \\
\text { materials }\end{array}$ & Solid & $\begin{array}{l}\text { Solid phase preparation of complex } \\
\text { metal hydrides/catalysts }\end{array}$ \\
\hline $\begin{array}{l}\text { Range of } \\
\text { catalysts }\end{array}$ & Any & Any \\
\hline \multicolumn{3}{|c|}{ Sample Testing } \\
\hline Throughput & 1 sample/day & 8/day - 48/day \\
\hline $\begin{array}{l}\text { Range of } \\
\text { materials }\end{array}$ & Solid & Solid/Slurry \\
\hline $\begin{array}{l}\text { Range of } \\
\text { catalysts }\end{array}$ & Any & Any \\
\hline $\begin{array}{l}\text { Pressures } \\
\text { and } \\
\text { Temperatur } \\
\text { es }\end{array}$ & $\begin{array}{l}1-150 \text { atm } \\
-30 \text { to } 300{ }^{\circ} \mathrm{C}\end{array}$ & $\begin{array}{l}\text { Pressure } 0 \text { - } 33 \text { bar } \\
\text { Temp } 40-350{ }^{\circ} \mathrm{C}\end{array}$ \\
\hline $\begin{array}{l}\text { Information } \\
\text { Available }\end{array}$ & $\begin{array}{l}\text { - Hydrogen Absorption } \\
\text { Thermodynamics/Kinetics } \\
\text {-Heats of Absorption /Desorption }\end{array}$ & $\begin{array}{l}\text { - Hydrogen Absorption } \\
\text { Thermodynamics/Kinetics } \\
\text { - Heats of absorption/desorption }\end{array}$ \\
\hline
\end{tabular}

An overview of the current status combinatorial capabilities at the end of the Project is provided in Table 3. Only two of the capabilities listed were able to be utilized in an as-is basis for the Project. All the others had to be customized. An example of the latter is the solid phase synthesis using ball milling techniques. For this development, UOP drew upon its own experience in developing several generations of combinatorial equipment and upon Professor Jensen's experience in laboratory-scale ball-milling methods. 
Table 3. Summary of Combinatorial Capability Status at the end of the Project

\begin{tabular}{|c|c|c|c|}
\hline Equipment & Throughput & Use & Current Status \\
\hline $\begin{array}{l}\text { Liquid } \\
\text { Phase } \\
\text { Synthesis }\end{array}$ & 12-48/day & $\begin{array}{l}\text { Delivery of various solutions/ } \\
\text { precipitation/ filtration }\end{array}$ & $\begin{array}{l}\text { New equipment was } \\
\text { purchased to handle air } \\
\text { sensitive compounds }\end{array}$ \\
\hline $\begin{array}{l}\text { Solid Phase } \\
\text { Synthesis }\end{array}$ & 16-48/day & Ball milling samples & $\begin{array}{l}\text { Equipment was } \\
\text { developed during } \\
\text { Project }\end{array}$ \\
\hline $\begin{array}{l}\text { IR Thermo- } \\
\text { graphy }\end{array}$ & 48/day & $\begin{array}{l}\text { Hydrogen Heats of } \\
\text { Adsorption }\end{array}$ & $\begin{array}{l}\text { Equipment was } \\
\text { developed during } \\
\text { Project }\end{array}$ \\
\hline $\begin{array}{l}\text { Hydrogen } \\
\text { Uptake }\end{array}$ & 8/day & $\begin{array}{l}\text { Hydrogen Absorption } \\
\text { Thermodynamics/Kinetics }\end{array}$ & $\begin{array}{l}\text { 48-bank pressure } \\
\text { system developed } \\
\text { during the Project }\end{array}$ \\
\hline XRF & 100/day & $\begin{array}{l}\text { Obtain information regarding } \\
\text { sample composition }\end{array}$ & $\begin{array}{l}\text { Automated XRF } \\
\text { established for non- } \\
\text { moisture sensitive } \\
\text { samples during the } \\
\text { Project }\end{array}$ \\
\hline XRD & 200/day & $\begin{array}{l}\text { Obtain information regarding } \\
\text { material phases }\end{array}$ & $\begin{array}{l}\text { New method for } \\
\text { handling air-sensitive } \\
\text { materials developed } \\
\text { during the Project }\end{array}$ \\
\hline XPS & 10/day & Perform chemical analysis & $\begin{array}{l}\text { System already in use } \\
\text { at start of Project }\end{array}$ \\
\hline NMR & 5/day & $\begin{array}{l}\text { Obtain detailed structural } \\
\text { information }\end{array}$ & $\begin{array}{l}\text { System already in use } \\
\text { at start of Project }\end{array}$ \\
\hline
\end{tabular}




\section{ACCOMPLISHMENTS versus MILESTONES}

Table 4. All Milestones appearing here were accomplished during the course of the Project. Comments regarding each accomplishment are provided herein.

\begin{tabular}{|c|c|c|c|}
\hline & Milestone & $\begin{array}{l}\text { Completion } \\
\text { Date }\end{array}$ & Comment \\
\hline 1 & Refined performance targets. & 2Q 2004 & $\begin{array}{l}\text { Target specifications for } \\
\text { hydride/catalyst combinations } \\
\text { defined as: } \\
\text { Useable, specific-energy from } \mathrm{H}_{2} \text { : } \\
2 \mathrm{kWh} / \mathrm{kg} \\
\text { Useable energy density from } \mathrm{H}_{2} \text { : } \\
1.5 \mathrm{kWh} / \mathrm{L} \\
\text { Storage system cost: } 4 \$ / \mathrm{kWh} \text { net } \\
\text { Cycle life: } 1,000 \mathrm{Cycles} \\
\text { Minimum and maximum delivery } \\
\text { temperature: }-40 / 85^{\circ} \mathrm{C} \\
\text { System fill time: } 3 \text { minutes for a 5- } \\
\mathrm{kg} \text { hydrogen system. }\end{array}$ \\
\hline 2 & $\begin{array}{l}\text { Developed and validated medium } \\
\text { throughput (parallel) synthesis and } \\
\text { testing tools. }\end{array}$ & 3Q 2004 & $\begin{array}{l}\text { Established an inert-atmosphere } \\
\text { laboratory for medium throughput } \\
\text { synthesis and testing of promoted } \\
\text { complex metal hydrides. }\end{array}$ \\
\hline 3 & $\begin{array}{l}\text { Developed and validated } \\
\text { high throughput (parallel) } \\
\text { characterization tools. }\end{array}$ & 4Q 2004 & $\begin{array}{l}\text { Established an approach to } \\
\text { characterize multiple hydride } \\
\text { samples using x-ray diffraction } \\
\text { (XRD). }\end{array}$ \\
\hline 4 & $\begin{array}{l}\text { Develop theoretical methods to } \\
\text { predict stable hydride mixtures. }\end{array}$ & $\begin{array}{l}4 Q 2004(1) \\
1 Q 2005(2) \\
2 Q 2005(3)\end{array}$ & $\begin{array}{l}\text { (1) Developed an empirical force- } \\
\text { field calculation that predicts } \\
\text { accurate geometries and } \\
\text { thermodynamic functions for alkali } \\
\text { hydrides, alkaline earth hydrides, } \\
\text { the lithium alanates and the } \\
\text { sodium alanates. } \\
\text { (2) Developed a simulated } \\
\text { annealing procedure to estimate } \\
\text { crystal structures of mixtures of } \\
\text { complex hydrides. } \\
\text { (3) Demonstrated VHTS of } \\
\text { complex hydrides at a rate of } \\
1,000 \text { phases per month using } \\
\text { empirical force-fields and } \\
\text { simulated annealing. }\end{array}$ \\
\hline
\end{tabular}




\begin{tabular}{|c|c|c|c|}
\hline & Milestone & $\begin{array}{l}\text { Completion } \\
\text { Date }\end{array}$ & Comment \\
\hline 5 & $\begin{array}{l}\text { Design and construct the high } \\
\text { throughput synthesis and testing } \\
\text { tools }\end{array}$ & $\begin{array}{l}4 Q 2004(1) \\
3 Q 2005(2) \\
4 Q 2005(3)\end{array}$ & $\begin{array}{l}\text { (1) Developed a design for the } \\
\text { high throughput assay ( } 48 \text { at a } \\
\text { time). } \\
\text { (2) Construction of the high- } \\
\text { throughput } \mathrm{H}_{2} \text { storage assay } \\
\text { completed. } \\
\text { (3) First high-throughput assays } \\
\text { carried out. }\end{array}$ \\
\hline 6 & $\begin{array}{l}\text { Phase I hydride/catalyst screening } \\
\text { completed }\end{array}$ & $2 Q 2005$ & $\begin{array}{l}\text { Used medium-throughput } \\
\text { combinatorial experimentation ( } 8 \\
\text { experiments per run) to screen the } \\
\text { Na-Li-Mg/AlH } H_{4} \text { phase diagram } \\
\text { using three different preparation } \\
\text { methods at } 21 \text { samples/each. }\end{array}$ \\
\hline 7 & $\begin{array}{l}\text { High throughput synthesis and } \\
\text { testing implemented }\end{array}$ & $3 Q 2008$ & $\begin{array}{l}\text { The High Throughput Synthesis } \\
\text { System was brought on-line and } \\
\text { was used for P.O.P. combinatorial } \\
\text { catalytic doping experiments. }\end{array}$ \\
\hline 8 & Modeling extended to catalysts & $2 Q 2007$ & $\begin{array}{l}\text { Completed a Virtual High } \\
\text { Throughput screen of } \sim 1200 \\
\text { mixtures containing } \mathrm{LiBH}_{4}, \mathrm{NaBH}_{4} \text {, } \\
\mathrm{Mg}\left(\mathrm{BH}_{4}\right)_{2}, \mathrm{Ca}\left(\mathrm{BH}_{4}\right)_{2} \text { and } \mathrm{Zn}\left(\mathrm{BH}_{4}\right)_{2} \text {. }\end{array}$ \\
\hline 9 & $\begin{array}{l}\text { Phase II hydride/catalyst screening } \\
\text { completed }\end{array}$ & 3Q 2007 & $\begin{array}{l}\text { Nearly } 900 \text { samples prepared, } \\
\text { characterized by XRD and } \\
\text { evaluated for hydrogen storage } \\
\text { properties. }\end{array}$ \\
\hline 10 & $\begin{array}{l}\text { Improved mechanistic } \\
\text { understanding }\end{array}$ & 4Q 2007 & $\begin{array}{l}\text { Screened destabilized reactions } \\
\text { based upon } \mathrm{LiBH}_{4} \text { and } \mathrm{Ca}\left(\mathrm{BH}_{4}\right)_{2} \text {; } \\
\text { identified thermodynamically } \\
\text { promising, but kinetically inhibited } \\
\text { reactions; formulated general } \\
\text { rules for designing } \\
\text { thermodynamically correct } \\
\text { destabilized reactions. }\end{array}$ \\
\hline 11 & $\begin{array}{l}\text { Candidate hydride identified and } \\
\text { optimized }\end{array}$ & $2 Q 2006$ & $\begin{array}{l}\text { Best system to date based upon } \\
\mathrm{LiBH}_{4}-\mathrm{LiNH}_{2}-\mathrm{MgH}_{2} \text {. }\end{array}$ \\
\hline
\end{tabular}




\section{EXPERIMENTAL and THEORETICAL METHODS and INFORMATICS}

5.1 Synthesis. All manipulations were carried out under a nitrogen atmosphere, either on a Schlenck line, in a glovebox or in a sealed nitrogen-filled vessel, such as a milling bowl. All equipment was dried before use and solvents were dried in a Solvent Purification System (available from Innovative Technology, Inc.). Sodium alanate/2 \% Ti (mole \%) was used as a hydrogen storage capacity standard in all experiments. Sodium alanate (Albemarle) was purified via Soxhlet extraction in THF, followed by vacuum removal of the THF. Other alanates ( $\mathrm{Li}$ and $\mathrm{Mg}$ ) were similarly purified, but instead employed ether in the soxhlet extraction. Alanates were characterized by XRD and ICP prior to use. To prepare the standard samples, $\mathrm{Ti}(\mathrm{OiPr})_{4},(99.999 \%$, Aldrich) was used as received. All other metal hydrides, metal borohydrides, metal amides, and other metal salts were used as purchased, usually in their high purity, anhydrous form. In a typical synthesis example, samples contained $1-1.5 \mathrm{~g}$ of sodium alanate, which was added to a tungsten carbide milling bowl containing $10 \mathrm{~mm}$ tungsten carbide balls. The appropriate amount of dopant $\mathrm{Ti}(\mathrm{OiPr})_{4}$ was added to attain a Al:Ti molar ratio of 50:1. The milling bowl was sealed with electrical tape and milled in either a Fritsch Pulverisette 5 or a Fritsch Pulverisette 7 planetary ball mill for a total of 30 minutes, 15 minutes each in forward and reverse directions. Throughout the project, samples were prepared according to this protocol unless otherwise indicated, with the most likely variations being the milling speed and time. The resulting powders were recovered in the glovebox and stored for testing and characterization.

5.2 Characterization. Both as-synthesized and spent (if they could be recovered) samples from the hydrogen storage capacity tests were characterized by XRD using an array plate with a capacity of 48 samples. The array plate was sealed with a polycarbonate film to protect the samples from atmospheric water and oxygen. XRD measurements were collected on the Bruker AXS GADDS diffractometer equipped with an automated $x-y-z$ stage employing 1 minute scans in which the $2 \Theta$ range $19.5-54.5^{\circ}$ was covered by the area detector. More detailed measurements were carried out in an isolation chamber on a Scintag X-1 X-ray powder diffractometer over a $2 \Theta$ range of $2-$ $90^{\circ}$. All diffractometers employed $\mathrm{Cu}$-Ka radiation.

Infrared spectra of the zinc borohydride complexes were determined with a Nicolet Nexus 470 FT-IR with EZ Omnic programming in the range of $400-4000 \mathrm{~cm}^{-1}$. Pellets were made in dry potassium bromide and placed in a nitrogen chamber for use in the instrument.

Solid-state ${ }^{11} \mathrm{~B}$ NMR experiments of the zinc borohydride complexes were performed on a Varian Unity Inova spectrometer operating at a ${ }^{1} \mathrm{H}$ resonance frequency of $399.992 \mathrm{MHz}$ using a $3.2 \mathrm{~mm}$ CPMAS probe (Varian Chemagnetics, Ft. Collins, CO). For these experiments, samples were packed into a $3.2 \mathrm{~mm}$ rotor. The sample spinning rate was $8 \mathrm{kHz}(+/-1 \mathrm{kHz})$. Chemical shifts were externally referenced to $1 \% \mathrm{H}_{3} \mathrm{BO}_{4}(\delta$ $\left.\left({ }^{11} \mathrm{~B}\right)=0.0 \mathrm{ppm}\right)$. All spectra were recorded using direct polarization (DP). The ${ }^{11} \mathrm{~B}$ frequency was $128.332 \mathrm{MHz}$ and the spectra were recorded using a $2.0 \mathrm{mS}$ pulse (approximately a $30^{\circ}$ tip angle) using a spectral width of $350 \mathrm{kHz}$, acquisition time of 10 $\mathrm{mS}$, and a recycle delay of $10 \mathrm{~S}$. ${ }^{1} \mathrm{H}$ broad band decoupling was used during acquisition. Spectra were processed using a $50 \mathrm{~Hz}$ line broadening function and zero filled to a final data size of $8 \mathrm{k}$.

Since the assays measure pressure and gas evolution and are not specific to any gas, some samples of interest where desorption of gases other than hydrogen (e.g., $\mathrm{NH}_{3}, \mathrm{~B}_{2} \mathrm{H}_{6}$ ) are possible were characterized by temperature programmed reactions with mass spectrometry (TPR/MS). In the UOP lab, an in-house built TPR/MS instrument 
employed a TCD detector in parallel with a Hiden Analytical RC RGA mass spectrometer. After drying the system at $120^{\circ} \mathrm{C}$ for $3 \mathrm{~h}$ and a helium purge, the reactions (desorptions) were conducted in a $5 \% \mathrm{H}_{2} / \mathrm{Ar}$ stream with a flow rate of 40 $\mathrm{cm}^{3} / \mathrm{min}$ with a linear ramp of $2^{\circ} \mathrm{C} / \mathrm{min}$ to $400^{\circ} \mathrm{C}$. In the University of Hawaii lab, thermal desorption mass spectrometric analysis was performed with a Heiden HPR20 Residual Gas Analysis Mass Spectrometer with a heated capillary inlet system fixed with an attachment to accommodate air-sensitive samples which was loaded under nitrogen in the glove box. For study of the starting materials, the heating rate was fixed at $2^{\circ} \mathrm{C} / \mathrm{min}$ until the sample reached $350{ }^{\circ} \mathrm{C}$. The sample was then held at $350{ }^{\circ} \mathrm{C}$ for one hour. For the study of the product mixtures, the heating rate was fixed at $2{ }^{\circ} \mathrm{C} / \mathrm{min}$ until the sample reached $200{ }^{\circ} \mathrm{C}$. The sample was then held at $200^{\circ} \mathrm{C}$ for one hour. The flow rate of nitrogen gas was set at $10 \mathrm{~mL} / \mathrm{min}$.

5.3 Materials Testing. In the initial stages of the project, a Medium Throughput Assay (MT) was used to record hydrogen storage capacities for the samples. The ChemScan system (from HEL, Inc.) consisted of 8 individual reactors in which hydrogen desorption is monitored by pressure rise. The entire unit is housed in a dedicated glovebox (Innovative Technology, Inc.). Desorption measurements were carried out on $0.50 \mathrm{~g}$ sample. Unless otherwise indicated, the assay protocol consisted of a) a hydrogen desorption step ramped at $2^{\circ} \mathrm{C} / \mathrm{min}$ to $220-240{ }^{\circ} \mathrm{C}$, b) a hydriding step carried out at $125^{\circ} \mathrm{C}$ and $1250 \mathrm{psig}_{2}$ (87 bar) for $12 \mathrm{hr}$, and c) a final desorption step that was also a ramp at $2^{\circ} \mathrm{C} / \mathrm{min}$ to $220-240{ }^{\circ} \mathrm{C}$. Step a) is a determination of the initial hydrogen content of the sample while step $\mathrm{c}$ ) is a measure of the reversible hydrogen storage capacity.

The High Throughput (HT) Assay came on line later in the project. This unit was built by Sintef and has the capability to analyze 48 samples in parallel. The hydrogen evolution is measured volumetrically against atmospheric pressure. The unit consists of 48 tubes into which hydrogen is evolved, the evolved hydrogen supporting "floating discs," which rise to a level in the tube that is dependent on the amount of hydrogen released. Hydrogen evolution is monitored by measuring the height of these discs in the tubes with cameras. The High Throughput Assay was run similarly to the Medium Throughput Assay, but had the capability to run desorptions/hydriding at temperatures up to $350{ }^{\circ} \mathrm{C}$ and hydriding at pressures up to 120 bar. The hydrogen desorbed during the second desorption cycle was again considered to be the reversible hydrogen storage capacity, if the shape of the desorption profile was similar. It was first important to validate the medium throughput assay to make sure that hydrogen evolution measurements in each of the eight

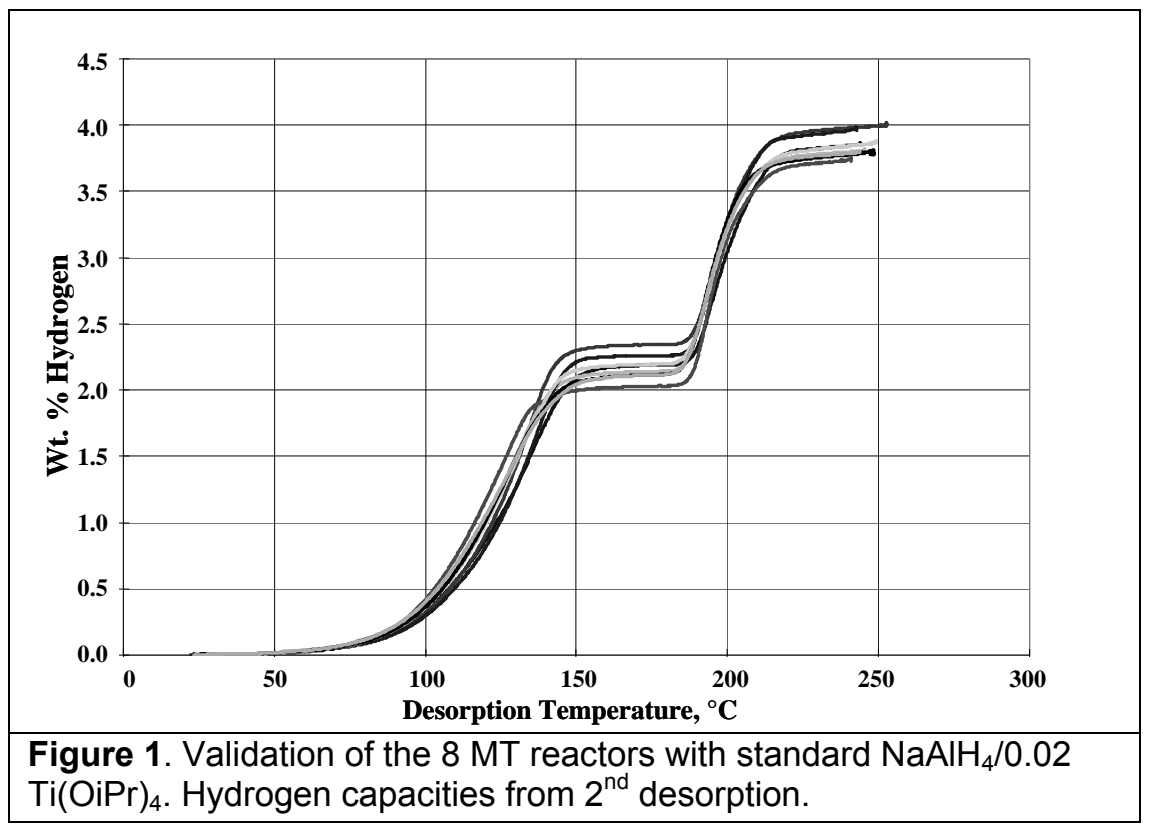


reactor positions were reproducible for a set of standard samples. The system validation was carried out with standard $\mathrm{NaAlH}_{4} / 0.02 \mathrm{Ti}(\mathrm{OiPr})_{4}$ samples. Figure 1 shows the results of the second desorption, yielding about $4 \mathrm{wt}$. \% reversible hydrogen capacity, consistent with literature observations. ${ }^{11}$ The eight desorption curves form a tight band within $0.2-0.3 \mathrm{wt}$. \% of each other and occur within $10-15^{\circ} \mathrm{C}$ on the temperature axis, which we consider to be an acceptable experimental error for screening. A similar standardization process was applied to the HT assay. Appendix A contains more information on the assay apparatus.

Dehydrogenation curves were determined with a calibrated Sieverts apparatus from

LESCA Co., Japan, with a high-precision pressure transducer and a silicon oil bath. The zinc borohydride samples were dehydrogenated at $100{ }^{\circ} \mathrm{C}$ from vacuum and rehydrogenated at $100{ }^{\circ} \mathrm{C}$ at $\sim 10 \mathrm{MPa}$.

5.4 Theoretical Methods. Two different theoretical modeling approaches were applied in this project: Virtual High Throughput Screening (VHTS) and First Principles calculations. Each of these approaches had the goal of identifying favorable hydrogen storage systems. The VHTS served as a virtual high throughput laboratory, computationally predicting structures and associated thermodynamic properties of phases to determine promising leads. First principles calculations were applied deliberately to a variety of candidate hydrogen storage systems (alanates, amide, and "destabilized" borohydrides), calculating phase diagrams and searching for favorable thermodynamics. The complete details of the VHTS work appears in Appendix B. The details of the first principles work is also presented in the appendices and will be cited in the appropriate sections of the report that deal with the same compositions. Key results will be incorporated into the body of the report as appropriate.

5.5 Informatics. Details on informatics can be found in Appendix C.

\section{RESULTS and DISCUSSION}

\subsection{Early Alanate Work}

\subsection{1 $\mathrm{AlH}_{4}-\mathrm{LiAlH}_{4}-\mathrm{Mg}\left(\mathrm{AlH}_{4}\right)_{2}$ Phase} Diagram. The initial phase of our work involved the application of the medium throughput assay and high throughput XRD to the pursuit of new hydrogen storage materials in the $\mathrm{NaAlH}_{4}(1)-$ $\mathrm{LiAlH}_{4}(2)-\mathrm{Mg}\left(\mathrm{AlH}_{4}\right)_{2}$ (3) mixed alanate system. ${ }^{32}$ While $\mathrm{NaAlH}_{4} / 2 \% \mathrm{Ti}\left(\mathbf{1}^{\prime}\right)(5.6$ wt. $\% \mathrm{H}$ ) is the state of the art, both 2 (8.0 wt. \% $\mathrm{H}$ ) and $3(7.0$ wt. \% $\mathrm{H})$, while not reversible, offer higher hydrogen capacity and could improve the capacity of $1 '$ ' in a new reversible mixed alanate. Figure 2 shows the 21 compositions that were covered, with each component varied in 0.2 mole increments between 0 and 1 with respect to Al content. All compositions, hydrogen storage capacities and structures encountered in this system can be found in Tables 1 and 2 of Appendix D. 
A new synthesis for the preparation of $\mathrm{Mg}\left(\mathrm{AlH}_{4}\right)_{2}$ included milling $\mathrm{NaAlH}_{4}$ with an appropriate amount of $\mathrm{MgCl}_{2}$ followed by soxhlet extraction with ether. $\mathrm{LiAlH}_{4}$ was soxhlet-extracted before use. The compositions on the phase diagram were achieved by mixing appropriate amounts of the pure alanates, adding 2 mole $\%$ $\mathrm{Ti}(\mathrm{iOPr})_{4}$ catalyst and using the standard milling conditions outlined in section 5 .

The endpoints

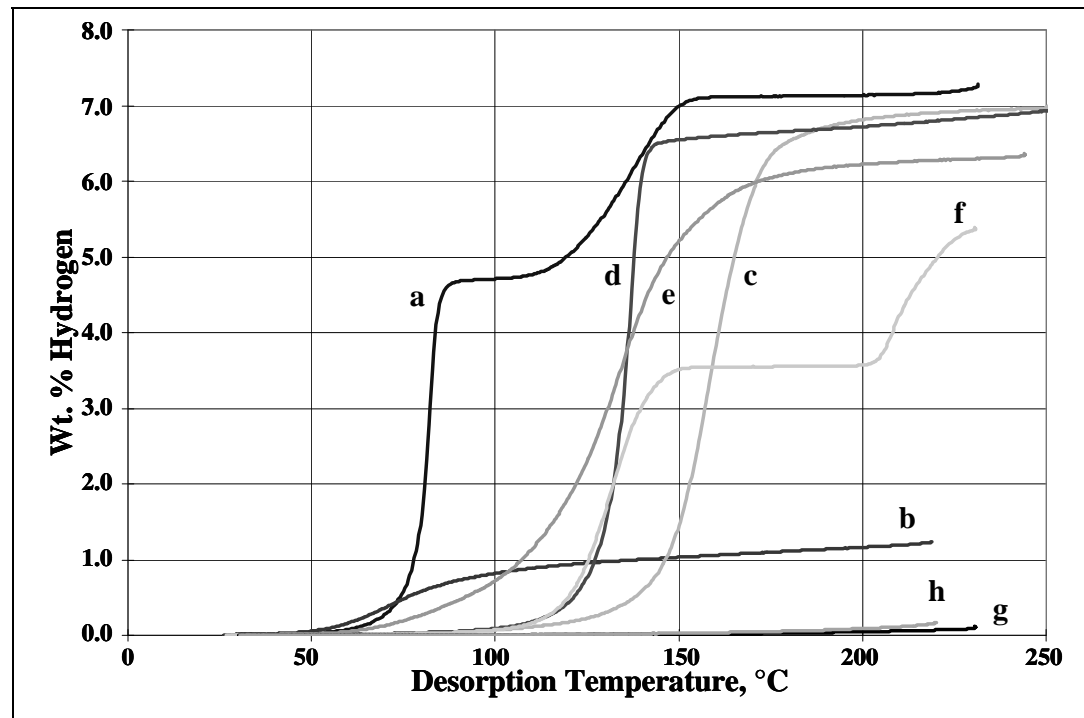

Figure 3. Hydrogen desorption curves for a) 2' after milling, b) 3' after milling, c) $\mathbf{3}$ as-synthesized, d) $\mathbf{3}$ after milling, e) 3' after mild milling, f) 1' after milling, g) 2', 2nd desorption, h) 3', 2nd desorption

of the phase diagram were studied first to provide a baseline to judge the behavior of the mixtures. Desorption curves for various $\mathrm{LiAlH}_{4}$ and $\mathrm{Mg}\left(\mathrm{AlH} \mathrm{H}_{4}\right)_{2}$ samples are shown in Figure 3. Both of these samples experienced significant hydrogen loss during milling, with $\mathrm{LiAlH}_{4} / \mathrm{Ti}\left(\mathbf{2}^{\prime}\right)$ yielding $7.2 \mathrm{wt} \% \mathrm{H}_{2}$ instead of 8 wt. \% while $\mathrm{Mg}\left(\mathrm{AlH} \mathrm{H}_{4}\right)_{2} / \mathrm{Ti}\left(\mathbf{3}^{\prime}\right)$ gave 1.5 wt. $\% \mathrm{H}_{2}$ rather than the expected 7 wt.\%. We instituted special safety precautions with these types of samples due to the $\mathrm{H}_{2}$ pressure build-up during milling. ${ }^{33}$

XRD patterns of these milled samples are shown in Figure 4. Milling converted 2' substantially to $\mathrm{Li}_{3} \mathrm{AlH}_{6}$ and $\mathrm{Al}$ (Figure 4a), which has $5.6 \mathrm{wt}$. \% hydrogen, while 3' was decomposed to mostly $\mathrm{Al}$ and $\mathrm{MgH}_{2}$ (Figure 4b). Even 1' partially decomposes during milling, forming some $\mathrm{Na}_{3} \mathrm{AlH}_{6}$ and $\mathrm{Al}$ (Figure 3f, 4f).

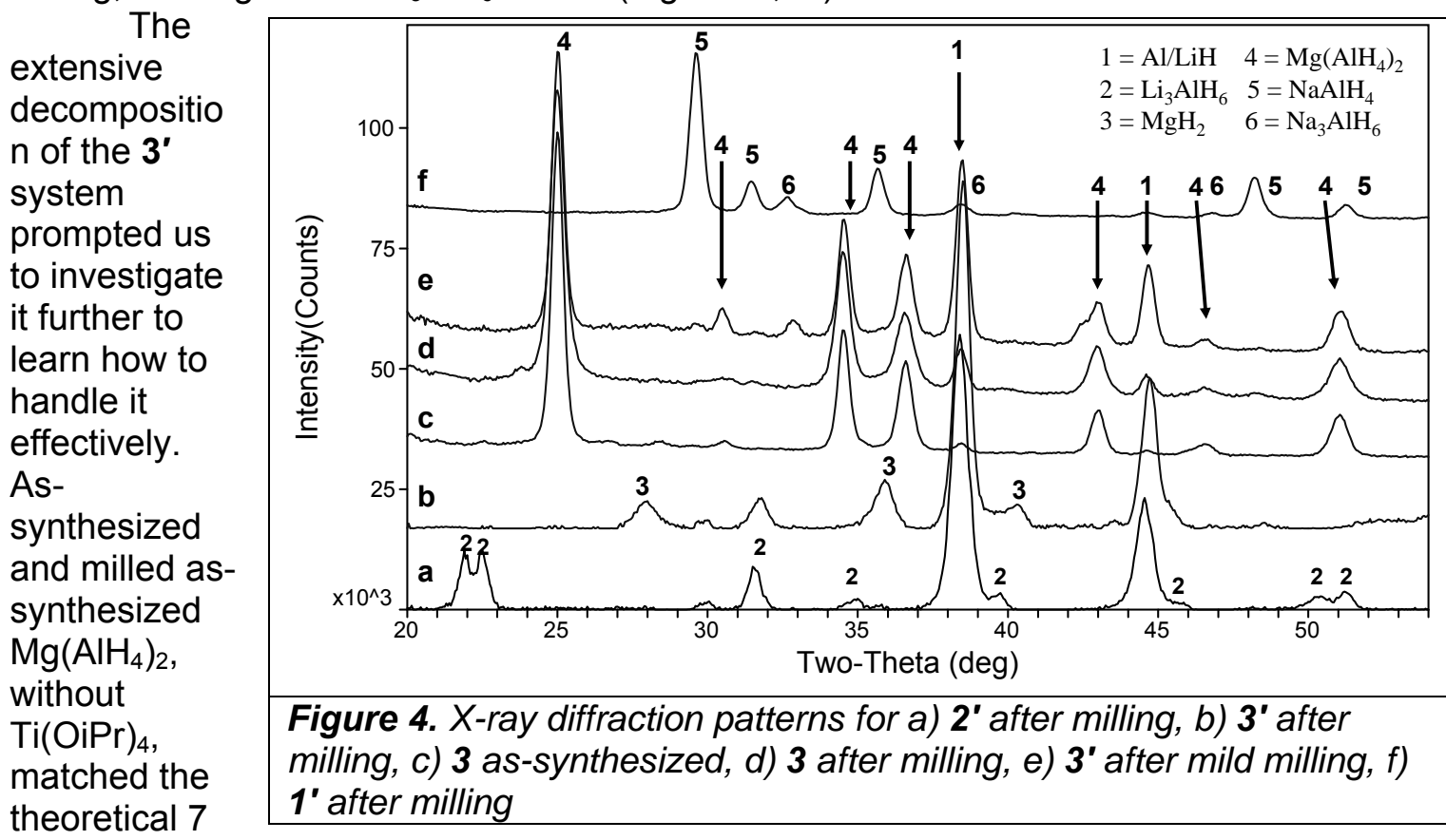


wt. \% $\mathrm{H}_{2}$ (Figure $3 \mathrm{c}$, d). Milling of the as-synthesized $\mathrm{Mg}\left(\mathrm{AlH}_{4}\right)_{2}$ lowered the hydrogen desorption temperature by $20^{\circ} \mathrm{C}$. Then $3^{\prime}$ was prepared again, using a milder milling condition, $130 \mathrm{rpm}$ for $10 \mathrm{~min}$., $5 \mathrm{~min}$. in each direction. The test result, shown in Figure $3 e$, is a desorption trace of gentler slope but with a maximum desorption rate near the same desorption temperature, $130{ }^{\circ} \mathrm{C}$, as the milled undoped $\mathrm{Mg}\left(\mathrm{AlH}_{4}\right)_{2}$. Only about $10 \%$ of the hydrogen was lost during the mild milling step. XRD on the as-synthesized, milled as-synthesized and "mildly milled" doped $\mathrm{Mg}\left(\mathrm{AlH}_{4}\right)_{2}$ shows progressing decomposition via increased Al content (Figure 4c, 4d, 4e).

The second desorption curves for 2' and 3' taken after rehydriding show that neither system reversibly stores hydrogen by itself (Figure 3g, 3h).

Mixed Alanates. Considering the changes Ti-doped alanates were undergoing during milling, it seemed that the prospect of preparing mixed $\mathrm{Na}-\mathrm{Li}-\mathrm{Mg}$ alanates might be hampered. However, since a lot of the chemistry happens in the reactor during the desorption and rehydriding cycles, we decided to stick with the established milling protocol. The results for the second hydrogen desorption, the reversible hydrogen capacity, is given as a function of composition for the mixture study in Figure 5. The salient features of the plot are a) a drop-off in reversible

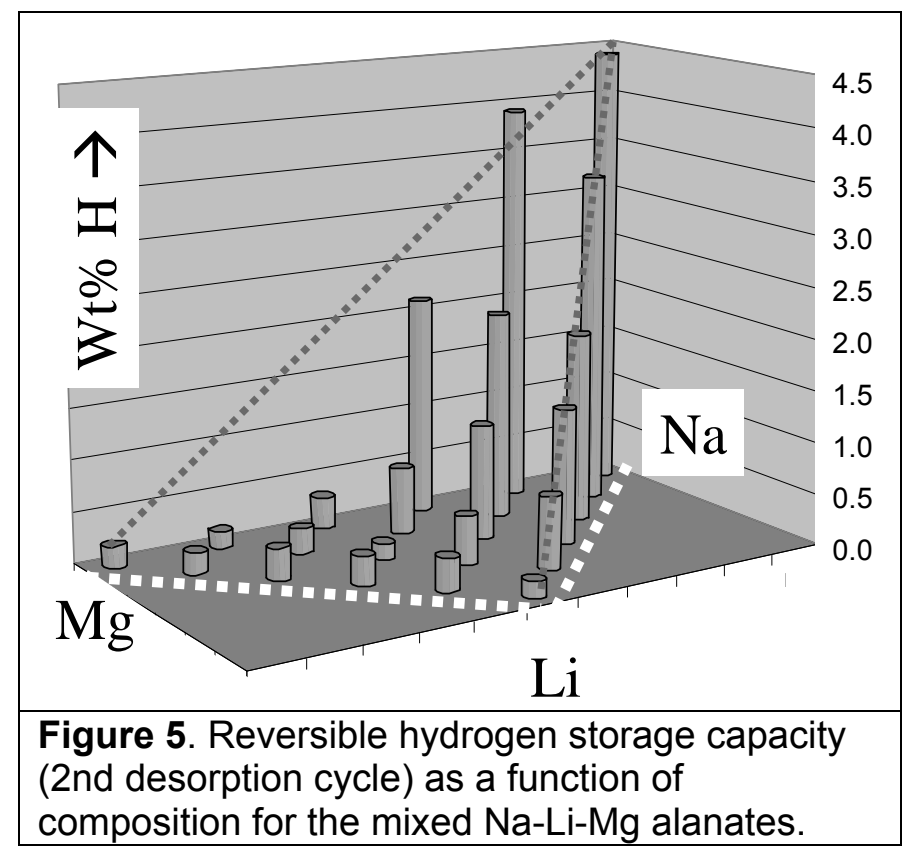
hydrogen storage capacity as one moves away from the pure $\mathrm{NaAlH}_{4}$ system, b) an almost linear decline in capacity along the $\mathrm{LiAlH}_{4}-\mathrm{NaAlH}_{4}$ axis, c) an abrupt decline in capacity about halfway along the $\mathrm{NaAlH}_{4}-\mathrm{Mg}\left(\mathrm{AlH}_{4}\right)_{2}$ axis, and d) very little capacity along the $\mathrm{LiAlH}_{4}-\mathrm{Mg}\left(\mathrm{AlH}_{4}\right)_{2}$ axis. The results for the $\mathrm{LiAlH}_{4}-\mathrm{Mg}\left(\mathrm{AlH}_{4}\right)_{2}$ axis are not surprising since the end members are not reversible. The compositions that contain all three components in the center of the diagram basically decline in capacity as the $\mathrm{NaAlH}_{4}$ content declines. A closer look at the results along the $\mathrm{LiAlH}_{4}$ $\mathrm{NaAlH}_{4}$ axis are given in Figure 6. Besides the observed reversible hydrogen capacity, the theoretical total capacity for $\mathrm{LiAlH}_{4}+\mathrm{NaAlH}_{4}$, and the theoretical capacities for both $\mathrm{NaAlH}_{4}$, and $0.86 * \mathrm{NaAlH}_{4}$ are plotted as a function of $x$ for $\mathrm{Li}_{x} \mathrm{Na}_{1-x} \mathrm{AlH}_{4}$. The factor of 0.86 was applied to the theoretical $\mathrm{NaAlH}_{4}$ capacity because this

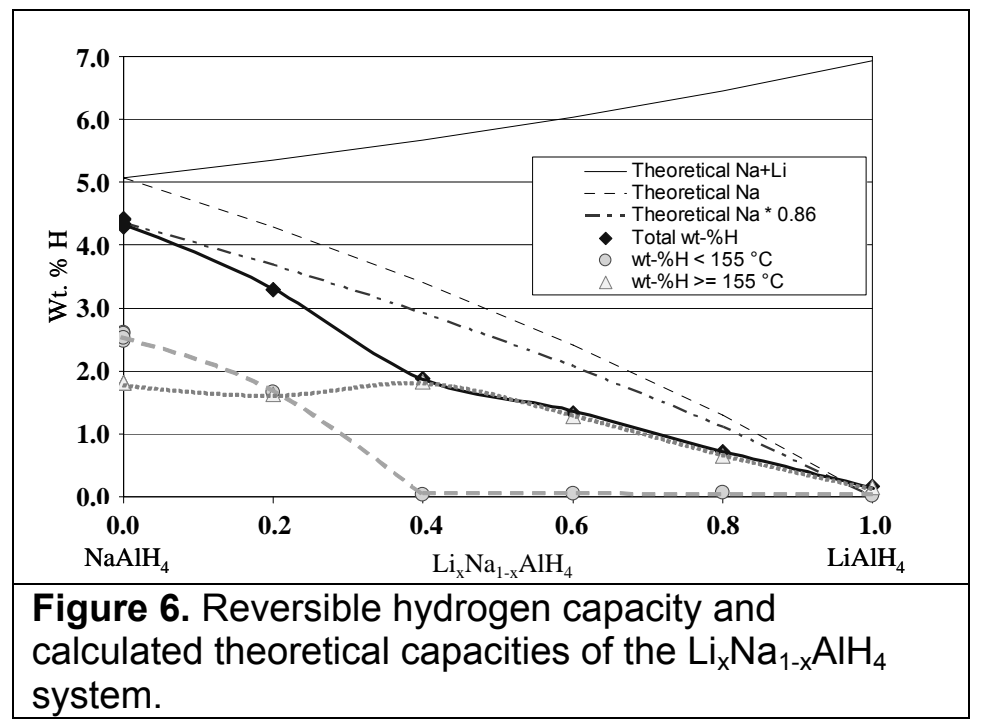


is what we observe as its reversible capacity. The observed (total) reversible hydrogen capacity is well below all of these, even the $0.86^{*} \mathrm{NaAlH}_{4}$ line, which represents the expected $\mathrm{NaAlH}_{4}$-only contribution as it is diluted by $\mathrm{LiAlH}_{4}$. Noting that the desorption curves for this series had a low temperature branch and a high temperature branch centered around $155^{\circ} \mathrm{C}$, the observed hydrogen capacity could be further

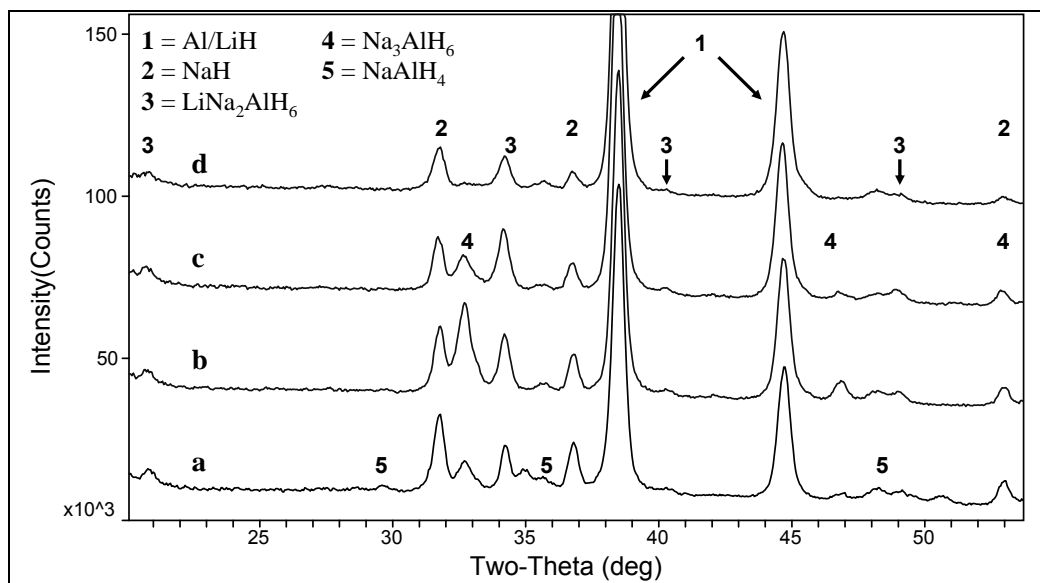

Figure 7. X-ray diffraction patterns of the $\mathrm{Li}_{x} \mathrm{Na}_{1-x} \mathrm{AlH}_{4}$ series after the second desorption: a) $x=0.2$; b) $x=0.4 \mathrm{c}$ ) $x=0.6$ d) $x=0.8$

broken down into the low and high temperature contributions, which are also plotted in Figure 6 as a function of composition. The plot shows that the low temperature contribution to the reversible hydrogen capacity falls essentially to 0 by the time $x=0.4$ and that the total observed hydrogen capacity is essentially equivalent to the high temperature contribution for $x \geq 0.4$ in $\mathrm{Li}_{x} \mathrm{Na}_{1-x} \mathrm{AlH}_{4}$. XRD of the spent samples (after the second desorption) for the compositions $0.2 \leq x \leq 0.8$ are shown in Figure 7. Besides the expected spent materials $\mathrm{Al}$, $\mathrm{LiH}$, and $\mathrm{NaH}$, the hexahydrides $\mathrm{LiNa}_{2} \mathrm{AlH}_{6}$ and $\mathrm{Na}_{3} \mathrm{AlH}_{6}$ figure prominently. The low temperature contributions observed at $x=0$ and 0.2 are probably due to $\mathrm{NaAlH}_{4}$ formation during the rehydriding process. Once $x>0.2$, there is enough $\mathrm{Li}$ to scavenge most of the $\mathrm{Na}$ to make $\mathrm{LiNa}_{2} \mathrm{AlH}_{6}$ during the rehydriding process, inhibiting $\mathrm{NaAlH}_{4}$ formation and the lower temperature contributions to the hydrogen desorption. The theoretical capacity of $\mathrm{LiNa}_{2} \mathrm{AlH}_{6}$, assuming decomposition to $\mathrm{Al}$ and $\mathrm{LiH}$, is about 3.5 wt. \%, and is thus less than the reversible $\mathrm{NaAlH}_{4}$-only contribution represented by the $0.86 * \mathrm{NaAlH}_{4}$ line.

A similar analysis for the binary $\mathrm{NaAlH}_{4}-\mathrm{Mg}\left(\mathrm{AlH}_{4}\right)_{2}$ system is shown in Figure 8. The observed reversible capacities for the compositions $\mathrm{Mg}_{\mathrm{x}} \mathrm{Na}_{1-2 x} \mathrm{AlH}_{4}$ initially appear to follow the $0.86^{*} \mathrm{NaAlH}_{4}(\mathrm{x}=$ 0.1 ), indicating the $\mathrm{Mg}\left(\mathrm{AlH}_{4}\right)_{2}$ serves only as a diluent for $\mathrm{NaAlH}_{4}$.

Progressing to higher $\mathrm{Mg}$ content, the capacities are seen to fall below those expected by dilution, falling abruptly at $x=0.3$ to 0.3 wt. $\% \mathrm{H}_{2}$, vs. the 2.0 wt. $\%$ $\mathrm{H}_{2}$ expected by dilution. XRD of the spent materials following the second desorption showed the presence of $\mathrm{NaMgH}_{3}$, which is formed during rehydriding, but does not

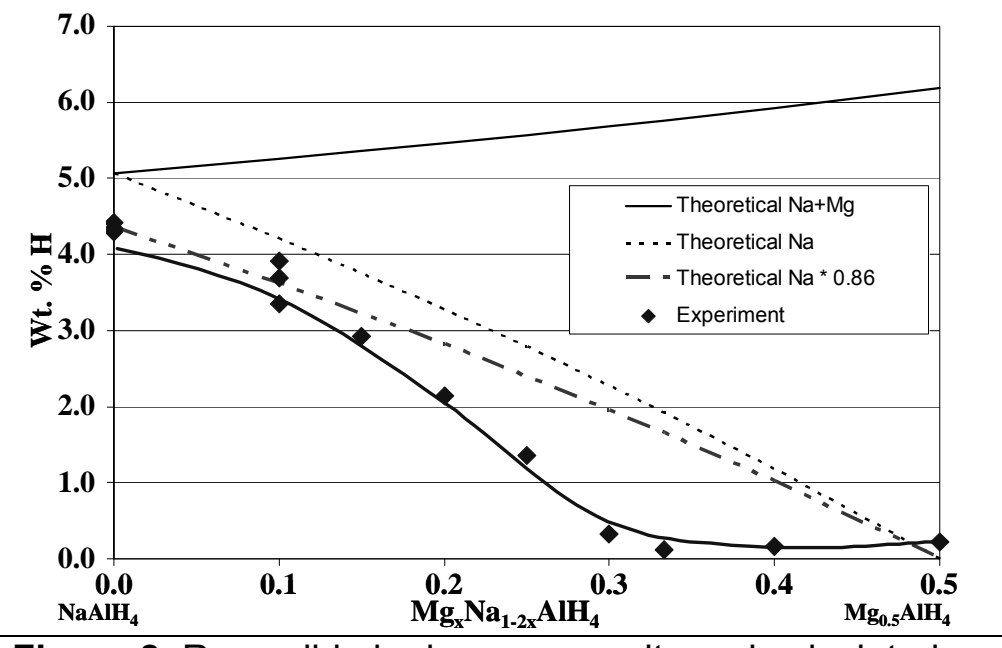

Figure 8. Reversible hydrogen capacity and calculated capacities for the $\mathrm{Mg}_{\mathrm{x}} \mathrm{Na}_{1-2 \mathrm{x}} \mathrm{AlH}_{4}$ binary system. 
decompose under the desorption conditions employed. As the Mg content increases, it eventually reacts with all of the $\mathrm{Na}$ to make $\mathrm{NaMgH}_{3}$ during rehydriding, inhibiting $\mathrm{NaAlH}_{4}$ formation and any observed reversible capacity.

As mentioned above, the compositions containing all 3 of the components seemed to follow a $\mathrm{NaAlH}_{4}$ dilution effect. Interestingly, the XRD for these materials taken after the second desorption did not show either $\mathrm{LiNa}_{2} \mathrm{AlH}_{6}$ or $\mathrm{NaMgH}_{3}$, the formation of which caused the deviations from capacities expected for $\mathrm{NaAlH}_{4}$ dilution in the binary systems.

Mild Milling. Because of the extensive decomposition observed when milling $\mathrm{LiAlH}_{4}$ and $\mathrm{Mg}\left(\mathrm{AlH}_{4}\right)_{2}$, the whole phase diagram was repeated using the mild milling protocol described above. While this greatly improved the desorption results for the first cycle, the amount of hydrogen desorbed in the second cycle was essentially the same. See Table 2 in Appendix D for storage capacities and structures.

Virtual High Throughput Screening (VHTS). A simulated annealing approach was used to predict structures for the mixed Na-Li-Mg alanates. The process consists of using an in-house program that locates cations to generate a starting structure, and then cycling through a molecular dynamics program to heat and monitor the evolution of the lattice, and an energy minimization program to optimize the structure. This technique can be used to screen thousands of phases per month. The method was

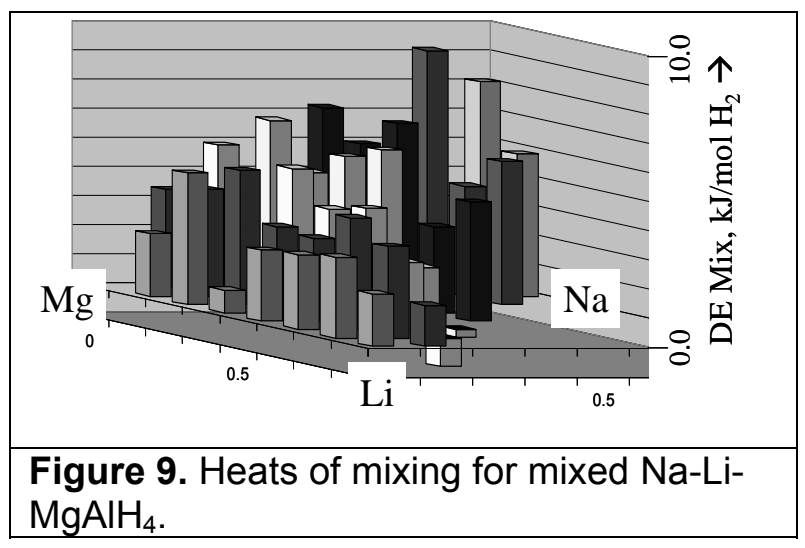
applied to 35 compositions in the $\mathrm{Na}-\mathrm{Li}-\mathrm{Mg} / \mathrm{AlH}_{4}$ phase diagram, the results of which are shown in Figure 9. The figure shows that only two of the phases of the 35 evaluated had a negative heat of mixing with respect to the alanates, $\mathrm{Li}_{3} \mathrm{NaAl}_{4} \mathrm{H}_{16}$ and $\mathrm{Li}_{5} \mathrm{Na}_{3} \mathrm{Al}_{8} \mathrm{H}_{32}$. However, these phases were found to be unstable with respect to dehydriding. The calculations are supported by the experimental observations that no mixed $\mathrm{NaAlH}_{4}-$ $\mathrm{LiAlH}_{4}-\mathrm{Mg}\left(\mathrm{AlH}_{4}\right)_{2}$ phases were observed.

6.1.2 Reversing the Alanate Reaction. Reversible chemistry is the most important aspect of a hydrogen storage system. The typical alanate reaction, exemplified here for $\mathrm{NaAlH}_{4}$,

$$
2 \mathrm{NaAlH}_{4} \leftrightarrow 2 \mathrm{NaH}+2 \mathrm{Al}+3 \mathrm{H}_{2}
$$

indicates that very different crystalline phases are forming over the course of the reaction as one proceeds back and forth from the form of the material that stores hydrogen (the alanate) to the materials that are hydrogen depleted and need to be regenerated $(\mathrm{Al}+\mathrm{NaH})$. The $\left.\mathrm{NaAlH}_{4}-\mathrm{LiAlH}_{4}-\mathrm{Mg}(\mathrm{AlH})_{4}\right)_{2}$ phase diagram study above sheds little light on the regeneration reaction as it proceeds through the hydrogen desorption/absorption cycles as there is no information as to the degree of segregation of the $\mathrm{Al}$ and $\mathrm{NaH}$ phases during this process or how large the crystallites of these species grow, both factors that will affect the hydrogen regeneration reaction. We decided to study the regeneration reaction under the best conditions, employing nano-Al (100 nm crystallites), the appropriate metal hydride, titanium isopropoxide catalyst, along with the same milling procedures used in the aforementioned phase diagram study to 
afford homogeneity of the reaction mixture. The same hydriding conditions were used in the medium throughput reactors, 87 bar psig $\mathrm{H}_{2}$ and $125^{\circ} \mathrm{C}$ for 12 hours. The desorption cycles were also run under the same conditions as the previous work. Hence the reaction protocol was a) hydride, b) desorb, c) hydride, and d) desorb. Mirroring the previous alanate study, the entire analogous $\mathrm{Na}-\mathrm{Li}-\mathrm{Mg}$ phase diagram was covered starting with $\mathrm{Al}$, and appropriate amounts of $\mathrm{NaH}, \mathrm{LiH}$ and $\mathrm{MgH}_{2} . \mathrm{KH}$ and $\mathrm{CaH}_{2}$ were also included in the study for selected points. The compositions covered in the study are given in the phase diagram in Figure 10, where adjacent points vary by 20 mole percent. Compositions, structures of as-synthesized and spent materials and hydrogen storage results are summarized in Table 3 of Appendix D.

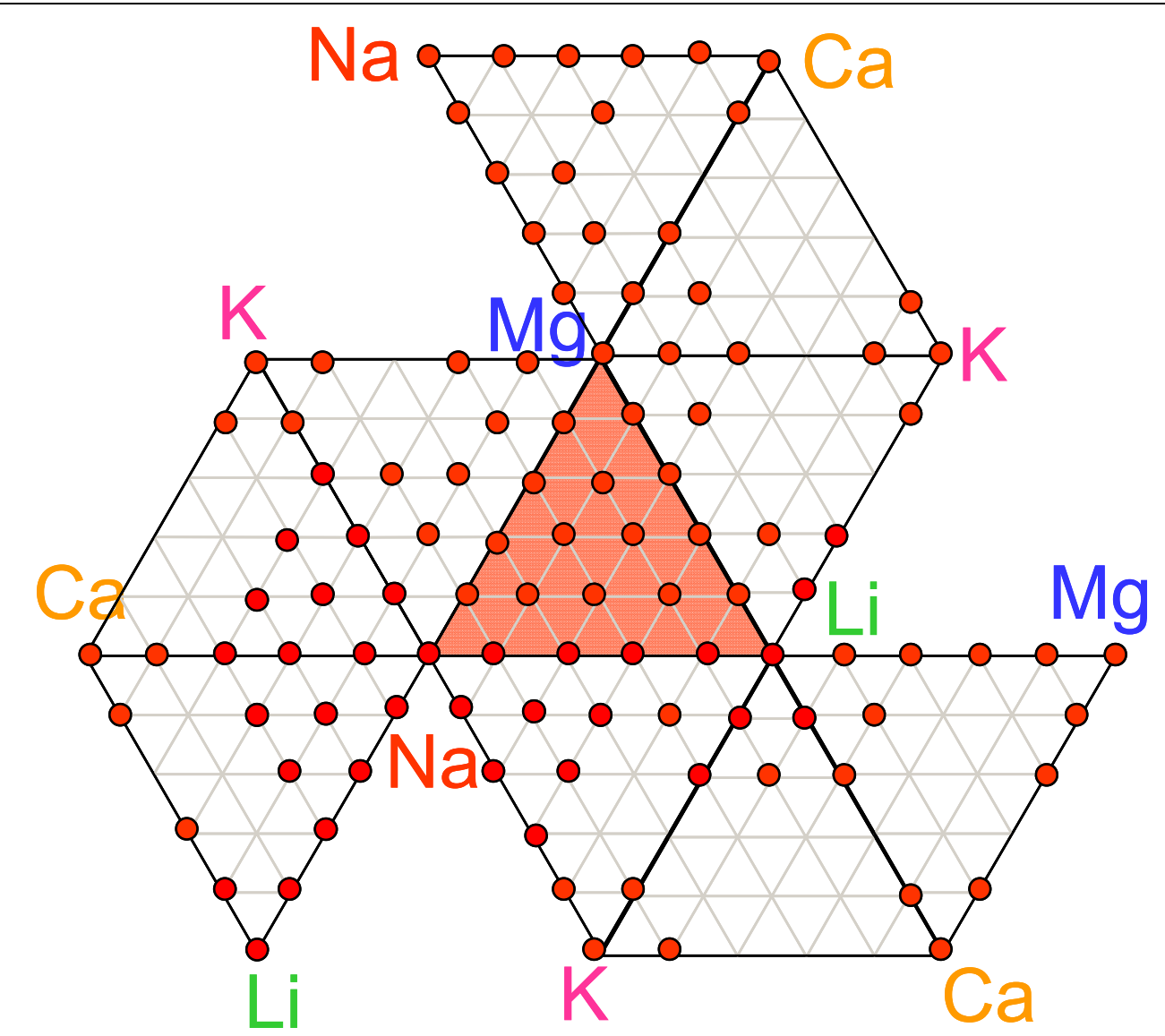

Figure 10. Phase diagram depicting the compositions used in the study of the reverse alanate reaction or hydriding reaction. Adjacent points in the phase diagram vary by 20 mole percent.

$\mathrm{NaH}-\mathrm{LiH}-\mathrm{MgH}_{2} / \mathrm{Al}$ phase diagram. Starting from dehydrided materials, the phase diagram corresponding to the $\mathrm{Na}$-Li-Mg alanate phase diagram reported on above was investigated. The results for reversible hydrogen storage, starting from dehydrided materials are shown in Figure 11, where it is compared to storage capacity results for the mixed alanate phases. It is seen in Figure $11 \mathrm{~b}$ that starting with nano Al was less effective than starting with the alanate with respect to the hydrogen stored for the pure $\mathrm{Na}$ phase by a factor of about $1 / 3$. For the phases containing $40 \% \mathrm{NaH}$, the hydrogen storage capacity was comparable or better than that observed for the corresponding 


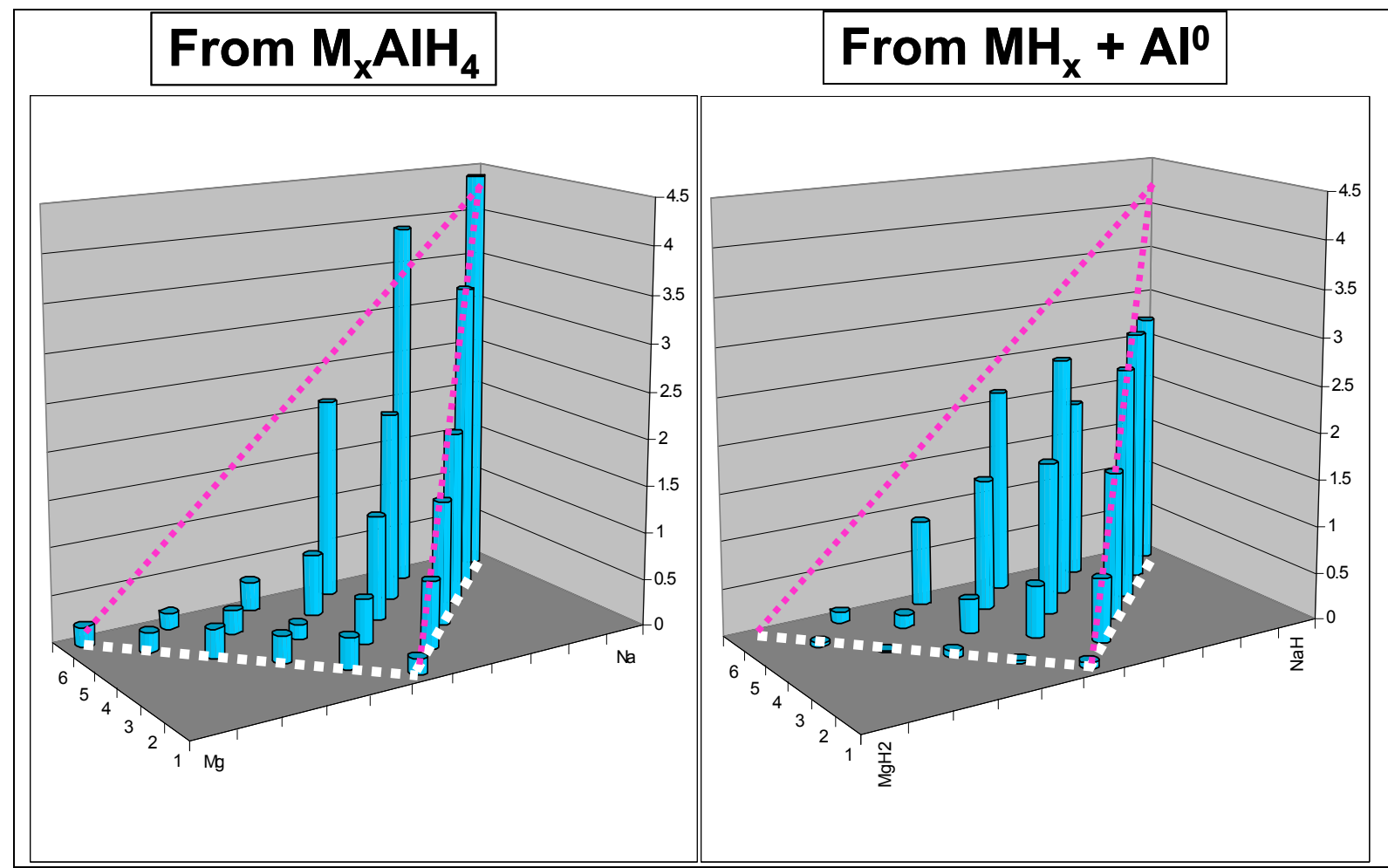

Figure 11. Reversible hydrogen storage (wt. \%) for the Na-Li-Mg phase diagram starting from a) alanates and b) Al and metal hydrides, the reverse reaction.

alanate systems. For many of the compositions, there was little change in the capacities observed between the first desorption and the second desorption. But in general, the capacities were less than those observed for the alanates.

XRD results for the spent samples were also collected and are summarized in Figure 12. The phases present in each spent material are shown in order of abundance for each composition on the phase diagram. As expected, Al and the corresponding metal hydride are often the major phases observed in the spents, especially for the pure $\mathrm{LiH}$ and $\mathrm{MgH}_{2}$ systems, which again showed little activity. As $\mathrm{NaH}$ was incorporated, the variety of phases observed grew as stable $\mathrm{NaMgH}_{3}$ was observed as well as other phases that had not been dehydrided, such as $\mathrm{LiNa}_{2} \mathrm{AlH}_{6}, \mathrm{Na}_{3} \mathrm{AlH}_{6}$, and even some $\mathrm{NaAlH}_{4}$. Because the desorptions are carried out in a fixed volume, the hydrogen pressure that develops is capable of rehydriding spent material as the reaction mixture is cooled after the final desorption. This is clearly the case for the $\mathrm{NaAlH}_{4}$-containing spents. In the more complicated compositions, many species were simultaneously observed, mostly metal hydrides and various binary aluminum hexahydrides. In some cases XRD lines were observed that could not be attributed to any known phase.

Compared to starting with the alanates, the $\mathrm{Na}-\mathrm{Li}-\mathrm{Mg}$ system starting from the hydrides and the metals was a lot less effective at converting the Al metal. $\mathrm{NaAlH}_{4}$ was the only alanate observed over the course of the study, there was no evidence for $\mathrm{Li}$ or $\mathrm{Mg}$ alanate formation, nor much activity from their combinations. The hydriding reaction was more facile when starting with the alanates. Although the alanate, in the case of $\mathrm{NaAlH}_{4}$, is segregated into $\mathrm{NaH}$ and $\mathrm{Al}$ on $\mathrm{H}_{2}$ desorption, they must be in a better position to do the hydriding reaction than the milled $\mathrm{NaH}$ and nano Al. This may be due to the properties of the nano Al employed. Either the crystallite size might have been too large or it may have had reduced reactivity due to an oxide overlayer. 


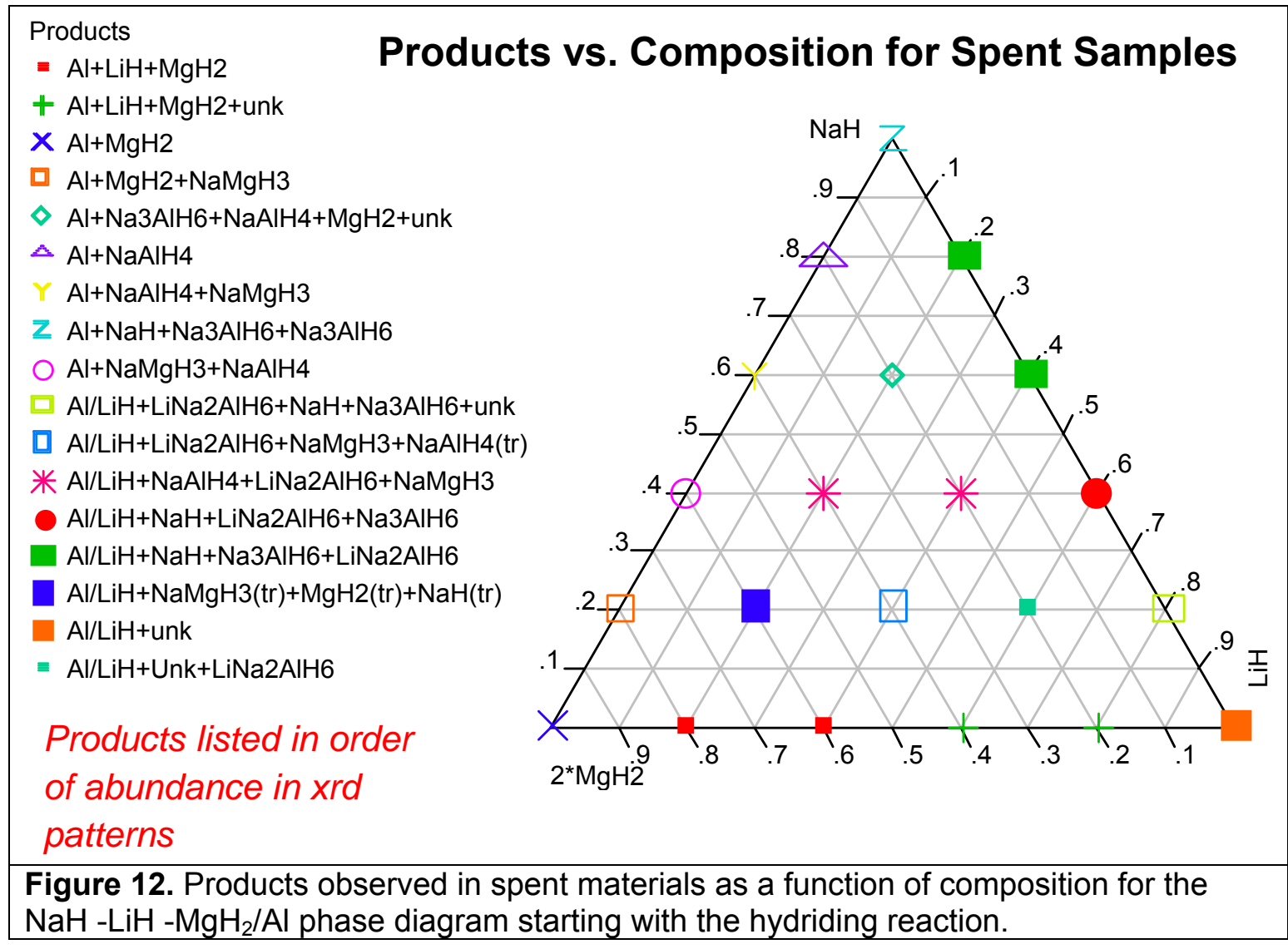

$\mathrm{LiH}-\mathrm{NaH}-\mathrm{KH} / \mathrm{Al}$ phase diagram. The $\mathrm{LiH}-\mathrm{NaH}-\mathrm{KH} / \mathrm{Al}$ system yielded $\mathrm{KAlH}_{4}$ in every K-containing formulation except the $0.8 \mathrm{LiH}-0.2 \mathrm{KH}$ formulation. The $\mathrm{KH}-\mathrm{Al}$ combination was the best at forming $\mathrm{KAlH}_{4}$ under hydriding conditions. This supports a cation effect in which the cation of the lowest charge density, which is $\mathrm{K}$ in the series $\mathrm{Mg}^{2+}(72 \mathrm{pm}), \mathrm{Li}^{+}(76 \mathrm{pm}), \mathrm{Na}^{+}(102 \mathrm{pm})$, and $\mathrm{K}^{+}(138 \mathrm{pm})$, is the best at restoring Al to fully hydrided alanate. The unfortunate flip side of this situation is that the $\mathrm{KAlH}_{4}$ was too stable to dehydride at $200{ }^{\circ} \mathrm{C}$. So while the $\mathrm{KH} / \mathrm{Al}$ combination efficiently stored hydrogen, it failed to release it under desorption conditions and was not reversible. Along the $\mathrm{NaH}-\mathrm{KH}$ edge of the phase diagram, $\mathrm{KAlH}_{4}$ was observed as well as some $\mathrm{K}_{2} \mathrm{NaAlH}_{6}$ and $\mathrm{Na}_{3} \mathrm{AlH}_{6}$, see Figure13. Reversible hydrogen storage of up to $1.6 \mathrm{wt} \%$ was due to desorption from $\mathrm{Na}_{3} \mathrm{AlH}_{6}$. Along the $\mathrm{KH}$ - LiH edge of the phase diagram, only unreacted hydrides and $\mathrm{Al}$ and $\mathrm{KAlH}_{4}$ were observed. No mixed $\mathrm{Li}-\mathrm{K}$ aluminum hydrides were observed. Reversible hydrogen storage capacity was less than $0.4 \mathrm{wt}$. \%. Among the ternary compositions studied, $\mathrm{KAlH}_{4}$ was always formed, accompanied by various combinations of the hexahydrides, $\mathrm{Na}_{3} \mathrm{AlH}_{6}$, $\mathrm{LiNa}_{2} \mathrm{AlH}_{6}$, and $\mathrm{NaK}_{2} \mathrm{AlH}_{6}$. There was very little reversible hydrogen storage capacity observed, only that associated with $\mathrm{LiNa}_{2} \mathrm{AlH}_{6}$ and $\mathrm{Na}_{3} \mathrm{AlH}_{6}$. Reversible hydrogen storage capacities for the phase diagram compositions are shown in Figure 14. 

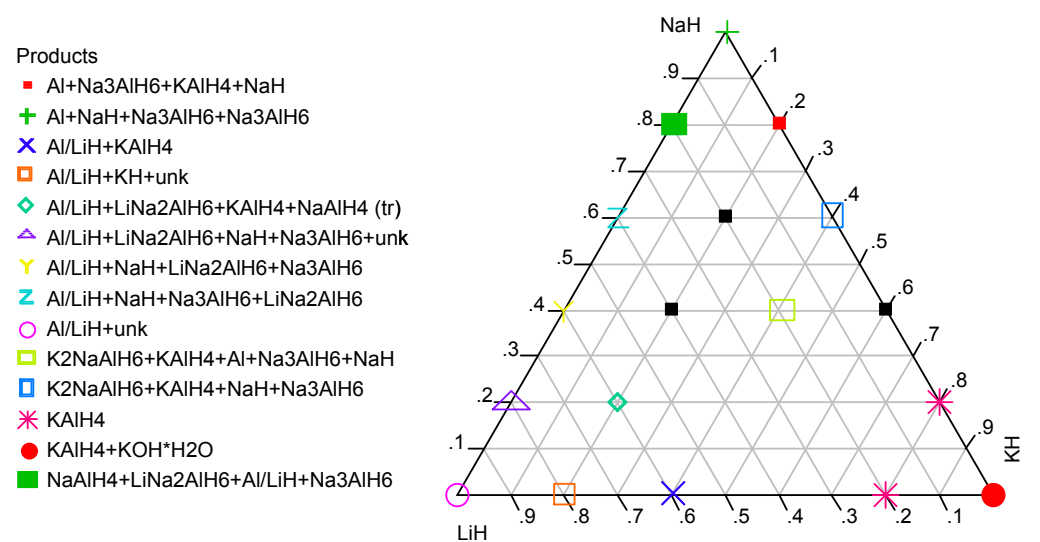

Figure 13. Products observed in spent materials from the $\mathrm{LiH}-\mathrm{NaH}-\mathrm{KH} / \mathrm{Al}$ phase diagram starting with the hydriding reaction.

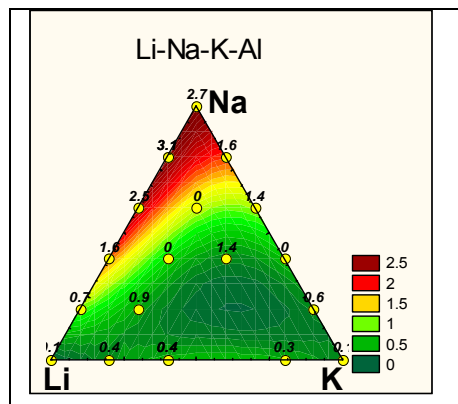

Figure 14. Reversible hydrogen storage capacities for the $\mathrm{LiH}$ $\mathrm{NaH}-\mathrm{KH} / \mathrm{Al}$ phase diagram.

$\mathrm{LiH}-\mathrm{NaH}-\mathrm{CaH}_{2}, \mathrm{LiH}-\mathrm{KH}-\mathrm{CaH}_{2}, \mathrm{LiH}-\mathrm{KH}-\mathrm{MgH}_{2}, \mathrm{LiH}-\mathrm{MgH}_{2}-\mathrm{CaH}_{2}, \mathrm{NaH}-\mathrm{KH}-\mathrm{MgH}_{2}, \mathrm{NaH}-$ $\mathrm{KH}-\mathrm{CaH}_{2}, \mathrm{NaH}-\mathrm{MgH}_{2}-\mathrm{CaH}_{2}, \mathrm{KH}-\mathrm{MgH}_{2}-\mathrm{CaH}_{2} / \mathrm{Al}$ phase diagrams. $\mathrm{CaH}_{2}$ was unreactive over all of the phase diagrams, forming no compounds with any of the other hydrides or Al. Other than when $\mathrm{MgH}_{2}$ was combined with $\mathrm{NaH}$ to make $\mathrm{NaMgH}_{3}, \mathrm{MgH}_{2}$ followed the same reactivity pattern as $\mathrm{CaH}_{2}$. The only compounds resulting from the hydriding reactions were previously observed in other systems, such as $\mathrm{KAlH}_{4}, \mathrm{NaAlH}_{4}$ and the hexahydrides seen in Figure 13. Similarly, the only reversible storage capacity was associated with $\mathrm{NaAlH}_{4}$ or the hexahydrides $\mathrm{Na}_{3} \mathrm{AlH}_{6}$ and $\mathrm{LiNa}_{2} \mathrm{AlH}_{6}$. More details can be found in Table 3 of Appendix D.

6.1.3 New Aluminum Hexahydrides. While it is more desirable to prepare alanates, $\mathrm{AlH}_{4}{ }^{-}$based species, because of their higher hydrogen storage capacities, we also looked at the possibility of preparing new alkali and alkaline earth-containing aluminum hexahydrides. In the well known double plateau hydrogen desorption profile for $\mathrm{NaAlH}_{4}$, it is $\mathrm{Na}_{3} \mathrm{AlH}_{6}$ that is the transitional species associated with the mid-run plateau. $\mathrm{Na}_{3} \mathrm{AlH}_{6}$ is a reversible storage material as is the mixed hexahydride $\mathrm{LiNa}_{2} \mathrm{AlH}_{6}$. A summary of the compositions prepared and their first and second cycle capacities are given in Table 4 of Appendix D.

The hexahydrides can be prepared via grinding in the ball mills from alanates and metal hydrides by reactions such as the following:

$$
\mathrm{NaAlH}_{4}+2 \mathrm{NaH} \rightarrow \mathrm{Na}_{3} \mathrm{AlH}_{6}
$$

Initial experiments involved adding a sub-stoichiometric amount of $\mathrm{NaH}, 0.05,0.1$ and 0.25 moles, to both $\mathrm{NaAlH}_{4}$ and $\mathrm{LiAlH}_{4}$ to help improve the reversibility of the alanates. The slight excess of $\mathrm{NaH}$ could help to more completely convert the Al that remains after the desorption process. In the $\mathrm{Na}$ system, these additions always produced some $\mathrm{Na}_{3} \mathrm{AlH}_{6}$ after milling in addition to the $\mathrm{NaAlH}_{4}$. On first cycle desorptions, the $\mathrm{NaAlH}_{4}$ materials usually had the higher desorption capacities, but sometimes the $\mathrm{NaH}$ enhanced materials showed slightly higher capacities, all in the range of $5.2+/-0.5$ wt. $\%$. The second cycle desorptions showed the same behavior, sometimes better, sometimes worse than the $\mathrm{NaAlH}_{4}$. The 0.1 mole of excess $\mathrm{NaH}$ gave a better reversible capacity in two of three experiments ranging from 3.4 to $3.75 \mathrm{wt}$. \% hydrogen, although these values are rather low for second desorption cycle results. 
When $\mathrm{NaH}$ is added to $\mathrm{LiAlH}_{4}, \mathrm{Al}$ and $\mathrm{LiH}$ are the major phases observed after milling. This is because of decomposition of the $\mathrm{LiAlH}_{4}$ in the presence of the Ti promoter during milling and due to ion exchange that is often observed in mixed systems containing $\mathrm{Li}$. In each case some $\mathrm{NaAlH}_{4}$ is seen after the milling. One of the $\mathrm{LiAlH}_{4}$ decomposition products observed from the milling is $\mathrm{Li}_{3} \mathrm{AlH}_{6}$. Reversible capacities for the Li-containing materials were very low at 0.8 wt. \% and less, most probably due to small amounts of $\mathrm{NaAlH}_{4}$ present.

Stoichiometric complex metalloaluminum hexahydrides were prepared from $\mathrm{NaAlH}_{4}$, via addition of $\mathrm{CaH}_{2}, \mathrm{MgH}_{2}, \mathrm{LiH}, \mathrm{NaH}$, and $\mathrm{KH}$. Several attempts were made to make $\mathrm{Na}_{3} \mathrm{AlH}_{6}$ via grinding $2 \mathrm{NaH} / \mathrm{NaAlH}_{4}$, with one of the reactions going to completion, showing $2.35 \mathrm{wt}$. \% reversible hydrogen capacity when tested in the medium throughput apparatus. This is a little low for $\mathrm{Na}_{3} \mathrm{AlH}_{6}$, which has a theoretical capacity of $2.96 \mathrm{wt}$ \% $\mathrm{H}_{2}$. The XRD of the spent sample showed $\mathrm{Na}_{3} \mathrm{AlH}_{6}$ as the major product, so incomplete desorption may explain the dip in capacity. Complete substitution of the $\mathrm{NaH}$ with $\mathrm{LiH}$ (2 $\mathrm{LiH} / \mathrm{NaAlH}_{4}$ ) gave a product with some unconverted $\mathrm{NaAlH}_{4}$, the mixed hexahydride $\mathrm{LiNa}_{2} \mathrm{AlH}_{6}$, and some leftover $\mathrm{LiH}$. The reversible capacity was $2.04 \mathrm{wt}$. $\% \mathrm{H}_{2}$, lower than the $\mathrm{Na}_{3} \mathrm{AlH}_{6}$. Using $\mathrm{LiH}$ and $\mathrm{NaH}$ and the proper stoichiometry for $\mathrm{LiNa}_{2} \mathrm{AlH}_{6}$, $\mathrm{NaH} / \mathrm{LiH} / \mathrm{NaAlH}_{4}$, yielded 2.79 wt. \% reversible $\mathrm{H}_{2}$ capacity, more than observed for $\mathrm{Na}_{3} \mathrm{AlH}_{6}$, as expected (but less than theoretical $3.52 \mathrm{wt}$. \%). Using an intermediate stoichiometry $\left(1.5 \mathrm{LiH} / 0.5 \mathrm{NaH} / \mathrm{NaAlH}_{4}\right)$ gave an almost identical result $(2.71$ wt. \% reversible $\mathrm{H}_{2}$ ). In the case of $\mathrm{KH}$ addition, $2 \mathrm{KH} / \mathrm{NaAlH}_{4}$, generated the hexahydride $\mathrm{K}_{2} \mathrm{NaAlH}_{6}$, but there was no detectable reversible desorption, again demonstrating the stability of K-containing aluminum hydrides. The addition of $\mathrm{MgH}_{2}$ and $\mathrm{CaH}_{2}$ to $\mathrm{NaAlH}_{4}$ resulted in materials with no reversible hydrogen capacity. Other than the formation of $\mathrm{NaMgH}_{3}$, no mixed compounds were observed with $\mathrm{Ca}$ or Mg hydrides.

Mixed hexahydrides were also prepared starting with $\mathrm{LiAlH}_{4}$. Another route to the hexahydride $\mathrm{LiNa}_{2} \mathrm{AlH}_{6}$ comes from reaction of the $\mathrm{LiAlH}_{4} / 2 \mathrm{NaH}$ system. During the initial milling, the ion exchange again was observed as evidenced by $\mathrm{NaAlH}_{4}$ formation. The desired hexahydride, $\mathrm{LiNa}_{2} \mathrm{AlH}_{6}$ was also formed. The reversible hydrogen storage capacity for this system was 2.96 wt. \%, slightly better than the 2.79 wt. \% observed above for the $\mathrm{NaAlH}_{4}$ derived system. The mixed hexahydride of the same stoichiometry in the $\mathrm{LiAlH}_{4} / 2 \mathrm{KH}$ system showed ion exchange to $\mathrm{KAlH}_{4}$ upon milling and ultimately no reversible hydrogen storage capacity. $\mathrm{K}_{3} \mathrm{AlH}_{6}$ was the major product observed in the spent sample. An intermediate stoichiometry between the Li-Na and Li-K systems, $\mathrm{LiAlH}_{4} / \mathrm{NaH} / \mathrm{KH}$ was also examined. After milling, XRD showed many products, including $\mathrm{NaAlH}_{4}, \mathrm{KAlH}_{4}, \mathrm{~K}_{2} \mathrm{NaAlH}_{6}$ and $\mathrm{LiNa}_{2} \mathrm{AlH}_{6}$, again showing the tendency for $\mathrm{LiAlH}_{4}$ to ion exchange. After both desorption cycles, the spent compounds were mostly $\mathrm{KAlH}_{4}$ and $\mathrm{K}_{2} \mathrm{NaAlH}_{6}$. The reversible $\mathrm{H}_{2}$ storage capacity was about 1.02 wt. \%, most probably due to residual $\mathrm{NaAlH}_{4}$ and $\mathrm{LiNa}_{2} \mathrm{AlH}_{6}$. Similar to the $\mathrm{NaAlH}_{4}$ system, attempts to make hexahydrides with $\mathrm{LiAlH}_{4}$ and either $\mathrm{MgH}_{2}$ or $\mathrm{CaH}_{2}$ resulted in no mixed phases and the reversible hydrogen storage was non-existent. More complex formulations were attempted with $\mathrm{MgH}_{2}$, $\mathrm{LiAlH}_{4} / \mathrm{KH} / 0.5 \mathrm{MgH}_{2}$ and $\mathrm{LiAlH}_{4} / \mathrm{NaH} / 0.5 \mathrm{MgH}_{2}$. In the $\mathrm{KH}$ formulation, the spent material showed $\mathrm{KAlH}_{4}$ and $\mathrm{KMgH}_{3}$ along with $\mathrm{MgH}_{2}$ and a small reversible $\mathrm{H}_{2}$ storage capacity of 0.70 wt. \%. In the $\mathrm{Na}$ version, $\mathrm{LiNa}_{2} \mathrm{AlH}_{6}$ was observed in the spent material along with $\mathrm{NaMgH}_{3}$ and a reversible hydrogen storage capacity of 1.06 wt. \% was observed. Basically, attempts to form complex hexahydrides with three different alkali/alkaline earth metals were unsuccessful.

Attempts to prepare aluminum hexahydrides from $\mathrm{Mg}\left(\mathrm{AlH}_{4}\right)_{2}$ were also made. $\mathrm{A}$ pure $\mathrm{Mg}$ version was attempted with the stoichiometry $\mathrm{Mg}\left(\mathrm{AlH}_{4}\right)_{2} / 2 \mathrm{MgH}_{2}$. No reaction was observed after milling, most likely due to decomposition of the alanate in the presence of the Ti promoter. There was no reversible hydrogen storage capacity. The 
mixed hexahydride formulations $\mathrm{Mg}\left(\mathrm{AlH}_{4}\right)_{2} / 2 \mathrm{LiH} / \mathrm{MgH} \mathrm{H}_{2}$ and $\mathrm{Mg}\left(\mathrm{AlH}_{4}\right)_{2} / 2 \mathrm{NaH} / \mathrm{MgH}_{2}$ were also attempted. Again this reaction was largely hampered by decomposition of $\mathrm{Mg}\left(\mathrm{AlH}_{4}\right)_{2}$ during milling, but in the $\mathrm{Na}$ case, some ion exchange and formation of $\mathrm{NaAlH}_{4}$ was observed. The reversible $\mathrm{H}_{2}$ storage capacities were less than $0.2 \mathrm{wt}$. \%.

6.1.4 Alane Reactions. Alane, $\mathrm{AlH}_{3}$, was briefly investigated as a starting material for the preparation of alanates. Alane was prepared by reacting $\mathrm{LiAH}_{4}$ with $\mathrm{AlCl}_{3}$ in ether. ${ }^{34}$ The alane starting material was tested for hydrogen storage capacity with and without the $\mathrm{Ti}(\mathrm{OiPr})_{4}$ dopant. After milling, the undoped material showed $\mathrm{AlH}_{3}$ and some $\mathrm{Al}$ by XRD whereas the doped material decomposed during milling, showing only Al. Both materials showed less than $0.1 \%$ reversible hydrogen storage. Reaction of $\mathrm{AlH}_{3}$ with one equivalent of $\mathrm{KH}$ yielded $\mathrm{KAlH}_{4}$ after milling, but when dopant was present, there was $\mathrm{Al}$ present due to decomposition. After testing, the spent material was $\mathrm{KAlH}_{4}$ in each case and the reversible hydrogen storage capacity was less than $0.2 \mathrm{wt} \%$, as $\mathrm{KAlH}_{4}$ is not decomposed under these conditions. $\mathrm{CaH}_{2}$ did not react with alane at any stage, during the milling or during the $\mathrm{H}_{2}$ capacity test. Reaction of $\mathrm{AlH}_{3}$ and $\mathrm{NaH}$ was also carried out with and without the Ti dopant. After milling, the undoped reaction yielded mostly $\mathrm{NaAlH}_{4}$ with some residual $\mathrm{NaH}$ and $\mathrm{Al}$, while the Ti-containing composition mostly decomposed to $\mathrm{Al}$ and $\mathrm{Na}_{3} \mathrm{AlH}_{6}$. During the first desorption, each sample gave about $3.3 \mathrm{wt} . \% \mathrm{H}_{2}$, while on the second desorption, the undoped sample gave $0.98 \mathrm{wt} . \% \mathrm{H}_{2}$, while the Ticontaining sample gave $3.2 \mathrm{wt} . \% \mathrm{H}_{2}$. These values are low for $\mathrm{NaAlH}_{4}$, but show the advantage of including the $\mathrm{Ti}$ dopant in the system. The addition of more $\mathrm{NaH}, 1.5$ $\mathrm{NaH} / \mathrm{AlH}_{3}$, increased the hydrogen yield to $3.9 \mathrm{wt}$. \% on the first desorption, but also leveled off at $3.2 \mathrm{wt}$. \% reversible hydrogen storage on the second desorption. Due to the sensitivity of alane and the subpar reversible storage capacities achieved in the compositions derived from alane, we decided to abandon further study with alane.

\subsection{Beyond Alanates to Other Material Families.}

6.2.1 $\mathrm{LiNH}_{2}-\mathrm{MgH}_{2}-\mathrm{LiBH}_{4}$ Phase Diagram. For the first application of the high throughput hydrogen storage assay system, we chose to investigate the compositions of the $\mathrm{LiNH}_{2}-\mathrm{MgH}_{2}-\mathrm{LiBH}_{4}$ phase diagram, which is shown in Figure 15. This system is intriguing because a number of the binary systems within this diagram have been investigated in the literature. The $2 \mathrm{LiBH}_{4}-\mathrm{MgH}_{2}$ system ${ }^{3}$ was investigated by Vajo et al. and found to yield $8-10 \mathrm{wt} . \%$ reversible hydrogen at temperatures around $350{ }^{\circ} \mathrm{C}$. The 2 $\mathrm{LiNH}_{2}-\mathrm{LiBH}_{4}$ system was studied by Pinkerton et al. and was found to yield $>10 \mathrm{wt} \%$ hydrogen at temperatures greater than $250{ }^{\circ} \mathrm{C}$, but was not reversible. This system yielded the new phase $\mathrm{Li}_{4} \mathrm{BH}_{4}\left(\mathrm{NH}_{2}\right)_{3}$ with the interesting property that it melts at very low temperatures, just above $100{ }^{\circ} \mathrm{C}$. ${ }^{4}$ The $2 \mathrm{LiNH}_{2}-\mathrm{MgH}_{2}$ system was investigated by Xiong et al. ${ }^{1}$ and by Luo. ${ }^{2}$ This system operates above $200^{\circ} \mathrm{C}$ and is reversible, ideally yielding nearly $5.6 \mathrm{wt}$ \% hydrogen. The phase diagram investigated in this study includes these particular binary compositions as well as other binary compositions along with ternary $\mathrm{LiNH}_{2}-\mathrm{MgH}_{2}-\mathrm{LiBH}_{4}$ compositions which to our knowledge had not been previously investigated. Given the richness of the chemistry observed in the binary systems, it follows that the ternary system should be fruitful as well. The first application of the HT assay system was to the compositions of this phase diagram. Compositions, structures of spent materials, medium throughput and high throughput results for this system are given in Table 5 of Appendix D. 


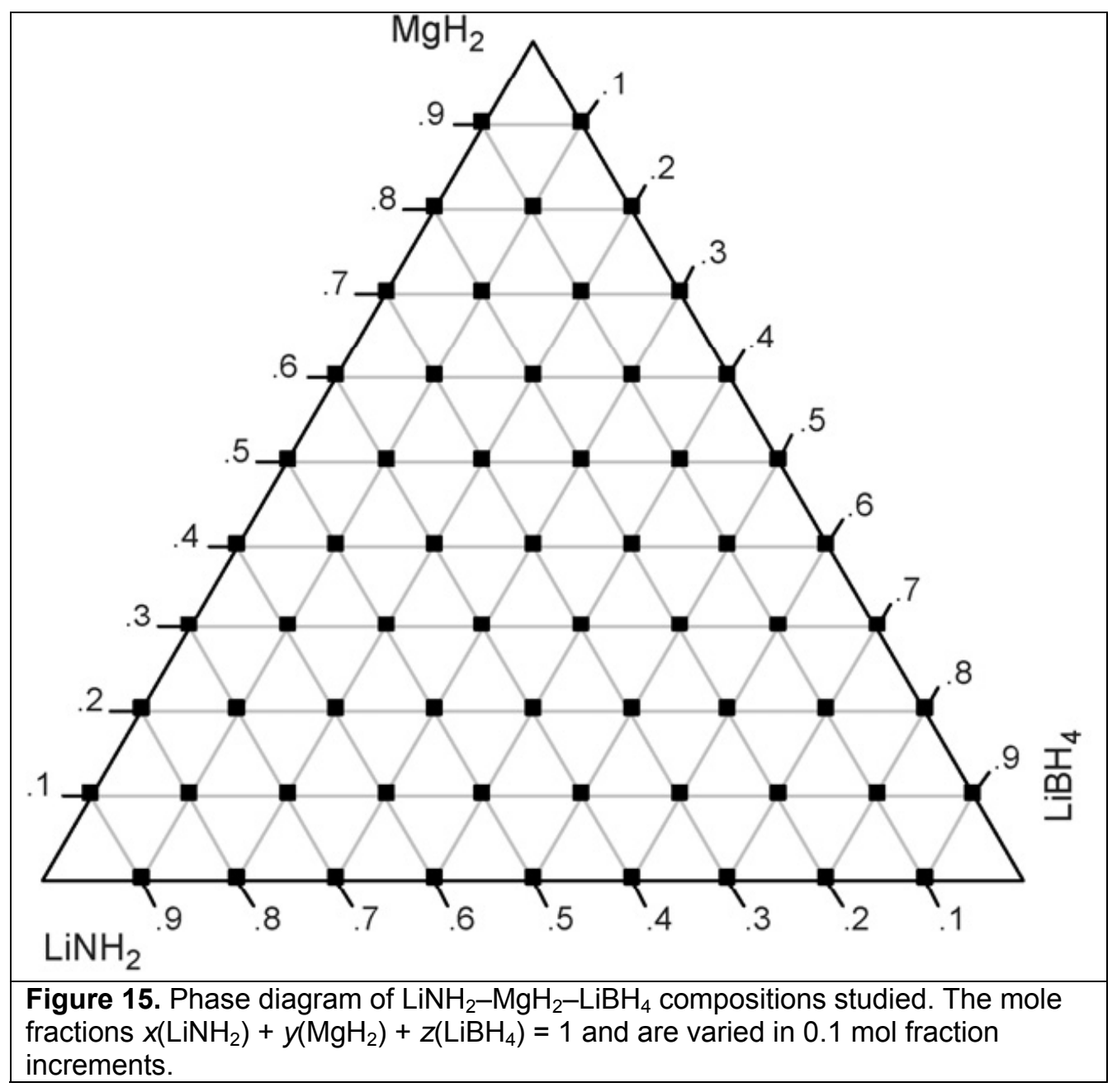

The $\mathrm{LiNH}_{2}-\mathrm{MgH}_{2}-\mathrm{LiBH}_{4}$ compositions were first examined in the medium throughput assay. The hydrogen capacity results from the second desorption, i.e. the reversible hydrogen stored, are shown on a 3D surface fitted to the data points as well as a corresponding contour plot in Figure 16. The composition with the best capacity was $0.6 \mathrm{LiNH}_{2}-0.3 \mathrm{MgH}_{2}-$ $0.1 \mathrm{LiBH}_{4}$, which yields 3.4 wt. $\% \mathrm{H}_{2}$ on the second desorption. The observed capacity then drops off rapidly as only four other adjacent compositions have reversible hydrogen capacities above 2 wt. \%, as shown in Table 5 . All of these are ternary compositions; none of the binary compositions
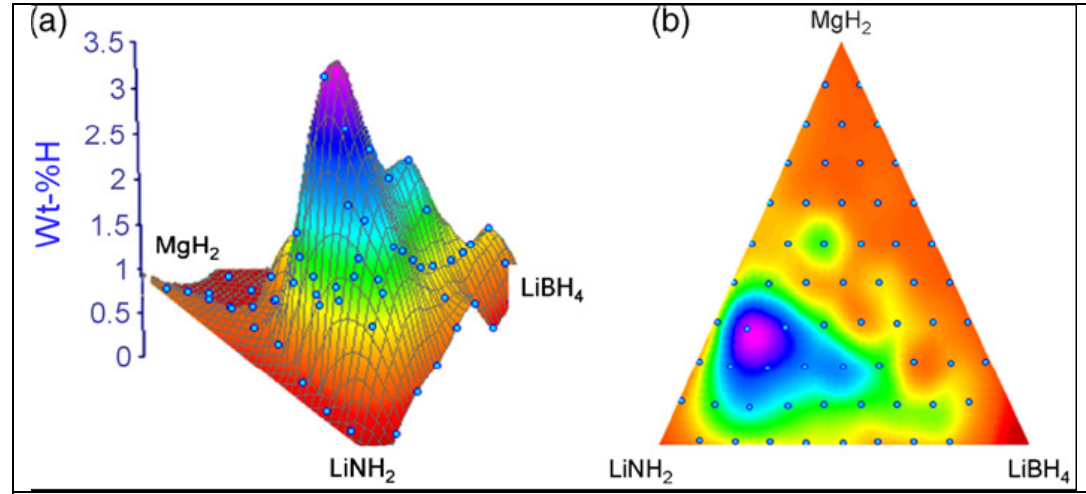

Figure 16. (a) 3D surface plot and (b) contour plot fitted to the observed reversible hydrogen storage capacity from second desorption to $220^{\circ} \mathrm{C}$ for $\mathrm{LiNH}_{2}-\mathrm{MgH}_{2}-\mathrm{LiBH}_{4}$ compositions. Highest hydrogen capacity is at $0.6 \mathrm{LiNH}_{2}-0.3 \mathrm{MgH}_{2}-0.1 \mathrm{LiBH}_{4}$. 
were among

the best

performers

under the

conditions

employed,

including the

literature

compositions.

To understand

the nature of

the reversible

species

involved, an

XRD study of a

composition

very close to

the best

composition,

$0.61 \mathrm{LiNH}_{2}-$

$0.27 \mathrm{MgH}_{2}-$

$0.12 \mathrm{LiBH}_{4}$, was

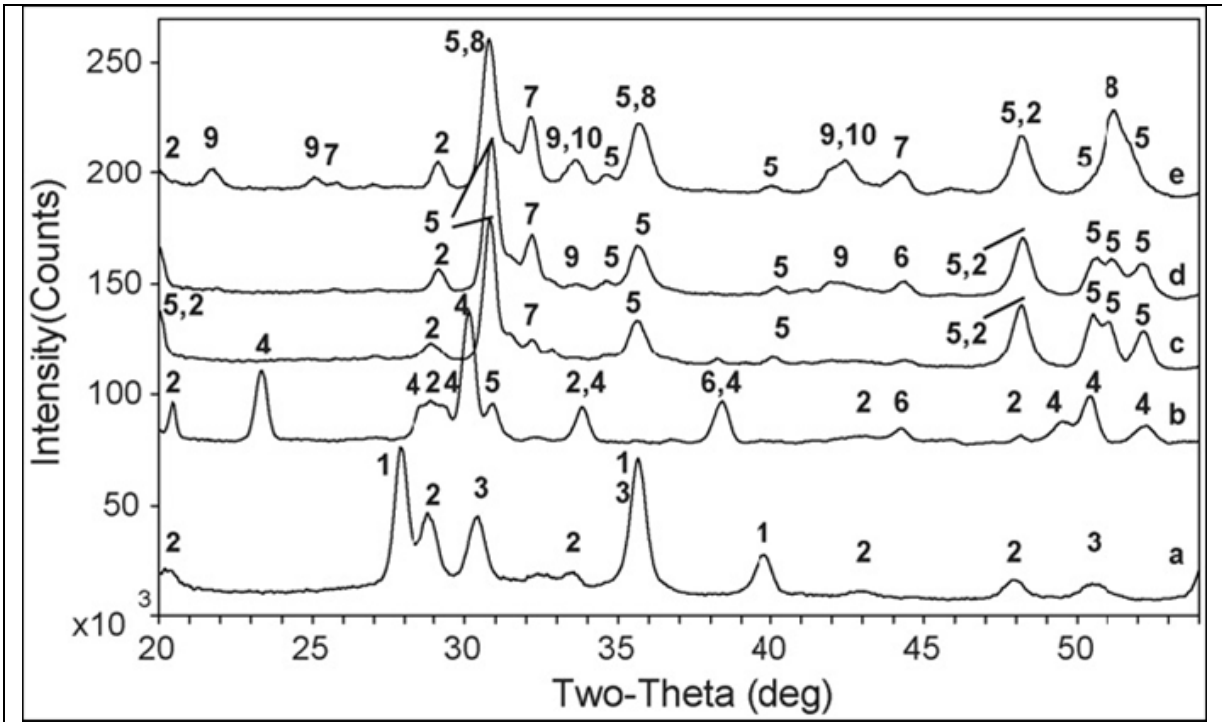

Figure 17. XRD study of $0.61 \mathrm{LiNH}_{2}-0.27 \mathrm{MgH}_{2}-0.12 \mathrm{LiBH}_{4}$ composition: (a) after milling, (b) after hydride-desorb-hydride-desorb-hydride cycle, (c) after desorption at $240^{\circ} \mathrm{C}$, (d) after desorption at $300^{\circ} \mathrm{C}$, (e) after desorption at $350{ }^{\circ} \mathrm{C} .1, \mathrm{MgH}_{2} ; 2, \mathrm{Li}_{4} \mathrm{BH}_{4}\left(\mathrm{NH}_{2}\right)_{3} ; 3, \mathrm{LiNH} 2 ; 4, \mathrm{Mg}\left(\mathrm{NH}_{2}\right)_{2} ; 5$, $\mathrm{Li}_{2} \mathrm{Mg}(\mathrm{NH})_{2} ; 6, \mathrm{LiH} ; 7, \mathrm{Li}_{3} \mathrm{BN}_{2} ; 8, " \mathrm{Li}_{2} \mathrm{NH}^{\prime} ; 9, \mathrm{Mg}_{3} \mathrm{~N}_{2} ; 10, \mathrm{MgB}_{2}$.

carried out, the results of which are shown in Figure 17. After milling, $\mathrm{MgH}_{2}$ and $\mathrm{LiNH}_{2}$ are present, but $\mathrm{LiBH}_{4}$ has disappeared, reacting with $\mathrm{LiNH}_{2}$ to form $\mathrm{Li}_{4} \mathrm{BH}_{4}\left(\mathrm{NH}_{2}\right)_{3}$

(Figure 17a). In the medium throughput apparatus, the sample was taken through a hydride-desorb-hydride-desorb-hydride program according to the conditions specified above before examination by XRD to determine the species present in the fully hydrided state.

The hydrided state of the reversible composition included $\mathrm{Mg}\left(\mathrm{NH}_{2}\right)_{2}, \mathrm{Li}_{4} \mathrm{BH}_{4}\left(\mathrm{NH}_{2}\right)_{3}$, $\mathrm{Li}_{2} \mathrm{Mg}(\mathrm{NH})_{2}$, and $\mathrm{LiH}$ (Figure 17b). The presence of the mixed imide, $\mathrm{Li}_{2} \mathrm{Mg}(\mathrm{NH})_{2}$, indicates that the hydriding process was incomplete. To examine the dehydrided state, a hydridedesorb cycle was carried out in the high throughput apparatus where the hydrogen is desorbed against atmospheric pressure, whereas the medium throughput apparatus desorbs hydrogen into a constant volume at pressures high enough to prevent complete desorption. The desorption was carried out by ramping to $240{ }^{\circ} \mathrm{C}$ at $2{ }^{\circ} \mathrm{C} / \mathrm{min}$. The XRD of the resulting material showed $\mathrm{Li}_{2} \mathrm{Mg}(\mathrm{NH})_{2}$ as the major phase, along with some $\mathrm{Li}_{4} \mathrm{BH}_{4}\left(\mathrm{NH}_{2}\right)_{3}$ and $\mathrm{Li}_{3} \mathrm{BN}_{2}$ (Figure 17c). These results suggest that the reversible reaction in this system is given by:

$$
\mathrm{Li}_{2} \mathrm{Mg}(\mathrm{NH})_{2}+2 \mathrm{H}_{2} \leftrightarrow \mathrm{Mg}\left(\mathrm{NH}_{2}\right)_{2}+2 \mathrm{LiH}
$$




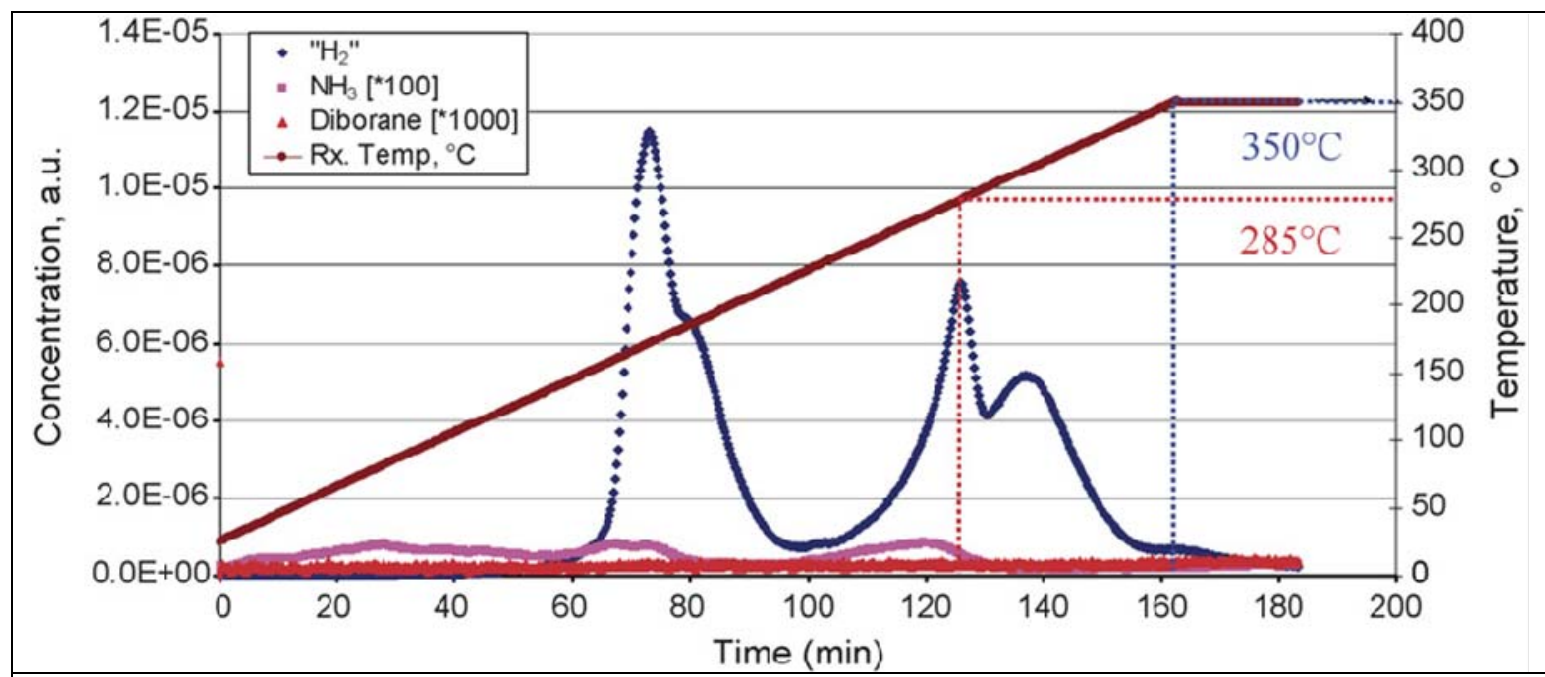

Figure 18. Thermal desorption mass spectrometry of $0.6 \mathrm{LiNH}_{2}-0.3 \mathrm{MgH}_{2}-0.1 \mathrm{LiBH}_{4}$ composition showing hydrogen, ammonia, and diborane signals. Ramp rate $=2{ }^{\circ} \mathrm{C} / \mathrm{min}$.

which operates in the presence of varying amounts of $\mathrm{Li}_{4} \mathrm{BH}_{4}\left(\mathrm{NH}_{2}\right)_{3}$. The active species are those previously reported for the $2 \mathrm{LiNH}_{2}-\mathrm{MgH}_{2}$ system. ${ }^{1,2}$ However, while the active species taking part in the hydrogen absorption/desorption reactions in this ternary system are similar to those in the binary $2 \mathrm{LiNH}_{2}-\mathrm{MgH}_{2}$ system, the reactivity is much higher. The two compositions in the phase diagram closest to $2 \mathrm{LiNH}_{2}-\mathrm{MgH}_{2}, 0.6 \mathrm{LiNH}_{2}-$ $0.4 \mathrm{MgH}_{2}$ and $0.7 \mathrm{LiNH}_{2}-0.3 \mathrm{MgH}_{2}$, yielded 0.5 and 0.2 wt. \% reversible $\mathrm{H}_{2}$, respectively, considerably less than the $3.4 \mathrm{wt} . \%$ observed in the ternary system. The theoretical hydrogen storage capacity of the $0.6 \mathrm{LiNH}_{2}-0.3 \mathrm{MgH}_{2}-0.1 \mathrm{LiBH}_{4}$ composition is 11.42 wt. $\%$, much more than accessed in the medium throughput study.

The higher temperature hydrogen and stability with respect to decomposition to $\mathrm{B}_{2} \mathrm{H}_{6}$ and $\mathrm{NH}_{3}$ were studied by thermal desorption mass spectrometry, shown in Figure 18. The hydrogen desorption occurs in lower temperature and higher temperature branches, each of which consists of two major peaks. The lower temperature branch shows a major peak at $170{ }^{\circ} \mathrm{C}$ and a shoulder at $195^{\circ} \mathrm{C}$. Since desorption is complete by about $225^{\circ} \mathrm{C}$, it is this hydrogen that was characterized by the medium throughput studies above. The higher temperature branch is characterized by desorption peaks at 285 and $300{ }^{\circ} \mathrm{C}$, with hydrogen evolution falling back to the baseline by $350{ }^{\circ} \mathrm{C}$. The mass spectrum shows small ammonia signals (multiplied by a factor of 100 in Figure 18) at about $100{ }^{\circ} \mathrm{C}$ and at 160 and $230{ }^{\circ} \mathrm{C}$, the latter two coincident with the onset of the low and high temperature branches of the hydrogen desorption. The diborane signal (multiplied by a factor of 1000 in Figure 18) remains in the baseline over the temperature range, suggesting good stability for the boron-containing species.

The phase diagram was then examined in the high throughput apparatus to characterize the higher temperature hydrogen. Using the mass spectrum of the $0.6 \mathrm{LiNH}_{2}-0.3 \mathrm{MgH}_{2}-0.1 \mathrm{LiBH}_{4}$ composition as a guideline, desorptions were carried out at $220^{\circ} \mathrm{C}, 285^{\circ} \mathrm{C}$, and twice at $350{ }^{\circ} \mathrm{C}$, with rehydriding steps using 120 bar $\mathrm{H}_{2}$ at $125^{\circ} \mathrm{C}$ in between. The inclusion of the $285^{\circ} \mathrm{C}$ desorption step in the program allows access to the lower temperature hydrogen within the higher temperature branch. The results are shown in the contour plots in Figure 19. The first desorption at $220^{\circ} \mathrm{C}$ yields the same best material, $0.6 \mathrm{LiNH}_{2}-0.3 \mathrm{MgH}_{2}-0.1 \mathrm{LiBH}_{4}$, at 4.8 wt. $\% \mathrm{H}_{2}$ (denoted by $\mathrm{X}$ in Figure 19a). This is higher than observed in the medium throughput apparatus because the hydrogen is desorbed against (lower) atmospheric pressure. After rehydriding, the second desorption at $285^{\circ} \mathrm{C}$ shows the reversible hydrogen for the $0.6 \mathrm{LiNH}_{2}-0.3 \mathrm{MgH}_{2}-$ 


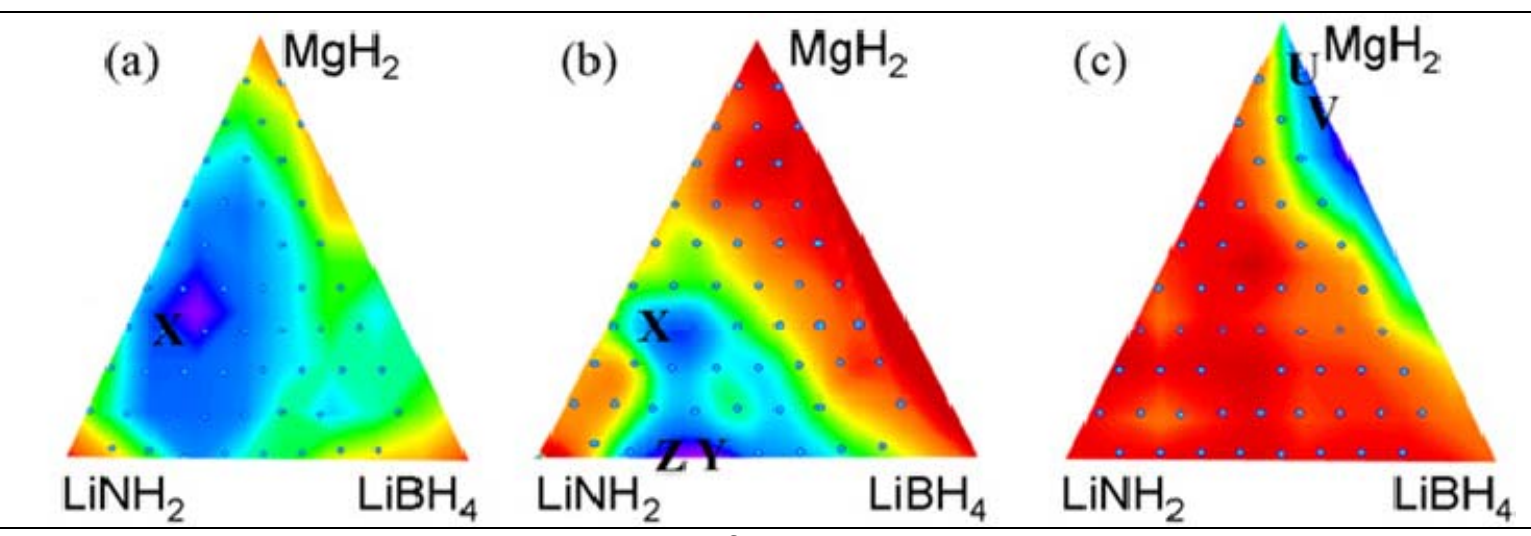

Figure 19. Hydrogen capacity measurements for the $\mathrm{LiNH}_{2}-\mathrm{MgH}_{2}-\mathrm{LiBH}_{4}$ phase diagram using the high throughput apparatus: (a) cycle 1 , desorption at $220^{\circ} \mathrm{C}$; (b) cycle 2 , desorption at $285^{\circ} \mathrm{C}$; (c) cycle 4 , desorption at $350{ }^{\circ} \mathrm{C}$. See text for symbols.

$0.1 \mathrm{LiBH}_{4}$ composition and that additionally new hydrogen has been accessed as the desorption increased to $6.1 \mathrm{wt} . \% \mathrm{H}_{2}$ (denoted by $\mathrm{X}$ in Figure 19b). However, the new maximum desorption compositions are along the $\mathrm{LiNH}_{2}-\mathrm{LiBH}_{4}$ binary line as $0.6 \mathrm{LiNH}_{2}-$ $0.4 \mathrm{LiBH}_{4}$ and $0.7 \mathrm{LiNH}_{2}-0.3 \mathrm{LiBH}_{4}$ yield 8.2 and 7.9 wt. $\% \mathrm{H}_{2}$, respectively (denoted by $\mathrm{Y}$ and $\mathrm{Z}$ in Figure 19b). Again the samples were hydrided and a third desorption was carried out at $350{ }^{\circ} \mathrm{C}$ (not shown in Figure 19). The compositions showing the best capacity in the previous desorptions were damaged and did not rehydride, all showing drastically reduced capacities of less than $1.5 \mathrm{wt}$ \%. The compositions showing the highest hydrogen capacities approached pure $\mathrm{MgH}_{2}$, including $0.9 \mathrm{MgH}_{2}-0.1 \mathrm{LiBH}_{4}, 5.6$ wt. $\%$, and $0.8 \mathrm{MgH}_{2}-0.2 \mathrm{LiBH}_{4}, 5.3 \mathrm{wt}$ \%. These compositions were not active in the lower temperature desorptions. After rehydriding and a fourth desorption at $350{ }^{\circ} \mathrm{C}$, these two compositions again showed the largest but diminished capacities of 3.62 and $4.05 \mathrm{wt}$. \% $\mathrm{H}_{2}$ (denoted by $\mathrm{U}$ and $\mathrm{V}$ in Figure 19c), respectively, perhaps because the hydriding conditions were too mild. Only six other compositions showed desorptions between 1 and 3 wt. $\% \mathrm{H}_{2}$ in this last desorption, indicating that the high temperature desorptions brought about the formation of phases that could not be reversed.

The nature of the irreversible phases was investigated by observing the XRD patterns of dehydrided $0.61 \mathrm{LiNH}_{2}-0.27 \mathrm{MgH}_{2}-0.12 \mathrm{LiBH}_{4}$ compositions after first desorptions to $300{ }^{\circ} \mathrm{C}$ (Figure $17 \mathrm{~d}$ ) and $350{ }^{\circ} \mathrm{C}$ (Figure 17e). While desorption to $300{ }^{\circ} \mathrm{C}$ still shows the formation of reversible $\mathrm{Li}_{2} \mathrm{Mg}(\mathrm{NH})_{2}$, it is apparent that this pattern is partly transforming to a $\mathrm{Li}_{2} \mathrm{NH}$ pattern by $350{ }^{\circ} \mathrm{C}$. Progressing from the reversible material isolated after desorption at $240{ }^{\circ} \mathrm{C}$ (Figure 17c) to that isolated after the $350{ }^{\circ} \mathrm{C}$ desorption (Figure 17e), the growing presence of irreversible components such as $\mathrm{Li}_{3} \mathrm{BN}_{2}, \mathrm{Mg}_{3} \mathrm{~N}_{2}$, and $\mathrm{MgB}_{2}$ is observed.

Since the operable reversible reaction for hydrogen storage in the optimum system appears to be reaction (3) above, we decided to make a direct comparison of the hydrogen desorption properties with the $2 \mathrm{LiNH}_{2}-\mathrm{MgH}_{2}$ composition by temperature programmed desorption, shown in Figure 20. While the lower temperature branch of the hydrogen desorption occurs at $190^{\circ} \mathrm{C}$ in the best composition, desorption in the 2 $\mathrm{LiNH}_{2}-\mathrm{MgH}_{2}$ system is just getting started at this temperature and does not reach a maximum in its low temperature desorption branch until $275^{\circ} \mathrm{C}$. While the operable storage reactions are the same for the two compositions, the reason for the lower temperature desorption in the $0.61 \mathrm{LiNH}_{2}-0.27 \mathrm{MgH}_{2}-0.12 \mathrm{LiBH}_{4}$ composition must be the 


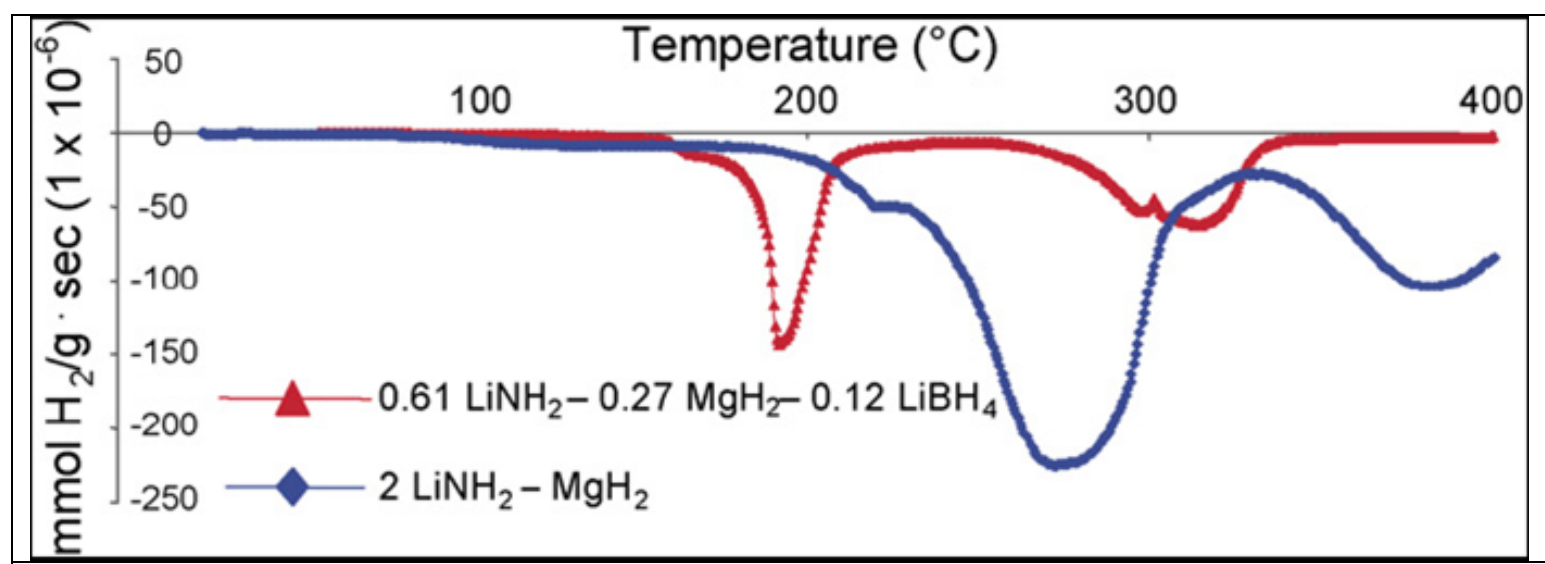

Figure 20. Comparison of hydrogen desorption properties of $0.61 \mathrm{LiNH}_{2}-0.27 \mathrm{MgH}_{2}-$ $0.12 \mathrm{LiBH}_{4}$ vs. $2 \mathrm{LiNH}_{2}-\mathrm{MgH}_{2}$ via temperature programmed reaction with mass spectrometry (TPR/MS).

presence of $\mathrm{Li}_{4} \mathrm{BH}_{4}\left(\mathrm{NH}_{2}\right)_{3}$, which is present in varying amounts throughout the reversible cycle. This phase was previously reported to melt. ${ }^{4}$ The $\mathrm{Li}_{4} \mathrm{BH}_{4}\left(\mathrm{NH}_{2}\right)_{3}$ would be melted at the temperatures over which the reversible hydrogen storage reactions occur in the best material. In the melted state, $\mathrm{Li}_{4} \mathrm{BH}_{4}\left(\mathrm{NH}_{2}\right)_{3}$ can act as a "solvent" to facilitate chemical transport of the species involved in the hydrogen storage reactions in the optimal composition, yielding much lower desorption temperatures than the $2 \mathrm{LiNH}_{2}-\mathrm{MgH}_{2}$ system, which relies purely on a solid state reaction.

Taking account of temperature reduction enhancement added by the presence $\mathrm{Li}_{4} \mathrm{BH}_{4}\left(\mathrm{NH}_{2}\right)_{3}$ and the fact that it does not contribute significantly to the hydrogen desorption capacity at temperatures of $220^{\circ} \mathrm{C}$ or less, we investigated lower $\mathrm{LiBH}_{4}$ levels of the best phase diagram composition, $0.6 \mathrm{LiNH}_{2}-0.3 \mathrm{MgH}_{2}-x \mathrm{LiBH}_{4}$, where $x=$ 0.05 and 0.025 , to see if the storage capacity could be optimized. The first and second desorption curves for these materials along with those for $2 \mathrm{LiNH}_{2}-\mathrm{MgH}_{2}(x=0)$ and the optimum $(x=0.1)$ are shown in Figure 21. As anticipated, the hydrogen storage capacities are higher for the lower values of $x$, because there is less of the non-
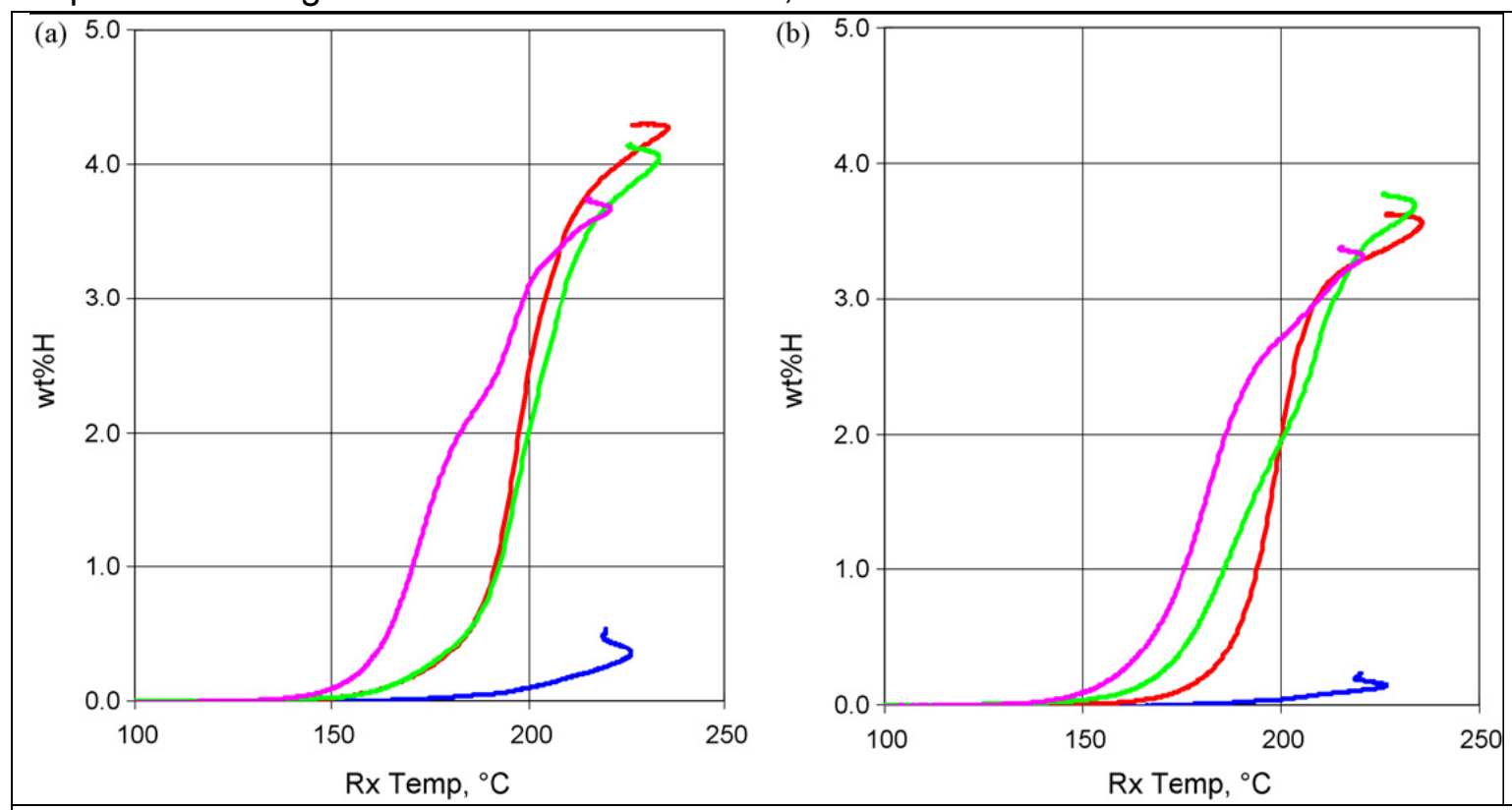

Figure 21. First (a) and second (b) desorption curves for the $0.6 \mathrm{LiNH}_{2}-0.3 \mathrm{MgH}_{2}-x \mathrm{LiBH}_{4}$ series. Key: $x=0.1$, magenta; $x=0.05$, green; $x=0.025$, red; $x=0$, blue. 
desorbing $\mathrm{Li}_{4} \mathrm{BH}_{4}\left(\mathrm{NH}_{2}\right)_{3}$. However, at the lower $\mathrm{LiBH}_{4}$ levels, desorption becomes more difficult as the temperature shifts upward by about $20^{\circ} \mathrm{C}$. This supports the idea that $\mathrm{Li}_{4} \mathrm{BH}_{4}\left(\mathrm{NH}_{2}\right)_{3}$ does not contribute to the $\mathrm{H}_{2}$ desorption, but rather serves to facilitate the chemistry in this system, allowing the $2 \mathrm{LiNH}_{2}-\mathrm{MgH}_{2}$ system to operate at lower temperatures.

A traditional hydrogen storage capacity measurement was performed on the 0.6 $\mathrm{LiNH}_{2}-0.3 \mathrm{MgH}_{2}-0.1 \mathrm{LiBH}_{4}$ material in the Jensen lab using the Sievert's apparatus (see Section 5.3) to document the reversible hydrogen storage properties of the ternary system. The first

\begin{tabular}{|c|c|c|}
\hline Cycle & $\mathrm{H}_{2} \mathrm{Wt} \%$ & $\begin{array}{l}\text { Hydrogenation } \\
\text { Conditions }\end{array}$ \\
\hline 1 & 4.2 & $120^{\circ} \mathrm{C}, 120$ bar $\mathrm{H}_{2}, 16 \mathrm{~h}$ \\
\hline 2 & 4.1 & $120^{\circ} \mathrm{C}, 120$ bar $\mathrm{H}_{2}, 16 \mathrm{~h}$ \\
\hline 3 & 3.5 & $120^{\circ} \mathrm{C}, 120$ bar $\mathrm{H}_{2}, 16 \mathrm{~h}$ \\
\hline 4 & 2.6 & $140^{\circ} \mathrm{C}, 120$ bar $\mathrm{H}_{2}, 16 \mathrm{~h}$ \\
\hline 5 & 3.3 & $\mathrm{n} / \mathrm{a}$ \\
\hline
\end{tabular}
dehydrogenation cycle evolved hydrogen at $100{ }^{\circ} \mathrm{C}$ and the rate of evolution increased drastically above $160{ }^{\circ} \mathrm{C}$. The material was rehydrogenated under the conditions of 120 ${ }^{\circ} \mathrm{C}$ at 120 bar for $16 \mathrm{~h}$. In subsequent cycles, the system begins dehydrogenation at 140 $-170{ }^{\circ} \mathrm{C}$. These conditions result in a material that can desorb/absorb $\sim 3 \mathrm{wt}$. $\%$ hydrogen reversibly. The results are shown in Table 6 and are similar to those found while utilizing the medium/high throughput assays.

Detailed investigation of $2 \mathrm{LiNH}_{2}-\mathrm{MgH}_{2}-\mathrm{LiBH}_{4}$. In the laboratory at Ford, this particular composition from the $\mathrm{LiNH}_{2}-\mathrm{MgH}_{2}-\mathrm{LiBH}_{4}$ ternary system was studied in great detail including kinetic hydrogen adsorption/desorption measurements, IR, in situ powder x-ray diffraction and first principles analysis of the thermodynamics. This system was chosen because of the possibility of a stoichiometry match of this hydrided composition with a known potential dehydrided material, $\mathrm{LiBMgN}_{2}$, the ability of this system to form the ionic liquid $\mathrm{Li}_{4}\left(\mathrm{NH}_{2}\right)_{3} \mathrm{BH}_{4}$ and to reduce desorption of ammonia because of the presence of $\mathrm{MgH}_{2}$. The results suggested that this system is "self-catalyzing" via a product seeding mechanism. This study appears in Appendix E.

6.2.2 Doped $\mathrm{LiNH}_{2}-\mathrm{LiBH}_{4}-\mathrm{MgH}_{2}$ Systems. It is well known that the success of $\mathrm{NaAlH}_{4}$ as a reversible hydrogen storage material was greatly improved once Ti was introduced as a catalyst by Bogdanovic. ${ }^{9}$ This approach was applied to optimum and near optimum $\mathrm{LiNH}_{2}-\mathrm{LiBH}_{4}-\mathrm{MgH}_{2}$ formulations utilizing a variety of transition metal catalysts to try to lower hydrogen desorption/absorption temperatures and increase reversible capacity, hopefully reaching the higher temperature hydrogen levels that these materials are known to possess. The compositions chosen for the doping studies were the $5 \mathrm{LiNH}_{2}$ : $2.2 \mathrm{MgH}_{2}: \mathrm{LiBH}_{4}(\mathbf{A})$ and $0.6 \mathrm{LiNH}_{2}: 0.3 \mathrm{MgH}_{2}: 0.1 \mathrm{LiBH}_{4}(\mathbf{B})$ formulations. The dopants included $\mathrm{Ni}, \mathrm{Ti}, \mathrm{Cr}, \mathrm{Yb}, \mathrm{Zr}$, and $\mathrm{Pd}$ and mixtures thereof added at $0.01-0.05$ mole fraction of the mole sum of $\mathrm{LiNH}_{2}+\mathrm{MgH}_{2}+\mathrm{LiBH}_{4}$. Sometimes carbon was used as a dopant at a level of $1 \mathrm{wt}$. \% of the sample. The results are summarized in Table 6 of Appendix D.

Hydrogen storage capacities observed from the medium throughput apparatus for these doped materials were definitely enhanced on the first desorption compared to the undoped materials. Figure 22 shows the effect of Ni doping of $\mathbf{A}$ at nickel levels of $0.01,0.02$, and 0.05 mole fraction. On the first desorption, all of the doped materials exceeded the capacity of the undoped material, with the 0.02 mole fraction Ni sample yielding $5.2 \mathrm{wt}$. \% $\mathrm{H}_{2}$. Desorption was more sluggish for the doped materials as desorption temperatures (taken at the temperature at which $1 \mathrm{wt} . \% \mathrm{H}_{2}$ had been 
evolved) shifted upwards $10-20^{\circ} \mathrm{C}$. Inspection of the desorption curves shows the doped materials did not reach any plateaus, but instead were in the process of desorbing more hydrogen at the end of the first desorption. In contrast, the undoped materials tend to nearly level off by the end of the desorption run. After rehydriding, the second desorption for the undoped material shifts $10^{\circ} \mathrm{C}$ to higher temperature and yields $0.2 \%$ less hydrogen, but the desorption curve has the same basic shape as that of the first desorption, suggesting reversibility. The doped materials showed completely different desorption curves in the second desorption. The curves were very flat, desorption temperatures were up to $50{ }^{\circ} \mathrm{C}$ higher, and the observed hydrogen evolved was in the range of $1-2.6 \mathrm{wt} . \% \mathrm{H}_{2}$, much lower than $4.2-5.2 \mathrm{wt}$. \% seen during the first desorption. The Ni doping definitely didn't enhance reversibility.

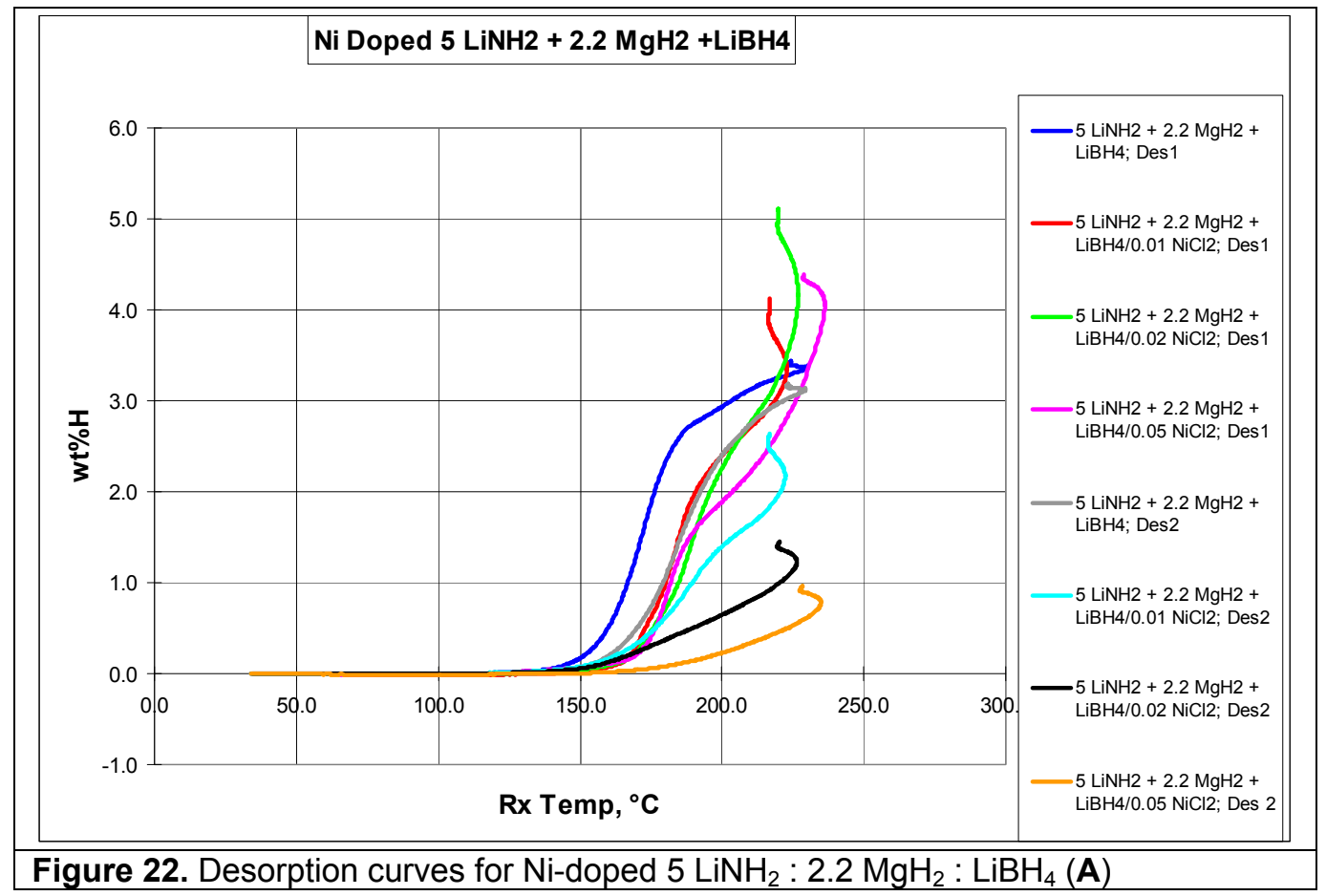

Figure 23 shows more desorption curves for $\mathbf{A}$ doped with various metals. Doping with $0.02 \mathrm{NiCl}_{2}+0.02 \mathrm{PdCl}_{2}$ (mole fraction basis) gave a desorption curve closer to, but inferior to the undoped $\mathbf{A}$, shifted by about $5-10^{\circ} \mathrm{C}$ to higher temperature (Figure 23, black curve). Once this material reached $220^{\circ} \mathrm{C}$, it continued to desorb, liberating 5.3 wt. $\% \mathrm{H}_{2}$. Early in the desorption $0.02 \mathrm{NiCl}_{2}+0.02 \mathrm{PdCl}_{2} / \mathbf{A}$ is about $15^{\circ} \mathrm{C}$ ahead of $0.02 \mathrm{NiCl}_{2} / \mathbf{A}$ (Figure 22, green curve), suggesting an enhancement due to $\mathrm{Pd}$. However, when $\mathbf{A}$ was doped with $0.02 \mathrm{PdCl}_{2}+1 \%$ carbon, desorption lagged $10-20{ }^{\circ} \mathrm{C}$ behind $0.02 \mathrm{NiCl}_{2}$ doped $\mathbf{A}$ and only reached 3.4 wt. $\% \mathrm{H}_{2}$ by $220{ }^{\circ} \mathrm{C}$ vs. 5.2 wt. $\% \mathrm{H}_{2}$ by Ni at the same temperature (Figure 23, gray curve). $\mathrm{NiCl}_{2}$ was also examined in the presence of 1 wt. \% carbon on A (Figure 23, green curve) and desorption occurred at slightly lower temperature (about $5^{\circ} \mathrm{C}$ ), although the total desorption was nearly $1 \mathrm{wt}$. \% less. A doped with $0.02 \mathrm{NiCl}_{2}+0.02 \mathrm{TiF}_{3}$ desorbed hydrogen at $5-10{ }^{\circ} \mathrm{C}$ higher temperature than $0.02 \mathrm{NiCl}_{2}+0.2 \mathrm{PdCl}_{2}$ and $5^{\circ} \mathrm{C}$ lower than Ni-doped $\mathbf{A}$, and also desorbed 5.3 wt. \% $\mathrm{H}_{2}$ (Figure 23, navy curve). This Ti-Ni doped material fared especially poorly on the second 


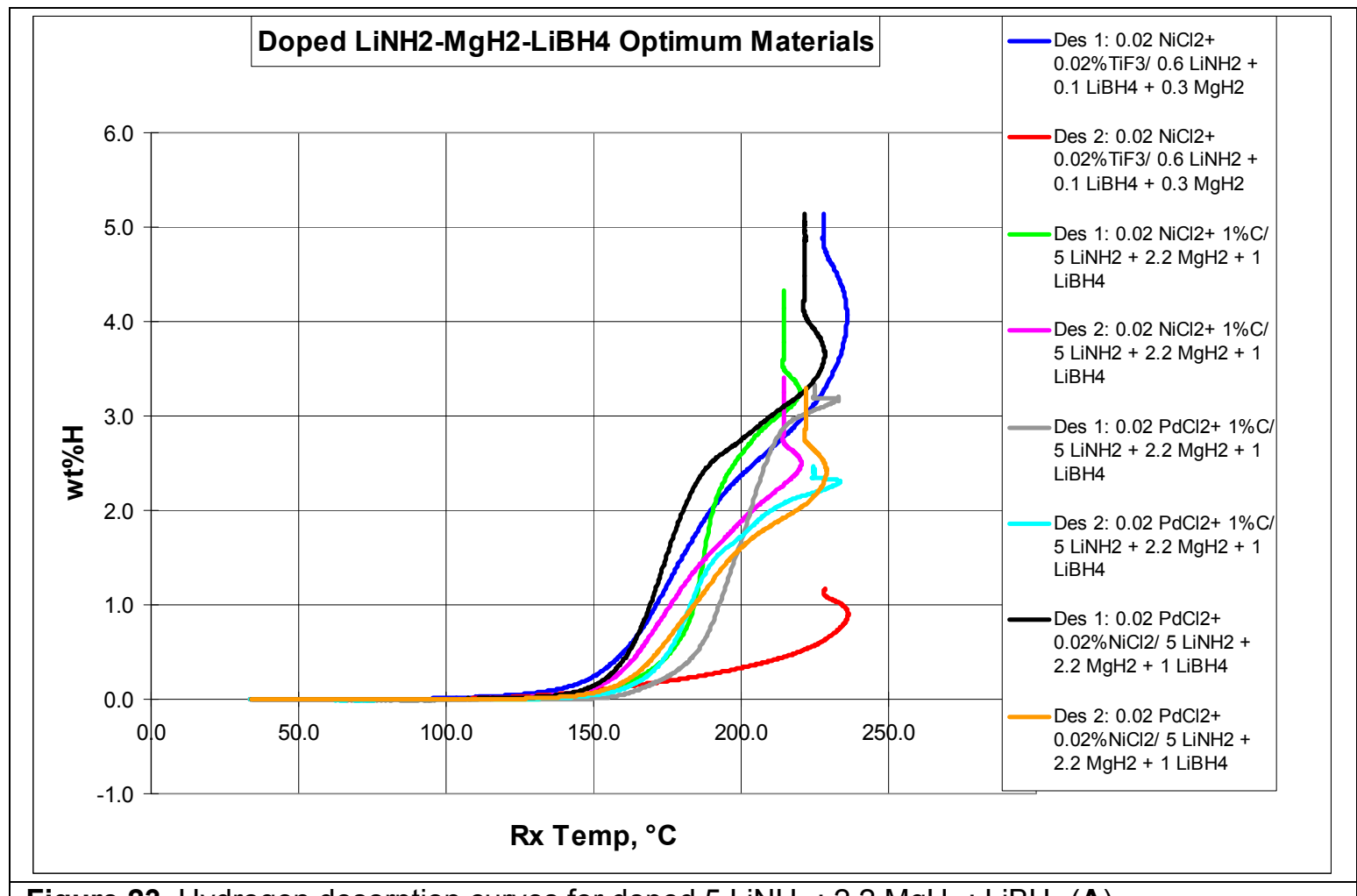

Figure 23. Hydrogen desorption curves for doped $5 \mathrm{LiNH}_{2}: 2.2 \mathrm{MgH}_{2}: \mathrm{LiBH}_{4}(\mathbf{A})$

desorption with a temperature shift of over $+50{ }^{\circ} \mathrm{C}$ giving up only 1 wt. $\% \mathrm{H}_{2}$ showing no reversibility (Figure 23, red curve). The $0.02 \mathrm{NiCl}_{2}+0.02 \mathrm{PdCl}_{2}$ fared a little better, with desorption shifted upward by about $30{ }^{\circ} \mathrm{C}$ and a decrease in capacity of about $2 \mathrm{wt} \%$ $\mathrm{H}_{2}$ (Figure 23, orange curve). The samples doped with carbon did a bit better showing reversible type behavior, but suffered capacity losses in each case. Interestingly, the $0.02 \mathrm{PdCl}_{2}+1 \%$ carbon doped $\mathbf{A}$ desorbed more hydrogen on the second desorption until near the end of the run at $200{ }^{\circ} \mathrm{C}$, at which time it fell behind the first desorption and ultimately desorbed 0.9 wt. \% less $\mathrm{H}_{2}$ (Figure 23 , teal curve). The same effect was observed in the $0.02 \mathrm{NiCl}_{2}+1 \%$ carbon with the second desorption leading the first desorption until $180{ }^{\circ} \mathrm{C}$, crossing at about $1.5 \mathrm{wt} \% \mathrm{H}_{2}$ desorbed (Figure 23, magenta curve). Again the total desorption fell by 0.9 wt. $\%$ in this case, closer to the $0.4 \%$ decrease in capacity seen in undoped $\mathbf{A}$. The reversible character, albeit poor, of these carbon containing samples is probably due to the suppressed desorption on the first desorption cycle. The metal-doped samples desorbed over $5 \mathrm{wt} . \% \mathrm{H}_{2}$, accessing some hydrogen that resulted in irreversible phase changes. The carbon containing samples did not desorb to this extent and did not form the hydrogen depleted irreversible phases.

Several runs were made in the high throughput (HT) apparatus starting at $350{ }^{\circ} \mathrm{C}$ desorption temperature. These were $\mathbf{B}$ doped with 0.02 mole $\mathrm{NiCl}_{2}$ and additional 0.02 mole $\mathrm{YbCl}_{3}, \mathrm{ZrF}_{4}$ or $\mathrm{CrF}_{3}$. The $\mathrm{H}_{2}$ desorption from these materials ranged from $3.5-6.4$ wt. \% on the first desorption, but didn't exceed $0.4 \%$ on the second desorption, having been rendered irreversible by the high desorption temperatures. See table 6 in Appendix D for details.

Several of the doped A materials were taken through a 4-cycle desorption program in the HT apparatus. The cycle consisted of two desorptions at $230{ }^{\circ} \mathrm{C}$ followed by two desorptions at $350^{\circ} \mathrm{C}$. There was a rehydriding step between each desorption step, carried out at 120 bar $\mathrm{H}_{2}$ and $230{ }^{\circ} \mathrm{C}$ after the first two desorptions and $350{ }^{\circ} \mathrm{C}$ 
after the third desorption. In the HT apparatus, desorption is carried out against atmospheric pressure, so the desorptions tend to be larger than those observed in the constant volume medium throughput apparatus. The $0.02 \mathrm{NiCl}_{2}+0.02 \mathrm{PdCl}_{2}$ doped $\mathbf{A}$ material, which yielded 5.3 and $3.4 \mathrm{wt} . \% \mathrm{H}_{2}$ on first and second desorptions in the medium throughput apparatus $\left(220^{\circ} \mathrm{C}\right)$, yielded $6.27,0.31,0.78$, and $2.19 \mathrm{wt} . \% \mathrm{H}_{2}$ in the HT apparatus. The higher degree of desorption during the first desorption cycle in the HT apparatus, despite being about the same desorption temperature as the MT runs, yielded a more damaged material as evidenced by the low second desorption capacity. This material retrieved some capacity on the fourth desorption when the rehydriding temperature was increased to $350{ }^{\circ} \mathrm{C}$.

Carbon also was confirmed to have a retarding effect on the desorption of $\mathrm{Ni}$ and Pd-doped $\mathbf{A}$ in the HT, just as seen in the MT apparatus. In the same 4-cycle desorption program, the $0.02 \mathrm{NiCl}_{2}+1 \mathrm{wt}$ \% carbon doped $\mathbf{A}$ yielded $5.75,1.13,1.61$ and 1.91 wt. $\% \mathrm{H}_{2}$, while $0.02 \mathrm{PdCl}_{2}+1 \%$ carbon doped $\mathbf{A}$ gave $4.19,3.50,5.05$, and $2.28 \mathrm{wt}$ \% $\mathrm{H}_{2}$. The Pd-carbon doped sample didn't suffer the dramatic drops in capacity after the first desorption as the other samples, looking almost reversible, while the $\mathrm{Ni}$ carbon doped sample had the only other second desorption of greater than $1 \mathrm{wt} . \% \mathrm{H}_{2}$. The $\mathrm{Pd}$-carbon had a surprisingly high third $\mathrm{H}_{2}$ desorption of $5.05 \mathrm{wt}$. \%, far above all of the other samples, the only other one above $1 \mathrm{wt}$. \% being the $\mathrm{Ni}$-carbon sample. The effect of carbon seemed to stabilize the Pd doped $\mathbf{A}$, but it was never tested on undoped A.

\subsubsection{Analogs of the $\mathrm{LiNH}_{2}-\mathrm{LiBH}_{4}-\mathrm{MgH}_{2}$ System}

6.2.3.1 $\mathrm{NaNH}_{2}-\mathrm{NaBH}_{4}-\mathrm{MgH}_{2}$ 'Na for $\mathrm{Li}$ ' Analog. The success of the $\mathrm{LiNH}_{2}-\mathrm{LiBH}_{4}$ $\mathrm{MgH}_{2}$ system suggested that the analogous $\mathrm{Na}$ system should be examined. The phase diagram for the compositions prepared is shown in Figure 24. Rather than evenly cover the phase diagram, the compositions were chosen to conform to some simple low whole number ratios. A rendering of the phase diagram that illustrates this is in Appendix A, last slide. Only one desorption cycle was carried out at $350{ }^{\circ} \mathrm{C}$ in the high throughput apparatus. The hydrogen storage capacity is also shown in Figure 24 according to the color coding.

Unfortunately some of the samples were ruined by air exposure before they could be run and these are shown in the phase diagram as the black points.

In terms of initial capacity, the best material had the composition 2 $\mathrm{NaNH}_{2}: \mathrm{NaBH}_{4}: \mathrm{MgH}_{2}$

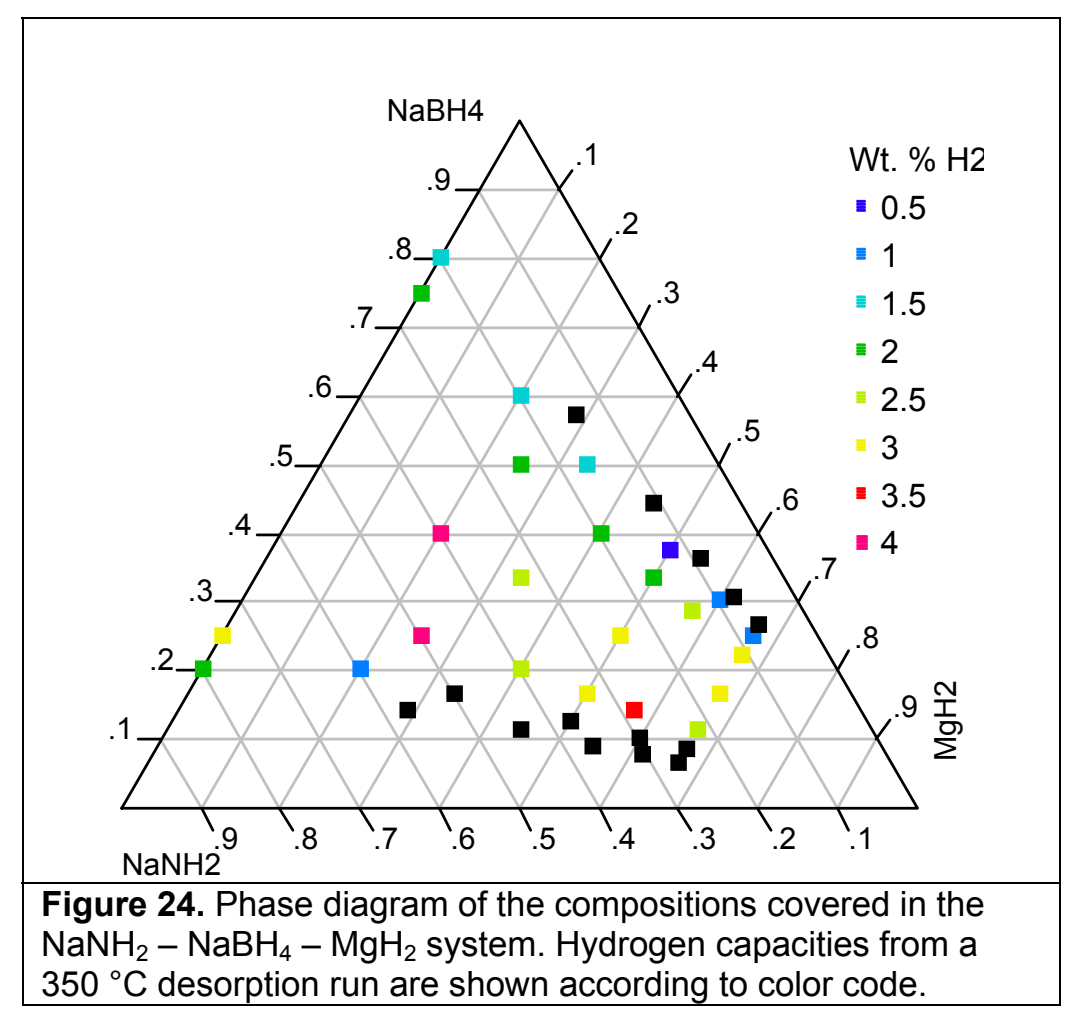


and yielded 4.49 wt. \% $\mathrm{H}_{2}$. The 2:1 ratio of $\mathrm{NaNH}_{2}: \mathrm{MgH}_{2}$ is reminiscent of the optimum composition in the corresponding Li system. However, this system was much more sluggish than the optimum Li system as shown in Figure 25. The four $\mathrm{NaNH}_{2}-\mathrm{NaBH}_{4}$ $\mathrm{MgH}_{2}$ compositions shown yield 0.50 wt. $\% \mathrm{H}_{2}$ by the time the desorption temperature reaches $200{ }^{\circ} \mathrm{C}$, while the Li systems have typically desorbed $2-3 \mathrm{wt} . \% \mathrm{H}_{2}$ by this temperature (see Figure 21). The desorption curves in Figure 25 are characterized by several plateaus, with the exception of the $\mathrm{MgH}_{2}$-richest phase. The red $\left(2 \mathrm{NaNH}_{2}+1\right.$ $\left.\mathrm{NaBH}_{4}+1 \mathrm{MgH}_{2}\right)$ and blue $\left(1 \mathrm{NaNH}_{2}+1 \mathrm{NaBH}_{4}+0.5 \mathrm{MgH}_{2}\right)$ traces in Figure 25 both contain 2:1 $\mathrm{NaNH}_{2}: \mathrm{MgH}_{2}$ and have nearly identical traces, the former yielding $4.49 \mathrm{wt}$ \% $\mathrm{H}_{2}$ vs. 4.25 wt. $\% \mathrm{H}_{2}$ for the latter, presumably due to the lower $\mathrm{NaBH}_{4}$ content. Both show a sudden jump in desorption at $225^{\circ} \mathrm{C}$ of about $0.7 \mathrm{wt} \%$. A phase richer in $\mathrm{MgH}_{2}$ (Figure 25, green trace, $2 \mathrm{NaNH}_{2}+1 \mathrm{NaBH}_{4}+4 \mathrm{MgH}_{2}$ ) exhibits at least three plateaus, with distinct increases in desorption at $190{ }^{\circ} \mathrm{C}, 265^{\circ} \mathrm{C}$ and $290{ }^{\circ} \mathrm{C}$. This material ultimately yielded $3.5 \mathrm{wt}$ \% $\mathrm{H}_{2}$ in this desorption run. As mentioned above, the $\mathrm{MgH}_{2}-$ rich material $1 \mathrm{NaNH}_{2}: 3 \mathrm{NaBH}_{4}: 8 \mathrm{MgH}_{2}$ (Figure 25, magenta trace) showed no plateaus and desorbed only $1.1 \mathrm{wt} . \% \mathrm{H}_{2}$. Unfortunately, no information on the phases associated with the aforementioned plateaus nor the reversibility was collected as the samples were ruined by exposure to the laboratory atmosphere. Because of the sluggish initial desorption in the samples tested, we opted not to repeat the syntheses of these compositions.

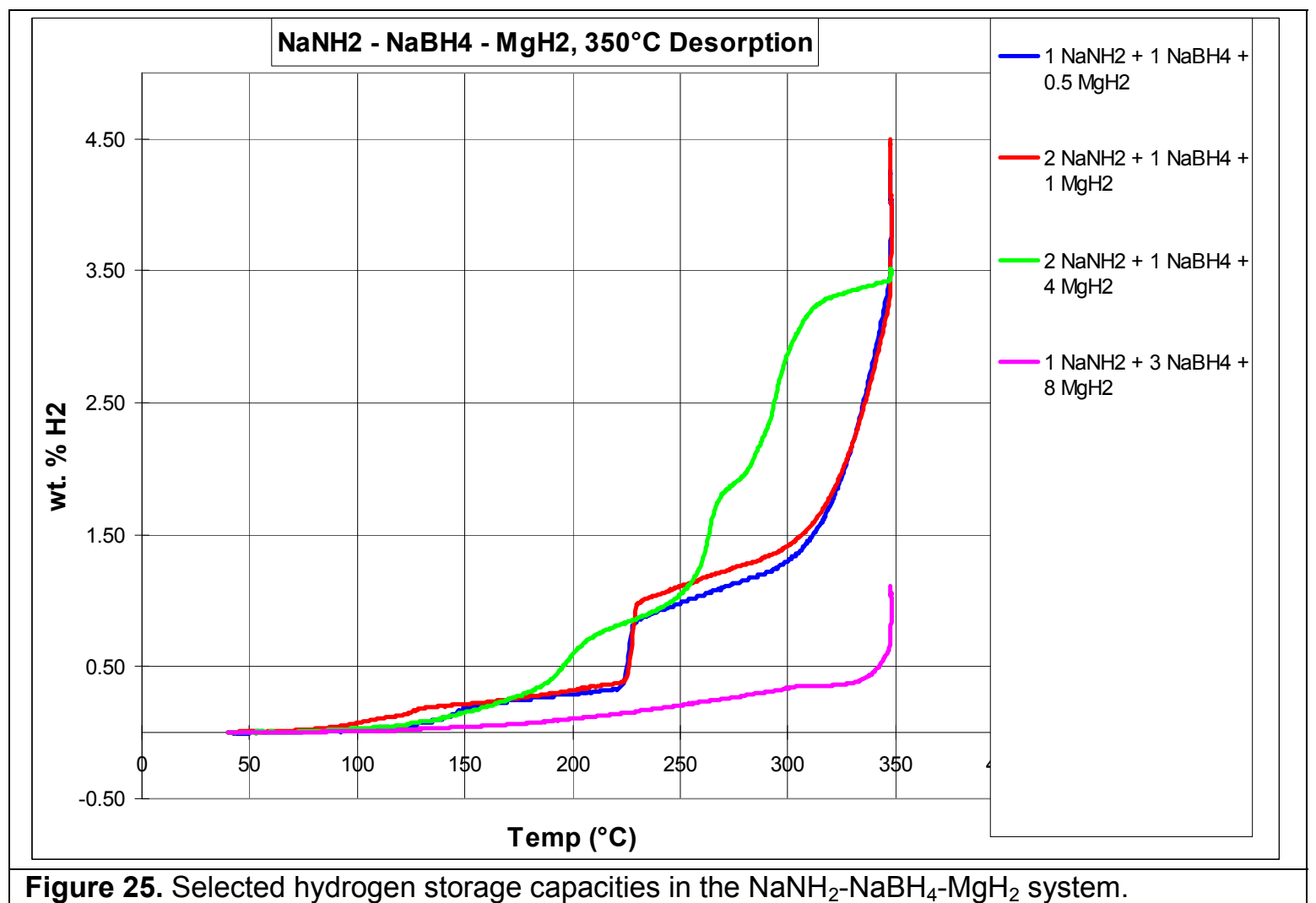


6.2.3.2 $\mathrm{LiNH}_{2}-\mathrm{LiBH}_{4}-\mathrm{CaH}_{2}$ ' $\mathrm{Ca}$ for $\mathrm{Mg}$ ' Analog. The $\mathrm{LiNH}_{2}-\mathrm{LiBH}_{4}-\mathrm{CaH}_{2}$ analog of the $\mathrm{LiNH}_{2}-\mathrm{LiBH}_{4}-\mathrm{MgH}_{2}$ system was investigated. Theoretical hydrogen storage capacities for the compositions investigated are shown in a phase diagram in Figure 26. Hydrogen storage capacities from both medium and high throughput assays and the structures of

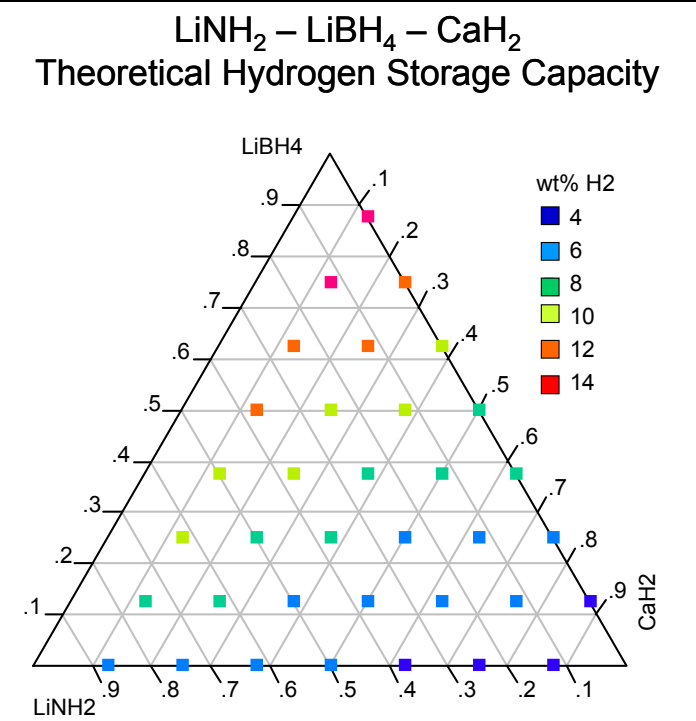

Figure 26. $\mathrm{LiNH}_{2}-\mathrm{LiBH}_{4}-\mathrm{CaH}_{2}$ phase diagram and theoretical storage capacities the spent materials from the medium throughput study are given in Table 7 in Appendix D. While hydrogen storage capacities of up to $14 \mathrm{wt}$ \% are possible, the results weren't nearly so promising. For example, in the medium throughput study, only two compositions exhibited storage capacities of over $1 \mathrm{wt}$. \% in both desorptions, $0.625 \mathrm{LiBH}_{4}+0.375 \mathrm{CaH}_{2}$ and $0.375 \mathrm{LiNH}_{2}+$ $0.25 \mathrm{LiBH}_{4}+0.375 \mathrm{CaH}_{2}$. The desorption profiles are nearly identical for these two materials and the similarities between the first and second desorptions show some reversible character, as seen in Figure 27. Interestingly, the $0.625 \mathrm{LiBH}_{4}+0.375 \mathrm{CaH}_{2}$ material contains no amide, which was a critical active reversible component in the analogous $\mathrm{LiNH}_{2}-\mathrm{LiBH}_{4}-\mathrm{MgH}_{2}$ system. This suggests the possibility that borohydride may have been activated, which is an important goal in this work. The alternatives are that the somewhat reversible desorption may be coming from $\mathrm{LiBH}_{4}$ or $\mathrm{CaH}_{2}$ rather than from the combination of these. Figure 27 shows the desorptions from the $\mathrm{CaH}_{2}$ - and $\mathrm{LiBH}_{4-}$

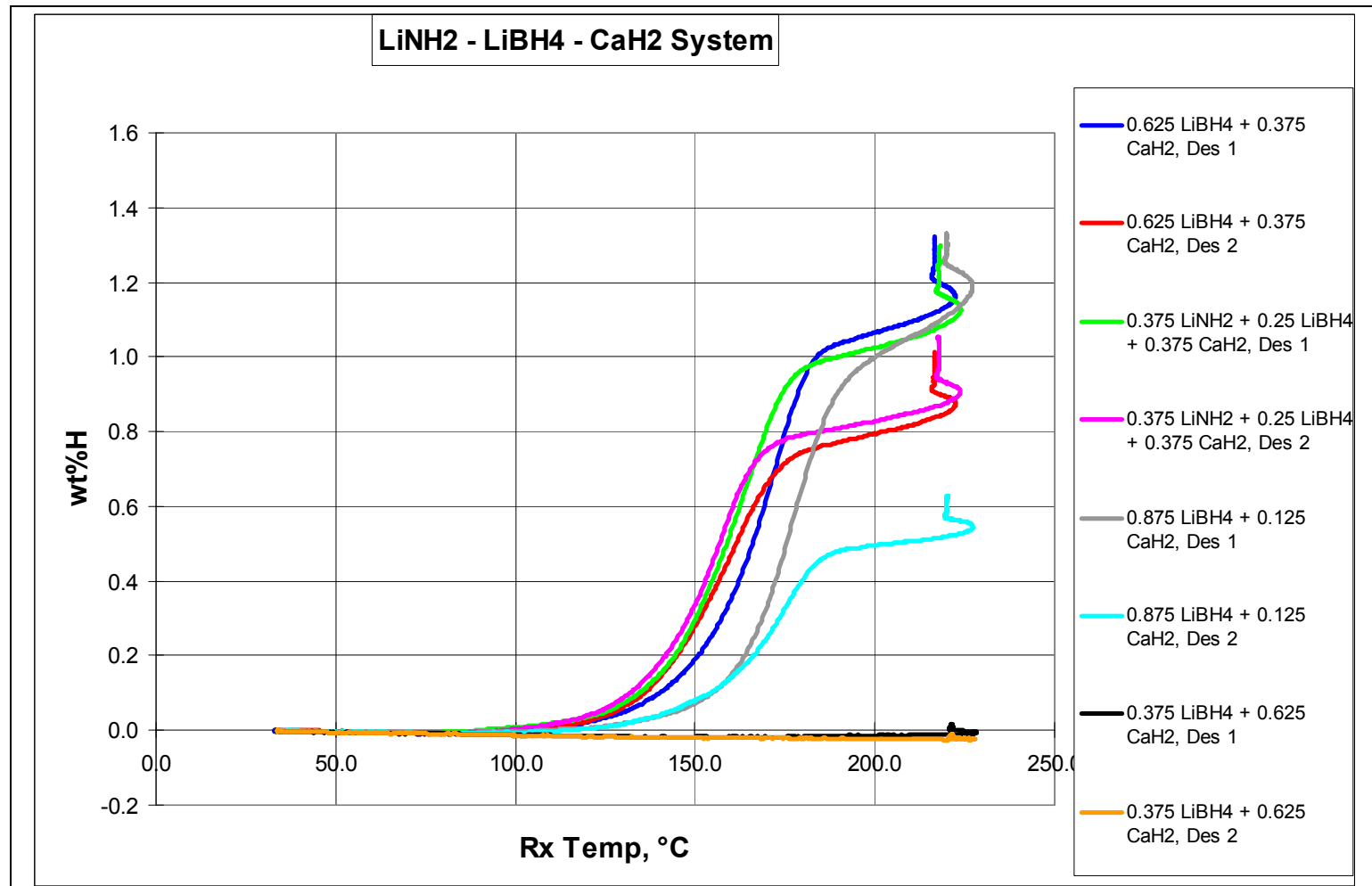

Figure 27. Medium throughput hydrogen desorption profiles for selected $\mathrm{LiNH}_{2}-\mathrm{LiBH}_{4}-\mathrm{CaH}_{2}$ compositions. 
rich combinations studied in the phase diagram, $0.625 \mathrm{CaH}_{2}+0.375 \mathrm{LiBH}_{4}$ and 0.875 $\mathrm{LiBH}_{4}+0.125 \mathrm{CaH}_{2}$. While the $\mathrm{CaH}_{2}$-rich system shows no hydrogen evolution on either desorption run, the borohydride-rich system shows evolution of $1.33 \mathrm{wt} . \% \mathrm{H}_{2}$ on the first desorption, but a marked decrease to $0.63 \mathrm{wt}$. $\% \mathrm{H}_{2}$ on the second desorption (Figure 27, gray and teal curves, respectively). The reversibility is better in the $0.625 \mathrm{LiBH}_{4}+$ $0.375 \mathrm{CaH}_{2}$ material which is very similar on the first desorption, $1.32 \mathrm{wt}$. \%, but falls less to $1.01 \mathrm{wt}$ \% hydrogen in the second desorption (Figure 27, navy and red traces, respectively). The amide-containing material $0.375 \mathrm{LiNH}_{2}+0.25 \mathrm{LiBH}_{4}+0.375 \mathrm{CaH}_{2}$ differs from the $0.625 \mathrm{LiBH}_{4}+0.375 \mathrm{CaH}_{2}$ in that the levels of $\mathrm{LiBH}_{4}$ and $\mathrm{CaH}_{2}$ are flipflopped in such a manner that their ratio in the former is similar to the $\mathrm{CaH}_{2}$-rich material $0.625 \mathrm{CaH}_{2}+0.375 \mathrm{LiBH}_{4}$ mentioned above, which had no hydrogen desorption (Figure 27, green and magenta curves, respectively). Yet the presence of the $\mathrm{LiNH}_{2}$ in 0.375 $\mathrm{LiNH}_{2}+0.25 \mathrm{LiBH}_{4}+0.375 \mathrm{CaH}_{2}$ is perhaps responsible for the $5-10{ }^{\circ} \mathrm{C}$ shift to lower temperature for hydrogen desorption vs. $0.625 \mathrm{LiBH}_{4}+0.375 \mathrm{CaH}_{2}$.

A quick look at Table 7 of Appendix $D$ shows the spent materials isolated for both the $0.625 \mathrm{LiBH}_{4}+0.375 \mathrm{CaH}_{2}$ and $0.375 \mathrm{LiNH}_{2}+0.25 \mathrm{LiBH}_{4}+0.375 \mathrm{CaH}_{2}$ to be materials that could not be identified by XRD. Figure 28 shows that the XRD of these spent materials are nearly identical, which perhaps explains the similar desorption

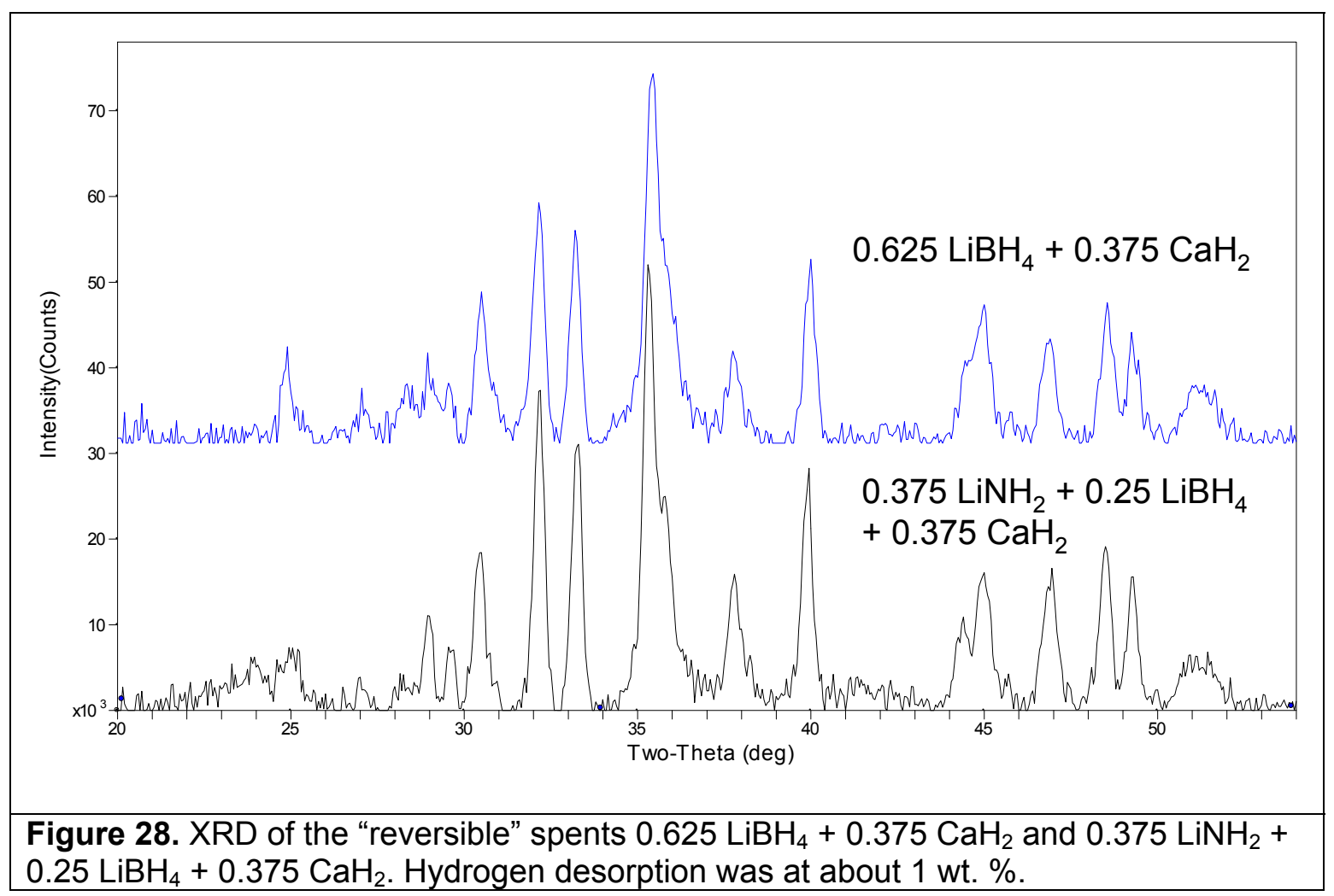

profiles. Portions of the pattern are similar to, but not a match for, $\mathrm{Ca}_{6} \mathrm{BN}_{5}$, which was seen in several other samples in this study (Table 7, Appendix D). It is interesting that two such different compositions yield a similar structure after the complicated chemistry that each sample experiences through the milling-desorption-rehydriding-desorption process that occurs before these spent materials are isolated. These particular materials were not investigated further owing to low storage capacity. However, this unknown also showed up as a component in the spents from the $0.75 \mathrm{LiBH}_{4}+0.25 \mathrm{CaH}_{2}$ and 0.875 $\mathrm{LiBH}_{4}+0.125 \mathrm{CaH}_{2}$ compositions. Other phases observed among the spent materials 
were unreacted starting materials, calcium and lithium imide, $\mathrm{CaNH}$ and $\mathrm{Li}_{2} \mathrm{NH}$, $\mathrm{Li}_{4}\left(\mathrm{NH}_{2}\right)_{3} \mathrm{BH}_{4}$ and spent Li-N-B-H phases which will be discussed elsewhere, and the nitrides $\mathrm{Li}_{3} \mathrm{BN}_{2}$ and $\mathrm{Ca}_{3} \mathrm{~N}_{2}$.

\subsection{Alkali/Alkaline Earth Single Metallohydride plus Single Hydride Systems.}

6.3.1 Metal - Amide System. This study examined combinations of metal amides $\left(\mathrm{NaNH}_{2}\right.$ and $\left.\mathrm{LiNH}_{2}\right)$ usually augmented by metal hydrides $\left(\mathrm{NaH}, \mathrm{LiH}\right.$, and $\left.\mathrm{MgH}_{2}\right)$. The phase diagrams in Figure 29 denote the majority of the majority of the compositions covered in the study. Some selected reactions were also carried out using $\mathrm{Mg}\left(\mathrm{NH}_{2}\right)_{2}$ and the hydrides $\mathrm{KH}$ and $\mathrm{CaH}_{2}$. Nearly all of the reactions included 0.02 mole $\mathrm{Ti}(\mathrm{OiPr})_{4}$ dopant. Tables $8 a$ and $8 b$ in Appendix $D$ give the compositions, XRD for as-synthesized and spent materials and medium throughput hydrogen storage capacity results for all of the reactions studied.

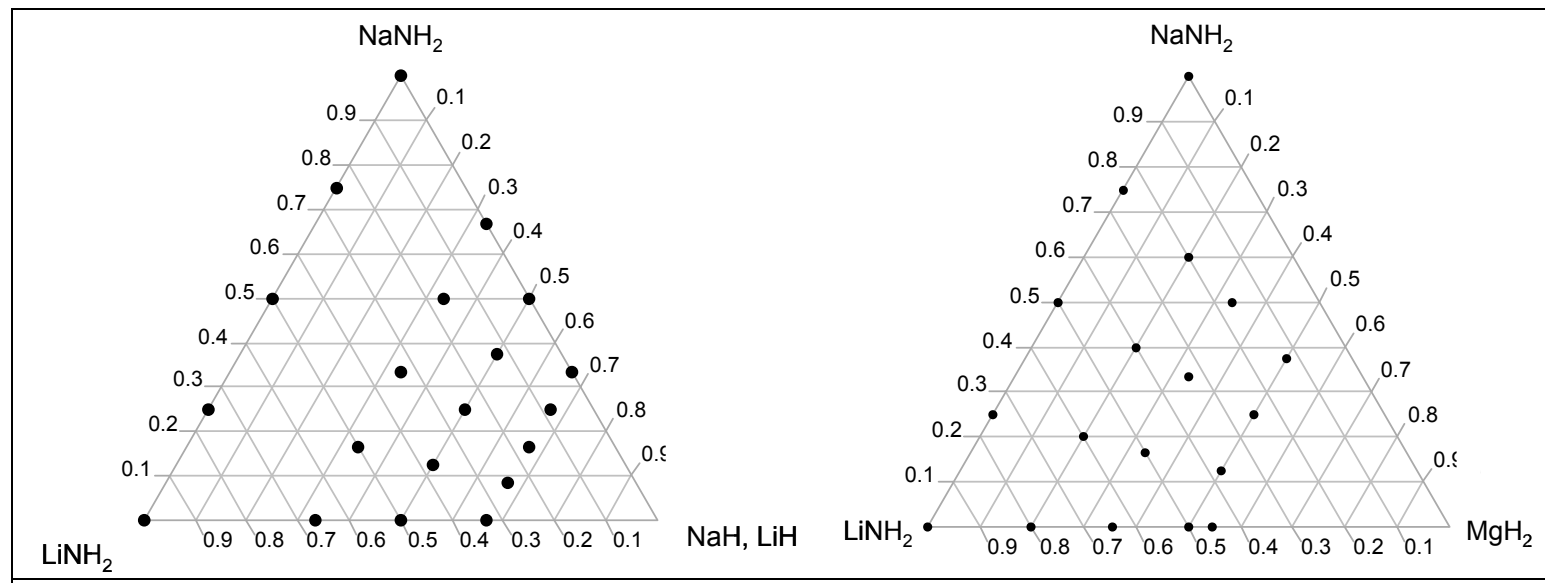

Figure 29. Phase diagrams depicting many of the compositions studied in the metal amide system.

The desorptions for the $\mathrm{LiNH}_{2}-\mathrm{NaNH}_{2}-(\mathrm{NaH}, \mathrm{LiH})$ phase diagram materials were conducted in the medium throughput apparatus. The maximum observed amount of hydrogen evolved in the first desorption was $1.4 \mathrm{wt} . \%$, far below the theoretical values. Typically, values ranged from $0.6-1.0 \mathrm{wt}$. $\% \mathrm{H}_{2}$. The maximum desorption temperature of $220{ }^{\circ} \mathrm{C}$ was probably not high enough to access the hydrogen, even in the presence of the Ti dopant. For the small amounts of hydrogen evolved in the first desorptions, there was absolutely no reversibility as the second desorptions yielded hydrogen storage capacities a factor of 5 less than that seen during the first desorptions. This lack of significant desorption is supported by the structures observed for the as-synthesized and the spent materials. After milling, XRD evaluation showed the materials to largely be unreacted starting materials. Exceptions were the combining of $\mathrm{Li}$ - and $\mathrm{Na}$-amides to make the mixed amide $\mathrm{Li}_{3} \mathrm{Na}\left(\mathrm{NH}_{2}\right)_{4}$ and some slight reaction between metal hydrides and amides to form the imide, $\mathrm{Li}_{2} \mathrm{NH}$. Ti and $\mathrm{TiH}_{2}$ were also observed in the XRD patterns of the milled materials. Several unidentified materials were observed in minor amounts consisting of only a couple peaks in the XRD pattern. Table 8a in Appendix D shows that the phase identifications for the spent materials are essentially the same as the as-synthesized. Differences include some observations of $\mathrm{Li}$ and $\mathrm{Na}$ hydroxide which may have come from environmental exposure. There were more observations of $\mathrm{Li}_{2} \mathrm{NH}$ formed as a result of the minor amount of hydrogen evolved. 
The reactions of $\mathrm{LiNH}_{2}$ and $\mathrm{NaNH}_{2}$ with $\mathrm{KH}$ and $\mathrm{CaH}_{2}$ gave similar results to the $\mathrm{LiH}$ and $\mathrm{NaH}$ reactions discussed above. The only sample to desorb over $1 \mathrm{wt} \% \mathrm{H}_{2}$ was $\mathrm{LiNH}_{2}+0.125 \mathrm{CaH}_{2}$, which yielded 0.22 wt. \% $\mathrm{H}_{2}$ on the second desorption, showing no reversible character. After milling, XRD analysis showed starting materials and some ion exchange as $\mathrm{KNH}_{2}$ was observed. In the case of the $\mathrm{CaH}_{2}$ reactions, milling always led to some reduction as both $\mathrm{CaNH}$ and $\mathrm{Li}_{2} \mathrm{NH}$ were observed. In the $\mathrm{KH}$ reactions with $\mathrm{NaNH}_{2}$, no reduced materials were observed even in the spent materials. The $\mathrm{CaH}_{2} / \mathrm{NaNH}_{2}$ reactions showed no reduced materials in the spents, even though the reduced $\mathrm{CaNH}$ was observed after milling. The mixed amide, $\mathrm{CaNa}\left(\mathrm{NH}_{2}\right)_{3}$ was observed in the spent materials. The spent materials from the $\mathrm{LiNH}_{2} / \mathrm{CaH}_{2}$ reactions contained reduced material only in the form of $\mathrm{Li}_{2} \mathrm{NH}$, while Ca was observed only in $\mathrm{CaH}_{2}$, presumably due to the greater stability of $\mathrm{Li}_{2} \mathrm{NH}$ vs. $\mathrm{CaNH}$.

The $\mathrm{LiNH}_{2}-\mathrm{NaNH}_{2}-\mathrm{MgH}_{2}$ reactions were much more successful than those discussed above, but all paled by comparison to the well known $2 \mathrm{LiNH}_{2}+\mathrm{MgH}_{2}$ system, which was included in the study. In this experiment, this model system yielded 3.47 and $2.55 \mathrm{wt} . \% \mathrm{H}_{2}$ on the first and second desorptions, respectively. The addition of $\mathrm{NaNH}_{2}$ to the system did nothing to enhance the desorption properties. While several of the ternary compositions exhibited first desorptions between 2-3 wt. $\% \mathrm{H}_{2}$, the second desorptions for the same materials ranged from $0.44-0.76 \mathrm{wt} . \% \mathrm{H}_{2}$, exhibiting little reversibility. The XRD analysis showed the as-synthesized materials to consist of $\mathrm{MgH}_{2}$ and $\mathrm{Na}$-, $\mathrm{Li}$-, and $\mathrm{Na}-\mathrm{Li}$ mixed amide, $\mathrm{NaLi}_{3}\left(\mathrm{NH}_{2}\right)_{4}$, and some $\mathrm{Li}_{2} \mathrm{NH}$ similar to the reactions above and the spent materials often did contain some $\mathrm{Li}_{2} \mathrm{Mg}(\mathrm{NH})_{2}$ and $\mathrm{Mg}\left(\mathrm{NH}_{2}\right)_{2}$, active reversible hydrogen storage materials in the $\mathrm{LiNH}_{2}-\mathrm{MgH}_{2}$ system. However, the spent material XRD also showed significant formation of $\mathrm{NaMgH}_{3}$, which is not reversible under these conditions and robs the $\mathrm{Mg}$ from participating in reversible storage chemistry. Hence the addition of $\mathrm{NaNH}_{2}$ to the $\mathrm{LiNH}_{2}-\mathrm{MgH}_{2}$ system had a negative impact on reversible hydrogen storage chemistry.

A few reactions were conducted using $\mathrm{Mg}\left(\mathrm{NH}_{2}\right)_{2}$ as the amide and combining this with either $\mathrm{LiH}, \mathrm{NaH}$, or $\mathrm{MgH}_{2}$. The compositions, structures, and hydrogen storage capacities are detailed in Table $8 \mathrm{~b}$ in Appendix $\mathrm{D}$. The results are very similar to the $\mathrm{LiNH}_{2}-\mathrm{NaNH}_{2}-\mathrm{MgH}_{2}$ system in that only the Li-containing systems showed first desorptions of over $3-4 \mathrm{wt} . \% \mathrm{H}_{2}$ and poor reversibility $\left(<2 \mathrm{wt} . \% \mathrm{H}_{2}\right)$ for these compositions. The XRD of the spent materials also showed some $\mathrm{Li}_{2} \mathrm{Mg}(\mathrm{NH})_{2}$ and $\mathrm{Mg}\left(\mathrm{NH}_{2}\right)_{2}$, which are active in reversible hydrogen storage, but in combination with other non-active phases. Overall, a few unknown diffraction patterns were observed in the metal-amide study, but they usually occurred in mixtures and they were not associated with compositions that had favorable hydrogen capacity values, so these materials were not pursued. They are described in Table 8a of Appendix D, where they are labeled A E.

Detailed first principles study of Li-Mg-N-H System. This study, carried out at UCLA and Ford, demonstrates the use of first principles to determine a multi-component hydride phase diagram, applying the method to the $\mathrm{Li}-\mathrm{Mg}-\mathrm{N}-\mathrm{H}$ quaternary system to predict the allowed hydrogen storage reactions within this system. The approach was able to identify all of the experimentally observed reaction pathways in this well studied system. This study can be found in Appendix F.

6.3.2 Metal - Borohydride System. An important goal and a great challenge in this work was to develop B-based hydrogen storage materials. Boron-based compounds are very desirable from gravimetric hydrogen storage considerations, but from the stability standpoint they are troublesome. The alkali borohydrides are extremely stable with 
$\mathrm{LiBH}_{4}$ and $\mathrm{NaBH}_{4}$ desorbing $\mathrm{H}_{2}$ at $380{ }^{\circ} \mathrm{C}$ and $400{ }^{\circ} \mathrm{C}$ respectively. On the other hand, transition metal borohydrides are extremely unstable with $\mathrm{Co}, \mathrm{Fe}$ and $\mathrm{Ni}$ borohydrides desorbing $\mathrm{H}_{2}$ at about $-30^{\circ} \mathrm{C}$ and $\mathrm{Cu}$ borohydride at $0{ }^{\circ} \mathrm{C}$. Zinc borohydride desorbs at a more reasonable $85^{\circ} \mathrm{C}$, but zinc is relatively heavy. ${ }^{35}$ The other problem with borohydride systems is the possibility of desorbing diborane, $\mathrm{B}_{2} \mathrm{H}_{6}$, rather than hydrogen. Here we attempt to make borohydrides of intermediate stability between the extremes mentioned above by combining the very stable alkali borohydrides with the more unstable transition metal borohydrides. The resulting alkali - transition metal borohydrides could be better behaved in hydrogen adsorption/desorption reactions than the constituent starting materials.

Anionic transition metal borohydrides have been synthesized by the ball milling for one hour transition metal chlorides with Group I borohydrides following the reaction:

$$
\begin{aligned}
& \mathrm{MCl}_{\mathrm{x}}+(\mathrm{X}+\mathrm{Y}) \mathrm{M}^{\prime} \mathrm{BH}_{4} \longrightarrow \underset{\mathrm{y}}{\mathrm{M}} \longrightarrow \mathrm{M}_{\mathrm{y}}^{\prime} \mathrm{M}\left(\mathrm{BH}_{4}\right)_{\mathrm{x}+\mathrm{y}}+\mathrm{x} \mathrm{MCl} \\
& \mathrm{M} \text { transition metal, } \mathrm{M}^{\prime}=\text { Group I metal }
\end{aligned}
$$

and by the ball milling for $1 \mathrm{~h}$ at $77 \mathrm{~K}$ of neutral transition metal borohydrides with Group I borohydrides:

$$
\mathrm{M}\left(\mathrm{BH}_{4}\right)_{\mathrm{x}}+\mathrm{YM}^{\prime} \mathrm{BH}_{4} \longrightarrow \mathrm{M}_{\mathrm{y}}^{\prime} \mathrm{M}\left(\mathrm{BH}_{4}\right)_{\mathrm{x}+\mathrm{y}}
$$

Analysis and characterization of the zinc complexes were completed within 48 hours as they undergo significant decomposition upon standing at room temperature after longer periods of time.

Infrared analysis has has been a primary method in characterizing various zinc borohydride materials. ${ }^{36,37,38}$ Solid state synthesis of zinc borohydride reported by Mal'tseva et.al. ${ }^{39,40}$ showed that completeness of the reaction could be monitored by the infrared spectra. This method is most useful because it provides information about the metal-ligand coordination geometry and bonding. The borohydride anion in alkali metal tetrahydroborates has a characteristic band at $2290 \mathrm{~cm}^{-1}$. In the spectrum for zinc borohydride this band disappears and the appearance of bands corresponding to the vibrations of bridging $\left(\sim 2100 \mathrm{~cm}^{-1}\right)$ and terminal $\left(\sim 2450 \mathrm{~cm}^{-1}\right) \mathrm{B}-\mathrm{H}$ bonds are observed. The presence of both bridging and terminal bands provides evidence that the borohydride groups are coordinated to the zinc metal center. In addition, the appearance of a band at $\sim 1410 \mathrm{~cm}^{-1}$ indicates a $\mathrm{Zn}-\mathrm{H}$ stretching mode that also provides evidence of coordination to this metal center.

Similar bands have been reported for a mechanically activated mixture of sodium borohydride and zinc chloride to form $\mathrm{NaZn}\left(\mathrm{BH}_{4}\right)_{3}\left(\mathrm{~B}-\mathrm{H}\right.$ bridging at $2060 \mathrm{~cm}^{-1}$ and $\mathrm{B}-\mathrm{H}$ terminal at $\left.2440 \mathrm{~cm}^{-1}\right) \cdot{ }^{41}$ This means that the presence of these bands is an indication of the formation of the anionic alkali derivatives of zinc borohydride as well. The B-H bridging band undergoes a greater shift (from $2100 \mathrm{~cm}^{-1}$ to $2060 \mathrm{~cm}^{-1}$ ) because the bridging bonds will have a more intense interaction with the presence of additional borohydride groups when compared to the terminal bonds (which only shift from 2450 $\mathrm{cm}^{-1}$ to $2440 \mathrm{~cm}^{-1}$ ).

The reaction of zinc chloride and lithium borohydride was monitored for five hours with an IR spectra obtained every hour. It was shown that at five hours the borohydride anion band at $\sim 2290 \mathrm{~cm}^{-1}$ had reduced intensity. On the other hand, the bands corresponding to the vibrations of bridging $\left(\sim 2100 \mathrm{~cm}^{-1}\right)$ and terminal $\left(\sim 2450 \mathrm{~cm}^{-1}\right)$ $\mathrm{B}-\mathrm{H}$ bonds were observed with greater intensity. ${ }^{39}$ In addition the appearance of the $\mathrm{Zn}$ $\mathrm{H}$ stretching band is observed at $1412 \mathrm{~cm}^{-1}$. These observations indicate the formation of bonds between the borohydride ligands and the zinc metal center. This signifies that 
the nature of the bonding transitioned from the ionic bonding of the lithium borohydride precursor to the covalent bonding of zinc borohydride. (Note: Bands around $1120 \mathrm{~cm}^{-1}$ correspond to $\mathrm{BH}_{2}$ bending). ${ }^{43}$ The resulting spectra indicate that, for all the product mixtures, a change took place in the nature of bonding because all the spectra show evidence of new and different peaks when compared to the spectra of the starting materials (see Table 7).

Table 7. Summary of major bands observed in IR spectra of reaction products. Note: While only the assumed products are noted in the table, bands corresponding to the starting materials are present after milling.

\begin{tabular}{|l|l|}
\hline Products & IR Peaks $\left(\mathbf{c m}^{-1}\right)$ \\
\hline $\mathrm{Zn}\left(\mathrm{BH}_{4}\right)_{2}+2 \mathrm{LiCl}$ & $2449,2288,2086,1412$ \\
\hline $\mathrm{LiZn}\left(\mathrm{BH}_{4}\right)_{3}+2 \mathrm{LiCl}$ & $2447,2290,2084,1387$ \\
\hline $\mathrm{Li} 2 \mathrm{Zn}\left(\mathrm{BH}_{4}\right)_{4}+2 \mathrm{LiCl}$ & $2448,2306,2084,1406$ \\
\hline $\mathrm{NaZn}\left(\mathrm{BH}_{4}\right)_{3}+2 \mathrm{NaCl}$ & $2450,2223,2090,1401$ \\
\hline $\mathrm{Na}_{2} \mathrm{Zn}\left(\mathrm{BH}_{4}\right)_{4}+2 \mathrm{NaCl}$ & $2451,2295,2089,1387$ \\
\hline $\mathrm{KZn}\left(\mathrm{BH}_{4}\right)_{3}+2 \mathrm{KCl}$ & $2365,2289,2216,1395$ \\
\hline $\mathrm{K}_{2} \mathrm{Zn}\left(\mathrm{BH}_{4}\right)_{4}+2 \mathrm{KCl}$ & $2280,2210,2088,1407$ \\
\hline $\mathrm{K}_{2} \mathrm{Zn}_{3}\left(\mathrm{BH}_{4}\right)_{8}+2 \mathrm{~K}_{3} \mathrm{Zn}_{2} \mathrm{Cl}_{7}$ & $2419,2290,2087,1404$ \\
\hline
\end{tabular}

This method of monitoring the formation of the anionic transition metal borohydride complexes was found to be generally applicable. For example, monitoring the milling of $\mathrm{NaBH}_{4}$ and $\mathrm{MnCl}_{2}$ by IR shows the formation of new peaks at 1213 and $1341 \mathrm{~cm}^{-1}$ together with shoulders at 2150 and $2400 \mathrm{~cm}^{-1}$ which increase with ball milling time (up to $7 \mathrm{hr}$ ).

For the material $\mathrm{K}_{2} \mathrm{Zn}_{3}\left(\mathrm{BH}_{4}\right)_{8}$, both Mal'tseva ${ }^{41}$ and Mikheeva ${ }^{42}$ reported XRD patterns that confirmed the formation of the complex from the starting materials zinc chloride and potassium borohydride. In addition, Jeon and $\mathrm{ChO}^{43}$ monitored the decomposition of $\mathrm{Zn}\left(\mathrm{BH}_{4}\right)_{2}(+\mathrm{NaCl})$ by $\mathrm{XRD}$ and observed the formation of free $\mathrm{Zn}$ metal. Our studies monitor the formation/presence of the alkali chloride salt by-product, which forms upon the synthesis of the complex zinc borohydride. This is useful because the borohydrides are novel complexes which have not been previously studied by powder XRD methods and there are no patterns by which to match our results. In addition, the borohydride complexes are often amorphous and do not have distinct peaks in the XRD patterns, while the alkali chlorides have definite peaks.

While the diffraction patterns of the desired compounds are currently unknown (except $\left.\mathrm{K}_{2} \mathrm{Zn}_{3}\left(\mathrm{BH}_{4}\right)_{8}\right){ }^{41,42}$ the patterns indicate successful synthesis upon the identification of the lithium-, sodium-, or potassium-chloride byproducts. The formation of the respective alkali chloride byproducts is evident in the X-ray patterns of $\mathrm{Zn}\left(\mathrm{BH}_{4}\right)_{2}$, $\mathrm{LiZn}\left(\mathrm{BH}_{4}\right)_{3}, \mathrm{Li} 2 \mathrm{Zn}\left(\mathrm{BH}_{4}\right)_{4}, \mathrm{NaZn}\left(\mathrm{BH}_{4}\right)_{3}$, and $\mathrm{Na}_{2} \mathrm{Zn}\left(\mathrm{BH}_{4}\right)_{4}$. However, this evidence is not obvious in the X-ray patterns of $\mathrm{KZn}\left(\mathrm{BH}_{4}\right)_{3}$ and $\mathrm{K}_{2} \mathrm{Zn}\left(\mathrm{BH}_{4}\right)_{4}$ where the diffraction peaks corresponding to the potassium chloride byproduct are not as obvious. For these patterns, the major peaks correspond to the potassium borohydride precursor. For the XRD pattern of the $\mathrm{K}_{2} \mathrm{Zn}_{3}\left(\mathrm{BH}_{4}\right)_{8}$ product mixture, peaks clearly matched X-ray patterns already obtained for the crystalline material. In this case, it is also not obvious if $\mathrm{KCl}$ is part of the product mixture or if the proposed $\mathrm{K}_{3} \mathrm{Zn}_{2} \mathrm{Cl}_{7}$ byproduct is present.

Another useful method of characterization of borohydrides is ${ }^{11} \mathrm{~B} N M R$. The ${ }^{11} \mathrm{~B}$ nucleus has a spin of $3 / 2$ and has a low quadrupole moment making it more sensitive than the ${ }^{10} \mathrm{~B}$ nucleus. ${ }^{44}$ Coupling to boron is observed only in small, symmetric molecules, such as $\mathrm{NaBH}_{4}$. The only reported ${ }^{11} \mathrm{~B}$ NMR data for zinc borohydrides has 
been for complexes analyzed in solution with solvated products. ${ }^{45,46}$ These reports examined $\mathrm{Zn}\left(\mathrm{BH}_{4}\right)_{2}$, $\mathrm{LiZn}\left(\mathrm{BH}_{4}\right)_{3}, \mathrm{Li}_{2} \mathrm{Zn}\left(\mathrm{BH}_{4}\right)_{4}, \mathrm{NaZn}\left(\mathrm{BH}_{4}\right)_{3}$, and $\mathrm{NaBH}_{4}$. Chemical shifts ranged from +35 to $+47 \mathrm{ppm}$. The differences in the chemical shifts of starting materials and products have sometimes been reported to vary by less than $1 \mathrm{ppm}$. However, this does constitute the formation of product. No prior studies have been reported using solid-state ${ }^{11} \mathrm{~B}$ NMR to study zinc borohydride and its alkali derivatives.

In the ${ }^{11} \mathrm{~B}$ NMR studies, examination of the central peak shifts show the trend that the peaks for the starting materials of lithium borohydride and sodium borohydride shift upfield upon reaction with zinc chloride (see Table 8). However, some shifts are more extreme than others. For example, those reaction mixtures synthesized from lithium borohydride starting material $(-60.887 \mathrm{ppm})$ resulted in the following shifts: $\mathrm{Zn}\left(\mathrm{BH}_{4}\right)_{2}$, 63.860 ppm; $\mathrm{LiZn}\left(\mathrm{BH}_{4}\right)_{3},-65.282 \mathrm{ppm}$; and $\mathrm{Li}_{2} \mathrm{Zn}\left(\mathrm{BH}_{4}\right)_{4},-61.215 \mathrm{ppm}$. Since a change in the chemical shift took place, the ball milling of the starting materials resulted in the formation of new complexes. Furthermore, because the chemical shifts of these three complexes are all different, it can be assumed that the three complexes have unique identities.

\begin{tabular}{|c|c|}
\hline Materials & Central ${ }^{11}$ B NMR Peak Chemical Shift (ppm) \\
\hline $\mathrm{LiBH}_{4}$ & -60.887 \\
\hline $\mathrm{NaBH}_{4}$ & -61.589 \\
\hline $\mathrm{KBH}_{4}$ & -57.819 \\
\hline $\mathrm{Zn}\left(\mathrm{BH}_{4}\right)_{2}+2 \mathrm{LiCl}$ & -63.860 \\
\hline $\mathrm{LiZn}\left(\mathrm{BH}_{4}\right)_{3}+2 \mathrm{LiCl}$ & -65.282 \\
\hline $\mathrm{Li}_{2} \mathrm{Zn}\left(\mathrm{BH}_{4}\right)_{4}+2 \mathrm{LiCl}$ & -61.215 \\
\hline $\mathrm{NaZn}\left(\mathrm{BH}_{4}\right)_{3}+2 \mathrm{NaCl}$ & -64.617 \\
\hline $\mathrm{Na}_{2} \mathrm{Zn}\left(\mathrm{BH}_{4}\right)_{4}+2 \mathrm{NaCl}$ & -61.806 \\
\hline $\mathrm{KZn}\left(\mathrm{BH}_{4}\right)_{3}+2 \mathrm{KCl}$ & -57.819 \\
\hline $\mathrm{K}_{2} \mathrm{Zn}\left(\mathrm{BH}_{4}\right)_{4}+2 \mathrm{KCl}$ & -57.819 \\
\hline $\mathrm{K}_{2} \mathrm{Zn}_{3}\left(\mathrm{BH}_{4}\right)_{8}+2 \mathrm{~K}_{3} \mathrm{Zn}_{2} \mathrm{Cl}_{7}$ & -62.471 \\
\hline
\end{tabular}

Standard shifts for the alkali borohydride starting materials were estabilished as follows: $\mathrm{LiBH}_{4},-60.5 \mathrm{ppm} ; \mathrm{NaBH}_{4}$ - $61.5 \mathrm{ppm} ; \mathrm{KBH}_{4},-56.81 \mathrm{ppm}$. Pure neutral $\mathrm{Zr}\left(\mathrm{BH}_{4}\right)_{4}$ was found to have a chemical shift of $-30.571 \mathrm{ppm}$. Upon milling with alkali borohydrides, the central peak is shifted to $-28.90 \mathrm{ppm},-27.24 \mathrm{ppm}$, and $-26.91 \mathrm{ppm}$, for milled mixtures with a 2:1 (alkali borohydide to zirconium borohydride) ratio of $\mathrm{LiBH}_{4}$, $\mathrm{NaBH}_{4}$, and $\mathrm{KBH}_{4}$, respectively.

The results of the Thermal Desorption Mass Spectroscopic (TDMS) studies for the anionic transition metal borohydrides showed varied results depending on the transition metal utilized. It was found that tandem hydrogen/diborane evolution occurs with anionic zinc borohydride complexes. On the other hand, hydrogen evolved from $\mathrm{M}^{\prime} \mathrm{Mn}\left(\mathrm{BH}_{4}\right)_{3}$ at low temperatures with insignificant amounts of tandem diborane production (50:1 hydrogen to diborane ratio). For the anionic zirconium borohydrides, no tandem diborane production was observed.

For the zinc borohydride complexes upon heating, the compounds (including the alkali chloride byproduct) release diborane and hydrogen simultaneously. However, the amount of hydrogen released is greater than the amount of diborane released because the hydrogen to diborane ratio is greater than one for all the complexes. Upon examination of the hydrogen to diborane ratios it can be seen that as the stoichiometric 
ratio of alkali borohydride to zinc chloride increases, the hydrogen to diborane ratio decreases. For example, $\mathrm{Zn}\left(\mathrm{BH}_{4}\right)_{2}\left(\mathrm{LiBH}_{4} / \mathrm{ZnCl} 2=2.0 ; \mathrm{H}_{2} / \mathrm{B}_{2} \mathrm{H}_{6}=4.66\right)$, $\mathrm{LiZn}\left(\mathrm{BH}_{4}\right)_{3}$ $\left(\mathrm{LiBH}_{4} / \mathrm{ZnCl} 2=3.0 ; \mathrm{H}_{2} / \mathrm{B}_{2} \mathrm{H}_{6}=4.46\right)$, and $\mathrm{Li} 2 \mathrm{Zn}\left(\mathrm{BH}_{4}\right)_{4}\left(\mathrm{LiBH}_{4} / \mathrm{ZnCl}_{2}=4.0 ; \mathrm{H}_{2} / \mathrm{B}_{2} \mathrm{H}_{6}=2.99\right)$. This indicates that diborane liberation increases as the alkali borohydride to zinc chloride ratio increases. Overall, the dehydrogenation properties of the synthesized complexes resulted in the elimination of $2-7 \mathrm{wt} \%$ hydrogen at around $100{ }^{\circ} \mathrm{C}$.

Of the zinc borohydride complexes, the highest weight percent was observed from $\mathrm{Zn}\left(\mathrm{BH}_{4}\right)_{2}\left(2.25\right.$ wt \%), followed by $\mathrm{NaZn}\left(\mathrm{BH}_{4}\right)_{3}(1.60 \mathrm{wt} \%)$, then $\mathrm{Na}_{2} \mathrm{Zn}\left(\mathrm{BH}_{4}\right)_{4}(1.40$ wt\%) and $\mathrm{K}_{2} \mathrm{Zn}_{3}\left(\mathrm{BH}_{4}\right)_{8}(1.00 \mathrm{wt} \%)$ (See Table 9). It was also found that the nature of the cation influences the amount of desorbed hydrogen and the desorption temperature of complexes like $\mathrm{M}_{2} \mathrm{Zn}\left(\mathrm{BH}_{4}\right)_{4}$. For example, $\mathrm{Li}_{2} \mathrm{Zn}\left(\mathrm{BH}_{4}\right)_{4}$ desorbed 0.9 wt\% hydrogen, while $\mathrm{Na}_{2} \mathrm{Zn}\left(\mathrm{BH}_{4}\right)_{4}$ evolved 1.40 wt \% hydrogen. Interestingly, TDMS results for these complexes show that for $\mathrm{Li}_{2} \mathrm{Zn}\left(\mathrm{BH}_{4}\right)_{4}$ the peak temperature at which hydrogen is evolved is $140{ }^{\circ} \mathrm{C}$, while for $\mathrm{Na}_{2} \mathrm{Zn}\left(\mathrm{BH}_{4}\right)_{4}$ the temperature is only $110^{\circ} \mathrm{C}$.

The rehydrogenation curves showed that no hydrogen uptake took place. This indicates that the dehydrogenation reactions of these

Table 9. Approximate $\mathrm{H}_{2} \mathrm{wt} \%$ released from product mixtures upon first dehydrogenation.

\begin{tabular}{|l|l|}
\hline Product Mixture & Appx. $\mathbf{H}_{\mathbf{2}} \mathbf{W t} \%$ \\
\hline $\mathrm{Zn}\left(\mathrm{BH}_{4}\right)_{2}+2 \mathrm{LiCl}$ & 2.25 \\
\hline $\mathrm{LiZn}\left(\mathrm{BH}_{4}\right)_{3}+2 \mathrm{LiCl}$ & 1.10 \\
\hline $\mathrm{Li} \mathrm{Zn}_{(}\left(\mathrm{BH}_{4}\right)_{4}+2 \mathrm{LiCl}$ & 0.90 \\
\hline $\mathrm{NaZn}\left(\mathrm{BH}_{4}\right)_{3}+2 \mathrm{NaCl}$ & 1.60 \\
\hline $\mathrm{Na}_{2} \mathrm{Zn}\left(\mathrm{BH}_{4}\right)_{4}+2 \mathrm{NaCl}$ & 1.40 \\
\hline $\mathrm{KZn}\left(\mathrm{BH}_{4}\right)_{3}+2 \mathrm{KCl}$ & 0.50 \\
\hline $\mathrm{K}_{2} \mathrm{Zn}\left(\mathrm{BH}_{4}\right)_{4}+2 \mathrm{KCl}$ & 0.45 \\
\hline $\mathrm{K}_{2} \mathrm{Zn}_{3}\left(\mathrm{BH}_{4}\right)_{8}+$ & \\
$2 \mathrm{~K}_{3} \mathrm{Zn}_{2} \mathrm{Cl}_{7}$ & 1.00 \\
\hline
\end{tabular}
materials are not reversible; they cannot be "recharged" with hydrogen for multiple cycles. The reverse reaction may not be possible if diborane was released during dehydrogenation. This would require recharging the samples with both hydrogen and diborane in an effort to reform the decomposition reaction precursors.

The expected hydrogen capacities for these materials are much higher. There are many reasons for the lower observed capacities. First, the product mixtures contain the alkali chloride salt byproducts. By taking this into consideration, the hydrogen weight percent for $\mathrm{Zn}\left(\mathrm{BH}_{4}\right)_{2}(+2 \mathrm{LiCl})$ becomes $4.48 \mathrm{wt} \%$ rather than the expected $8.50 \mathrm{wt} \%$. Another reason for the discrepancy between the expected and actual results is due to the release of diborane. The TD-MS studies showed that diborane is released from the product mixtures. However, the calculations performed in the determination of hydrogen capacity assume the release of hydrogen only. This is because the exact ratio of hydrogen to diborane released from the materials is unknown. (The TD-MS data was obtained under conditions different from those used to obtain the dehydrogenation curves). Further, the experimental hydrogen capacities may also be lower due to decomposition during ball milling. This observation was made during the synthesis when after five hours of milling some discoloration of the product mixture began to occur. The mixture changed from a bright white color to an off-white color. This discoloration is the first indication of decomposition. If decomposition was actually occurring during ball milling, then hydrogen may have been released during synthesis. This means that the observed hydrogen capacity would be much lower for these materials. A final reason for the lower observed hydrogen capacities is the low temperature used in these studies. All dehydrogenation curves were obtained at $100^{\circ} \mathrm{C}$. This is well below the maximum hydrogen release observed in the TD-MS data. The low temperature was used in an attempt to target a temperature at which the materials might only release hydrogen and not a hydrogen and diborane mixture (as the release of diborane would deem the 
materials impractical as hydrogen storage materials). This means that the maximum amount of hydrogen contained in these materials may not have been released.

The zinc borohydride product mixture was also studied under the conditions of dehydrogenation at $120^{\circ} \mathrm{C}$. However, this gave the same result as observed at $100{ }^{\circ} \mathrm{C}$. The hydrogen capacity was observed at a maximum of $2.25 \mathrm{wt} \%$ and no hydrogen was released during the second dehydrogenation.

High throughput (HT) screening was carried out on the materials obtained from ball milling $\mathrm{Sc}, \mathrm{Ti}, \mathrm{V}, \mathrm{Cr}, \mathrm{Mn}, \mathrm{Fe}, \mathrm{Co}, \mathrm{Ni}$, and $\mathrm{Cu}$ chlorides with each of the alkali metal borohydrides, $\mathrm{LiBH}_{4}, \mathrm{NaBH}_{4}$, and $\mathrm{KBH}_{4}$. Compositions and hydrogen storage capacities are given in Table 9 of Appendix D. XRD analysis showed that in general no reaction occurred when the chlorides were ball milled with $\mathrm{KBH}_{4}$ but that the desired metathesis reaction occurred with both $\mathrm{LiBH}_{4}$ and $\mathrm{NaBH}_{4}$ as judged by the formation of $\mathrm{LiCl}$ and $\mathrm{NaCl}$. The $\mathrm{Li}$ and $\mathrm{Na}$ salts of the anionic borohydride complexes of all nine metals were found to undergo much cleaner dehydrogenation than the $\mathrm{Zn}$ complexes.

Hydrogen/ diborane ratios ranging from 10:1 to >1000:1 were found upon mass spectral analysis of the evolved gases. The Mn complexes exhibited the most promising dehydrogenation behavior. The sample of $\mathrm{Li}_{3} \mathrm{Mn}\left(\mathrm{BH}_{4}\right)_{6}$ was found to eliminate $3.2 \mathrm{wt} \%$ hydrogen upon heating at $100^{\circ} \mathrm{C}$ for $1 \mathrm{~h}$ and $\mathrm{Na}_{3} \mathrm{Mn}\left(\mathrm{BH}_{4}\right)_{6}$ evolves $2.7 \mathrm{wt} \%$ hydrogen upon heating to $150^{\circ} \mathrm{C}$ for $1 \mathrm{~h}$. These samples, respectively, contained three equivalents of $\mathrm{LiCl}$ and $\mathrm{NaCl}$ that was not removed prior to the dehydrogenation studies. Thus significantly higher weight percent hydrogen would be available from the purified hydrides. Because the transition metal borohydrides were showing significant desorption at low temperatures, the protocol in the HT hydrogen capacity assay was changed to a three-step process with a first desorption at $100{ }^{\circ} \mathrm{C}$, second desorption at $230^{\circ} \mathrm{C}$, with a third desorption at $350{ }^{\circ} \mathrm{C}$. The rehydriding steps were carried out at $100{ }^{\circ} \mathrm{C}$ for these metal borohydrides vs. the standard $125^{\circ} \mathrm{C}$.

Figure 30 shows a $100{ }^{\circ} \mathrm{C}$ desorption for some of the $\mathrm{Mn}$ and $\mathrm{Zn}$ compositions,

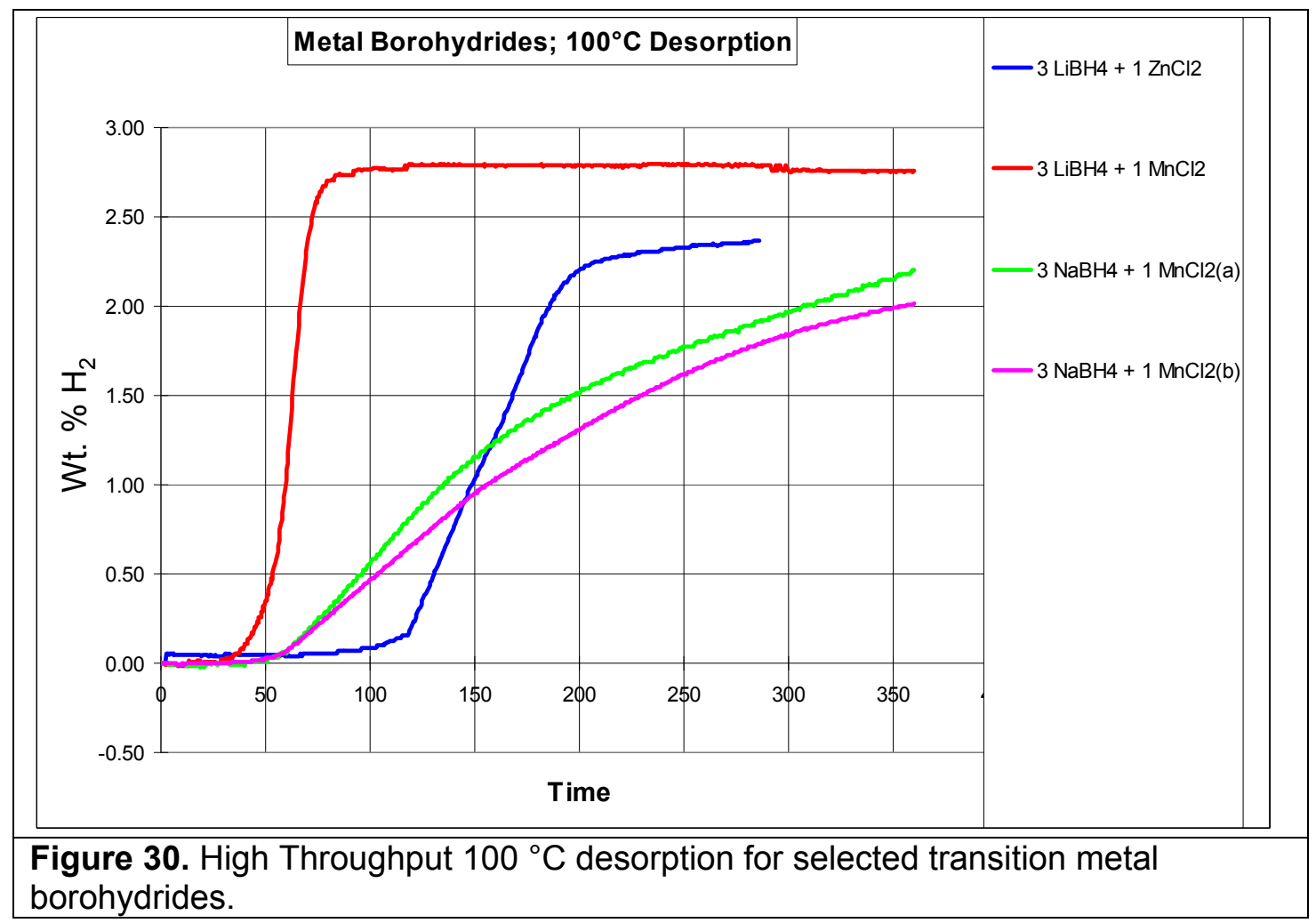


this time plotted versus time because the ramping period was very short. Hence, most of the desorption occurred while the materials sat at $100{ }^{\circ} \mathrm{C}$. The $3 \mathrm{LiBH}_{4}+\mathrm{MnCl}_{2}$ system desorbs hydrogen rather rapidly, yielding 2.75 wt. \% $\mathrm{H}_{2}$ (Figure 30 , red curve). The analogous $\mathrm{Zn}$ system is a little more sluggish in desorption and yields slightly less hydrogen at $2.36 \mathrm{wt}$ \% (Figure 30 , navy curve). Two runs with $3 \mathrm{NaBH}_{4}+\mathrm{MnCl}_{2}$ show fairly consistent behavior with desorption starting a little later than observed in the corresponding $3 \mathrm{LiBH}_{4}+\mathrm{MnCl}_{2}$ system and a more steady desorption that does not plateau at $100{ }^{\circ} \mathrm{C}$ (Figure 30, green and magenta curves). After rehydriding and moving to the second desorption at $230^{\circ} \mathrm{C}$, neither of the $\mathrm{M}-\mathrm{LiBH}_{4}$ materials gave desorption over 0.2 wt. $\% \mathrm{H}_{2}$, while the $\mathrm{Mn}-\mathrm{NaBH}_{4}$ materials seemed to continue desorbing where they left off, but giving much less hydrogen. Hence, these materials showed no reversible character.

A number of the metal borohydrides were run in the medium throughput apparatus, which features two desorptions carried out to $220^{\circ} \mathrm{C}$. The results are shown in Figure 31. The desorption behavior from these systems basically fall into two different categories. In the first category, both $6 \mathrm{NaBH}_{4}+\mathrm{TiCl}_{4}$ and $6 \mathrm{NaBH}_{4}+\mathrm{TiCl}_{3}$ (Figure 31, green and magenta curves, respectively) are early desorbers with the onset of desorption occurring at about $80{ }^{\circ} \mathrm{C}$. Both of these samples nearly plateau by the end of the run, with the $\mathrm{TiCl}_{3}$ and $\mathrm{TiCl}_{4}$ systems yielding 2.77 and $1.91 \mathrm{wt} . \% \mathrm{H}_{2}$, respectively. $\mathrm{A}$ $6 \mathrm{NaBH}_{4}+\mathrm{CrCl}_{3}$ sample showed a similar desorption pattern with early desorption and a plateau in the desorption profile, ultimately yielding $2.06 \mathrm{wt} . \% \mathrm{H}_{2}$ (Figure 31, gray curve). The rest of the samples showed comparatively lethargic desorption with very similar profiles. Only about $0.5 \mathrm{wt} . \% \mathrm{H}_{2}$ was evolved by $200{ }^{\circ} \mathrm{C}$ with these samples, with most of the desorption occurring at the end of the run as the MT assay system sat at 220 ${ }^{\circ} \mathrm{C}$. The transition metals $\mathrm{Cr}$, $\mathrm{Co}$ and $\mathrm{Ni}$ were employed in these samples, with the 4 $\mathrm{NaBH}_{4}+\mathrm{NiCl}_{2}$ and $4 \mathrm{LiBH}_{4}+\mathrm{NiCl}_{2}$ yielding the most hydrogen at 2.93 and $2.47 \mathrm{wt}$ \%, respectively (Figure 31, navy and red curves). Regardless of the character of the first

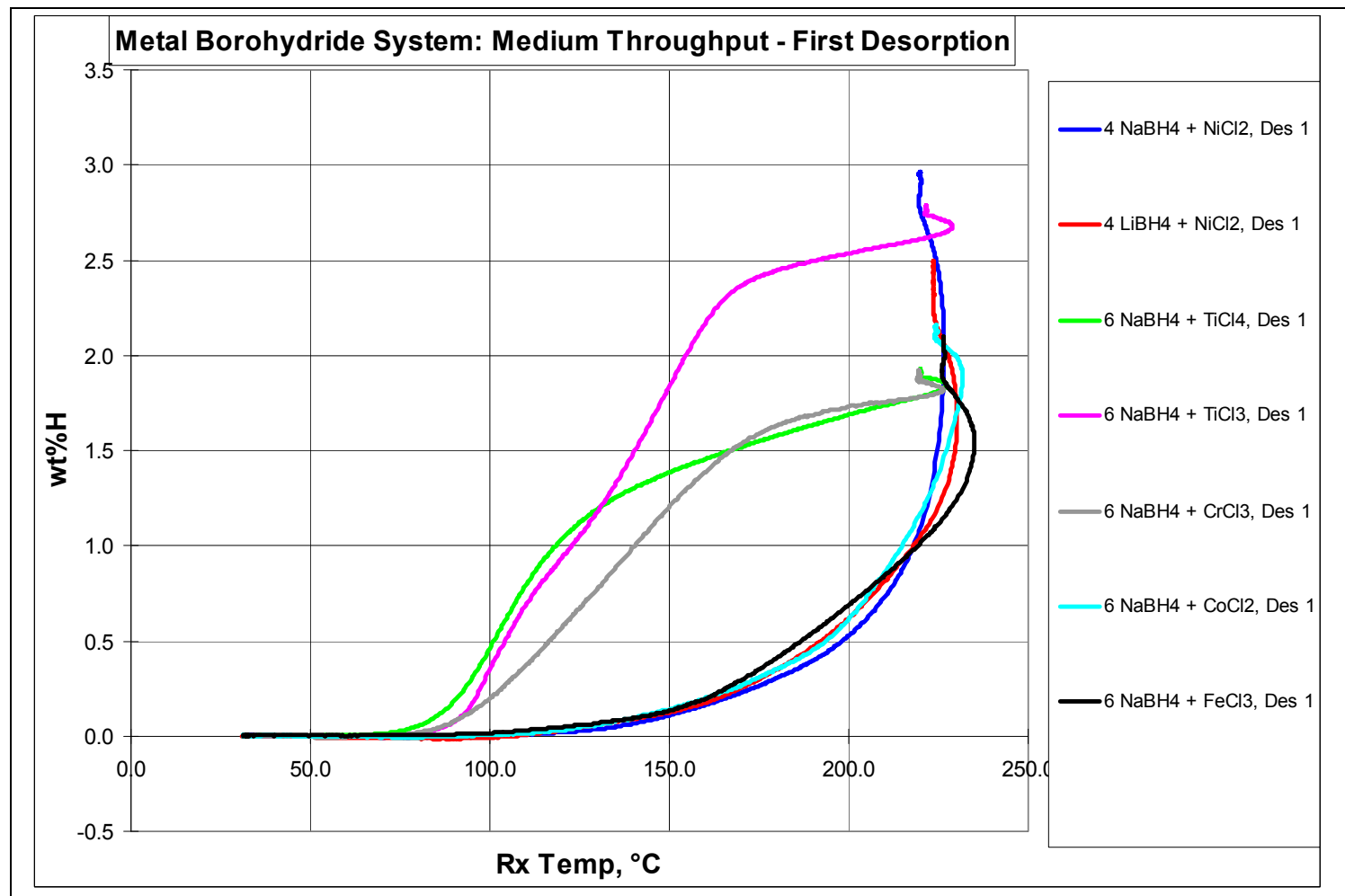

Figure 31. Medium throughput results for selected transition metal borohydrides. 
desorption, none of these materials showed any hint of reversible behavior in the second desorption. While these compounds desorbed nearly 2 wt. $\% \mathrm{H}_{2}$ the first time around, none desorbed more than $0.2 \mathrm{wt}$. \% on the second desorption.

The second $\mathrm{HT}$ desorption run to $230{ }^{\circ} \mathrm{C}$ gave results similar to that seen for the first MT desorption run just described. Both $4 \mathrm{LiBH}_{4}+\mathrm{NiCl}_{2}$ and $4 \mathrm{NaBH}_{4}+\mathrm{NiCl}_{2}$ yielded the same lethargic desorption curve with desorption commencing near $150{ }^{\circ} \mathrm{C}$ and mostly occurring at the end of the run. The $6 \mathrm{LiBH}_{4}+\mathrm{ScCl}_{3}$ and $6 \mathrm{NaBH}_{4}+\mathrm{ScCl}_{3}$ systems also fell on this desorption profile each yielding about $2 \mathrm{wt}$. \% $\mathrm{H}_{2}$. Neither of the Sc systems were run in the third desorption at $350{ }^{\circ} \mathrm{C}$, so the reversibility was not determined.

The results from the third $\mathrm{HT}$ desorption to $350{ }^{\circ} \mathrm{C}$ are shown in Figure 32 . The 4 $\mathrm{LiBH}_{4}+\mathrm{NiCl}_{2}$ system mentioned above, which had been through two previous desorption steps, doesn't yield 0.5 wt. $\% \mathrm{H}_{2}$ until $300{ }^{\circ} \mathrm{C}$, a $100{ }^{\circ} \mathrm{C}$ shift to higher temperature versus what is seen in the MT run to $220^{\circ} \mathrm{C}$ in Figure 31 (compare Figure 32, magenta curve, to Figure 31, red curve). This is yet another indication of the lack of reversibility in this system. The $4 \mathrm{KBH}_{4}+\mathrm{NiCl}_{2}$ system is also shown in Figure 32, gray

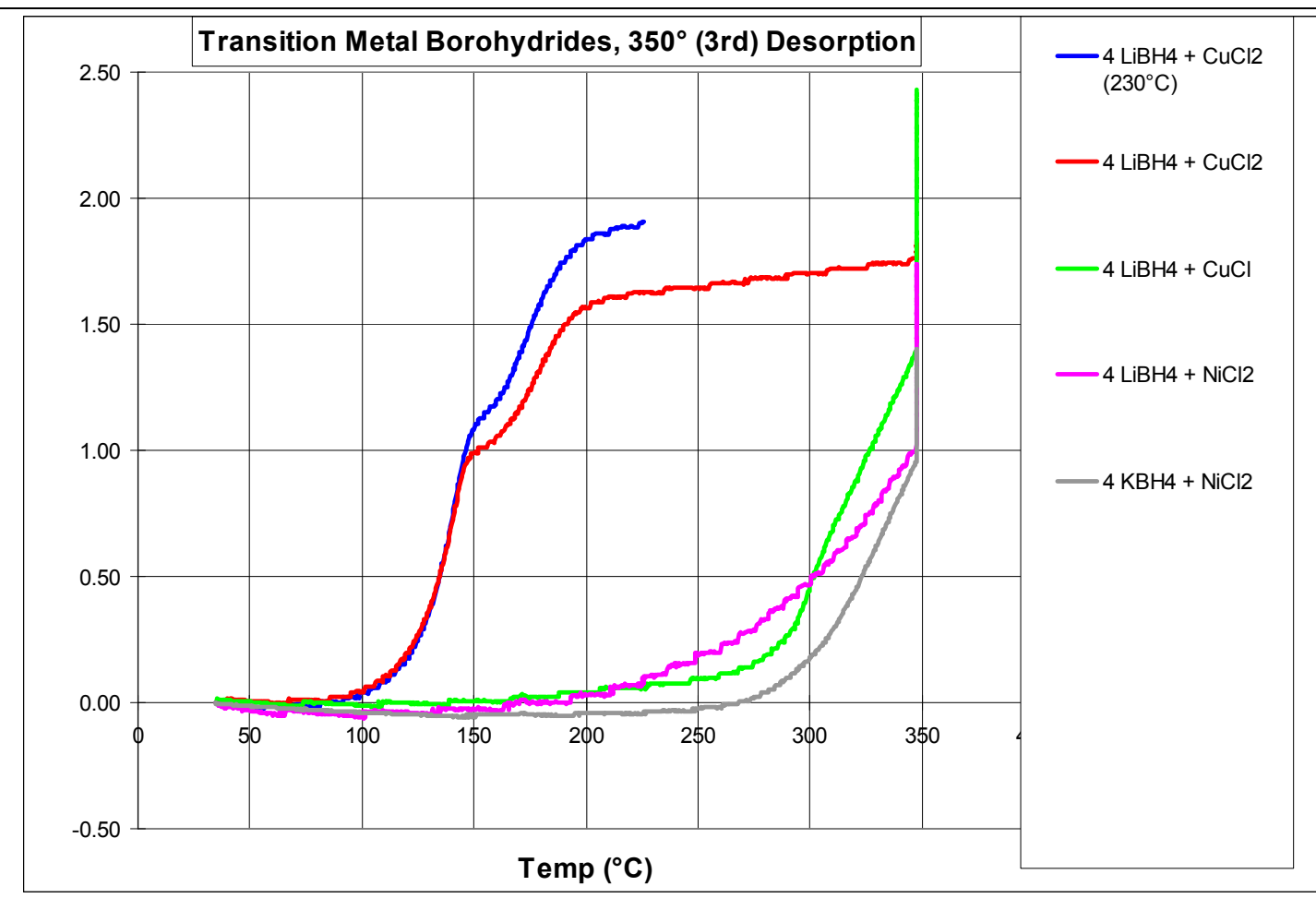

Figure 32. $\mathrm{HT} 350{ }^{\circ} \mathrm{C}$ desorption results for selected transition metal borohydrides curve. The $\mathrm{KBH}_{4}$ systems did not perform well in these studies and for $4 \mathrm{KBH}_{4}+\mathrm{NiCl}_{2}$, there was no significant hydrogen evolution in the previous $100^{\circ} \mathrm{C}$ or $230^{\circ} \mathrm{C}$ desorption cycles. Here it can be seen that desorption doesn't begin until $275^{\circ} \mathrm{C}$. This system does ultimately desorb $1.40 \mathrm{wt} . \% \mathrm{H}_{2}$, but most of this desorption occurs at the end of the run when the $\mathrm{HT}$ assay unit is sitting at $350{ }^{\circ} \mathrm{C}$. The $4 \mathrm{LiBH}_{4}+\mathrm{CuCl}$ system behaved much like the $4 \mathrm{LiBH}_{4}+\mathrm{NiCl}_{2}$ system with most of the desorption at the end of the run and gave 2.43 wt. $\% \mathrm{H}_{2}$ (Figure 32 , green curve).

A very different desorption profile was seen for $4 \mathrm{LiBH}_{4}+\mathrm{CuCl}_{2}($ Figure 32, red curve). Desorption begins at about $100{ }^{\circ} \mathrm{C}$, which had not been seen for any of the other materials that had been through a previous desorption cycle at $230{ }^{\circ} \mathrm{C}$. This is an indicator of reversible absorption/desorption character for this material. Desorption is 
also pretty rapid and it appears that the $4 \mathrm{LiBH}_{4}+\mathrm{CuCl}_{2}$ plateaus at about $200{ }^{\circ} \mathrm{C}$. The amount of hydrogen evolved is pretty modest at $1.82 \mathrm{wt}$. \%. In the first desorption cycle at $100{ }^{\circ} \mathrm{C}$, almost nothing is desorbed. The second desorption cycle at $230^{\circ} \mathrm{C}$ (Figure 32 , navy curve) shows that up to $150^{\circ} \mathrm{C}$, the second and third desorption profiles for 4 $\mathrm{LiBH}_{4}+\mathrm{CuCl}_{2}$ are super-imposable, and the third desorption loses only about 0.25 wt \% by $200{ }^{\circ} \mathrm{C}$, before each start to plateau at just above $1.5 \mathrm{wt} . \% \mathrm{H}_{2}$. A little more hydrogen was extracted from the system in the second desorption, $1.95 \mathrm{wt} \% \% \mathrm{H}_{2}$. There is also a slight step in the desorption profile of this material at $150{ }^{\circ} \mathrm{C}$. This $4 \mathrm{LiBH}_{4}+\mathrm{CuCl}_{2}$ system shows a high degree of reversible character, although the hydrogen storage capacity is low. This system could potentially be operated reversibly to yield about 1.5 wt. \% hydrogen in the $150-175^{\circ} \mathrm{C}$ temperature range. While this is quite short of DOE targets, it's exciting to consider that $B$ has been activated as a reversible hydrogen storage material in a transition metal system.

Overall, these materials do not exhibit ideal storage properties to meet today's standards for on-board applications. They exhibit low hydrogen storage capacities and are not reversible. In addition, the release of diborane is dangerous and toxic.

Nevertheless, the presence of the transition metal chloride proved advantageous in that the overall dehydrogenation temperature of the alkali borohydride starting materials were lowered upon milling with zinc chloride.

6.3.3 Reverse Reactions: Metal Borides and Metal Nitrides. As we did in the alanate section presented earlier, we pursued the reverse reactions associated with borohydride and amide-based hydrogen storage materials. The reverse reaction or the "hydriding" of spent materials is an important part of the process if one is to achieve reversibility in these systems. It is instructive to start with dehydrided materials to better focus on their properties without the complications and complexities introduced by the hydrogen evolution reaction of the storage material. In theory, metal borohydrides and amides can be dehydrided to metal borides and metal nitrides. In this section, we use these materials and try to find conditions to rehydride them.

The compositions and medium throughput hydrogen storage capacities for the compositions studied are given in Table 10 in Appendix D. The metal boride and nitride starting materials were treated with metal hydrides, amides and alanates via ball milling according to the protocol described in Section 5 . The reactions usually contained $\mathrm{Ti}(\mathrm{OiPr})_{4}$ as a catalyst. The starting materials for the reactions of this section are listed in Table 10.The XRD of these as-synthesized materials generally showed no reaction, but that a mixture of the starting materials had resulted. This mixture was then pre-hydrided $\left(125^{\circ} \mathrm{C}, 1250 \mathrm{psig}\right)$, sometimes twice before running desorption cycles in the MT hydrogen storage assay unit.

Desorption studies on the "hydrided" materials were very disappointing and not a single boride or nitride composition appeared to have been successfully hydrided. Any hydrogen observed on desorption was that expected from one of the other components of the composition acting independently. These reactions were performed in the MT hydrogen assay unit, which has limitations with respect to the temperatures and hydrogen pressures that can be employed for hydriding $\left(125^{\circ} \mathrm{C}, 87\right.$ bar vs. $350{ }^{\circ} \mathrm{C}, 120$ bar for the HT unit). This work may have been more successful in the HT assay unit with different rehydriding conditions.

Table 10. Metal boride and metal nitride reverse reactions. Starting materials combined to derive the compositions studied.

Metal borides and nitrides Metal hydrides, alanates, and amides $\mathrm{AlB}_{2}, \mathrm{MgB}_{2}, \mathrm{CrB}, \mathrm{VB}_{2} ; \mathrm{AIN}, \mathrm{Li}_{3} \mathrm{~N}, \quad \mathrm{LiH}, \mathrm{NaH}, \mathrm{KH}, \mathrm{MgH}{ }_{2}, \mathrm{CaH}_{2} ; \mathrm{LiNH}_{2}, \mathrm{NaNH}_{2}$; $\mathrm{Mg}_{3} \mathrm{~N}_{2}$ $\mathrm{LiAlH}_{4}, \mathrm{NaAlH}_{4}, \mathrm{Mg}\left(\mathrm{AlH}_{4}\right)_{2}$ 


\subsection{Binary Alanate and Amide plus Single Hydride Systems}

6.4.1 Metal Alanate - Metal Amide - Metal Hydride System. Among the most successful reversible complex metal hydride hydrogen storage materials are the aluminum hydrides (e.g., $\mathrm{NaAlH}_{4}, \mathrm{Na}_{3} \mathrm{AlH}_{6}$ and $\mathrm{LiNa}_{2} \mathrm{AlH}_{6}$ ) and the metal amides (e.g., 2 $\mathrm{LiNH}_{2}+\mathrm{MgH}_{2}$ ). One might reason that working in the mixed alanate-amide system that it should also be possible to make new reversible hydrogen storage materials. The mixed metal alanate-amide compositions studied are shown in the phase diagram in Figure 33.

While the majority of the study was confined to the metal alanate-metal amide line, a number of these compositions were also augmented with metal hydrides, giving the phase diagram its ternary character. Many of the compositions included $\mathrm{Ti}(\mathrm{OiPr})_{4}$ dopant to enhance reversibility. The results from this study appear in Table 11 in Appendix D. Table 11a includes the compositions studied and the assynthesized structures, Table $11 \mathrm{~b}$ gives the structures of the spent materials after the hydrogen storage assay for the compositions and Table $11 \mathrm{c}$ gives the hydrogen

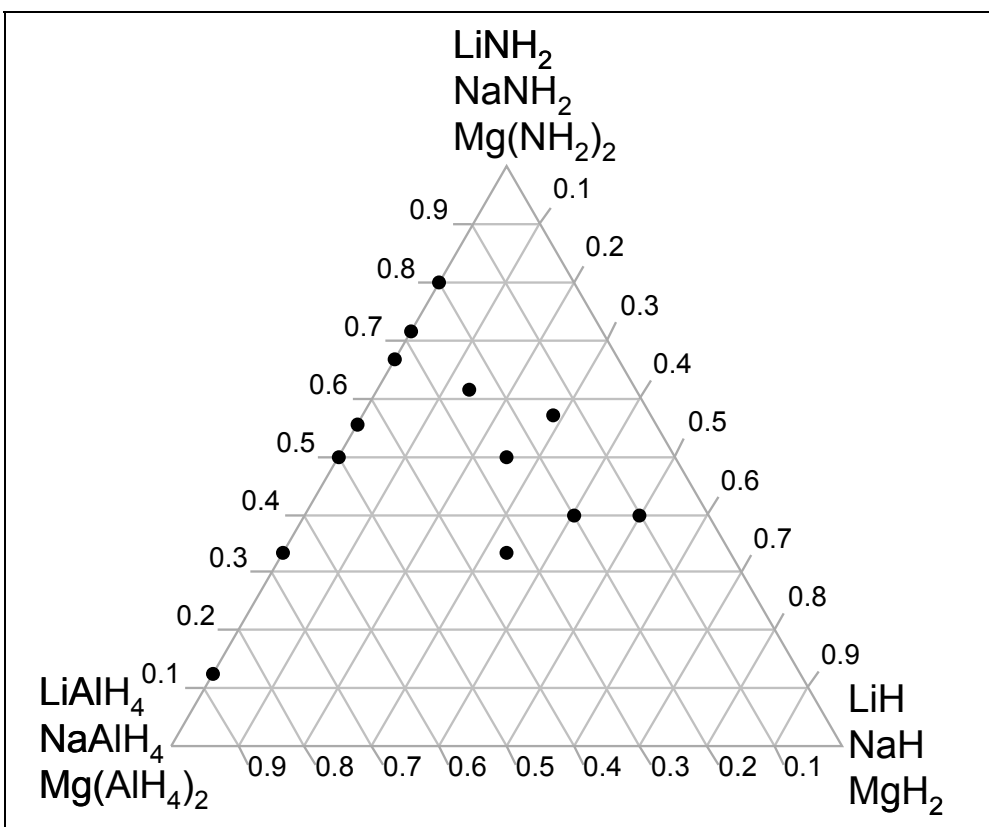

Figure 33. Phase Diagram of the compositions covered in the metal alanate-amide-hydride system. storage capacities for each composition.

The as-synthesized materials isolated after the milling of the starting materials showed two general characteristics; a redox reaction often occurred between the starting materials, frequently accompanied by an ion-exchange reaction. Alanate, $\mathrm{AlH}_{4}{ }^{-}$, tended to react with the amide, $\mathrm{NH}_{2}^{-}$, to form the imide, $\mathrm{NH}^{2-}$, and an aluminum hexahydride and sometimes Al. Metal hydrides were also sometimes formed after milling. This reaction scenario implies that some hydrogen was evolved during milling. Examples of some of the reactions that occurred are as follows:

$$
\begin{aligned}
& 2 \mathrm{NaAlH}_{4}+\mathrm{LiNH}_{2} \rightarrow \mathrm{NaAlH}_{4}+\mathrm{Li}_{2} \mathrm{NH}+\mathrm{Na}_{3} \mathrm{AlH}_{6}+\mathrm{Li}_{3} \mathrm{AlH}_{6} \\
& 2 \mathrm{LiAlH}_{4}+\mathrm{NaNH}_{2} \rightarrow \mathrm{NaAlH}_{4}+\mathrm{Li}_{2} \mathrm{NH}+\mathrm{Al} \\
& \mathrm{LiAlH}_{4}+\mathrm{NaNH}_{2} \rightarrow \mathrm{NaH}+\mathrm{LiNa}_{2} \mathrm{AlH}_{6}+\mathrm{NaNH}_{2} \\
& \mathrm{NaAlH}_{4}+\mathrm{LiNH}_{2} \rightarrow \mathrm{LiNa}_{2} \mathrm{AlH}_{6}+\mathrm{Li}_{2} \mathrm{NH}+\mathrm{NaH} \\
& \mathrm{Mg}\left(\mathrm{AlH}_{4}\right)_{2}+\mathrm{LiNH}_{2} \rightarrow \mathrm{Li}_{2} \mathrm{NH}+\mathrm{MgH}_{2} \\
& \mathrm{Mg}\left(\mathrm{AlH}_{4}\right)_{2}+\mathrm{NaNH}_{2} \rightarrow \mathrm{Al}+\mathrm{NaMgH}_{3}+\mathrm{MgH}_{2}+\mathrm{NaH}
\end{aligned}
$$


Earlier studies with the alanates showed $\mathrm{Mg}\left(\mathrm{AlH}_{4}\right)_{2}$ decomposed easily upon milling in the presence of $\mathrm{Ti}(\mathrm{OiPr})_{4}$, so the dopant was eliminated in these reactions. Still the $\mathrm{Mg}\left(\mathrm{AlH}_{4}\right)_{2}$ reactions generally decomposed to $\mathrm{Al}$ and $\mathrm{MgH}_{2}$ or $\mathrm{NaMgH}_{3}$, presumably via reducing the amide (Table 11a, Appendix D). Over the course of the many reactions studied, no mixed alanate-amide materials were observed after the milling process. Unknown materials that were seen were often just a random line or two in the diffraction pattern, nearly all of the lines were assigned to a phase in each case. Even after two desorptions and the intermediate hydriding processes, the structures observed for the spent materials (Table 11b, Appendix D), fell into the same set of known compounds as observed with the as-synthesized materials, with the exception of the imide, $\mathrm{Li}_{2} \mathrm{Mg}(\mathrm{NH})_{2}$, and the mixed amide $\mathrm{Li}_{3} \mathrm{Na}\left(\mathrm{NH}_{2}\right)_{4}$ showing up, the former a known component of reversible Li-Mg- $\mathrm{NH}_{2}$ systems.

The hydrogen storage assay results showed that both storage capacity and overall reversibility was poor in these systems. Very few of the compositions desorbed more than $2 \mathrm{wt}$ \% hydrogen on the first desorption or managed $1 \mathrm{wt} \%$ hydrogen during the second cycle. Some of the better performers are shown in Figure 34.

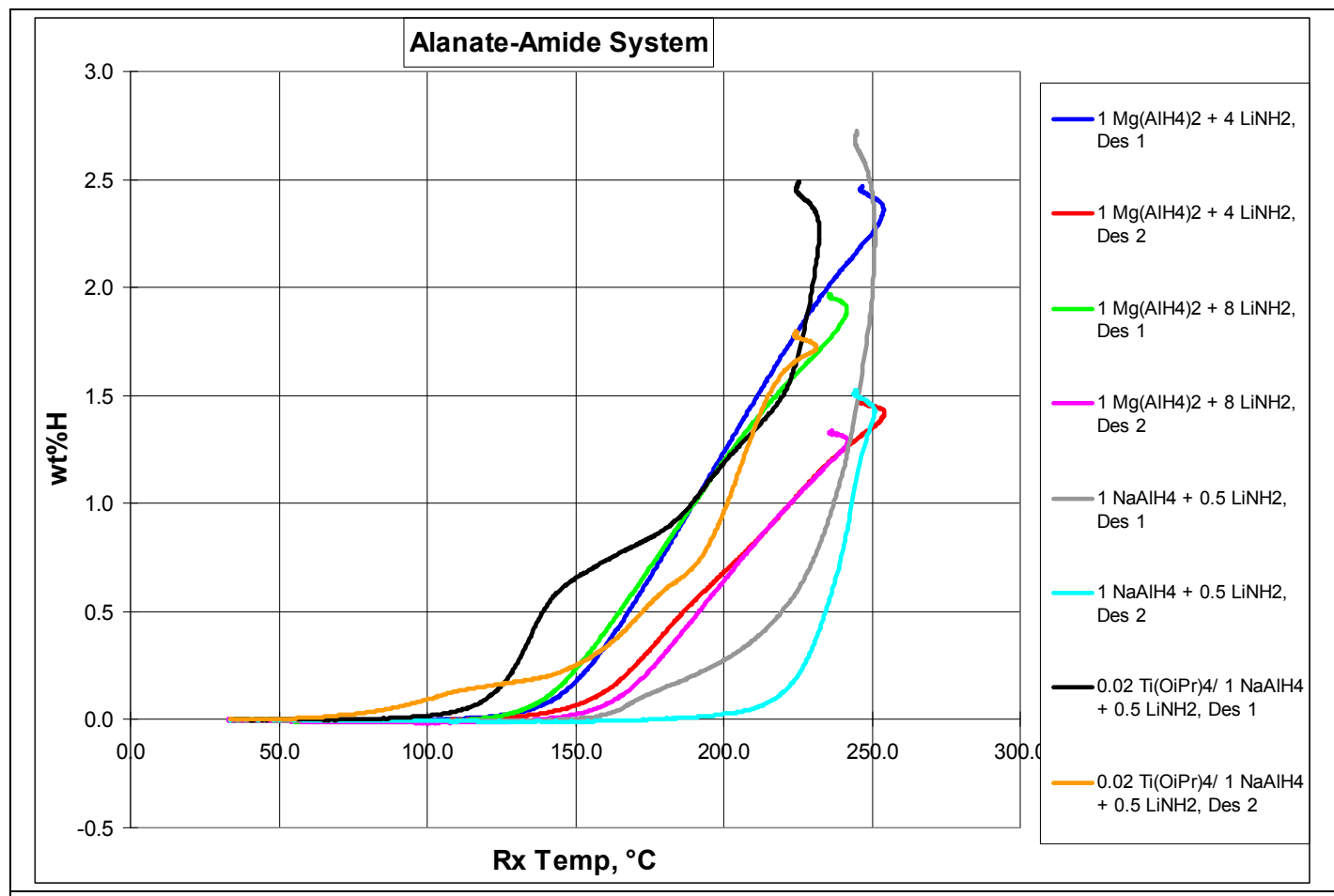

Figure 34. Hydrogen desorption curves for selected amide-alanate compositions

Two compositions were examined in the $\mathrm{Mg}\left(\mathrm{AlH}_{4}\right)_{2}-\mathrm{LiNH}_{2}$ system with $\mathrm{LiNH}_{2} / \mathrm{Mg}\left(\mathrm{AlH}_{4}\right)_{2}=4$ and 8 that yielded 2.46 and $1.96 \mathrm{wt}$. \% hydrogen. As seen in Figure 34 , navy and green curves, desorption in each system started at about $130{ }^{\circ} \mathrm{C}$ and about $1.25 \mathrm{wt} \% \mathrm{H}_{2}$ desorbed by $200^{\circ} \mathrm{C}$ in a very linear fashion, with the desorption curves overlapping. The excess $\mathrm{LiNH}_{2}$ in the $8 \mathrm{LiNH}_{2}+\mathrm{Mg}\left(\mathrm{AlH}_{4}\right)_{2}$ material merely added dead weight to the sample compared to the $4 \mathrm{LiNH}_{2}+\mathrm{Mg}\left(\mathrm{AlH}_{4}\right)_{2}$ material. On the second desorption, there was a $30^{\circ} \mathrm{C}$ temperature shift with respect to initial hydrogen evolution temperature to about $160^{\circ} \mathrm{C}$ (Figure 34, red and magenta curves). Desorption was very linear and again overlapping for both samples, falling significantly for each sample, up to 
1 wt.\%. The spent materials contained $\mathrm{Al}$ and $\mathrm{Li}_{2} \mathrm{NH}$, and surprisingly no reversible $\mathrm{Li}-$ $\mathrm{Mg}-\mathrm{NH}_{2}$ materials.

Also shown in Figure 34 are NaAlH4 $+0.5 \mathrm{LiNH}_{2}$, both with and without $\mathrm{Ti}(\mathrm{OiPr})_{4}$ dopant (Figure 34, gray and black curves). The doped composition behaved quite differently than doped $\mathrm{NaAlH}_{4}$, our typical reference material (see Figure 1). The storage capacity was reduced proportionately to the amount of $\mathrm{LiNH}_{2}$ in the sample which just added dead weight. While the storage capacities observed were only $2.5 \mathrm{wt}$. \% vs. the $4+\%$ usually observed, this is one of the only systems to show some reversibility. It can be seen that the second desorption lags behind the first desorption $10-20{ }^{\circ} \mathrm{C}$, but catches up with the first desorption at just over $200{ }^{\circ} \mathrm{C}$ (Figure 34 , teal and orange curves). The undoped material was relatively hampered with desorption temperature shifts of $50-100{ }^{\circ} \mathrm{C}$ to higher temperature, as expected in undoped alanate systems.

Figure 35 shows the best performers in the study, $0.875 \mathrm{NaAlH}_{4}+0.125 \mathrm{LiNH}_{2}$ with a variety of dopants. With the small amount of $\mathrm{LiNH}_{2}$, these compositions can be considered to be a perturbed $\mathrm{NaAlH}_{4}$. Unlike the $\mathrm{NaAlH}_{4} / 0.02 \mathrm{Ti}$ standards (see Figure 1), these materials reach their first plateau at $2-2.5 \mathrm{wt} . \% \mathrm{H}_{2}$ at $100{ }^{\circ} \mathrm{C}$, a full $50{ }^{\circ} \mathrm{C}$ faster than the standards. By $150^{\circ} \mathrm{C}$, these materials have desorbed between $3.25-$ $3.75 \mathrm{wt}$, \% hydrogen and are approaching their second plateau. By comparison, the standard is just at $2-2.25 \mathrm{wt} \%$ hydrogen evolved. Clearly the system is enhanced, probably due to the $\mathrm{LiNH}_{2}$. All of the systems have at least 0.02 mole Ti as part of the dopant and either $\mathrm{AlF}_{3}$ or $\mathrm{CoCl}_{2}$ as a supplemental dopant. Perhaps the different dopants are responsible for the low temperature activity. By $240^{\circ} \mathrm{C}$, the $0.02 \mathrm{AlF}_{3}+0.02$ $\mathrm{TiF}_{3}$ doped system evolves $4.5 \mathrm{wt} \% \mathrm{H}_{2}$ (Figure 35, gray trace), followed by 4 and 3.65 wt, \% for the $0.02 \mathrm{CoCl}_{2}+0.02 \mathrm{TiF}_{3}$ and $0.02 \mathrm{TiCl}_{3}+0.02 \mathrm{CoCl}_{2}$ doped systems (Figure 35 , navy and green traces, respectively). These first desorption values fall short of the

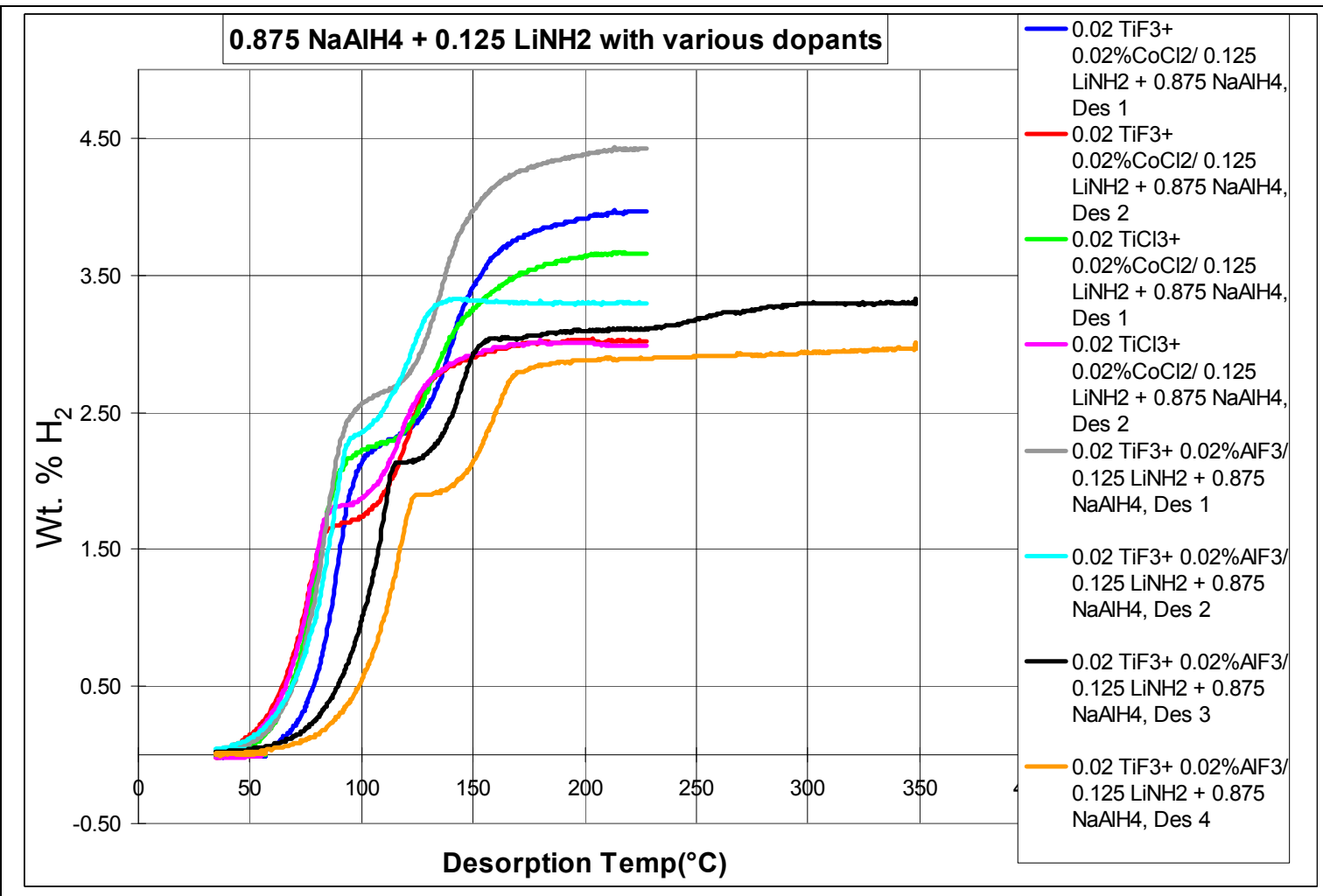

Figure 35. Metal alanate-amide system. Hydrogen desorption curves from $0.875 \mathrm{NaAlH}_{4}$ $-0.125 \mathrm{LiNH}_{2}$ with various dopants 
best $\mathrm{NaAlH}_{4}$ standards for capacity, but there is more dopant overall, which is a burden as the dopant doesn't produce hydrogen. These materials are very reversible, with the second desorptions following in the paths of the first desorptions until $80-90^{\circ} \mathrm{C}$. At this point of divergence between the two desorptions, $1.75-2.25 \mathrm{wt} . \% \mathrm{H}_{2}$ has already been evolved. For the composition $0.875 \mathrm{NaAlH}_{4}+0.125 \mathrm{LiNH}_{2} / 0.02 \mathrm{TiF}_{3}+0.02 \mathrm{AlF}_{3}$ (Figure 35 , teal trace) the third and fourth desorptions are shown to $350{ }^{\circ} \mathrm{C}$ (Figure 35 , black and orange traces, respectively). While reversibility is declining, the third desorption hits $3 \mathrm{wt}$. $\% \mathrm{H}_{2}$ evolved by $150{ }^{\circ} \mathrm{C}$, and each exhibits plateaus for the last $200{ }^{\circ} \mathrm{C}$ of the run between $150{ }^{\circ} \mathrm{C}$ and $350{ }^{\circ} \mathrm{C}$. These materials could best be operated reversibly attaining a maximum temperature of $150{ }^{\circ} \mathrm{C}$, because there isn't significant desorption after this point and lower temperature operation would reduce damage to the material that causes irreversible behavior.

Finally, one composition studied notably was a combination of two known reversible systems: $4 \mathrm{LiNH}_{2}+2.2 \mathrm{MgH}_{2}+1 \mathrm{NaAlH}_{4} / 0.02 \mathrm{Ti}(\mathrm{OiPr})_{4}$. After milling, there was no sign of the Al as $\mathrm{MgH}_{2}, \mathrm{Li}_{2} \mathrm{NH}$ and $\mathrm{NaH}$ was observed in the XRD of the assynthesized material, indicating that the alanate served to convert the amide to the imide. In the medium throughput apparatus, the first desorption yielded $2.69 \mathrm{wt} . \% \mathrm{H}_{2}$, while the second desorption evolved $1.0 \mathrm{wt} \% \mathrm{H}_{2}$, a large drop that clearly indicates the irreversible character of the system. While XRD of the spent sample showed the presence of some of the components of reversible systems such as $\mathrm{Li}_{2} \mathrm{Mg}(\mathrm{NH})_{2}$, and $\mathrm{Na}_{3} \mathrm{AlH}_{6}$, these active amide and alanate components were acting independently of each other. The other phases present, $\mathrm{NaMgH}_{3}, \mathrm{MgH}_{2}$, and $\mathrm{NaH}$, indicate that having the $\mathrm{Na}$ and $\mathrm{Mg}$ hydrides together is probably what kills the system as the formation of the irreversible thermodynamic sink, $\mathrm{NaMgH}_{3}$ robs the $\mathrm{Li}-\mathrm{Mg}$ amide system of needed $\mathrm{MgH}_{2}$, while at the same time depriving the alanate system of $\mathrm{NaH}$ required for reversible operation.

6.4.2 Alanate-Borohydride $\left(\mathrm{NaAlH}_{4}-\mathrm{LiBH}_{4} / \mathrm{NaBH}_{4}\right)$ System. As previously mentioned, an important goal in this project is to find an active form of boron that can participate in low temperature reversible hydrogen adsorption/desorption processes. It is known that $\mathrm{Al}\left(\mathrm{BH}_{4}\right)_{3}$ can evolve hydrogen at low temperature, but explosively at $70{ }^{\circ} \mathrm{C} .{ }^{35}$ On the other hand, alkali borohydrides are notoriously stable. The combination of the two, alkali borohydrides with aluminum borohydrides might lead to a useful alkali aluminum borohydride that might release hydrogen under more reasonable conditions. To achieve this both $\mathrm{LiBH}_{4}$ and $\mathrm{NaBH}_{4}$ were treated with $\mathrm{NaAlH}_{4}$ and $\mathrm{Ti}(\mathrm{OiPr})_{4}$ dopant. The compositions ran for example, from $\mathrm{LiBH}_{4}$ to pure $\mathrm{NaAlH}_{4}$ in the ratios 1, 4/1, 2/1, $3 / 2,1 / 1,2 / 3,1 / 2,1 / 4$ and 1 . The compositions, structures of the as-synthesized and spent materials and the medium throughput hydrogen storage capacities are given in Table 12 of Appendix D.

The study confirmed the low activity of both $\mathrm{LiBH}_{4}$ and $\mathrm{NaBH}_{4}$, which by $220{ }^{\circ} \mathrm{C}$ yielded only $0.56 \mathrm{wt}$. \% and $0.21 \mathrm{wt}$. \%, respectively. Other than the observation of $\mathrm{AlB}_{2}$, no known inter Al-B species were observed, although a few unknown materials were seen. The diffraction lines for these materials are given in Table 12 of Appendix D. For the most part the alkali borohydrides were unreactive and observed in both the assynthesized and spent materials unchanged. lon-exchange reactions were observed as $\mathrm{Na}$ starting out in the alanate tended to migrate to borohydride, while Li from the borohydride would prefer to reside in the aluminum hexahydrides that formed, such as $\mathrm{LiNa}_{2} \mathrm{AlH}_{6}$ and $\mathrm{Li}_{3} \mathrm{AlH}_{6}$. First cycle desorptions approached $4.0 \mathrm{wt} \% \mathrm{H}_{2}$ in systems that had the highest levels of $\mathrm{NaAlH}_{4}$, but the reversibility was poor. The only role the borohydrides seemed to play was to suppress the reversible chemistry of the $\mathrm{NaAlH}_{4}$. 
6.4.3 Augmented Aluminum Hexahydride Reactions. Over the course of our investigations of the alanate $\left(\mathrm{AlH}_{4}{ }^{-}\right)$- based systems, we encountered many aluminum hexahydride systems that were also reversible, such as $\mathrm{Na}_{3} \mathrm{AlH}_{6}$ and $\mathrm{LiNa}_{2} \mathrm{AlH}_{6}$. While the hydrogen storage capacity is less than that seen for the corresponding alkali alanates, they are more stable than the alanates and may fare better in the milling process, being less susceptible to decomposition to Al, especially in the presence of $\mathrm{Ti}(\mathrm{OiPr})_{4}$. Reactions of of the aluminum hexahydrides $\mathrm{Na}_{3} \mathrm{AlH} \mathrm{H}_{6}, \mathrm{Na}_{2} \mathrm{LiAlH}_{6}$ and $\mathrm{K}_{2} \mathrm{NaAlH}_{6}$ with either $\mathrm{LiNH}_{2}, \mathrm{LiBH}_{4}, \mathrm{MgH}_{2}, \mathrm{LiAlH}_{4}$ or $\mathrm{NaAlH}_{4}$ were investigated in attempts to make new hydrogen storage materials. The compositions covered in the study are compiled in Table 13 of Appendix D, along with the structures of the spent materials and the medium throughput hydrogen storage capacities.

The aluminum hexahydrides $\mathrm{Na}_{3} \mathrm{AlH}_{6}, \mathrm{Na}_{2} \mathrm{LiAlH}_{6}$ and $\mathrm{K}_{2} \mathrm{NaAlH}_{6}$ were prepared by ball milling $\mathrm{NaAlH}_{4}$ with either $2 \mathrm{NaH}$, $\mathrm{LiH}+\mathrm{NaH}$, or $2 \mathrm{KH}$, respectively. While the $\mathrm{Na}_{3} \mathrm{AlH}_{6}$ and $\mathrm{Na}_{2} \mathrm{LiAlH}_{6}$ are reversible hydrogen storage materials, $\mathrm{K}_{2} \mathrm{NaAlH}_{6}$ evolved no hydrogen in the medium throughput hydrogen storage assay $\left(220^{\circ} \mathrm{C}\right)$ without $\mathrm{Ti}(\mathrm{OiPr})_{4}$ dopant and only $0.2 \mathrm{wt} \% \mathrm{H}_{2}$ with the dopant. The stoichiometries employed for the reactions, aluminum hexahydrides/(amides, borohydrides, alanate, etc) were $5 / 1,3 / 1$, $2 / 1,1 / 1,1 / 2,1 / 3$, and $1 / 5$.

From a hydrogen storage perspective, the best performers of this group were the hexahydrides treated by alanates. Hydrogen desorption curves for some of these compositions are shown in Figure 36. The composition $0.5 \mathrm{Na}_{2} \mathrm{LiAlH}_{6}+\mathrm{NaAlH}_{4}$ yielded $4.4 \mathrm{wt}$ \% hydrogen on the first desorption, showing adsorption curve similar to that expected for $\mathrm{NaAlH}_{4}$, but shifted to higher temperature and never reaching a second plateau, slowly desorbing the last third of the hydrogen at the end of the run at $220^{\circ} \mathrm{C}$ (Figure 36, navy curve). After rehydriding, the second desorption started evolving

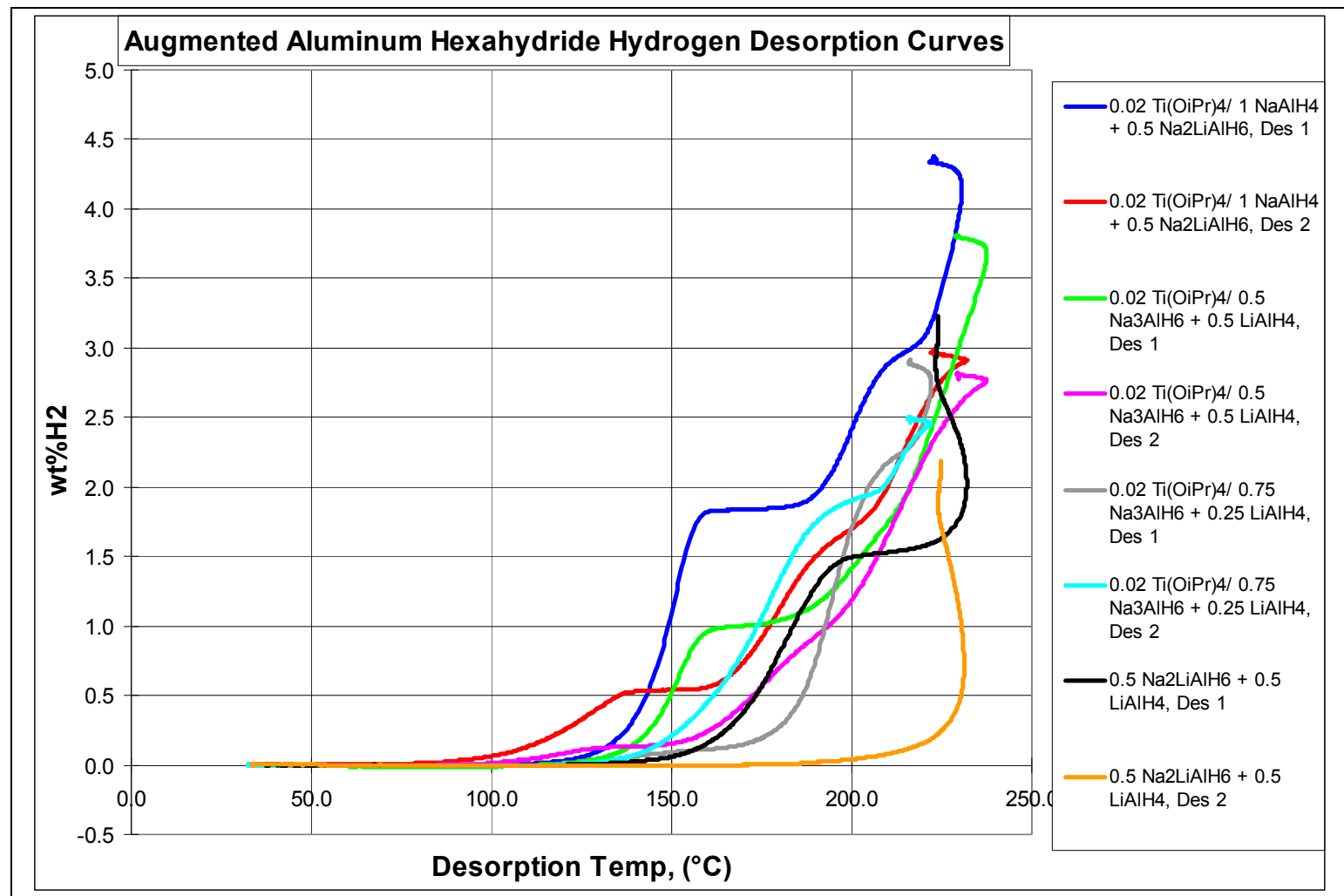

Figure 36. Medium throughput hydrogen desorption curves for aluminum hexahydrides treated with alanates. 
hydrogen at $90{ }^{\circ} \mathrm{C}$, about $30^{\circ} \mathrm{C}$ less than the first desorption, but starts lagging behind the first desorption after reaching $140^{\circ} \mathrm{C}$. The second cycle also shows the doublehumped diminished $\mathrm{NaAlH}_{4}$-type desorption curve, again with very slow desorption after $200{ }^{\circ} \mathrm{C}$, due to the presence of the hexahydride. There was a considerable capacity loss on the second desorption, which only yielded 3.0 wt. \% $\mathrm{H}_{2}$ (Figure 36, red curve).

Similar compositions can be attained by introducing $\mathrm{Li}$ in the alanate rather than the hexahydride. The composition $0.5 \mathrm{Na}_{3} \mathrm{AlH}_{6}+0.5 \mathrm{LiAlH}_{4}$ showed a single hump in the and lagged behind the $0.5 \mathrm{Na}_{2} \mathrm{LiAlH}_{6}+1 \mathrm{NaAlH}_{4}$ material mentioned above by up to 50 ${ }^{\circ} \mathrm{C}$ in desorption activity (Figure 36 , green curve). This material yielded $3.8 \mathrm{wt} . \% \mathrm{H}_{2}$ on the first desorption and the release of hydrogen was more strained on the second desorption until $200{ }^{\circ} \mathrm{C}$, after which the two curves followed each other closely (Figure 36 , magenta curve). The second desorption yielded $2.8 \mathrm{wt} . \% \mathrm{H}_{2}$. The XRD of the spent materials after this second desorption showed $\mathrm{Na}_{2} \mathrm{LiAlH}_{6}, \mathrm{Na}_{3} \mathrm{AlH}_{6}, \mathrm{NaH}$ and some $\mathrm{NaAlH}_{4}$. No Al was seen; these phases had rehydrided to some extent via standing under the desorbed hydrogen at the end of the run.

Also shown in Figure 36 are the desorption curves for $0.75 \mathrm{Na}_{3} \mathrm{AlH}_{6}+0.25 \mathrm{LiAlH}_{4}$ (Figure 36, gray curve), which contains a little less $\mathrm{Li}$ than the $0.5 \mathrm{Na}_{2} \mathrm{LiAlH}_{6}+0.5 \mathrm{LiAlH}_{4}$ composition (Figure 36, black curve). The storage capacities were less for this material, 2.50 wt. \% (second desorption, Figure 36, teal curve), and lagged behind with respect to desorption temperature until $200^{\circ} \mathrm{C}$. It is interesting that hydrogen is evolved more easily in the second desorption than in the first desorption as the second desorption is shifted to $20-30{ }^{\circ} \mathrm{C}$ to lower temperature up to just over a desorption temperature of $200{ }^{\circ} \mathrm{C}$. The XRD of the spent material is an unknown that has some features of the $\mathrm{Na}_{3} \mathrm{AlH}_{6}$ and $\mathrm{Na}_{2} \mathrm{LiAlH}_{6}$ materials, but not all the features and contains lines that aren't part of either. The diffraction lines are tabulated in Table 13 of Appendix D.

More $\mathrm{Li}$ is added to the system in the composition $0.5 \mathrm{Na}_{2} \mathrm{LiAlH}_{6}+0.5 \mathrm{LiAlH}_{4}$. This system evolved 3.20 and $2.32 \mathrm{wt}$ \% hydrogen on the first and second desorptions (Figure 36, black and orange curves, respectively), but was the most sluggish of the systems in this series as most of the desorption took place at the maximum desorption temperature of $220^{\circ} \mathrm{C}$. The XRD of the spent material showed on $\mathrm{Na}_{2} \mathrm{LiAlH}_{6}$, which has probably had some of its absorption/desorption activity suppressed by the presence of the excess Li.

The reactions of the aluminum hexahydrides with $\mathrm{LiNH}_{2}$ and $\mathrm{LiBH}_{4}$ gave materials that performed very poorly. The reactions with $\mathrm{LiNH}_{2}$ didn't desorb more than 1 wt. \% $\mathrm{H}_{2}$ unless the $\mathrm{LiNH}_{2}$ was present in a minor amount, where it basically acted as "dead weight" in the desorption process. When $\mathrm{LiNH}_{2}$ was present in excess over the aluminum hexahydride, it was converted to $\mathrm{Li}_{2} \mathrm{NH}$, as shown by XRD. This indicates loss of hydrogen during milling, which accounts for the poor desorption. Sometimes $\mathrm{LiNH}_{2}$ underwent ion-exchange with $\mathrm{Na}$ from the aluminum hexahydride to form $\mathrm{NaNH}_{2}$, which has poor hydrogen desorption properties. Similarly, $\mathrm{LiBH}_{4}$ ion-exchanged with the aluminum hexahydrides to form $\mathrm{NaBH}_{4}$. Figure 37 shows the first and second desorptions for $0.5 \mathrm{Na}_{3} \mathrm{AlH}_{6}+0.5 \mathrm{LiBH}_{4}$, which yield 2.2 and 2.0 wt. \% hydrogen, respectively. All of the desorption occurs at the maximum temperature in the run in each case as the desorption curves are nearly identical. The XRD of the spent material shows that ion-exchange had occurred with $\mathrm{Na}_{2} \mathrm{LiAlH}_{6}$ and $\mathrm{NaBH}_{4}$ being present, the latter being a very poor hydrogen desorber.

The reactions of the aluminum hexahydrides with $\mathrm{MgH}_{2}$ were a little more promising. In most cases, the spent materials showed the presence of $\mathrm{NaMgH}_{3}$, a material that is not reversible under these conditions. In the case of $\mathrm{K}_{2} \mathrm{NaAlH}_{6}$, some $\mathrm{KMgH}_{3}$ was seen in the spent material. Desorption curves for selected compositions are 


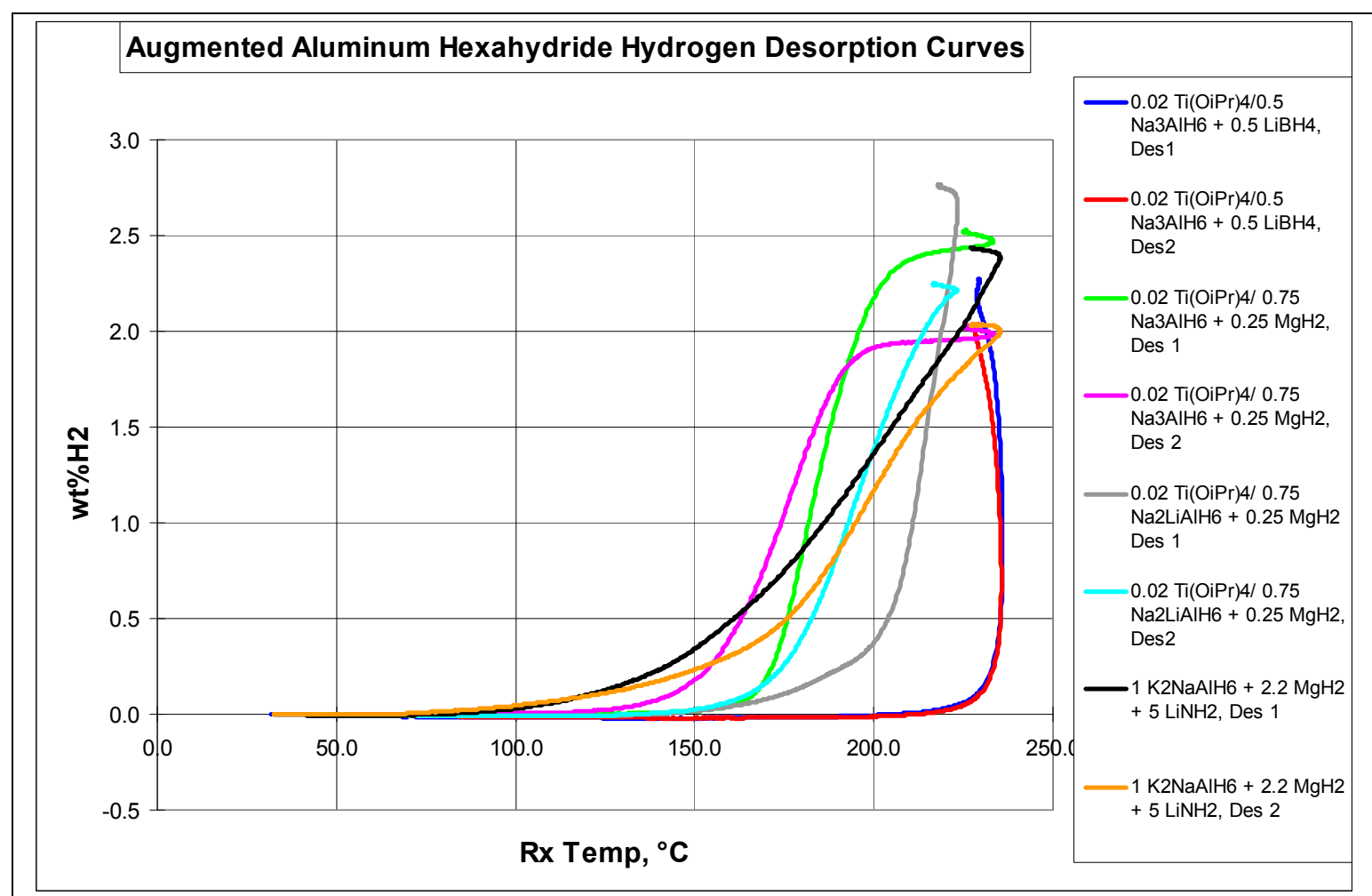

Figure 37. Hydrogen desorption curves for aluminum hexahydrides treated with $\mathrm{LiBH}_{4}$, $\mathrm{LiNH}_{2}$ and $\mathrm{MgH}_{2}$.

shown in Figure 37. The composition $0.75 \mathrm{Na}_{3} \mathrm{AlH}_{6}+0.25 \mathrm{MgH}_{2}$ desorbed 2.5 wt. \% $\mathrm{H}_{2}$ in the first desorption, plateauing at $210^{\circ} \mathrm{C}$ (Figure 37, green curve). The desorption occurred smoothly in a tight temperature range around $175^{\circ} \mathrm{C}$. After hydriding, the second desorption evolved hydrogen more quickly than the first up to $185^{\circ} \mathrm{C}$, suggesting reversible character. The second desorption lagged in total desorption yielding only $2 \mathrm{wt}$. $\% \mathrm{H}_{2}$ (Figure 37, magenta curve). Similar behavior was observed for the composition $0.75 \mathrm{Na}_{2} \mathrm{LiAlH}_{6}+0.25 \mathrm{MgH}_{2}$ as the second desorption evolves hydrogen earlier than the first desorption throughout the course of the entire run (Figure 37, gray and teal curves, respectively). The first and second desorptions yield 2.77 and $2.25 \mathrm{wt} . \% \mathrm{H}_{2}$ and contain none of the humps characteristic of $\mathrm{NaAlH}_{4}$. The spent material contains a large amount of $\mathrm{NaMgH}_{3}$ along with $\mathrm{NaH}$ and Al. Thus, the active hydrogen storage material is likely $\mathrm{Na}_{3} \mathrm{AlH}_{6}$.

Finally, a reaction of $\mathrm{K}_{2} \mathrm{NaAlH}_{6}$ with $\mathrm{MgH}_{2}$ and excess $\mathrm{LiNH}_{2}, 1 \mathrm{~K}_{2} \mathrm{NaAlH}_{6}+2.2$ $\mathrm{MgH}_{2}+5 \mathrm{LiNH}_{2}$, was carried out. The desorption curves are shown in Figure 37, black and orange curves for first and second desorption, respectively. The system is reversible, as the desorptions nearly coincide. Desorption is smooth as the temperature increases, starting at less than $100^{\circ} \mathrm{C}$ and continuing until the end of the run, never reaching a plateau. The spent material contained the mixed imide $\mathrm{K}_{2} \mathrm{Mg}(\mathrm{NH})_{2}$, the only time this material was observed in this project. Also in the spent was the starting hexahydride $\mathrm{K}_{2} \mathrm{NaAlH}_{6}$, which was shown earlier not to desorb hydrogen under these desorption conditions. One might suspect that $\mathrm{Li}_{2} \mathrm{Mg}(\mathrm{NH})_{2}$ may be the active material, but it was not observed in the spent. The spent also shows $\mathrm{Al}$, which via the Na present allows the possibility of $\mathrm{NaAlH}_{4}$ or $\mathrm{Na}_{2} \mathrm{LiAlH}_{6}$ also participating in reversible hydrogen storage reactions. Hence, it is difficult to say what the active ingredient in this reversible system is, but this system yields over 2 wt. \% $\mathrm{H}_{2}$. 
6.5 Binary Metal Borohydride-Amide Systems. The $\mathrm{LiNH}_{2}-\mathrm{LiBH}_{4}$ system was originally studied by Pinkerton. ${ }^{4}$ This system has a very high hydrogen content $\left(\mathrm{LiBH}_{4}-\right.$ 18.5 wt. \%; $\mathrm{LiNH}_{2}-8.8$ wt. \%) and yielded over 10 wt. \% hydrogen, but was irreversible, even with dopants. Pinkerton also reported the new compound $\mathrm{Li}_{4}\left(\mathrm{NH}_{2}\right)_{3} \mathrm{BH}_{4}$, a mixed amide-borohydride material that forms an ionic liquid just above $100{ }^{\circ} \mathrm{C}$. ${ }^{4}$ Our investigation of the ternary $\mathrm{LiNH}_{2}-\mathrm{LiBH}_{4}-\mathrm{MgH}_{2}$ system, reported in section 6.2.1, showed that the presence of this ionic liquid greatly enhanced the chemistry in the $\mathrm{LiNH}_{2}-\mathrm{MgH}_{2}$ reversible hydrogen storage system, considerably lowering desorption temperatures and enhancing reversibility. ${ }^{47}$ The $\mathrm{Li}_{4}\left(\mathrm{NH}_{2}\right)_{3} \mathrm{BH}_{4}$ ionic liquid changes the nature of hydrogen storage chemistry, which had traditionally relied on solid state chemistry processes. This surprisingly low temperature inorganic ionic liquid can solubilize inorganic species thus easing atomic transfer during hydrogen absorption/desorption processes. Based on the high hydrogen content, the ability to make mixed amide-borohydride compounds, and the ability to make chemistry more facile via a low melting temperature, the $\mathrm{LiNH}_{2}-\mathrm{LiBH}_{4}$ system became a key compositional component of our search for new reversible hydrogen storage systems. Most of the rest of this report features various transition metal- $\mathrm{LiNH}_{2}-\mathrm{LiBH}_{4}$ systems. In this section, the alkali and alkaline earth borohydrideamide systems are investigated, often enhanced with additional alkali or alkaline earth metal hydrides and transition metal dopants. The main focus is on the $\mathrm{LiNH}_{2}-\mathrm{LiBH}_{4}$ system. A phase diagram showing the borohydride-amide-metal hydride compositions studied is shown in Figure 38, although not all of the compositions were made with each starting material depicted at the phase diagram corners. The compositions studied and evaluated using the medium throughput hydrogen storage assay are listed in Table 14a in Appendix D. The compositions studied with the high throughput hydrogen storage assay are given in Table 14b in Appendix D. The structures present in the spent materials are given in Table $14 \mathrm{c}$ of Appendix D.

The results of the medium throughput hydrogen capacity assay, which has a maximum desorption temperature of $220^{\circ} \mathrm{C}$, showed that many of the systems failed to desorb much hydrogen, especially those compositions containing metals other than just Li and $\mathrm{Mg}$ (Table 14a, Appendix D). The compositions containing Mg tended to desorb reversibly in the 3 wt. $\% \mathrm{H}_{2}$ range, indicative of of the $\mathrm{LiNH}_{2}-\mathrm{MgH}_{2} / \mathrm{Li} 2 \mathrm{Mg}(\mathrm{NH})_{2}$ system. The desorption temperature of $220^{\circ} \mathrm{C}$ is too low for a lot of these systems. The $\mathrm{LiNH}_{2}-\mathrm{LiBH}_{4}$ systems, however, showed significant desorption capacity especially in the presence of dopants. Figure 39 shows that desorption from $2 \mathrm{LiNH}_{2}+$ $1 \mathrm{LiBH}_{4}$ systems are highly dependent on the dopant

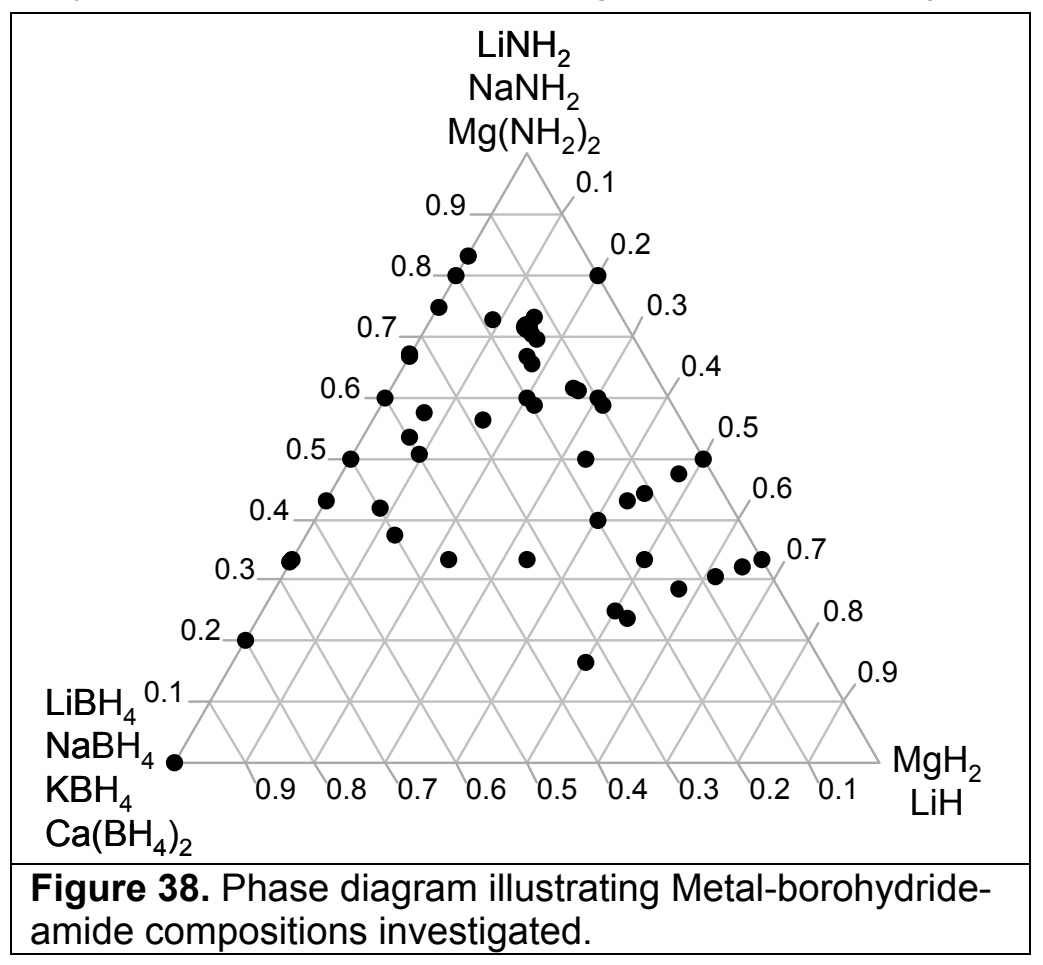




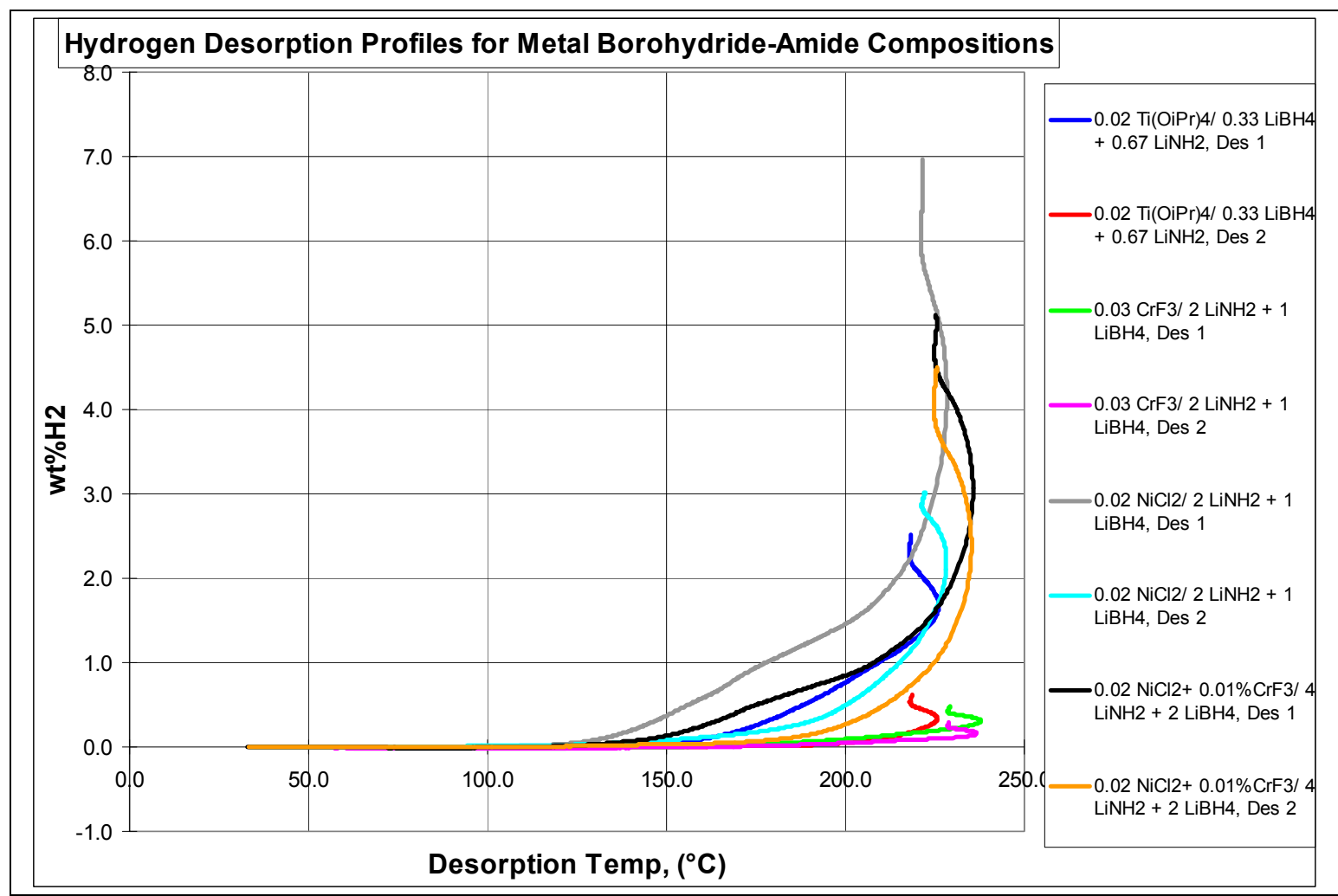

Figure 39. Medium throughput hydrogen desorption profiles for $2 \mathrm{LiNH}_{2}-\mathrm{LiBH}_{4}$ compositions with various dopants.

included in the formulation. Desorption in these systems generally starts between 125 ${ }^{\circ} \mathrm{C}$ and $180{ }^{\circ} \mathrm{C}$. When doped with $0.02 \mathrm{Ti}(\mathrm{OiPr})_{4} / \mathrm{LiBH}_{4}$, desorption starts just above 150 ${ }^{\circ} \mathrm{C}$ and reaches just under 1 wt. \% hydrogen by $200{ }^{\circ} \mathrm{C}$ (Figure 39 , navy curve). Most of the desorption occurs at the maximum desorption temperature of $220^{\circ} \mathrm{C}$, which eventually reaches 2.47 wt. \% $\mathrm{H}_{2}$. After hydriding, the second desorption evolved $0.6 \mathrm{wt}$. $\%$ hydrogen, showing no reversible character as desorption occurred at $220{ }^{\circ} \mathrm{C}$ (Figure 39 , red curve). With $\mathrm{CrF}_{3}$ as dopant, there was little desorption at all (Figure 39, green curve), while with $0.02 \mathrm{NiCl}_{2} / \mathrm{LiBH}_{4} 7.2 \mathrm{wt}$. $\% \mathrm{H}_{2}$ was desorbed (Figure 39, gray curve). Desorption started at about $125^{\circ} \mathrm{C}$ and had evolved $1.5 \mathrm{wt} . \% \mathrm{H}_{2}$ by $200{ }^{\circ} \mathrm{C}$, but as in the other systems, most of the desorption occurred during a hold at $220^{\circ} \mathrm{C}$. The second cycle was slower to desorb, shifted $50{ }^{\circ} \mathrm{C}$ to higher temperature early on, but eventually evolved 3 wt \% hydrogen - far short of being reversible (Figure 39, teal curve). However, it is difficult to make this assessment, because in each of the desorption cycles, desorption occurs during a hold at $220^{\circ} \mathrm{C}$ at the end of the run. This is exemplified by the example of $2 \mathrm{LiNH}_{2}+\mathrm{LiBH}_{4} / 0.02 \mathrm{NiCl}_{2}+0.01 \mathrm{CrF}_{3}$, also shown in Figure 39, black curve. This system yields $5.0 \mathrm{wt} . \% \mathrm{H}_{2}$ in the first desorption cycle and $4.3 \mathrm{wt} . \% \mathrm{H}_{2}$ during the second cycle, with the desorption profiles within $15^{\circ} \mathrm{C}$ of each other (Figure 39 , orange curve). While this appears to be reversible behavior, because most of the desorption occurs at the maximum temperature, it can't be ruled out that the second desorption is merely a continuation of the first desorption process without any regeneration during rehydriding. The high throughput apparatus, which goes to $350{ }^{\circ} \mathrm{C}$ should be able to shed light on the reversibility issue.

The hydrogen storage capacities for the materials studied with the high throughput assay are tabulated in Table 14b of Appendix D. Unlike the constant volume 


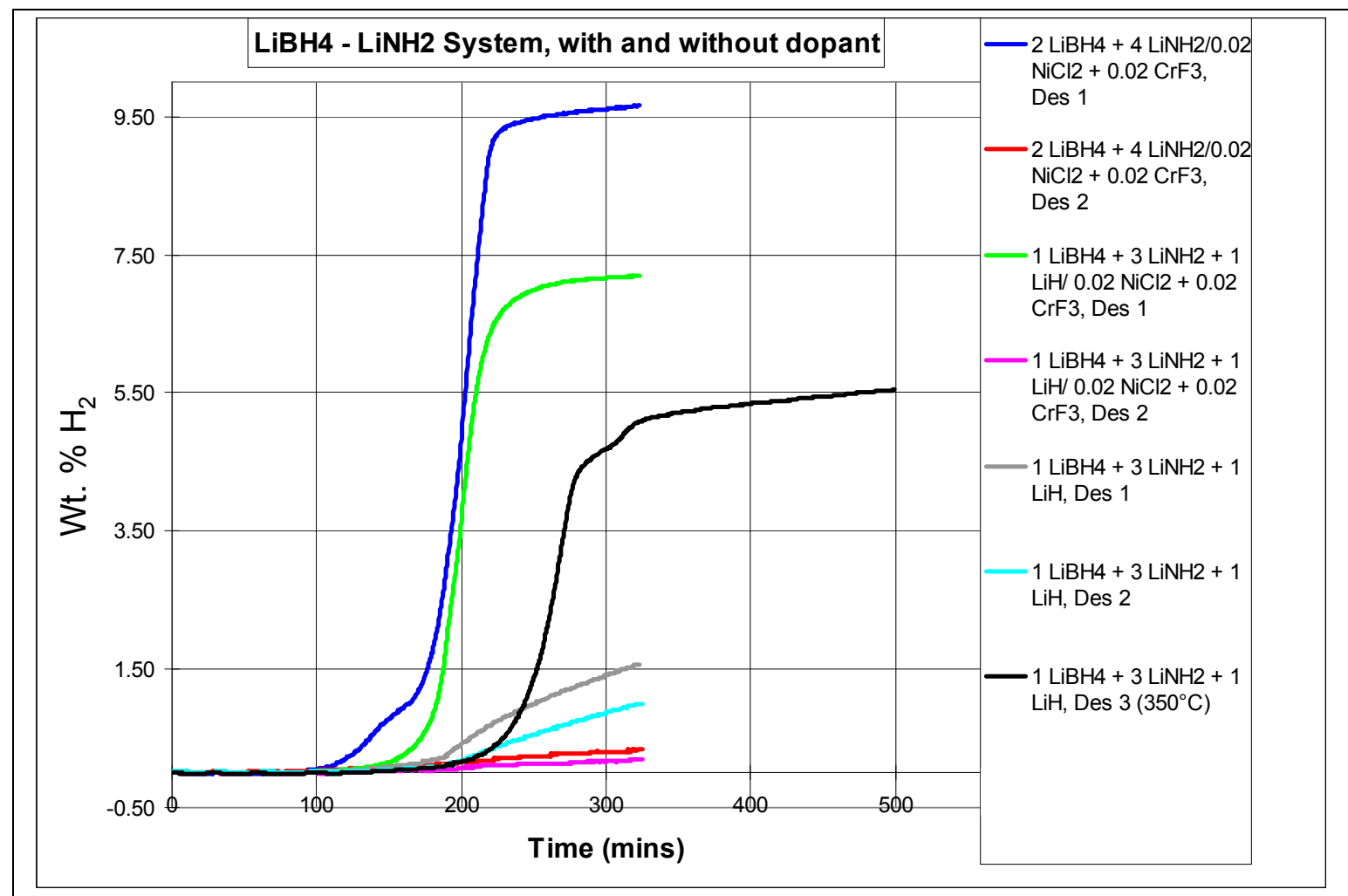

Figure 40. High throughput hydrogen desorption profiles for $\mathrm{LiNH}_{2}-\mathrm{LiBH}_{4}$ compositions with and without dopant. Desorption program: Des 1, Des 2-230 ${ }^{\circ} \mathrm{C}$; Des 3, Des $4-350^{\circ} \mathrm{C}$.

medium throughput apparatus, the high throughput assay features desorption against constant (atmospheric) pressure, so at any particular temperature desorption is more extensive. On the first desorption cycle, many of the materials showed desorptions of over 9 wt. \% $\mathrm{H}_{2}$. Exceptions included compositions that lacked dopant and compositions that contained excess $\mathrm{LiH}$ or $\mathrm{MgH}_{2}$. Figure 40 shows the desorption profiles for representative compositions plotted versus time because the desorptions were run on different temperature programs. In the first desorption, it can be seen that $2 \mathrm{LiNH}_{2}+$ $\mathrm{LiBH}_{4} / 0.02 \mathrm{NiCl}_{2}+0.02 \mathrm{CrF}_{3}$ evolves $9.66 \mathrm{wt}$. $\% \mathrm{H}_{2}$ by the end of the desorption cycle at $230{ }^{\circ} \mathrm{C}$ (Figure 40 , navy curve). After hydriding, the second desorption cycle $\left(230^{\circ} \mathrm{C}\right)$ for the same sample yields only $0.33 \mathrm{wt} . \% \mathrm{H}_{2}$ and the sample seems to be completely depleted (Figure 40, red curve). The third and fourth desorption cycles (to $350{ }^{\circ} \mathrm{C}$ ) confirm this yielding less than $1 \mathrm{wt} . \% \mathrm{H}_{2}$ (data not shown). Another composition containing $\mathrm{LiH}, 3 \mathrm{LiNH}_{2}+\mathrm{LiBH}_{4}+\mathrm{LiH} / 0.02 \mathrm{NiCl}_{2}+0.02 \mathrm{CrF}_{3}$, yielded 7.2 wt. \% hydrogen on the first desorption (Figure 40, green curve), but only $0.2 \mathrm{wt}$. \% on the second desorption, showing no reversibility (Figure 40, magenta curve). The third and fourth cycles each yielded a little over $1 \mathrm{wt} . \%$ hydrogen at $350{ }^{\circ} \mathrm{C}$, accessing higher temperature hydrogen not available at the lower temperatures (data not shown). Finally, the desorption profiles for the same composition without dopant, $3 \mathrm{LiNH}_{2}+\mathrm{LiBH}_{4}+\mathrm{LiH}$, are interesting. Without the $\mathrm{NiCl}_{2}+\mathrm{CrF}_{3}$ dopant, the first desorption evolves 1.4 wt. \% hydrogen (Figure 40, gray curve) vs. the $7.2 \mathrm{wt}$. \% seen with dopant. The second desorption yields another 0.7 wt. $\% \mathrm{H}_{2}$ (Figure 40 , teal curve). The third desorption at $350{ }^{\circ} \mathrm{C}$ can finally access the hydrogen in the undoped sample as $5.6 \mathrm{wt} \%$ hydrogen is evolved as much of the hydrogen is desorbed between $260^{\circ} \mathrm{C}$ and $300{ }^{\circ} \mathrm{C}$, about a 60 ${ }^{\circ} \mathrm{C}$ shift to higher temperature from the 205 to $235^{\circ} \mathrm{C}$ range observed for the doped sample (Figure 40, black curve). The fourth desorption showed this material to be irreversible under these conditions, yielding $1.7 \mathrm{wt}$ \% hydrogen. None of the samples in 


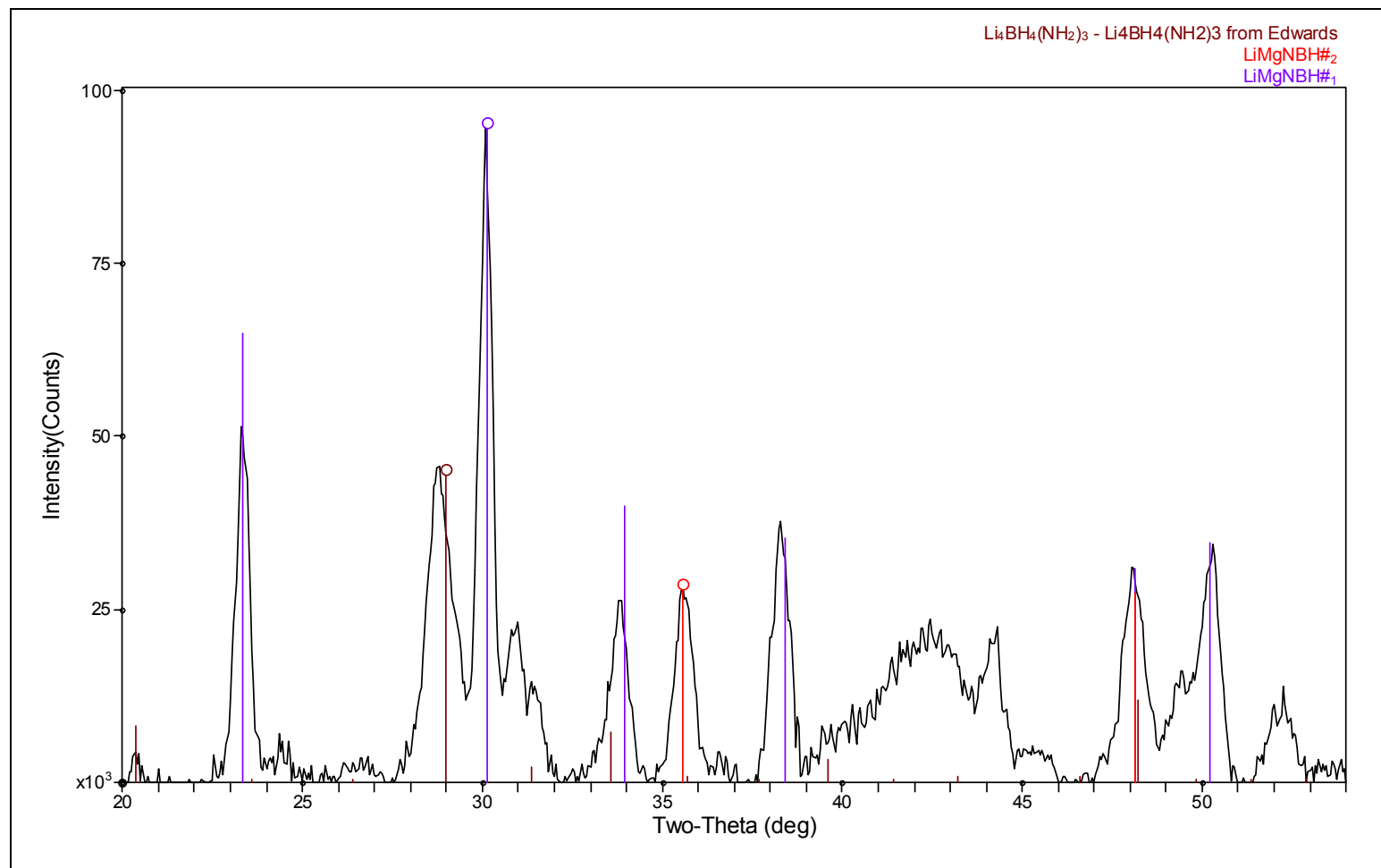

Figure 41. XRD of new materials observed in the spent samples from metal amideborohydride reactions: Li-Mg-N-B-H \#1 (blue) and Li-Mg-N-B-H \#2 (red) and $\mathrm{Li}_{4}\left(\mathrm{NH}_{2}\right)_{3} \mathrm{BH}_{4}$ (black).

this study, other than those containing Mg, showed any hints of reversibility, even though some of the observed storage capacities were very impressive.

The structures of the spent materials for many of the compositions are listed in Table $14 \mathrm{c}$ of Appendix D. The doped 2-3 $\mathrm{LiNH}_{2}+\mathrm{LiBH}_{4}$ systems contained $\mathrm{Li}_{3} \mathrm{BN}_{2}$ and $\mathrm{BN}$ in the spent samples. These materials were not regenerated with the hydriding conditions employed: $125^{\circ} \mathrm{C}$ and 120 bar $\mathrm{H}_{2}$. Also seen in the spents was $\mathrm{Li}_{4}\left(\mathrm{NH}_{2}\right)_{3} \mathrm{BH}_{4}$. The starting borohydrides $\mathrm{NaBH}_{4}$ and $\mathrm{KBH}_{4}$ often end up in the spents unreacted or are sometimes formed via an ion-exchange process. lon-exchange processes also generated the mixed amides $\mathrm{Li}_{3} \mathrm{Na}\left(\mathrm{NH}_{2}\right)_{4}$ and $\mathrm{KLi}_{3}\left(\mathrm{NH}_{2}\right)_{4}$. As seen previously, amides often ended up as imides in the spents, including $\mathrm{Li}_{2} \mathrm{NH}, \mathrm{CaNH}$ and $\mathrm{Li}_{2} \mathrm{Mg}(\mathrm{NH})_{2}$. In the Ca systems, $\mathrm{CaB}_{6}$ and $\mathrm{Ca}\left(\mathrm{NH}_{2}\right)_{2}$ were also seen in the spent materials.

Several new materials were also observed among the spent materials. Figure 41 shows the XRD pattern of two of these new materials, Li-Mg-N-B \#1 and Li-Mg-N-B \#2, that have shown up in spents in amide borohydride reactions containing $\mathrm{Mg}$ and were first seen in the ternary $\mathrm{LiNH}_{2}-\mathrm{LiBH}_{4}-\mathrm{MgH}_{2}$ phase diagram study. These two materials always occur in mixtures. Figure 42 shows the XRD of the new material Li-Ca-N-B-H \#1 that came from the spent the reaction $5 \mathrm{LiNH}_{2}+\mathrm{NaNH}_{2}+\mathrm{Ca}\left(\mathrm{BH}_{4}\right)_{2}+1.2 \mathrm{MgH}_{2}$, in which $\mathrm{LiBH}_{4}$ was replaced with $\mathrm{Ca}\left(\mathrm{BH}_{4}\right)_{2}$. In the MT assay, the parent composition desorbed 4.6 and 3.1 wt. $\% \mathrm{H}_{2}$ on the first and second desorptions $\left(220^{\circ} \mathrm{C}\right)$, respectively. While hydrogen evolution began at $125^{\circ} \mathrm{C}$ on the first desorption, it was delayed to $150{ }^{\circ} \mathrm{C}$ during the second desorption cycle. The second desorption began to lag further behind the first as desorption continued, exhibiting a $40{ }^{\circ} \mathrm{C}$ shift to higher temperature at the point where each sample desorbed $1 \mathrm{wt} \% \mathrm{H}_{2}$. More than half of the hydrogen was liberated at the end of the run for each sample. It appeared that this system and thus the dehydrided new compound Li-Ca-N-B-H \#1 were not reversible. Finally, Figure 43 shows 


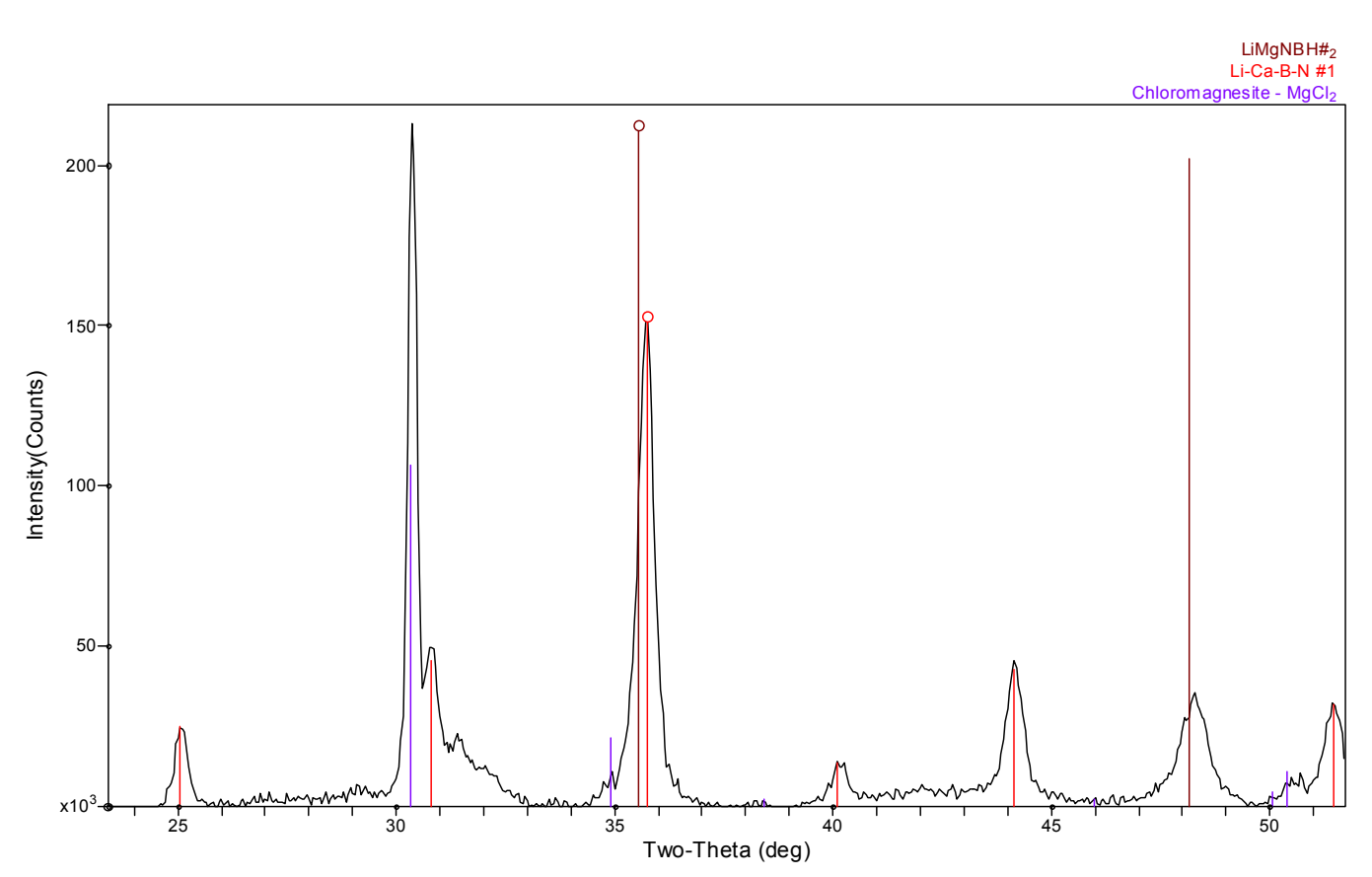

Figure 42. XRD of new materials observed in the spent samples from metal amide-borohydride reactions: $\mathrm{Li}-\mathrm{Ca}-\mathrm{B}-\mathrm{N} \# 1$ (red) from $5 \mathrm{LiNH}_{2}+\mathrm{NaNH}_{2}+\mathrm{Ca}\left(\mathrm{BH}_{4}\right)_{2}+1.2 \mathrm{MgH}_{2}$. Also present: $\mathrm{MgCl}_{2}$ (blue), Li-Mg-N-B-H \#2.

the XRD of the new material Li-N-B-H \#2. This spent material was first observed in 2 $\mathrm{LiNH}_{2}+\mathrm{LiBH}_{4}$ systems as the spent and is definitely not part of a reversible hydrogen storage system. This material occurs frequently in the spents throughout the project

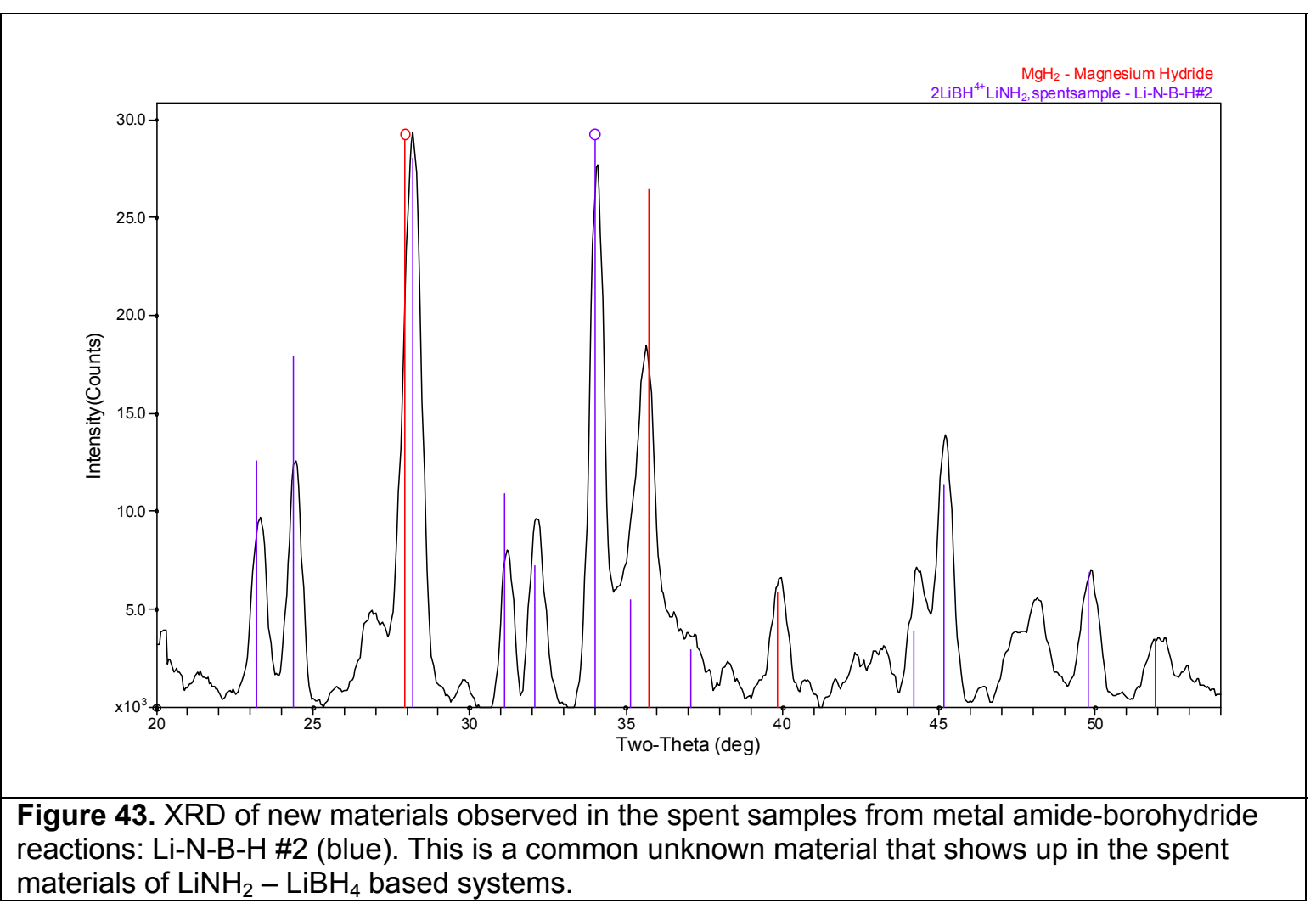


since $\mathrm{LiNH}_{2}$ and $\mathrm{LiBH}_{4}$ are key components of the formulations. It is most commonly observed as a spent material from a HT assay, where desorption temperatures reach $350{ }^{\circ} \mathrm{C}$.

6.6 Ternary Amide-Alanate-Borohydride Systems. In Section 6.5, we discussed the binary combinations of systems based on the high hydrogen content amides, borohydrides and alanates. In this section, we extend our investigation to ternary amideborohydride-alanate systems. Specifically, the $\mathrm{LiNH}_{2}-\mathrm{LiBH}_{4}-\mathrm{LiAlH}_{4}, \mathrm{LiNH}_{2}-\mathrm{LiBH}_{4}-$ $\mathrm{NaAlH}_{4}$, and $\mathrm{NaNH}_{2}-\mathrm{NaBH}_{4}-\mathrm{NaAlH}_{4}$ phase diagrams were studied. Identification of the structures in some of the spent samples and hydrogen storage capacity results tabulated in tables 15a-15d in Appendix D. The $\mathrm{LiAlH}_{4}-\mathrm{LiBH}_{4}-\mathrm{NaAlH}_{4}$ compositions were studied in the presence a variety of dopants.

6.6.1 $\mathrm{LiNH}_{2}-\mathrm{LiBH}_{4}-\mathrm{LiAlH}_{4} \mathrm{Phase}$ Diagram. The compositions, their medium throughput hydrogen storage capacities, and structures of the spent products for the $\mathrm{LiNH}_{2}-\mathrm{LiBH}_{4}-\mathrm{LiAlH}_{4}$ system are given in Table 15a of Appendix D. Alternatively, these results are rendered graphically in the phase diagrams in Figure 44, which may be a more convenient way to view the many data points generated by combinatorial high throughput studies. The compositional points on the diagram are colorcoded from dark purple/black to blue to green to yellow to dark red in order of increasing hydrogen evolved during the desorption cycles. The color coding makes it easy to identify the nature of and trends in the hydrogen storage capacities as a function of composition and is especially useful for comparing the performance of the compositions between different

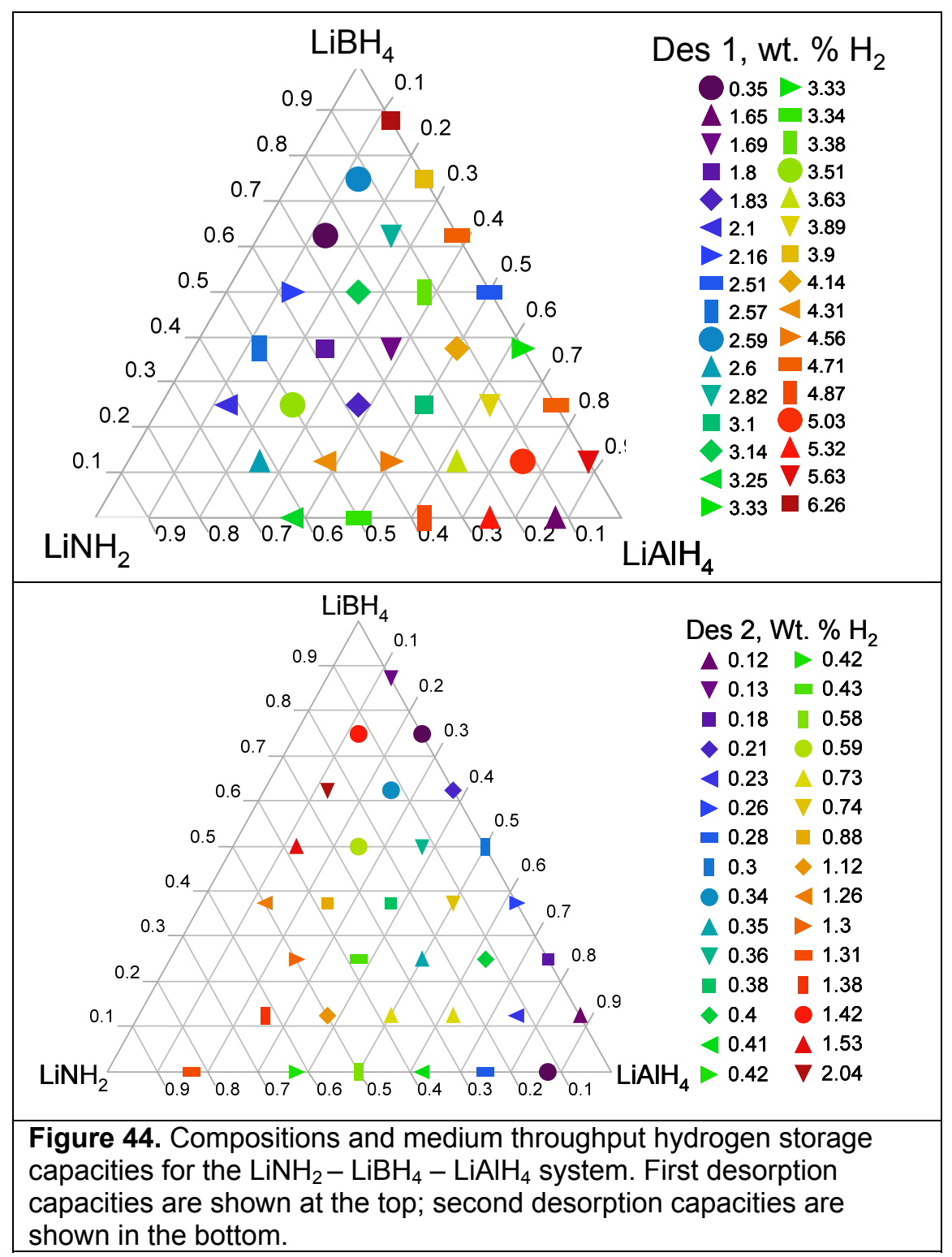


desorption cycles. The compositions are additionally coded via the marker shapes which identify the exact amount of hydrogen evolved at each composition. Figure 44 shows the results for both desorption runs in the medium throughput assay. Quick inspection of the top of Figure 44 shows that hydrogen desorption trended with $\mathrm{LiAlH}_{4}$ content during the first desorption cycle. A surprising exception was the top performer, $0.875 \mathrm{LiBH}_{4}+0.125$ $\mathrm{LiAlH}_{4}$, which yielded $6.3 \mathrm{wt} . \% \mathrm{H}_{2}$. The trend is reversed in the second desorption (bottom of Figure 44) where the most desorption (red) occurs at the lowest $\mathrm{LiAlH}_{4}$ levels $\left(0.125 \mathrm{LiAlH}_{4}\right)$ while the highest $\mathrm{LiAlH}_{4}$ levels desorb $0.3 \mathrm{wt}$. \% hydrogen or less. By comparison, the amount of hydrogen desorbed per composition in the second cycle was much less than that observed during the first cycle, suggesting a lack of reversible character. The hydrogen desorption from $0.875 \mathrm{LiBH}_{4}+0.125 \mathrm{LiAlH}_{4}$ drastically fell to 0.13 from 6.3 wt. $\% \mathrm{H}_{2}$ on the second cycle.

The XRD results from the spent materials were unremarkable (Table 15a, Appendix D). Many of the samples were amorphous and Al and LiH were frequently

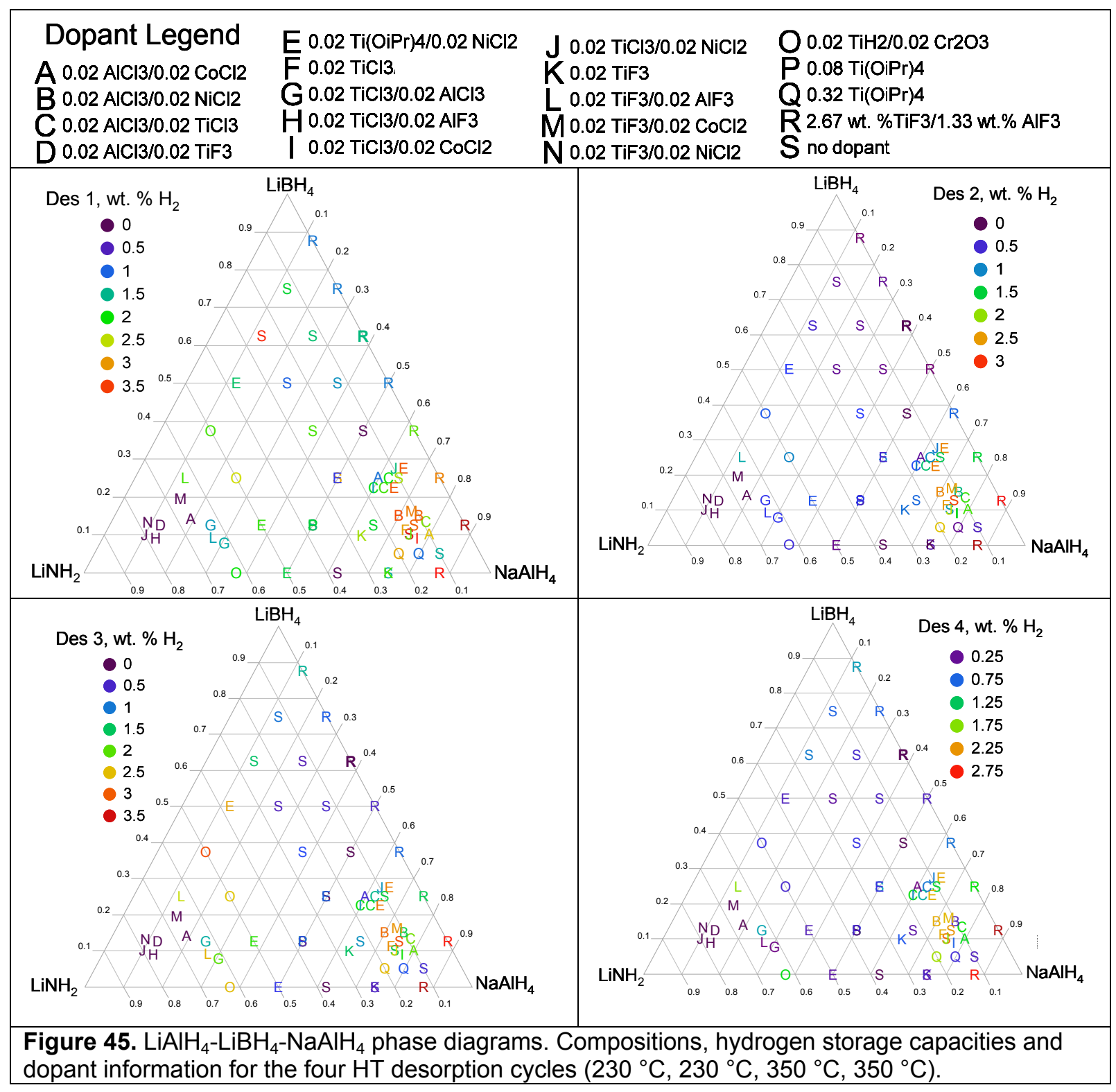


observed, which is expected in spents from $\mathrm{LiAlH}_{4}$-based materials. Surprisingly, there was not a single occurrence of $\mathrm{Li}_{2} \mathrm{NH}$, which had been observed earlier in the alanateamide study as a hydrogen-producing product. There were a few occurrences of $\mathrm{Li}_{4}\left(\mathrm{NH}_{2}\right) \mathrm{BH}_{4}$ and the only other $\mathrm{N}$-containing compound identified was LiAIN ${ }_{2}$. Some unknown materials were observed, but only in single occurrences, so it is not known if they are pure compounds. The diffraction lines are listed in Table 15a, Appendix D.

6.6.2 $\mathrm{LiNH}_{2}-\mathrm{LiBH}_{4}-\mathrm{NaAlH}_{4}$ System. The $\mathrm{LiNH}_{2}-\mathrm{LiBH}_{4}-\mathrm{NaAlH}_{4}$ system was evaluated in the HT assay (Table 15b, Appendix D) and in both the MT and HT assay for some compositions (Table 15d, Appendix D). A variety of dopants were also included in this study. Figure 45 shows the compositions studied in four phase diagrams, one for each of the high throughput desorption cycles. The composition markers are color-coded from purple to red by increasing amounts of hydrogen evolved during the cycle, but grouped in ranges of $0.5 \mathrm{wt}$. \%, i.e., each value is not shown. The markers are also alphanumeric, coded according to the dopant used with the $\mathrm{LiNH}_{2}-\mathrm{LiBH}_{4}-\mathrm{LiAlH}_{4}$ composition. The key to the dopants is at the top of Figure 45 and each phase diagram contains a color scale that spans the range of hydrogen evolved during that desorption run. With the goal of high throughput exploration to quickly identify promising leads, plotting the data in this manner allows quick identification of trends and standout samples.

It is easily seen in Figure 45 that the compositions rich in $\mathrm{NaAlH}_{4}$ (over 60 mole $\%)$ are consistently giving the most hydrogen desorption, while the compositions rich in $\mathrm{LiNH}_{2}$ (over 70 mole \%) were the worst. The compositions with the best desorption properties are $0.875 \mathrm{NaAlH}_{4}+0.125 \mathrm{LiBH}_{4}$ and $0.875 \mathrm{NaAlH}_{4}+0.125 \mathrm{LiNH}_{2}$. Each contain 2.67 wt. \% $\mathrm{TiF}_{3} / 1.33$ wt. $\% \mathrm{AlF}_{3}$ and desorb $2.75-3.5$ wt. \% hydrogen consistently and perhaps reversibly. However, these desorption values suggest that these materials are acting like $\mathrm{NaAlH}_{4}$ (4-5 wt. \% expected), but diminished by the addition of either the $\mathrm{LiBH}_{4}$ or the $\mathrm{LiNH}_{2}$.

A few compositions were treated with a variety of dopants, such as $0.625 \mathrm{NaAlH}_{4}$ $+0.125 \mathrm{LiNH}_{2}+0.25 \mathrm{LiAlH}_{4}$. Five different dopants were employed at this composition. Dopant $\mathrm{E}, 0.02 \mathrm{Ti}(\mathrm{OiPr})_{4} / 0.02 \mathrm{NiCl}_{2}$, was consistently the best, desorbing over 2 wt. \% $\mathrm{H}_{2}$ on each cycle. Dopant $\mathrm{A}, 0.02 \mathrm{AlCl}_{3} / 0.02 \mathrm{CoCl}_{2}$, always had the worst performance, even worse than no dopant (Dopant S). The composition $0.75 \mathrm{NaAlH}_{4}+0.125 \mathrm{LiNH}_{2}+$ $0.125 \mathrm{LiBH}_{4}$ was also treated with several dopants. Dopants $\mathrm{B}, 0.02 \mathrm{AlCl}_{3} / 0.02 \mathrm{NiCl}_{2}, \mathrm{~F}$, $0.02 \mathrm{TiCl}_{3}, \mathrm{M}, 0.02 \mathrm{TiF}_{3} / 0.02 \mathrm{CoCl}_{2}$, and $\mathrm{S}$, no dopant, performed consistently the best, yielding 2-3 wt. \% $\mathrm{H}_{2}$ on all four desorptions. Dopants $\mathrm{A}, 0.02 \mathrm{AlCl}_{3} / \mathrm{CoCl}_{2}, \mathrm{C}, 0.02$ $\mathrm{AlCl}_{3} / 0.02 \mathrm{TiCl}_{3}$, and I, $0.02 \mathrm{TiCl}_{3} / 0.02 \mathrm{CoCl}_{2}$ all performed worse over the course of the four desorption cycles, yielding $0.5-2 \mathrm{wt} . \% \mathrm{H}_{2}$. Further delineation between the similar performers would require plotting of the desorption profiles. In the case of these data, it is easily determined that there is no need for further study since the best samples are consistently worse than $\mathrm{NaAlH}_{4}$.

6.6.3. $\mathrm{NaNH}_{2}-\mathrm{NaBH}_{4}-\mathrm{NaAlH}_{4}$ System. The compositions and HT hydrogen storage capacities are given in Table $15 \mathrm{c}$ of Appendix D. Figure 46 shows the $\mathrm{NaNH}_{2}-\mathrm{NaBH}_{4}-$ $\mathrm{NaAlH}_{4}$ phase diagram with the compositions color-coded by the wt. \% hydrogen desorbed for desorption cycles $1\left(230^{\circ} \mathrm{C}\right)$ and $3\left(350^{\circ} \mathrm{C}\right)$. There were no dopants used in this study. It is easily seen for the first desorption that the best desorbers are the $\mathrm{NaAlH}_{4}$-rich materials, while the worst were $\mathrm{NaNH}_{2}$-rich. The best values of $4 \mathrm{wt} \% \mathrm{H}_{2}$ at $230{ }^{\circ} \mathrm{C}$ were good for dopant-free compositions. The second desorption cycle (Table $15 \mathrm{c}$, Appendix D), also ramped up to $230{ }^{\circ} \mathrm{C}$, showed no reversible behavior as the hydrogen evolved was less than $1 \mathrm{wt}$. $\% \mathrm{H}_{2}$, with a maximum occurring at $1.3 \mathrm{wt}$. \%. The 


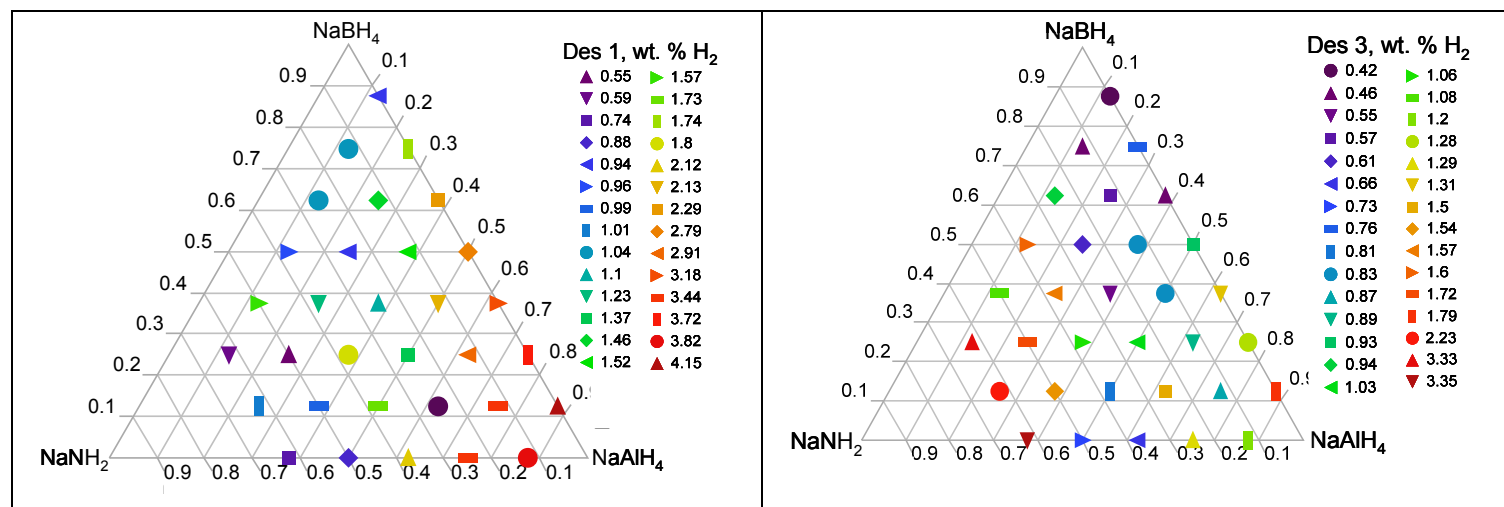

Figure 46. $\mathrm{NaNH}_{2}-\mathrm{NaBH}_{4}-\mathrm{NaAlH}_{4}$ phase diagram. Compositions and $\mathrm{HT}$ hydrogen storage capacities for desorption $1\left(230^{\circ} \mathrm{C}\right)$ and desorption $3\left(350^{\circ} \mathrm{C}\right)$.

third desorption cycle (Figure 46) shows increased hydrogen evolution at $350{ }^{\circ} \mathrm{C}$, up to $3.3 \mathrm{wt}$. \%. The color-coding in the phase diagram shows this best desorption is now occurring from the $\mathrm{NaNH}_{2}$ - rich phases, not $\mathrm{NaAlH}_{4}$-rich materials. The desorption activity crashes again in the fourth desorption, again there is no sign of reversibility. In summary, the amide-borohydride-alanate system performed poorly and didn't open up any new chemistry. At its best it performed like diluted $\mathrm{NaAlH}_{4}$.

\subsection{Destabilization Reactions}

6.7.1 Silicon-Based Hydrogen Storage Materials. The search for new hydrogen storage materials focuses on gravimetrically attractive options leading to intense scrutiny of $\mathrm{B}-, \mathrm{N}$ - and Al- based materials. Noticeably missing is $\mathrm{Si}$, which is also a gravimetrically attractive material, but unfortunately forms volatile hydrides such as silane, $\mathrm{SiH}_{4}$. However, in combination with alkali or Al, B, or N, solid state gravimetrically attractive hydrogen storage materials could be prepared. The combination of $\mathrm{Na}$ and $\mathrm{Si}$ forms $\mathrm{NaSi}$, which has been reported as a "one-use" hydrogen storage material when it reacts with water. ${ }^{48}$ Reaction of $\mathrm{Si}$ with other strong reducing agents, such as various metal hydrides and complex metal hydrides, may be a route to new hydrogen storage materials. In fact, silicon has been used to "destabilize" $\mathrm{LiH}$ and $\mathrm{MgH}_{2} \cdot{ }^{49}$ Finely divided silicon metal powder was reacted $\mathrm{Li}$ and $\mathrm{Na}$ borohydrides, $\mathrm{Li}$ and $\mathrm{Na}$ alanates; $\mathrm{Li}, \mathrm{Na}, \mathrm{K}$, $\mathrm{Mg}$ and $\mathrm{Ca}$ hydrides in various stoichiometries. All of the compositions included $\mathrm{Ti}(\mathrm{OiPr})_{4}$ dopant. The compositions of the materials studied, the structures of as-synthesized and spent materials, and hydrogen storage capacities from the medium throughput assay are given in Table 16 of Appendix D.

After milling, XRD results showed that the materials present were just the starting materials with unreacted Si observed in every case. The only exceptions were reactions with $\mathrm{NaAlH}_{4}$ and $\mathrm{LiAlH}_{4}$, which seemed to react independently, forming their respective aluminum hexahydrides and Al metal. No new materials were observed after milling.

It was anticipated that new compounds might not be formed until the materials were taken to higher temperature during the hydrogen desorption/absorption cycles. Before the first desorption, the materials were pre-hydrided at $125^{\circ} \mathrm{C}$ and 87 bar $\mathrm{H}_{2}$ for 12 hours. The results of the first desorption showed $\left(220^{\circ} \mathrm{C}\right)$ almost no hydrogen evolved. The same was the case in the second desorption cycle after a second hydriding process. The XRD results on the spent materials supported desorption results as they were nearly identical to those observed for the as-synthesized materials. Hence, the conditions that the reaction materials experienced over the course of the hydriding/desorption processes were not severe enough to affect any changes. Perhaps 
this chemistry may have been more successful in the high throughput unit where temperatures to $350{ }^{\circ} \mathrm{C}$ and 120 bar $\mathrm{H}_{2}$ could have been used in the hydriding/desorption processes.

6.7.2 Other Destabilized Reactions. The so-called "destabilized" hydrogen storage reactions involve systems which when combined, yield hydrogen more easily than the individual systems by themselves on a thermodynamic basis. One of the first examples of this in the literature is the $\mathrm{LiBH}_{4}+\mathrm{MgH}_{2}$ system. ${ }^{3}$ In this scenario, the reaction:

$$
\mathrm{LiBH}_{4}+1 / 2 \mathrm{MgH}_{2} \rightarrow \mathrm{LiH}+1 / 2 \mathrm{MgB}_{2}+2 \mathrm{H}_{2}
$$

has an observed $\Delta \mathrm{H}=42 \mathrm{~kJ} /$ Mole $\mathrm{H}_{2}$. This is lower than that observed for the individual components:

$$
\begin{aligned}
& \mathrm{LiBH}_{4} \rightarrow \mathrm{LiH}+\mathrm{B}+3 / 2 \mathrm{H}_{2} ; \quad \Delta \mathrm{H}=67 \mathrm{~kJ} / \mathrm{mole}_{2} \\
& \mathrm{MgH}_{2} \rightarrow \mathrm{Mg}+1 / 2 \mathrm{H}_{2} ; \Delta \mathrm{H}=70 \mathrm{~kJ} / \text { mole } \mathrm{H}_{2}
\end{aligned}
$$

Mixing $\mathrm{LiBH}_{4}$ and $\mathrm{MgH}_{2}$ allows the formation of the stable $\mathrm{MgB}_{2}$, which favors the release of hydrogen from these materials. The starting materials $\mathrm{LiBH}_{4}$ and $\mathrm{MgH}_{2}$ are said to be "destabilized" by the $\mathrm{MgB}_{2}$ formation as hydrogen evolution is less endothermic in the combined system.

This strategy was used as a basis for a search for new hydrogen storage systems using first principles calculations. ${ }^{50}$ This approach serves as a guiding principle to choose which hydrogen storage systems to study experimentally, saving a great deal of time compared to an intuitive approach for choosing which systems to study. The combined systems studied consisted of either $\mathrm{LiBH}_{4}$ or $\mathrm{Ca}\left(\mathrm{BH}_{4}\right)_{2}$ combined with a variety of metals and metal hydrides. The thermodynamics of each system calculated considered only known materials within the compositional system; no allowances were made for new materials that might be observed. Several guidelines emerged from the study regarding system choices. As mentioned above, the enthalpy of formation for the destabilized system must be less than the decomposition enthalpies of the reactant phases. A second guideline suggests that if the sample contains unstable reactants, such as those that absorb hydrogen, that the enthalpy for the associated reaction cannot exceed that of the expected destabilized reaction; i.e., the reaction will not proceed. Finally, a third guideline addressed adjusting the stoichiometry of the reactants to attempt to make different destabilized systems with different thermodynamics within a particular composition. The third guideline states that regardless of the stoichiometry, the reactions within the system will be dominated by the stoichiometry that evolves hydrogen with the least enthalpy, with off stoichiometry reactions proceeding in multi-step processes, with the reaction of least enthalpy being the first reaction step. The details of the approach and the results of the study are presented in Appendix F.

The study identified several systems with promising hydrogen storage thermodynamics for on-board vehicle applications. The system $2 \mathrm{LiBH}_{4}+\mathrm{TiH}_{2}$, potentially destabilized by the formation of $\mathrm{TiB}_{2}$, yielded an enthalpy, $\Delta \mathrm{H}=4.5 \mathrm{~kJ} / \mathrm{mole}$ $\mathrm{H}_{2}$, thought to yield $\mathrm{H}_{2}$ just a little too easily to be practical. More practical systems identified consisted of either $\mathrm{LiBH}_{4}$ or $\mathrm{Ca}\left(\mathrm{BH}_{4}\right)_{2}$ with either metallic $\mathrm{Cr}$ or $\mathrm{ScH}_{2}$, which yielded enthalpies in the range $\Delta \mathrm{H}=25-35 \mathrm{~kJ} / \mathrm{mole}_{2}$. These systems were destabilized by the formation of the borides $\mathrm{CrB}_{2}$ and $\mathrm{ScB}_{2}$. Both the $\mathrm{ScH}_{2}$ and $\mathrm{Cr}$ systems were calculated to evolve 1 bar $\mathrm{H}_{2}$ at about $25^{\circ} \mathrm{C}$ in the case of $\mathrm{LiBH}_{4}$ (see Appendix F). 
Several of the systems studied in this theoretical study were also prepared and examined via XRD and the medium throughput hydrogen capacity assay. The results are shown at the bottom of Table 16 in Appendix D. The $\mathrm{LiBH}_{4}+\mathrm{Cr}$ system was studied at $1 / 1$ and $2 / 1$ stoichiometry; the latter calculated to have an enthalpy $\Delta \mathrm{H}=31.7 \mathrm{~kJ} / \mathrm{mole}$ $\mathrm{H}_{2}$ for the reaction:

$$
2 \mathrm{LiBH}_{4}+\mathrm{Cr} \rightarrow 2 \mathrm{LiH}+\mathrm{CrB}_{2}+3 \mathrm{H}_{2}
$$

Similarly studied were the reactions of $\mathrm{LiBH}_{4}$ with $\mathrm{TiH}_{2}, \mathrm{Al}$ and $\mathrm{Mg}$, which were also part of the theoretical study. With the exception of the reaction with $\mathrm{Al}$, all of these systems were expected to react enough to provide 1 bar $\mathrm{H}_{2}$ under $200{ }^{\circ} \mathrm{C}$. However, none of these four systems desorbed significant amounts of hydrogen up to the maximum desorption temperature of $220^{\circ} \mathrm{C}$ on either cycle. Examination of the XRD of the spent materials supports the fact that none of the expected reactions occurred. In each case even in the $2 \mathrm{LiBH}_{4}+\mathrm{TiH}_{2}$ reaction that was deemed to evolve hydrogen too easily - the spent materials contained unreacted starting materials and no sign of metal carbide formation $\left(\mathrm{TiB}_{2}, \mathrm{CrB}_{2}\right.$, or $\left.\mathrm{MgB}_{2}\right)$ or that of the associated $\mathrm{LiH}$ that would indicate progression of the reaction. A reaction with metallic $\mathrm{V}$ only produced some vanadium hydride along with insignificant hydrogen desorption. While the thermodynamics are in place for these systems, the kinetics obviously are not, even with the help of $\mathrm{Ti}(\mathrm{OiPr})_{4}$ dopant (See Table 16 Appendix D). Hence, enabling the kinetics must also be an important part in identifying successful hydrogen storage systems.

6.8 $\mathrm{LiNH}_{2}-\mathrm{LiBH}_{4}-$ Transition Metal (TM) Systems. The last family of materials investigated in this project belong to the $\mathrm{LiNH}_{2}-\mathrm{LiBH}_{4}-$ transition metal family. As enumerated above in the discussion of the metal-amide-borohydride (Section 6.2), which focused on alkali and alkaline earth metals, the reasons to use of $\mathrm{LiNH}_{2}-\mathrm{LiBH}_{4}$ as components of new hydrogen storage materials are plentiful:

- High hydrogen content in $\mathrm{LiBH}_{4}\left(18.5\right.$ wt. \%) and $\mathrm{LiNH}_{2}$ (8.8 wt. \%)

- Ability to form mixed amide-borohydride compounds, which may not be unique to $\mathrm{Li}$ and extended to more complex systems including transition metals

- Ability of $\mathrm{LiNH}_{2}-\mathrm{LiBH}_{4}$ mixtures to form low temperature ionic liquids which can facilitate the synthesis and interconversion of the phases involved in hydrogen absorption/desorption chemistry as observed above in the $\mathrm{LiNH}_{2}-\mathrm{LiBH}_{4}-\mathrm{MgH}_{2}$ system (Section 6.2.1)

- Addition of small amounts of transition metal dopants to the $\mathrm{LiNH}_{2}-\mathrm{LiBH}_{4}$ system evolved large amounts of hydrogen (up to $10 \mathrm{wt}$. \%, Section 6.2.2); perhaps larger amounts of the transition metal may lead to more stable reversible systems

- Attempts to make alkali transition metal borohydrides (Section 6.3.2) yielded unstable materials; the greater stability of transition metal amides may help stabilize borohydrides in a Li-amide-borohydride-transition metal matrix

In general, $\mathrm{LiNH}_{2}-\mathrm{LiBH}_{4}$-TM phase diagrams are investigated exploring a variety of stoichiometries in which the transition metal is generally a half or less of the material on a molar basis. The synthesis strategy is a variation of that used in the alkali transition metal borohydride study (section 6.3.2) in which $\mathrm{LiNH}_{2}$ and $\mathrm{LiBH}_{4}$ are ball-milled with transition metal chlorides, allowing the formation of $\mathrm{LiCl}$ to drive the reaction. At times, metal hydrides are employed, but these are not available for most of the metals studied. The addition of a $\mathrm{LiH}$ component to the phase diagrams was used to generate metal 
hydride in situ via an exchange reaction with the transition metal chlorides. Most of the hydrogen capacity assays were run in the HT assay unit, which provided a more complete evaluation of the materials without the temperature limitations of the MT assay unit. XRD results on the spent materials were often not available because of the difficulty of retrieving the small samples from the HT assay unit.

6.8.1 $\mathrm{LiNH}_{2}-\mathrm{LiBH}_{4}-\mathrm{CoCl}_{2}$ System. The phase diagrams studied in the $\mathrm{LiNH}_{2}-\mathrm{LiBH}_{4}-$ $\mathrm{CoCl}_{2}$ system are shown in Figure 47. Both diagrams show the same compositions, but the point markers are colored according to a spectral scheme corresponding to the hydrogen evolved during the different desorptions. In this scheme, dark colors (black, purple and blue) indicate the poorest desorption, while intermediate desorptions are indicated by shades of green and yellow, and finally the higher desorption activity is indicated by orange, red and very dark red at the highest desorption level. The color scheme makes it easy to pick out hydrogen evolution trends. The compositions, structures of the as-synthesized materials, and the high throughput hydrogen storage results are given in Table 17 of Appendix D.

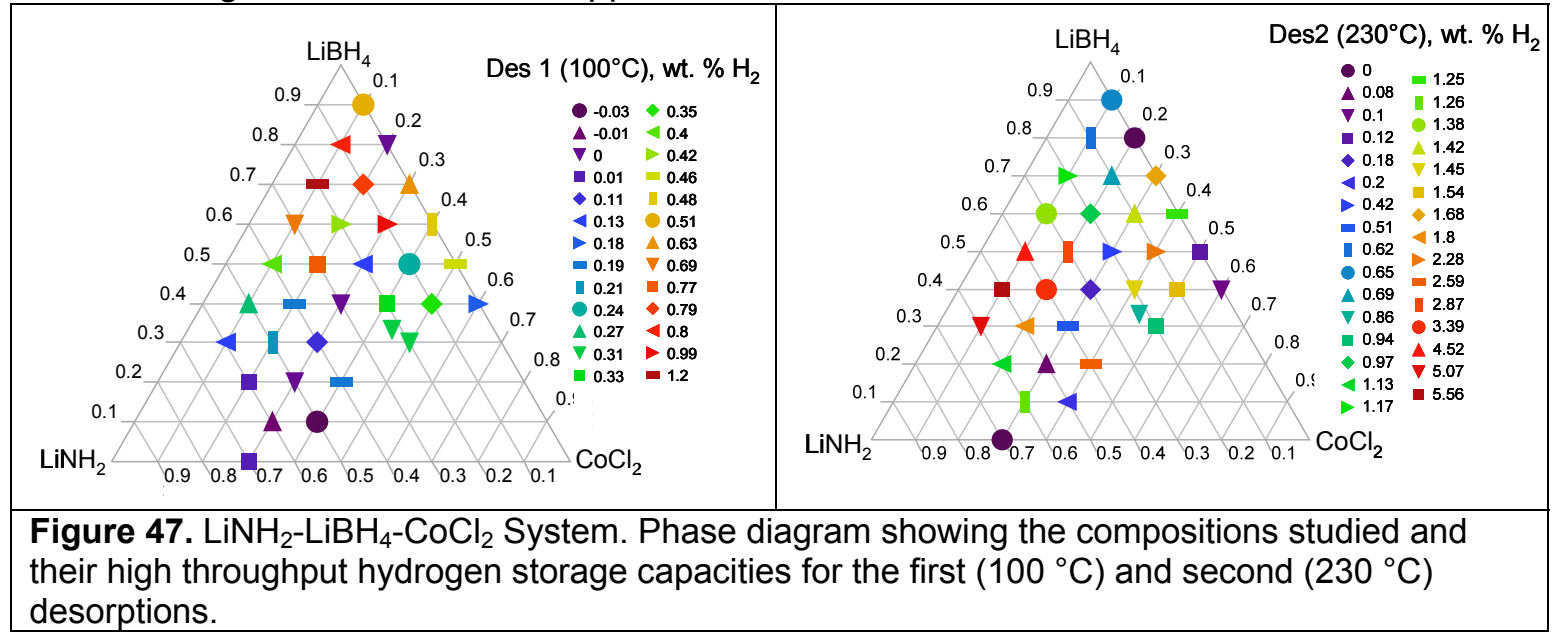

The XRD results for the as-synthesized materials showed the most common materials to be amorphous and $\mathrm{LiCl}$, results similar to those observed in the synthesis of the alkali transition metal borohydrides. The presence of $\mathrm{LiCl}$ demonstrated that the exchange reaction occurred to form the desired metal-borohydride-amides. Most of the other phases observed were starting materials and $\mathrm{Li}_{2} \mathrm{NH}$ (Table 17, Appendix D). The first desorption was carried out at $100{ }^{\circ} \mathrm{C}$ so that any reversible low temperature desorbing materials would not be destroyed and could be identified on the second desorption. Desorption was very moderate at about $1 \mathrm{wt}$. \% for $\mathrm{LiBH}_{4}$-rich materials. After rehydriding at $100^{\circ} \mathrm{C}$, the second desorption was carried out up to $230^{\circ} \mathrm{C}$. The best desorbing compositions were clustered together in the phase diagram;

$$
\begin{aligned}
& \text { 0.6 } \mathrm{LiNH}_{2}+0.3 \mathrm{LiBH}_{4}+0.1 \mathrm{CoCl}_{2} ; 5.07 \text { wt. \% } \mathrm{H}_{2} \\
& \text { 0.5 } \mathrm{LiNH}_{2}+0.4 \mathrm{LiBH}_{4}+0.1 \mathrm{CoCl}_{2} ; 5.56 \text { wt. \% } \mathrm{H}_{2} \\
& \text { 0.4 } \mathrm{LiNH}_{2}+0.5 \mathrm{LiBH}_{4}+0.1 \mathrm{CoCl}_{2} ; 4.52 \text { wt. \% } \mathrm{H}_{2}
\end{aligned}
$$

The desorption profile for the $0.4 \mathrm{LiNH}_{2}+0.5 \mathrm{LiBH}_{4}+0.1 \mathrm{CoCl}_{2}$ material is shown in Figure 48. Desorption of hydrogen begins slowly at $130{ }^{\circ} \mathrm{C}$, but becomes very rapid at $170{ }^{\circ} \mathrm{C}$, plateauing at $200{ }^{\circ} \mathrm{C}$, after evolving 3.75 wt. \% $\mathrm{H}_{2}$ (Figure 48, navy trace) After rehydriding, this phase and the other good desorbers yielded almost no hydrogen on the 


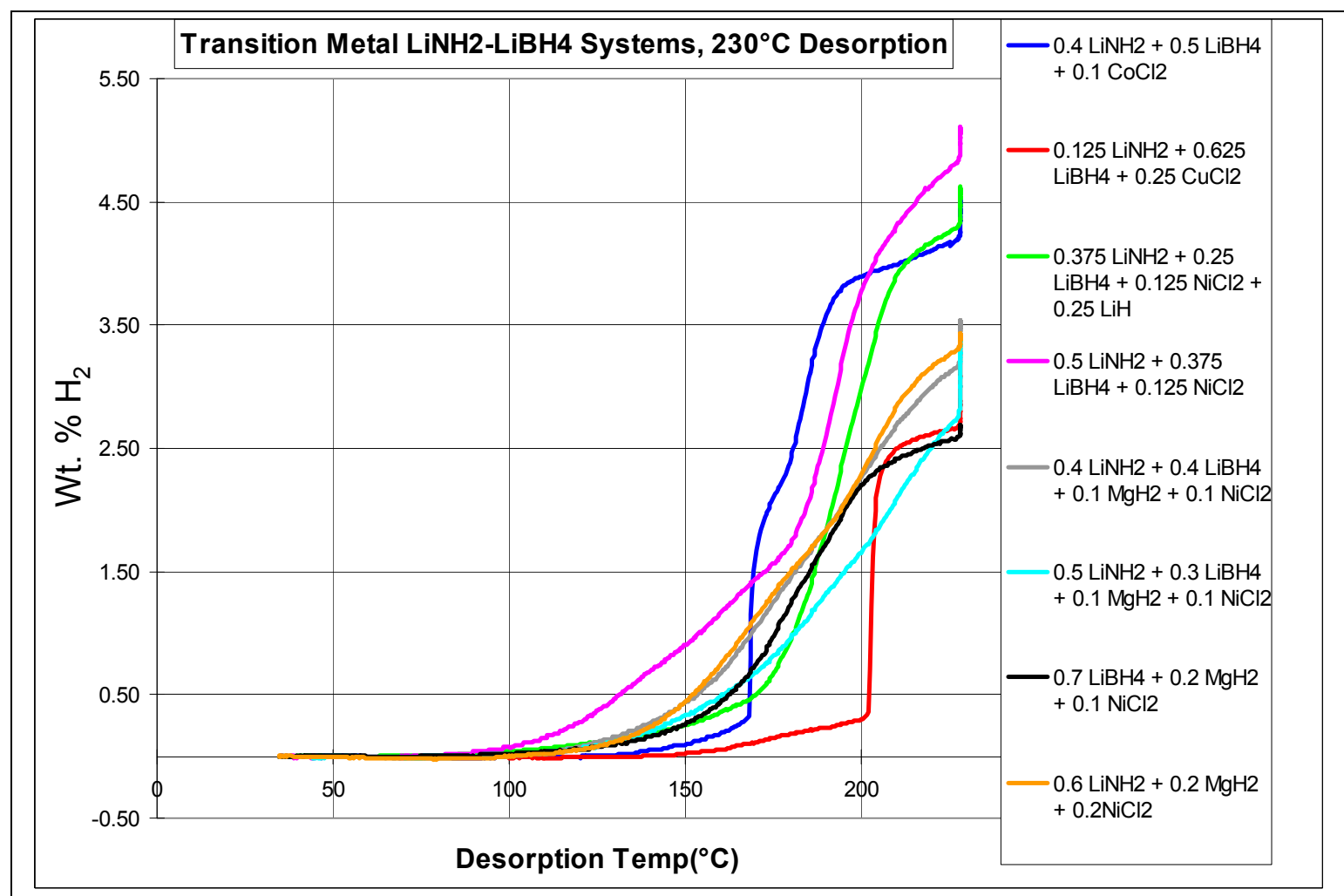

Figure 48. $\mathrm{LiNH}_{2}-\mathrm{LiBH}_{4}$-Transition Metal Systems. Desorption profiles showing wt. \% $\mathrm{H}_{2}$ evolved as a function of temperature for selected compositions, $230^{\circ} \mathrm{C}$ desorption.

third desorption, showing no reversible character. Most of the third desorptions were carried out at $230{ }^{\circ} \mathrm{C}$, while a few were carried out at $350{ }^{\circ} \mathrm{C}$. Only a few of the materials taken to the higher temperature yielded over $2 \mathrm{wt} \% \% \mathrm{H}_{2}$, but these had very moderate desorption in the first two cycles. Because of the lack of reversible character, none of these materials were addressed any further.

\subsection{2 $\mathrm{LiNH}_{2}-\mathrm{LiBH}_{4}-\mathrm{CuCl}_{2}-$ LiH System. The phase} diagram for the $\mathrm{LiNH}_{2}-\mathrm{LiBH}_{4}$ $\mathrm{CuCl}_{2}$-LiH system showing the compositions studied and their HT hydrogen storage capacities for the $230^{\circ} \mathrm{C}$ desorption is portrayed in Figure 49. The inclusion of $\mathrm{LiH}$ in the system gives the phase diagram a much more complicated look. Expressing the formulations as the sum $\mathrm{LiNH}_{2}+\mathrm{LiBH}_{4}+\mathrm{CuCl}_{2}+\mathrm{LiH}$ $=1$, the 4 dimensions needed to cover the formulations are reduced to three by this constraint. The

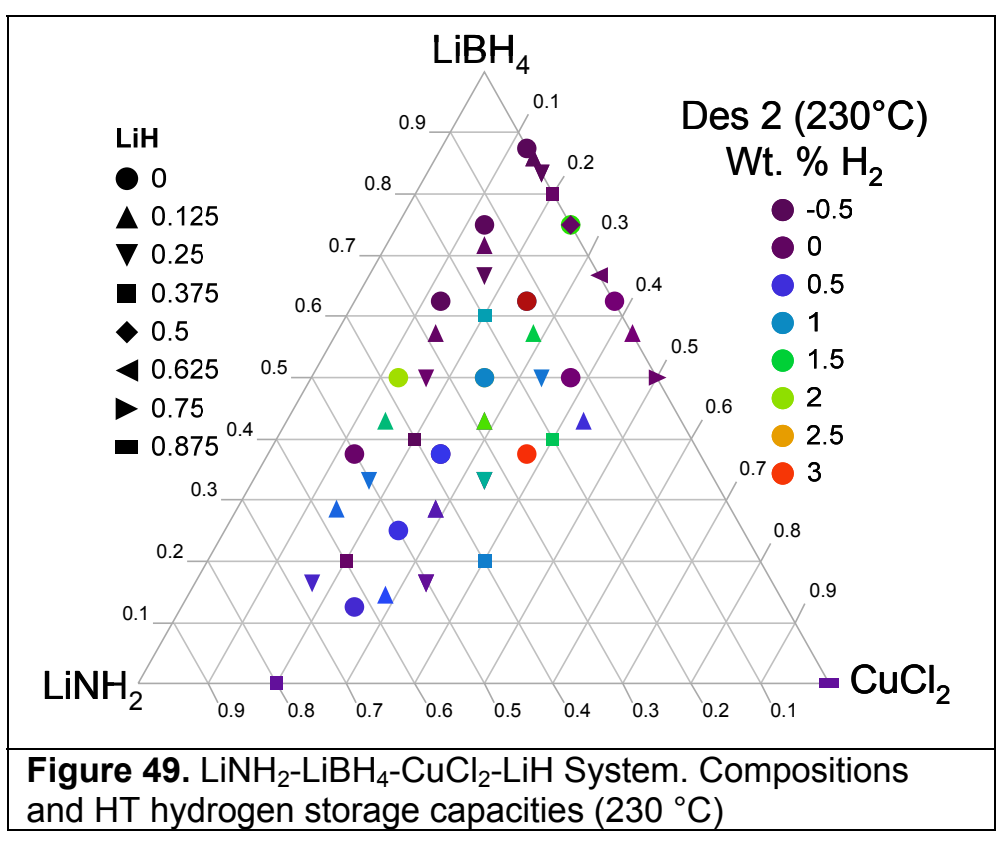


shape of the point markers on the phase diagram indicate the mole fraction of the $\mathrm{LiH}$ included in the formulation according to the equation above. However, the synthesis space spanned by the values of the $\mathrm{LiNH}_{2}, \mathrm{LiBH}_{4}$, and $\mathrm{CuCl}_{2}$ components are no longer constrained as they no longer sum to 1 , so their components are renormalized to fit into the $\mathrm{LiNH}_{2}+\mathrm{LiBH}_{4}+\mathrm{CuCl}_{2}=1$ ternary plot shown. To easily view the pattern of the experimental design, it is instructive to look at the points where $\mathrm{LiH}=0$, the circles in Figure 49. In this instance, $\mathrm{LiNH}_{2}+\mathrm{LiBH}_{4}+\mathrm{CuCl}_{2}=1$ holds without the renormalization. The circles form a pattern in the phase diagram similar to that seen in Figure 47 for the $\mathrm{LiNH}_{2}-\mathrm{LiBH}_{4}-\mathrm{CoCl}_{2}$ system. Similarly, the up-pointing triangles represent compositions with the mole fraction of $\mathrm{LiH}=0.125$. One can see that these also form a regular pattern that is offset from the pattern of circles for $\mathrm{LiH}=0$. This also is the case for the other $\mathrm{LiH}$ levels employed. This representation of the synthesis space will be used in the discussions to come. The point markers are color-coded by wt $\% \mathrm{H}_{2}$ evolved using the same spectral pattern discussed above, but the values are placed in $0.5 \mathrm{wt}$ \% bins, with a different color for each bin. The compositions and the HT hydrogen storage capacities are given in Table 18 of Appendix D.

Several different desorption programs were used in the HT assay as we searched for the proper conditions (Table 18, Appendix D). Initially, not wanting to destroy delicate low temperature desorbers, the program consisted of two $100^{\circ} \mathrm{C}$ desorptions and two $230{ }^{\circ} \mathrm{C}$ desorptions. Hydriding between desorption runs was carried out at $100{ }^{\circ} \mathrm{C}, 120$ bar $\mathrm{H}_{2}$, until the desorption temperature was raised above 100 ${ }^{\circ} \mathrm{C}$. Then hydriding was carried out at $125^{\circ} \mathrm{C}$. Because of the poor desorption observed at $100{ }^{\circ} \mathrm{C}$, the program was shortened to one desorption each at $100{ }^{\circ} \mathrm{C}, 230^{\circ} \mathrm{C}$, and $350{ }^{\circ} \mathrm{C}$. This assay program was the one most frequently used. Also tried was the 4cycle program $230{ }^{\circ} \mathrm{C}, 230^{\circ} \mathrm{C}, 350{ }^{\circ} \mathrm{C}$, and $350{ }^{\circ} \mathrm{C}$. The hydrogen capacity values reported in Figure 49 are from the first $230^{\circ} \mathrm{C}$ desorption for each compound. It is easily seen from Figure 49 that samples rich in $\mathrm{LiBH}_{4}$ were among the poorest performers in hydrogen evolution, while all of the materials rich in $\mathrm{LiNH}_{2}$ were marginal performers, desorbing below 2 wt. \% hydrogen. The best desorbers contain no $\mathrm{LiH}$ and are denoted by the blood-red and orange circles with the following compositions and hydrogen capacities:

$$
\begin{aligned}
& 0.125 \mathrm{LiNH}_{2}+0.625 \mathrm{LiBH}_{4}+0.25 \mathrm{CuCl}_{2} ; 3.38 \text { wt. \% } \mathrm{H}_{2} \\
& 0.25 \mathrm{LiNH}_{2}+0.375 \mathrm{LiBH}_{4}+0.375 \mathrm{CuCl}_{2} ; 3.04 \text { wt. \% } \mathrm{H}_{2}
\end{aligned}
$$

The desorption profile for the $0.125 \mathrm{LiNH}_{2}+0.625 \mathrm{LiBH}_{4}+0.25 \mathrm{CuCl}_{2}$ material is shown in Figure 48, red trace. Desorption starts at $150{ }^{\circ} \mathrm{C}$ and just after $200{ }^{\circ} \mathrm{C}$, the desorption takes off, shooting to over $2.5 \mathrm{wt}$. \% in a matter of $5-10{ }^{\circ} \mathrm{C}$. Desorption then plateaus at about 2.60 wt. \% before reaching the maximum temperature of the desorption cycle, 230 ${ }^{\circ} \mathrm{C}$, where the material desorbed another $0.8 \mathrm{wt} . \% \mathrm{H}_{2}$. This desorption pattern for this material is somewhat reminiscent of that seen for the reversible $4 \mathrm{LiBH}_{4}+\mathrm{CuCl}_{2}$ material shown in Figure 32. Hydrogen desorption occurs much earlier in that system, starting near $100^{\circ} \mathrm{C}$, but has the same abrupt desorption characteristic. This amide-containing system desorbs more hydrogen though, but desorbs almost no hydrogen on the third desorption to $350^{\circ} \mathrm{C}$. Across the board, there was no reversible character seen for the phases that desorbed reasonable amounts of hydrogen in their first $230{ }^{\circ} \mathrm{C}$ cycle.

Several compositions did desorb over $2 \mathrm{wt} . \% \mathrm{H}_{2}$ in the $350{ }^{\circ} \mathrm{C}$ desorption cycle, but this was just high temperature desorption as these materials showed little desorption during the lower temperature cycles. 
6.8.3 $\mathrm{LiNH}_{2}-\mathrm{LiBH}_{4}-\mathrm{MnCl}_{2}$ - $\mathrm{LiH}$ System. The phase diagram showing the compositions studied in the $\mathrm{LiNH}_{2}-\mathrm{LiBH}_{4}-\mathrm{MnCl}_{2}-\mathrm{LiH}$ system and their hydrogen storage capacities during the first desorption at $230^{\circ} \mathrm{C}$ are shown in Figure 50. The compositions, structures of some of the spent materials, and HT hydrogen storage capacities are given in Table 19 of Appendix D. wt. \% $\mathrm{H}_{2}$ :

A quick examination of Figure 50 shows several compositions desorbing nearly 3

$0.6 \mathrm{LiNH}_{2}+0.2 \mathrm{LiBH}_{4}+0.2 \mathrm{MnCl}_{2} ; 2.95$ wt. \% $\mathrm{H}_{2}$

$0.4 \mathrm{LiNH}_{2}+0.4 \mathrm{LiBH}_{4}+0.2 \mathrm{MnCl}_{2} ; 2.91$ wt. \% $\mathrm{H}_{2}$

$0.4 \mathrm{LiNH}_{2}+0.2 \mathrm{LiBH}_{4}+0.2 \mathrm{MnCl}_{2}+0.2 \mathrm{LiH} ; 2.78$ wt. \% $\mathrm{H}_{2}$

$0.6 \mathrm{LiNH}_{2}+0.2 \mathrm{LiBH}_{4}+0.2 \mathrm{MnCl}_{2} ; 2.90$ wt. \% $\mathrm{H}_{2}$, repeat

The results for the $0.6 \mathrm{LiNH}_{2}+0.2 \mathrm{LiBH}_{4}+0.2 \mathrm{MnCl}_{2}$ material were the best and highly reproducible, as seen above. The formulations containing high $\mathrm{LiH}$ seemed to suppress hydrogen desorption. Desorption profiles for these "good desorbers" showed that less than $1 \mathrm{wt} . \% \mathrm{H}_{2}$ had been desorbed by the time the maximum temperature in the desorption run had been reached. Most of the hydrogen was evolved while the system sat post run at $230^{\circ} \mathrm{C}$. The desorption program for this phase diagram consisted of two desorptions at $230{ }^{\circ} \mathrm{C}$ followed by two desorptions at $350{ }^{\circ} \mathrm{C}$. None of these materials showed significant desorption activity in the second desorption cycle at $230{ }^{\circ} \mathrm{C}$, nor at $350{ }^{\circ} \mathrm{C}$. Examination of the spent materials by XRD showed $\mathrm{LiCl}$ in all of the phases, indicating the exchange reaction required to make the $\mathrm{Mn}$ amide borohydride had occurred. The $\mathrm{LiCl}$ was often accompanied by amorphous material. Also prevalent was the presence of the nitrides $\mathrm{Mn}_{3} \mathrm{~N}_{2}$, $\mathrm{MnN}$ and $\mathrm{Li}_{3} \mathrm{~N}$, phases that can't be rehydrided under the relatively mild conditions employed here. The fact that there was not more extensive desorption in the second through fourth desorption cycles, especially at $350{ }^{\circ} \mathrm{C}$, indicates there was possibly extensive decomposition during milling. No reversible hydrogen storage materials emerged from this study.

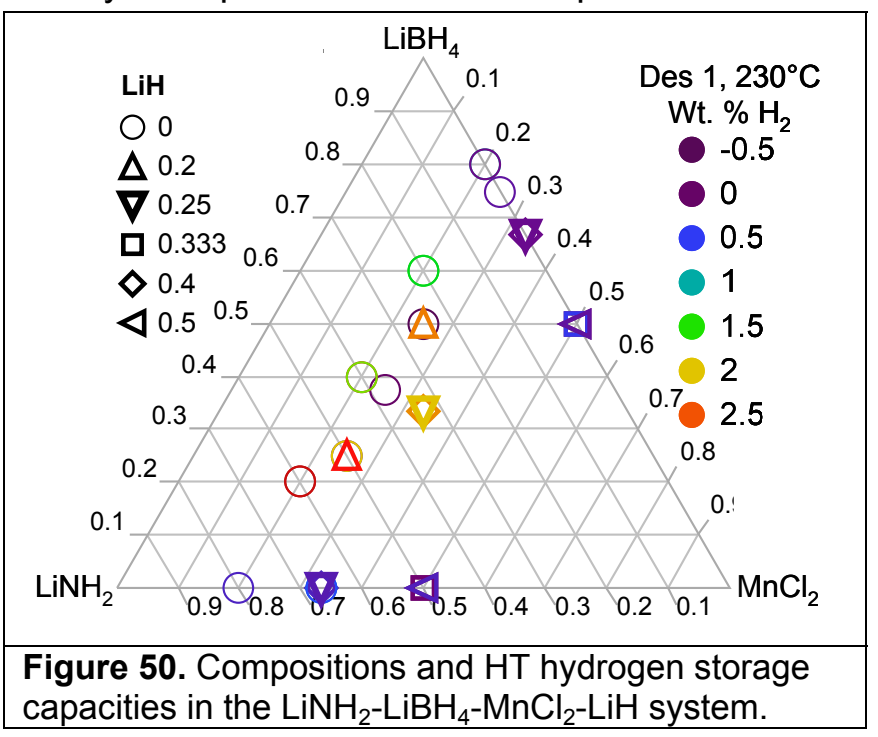




\subsection{4 $\mathrm{LiNH}_{2}-\mathrm{LiBH}_{4}-\mathrm{NiCl}_{2}-\mathrm{LiH}$ System. The phase diagram} containing the compositions studied and HT assay results from the first desorption cycle for the $\mathrm{LiNH}_{2}-\mathrm{LiBH}_{4}-\mathrm{NiCl}_{2}-\mathrm{LiH}$ system are shown in Figure 51. Compositions and complete HT hydrogen storage results are given in Table 20 of Appendix D.

Examination of Figure 51 quickly shows (via orange and red colored points) the best performers clustered in a group containing low or no $\mathrm{LiH}$, the lowest levels of $\mathrm{NiCl}_{2}$, and about $25-50$ mole \% $\mathrm{LiNH}_{2}$ and $\mathrm{LiBH}_{4}$. The compositions that yielded the most hydrogen are:

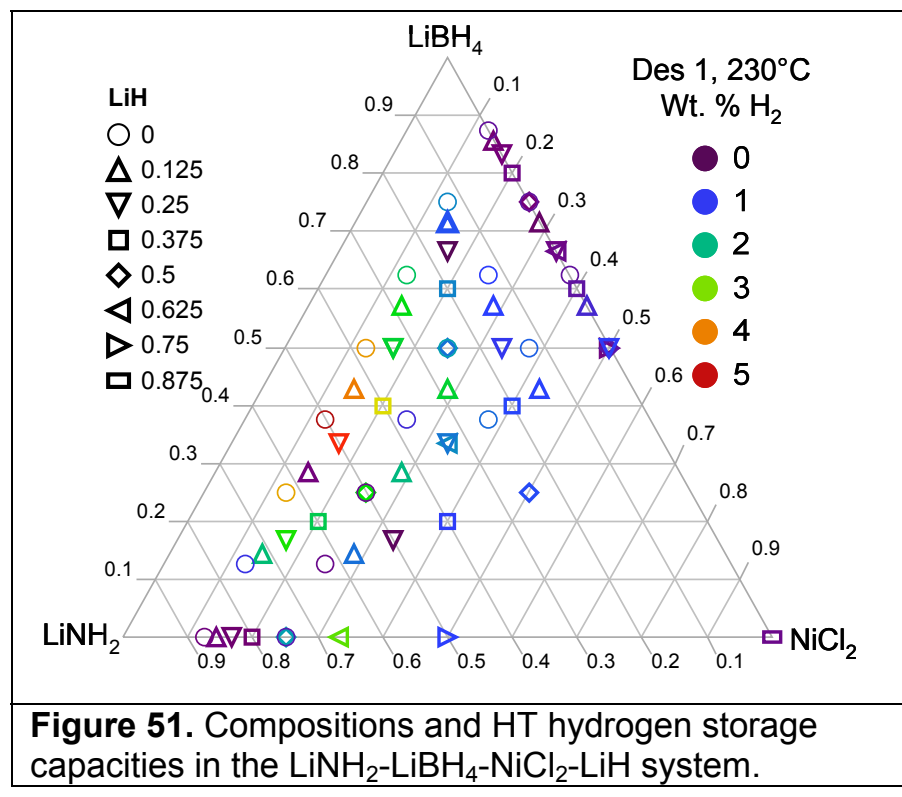

$0.375 \mathrm{LiNH}_{2}+0.25 \mathrm{LiBH}_{4}+0.125 \mathrm{NiCl}_{2}+0.25 \mathrm{LiH} ; 4.62$ wt. \% $\mathrm{H}_{2}$

$0.5 \mathrm{LiNH}_{2}+0.375 \mathrm{LiBH}_{4}+0.125 \mathrm{NiCl}_{2} ; 5.07$ wt. \% $\mathrm{H}_{2}$

$0.375 \mathrm{LiNH}_{2}+0.375 \mathrm{LiBH}_{4}+0.125 \mathrm{NiCl}_{2}+0.125 \mathrm{LiH} ; 4.04$ wt. \% $\mathrm{H}_{2}$

Desorption profiles for the $0.375 \mathrm{LiNH}_{2}+0.25 \mathrm{LiBH}_{4}+0.125 \mathrm{NiCl}_{2}+0.25 \mathrm{LiH}$ (1) and 0.5 $\mathrm{LiNH}_{2}+0.375 \mathrm{LiBH}_{4}+0.125 \mathrm{NiCl}_{2}$ (2) compositions are shown in Figure 48. These two materials are among the best desorbers seen in the $\mathrm{LiNH}_{2}-\mathrm{LiBH}_{4}-\mathrm{TM}$ study. Desorption starts for 2 at $100{ }^{\circ} \mathrm{C}$ and takes an upturn at $175^{\circ} \mathrm{C}$ getting up to over 3.5 wt. $\% \mathrm{H}_{2}$ by $200{ }^{\circ} \mathrm{C}$. Desorption slows down a little above $200{ }^{\circ} \mathrm{C}$, but continues to $5 \mathrm{wt}$. \% by the maximum temperature of $230^{\circ} \mathrm{C}$ (Figure 48, magenta trace). Composition 1 contains $\mathrm{LiH}$. Desorption by 1 is initially delayed by about $20-30^{\circ} \mathrm{C}$ relative to 2 until $175^{\circ} \mathrm{C}$ when desorption from 1 increased rapidly, pulling within $10^{\circ} \mathrm{C}$ of 2 (Figure 48 , green trace). Hence, overall, the desorption curves were similar. Other than one outlier, none of the materials in the entire phase diagram, including 1 and 2 , showed significant desorption in the second desorption cycle at $230{ }^{\circ} \mathrm{C}$. As in the case of the Mn system above, desorption was surprisingly light at $350{ }^{\circ} \mathrm{C}$. Since there was significant desorption in this system at lower temperatures, this suggests that with $\mathrm{Ni}$ as a component that most of the hydrogen can be accessed in this system without going to high temperature. There was no sign of reversible behavior for any of the materials in this system.

6.8.5 $\mathrm{LiNH}_{2}-\mathrm{LiBH}_{4}-\mathrm{VCl}_{3}$-LiH System. The $\mathrm{LiNH}_{2}-\mathrm{LiBH}_{4}-\mathrm{VCl}_{3}-\mathrm{LiH}$ system was also investigated. The compositions and the hydrogen capacity results of the second desorption $\left(230^{\circ} \mathrm{C}\right)$ of the HT assay are shown in the phase diagram in Figure 52. Compositions and all of the HT assay hydrogen capacity results are given in Table 21 of Appendix D.

The $\mathrm{LiNH}_{2}-\mathrm{LiBH}_{4}-\mathrm{VCl}_{3}-\mathrm{LiH}$ compositions were evaluated in a three desorption program with desorptions at $100{ }^{\circ} \mathrm{C}, 230^{\circ} \mathrm{C}$, and $350{ }^{\circ} \mathrm{C}$. The $100{ }^{\circ} \mathrm{C}$ desorption was not energetic enough to evolve much hydrogen from any composition other than 0.125 $\mathrm{LiNH}_{2}+0.5 \mathrm{LiBH}_{4}+0.125 \mathrm{VCl}_{3}+0.25 \mathrm{LiH}(3)$, which yielded 1.62 wt. \% $\mathrm{H}_{2}$. No other 
composition yielded over 1 wt. $\% \mathrm{H}_{2}$. The assay results at $230{ }^{\circ} \mathrm{C}$ are shown in Figure 52. The best performer at $100{ }^{\circ} \mathrm{C}, 3$, yielded only 0.94 wt. $\% \mathrm{H}_{2}$ at $230^{\circ} \mathrm{C}$, a significant decrease when almost all of the other compositions showed increased hydrogen desorption. The best performers at $230{ }^{\circ} \mathrm{C}$ did not contain any $\mathrm{LiH}$ :

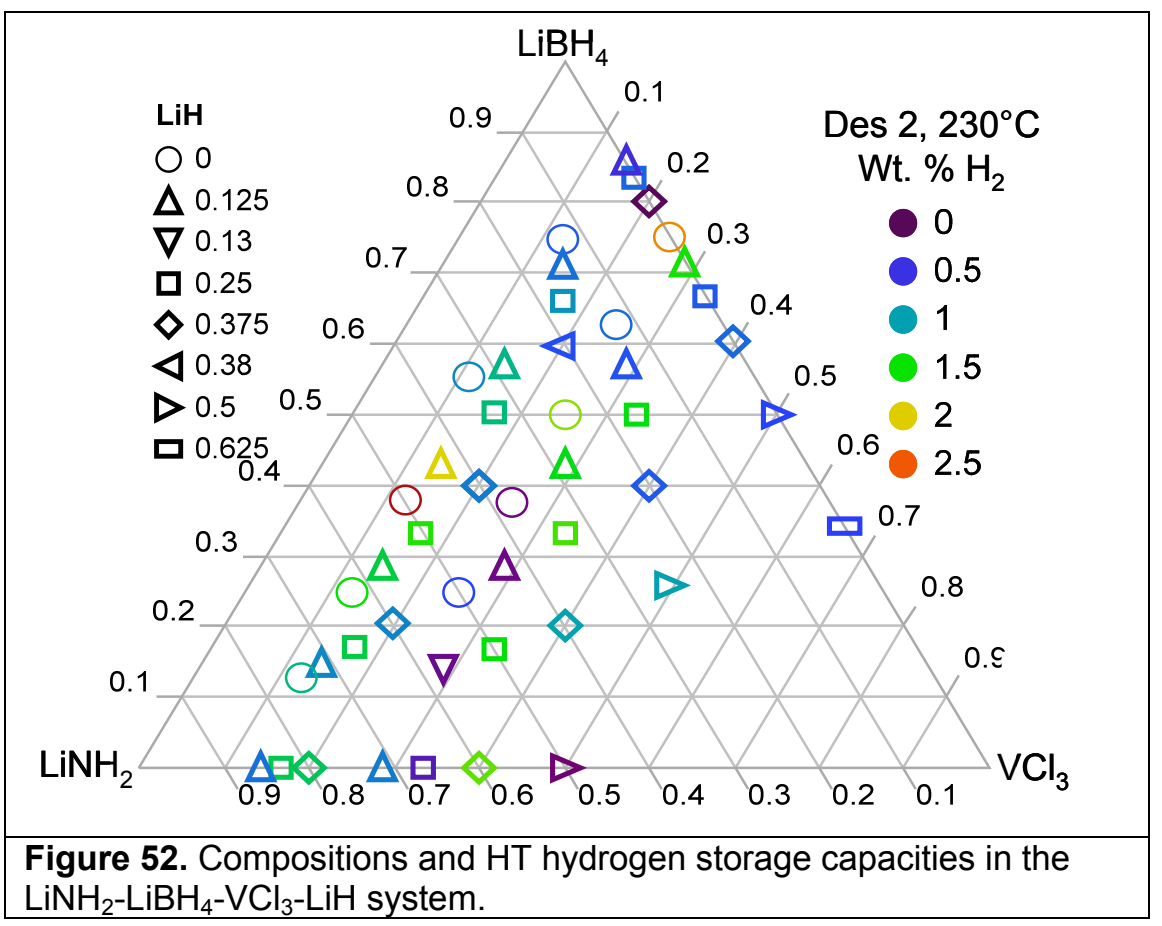

$\mathrm{LiNH}_{2}-\mathrm{LiBH}_{4}-\mathrm{VCl}_{3}-\mathrm{LiH}$ system.

$4=0.5 \mathrm{LiNH}_{2}+0.375 \mathrm{LiBH}_{4}+0.125 \mathrm{VCl}_{3} ; 2.97$ wt. \% $\mathrm{H}_{2}$

$5=0.75 \mathrm{LiBH}_{4}+0.25 \mathrm{VCl}_{3} ; 2.30$ wt. $\% \mathrm{H}_{2}$

The desorption profiles show that 4 desorbs half of the nearly 3 wt. $\% \mathrm{H}_{2}$ after reaching the maximum desorption temperature of $230^{\circ} \mathrm{C}$, while 5 desorbs hydrogen a little faster reaching nearly $2 \mathrm{wt} . \% \mathrm{H}_{2}$ by $230{ }^{\circ} \mathrm{C}$. Each showed slow desorption starting between 100 and $120^{\circ} \mathrm{C}$. After rehydriding $\left(125^{\circ} \mathrm{C}, 120\right.$ bar $\mathrm{H}_{2}, 12$ hours), 4 and 5 desorbed considerably less hydrogen in the subsequent $350{ }^{\circ} \mathrm{C}$ desorption, less than $0.4 \mathrm{wt}$ \% by the time the temperature reached $230^{\circ} \mathrm{C}$. There was no indication of reversible behavior among the compositions studied.

6.8.6 $\mathrm{LiNH}_{2}-\mathrm{LiBH}_{4}-\mathrm{TiCl}_{3}-\mathrm{VCl}_{3}$ System. The $\mathrm{LiNH}_{2}-\mathrm{LIBH}_{4}-\mathrm{TiCl}_{3}-\mathrm{VCl}_{3}$ system was studied with the sum of the mole fractions of $\mathrm{VCl}_{3}+\mathrm{TiCl}_{3}$ ranging from $0.1-0.25$, with the minimum value for each being 0.05 . The compositions and their HT hydrogen storage assays for the second desorption $\left(230^{\circ} \mathrm{C}\right)$ are shown in Figure 53. Compositions, MT assay and HT assay hydrogen storage capacity results are given in Table 22 of Appendix D.

A portion of the compositions were examined for hydrogen capacity in the MT assay. While several compositions showed desorption over $3 \mathrm{wt} . \% \mathrm{H}_{2}$ in the first desorption cycle, none of these showed desorption over $0.7 \mathrm{wt} . \% \mathrm{H}_{2}$ in the second cycle. In the HT assay, the compositions were tested in $100{ }^{\circ} \mathrm{C}, 230^{\circ} \mathrm{C}$ and $350{ }^{\circ} \mathrm{C}$ desorption cycles. Two of the compositions yielded significant desorption at $100^{\circ} \mathrm{C}$ :

$6=0.45 \mathrm{LiNH}_{2}+0.4 \mathrm{LiBH}_{4}+0.1 \mathrm{TiCl}_{3}+0.05 \mathrm{VCl}_{3} ; 1.76$ wt. \% $\mathrm{H}_{2}$ $7=0.25 \mathrm{LiNH}_{2}+0.6 \mathrm{LiBH}_{4}+0.1 \mathrm{TiCl}_{3}+0.05 \mathrm{VCl}_{3} ; 2.09$ wt. \% $\mathrm{H}_{2}$ 
These compositions are the same ones that performed the best in the MT assay, with 6 evolving 3.26 wt. $\% \mathrm{H}_{2}$ and 7 yielding 3.58 wt. $\% \mathrm{H}_{2}$ in the first desorption, yet both were irreversible on the second desorption cycle to $220^{\circ} \mathrm{C}$. It is possible that the conditions in the medium throughput assay were too severe and ruined the reversibility, and this can be verified in the HT assay since the first desorption was only at 100 ${ }^{\circ} \mathrm{C}$. During the $100{ }^{\circ} \mathrm{C}$ desorption, 6 and 7 began

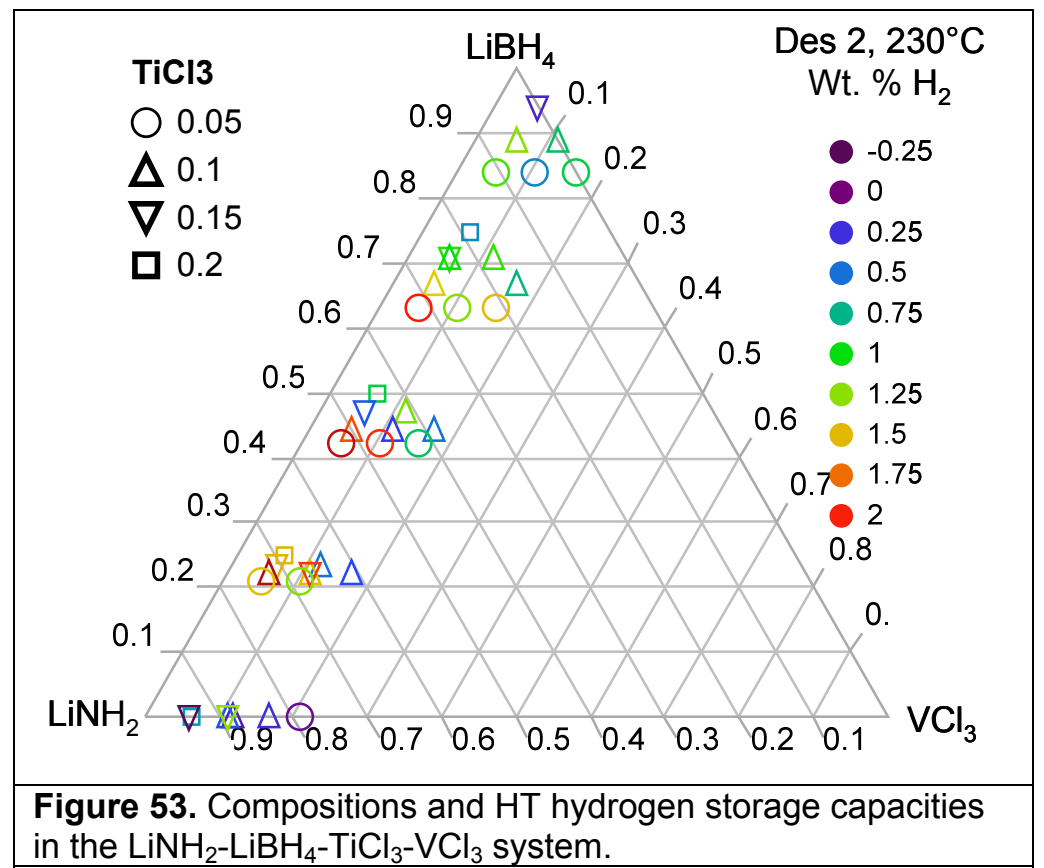
evolving hydrogen at $75-80^{\circ} \mathrm{C}$. After hydriding $\left(100{ }^{\circ} \mathrm{C}, 120\right.$ bar $\mathrm{H}_{2}, 12$ hours), the second desorption cycle to $230^{\circ} \mathrm{C}$ showed that this low temperature desorption was not recovered for 6 or 7 , as initial evolution of hydrogen was delayed until $140-150{ }^{\circ} \mathrm{C}$. On this second desorption, 6 and 7 evolved 1.85 and 1.42 wt. $\% \mathrm{H}_{2}$, respectively, far short of the MT first desorption results to nearly the same temperature. The sum of the $100{ }^{\circ} \mathrm{C}$ and $230{ }^{\circ} \mathrm{C} \mathrm{HT}$ desorption results for 6 and 7 are 3.61 and 3.51 wt. $\% \mathrm{H}_{2}$ respectively, which compare favorably with the MT assay first desorption results of 3.26 and $3.58 \mathrm{wt}$. $\%$ hydrogen. This further supports a continuous desorption process and that a possible low temperature reversible hydrogen absorption/desorption process had been overlooked. In the $350{ }^{\circ} \mathrm{C}$ desorption cycle, desorption from 6 and 7 did not start until $250-300^{\circ} \mathrm{C}$, indicating no reversible character.

6.8.7 $\mathrm{LiNH}_{2}-\mathrm{LiBH}_{4}-\mathrm{ZnCl}_{2}$ System. Due to our previous experience with $\mathrm{Zn}$ borohydrides, we anticipated that the $\mathrm{LiNH}_{2}-\mathrm{LiBH}_{4}-\mathrm{ZnCl}_{2}$ system would be delicate to work with. The HT assay program used was desorption at $100{ }^{\circ} \mathrm{C}, 100{ }^{\circ} \mathrm{C}, 120^{\circ} \mathrm{C}$, and $120^{\circ} \mathrm{C}$. The rehydride steps between cycles were carried out at $100^{\circ} \mathrm{C}$. The compositions studied and the hydrogen storage results from the first desorption cycle are shown in the phase diagram in Figure 54. Compositions and all HT assay results are given in Table 23 of Appendix D. The concentration of orange and red in the upper

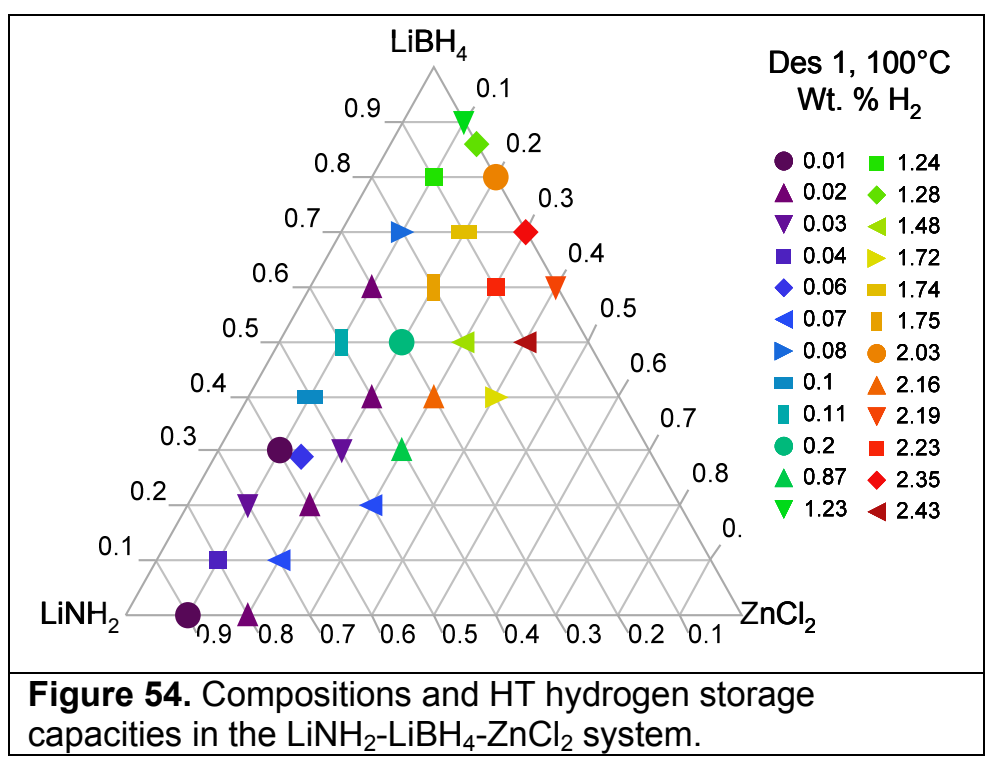


right of the phase diagram show the materials yielding the most hydrogen are $\mathrm{Zn}-\mathrm{LiBH}_{4}$ materials and definitely poor in $\mathrm{LiNH}_{2}$. The low temperature desorption of about 2 - 2.4 wt. $\% \mathrm{H}_{2}$ was not recovered in the subsequent hydriding and desorption cycles, indicating no reversibility.

6.8.8 $\mathrm{LiNH}_{2}-\mathrm{LiBH}_{4}-\mathrm{ZrCl}_{4}-\mathrm{LiH}$ System. The $\mathrm{LiNH}_{2}-\mathrm{LiBH}_{4}-\mathrm{ZrCl}_{4}-\mathrm{LiH}$ system was studied in the HT assay using two different desorption programs; the first consisting of four desorption cycles carried out at $100^{\circ} \mathrm{C}, 100{ }^{\circ} \mathrm{C}, 230$ ${ }^{\circ} \mathrm{C}$, and $230{ }^{\circ} \mathrm{C}$ and $\mathrm{a}$ second consisting of three desorption cycles carried out at $100{ }^{\circ} \mathrm{C}, 230{ }^{\circ} \mathrm{C}$ and $350{ }^{\circ} \mathrm{C}$. The compositions and the HT hydrogen storage assay results are given in Table 24 of Appendix D. A phase diagram showing the compositions and their hydrogen storage capacities is shown in Figure 55.

As seen in the phase diagram, the results from the first desorption at

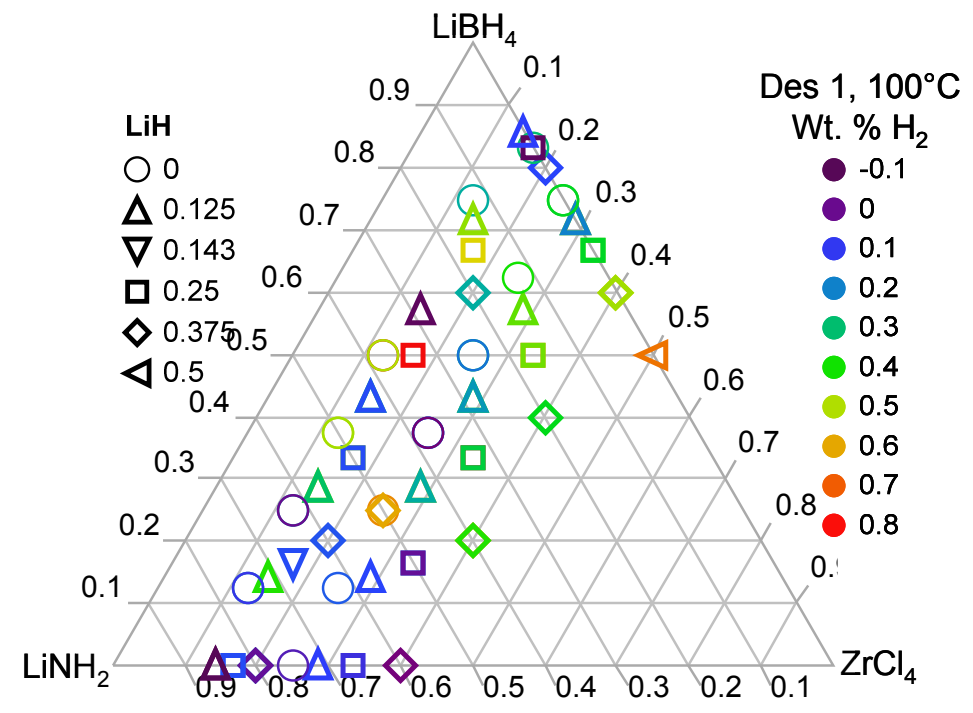

Figure 55. Compositions and HT hydrogen storage capacities in the $\mathrm{LiNH}_{2}-\mathrm{LiBH}_{4}-\mathrm{ZrCl}_{4}$ system. $100{ }^{\circ} \mathrm{C}$ were very poor, yielding less than $1 \mathrm{wt} . \% \mathrm{H}_{2}$ for all of the compositions. For the compositions following the first four-desorption program, the second desorption at 100 ${ }^{\circ} \mathrm{C}$ yielded less than $0.1 \mathrm{wt} . \% \mathrm{H}_{2}$, almost no hydrogen in any case (Table 24, Appendix D). When these materials proceeded to the third desorption cycle at $230{ }^{\circ} \mathrm{C}$, a maximum of 1.14 wt. $\% \mathrm{H}_{2}$ was evolved, an uncharacteristically low value for amide-borohydridebased systems. Finally on the fourth desorption, also at $230^{\circ} \mathrm{C}$, there was another big drop in hydrogen evolved, just like there was on the second $100{ }^{\circ} \mathrm{C}$ desorption, as only a few materials desorbed more than $0.2 \mathrm{wt}$. $\% \mathrm{H}_{2}$. Since neither the $100{ }^{\circ} \mathrm{C}$ nor the $230{ }^{\circ} \mathrm{C}$ desorptions could recover their hydrogen for their respective second desorptions, there was no sign of reversibility in these systems.

For the compositions that went through three desorption cycles, the results for the second desorption at $230{ }^{\circ} \mathrm{C}$ were also suspicious as the maximum desorption observed was $1.88 \mathrm{wt} . \% \mathrm{H}_{2}$. With such low values observed in the second desorption, it was expected that the third desorption at $350{ }^{\circ} \mathrm{C}$ may yield significant hydrogen. But this was not the case, the desorption values were even lower. These poor desorption results for $\mathrm{LiNH}_{2}$ - $\mathrm{LiBH}_{4}$-based compositions, especially at high temperature, suggest that the materials might have reacted during milling and evolved hydrogen at that time.

6.8.9 $\mathrm{LiNH}_{2}-\mathrm{LiBH}_{4}-\mathrm{MgH}_{2}-\mathrm{NiCl}_{2}-\mathrm{LiH}$ System. The reversible hydrogen storage material $\mathrm{Mg}_{2} \mathrm{NiH}_{4}$ yields 3.8 wt. \% $\mathrm{H}_{2},{ }^{51}$ but falls short of DOE standard of $6.5 \mathrm{wt} . \% \mathrm{H}_{2}$ for on board hydrogen storage systems. In the $\mathrm{LiNH}_{2}-\mathrm{LiBH}_{4}-\mathrm{MgH}_{2}-\mathrm{NiCl}_{2}-\mathrm{LiH}$ system, it may be possible to generate this and related phases in situ via exchange reactions between $\mathrm{LiH}$ and $\mathrm{NiCl}_{2}$ to form $\mathrm{LiCl}$ and reactive $\mathrm{NiH}_{2} . \mathrm{Mg}_{2} \mathrm{NiH}_{4}$ may interact favorably with $\mathrm{LiNH}_{2}$ and $\mathrm{LiBH}_{4}$ as did $\mathrm{MgH}_{2}$ to make new reversible hydrogen storage systems. In our previous studies disclosed above, Ni has shown good activity in releasing hydrogen from $\mathrm{LiNH}_{2}-$ 
$\mathrm{LiBH}_{4}$-based systems. The compositions and $\mathrm{HT}$ hydrogen storage capacities are given in Table 25 of Appendix D. The compositions studied and their hydrogen storage capacities measured in the second desorption cycle $\left(230^{\circ} \mathrm{C}\right)$ are shown in Figure 56.

The compositions were evaluated in three desorption cycles in the HT unit, carried out at $100{ }^{\circ} \mathrm{C}$, $230{ }^{\circ} \mathrm{C}$ and $350^{\circ} \mathrm{C}$.

The $100{ }^{\circ} \mathrm{C}$ desorption cycle didn't yield any standout materials as desorption never exceeded 0.75 wt. \%. Examination of the results from the 230 ${ }^{\circ} \mathrm{C}$ desorption cycle in Figure 56 shows that the compositions that included $\mathrm{LiH}$ were among the poorer desorbers. The best

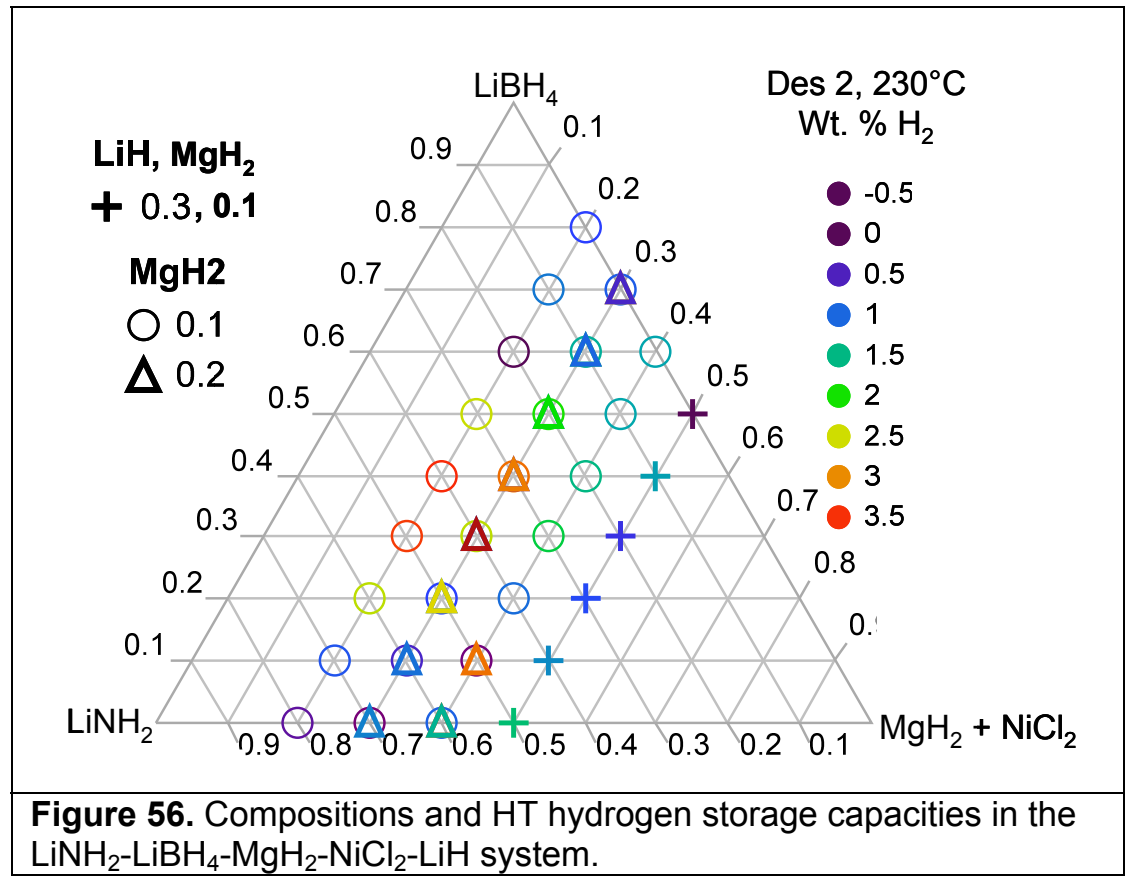
desorbers (red and orange) exceed 3 wt. $\% \mathrm{H}_{2}$ and are clustered toward the center of the phase diagram, containing moderate amounts of $\mathrm{LiNH}_{2}$ and $\mathrm{LiBH}_{4}$. The formulations that yielded the most hydrogen are:

$8=0.4 \mathrm{LiNH}_{2}+0.3 \mathrm{LiBH}_{4}+0.2 \mathrm{MgH}_{2}+0.1 \mathrm{NiCl}_{2} ; 3.90$ wt. $\% \mathrm{H}_{2}$

$9=0.4 \mathrm{LiNH}_{2}+0.4 \mathrm{LiBH}_{4}+0.1 \mathrm{MgH}_{2}+0.1 \mathrm{NiCl}_{2} ; 3.54$ wt. $\% \mathrm{H}_{2}$

$10=0.5 \mathrm{LiNH}_{2}+0.3 \mathrm{LiBH}_{4}+0.1 \mathrm{MgH}_{2}+0.1 \mathrm{NiCl}_{2} ; 3.44$ wt. $\% \mathrm{H}_{2}$

$11=0.6 \mathrm{LiNH}_{2}+0.2 \mathrm{MgH}_{2}+0.2 \mathrm{NiCl}_{2} ; 3.38$ wt. \% $\mathrm{H}_{2}$

$12=0.7 \mathrm{LiBH}_{4}+0.2 \mathrm{MgH}_{2}+0.1 \mathrm{NiCl}_{2} ; 2.68$ wt. \% $\mathrm{H}_{2}$

Compositions 8, 9 and $\mathbf{1 0}$ were the top desorbers and are clustered with regard to $\mathrm{LiNH}_{2}$ and $\mathrm{LiBH}_{4}$ contents with mole fractions of 0.3 to 0.5 . Desorption profiles are shown for the adjacent compositions 9 and 10 in Figure 48, gray trace and teal trace, respectively. Composition 9 starts desorbing at $100{ }^{\circ} \mathrm{C}$, evolving 0.5 wt. $\% \mathrm{H}_{2}$ by $150{ }^{\circ} \mathrm{C}$ and henceforth steadily at a rate of 0.04 wt. $\% \mathrm{H}_{2} /{ }^{\circ} \mathrm{C}$ up to $200{ }^{\circ} \mathrm{C}$, reaching 2.5 wt. $\% \mathrm{H}_{2}$. Desorption tailed off after $200{ }^{\circ} \mathrm{C}$. By comparison, composition 10 with the adjusted $\mathrm{LiNH}_{2}$ and $\mathrm{LiBH}_{4}$ levels lags behind in the desorption profile by 10 or $20{ }^{\circ} \mathrm{C}$, but desorbs hydrogen at a similar rate after $170{ }^{\circ} \mathrm{C}$. Composition 10 has additional $\mathrm{LiNH}_{2}$ and less $\mathrm{LiBH}_{4}$, which may have suppressed the rate of desorption. Compositions 11 and 12 are also good desorbers that may help de-convolute the effect of $\mathrm{LiNH}_{2}$ and $\mathrm{LiBH}_{4}$ as 11 only contains $\mathrm{LiNH}_{2}$ and 12 only contains $\mathrm{LiBH}_{4}$. Desorption curves for 11 and 12 are shown in Figure 48, orange trace and black trace, respectively. The desorption profile for 11 nearly overlaps that for composition 9 , despite having no borohydride. Composition 12 falls between compositions 8 and $\mathbf{9}$ despite having no amide. It seems the major effect in the pure borohydride system, 12, is that the total desorption is suppressed. Once desorption starts, the rates of desorption for the four compositions are similar with the pure borohydride system being slightly enhanced. The desorption in 
some of these compositions could be due to the $\mathrm{LiNH}_{2}-\mathrm{MgH}_{2}$ system in action, but looking back at Figure 7, the desorption observed here is not nearly as steep between 150 and $200{ }^{\circ} \mathrm{C}$. Figure 48 also shows some results from the $\mathrm{LiNH}_{2}-\mathrm{LiBH}_{4}-\mathrm{NiCl}_{2}$ system, which also exhibits steeper desorption profiles between 150 and $200{ }^{\circ} \mathrm{C}$. By comparison to these related systems, the $\mathrm{LiNH}_{2}-\mathrm{LiBH}_{4}-\mathrm{MgH}_{2}-\mathrm{NiCl}_{2}$ systems studied here (8-12) behave like suppressed $\mathrm{LiNH}_{2}-\mathrm{MgH}_{2}$ systems.

Compositions 7, 8 and $\mathbf{9}$ desorbed much less hydrogen in the third desorption at $350{ }^{\circ} \mathrm{C}, 0.38,0.43$, and $0.82 \mathrm{wt} . \% \mathrm{H}_{2}$ respectively. Significant desorption did not occur until the temperature was above $230^{\circ} \mathrm{C}$, suggesting that little of the hydrogen desorbed in the previous step was recovered during hydriding. A few systems evolved about 2 wt. $\% \mathrm{H}_{2}$ in the $350{ }^{\circ} \mathrm{C}$ desorption, such as $0.7 \mathrm{LiBH}_{4}+0.2 \mathrm{MgH}_{2}+0.1 \mathrm{NiCl}_{2}, 2.01$ wt. \% $\mathrm{H}_{2} ; 0.7 \mathrm{LiNH}_{2}+0.1 \mathrm{LiBH}_{4}+0.1 \mathrm{MgH}_{2}+0.1 \mathrm{NiCl}_{2} ; 1.98$ wt. \% $\mathrm{H}_{2} ;$ and $0.1 \mathrm{LiNH}_{2}+0.7$ $\mathrm{LiBH}_{4}+0.1 \mathrm{MgH}_{2}+0.1 \mathrm{NiCl}_{2}, 19.5$ wt. \% $\mathrm{H}_{2}$. These best performers, which only desorbed $1 \mathrm{wt} . \%$ or less in the previous desorption cycle, didn't evolve any hydrogen until above $230{ }^{\circ} \mathrm{C}$ and desorbed about $1 \mathrm{wt} . \% \mathrm{H}_{2}$ by the time the desorption temperature reached $350{ }^{\circ} \mathrm{C}$. Half of the hydrogen was desorbed while the samples were held at $350{ }^{\circ} \mathrm{C}$ at the end of the run. There were no candidates exhibiting reversible behavior in the $\mathrm{LiNH}_{2}-\mathrm{LiBH}_{4}-\mathrm{MgH}_{2}-\mathrm{NiCl}_{2}$ system in this study.

\begin{tabular}{|c|c|}
\hline$\sum^{0.3}=0.2$ & 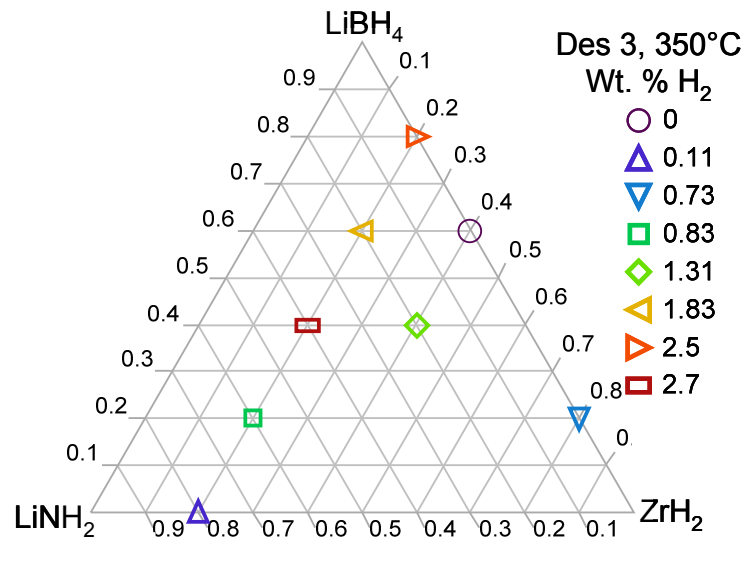 \\
\hline 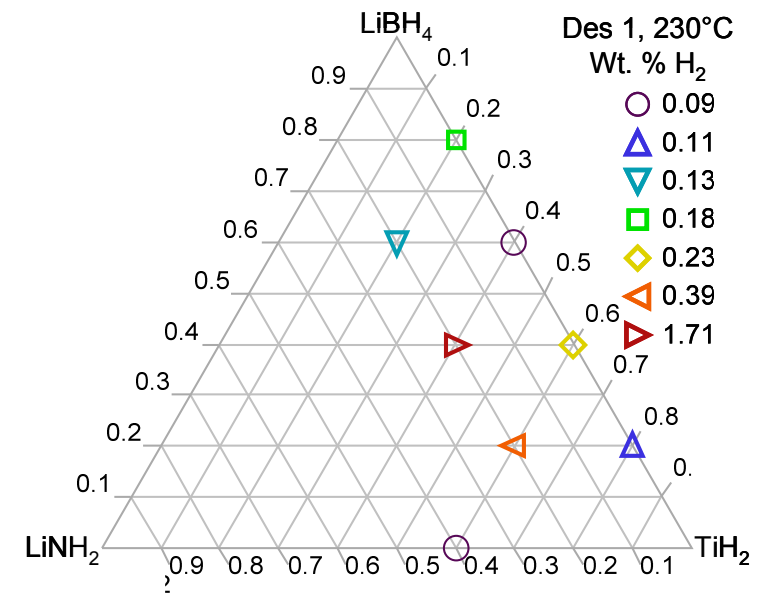 & $\begin{array}{c}\text { Des } 3,350^{\circ} \mathrm{C} \\
\text { Wt. \% H } \\
O 0.28 \\
\Delta 0.35 \\
\nabla 0.38 \\
\square 0.41 \\
\diamond 0.87 \\
\triangle 1.04 \\
\triangleright 2.16 \\
0.7 \square 2.9 \\
0.8 \\
0 .\end{array}$ \\
\hline \multicolumn{2}{|c|}{$\begin{array}{l}\text { Figure 57. } \mathrm{LiNH}_{2}-\mathrm{LiBH}_{4}-\left(\mathrm{TiH}_{2}, \mathrm{ZrH}_{2}\right) \text { systems: compositions and } \mathrm{HT} \text { hydrogen storage capacities. } \\
\text { Upper left - } \mathrm{LiNH}_{2}-\mathrm{LiBH}_{4}-\mathrm{ZrH}_{2} \text {, first desorption }\left(230^{\circ} \mathrm{C}\right) \text {; Upper right }-\mathrm{LiNH}_{2}-\mathrm{LiBH}_{4}-\mathrm{ZrH}_{2} \text {, third } \\
\text { desorption }\left(350{ }^{\circ} \mathrm{C}\right) \text {; Lower left }-\mathrm{LiNH}_{2}-\mathrm{LiBH}_{4}-\mathrm{TiH}_{2} \text {, first desorption }\left(230{ }^{\circ} \mathrm{C}\right) \text {; Lower right }-\mathrm{LiNH}_{2}- \\
\mathrm{LiBH}_{4}-\mathrm{TiH}_{2} \text {, third desorption }\left(350^{\circ} \mathrm{C}\right)\end{array}$} \\
\hline
\end{tabular}


6.8.10 $\mathrm{LiNH}_{2}-\mathrm{LiBH}_{4}-\left(\mathrm{TiH}_{2}, \mathrm{ZrH}_{2}\right)$ Systems. The $\mathrm{LiNH}_{2}-\mathrm{LiBH}_{4}-\mathrm{ZrH}_{2}$ and $\mathrm{LiNH}_{2}-\mathrm{LiBH}_{4}-\mathrm{TiH}_{2}$ were evaluated both in the MT and HT assays. Compositions studied, spent structures from both the MT and HT assays, and hydrogen storage capacities from both assays are reported in Tables 26a and 26b of Appendix D.

The MT assay revealed a superior composition in each system: $0.6 \mathrm{LiNH}_{2}+0.2$ $\mathrm{LiBH}_{4}+0.2 \mathrm{ZrH}_{2}$ (13), 1.48 wt. \% H $\mathrm{H}_{2}$; and $0.2 \mathrm{LiNH}_{2}+0.4 \mathrm{LiBH}_{4}+0.4 \mathrm{TiH}_{2}$ (14), 1.35 wt. $\% \mathrm{H}_{2}$. Both materials desorbed a little over half as much hydrogen on the second desorption cycle, falling short of being reversible.

The structures of the spent materials from the MT assay showed many expected materials, such as $\mathrm{ZrH}_{2}$ and $\mathrm{Li}_{4}\left(\mathrm{NH}_{2}\right)_{3} \mathrm{BH}_{4}$ in the spent of 13, but also some unexpected materials such as $\mathrm{ZrO}_{2}, \mathrm{Li}_{2} \mathrm{ZrO}_{3}, \mathrm{Li}_{4} \mathrm{~B}_{2} \mathrm{O}_{5}$, and $\mathrm{LiOH}^{*} \mathrm{H}_{2} \mathrm{O}$. The presence of oxide suggests that the samples may have been contaminated during the collection of the XRD data.

Phase diagrams showing the compositions studied and HT hydrogen storage capacities for the first $\left(230^{\circ} \mathrm{C}\right)$ and third $\left(350^{\circ} \mathrm{C}\right)$ desorption cycles are portrayed in Figure 57. The first desorption for both the $\mathrm{ZrH}_{2}$ (upper left, Figure 57) and $\mathrm{TiH}_{2}$ (Figure 57 , lower left) identify single formulations with superior desorption properties, 13 (2.7 wt. $\% \mathrm{H}_{2}$ ) and 14 (1.71 wt. \% $\mathrm{H}_{2}$ ), respectively, consistent with the MT results. The other samples evolve less hydrogen by a factor of 3 or more. After rehydriding, 13 and14 evolved considerably less hydrogen in the second desorption $\left(230{ }^{\circ} \mathrm{C}\right)$, confirming the non-reversible behavior seen in the MT assay.

The results of the third desorption cycles $\left(350{ }^{\circ} \mathrm{C}\right)$ are shown in the phase diagrams for the $\mathrm{ZrH}_{2}$ (upper right, Figure 57) and $\mathrm{TiH}_{2}$ (lower right, Figure 57) systems. The compositions most active at low temperature, $13\left(0.83 \mathrm{wt} \% \mathrm{H}_{2}\right)$ and $14(0.38 \mathrm{wt}$ \% $\mathrm{H}_{2}$ ), performed miserably at higher temperature. The phase diagram shows that each system had several good performers with regard to storage capacity:

$15=0.4 \mathrm{LiNH}_{2}+0.4 \mathrm{LiBH}_{4}+0.2 \mathrm{ZrH}_{2} ; 2.7$ wt. \% $\mathrm{H}_{2}$

$16=0.8 \mathrm{LiBH}_{4}+0.2 \mathrm{ZrH}_{2} ; 2.5$ wt. $\% \mathrm{H}_{2}$

$17=0.8 \mathrm{LiBH}_{4}+0.2 \mathrm{TiH}_{2} ; 2.9$ wt. $\% \mathrm{H}_{2}$

$18=0.2 \mathrm{LiNH}_{2}+0.2 \mathrm{LiBH}_{4}+0.6 \mathrm{TiH}_{2} ; 2.16$ wt. \% $\mathrm{H}_{2}$

The borohydride rich compositions 16 and 17 started to desorb hydrogen at $300{ }^{\circ} \mathrm{C}$ evolving $1 \mathrm{wt} . \% \mathrm{H}_{2}$ by the time the temperature reached $350{ }^{\circ} \mathrm{C}$. Most of the hydrogen was evolved during a hold at $350{ }^{\circ} \mathrm{C}$ at the end of the run. The similarity of the desorption profiles suggest that this may just be the decomposition of $\mathrm{LiBH}_{4}$. The compositions 15 and 18 started desorbing hydrogen just under $250{ }^{\circ} \mathrm{C}$, with the desorption becoming rapid in the temperature range $280-320^{\circ} \mathrm{C}$. Both systems reached desorption plateaus before reaching the maximum desorption temperature. None of these high temperature desorbing systems were reversible as no material evolved more than 0.9 wt. $\% \mathrm{H}_{2}$ on the final desorption cycle.

A few of the spent materials were isolated and analyzed by XRD (Table 26b, Appendix D). As expected, $\mathrm{ZrH}_{2}$ was observed, but as with the MT spent samples, oxide containing materials such as $\mathrm{ZrO}_{2}, \mathrm{LiOH}$, and $\mathrm{LiB}(\mathrm{OH})_{4}$ were observed. Since there was no mechanism in this system to introduce oxide chemistry, the samples must have been exposed to the environment during XRD measurement process. 


\section{9 $\mathrm{LiNH}_{2}-\mathrm{LiBH}_{4}$-Transition Metal Oxide Systems.}

Thus far, the syntheses of many of the hydrogen storage materials in the $\mathrm{LiNH}_{2}-\mathrm{LiBH}_{4}$ TM systems fall into two basic categories:

a) Reaction of $\mathrm{LiNH}_{2}-\mathrm{LiBH}_{4}$ with transition metal halides. Using the formation of $\mathrm{LiCl}$ to drive the reaction, TM borohydrides, TM amides, Li-TM-borohydrides, Li-TMamides and the more complex Li-TM-amide-borohydride species. Depending on the oxidation state of the $\mathrm{TM}$ in $\mathrm{TMCl}_{\mathrm{x}}$, the in situ formation of a transition metal hydride, $\mathrm{TMH}_{\mathrm{y}}$, is also possible. Generation of the new material may take place during milling.

b) Reaction of $\mathrm{LiNH}_{2}-\mathrm{LiBH}_{4}$ with transition metal hydrides. This strategy is a little more complex and may require the conditions attained in the assay to proceed, depending on the redox potentials of the particular species involved. All of the species are relatively reduced, so there is no strong driving force for reaction and upon milling, one might only expect attaining an intimate mixture of the species versus a reaction occurring. Upon heating materials in the assay, a reaction might occur, such as in the example of $\mathrm{LiNH}_{2}+\mathrm{MgH}_{2}$ :

$$
2 \mathrm{LiNH}_{2}+\mathrm{MgH}_{2} \leftrightarrow \mathrm{Li}_{2} \mathrm{Mg}(\mathrm{NH})_{2}+2 \mathrm{H}_{2}
$$

This reaction occurs to some extent in milling, but generally not to completion. A variation of this reaction includes a combination of both approaches using $\mathrm{LiH}$ in combination with a TM halide to generate the TM hydride in situ, accompanied by $\mathrm{LiCl}$ formation.

Approach a) above is very effective in making new materials. A reaction will usually occur, but sometimes too effectively, leading to decomposition. The $\mathrm{LiCl}$ formed that drives the reaction is along for the ride, as it doesn't participate in the hydrogen storage reactions and the chloride doesn't provide any stabilizing influence in the new material formed and doesn't interact with the TM species any further after the initial exchange reaction. Also the formation of elemental TM due to rapid decomposition can lead to a dead end. In approach $b$ ), moderate temperatures are employed during the assay and reducing conditions are employed during hydriding, so the TM hydride often does not react and this approach is often not effective in making new materials.

Another approach to add transition metals is to introduce them as the oxide. Transition metals can attain a number of oxidation states, so it is possible to control the amount of oxide introduced and the redox activity of the transition metal species being introduced. New materials may be generated via a redox process, rather than the exchange process of approach a) above, which tends to lead to salts. Oxide level associated with the transition metal may be further adjusted in the assay via treatment with hydrogen as some water may be released during a reduction process. Oxide may be distributed/associated with the other species such as Li and B. It is well known that $\mathrm{Li}$ inserts into lattice positions of transition metal oxides and thus may participate in the chemistry and stabilization of hydrogen storage materials rather act as inert dead weight as in the case of $\mathrm{LiCl}$ evolved in approach a). Low levels of oxygen in the system may also stabilize the transition metals from complete reduction to the elemental state, a state which has been observed to be rather unreactive in our previous work. The maximum amount of hydrogen can be extracted from the amide-borohydride systems if they can be completely converted to nitrides and borides during the desorption process. 
These materials have been very difficult to regenerate during hydriding. The presence of oxide to make transition metal oxoboronitrides as the dehydrided species may have a better chance of being regenerated.

Following this strategy, we studied two transition metal oxide systems, $\mathrm{V}_{2} \mathrm{O}_{5}$, which contains $\mathrm{V}$ in its maximum oxidation state and should be very reactive with $\mathrm{LiBH}_{4} / \mathrm{LiNH}_{2}$, and $\mathrm{Cr}_{2} \mathrm{O}_{3}$, which is at an intermediate oxidation state and should be less reactive.

6.9.1 $\mathrm{LiNH}_{2}-\mathrm{LiBH}_{4}-\mathrm{Cr}_{2} \mathrm{O}_{3}$ System. The phase diagram showing the compositions and the HT hydrogen capacity results from third desorption $\left(350^{\circ} \mathrm{C}\right)$ is shown in Figure 58. The compositions studied, MT and HT hydrogen capacity assay results and the structures of spent materials from the MT assay are given in Table 27 of Appendix D.

The medium throughput assay results showed negligible desorption of hydrogen in both desorption cycles $\left(220{ }^{\circ} \mathrm{C}\right)$.

Examination of the XRD results from the spent materials largely showed the unreacted starting materials $\mathrm{LiBH}_{4}$, $\mathrm{Li}_{4}\left(\mathrm{NH}_{2}\right)_{3} \mathrm{BH}_{4}$, and $\mathrm{Cr}_{2} \mathrm{O}_{3}$. Clearly more severe conditions would be required to activate this system.

The HT assay

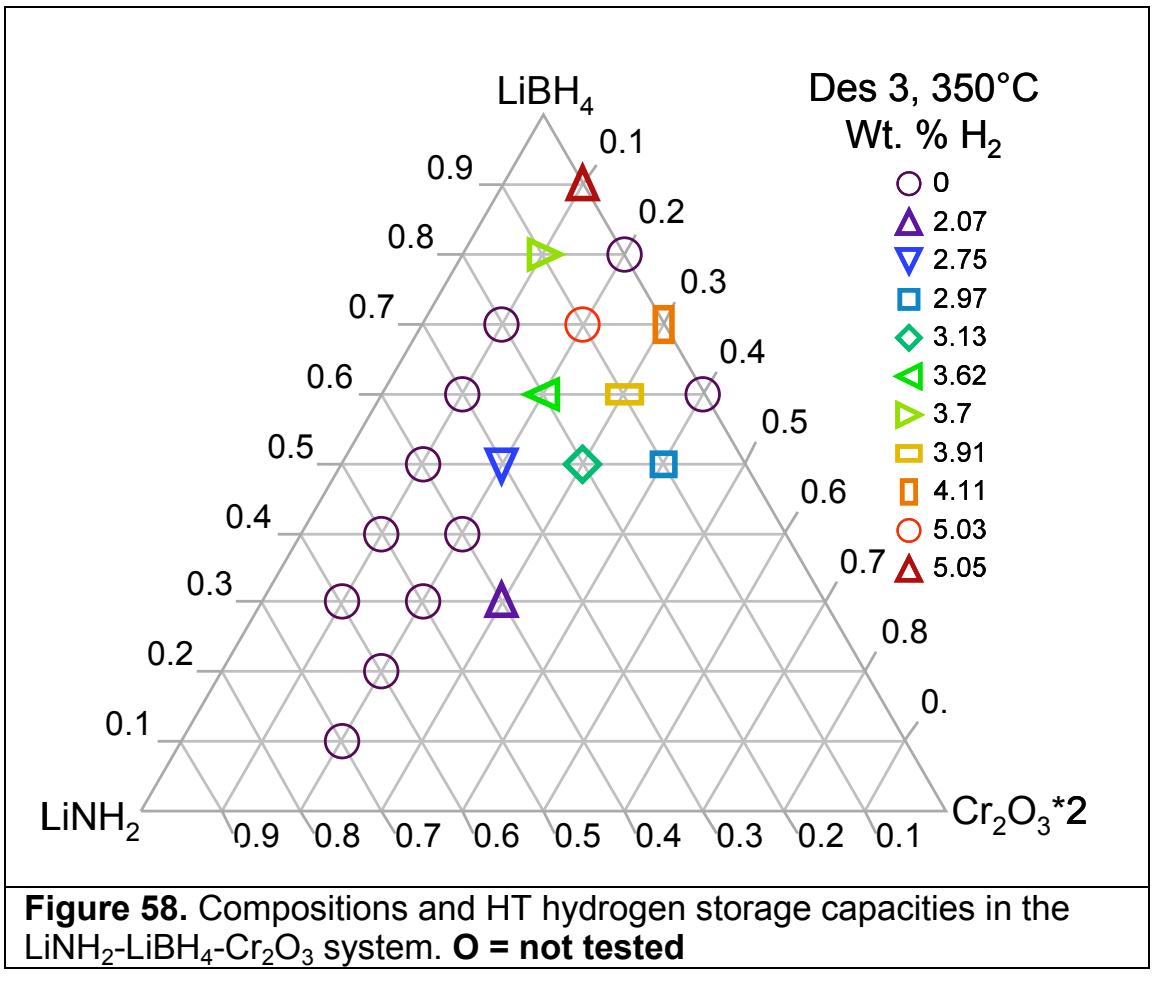
consisted of four desorption cycles conducted at $230^{\circ} \mathrm{C}, 230^{\circ} \mathrm{C}, 350^{\circ} \mathrm{C}$ and $350{ }^{\circ} \mathrm{C}$. The results from the first two desorption cycles were similar to those from the MT assay; desorption was negligible. The phase diagram in Figure 58 shows the results for the third desorption at $350{ }^{\circ} \mathrm{C}$. All the samples tested evolved between 2 and 5.1 wt. $\% \mathrm{H}_{2}$. From the phase diagram it is easily seen that the compositions showing the most desorption are rich in $\mathrm{LiBH}_{4}$ :

$19=0.1 \mathrm{LiNH}_{2}+0.6 \mathrm{LiBH}_{4}+0.15 \mathrm{Cr}_{2} \mathrm{O}_{3} ; 3.91$ wt. \% $\mathrm{H}_{2}$

$20=0.7 \mathrm{LiBH}_{4}+0.15 \mathrm{Cr}_{2} \mathrm{O}_{3} ; 4.11$ wt. \% $\mathrm{H}_{2}$

$21=0.1 \mathrm{LiNH}_{2}+0.7 \mathrm{LiBH}_{4}+0.1 \mathrm{Cr}_{2} \mathrm{O}_{3} ; 5.03$ wt. $\% \mathrm{H}_{2}$

$22=0.9 \mathrm{LiBH}_{4}+0.05 \mathrm{Cr}_{2} \mathrm{O}_{3} ; 5.05$ wt. \% $\mathrm{H}_{2}$

The desorption profiles of $\mathbf{2 0}$ and $\mathbf{2 1}$, which are adjacent compositions on the phase diagram, are shown in Figure 59, red trace and blue trace, respectively. Desorption begins at about $250{ }^{\circ} \mathrm{C}$ for each sample and follows a similar steady profile until $325^{\circ} \mathrm{C}$, with desorption occurring at a rate of about $0.02 \mathrm{wt} . \% \mathrm{H}_{2} /{ }^{\circ} \mathrm{C}$. At this point, 21 evolves 


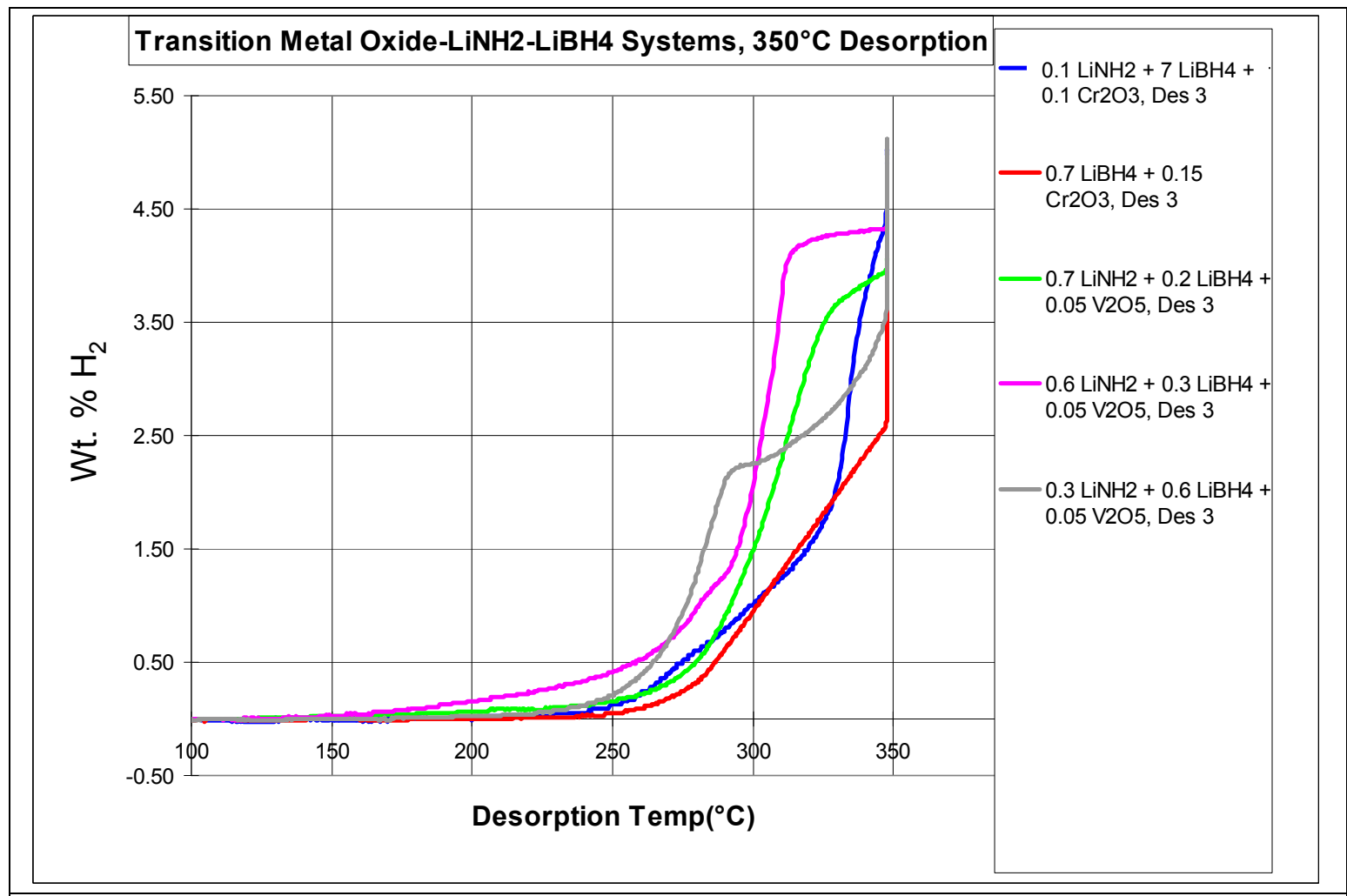

Figure 59. Hydrogen $\mathrm{HT}$ desorption profiles for selected $\mathrm{LiNH}_{2}-\mathrm{LiBH}_{4}-\mathrm{Cr}_{2} \mathrm{O}_{3}$ and $\mathrm{LiNH}_{2}-$ $\mathrm{LiBH}_{4}-\mathrm{V}_{2} \mathrm{O}_{5}$ compositions from the third desorption $\left(350^{\circ} \mathrm{C}\right)$

hydrogen much more rapidly, reaching $4.3 \mathrm{wt} . \% \mathrm{H}_{2}$ by $350{ }^{\circ} \mathrm{C}$ and desorbs another 0.7 wt. \% during a hold at $350{ }^{\circ} \mathrm{C}$. Meanwhile, 20 continues on its linear desorption path until it reaches $350{ }^{\circ} \mathrm{C}$, by which point it has desorbed $2.5 \mathrm{wt} . \% \mathrm{H}_{2}$. It desorbs another 1.6 wt. $\% \mathrm{H}_{2}$ during the hold at the end of the run. These desorption profiles were typical of the good desorbers in this system.

Compositions $\mathbf{2 0}$ and $\mathbf{2 1}$ were among the best hydrogen desorbers on the fourth cycle, 1.58 and $1.12 \mathrm{wt} \% \mathrm{H}_{2}$, but this evolution was greatly diminished over that observed on the third cycle. These materials desorbed less than 1 wt. $\% \mathrm{H}_{2}$ by $350{ }^{\circ} \mathrm{C}$, indicating a lack of reversible character.

6.9.2 $\mathrm{LiNH}_{2}-\mathrm{LiBH}_{4}-\mathrm{V}_{2} \mathrm{O}_{5}$ System. The phase diagrams showing the compositions studied in the $\mathrm{LiNH}_{2}-\mathrm{LiBH}_{4}-\mathrm{V}_{2} \mathrm{O}_{5}$ system are shown in Figure 60, along with $\mathrm{HT}$ hydrogen storage capacities from the first $\left(230^{\circ} \mathrm{C}\right.$, upper Figure 60$)$ and third $\left(350^{\circ} \mathrm{C}\right.$, lower figure $60)$ desorption cycles. The compositions studied, structures of spent materials from the medium throughput assay, and hydrogen storage capacities from both the MT and HT assays are given in Table 28 of Appendix D.

The MT assay results showed several materials with very average desorption characteristics. Among the best performers in the first desorption were:

$23=0.2 \mathrm{LiNH}_{2}+0.6 \mathrm{LiBH}_{4}+0.1 \mathrm{~V}_{2} \mathrm{O}_{5} ; 1.79$ wt. \% $\mathrm{H}_{2}$ $24=0.3 \mathrm{LiNH}_{2}+0.5 \mathrm{LiBH}_{4}+0.1 \mathrm{~V}_{2} \mathrm{O}_{5} ; 1.69$ wt. \% $\mathrm{H}_{2}$ $25=0.1 \mathrm{LiNH}_{2}+0.8 \mathrm{LiBH}_{4}+0.05 \mathrm{~V}_{2} \mathrm{O}_{5} ; 1.09$ wt. $\% \mathrm{H}_{2}$ $26=0.2 \mathrm{LiNH}_{2}+0.7 \mathrm{LiBH}_{4}+0.05 \mathrm{~V}_{2} \mathrm{O}_{5} ; 1.05$ wt. \% $\mathrm{H}_{2}$ 
The good desorbers were rich in $\mathrm{LiBH}_{4}$. This assay showed completely different results from the $\mathrm{Cr}_{2} \mathrm{O}_{3}$ study above as all of the samples showed some significant desorption activity. It was anticipated that $\mathrm{V}_{2} \mathrm{O}_{5}$ would be more reactive. The structures of the spent materials confirmed this.

The spent material isolated from 25 contained $\mathrm{LiV}_{2} \mathrm{O}_{4}$, $\mathrm{LiBH}_{4}, \mathrm{Li}_{3} \mathrm{BN}_{2}$, and $\mathrm{Li}_{4}\left(\mathrm{NH}_{2}\right)_{3} \mathrm{BH}_{4}$. The $\mathrm{V}_{2} \mathrm{O}_{5}$ was reduced from $\mathrm{V}^{5+}$ to the mixed oxidation state. $\mathrm{V}^{3.5^{+}}$. The presence of the boro-nitride $\mathrm{Li}_{3} \mathrm{BN}_{2}$ is unusual at 220 ${ }^{\circ} \mathrm{C}$, but indicating complete dehydrogenation. $\mathrm{Li}_{2} \mathrm{VO}_{4}$ was seen in every sample examined. The spent material isolated from 26 contained the new material Li-N-B-H \#2 (see Figure 43,

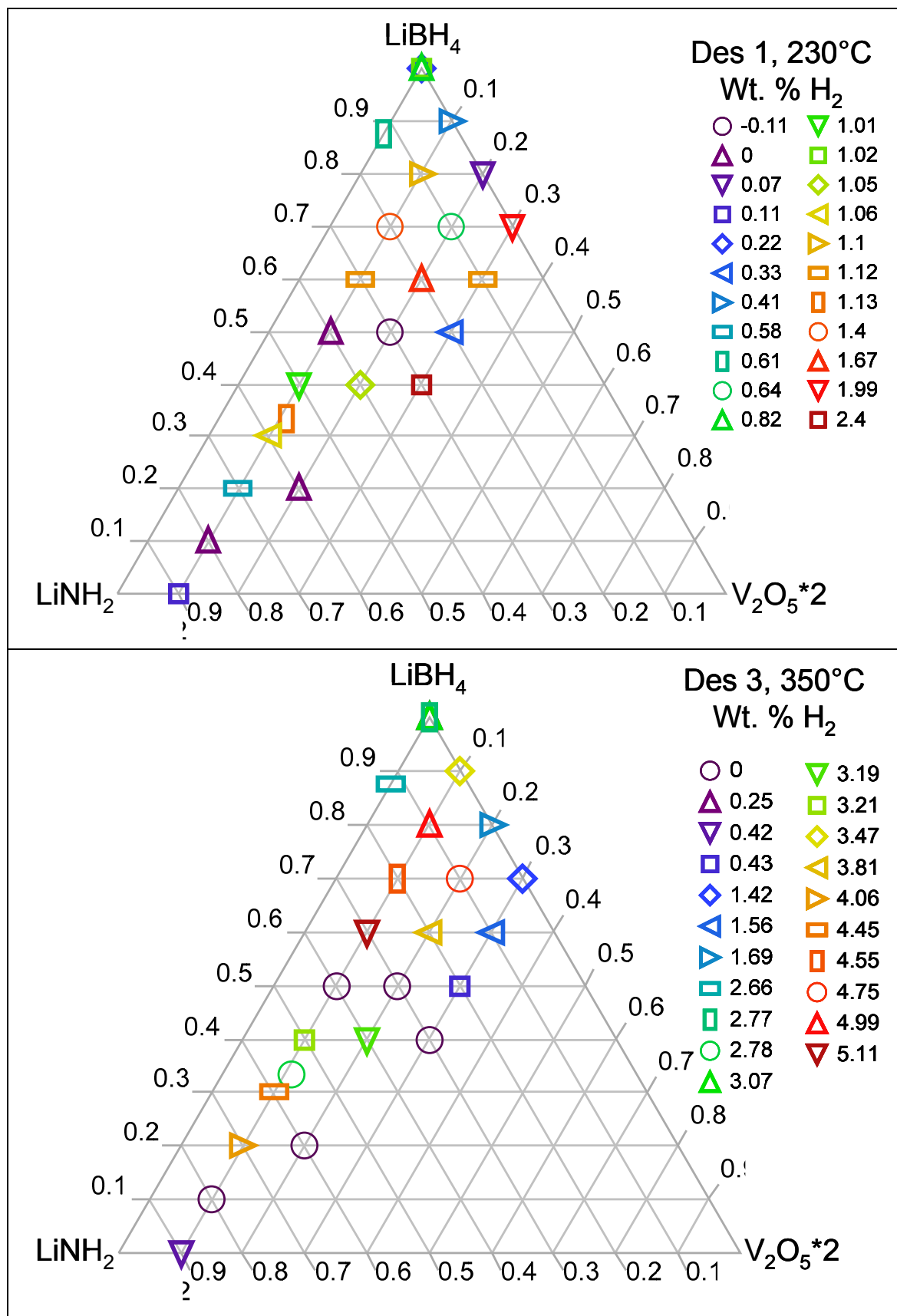

Figure 60. Compositions and $\mathrm{HT}$ hydrogen storage capacities in the $\mathrm{LiNH}_{2}-\mathrm{LiBH}_{4}-\mathrm{V}_{2} \mathrm{O}_{5}$ system. Upper - First desorption, $\left(230{ }^{\circ} \mathrm{C}\right)$; Lower - Third desorption, $\left(350^{\circ} \mathrm{C}\right)$

first seen as a

spent material in $\mathrm{LiNH}_{2}-\mathrm{LiBH}_{4}$ materials), and $\mathrm{LiV}_{2} \mathrm{O}_{4}$. On the second desorption, the performance of all the materials were greatly hindered as hydrogen evolution no more than half of that in the first cycle was observed. These results suggested there was no low temperature reversible material in this system.

The HT assay for the $\mathrm{LiNH}_{2}-\mathrm{LiBH}_{4}-\mathrm{V}_{2} \mathrm{O}_{5}$ system consisted of a four cycle program with maximum desorption temperatures of $230{ }^{\circ} \mathrm{C}, 230^{\circ} \mathrm{C}, 350^{\circ} \mathrm{C}$ and $350{ }^{\circ} \mathrm{C}$. The upper phase diagram in Figure 60 shows the results from the first desorption cycle. The three top desorbers were: 
$27=0.3 \mathrm{LiNH}_{2}+0.4 \mathrm{LiBH}_{4}+0.15 \mathrm{~V}_{2} \mathrm{O}_{5} ; 2.40$ wt. \% $\mathrm{H}_{2}$

$28=0.7 \mathrm{LiBH}_{4}+0.15 \mathrm{~V}_{2} \mathrm{O}_{5} ; 1.99$ wt. $\% \mathrm{H}_{2}$

$23=0.2 \mathrm{LiNH}_{2}+0.6 \mathrm{LiBH}_{4}+0.1 \mathrm{~V}_{2} \mathrm{O}_{5} ; 1.67$ wt. \% $\mathrm{H}_{2}$

The composition that yielded the best results in the MT assay, 23, was third best in the $\mathrm{HT}$ assay. The best hydrogen desorber in the HT assay, 27, is not as rich in $\mathrm{LiBH}_{4}$ as the other top desorbers. There is some compositional spread among the best performers as only two of the best four desorbers are adjacent compositions in the phase diagram. The second desorption cycle at $230{ }^{\circ} \mathrm{C}$ yielded less than $1 \mathrm{wt} . \% \mathrm{H}_{2}$ for all materials, consistent with the MT assay result that there was no low temperature reversibility.

The results of the third desorption $\left(350^{\circ} \mathrm{C}\right)$ are shown in the lower phase diagram in Figure 60. There were six different compositions that desorbed over 4 wt. \% $\mathrm{H}_{2}$; the top four are adjacent compositions in the phase diagram:

$29=0.3 \mathrm{LiNH}_{2}+0.6 \mathrm{LiBH}_{4}+0.05 \mathrm{~V}_{2} \mathrm{O}_{5} ; 5.11$ wt. \% $\mathrm{H}_{2}$ $25=0.1 \mathrm{LiNH}_{2}+0.8 \mathrm{LiBH}_{4}+0.05 \mathrm{~V}_{2} \mathrm{O}_{5} ; 4.99$ wt. \% $\mathrm{H}_{2}$ $30=0.1 \mathrm{LiNH}_{2}+0.7 \mathrm{LiBH}_{4}+0.1 \mathrm{~V}_{2} \mathrm{O}_{5} ; 4.75$ wt. \% $\mathrm{H}_{2}$ $26=0.2 \mathrm{LiNH}_{2}+0.7 \mathrm{LiBH}_{4}+0.05 \mathrm{~V}_{2} \mathrm{O}_{5} ; 4.55$ wt. \% $\mathrm{H}_{2}$ $31=0.6 \mathrm{LiNH}_{2}+0.3 \mathrm{LiBH}_{4}+0.05 \mathrm{~V}_{2} \mathrm{O}_{5} ; 4.45$ wt. $\% \mathrm{H}_{2}$ $32=0.7 \mathrm{LiNH}_{2}+0.2 \mathrm{LiBH}_{4}+0.05 \mathrm{~V}_{2} \mathrm{O}_{5} ; 4.06$ wt. \% $\mathrm{H}_{2}$

The four top desorbers contain high $\mathrm{LiBH}_{4}$ and low $\mathrm{V}_{2} \mathrm{O}_{5}$ and $\mathrm{LiNH}_{2}$, while the fifth and sixth best contain high $\mathrm{LiNH}_{2}$. The desorption profile of 29 , which is borohydride rich, is seen in Figure 59 , gray trace. Desorption starts at $225^{\circ} \mathrm{C}$, right where the second desorption left off. By $275^{\circ} \mathrm{C}$, the desorption rate increases, hitting a plateau at $290{ }^{\circ} \mathrm{C}$ and 2.25 wt. $\% \mathrm{H}_{2}$. At $305{ }^{\circ} \mathrm{C}$, the desorption rate increased again, reaching $3.5 \mathrm{wt} . \%$ by $350{ }^{\circ} \mathrm{C}$. The last $1.5 \mathrm{wt}$. \% hydrogen was desorbed during a hold at $350{ }^{\circ} \mathrm{C}$ at the end of the run. The desorption profile for 31 (Figure 59, magenta trace), which is a $\mathrm{LiNH}_{2}$-rich composition, starts desorbing hydrogen much earlier at $150{ }^{\circ} \mathrm{C}$. Desorption is slow at first, but between $280-320{ }^{\circ} \mathrm{C}$, about $3.5 \mathrm{wt} . \% \mathrm{H}_{2}$ is evolved. The desorption plateaus at 4.45 wt. $\% \mathrm{H}_{2}$. The adjacent composition, 32, (Figure 59, green trace) contains a little more $\mathrm{LiNH}_{2}$. Desorption starts at $230{ }^{\circ} \mathrm{C}$, with the rate increasing between $260-330{ }^{\circ} \mathrm{C}$, a little wider window than observed for 31 , with about $3.6 \mathrm{wt}$. \% of the total $4.06 \mathrm{wt}$. \% hydrogen evolved in this segment of the profile. Comparing these three desorption profiles, it appears the $\mathrm{LiNH}_{2}$-rich materials have a smoother continuous profile, while the borohydride-rich material contained more plateaus. More detailed investigation at intermediate temperatures are required to understand the nature of these plateaus. It can also be seen in Figure 59 that the $\mathrm{LiNH}_{2}-\mathrm{LiBH}_{4}-\mathrm{V}_{2} \mathrm{O}_{5}$ materials desorb hydrogen at lower temperatures than the $\mathrm{LiNH}_{2}-\mathrm{LiBH}_{4}-\mathrm{Cr}_{2} \mathrm{O}_{3}$ compositions.

After hydridng, the fourth desorption gave greater than 1 wt. $\% \mathrm{H}_{2}$ for four compositions with a maximum desorption of 1.64 wt. \% $\mathrm{H}_{2}$ observed for composition 25 . The desorption profiles showed desorption starting at $250{ }^{\circ} \mathrm{C}$. Thus, there is no reversible hydrogen storage material operating in the high temperature branch (230-350 ${ }^{\circ} \mathrm{C}$ ) of this system. 


\subsection{High Throughput Synthesis of Hydrogen Storage Materials.}

This project called for the development of high throughput synthesis capability to match the high throughput hydrogen storage assay capabilities already implemented. The basic requirements for the high throughput synthesis were:

- Capability to do air and water sensitive chemistry

- Freezer to store sensitive materials

- Automated dosing of both liquids $(+/-5 \mu \mathrm{L})$ and powders $(+/-1 \mathrm{mg})$

- Conduct sealed reactions up to $250^{\circ} \mathrm{C}$

- Up to 48-parallel reactions

- Agitation/Shaking during reactions

- Reaction work-up capabilities, parallel washing, filtering and drying

- Parallel milling of samples to prepare for HT Assay

- Interface with HT Assay - parallel loading of HT assay reactors

An augmented Zinsser Sophas-Cat was chosen as the automated synthesizer platform. The system is capable of dosing both liquids and solids, carrying out four simultaneous sealed reactions with heating and agitation, and washing and filtration at both the plate level (48 parallel samples) and individually with specially designed pipettes. This instrument was housed in a custom glovebox from Innovative Technologies, Inc., which was equipped with a freezer ( $-40^{\circ} \mathrm{C}$ capability), quick release panels so that we could access the Sophas-Cat inside, and an antechamber equipped with a trap so that solvent evaporations from samples in the synthesis arrays could be conducted. The HT synthesizer can be seen in Appendix A.

The first challenge was the interface between the Sophas-CAT in the glovebox and the environment outside the glovebox. The Sophas-Cat required connections to the computer, gasses, vacuum, electrical and waste vessels, all located outside of the glovebox. A variety of different solvents had to be handled along with materials that were potentially flammable. Zinsser designed materials compatible systems with valves that were controlled by the computer to allow the activation of vacuum and the purging of waste materials without contaminating the glovebox environment. Zinsser and Innovative Technologies collaborated on a custom design to implement these devices at the glovebox interface. Within the glovebox, synthesis solvent reservoirs had to be designed so that the glovebox wasn't flooded with solvent vapor. These custom items delayed the delivery and the setup of the high throughput synthesis system. The actual sealing of the glovebox from the outside environment also took a longer time than expected as a lot of redesign had to be done on site as the composite system was being assembled. The high throughput synthesis system wasn't ready for operation until very late in the project.

Once synthesis began, a problem quickly developed with accurate transfer of powders. Hydrogen storage materials engage in solid state reactions and interact with gases; the particles must necessarily be small. Highly energetic milling of materials is a standard operating procedure in attaining small particles and this processing step is impossible to do on the small HT scale. Therefore, the project used pre-milled starting materials which the Sophas-Cat needed to deliver reproducibly. The Sophas-Cat had two types of powder handlers - an array of constant volume pipettes that used vacuum to aspirate powders and two variable volume powder handlers, also operated by vacuum that handled smaller and larger ranges in volume, respectively. The latter were calibrated for each powder to operate with a scale and the "Weighing Wizard" software so that they could deliver desired weights of solid. Once experimentation began, it was found that the Sophas-Cat could not accurately deliver the desired weights of power. 
Problems included errors in the algorithm in the "Weighing Wizard" software and more seriously, seizing of the piston plunger when powder became lodged between the piston and the cylindrical wall in which it was housed. Also, plugging of the powder dispensing tool near the vacuum inlet by the fine powders was a significant problem.

Attempts were initially made to change the filter material, a screen that protected the powder tool from being plugged up by the small powder particles, but these were unsuccessful. Progress was made as another powder tool was designed, but this also plugged. Then a new series of constant volume dispensing tools were designed that operated with the software and the scale, but Zinsser decided they weren't good enough for our purpose and never delivered them. Instead, they developed a new and simpler variable volume pipette tool that operated in the range from to $20 \mu \mathrm{L}$ to $200 \mu \mathrm{L}$. This simple version avoided the problem with the small particulate of powder interfering with the operation a moving piston. The smaller volumes were to be delivered with constant volume tools that delivered from $0.5 \mu \mathrm{L}-10 \mu \mathrm{L}$ of powder. These two sets of tools were to work with the software to deliver a target weight. Problems with the weighing algorithm emerged and these were mostly addressed, but there were still some problems with delivery of small volumes making up the last bit of material. Despite this, this system looked very promising, but ultimately plugging of the power tool at the vacuum inlet remained a problem. With no resolution of the problem in sight after nearly two years of failures, we had to abandon our attempts to get this system operating.

Several other tools were developed with regard to HT synthesis. One of the steps in the synthesis was to involve milling once the pre-milled powders were combined in the HT synthesis unit with appropriate solvents or solutions. The 48-well plates in which synthesis was conducted needed to be protected from the environment during milling to avoid contamination or possibly an accident. A housing for the plates was built in-house. The synthesis plate could be placed in the housing inside the glovebox in an inert atmosphere where it could be sealed. The housing fit into the Pulverisette 5 ball mill and could be clamped in with clamps available from the ball mill company. This was used in a doping experiment, where $\mathrm{NaAlH}_{4}$ was doped with a $\mathrm{Ti}(\mathrm{OiPr})_{4} /$ pentane solution. After milling, this experiment made use of the trap on the glovebox antechamber, which is where the pentane removed. Tests were also conducted to evaluate the intensity of combi-milling to see if reactions that could be accomplished in the larger milling bowls could be accomplished in the combi-milling apparatus. The test reaction was the synthesis of $\mathrm{Mg}\left(\mathrm{AlH}_{4}\right)_{2}$ from $\mathrm{MgCl}_{2}$ and $\mathrm{NaAlH}_{4}$. It was found that the reaction did not proceed for dry powders, but it the powders were slurried in THF, the desired reaction occurred. The results of some of the combi milling work are presented in Appendix A. $A$ rack and transfer device was also developed for the transfer of the samples isolated from synthesis to the reaction vessels of the HT assay unit. Unfortunately, these latter two devices never saw much use. 


\section{CONCLUSIONS and OUTLOOK}

\subsection{CONCLUSIONS}

This project developed and applied the tools necessary to accelerate the discovery and evaluation of new hydrogen storage materials. The multi-faceted approach included the integration of newly developed custom high throughput instrumentation, Virtual High Throughput Screening (VHTS) and First Principles theoretical methods, and informatics, all applied to the investigation of potential hydrogen storage material families to quickly identify promising leads that merit further development with the ultimate goal of meeting DOE hydrogen storage targets.

The development of the medium and high throughput hydrogen storage assays were the key advances in the acceleration of hydrogen storage materials research. Evaluation of hydrogen storage materials had traditionally been carried out serially by the PCT (Pressure-Composition-Temperature) method, which consists of equilibrium measurements that can take a week per sample. By contrast, the dynamic measurements made in high throughput assay could evaluate $50+$ samples in this time frame. Key aspects of the new assay systems are

- Ability to handle hundreds of small air- and water-sensitive samples

- Parallel processing of 8 samples (MT) or 48 samples (HT)

- Ability to desorb hydrogen at $220^{\circ} \mathrm{C}(\mathrm{MT})$ or to $350{ }^{\circ} \mathrm{C}(\mathrm{HT})$

- Ability to hydrogenate at $125^{\circ} \mathrm{C}, 87$ bar $\mathrm{H}_{2}(\mathrm{MT})$ or up to $350{ }^{\circ} \mathrm{C}, 120$ bar $\mathrm{H}_{2}(\mathrm{HT})$

- Ability to determine reversible character of hydrogen storage materials and distinguish between reversible and continuous absorption/desorption processes

Characterization of the chemistry occurring in the MT and HT assays was supplemented by HT powder x-ray diffraction, which was also adapted to handle environmentally sensitive materials. X-ray diffraction helped identify both active and undesirable species involved in the hydrogen storage reactions, including shedding light on whether hydrogen was lost during synthesis. Ion-exchange reactions and non reaction of reagents were also documented.

The MT and HT assay tools were validated via investigation of the $\mathrm{NaAlH}_{4}-$ $\mathrm{LiAlH}_{4}-\mathrm{Mg}\left(\mathrm{AlH}_{4}\right)_{2}$ phase diagram, where we searched for a mixed alanate with higher hydrogen storage capacity than $\mathrm{NaAlH}_{4}$ :

- No new mixed alanates were found

- $\mathrm{NaAlH}_{4}$ was the best performer

- Decomposition during synthesis was dependent on the cation and was especially bad for $\mathrm{Mg}\left(\mathrm{AlH} \mathrm{H}_{4}\right)_{2}$, which was partially alleviated by mild milling

- VHTS confirmed the experimental findings as two mixed alanates were identified, but they were unstable with respect to hydrogen loss at room temperature and thus not observed

- Reverse reactions, regeneration of the alanates from Al and metal hydrides, also showed cation effects, being difficult for $\mathrm{Li}^{+}$and easy for $\mathrm{K}^{+}$

The MT and HT assay tools were then applied to the $\mathrm{LiNH}_{2}-\mathrm{LiBH}_{4}-\mathrm{MgH}_{2}$ phase diagram, a complex ternary system for which selected binary compositions had been previously investigated. The HT assay was a necessity for this undertaking and key results were:

- A new reversible hydrogen storage material of composition $0.6 \mathrm{LiNH}_{2}-0.3 \mathrm{MgH}_{2}$ $-0.1 \mathrm{LiBH}_{4}$ that reversibly stored about 4 wt. \% hydrogen in our dynamic 
- The new reversible $0.6 \mathrm{LiNH}_{2}-0.3 \mathrm{MgH}_{2}-0.1 \mathrm{LiBH}_{4}$ material consisted of the active hydrogen storage species of the $2 \mathrm{LiNH}_{2}+\mathrm{MgH}_{2} \leftrightarrow \mathrm{Li}_{2} \mathrm{Mg}(\mathrm{NH})_{2}+2 \mathrm{H}_{2}$ system along with $\mathrm{Li}_{4}\left(\mathrm{NH}_{2}\right)_{3} \mathrm{BH}_{4}$, which forms an ionic liquid and allowed this system to operate at lower temperature, a completely unanticipated result

- The HT approach allowed the identification and optimization of this unanticipated new hydrogen storage material as well as pointing to the trends in the system as a whole

- First principles calculations were validated when applied to determine the phase diagram in the $\mathrm{Li}-\mathrm{N}-\mathrm{Mg}-\mathrm{H}$ system and successfully calculated the hydrogen storage reaction pathways within this well-studied system.

- Doping studies suggested an enhancement of $0.6 \mathrm{LiNH}_{2}-0.3 \mathrm{MgH}_{2}-0.1 \mathrm{LiBH}_{4}$ by $\mathrm{Pd} /$ carbon

This study was extended to several other amide-borohydride-hydride systems including the $\mathrm{LiNH}_{2}-\mathrm{LiBH}_{4}-\mathrm{CaH}_{2}$ system:

- A new reversible hydrogen storage material was found operating for the 0.625 $\mathrm{LiBH}_{4}+0.375 \mathrm{CaH}_{2}$ and $0.375 \mathrm{LiNH}_{2}+0.25 \mathrm{LiBH}_{4}+0.375 \mathrm{CaH}_{2}$ compositions operating at $1 \mathrm{wt} . \%$ reversible hydrogen below $175^{\circ} \mathrm{C}$

- The results suggest boron had been activated in a reversible material, an important goal in this project

- The spent materials from these compositions exhibit a new structure

Attempts were made to activate boron by combining stable alkali borohydrides with unstable transition metal borohydrides to make alkali-transition metal borohydrides:

- Synthesis of the desired materials were confirmed indirectly by XRD

- Many of the materials were unstable, releasing hydrogen during milling before it could be measured

- A new material of composition $4 \mathrm{LiBH}_{4}+\mathrm{CuCl}_{2}$ was found to reversibly store about 1.5 wt. $\% \mathrm{H}_{2}$, operating at up $150{ }^{\circ} \mathrm{C}$, again suggesting that $\mathrm{B}$ had been activated in a reversible material

To address the aggressive DOE gravimetric hydrogen storage requirements of $6.5 \mathrm{wt} . \%$ $\mathrm{H}_{2}$, many of our search for new materials focused on amide-alanate-borohydride based systems. These were not very successful, but notable results include:

- Metal boride and nitrides could not be hydrogenated

- Alkali and alkaline earth amide/hydride systems underwent ion-exchange and non-reversible hydrogen evolution, often during synthesis

- Alanates tended to react with amides to evolve hydrogen during synthesis, and $\mathrm{NaAlH}_{4}$ was slightly enhanced by the presence of small amounts $\mathrm{LiNH}_{2}$ in the first desorption cycle

- Aluminum hexahydrides $\mathrm{Na}_{3} \mathrm{AlH}_{6}$ and $\mathrm{LiNa}_{2} \mathrm{AlH}_{6}$ were reversible, but did not form new compounds in their reactions with amides and borohydrides

- Alanate and borohydrides did not form reversible materials, but only suppressed the alanates; there was one observation of $\mathrm{AlB}_{2}$ in the synthesis

- The amide-borohydride study focused on $\mathrm{LiNH}_{2}-\mathrm{LiBH}_{4}$ system which doped with different metals yielded up to $10 \mathrm{wt} \% \mathrm{H}_{2}$, but not reversibly.

- There were four different new materials characterized by XRD among the spents from the alakali/alkaline earth metal amide-borohydride-hydride study, which always came in mixtures and were not part of reversible hydrogen storage reactions 
First Principles calculation identified "destabilized" reactions to have favorable thermodynamics for hydrogen storage reactions. Examples of such are the reactions of $\mathrm{LiBH}_{4}$ with $\mathrm{TiH}_{2}$ or $\mathrm{Cr}$. These reactions were pursued experimentally, but the predicted reactions were not realized. The kinetics of the reactions was not favorable, an aspect not taken into account by the calculations.

The final stage of the materials investigation continued to address the activation of $B$ as the $\mathrm{LiNH}_{2}-\mathrm{LiBH}_{4}$ matrix was used with transition metal chlorides to take advantage of the ability to form an ionic liquid and enhance reactivity, to add stability to transition metal borohydride systems via the presence of lithium amide and its ability to form mixed salts with $\mathrm{Li}$ borohydride. This is an augmented approach similar to that of the alkali borohydride-transition metal borohydride strategy. LiH was often additionally used in the experiments to generate $\mathrm{TMH}_{\mathrm{x}}$ in situ. Key results were:

- Co and Ni showed good desorption (> $5 \mathrm{wt}$. \%), but no reversibility

- $\mathrm{Mn}, \mathrm{Zn}$, and $\mathrm{Zr}$ were not stable enough during milling to desorb much hydrogen during the assay; evolving hydrogen during synthesis

- The Mg-Ni system, which also forms the hydrogen storage material $\mathrm{Mg}_{2} \mathrm{NiH}_{4}$, was suppressed with respect to hydrogen evolution; not characteristic of either $\mathrm{Ni}$-doped $\mathrm{LiNH}_{2}-\mathrm{LiBH}_{4}$ or the reversible $2 \mathrm{LiNH}_{2}-\mathrm{MgH}_{2}$ system

- V-Ti as chlorides was a mediocre desorber while $\mathrm{TiH}_{2}, \mathrm{ZrH}_{2}$ and $\mathrm{V}$ were systems with very poor desorption.

- The oxides $\mathrm{Cr}_{2} \mathrm{O}_{3}$ and $\mathrm{V}_{2} \mathrm{O}_{5}$ were also used as the transition metal source. $\mathrm{Cr}_{2} \mathrm{O}_{3}$ was not very reactive, while $\mathrm{V}_{2} \mathrm{O}_{5}$ shows $4-5$ wt. $\% \mathrm{H}_{2}$ desorption, but not reversible.

- LiH generally suppressed the hydrogen desorption reactions

- Unfortunately, this methodology did not yield any new reversible hydrogen storage materials

A final aspect of this project was to develop a high throughput synthesis system. An automated synthesis system was set up in a glovebox. It could handle liquids and powders and conduct reactions to $250{ }^{\circ} \mathrm{C}$. Unfortunately, the nature of the fine powders required for hydrogen storage proved to be problematic for the powder handling tool of the HT synthesizer and this was never resolved despite great effort. The HT synthesis of hydrogen storage compounds was never realized.

\subsection{OUTLOOK}

It is obvious from the work presented above that high throughput methods can have a great impact on speeding up the discovery process and will be increasingly a part of everyday research in the future. The savings of time, energy and materials justify it. The important part of designing a high throughput process is to make sure that it is relevant to the real life process that is being addressed. The HT assay used in this hydrogen storage project was designed with the DOE hydrogen capacity targets for onboard systems in mind, with regard to both capacity and temperature/thermodynamics of operation. This placed some limitations on us for instance when we tried to hydrogenate some materials; we could not achieve severe enough conditions. Much of the work from the last section, the $\mathrm{LiNH}_{2}-\mathrm{LiBH}_{4}-\mathrm{TM}$ could be re-examined in terms of the regeneration parameters. This would also be a key to succeeding in other reactions where thermodynamics suggested a reaction, but the kinetics were not cooperative. The high throughput method is a great methodology that provides a wealth of information, 
especially systemic trends. However, in the end, it is just a tool. To be successful, one has to make sure that the HT system is the right tool as well as showing up with the best ideas to investigate with the tool, always the case in research.

Moving forward to a hydrogen storage material with excellent gravimetric capacity, it seems that an advance has to be made in boron chemistry. Some excellent prospects were seen in this project in the $\mathrm{LiNH}_{2}-\mathrm{LiBH}_{4}-\mathrm{TM}$ system, even when the TM was present as a dopant. The ionic liquid aspect for increasing reactivity and lowering reaction temperature is very attractive. However, as mentioned above, we may not have chosen or had access to the appropriate conditions to reverse these reactions, this should be readdressed. The use of $\mathrm{V}_{2} \mathrm{O}_{5}$ seemed promising in our work and other reducible transition metal oxides should be investigated. Transition metal oxoboronitrides may be easier to rehydrogenate. The alanates seemed to be too reactive to control, even in their reactions with other species (amides) and probably should not be looked at any further.

A recurring issue in our syntheses of materials was the evolution of hydrogen during milling. Milling, while effective in many systems, is a very crude method of synthesis. Combining the catalyst with the hydrogen storage materials during the milling further enhanced decomposition and on many occasions, didn't allow us to make the desired materials. More variation and control in synthesis could be achieved by synthesis from solution. A route to $\mathrm{B}$ - and $\mathrm{N}$ - based complex transition metal hydride materials could start with amino-borane, $\mathrm{NH}_{3}-\mathrm{BH}_{3}$ as a synthon. There are also a variety of soluble borohydrides available. More careful, gentler synthesis of material will lead to new materials and possibilities that could never be achieved by the brute force milling method.

The application of theoretical methods to help guide the chemistry still has its pros and cons. At its best, theory is useful for identifying thermodynamically favorable target reactions. These may not work outright, because the kinetics may be such that the reaction isn't easily accessible. But there is the possibility of catalyzing such a reaction. Theory may also be used to dismiss some systems as not being feasible. This must be done carefully, since theoretical methods take into account and base their calculations on known phases within a system and often don't account for the unknown phases, particularly those that are metastable. It is possible to miss a promising reaction. A case in point is the surprise of the mixed salt $\mathrm{Li}_{4}\left(\mathrm{NH}_{2}\right)_{3} \mathrm{BH}_{4}$ discovered ${ }^{4,5}$ during the course of this project, its low-melting point, and its surprise enhancement of the chemistry in the 2 $\mathrm{LiNH}_{2}+\mathrm{MgH}_{2} \leftrightarrow \mathrm{Li}_{2} \mathrm{Mg}(\mathrm{NH})_{2}+2 \mathrm{H}_{2}$ reaction. 


\section{AWARD PRODUCTS GENERATED}

The following products were developed under the Project award:

\section{a. Publications}

"High Throughput Screening of Complex Metal Hydrides for Hydrogen Storage," Lewis, G. J.; Sachtler, J.W.A.; Low, J. J.; Lesch, D. A.; Faheem, S. A.; Dosek, P. M.; Knight, L. M.; Jensen, C. M., Mater. Res. Soc. Symp. Proc., 2006, 885, 135

"High Throughput Screening of the Ternary $\mathrm{LiNH}_{2}-\mathrm{MgH}_{2}-\mathrm{LiBH}_{4}$ Phase Diagram," Journal of Alloys and Compounds, 2007, 446-447, 355. G. J. Lewis, J.W.A. Sachtler, J.J. Low, D.A. Lesch, S.A. Faheem, P.M. Dosek, L.M. Knight, L. Halloran, C.M. Jensen, Jun Yang, Andrea Sudik, Donald J. Siegel, Devin Halliday, Andy Drews, Roc Carter, Christopher Wolverton, Vidvuds Ozolins, and Shu Zhang

"Hydrogen storage in calcium alanate: First-principles thermodynamics and crystal structures," Phys. Rev. B 75, 064101 (2007), C. Wolverton and V. Ozolins.

"First-principles determination of multicomponent hydride phase diagrams: Application to the Li-Mg-N-H system," Advanced Materials 19, (2007), 3233 - 3239. A. Akbarzadeh, V. Ozolins, and C. Wolverton.

"A Self-Catalyzing Hydrogen-Storage Material," Angewante Chemie, International Edition 2008, 47, 882-887, Jun Yang, ${ }^{*}$ Andrea Sudik, Donald J. Siegel, Devin Halliday, Andrew Drews, Roscoe O. Carter, III, Christopher Wolverton, Gregory J. Lewis, J. W. Adriaan Sachtler, John J. Low, Syed A. Faheem, David A. Lesch, and Vidvuds Ozolins

"Thermodynamic guidelines to the prediction of hydrogen storage reactions and their application to destabilized hydride mixtures," Siegel, D.J.; Wolverton, C.; Ozolins, V., Phys. Rev. B, 2007, 76, 134102.

\section{b. Conference papers}

"Discovery of Novel Complex Metal Hydrides for Hydrogen Storage through Molecular Modeling and Combinatorial Methods," presentation to the 2004 HFCIT Annual Program Review, May 24-27, 2004, Philadelphia, PA, by J.W. Adriaan Sachtler.

"Discovery of Novel Complex Metal Hydrides for Hydrogen Storage Through Molecular Modeling and Combinatorial Methods," presentation to the 2005 Hydrogen Program Annual Review, May 25, 2005, Crystal City, VA, by J.W. Adriaan Sachtler.

"Discovery of Novel Complex Metal Hydrides for Hydrogen Storage Through Molecular Modeling and Combinatorial Methods," poster at the IPHE International Hydrogen Storage Technology Conference, June 19 - 22, 2005, Lucca, by J.W. Adriaan Sachtler, Gregory J. Lewis, John J. Low, David A. Lesch, Paul M. Dosek, Syed A. Faheem, Yune D.T. Le, Craig M. Jensen, Vidvuds Ozolins, Blanka Magyari-Kope, and C. Wolverton.

"High Throughput Screening of Complex Metal Hydrides for Hydrogen Storage," Fall Materials Research Society Meeting, Symposium A5.5, Boston, Nov. 30, 2005, Gregory 
J. Lewis, J. W. Adriaan Sachtler, John J. Low, David A. Lesch, Syed A. Faheem, Paul M. Dosek, Lisa M. Knight, and Craig M. Jensen

"High Throughput Screening of Complex Metal Hydrides for Hydrogen Storage," submitted to MRS Proceedings, Gregory J. Lewis, J. W. Adriaan Sachtler, John J. Low, David A. Lesch, Syed A. Faheem, Paul M. Dosek, Lisa M. Knight, and Craig M. Jensen

"High Throughput Screening of Complex Metal Hydrides for Hydrogen Storage," Fall Materials Research Society Meeting, Symposium A5.5, Boston, Nov. 30, 2005, Gregory J. Lewis, J. W. Adriaan Sachtler, John J. Low, David A. Lesch, Syed A. Faheem, Paul M. Dosek, Lisa M. Knight, and Craig M. Jensen

"High Throughput Screening of Complex Metal Hydrides for Hydrogen Storage," submitted to MRS Proceedings, Gregory J. Lewis, J. W. Adriaan Sachtler, John J. Low, David A. Lesch, Syed A. Faheem, Paul M. Dosek, Lisa M. Knight, and Craig M. Jensen

"A Novel Li-Based Hydrogen Storage System," Presentation at MH2006 conference, Kanaapali, HI, Oct 1-6, 2006, by Jun Yang, Andrea Sudik, Donald Siegel, Devin Halliday, Andy Drews, Roc Carter, Christopher Wolverton, Gregory J. Lewis, J. W. A. Sachtler, John J. Low, Syed A. Faheem, David A. Lesch, and Vidvuds Ozolins

"Global Optimization of Complex Anionic Hydride Crystal Structures," Presentation at MH2006 conference, Kanaapali, HI, Oct 1-6, 2006, by E.H. Mazoub and V. Ozolins.

"High Throughput Screening of a Novel Ternary Complex Hydride System," Presentation at MH2006 conference, Kanaapali, HI, Oct 1-6, 2006, by G.J. Lewis, J.W.A. Sachtler, J.J. Low, D.A. Lesch, S.A. Faheem, P.M. Dosek, L.M. Knight, L. Halloran, C.M. Jensen, Jun Yang, Andrea Sudik, Donald Siegel, Chris Wolverton, Vidvuds Ozolins,Shu Zhang

"Transition Metal Borohydride Complexes as Reversible Hydrogen Storage Materials," Presentation at MH2006 conference, Kanaapali, HI, Oct 1-6, 2006, by G. Severa, J. Eliseo, and C.M. Jensen

"Developments in Advanced Borohydride Materials for Hydrogen Storage," Poster at MH2006 conference, Kanaapali, HI, Oct 1-6, 2006, by Jennifer R. Eliseo and C.M. Jensen

"High Throughput Screening of Complex Hydrides for Hydrogen Storage," Poster at MH2006 conference, Kanaapali, HI, Oct 1-6, 2006, by J.W.A. Sachtler, G.J. Lewis, J.J. Low, D.A. Lesch, S.A. Faheem, P.M. Dosek, L.M. Knight, and C.M. Jensen

"Virtual High Throughput Screening of Complex Hydrides for Hydrogen Storage," Poster at MH2006 conference, Kanaapali, HI, Oct 1-6, 2006, by John J. Low, J.W. Adriaan Sachtler, Gregory J. Lewis, David A. Lesch, and Craig M. Jensen

"First-Principles Studies of Thermodynamic and Structural Properties of the Li-Mg-N-H System," Presentation at MH2006 conference, Kanaapali, HI, Oct 1-6, 2006, by A. Akbarzadeh, C. Wolverrton, and V. Ozolins 
"First-Principles Studies of Thermodynamic and Structural Properties of the Li-Mg-N-H System," Presentation at the MRS Fall Meeting in Boston, MA, November 27 -

December 1, 2006, by A. Akbarzadeh, C. Wolverton, and V. Ozolins

c. Other public releases of results

"Discovery of Novel Complex Metal Hydrides for Hydrogen Storage through Molecular Modeling and Combinatorial Methods," presentation to the $\mathrm{H}_{2}$ Storage Tech Team Meeting, 3/18/2004, Detroit, MI by J.J. Low.

"Discovery of Novel Complex Metal Hydrides for Hydrogen Storage Through Molecular Modeling and Combinatorial Methods," presentation to the $\mathrm{H}_{2}$ Storage Tech Team Meeting, 1/20/2004, Detroit, MI by Gregory J. Lewis.

"Discovery Of Novel Complex Metal Hydrides For Hydrogen Storage Through Molecular Modeling And Combinatorial Methods," Presentation to FreedomCAR Tech-Team, Detroit MI, January 12, 2006, presented by J.W.A. Sachtler

"Discovery of Novel Complex Metal Hydrides for Hydrogen Storage Through Molecular Modeling And Combinatorial Methods," U.S. DOE Hydrogen Program Annual Merit Review, May 18, 2006, Presented by G.J. Lewis

"Predictions of New Hydrogen Storage Compounds and Mixtures," invited talk given at the Theory Focus Session on Hydrogen Storage Materials, held in conjunction with the U.S. DOE Hydrogen Program Annual Merit Review, May 18, 2006, V. Ozolins

"First-Principles Computational Search for Reversible Room-Temperature Hydrides," poster presented at the U.S. DOE Hydrogen Program Annual Merit Review, May 16-19, 2006, V. Ozolins

"High Throughput/Combinatorial Screening of Hydrogen Storage Materials: UOP Approaches," Adriaan Sachtler; DOE Meeting on High Throughput/Combinatorial Analysis of Hydrogen Storage Materials, June 26, 2007

"Discovery of Novel Complex Metal Hydrides for Hydrogen Storage through Molecular Modeling and Combinatorial Methods," Gregory J. Lewis, J. W. A. Sachtler, John J. Low, David A. Lesch, Paul Dosek, Syed Faheem, Lisa M. Knight, Leon Halloran; DOE Hydrogen Program Peer Review, Washington, D.C., June 9, 2008.

d. Inventions/Patent Applications, licensing agreements

Two patents were filed and have issued as a result of this project:

(1) "High Density Hydrogen Storage Material," USP 7,678,362; C.M. Wolverton, G.J. Lewis, and J.J. Low, assigned to UOP LLC and Ford Global technologies, LLC.

(2) "Multi-Component Hydrogen Storage Material," USP 7,790,133; S.A. Faheem, G.J. Lewis, J.W.A. Sachtler, J.J. Low, D.A. Lesch, P.M. Dosek, C.M. Wolverton, D.J. Seigel, A.C. Sudik, and J. Yang, assigned to UOP LLC, and Ford Global Technologies, LLC. 


\section{VHTS COMPUTER MODELING DETAILS}

The following information for the VHTS modeling work carried out for the Project can be found in Appendix B:

a. Model description, key assumptions, version, source and intended use

b. Performance criteria for the model

c. Test results that demonstrate the model performance criteria were met

d. Theory behind the model, expressed in non-mathematical terms

e. Mathematics to be used, including formulas and calculation methods

f. A summary of theoretical strengths and weaknesses for this peer-reviewed approach

g. Hardware requirements

h. References to model code

\section{REFERENCES}

\footnotetext{
${ }^{1}$ Xiong, Z.; Hu, G.; Chen. P., Adv. Mater., 2004, 16, 1522.

${ }^{2}$ Luo, W., J. Alloys Compd., 2004, 381, 284.

${ }^{3}$ Vajo, J. J.; Skeith, S. L.; Mertens, F., J. Chem. Phys. B, 2005, 109, 3719.

${ }^{4}$ a) Meissner, G. P.; Scullin, M. I.; Balogh, M. P.; Pinkerton, F. E.; Meyer, M. S., J. Chem. Phys. B, 2006, 110, 4186; b) Fillinchuk, Y. E.; Yvon, K.; Meissner, G. P.; Pinkerton, F. E.; Balogh, M. P., Inorg. Chem., 2006, 45, 1433.

${ }^{5}$ Chater, P. A.,; David, W. I. F.; Johnson, S. R.; Edwards, P. P.; Anderson, P. A., Chem. Comm., 2006, 23, 2439

${ }^{6}$ G. Sandrock, S. Suda, L. Schlapbach, in L. Schlapbach (ed.), Hydrogen in Intermetallic Compounds II, Topics in Applied Physics, Vol. 76, Springer-Verlag, 1992, p. 197, Chapter 5.

${ }^{7}$ G. Sandrock, in Y. Yurum (ed.): Hydrogen Energy Systems: Production and Utilization of Hydrogen and Future Aspects, NATO ASI Series, Kluwer Academic Publishers, 1994, p 253.

${ }^{8}$ B. Bogdanovic, M. Schwickardi (to Studiengesellschaft Kohle mgH): US Patent Appln S.N. 08/983.320 (1998), corresponding to PCT-EP 96/03333 076; German patent application 19526 434.7 (19 July 1995).

${ }^{9}$ B. Bogdanovic, M. Schwickardi, J. Alloys Comp. 1997, 253, 1.

${ }^{10}$ C.M. Jensen, R.A. Zidan, N. Mariels, A.G. Hee, C. Hagen, Int. J. Hydrogen Energy, 1999, 24 , 461.

${ }_{11}^{11}$ R.A. Zidan, S. Takara, A.G. Hee, C.M. Jensen, J. Alloys Comp. 1999, 285, 119.

12 B. Bogdanovic, R.A. Brand, A. Marjanovic, M. Schwickardi, J. Tolle, J. Alloys Comp. 2000, 302, 36.

${ }^{13}$ K.J. Gross, S. Guthrie, S. Takara, G. Thomas, J. Alloys Comp. 2000, 297, 270.

${ }_{14}^{14}$ A. Zaluska, L. Zaluski, J.O. Ström-Olsen, J. Alloys Comp. 2000, 298, 125.

${ }^{15}$ C.M. Jensen and K.J. Gross, Appl. Phys. A. 2001, 72, 213.

${ }^{16}$ B. Bogdanovic and M. Schwickardi, Appl. Phys. A. 2001, 72, 221.

${ }^{17}$ K.J. Gross, C.M. Jensen, G.J. Thomas, J. Alloys Comp. 2002, 330-332, 683.

${ }^{18}$ G. Sandrock, K. Gross, G. Thomas, C. Jensen, D. Meeker, S. Takara, J. Alloys Comp. 2002, 330-332, 696.

${ }_{19}$ G.J. Thomas, K.J. Gross, N.Y.C. Yang, C. M. Jensen, J. Alloys Comp. 2002, 330-332, 702.

${ }^{20}$ G.P. Meisner, G.G. Tibbetts, F.E. Pinkerton, C.H. Olk, M.P. Balogh, J. Alloys Comp. 2002, 337, 254.

${ }^{21}$ D. Sun, T. Kiyobayashi, H. T. Takeshita, N. Kuriyama, C. M. Jensen, J. Alloys Comp. 2002, 337, L8.
} 
${ }^{22}$ C.M. Jensen, D. Sun, B. Lewandowski, K.K. Kumashiro, W.P. Niemczura, D. Morales-Morales, Z. Wang, Catalytically Enhanced Systems for Hydrogen Storage, in: Proceedings of the 2001 Hydrogen Program Review, Baltimore, MD. 2001.

${ }^{23}$ C.M. Jensen, D. Sun, S.S. Raman, K. Murphy, W.P. Niemczura, K.K. Kumashiro, M. Eberhard, Z. Wang, X.-Q. Gu, Catalytically Enhanced Systems for Hydrogen Storage, in: Proceedings of the 2002 Hydrogen Program Review, Golden, CO. 2002.

${ }^{24}$ Tim Eggeman, "Hydrides" in the "Kirk-Othmer Encyclopedia of Chemical Technology", Online Posting date April 16, 2001.

${ }^{25}$ P. Claudy, B. Bonnetot, J. M. Letoffe, J. Therm. Anal. 1979,15, 119.

${ }^{26}$ M.W. Chase, Jr., "NIST-JANAF Themochemical Tables, Fourth Edition", J. Phys. Chem. Ref. Data, Monograph 9, 1998

${ }^{27}$ A.Zaluska, L. Zaluski, J.O. Strom-Olsen, J. Alloys Comp. 2000, 298, 125.

${ }^{28}$ W. H. Press, B. P. Flannery, S. A. Teukolsky, W.T. Vetterling, "Numerical Recipes (Fortran)", 326.

${ }^{29}$ J. J. Low, J. D. Sherman, L. S. Cheng, R. L. Patton, A. Gupta, R. Q. Snurr, in "Fundamentals of adsorption 7: : proceedings of the Seventh International Conference on Fundamentals of Adsorption", edited by K. Kasumi, et al., IK International, Chiba City JP, 2002.

${ }^{30}$ R.A. Jackson, C.R.A. Catlow, Molecular Simulation, 1988, 1, 207.

31 J.D.Gale, J.Chem.Soc., Faraday Trans. 1997, 93, 629.

${ }^{32}$ Lewis, G. J.; Sachtler, J.W.A.; Low, J. J.; Lesch, D. A.; Faheem, S. A.; Dosek, P. M.; Knight, L. M.; Jensen, C. M. Mater. Res. Soc. Symp. Proc., 2006, 885, 135

${ }^{33}$ Safety precautions were instituted to mitigate a possible hydrogen explosion during the ballmilling step. The ball mills were equipped with blow-out panels to avoid any pressure build-up within the milling housing. If hydrogen is released during milling, another dangerous operation is the extraction of the milling bowl from the mill. Once the clamp is released, hydrogen can escape from the milling bowl and carry flammable powder with it. With $\mathrm{Mg}\left(\mathrm{AlH}_{4}\right)_{2}$, this powder burst into flame upon hitting air, igniting the hydrogen and causing a minor explosion. This was dealt with by developing a shroud, essentially an inverted cup, which fit over the milling bowl within the clamping device. Any material expelled by a hydrogen release would be contained by the shroud and would not spread around the mill. To prevent any fires, a plastic bag connected to a nitrogen gas line was placed over the milling bowl and was purged with nitrogen as the clamp on the milling bowl was loosened. In this inert environment, any hydrogen and powder released would not be able to catch fire.

${ }^{34}$ Schmidt, D. L.; Roberts, C. B.; Reigler, P. F., Inorganic Syntheses, 1973, $14,47$.

${ }^{35}$ Grochala, W; Edwards, P.P., Chem. Rev., 2004, 104, 1283.

${ }^{36}$ Mal'tseva, N.N.; Golovanova, A.I.; Kedrova, N.S.; Minaeva, N.A. Mekhanokhim. Neorg. Khim., $1991,139$.

${ }^{37}$ Mal'tseva, N.N; Golovanova, A.I.; Kedrova, N.S.; Saidov, B.I.; Kuznetsov, N.T. Khim. Neorg. Gidridov. Meeting date 1990, 4, 107.

${ }^{38}$ Mal'tseva, N.N.; Myakishev, K.G.; Saidov, B.I.; Kedrova, N.S.; Gorbacheva, I.I.; Potapova, O.G. Z. Neorg. Khim.,. 1989, 34(6), 1430.

${ }^{39}$ Mal'tseva, N.N.; Kedrova, N.S; Gorobinskii, L.V.; Petrova, L.A.; Makhaev, V.D. Russian J. Coord. Chem,. 1999, 25(4), 246.

${ }^{40}$ Mal'tseva, N.N.; Golovanova, A.I.; Kedrova, N.S.; Gorobinskii, L.V.; Petrova, L.A.; Makhaev, V.D. Khim. Intereskh ustoichivogo razvitiia. 1998, 6 (2-3), 121.

${ }^{41}$ Mal'tseva, N.N.; Sheiko, O.V.; Bakulina, V.M.; Mikheeva, V.I. Russian J. Inorg. Chem., 1970, 15(3), 363.

${ }^{42}$ Mikheeva, V.I.; Mal'tseva, N.N.; Alekseeva, L.S. Russian J. Inorg. Chem., 1968, 13(5), 682.

${ }^{43}$ Jeon, E.; Cho, Y.W. J. Alloy Compd., article in press, 2006.

${ }^{44}$ Boron NMR. Webiste: http://drx.ch.huji.ac.il/nmr/techniques/1d/row2/b.html

${ }^{45}$ Noeth, H.; Wiberg, E.; Winter, L.P. Z. Anorg. Allg. Chem., 1971. 386, 73.

${ }^{46}$ Noeth, H.; Wiberg, E.; Winter, L.P. Z. Anorg. Allg. Chem., 1969, 370(5-6), 209.

${ }^{47}$ Lewis, G. J.; Sachtler, J. W.A.; Low, J. J.; Lesch, D. A.; Faheem, S. A.; Dosek, P. M.; Knight, L. M.; Halloran, L.; Jensen, C. M.; Yang, J.; Sudik, A.; Siegel, D. J.; Wolverton, C.; Ozolins, V.;

Zhang, S., J. Alloys Compd., 2007, 446-447, 355. 
${ }^{48}$ Dye, J. L.; Cram, K. D.; Urbin, S. A.; Redko, M. Y.; Jackson, J. E.; Lefenfeld, M, J. Am. Chem. Soc., 2005, 127, 9338.

${ }^{49}$ Vajo, J. J.; Mertens, F.; Ahn, C. C.; Bowman Jr., R. C.; Fultz, B., J. Phys. Chem. B, 2004, 108, 13977 .

${ }^{50}$ Siegel, D.J.; Wolverton, C.; Ozolins, V., Phys. Rev. B, 2007, 76, 134102.

${ }^{51}$ Yvon, K.; Schefer, J.; Stucki, F., Inorg. Chem., 1981, 20, 2776 


\section{Appendix A}

High Throughput Combinatorial Equipment used in Discovery of Novel Complex Metal Hydrides for Hydrogen Storage through Molecular Modeling and Combinatorial Methods - G014013 


\section{Appendix A: Content}

- MT Hydrogen Storage Assay Equipment

$98-100$

- HT Hydrogen Storage Assay Equipment

$101-125$

- UOP Inert Atmosphere Laboratory

$126-131$

- HT Hydrogen Storage Synthesis Equipment

$132-145$

- Evaluation of Combi Milling

$146-155$

- $\mathrm{NaNH} 2-\mathrm{NaBH} 4-\mathrm{MgH} 2$ attempt in HT Equipment 156 
Medium Throughput Hydrogen Storage Assay Schematic

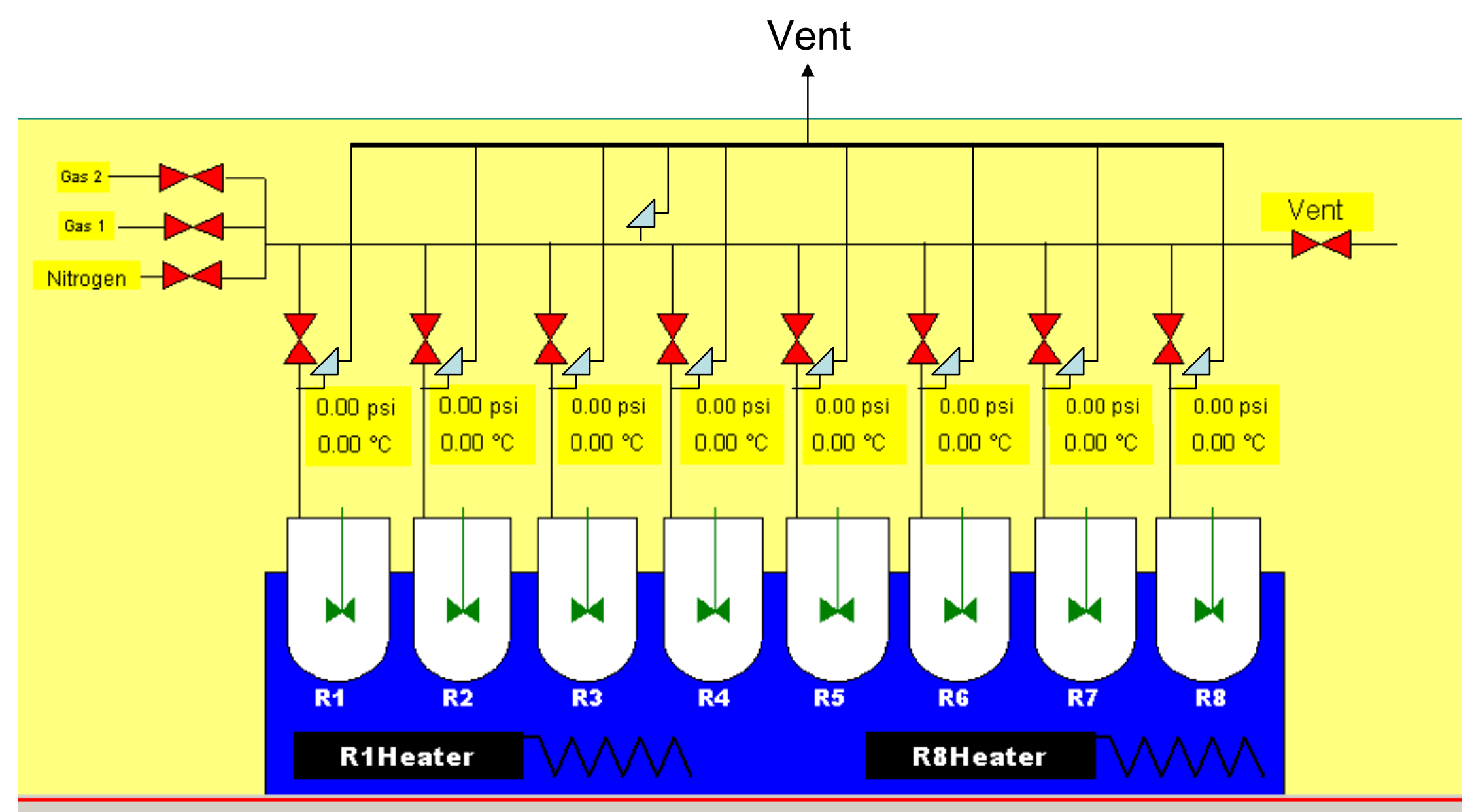




\section{MT Assay in glovebox}

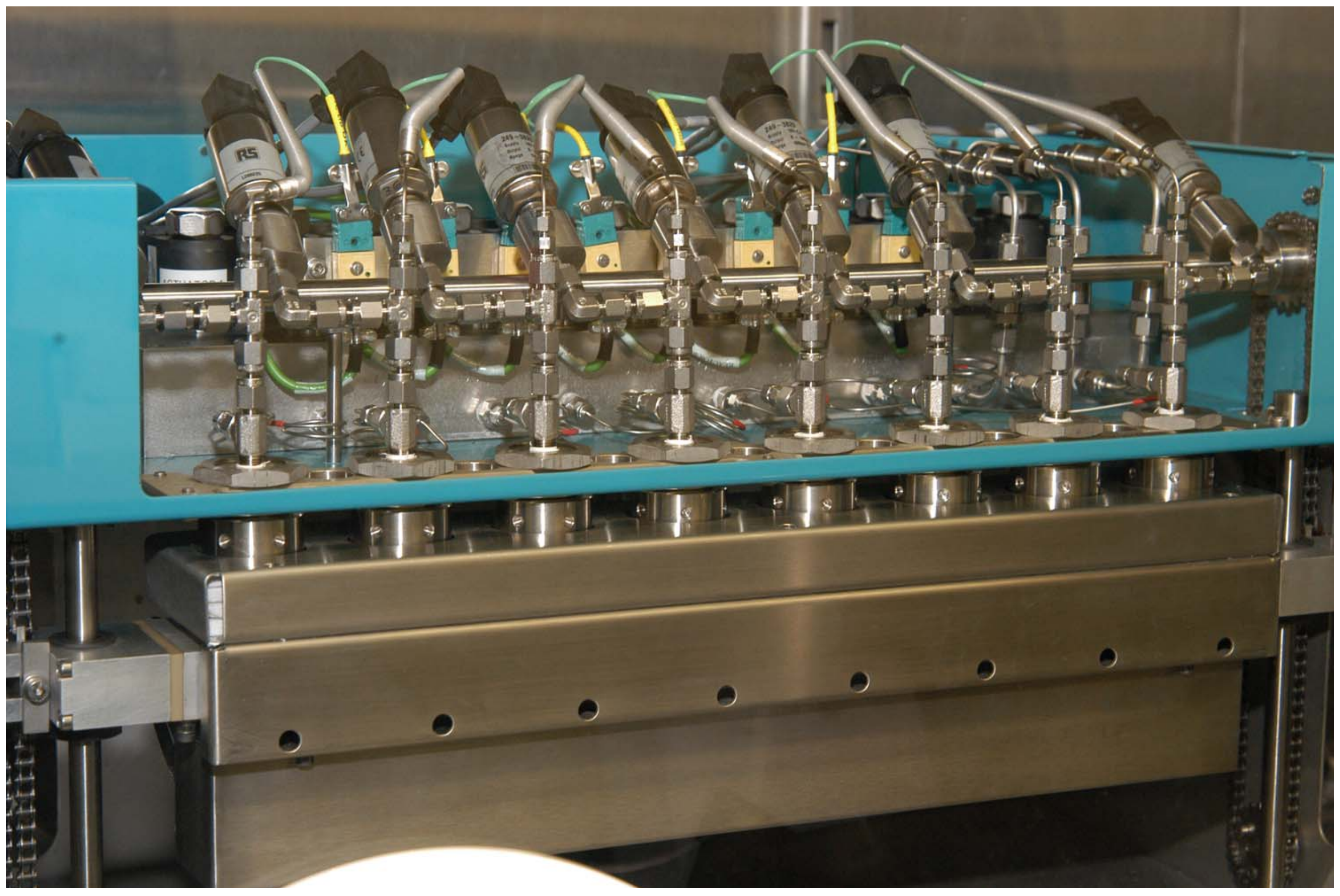


MT Assay in glovebox

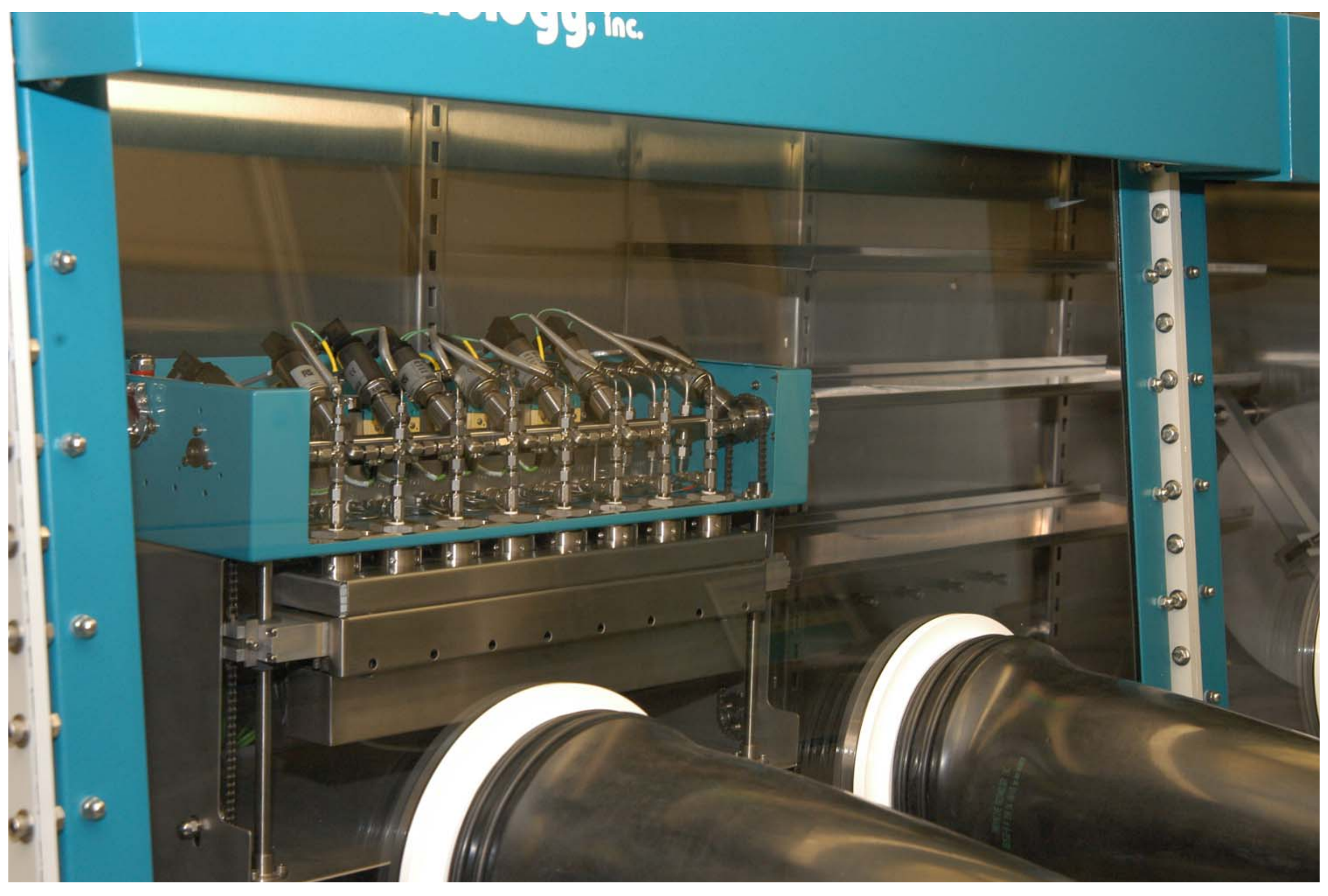


HT Hydrogen Storage Assay 


\section{High-Throughput $\mathrm{H}_{2}$ Storage Assay Concept}

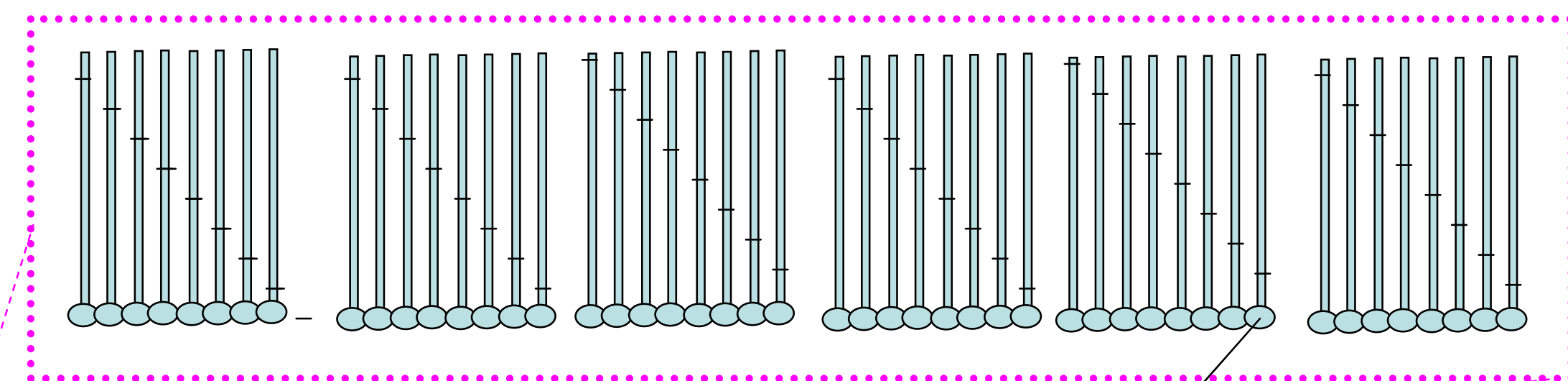

\section{Parallel Detection 48 Reactors}

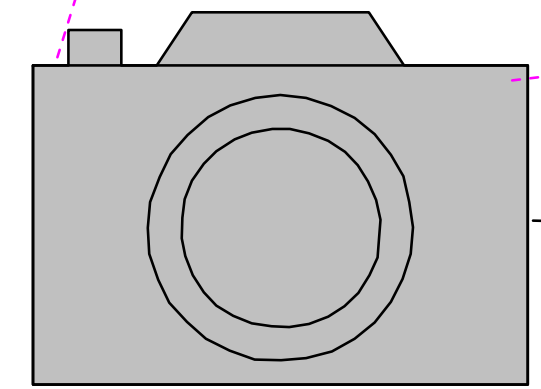

Video Camera

Measurement 1 atm $\rightarrow$ Not EQ Limited

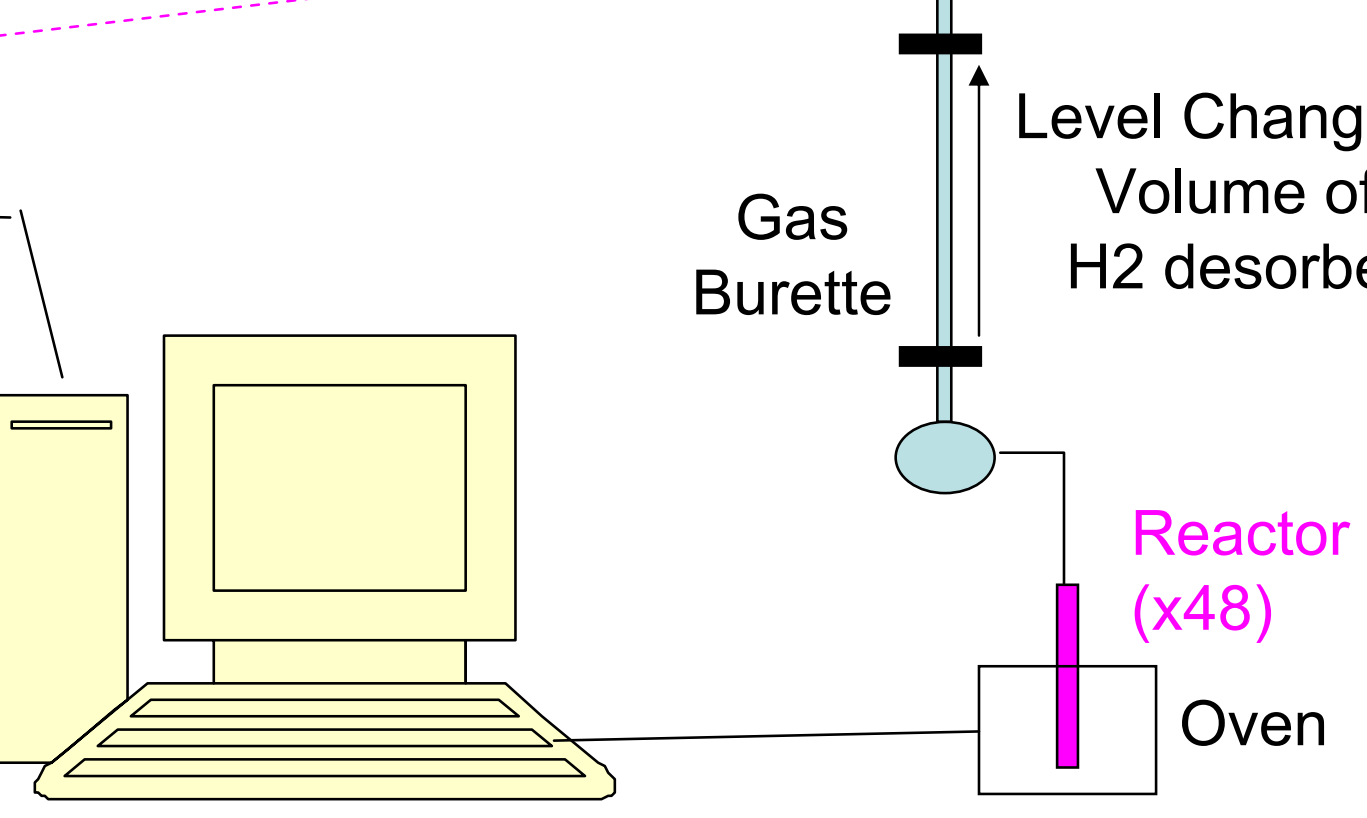




\section{Control Screen}

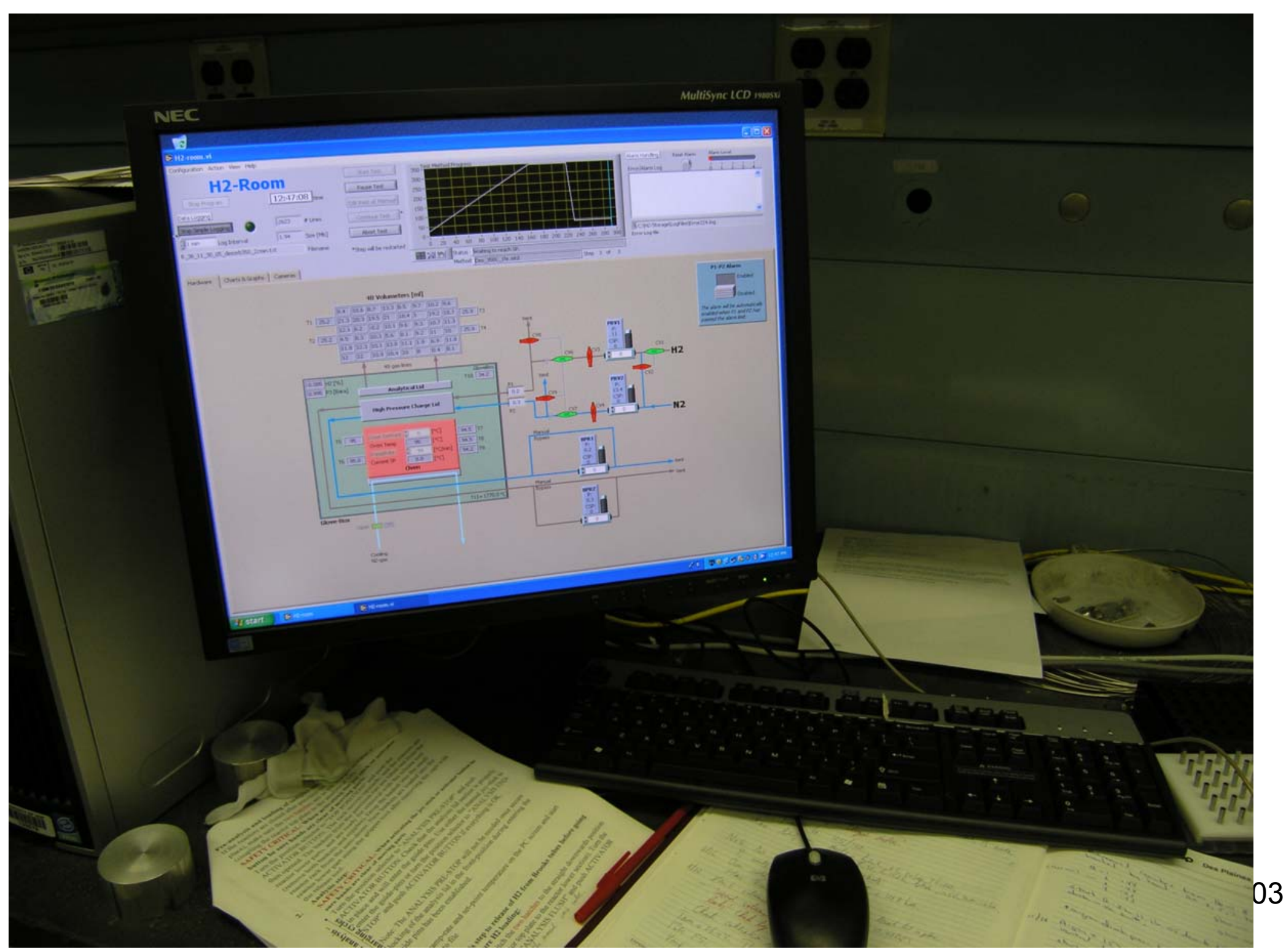




\section{Overview}

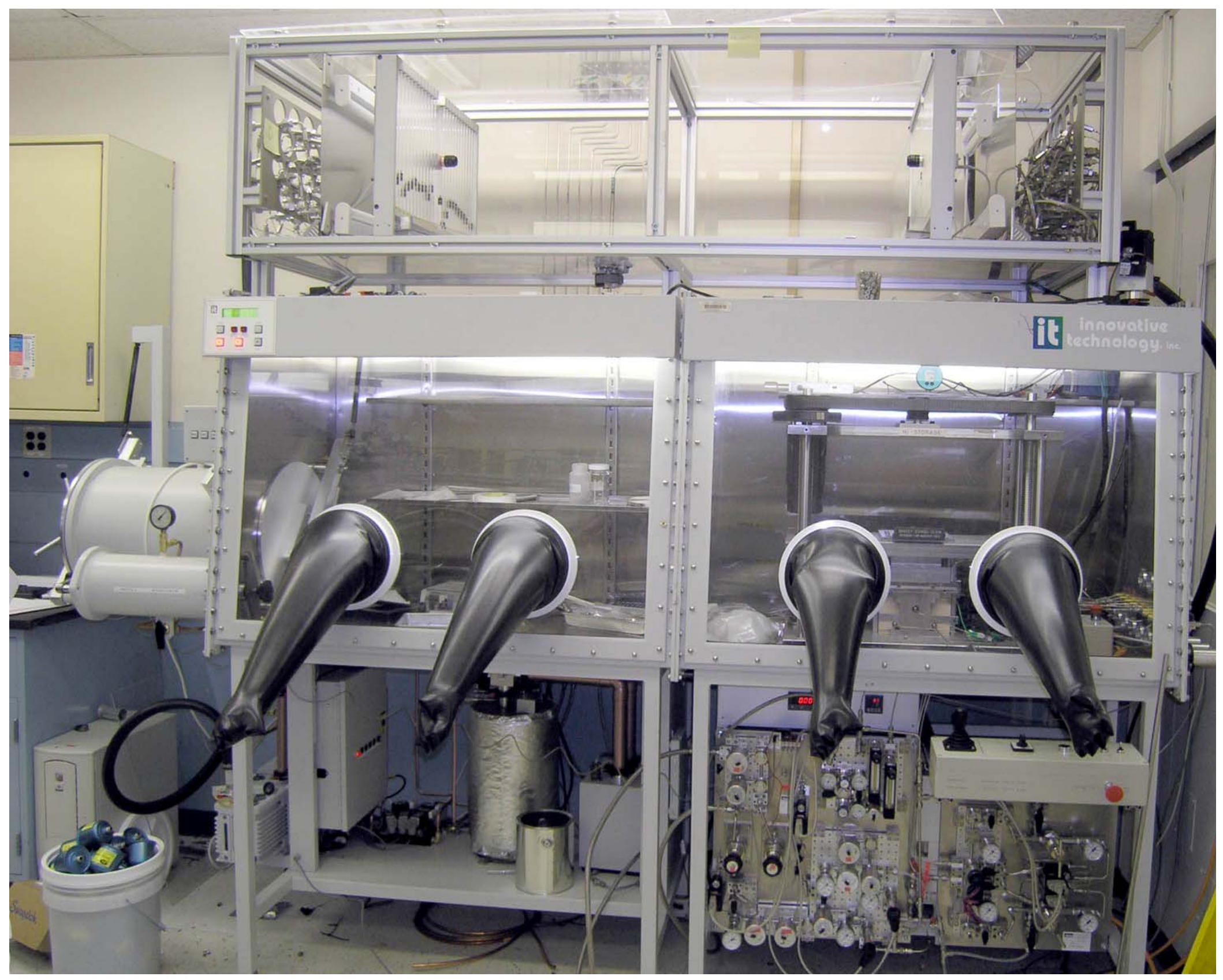




\section{HT Manifold}

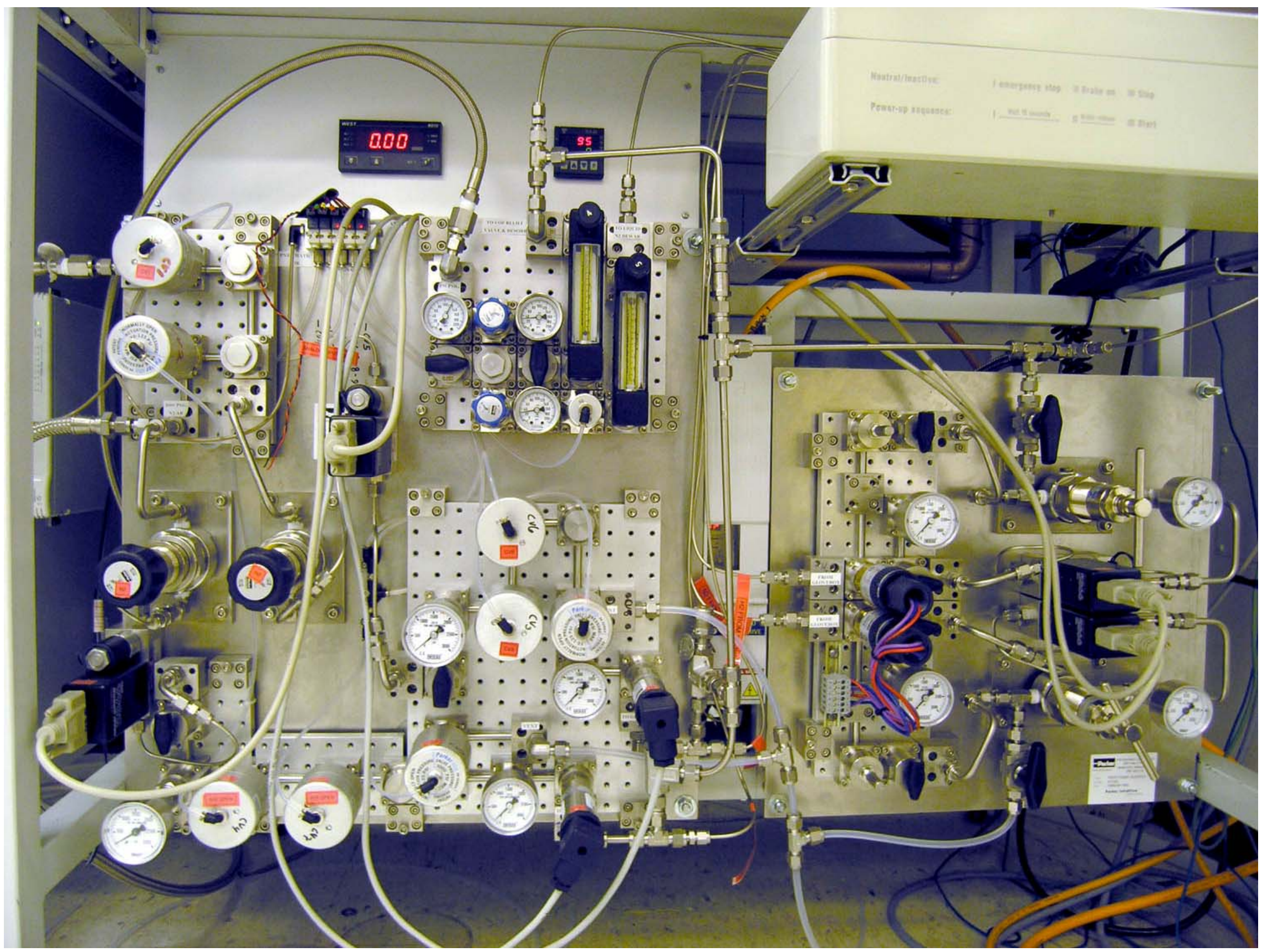


Desorption tubes and one camera; similar setup faces this one

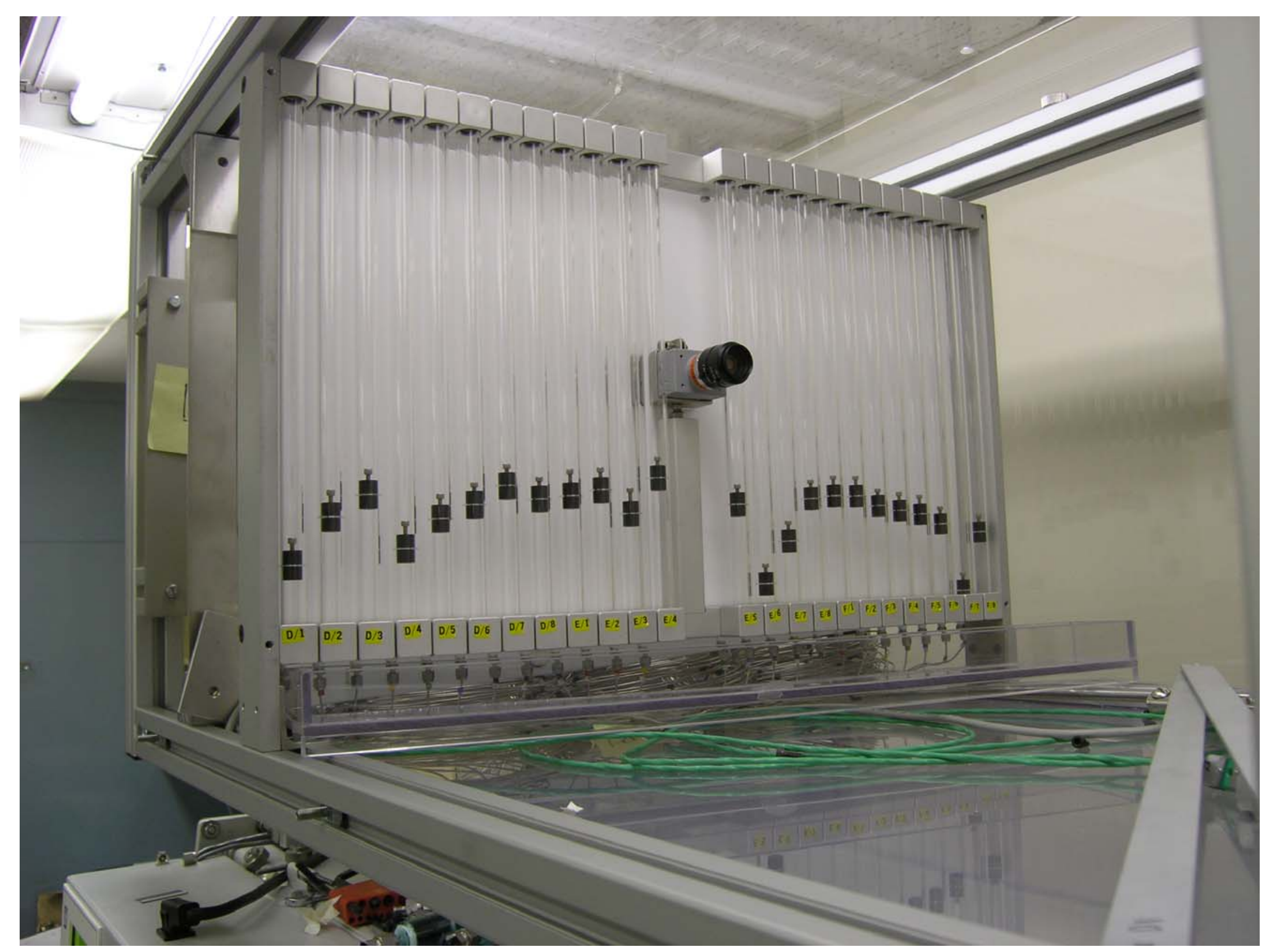


Floating discs with Mercury seals in desorption tubes

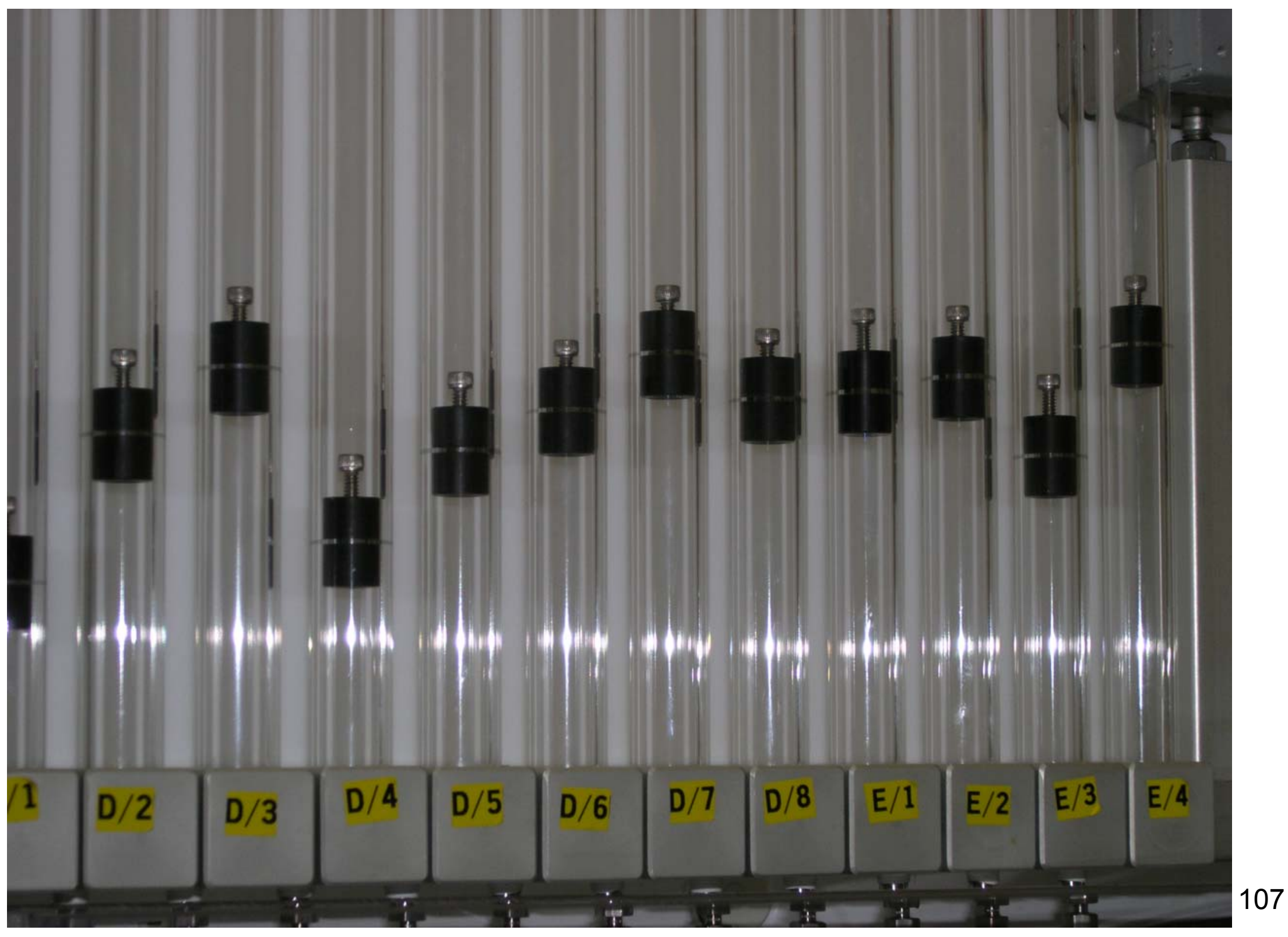




\section{HT Hydrogen Storage Assay}

Reactor Details 


\section{Choice of "reactor" generic part - alt 1: Basket}

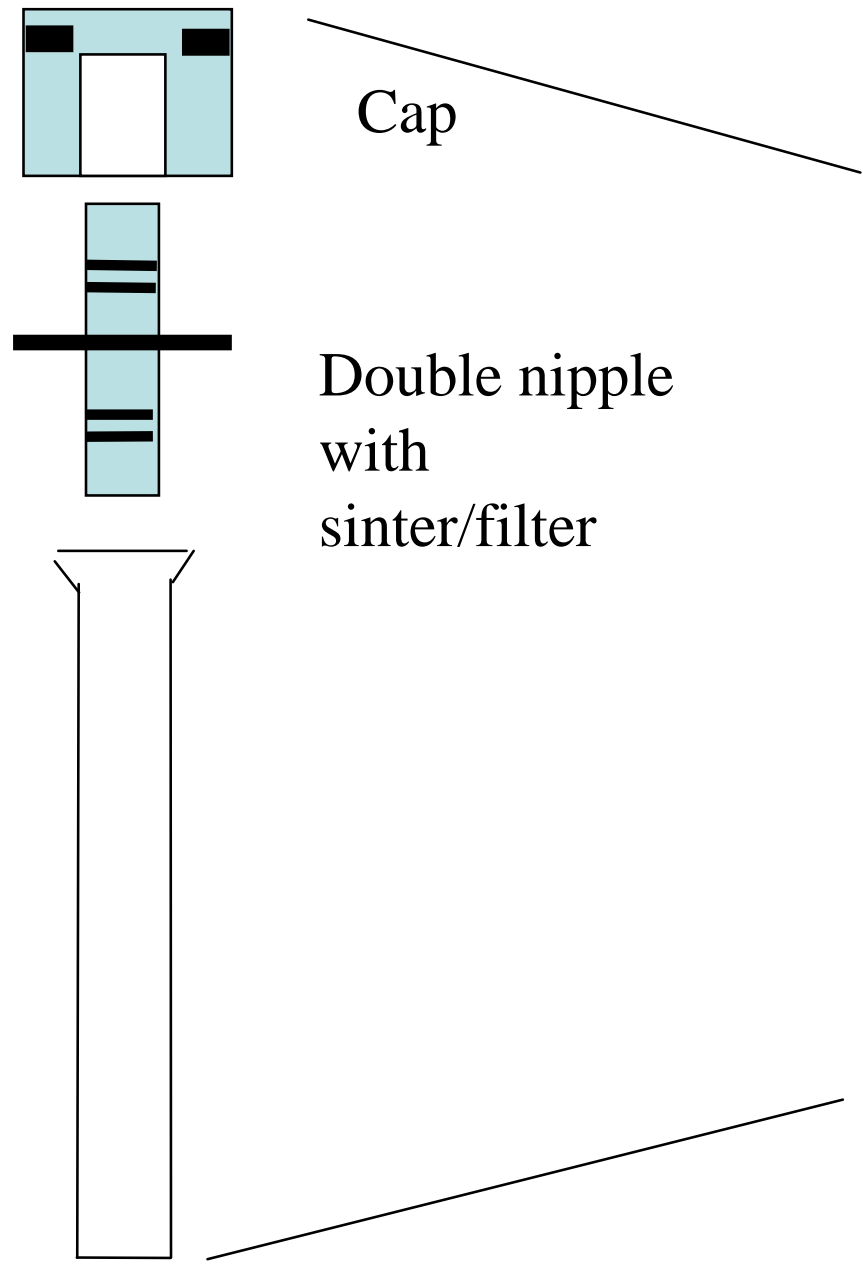

Basket

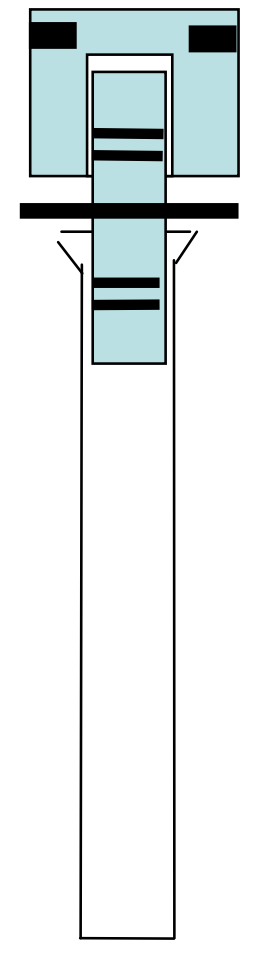

Individual assembly/unit for charging sample in a basket inside a glove box, introducing a filter to avoid fine powder from "fuming" under subsequent handling, and finally capping the unit for weighting in room atmosphere and transfer to a second glove box (inert handling of the sample during the initial workflow) 

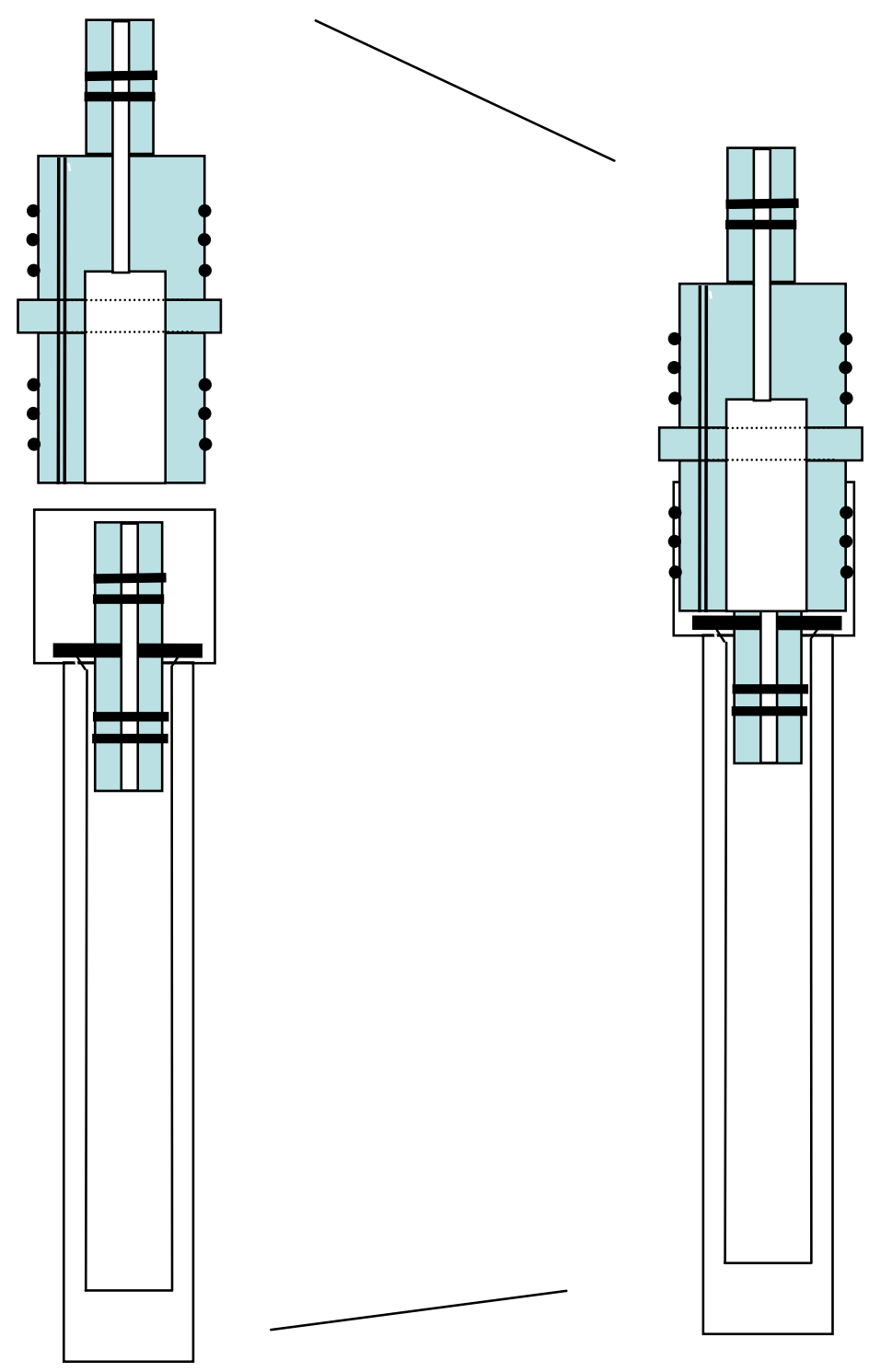

Modified/simplified design that would allow double wall operation during charging

Outer sheathe and basket 
Connect to parallel manifold unit for charging with $\mathrm{H} 2$ and pressurize the double wall with
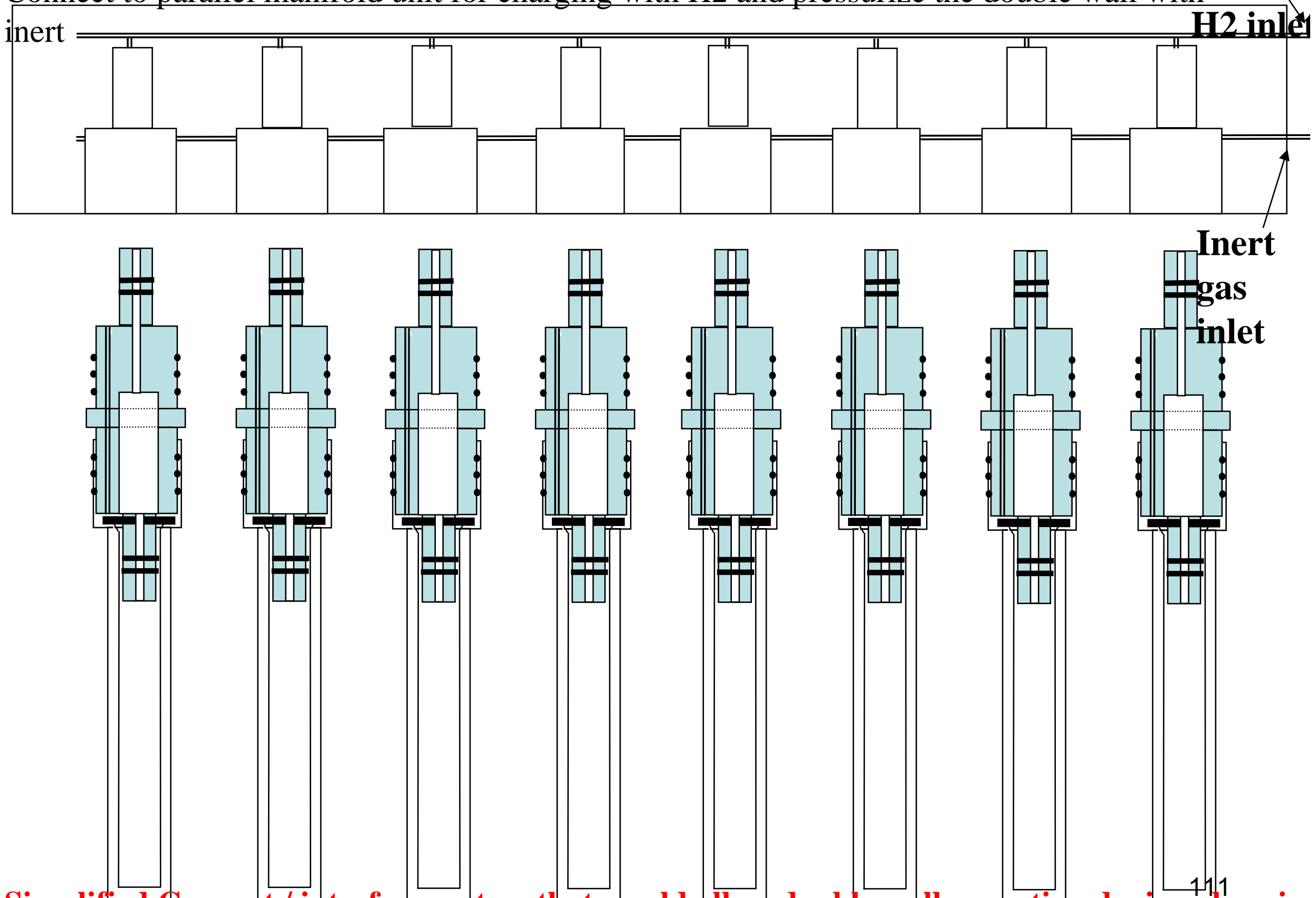

Simplified Conneфt / interface system that would allow double wall operation during charging 
Connect to parallel manifold unit for charging with $\mathrm{H} 2$ and pressurize the double wall with inert

\section{H2 inlet}

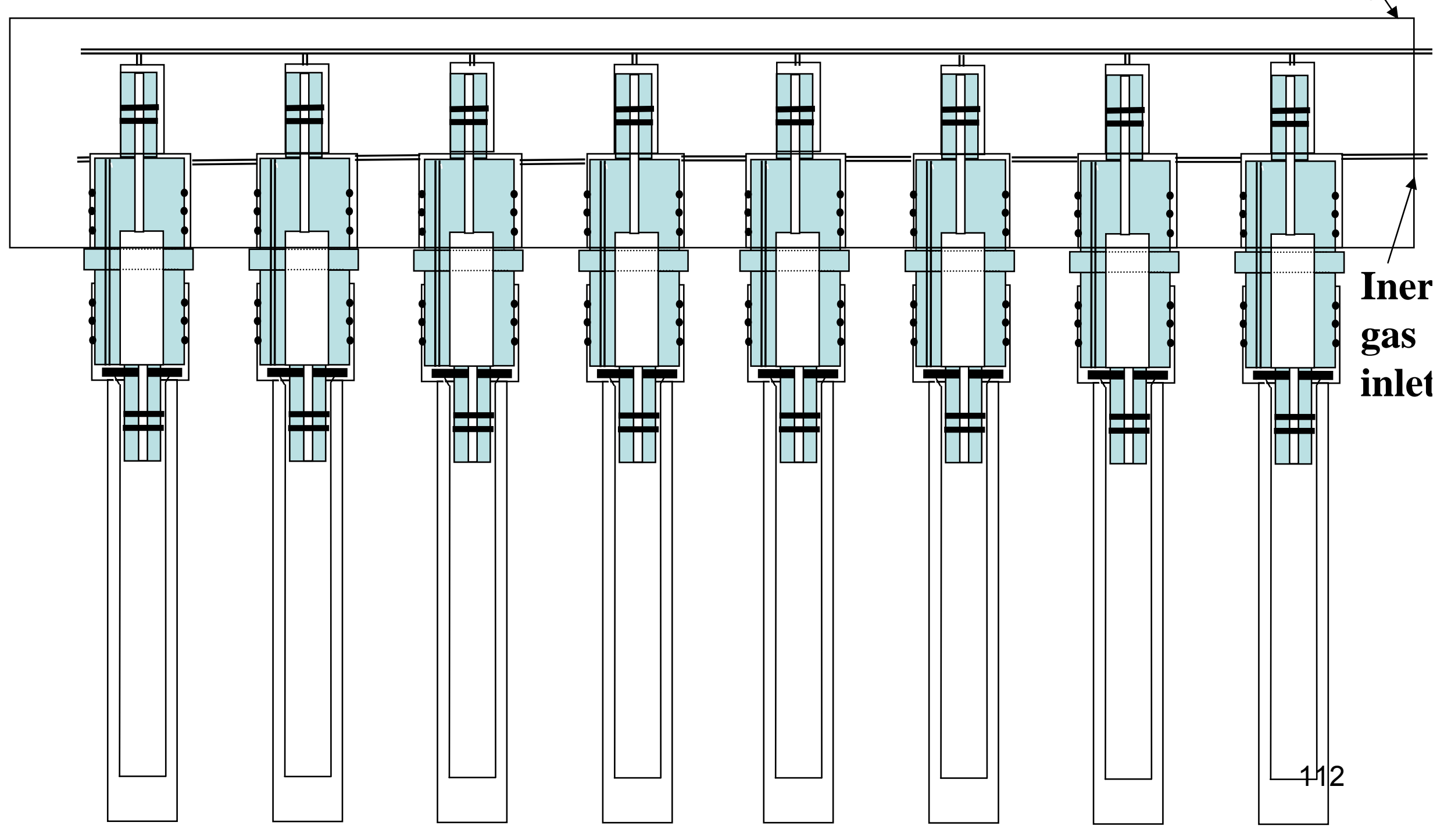


Connect to H2 - analytical interface plate

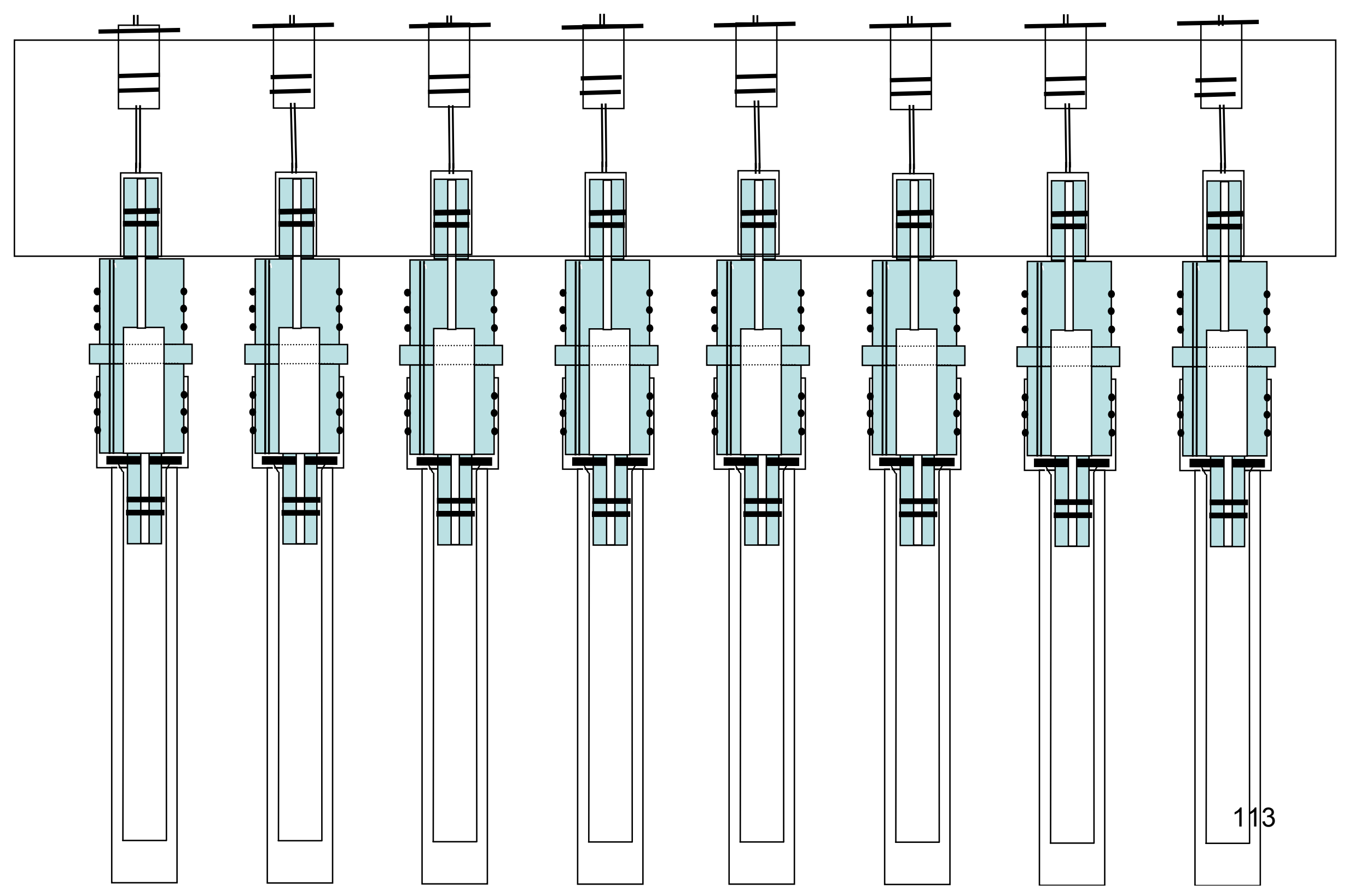


Assembly handling and transfer to Test Assay Glovebox

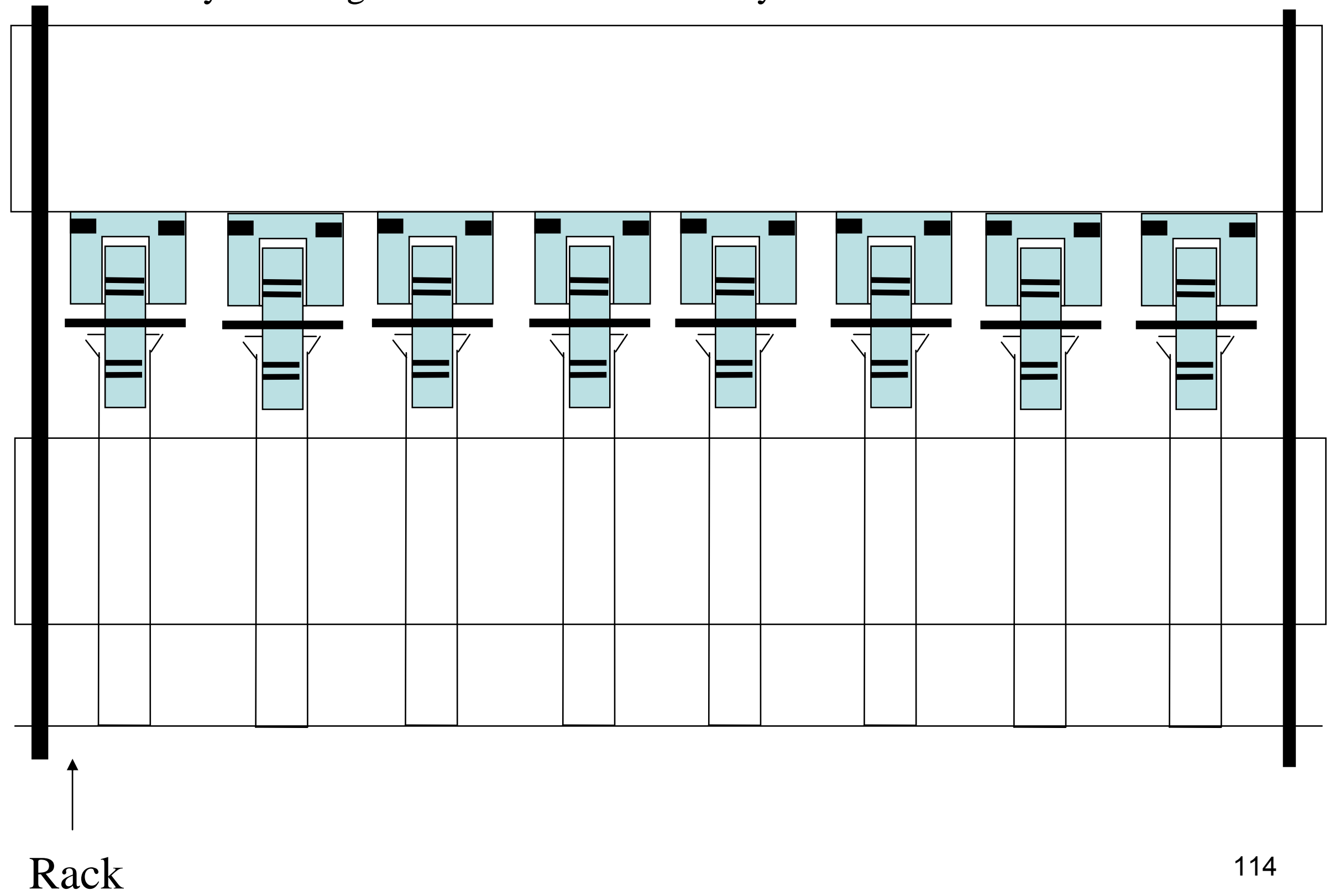


De-capping

Cap grip- and release-combi-plate

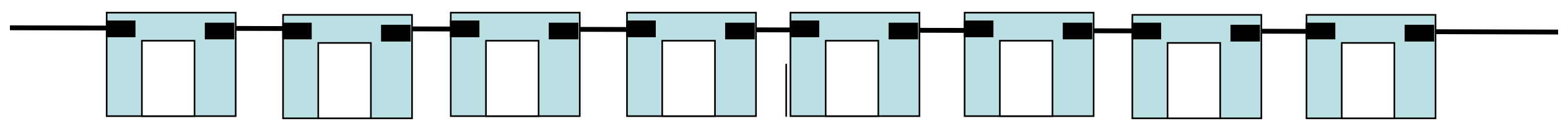

Double nipple hold combi-plate
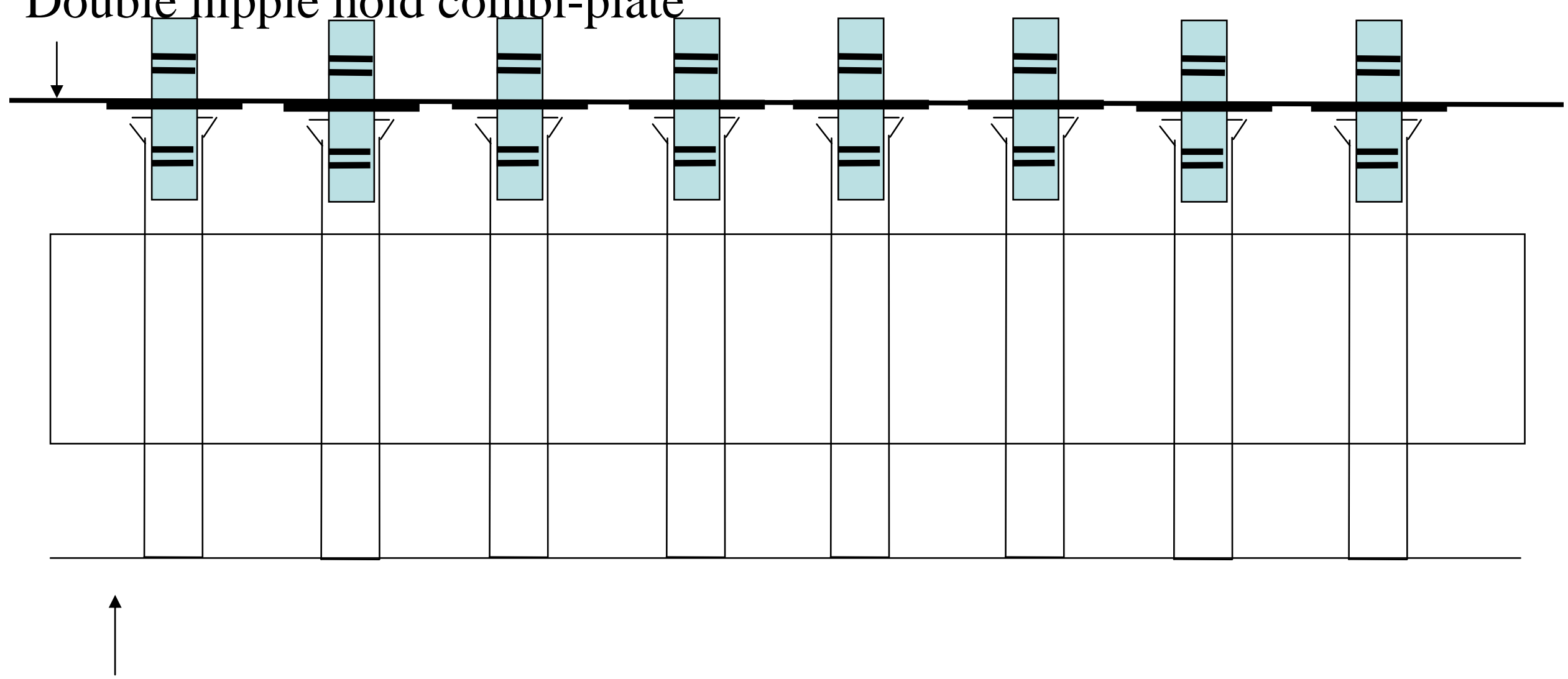

Rack 
Ready for testing or charging or transfer to the reactor outer sheath section
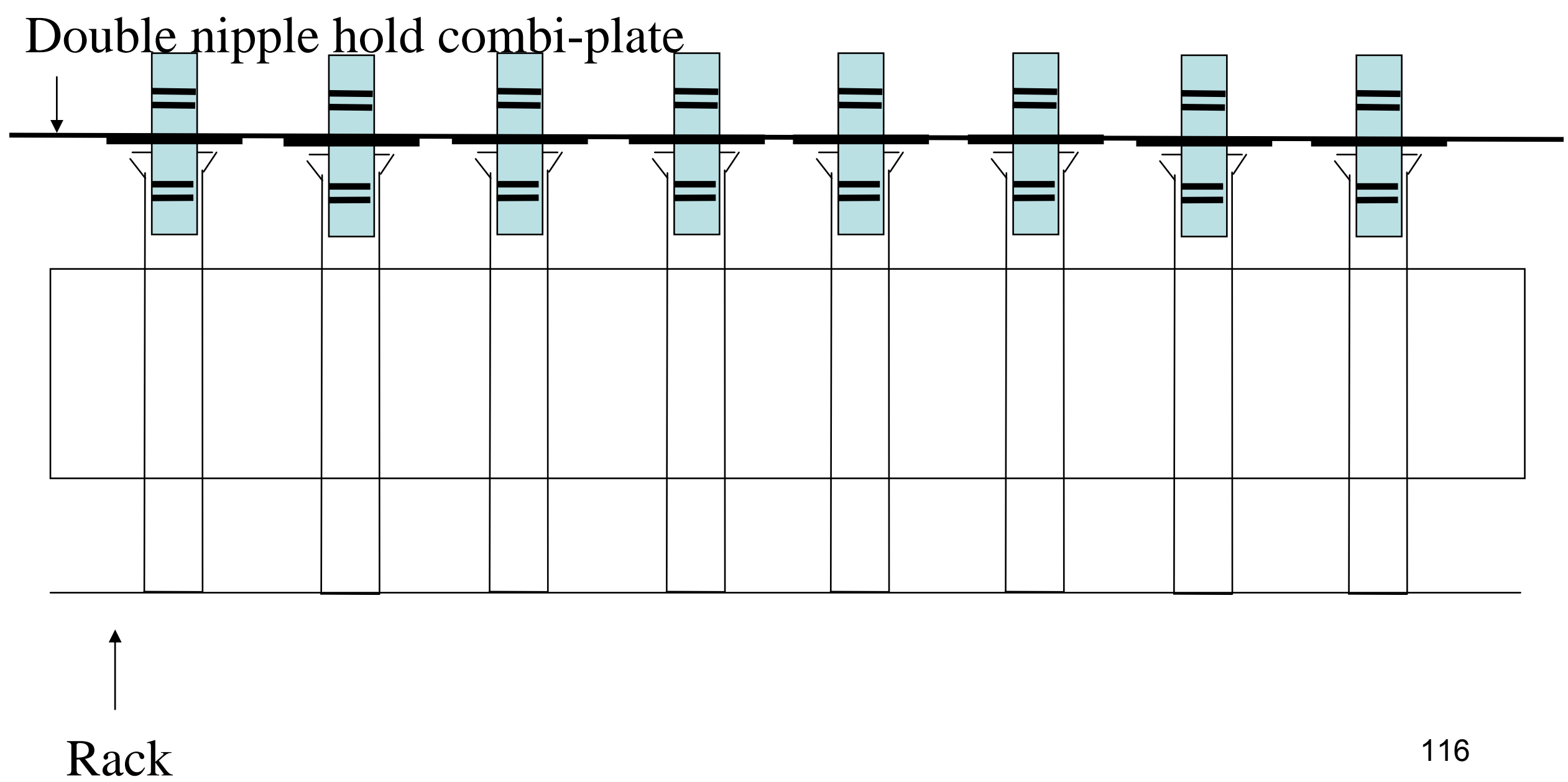

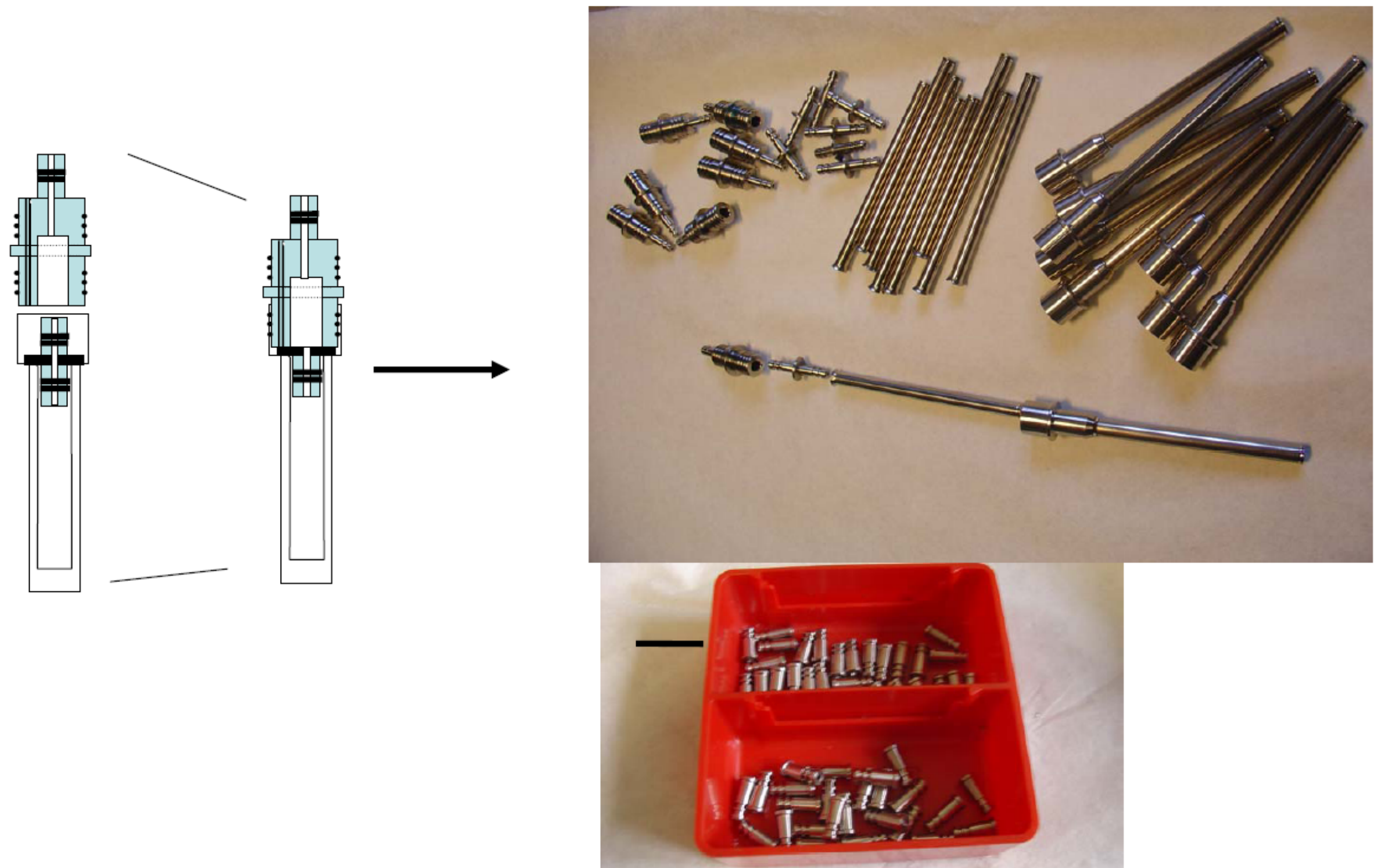

Nipples for analytical manifold 


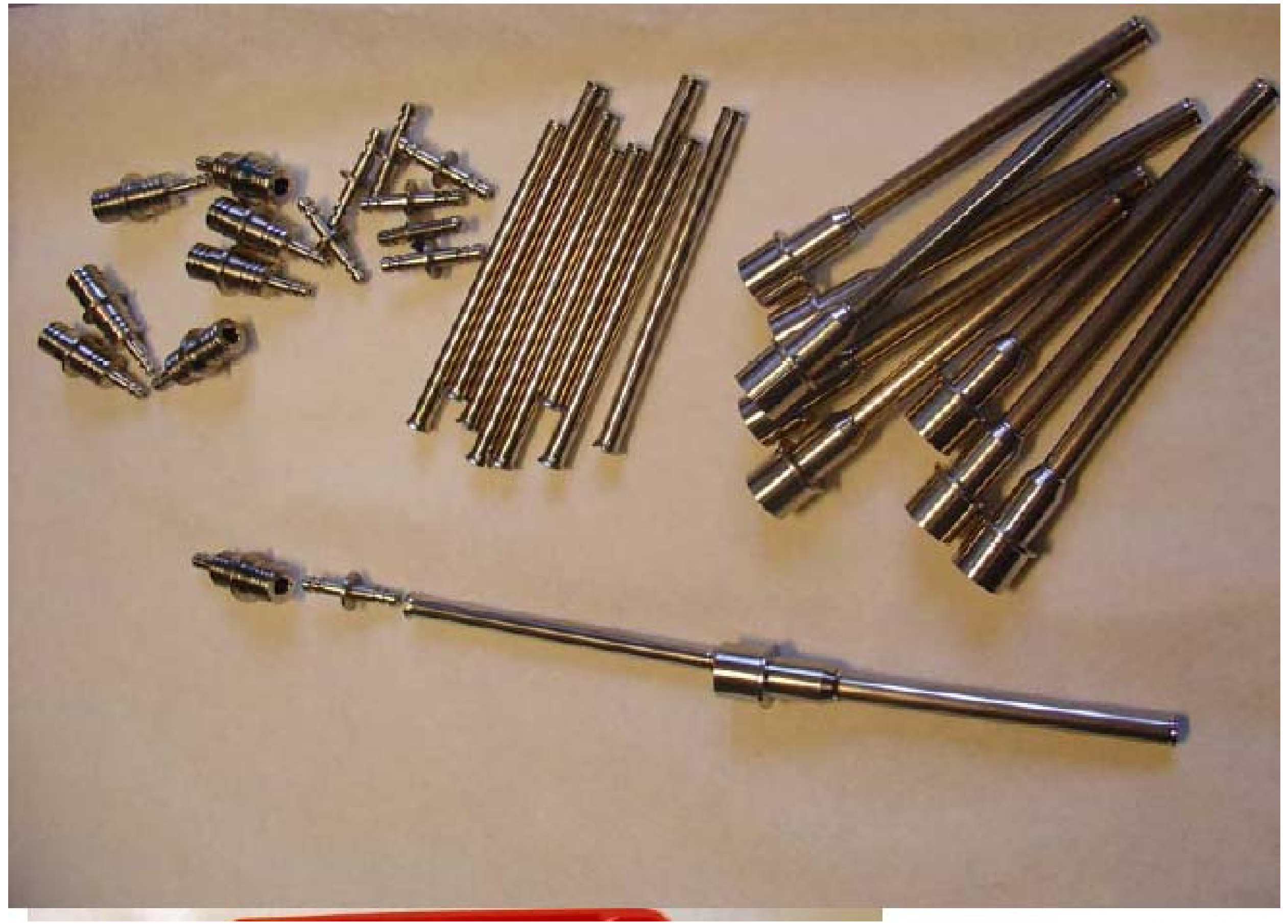


Heavy duty “outer rack” construction secure safe operation with high pressures

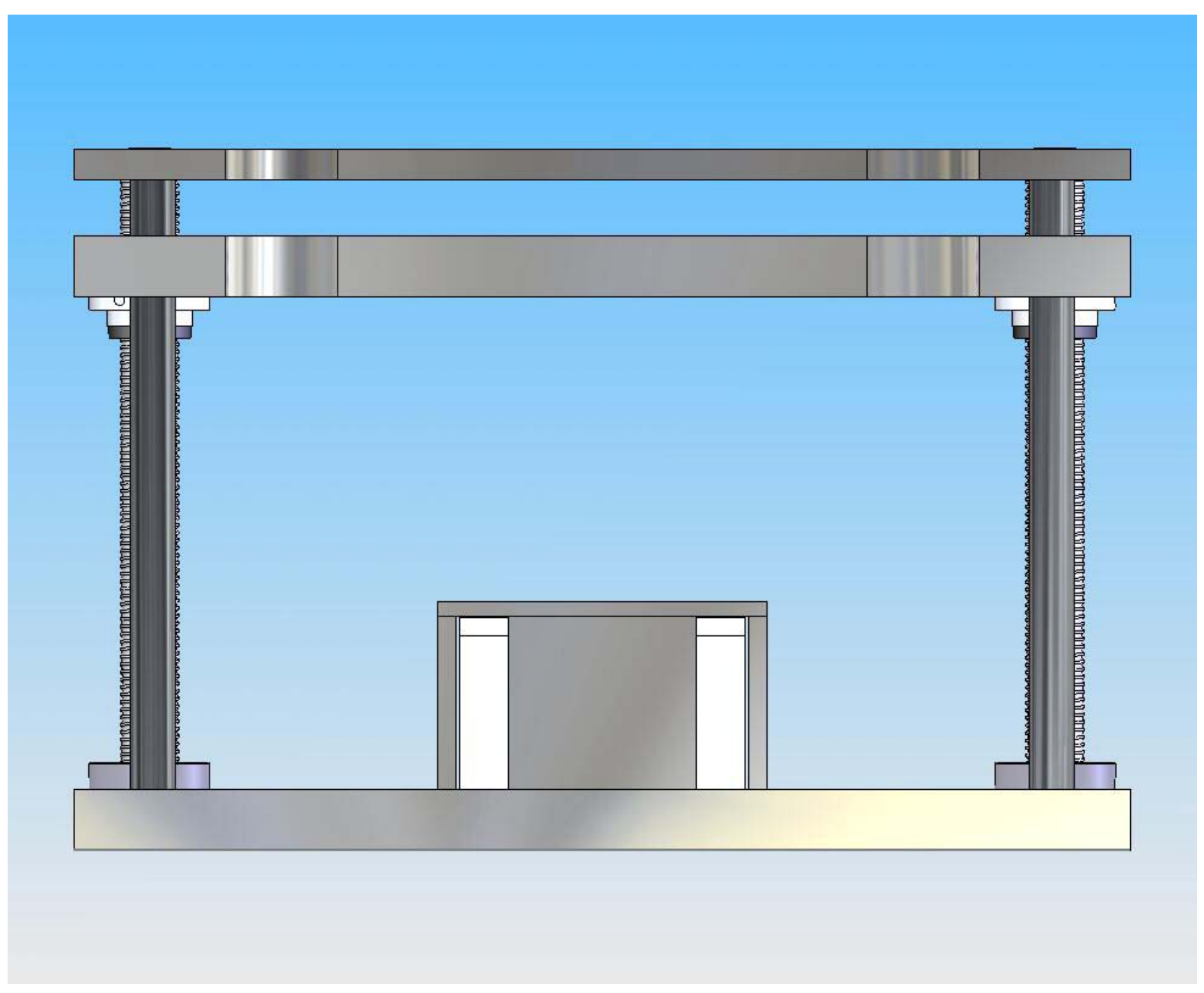


Likely overall dimensions with step motor and wheel indicated

Step motor

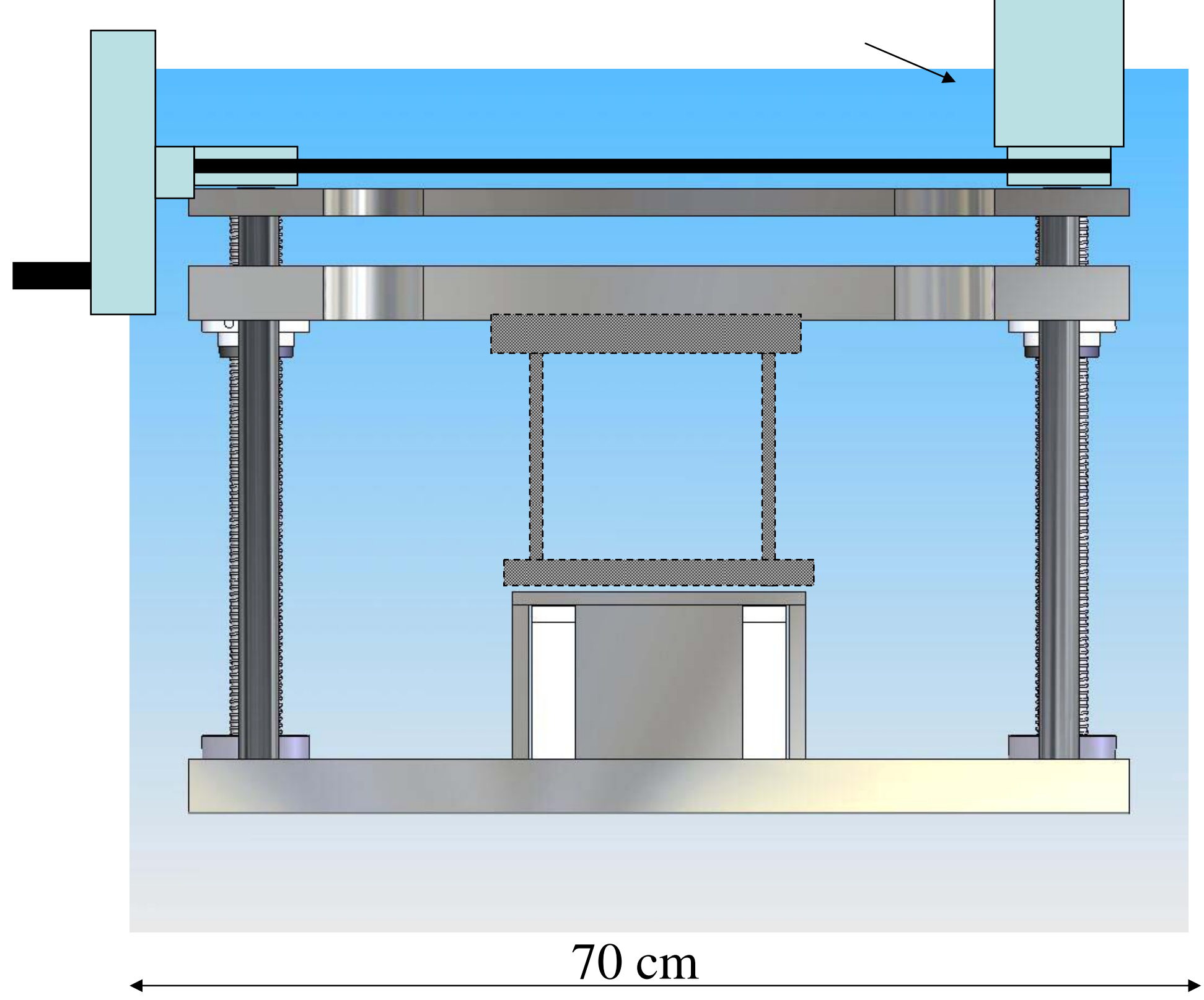

$70 \mathrm{~cm}$ 
3-D view of the outer frame system

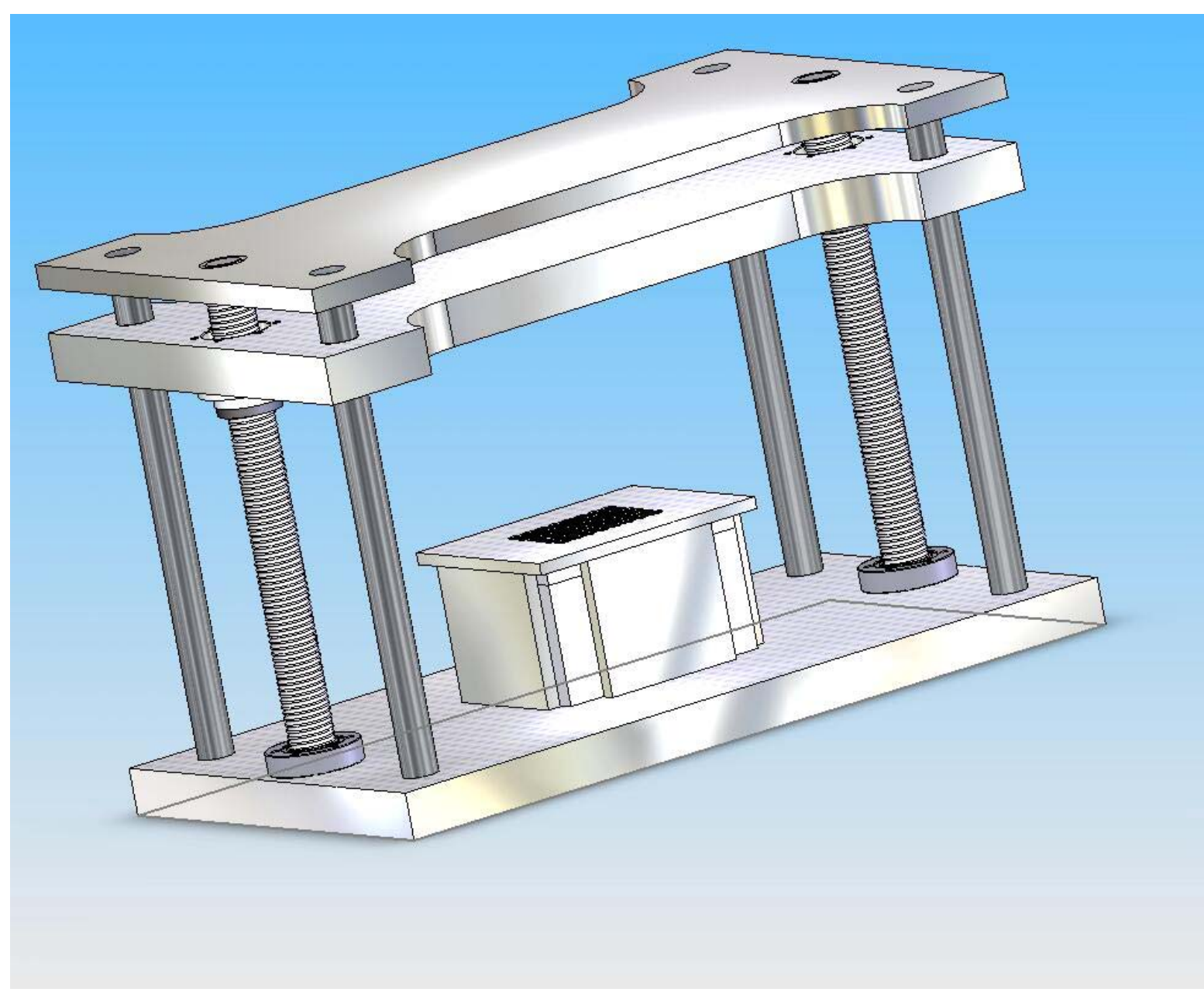




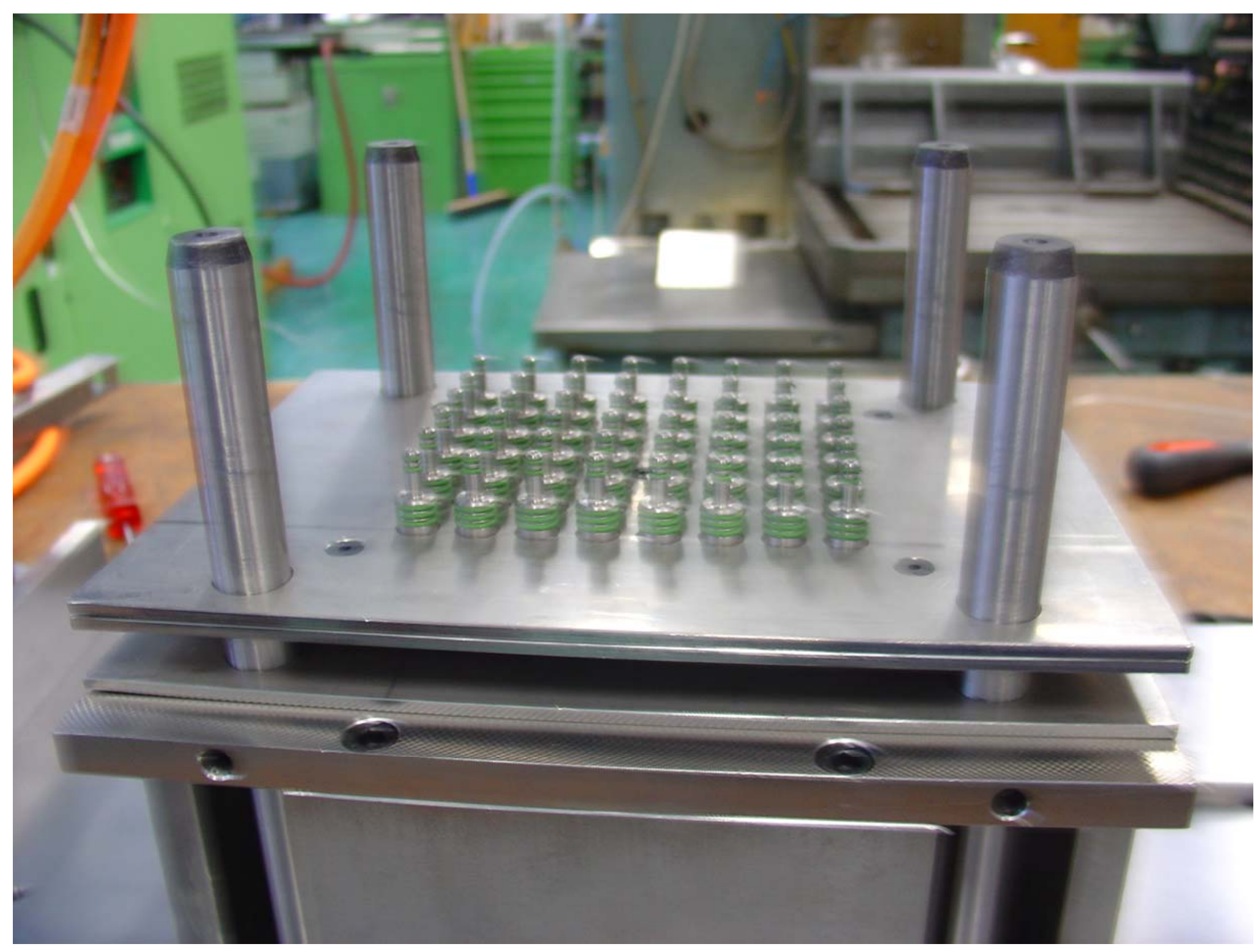




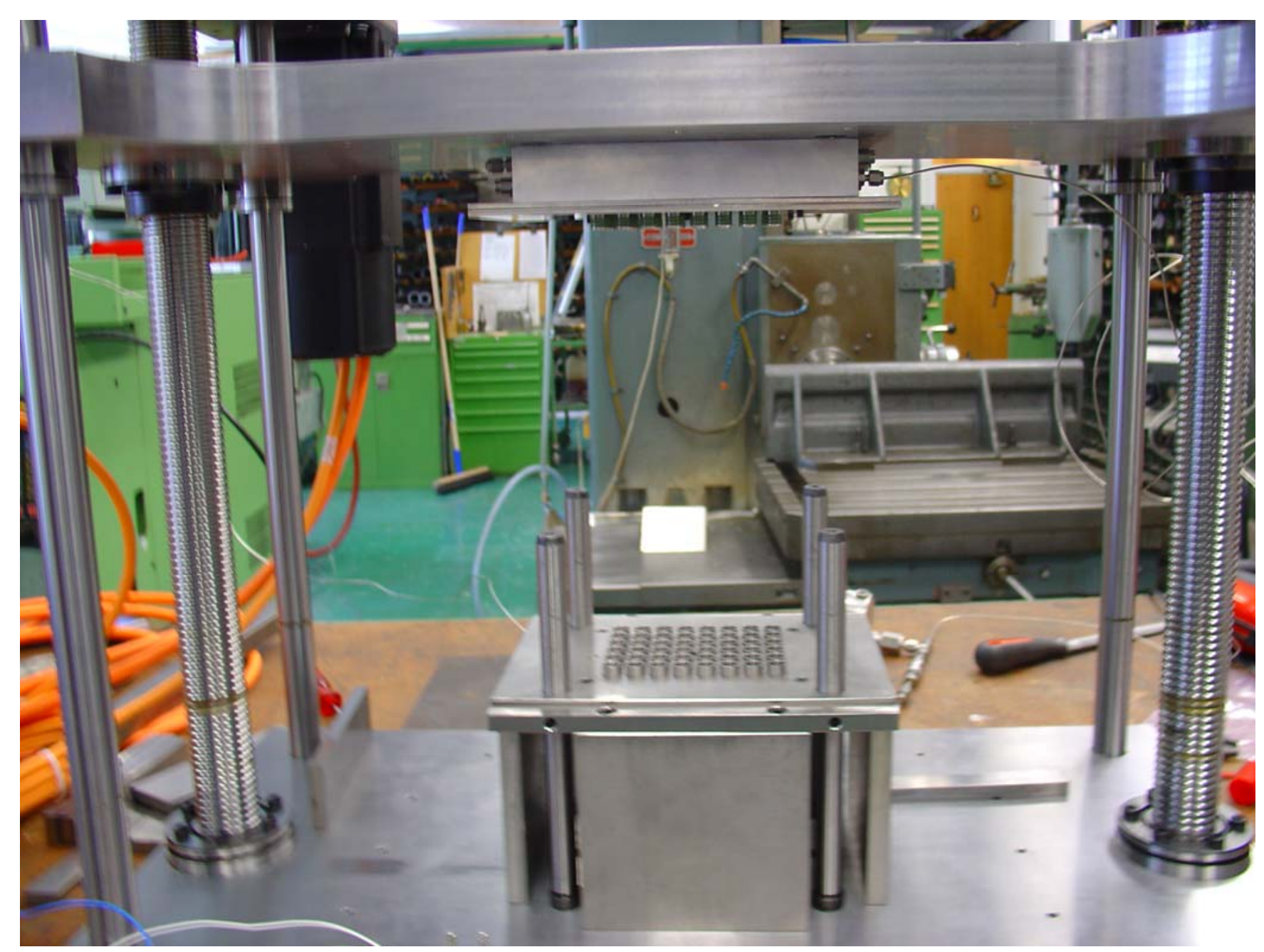




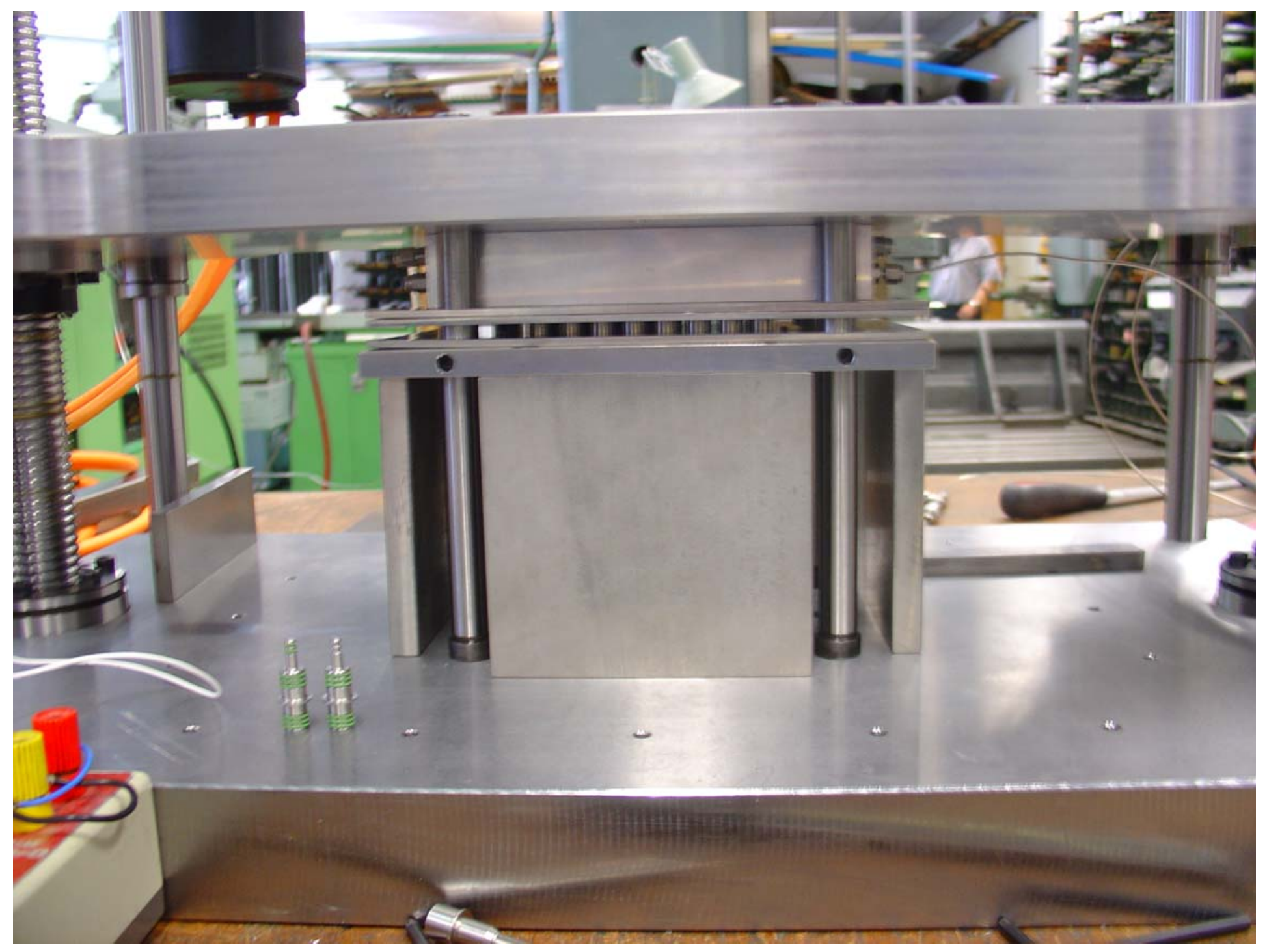




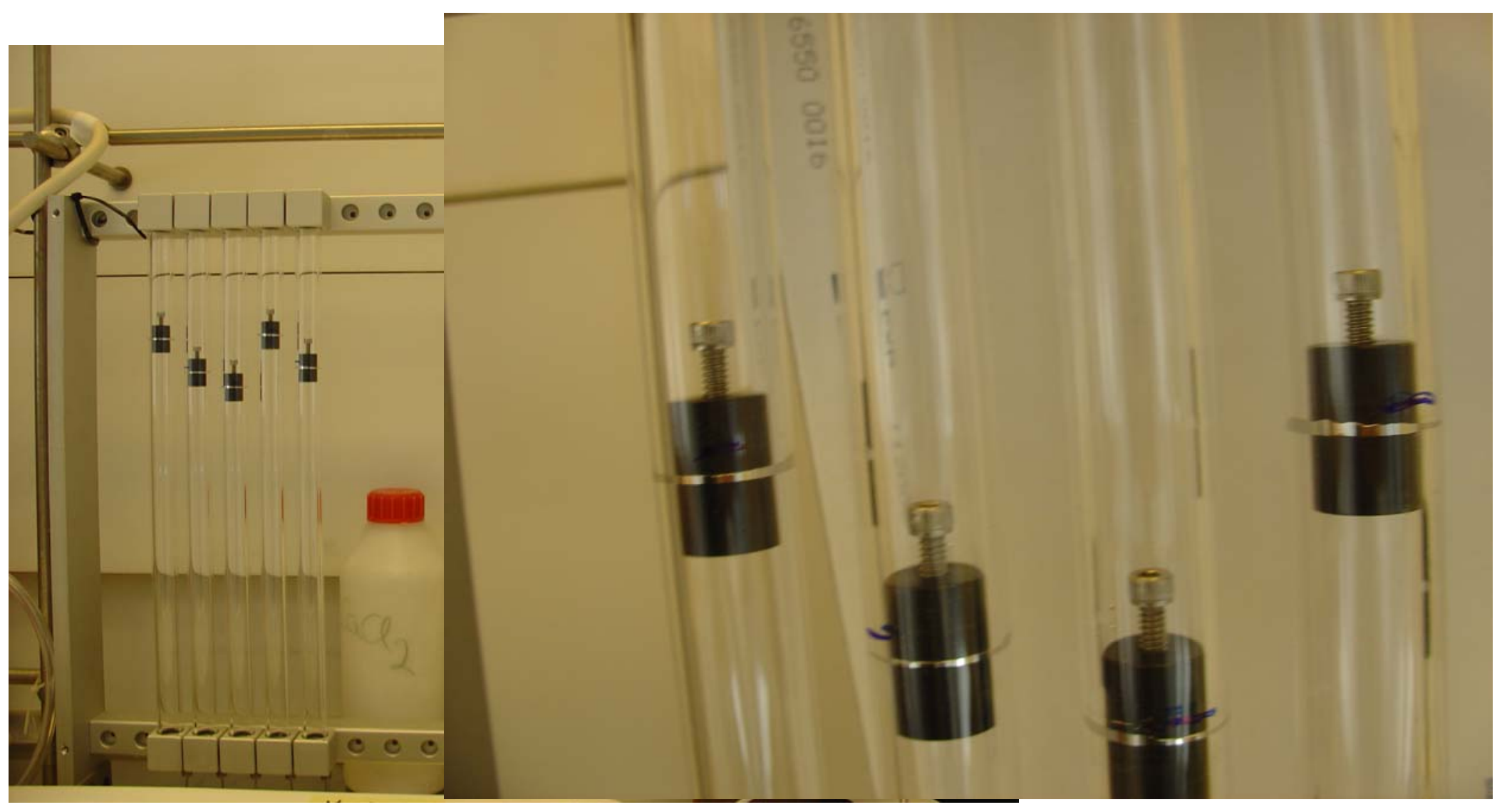

Desorption tubes shown, with floating discs raised to levels dependent on hydrogen evolution. Height Of discs recorded with camera throughout the run 


\section{UOP Inert Atmosphere Lab}

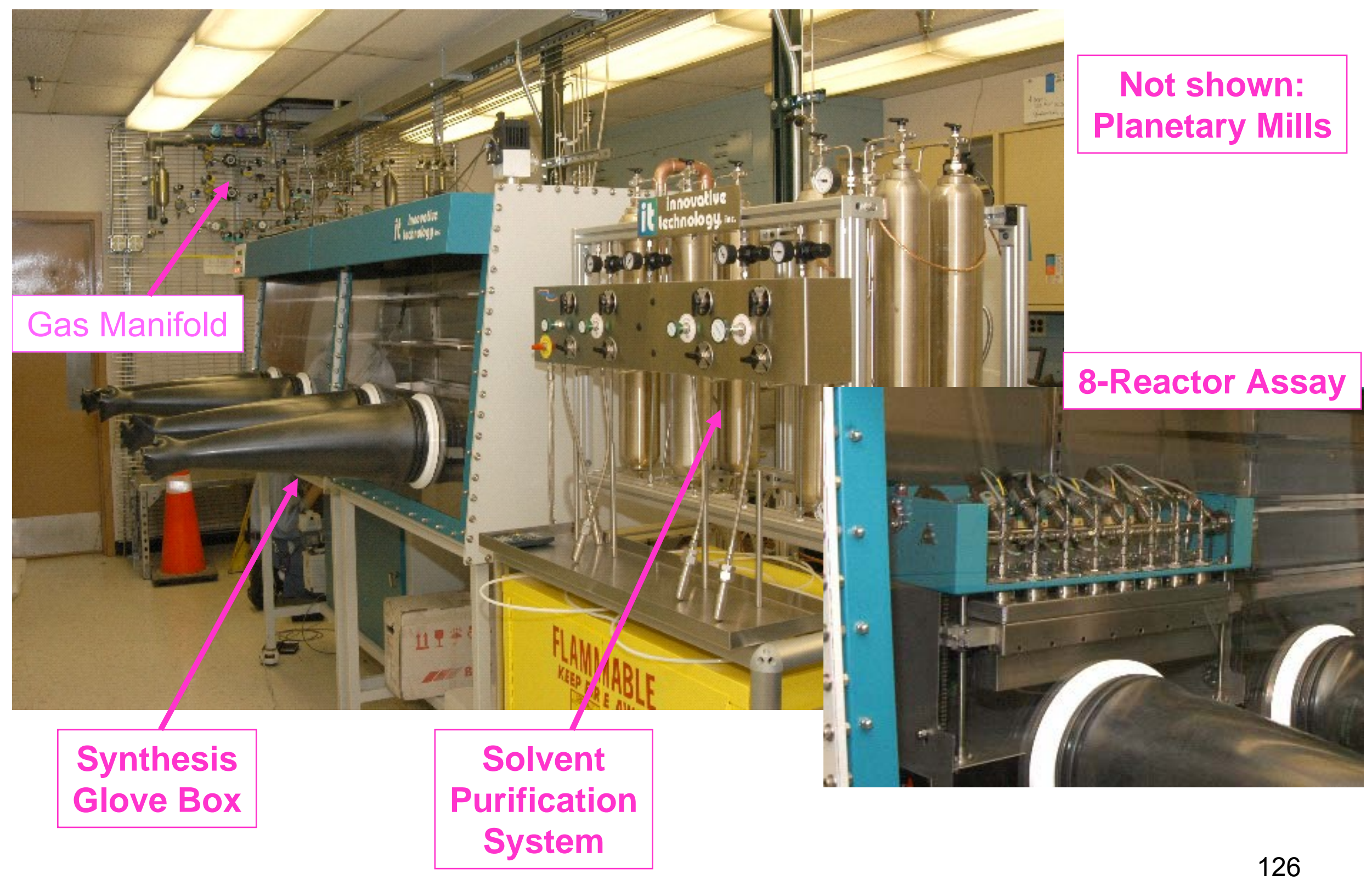




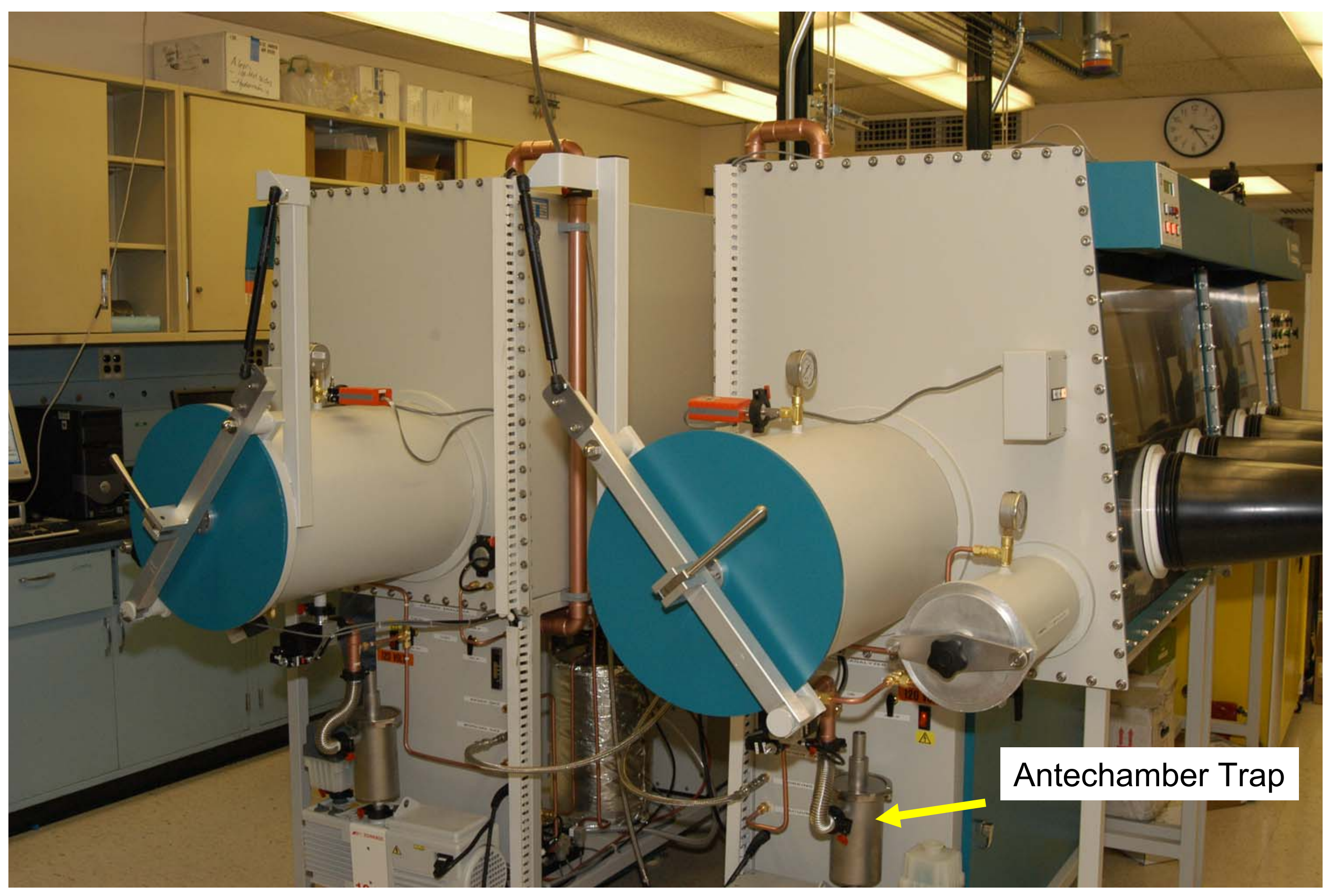


Synthesis

Planetary Ball Mills

- Bowls revolve around central axis, rotate on own axis

- 2 and 8 sample capacities

- 30 min, 350 rpm, forward and reverse

- WC bowls and balls

- minimize contamination

- high energy induces reaction

- generates small particulates

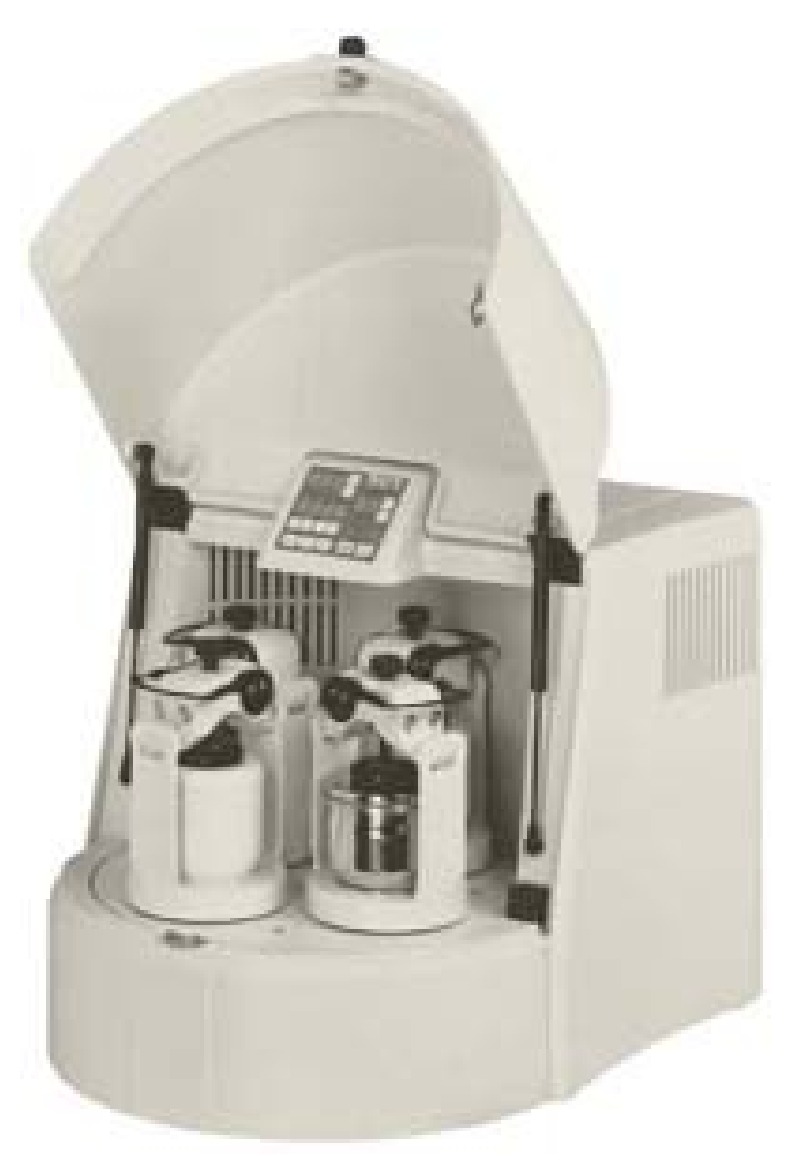




\section{Catalyst Dispersion via Milling (SEM/EDX)}

- Liquid $\mathrm{Ti}(\mathrm{OiPr})_{4}$ source disperses better than solid $\mathrm{TiH}_{2}$ source via Ball Mill (High intensity Grinding)

- Parallel Low Intensity grinding is just as good as the Ball Mill dispersing solid $\mathrm{TiH}_{2}$

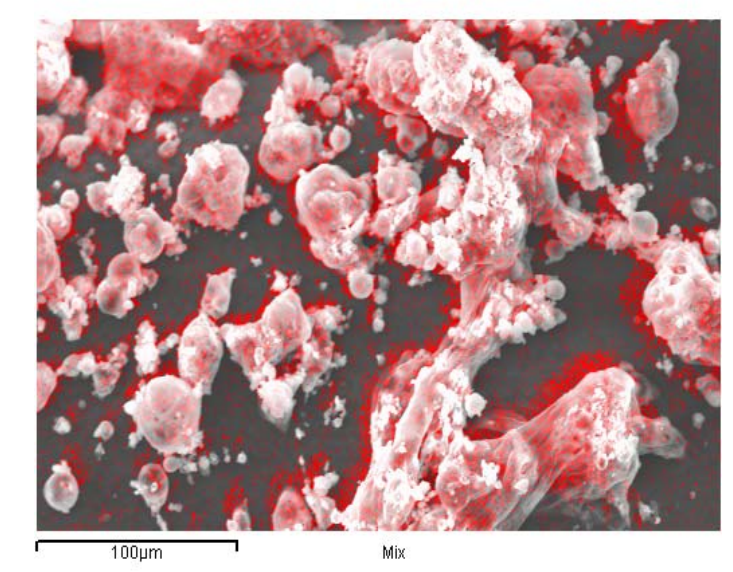

High Intensity/Ti(OiPr) ${ }_{4}$

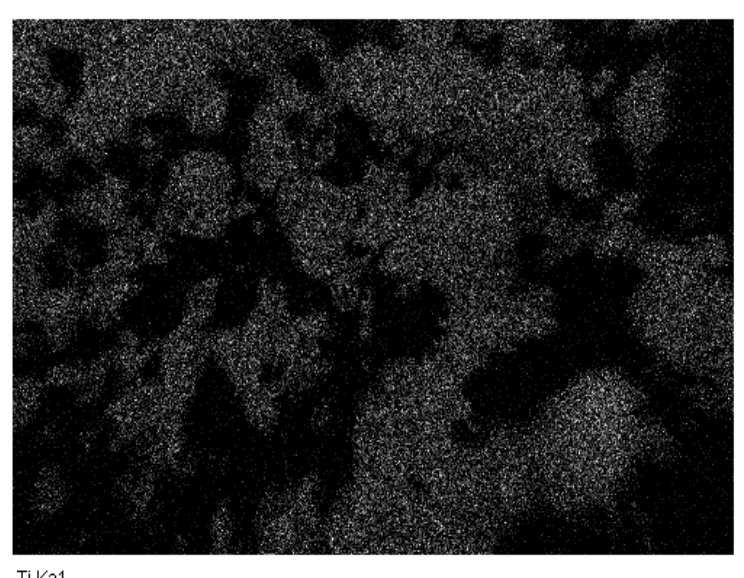

Above:Ti Elemental Maps overlain on samples; Below: Ti Elemental Maps

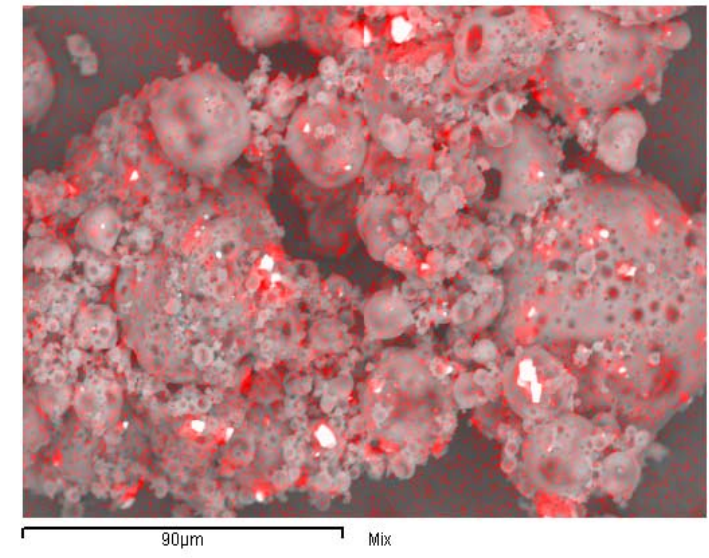

Parallel low intensity/ $\mathrm{TiH}_{2}$
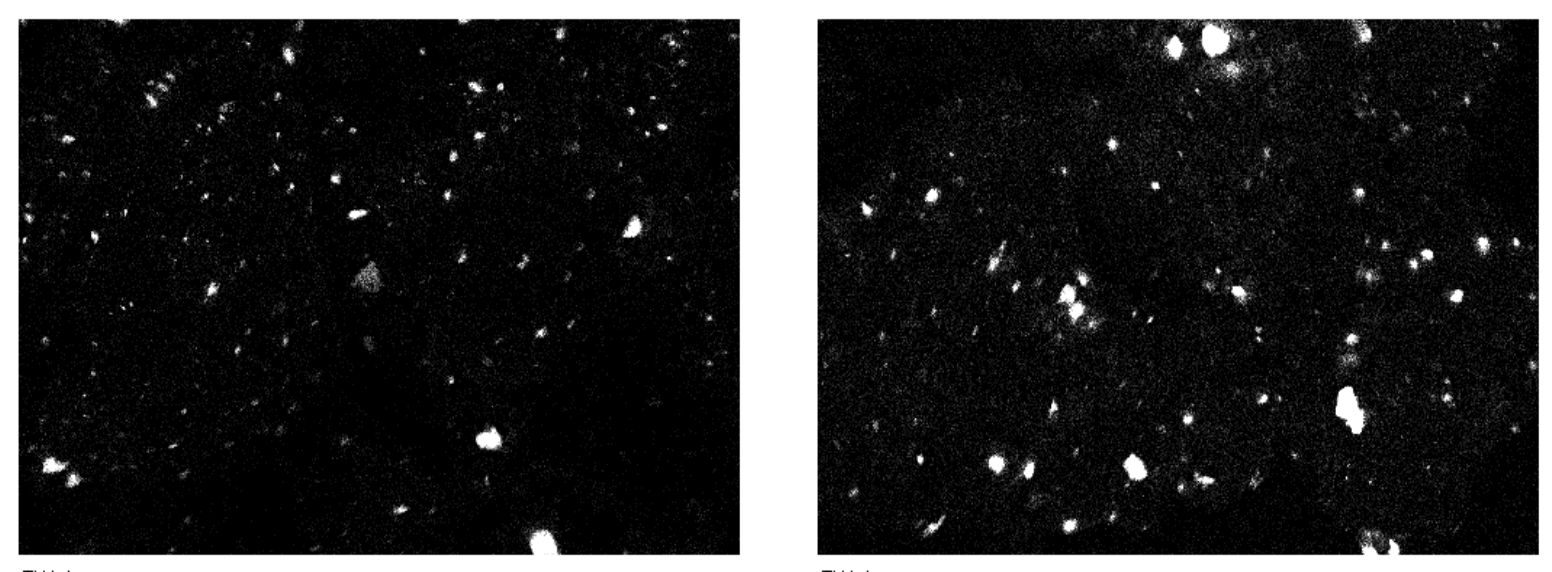

129 


\section{HT XRD Capability}

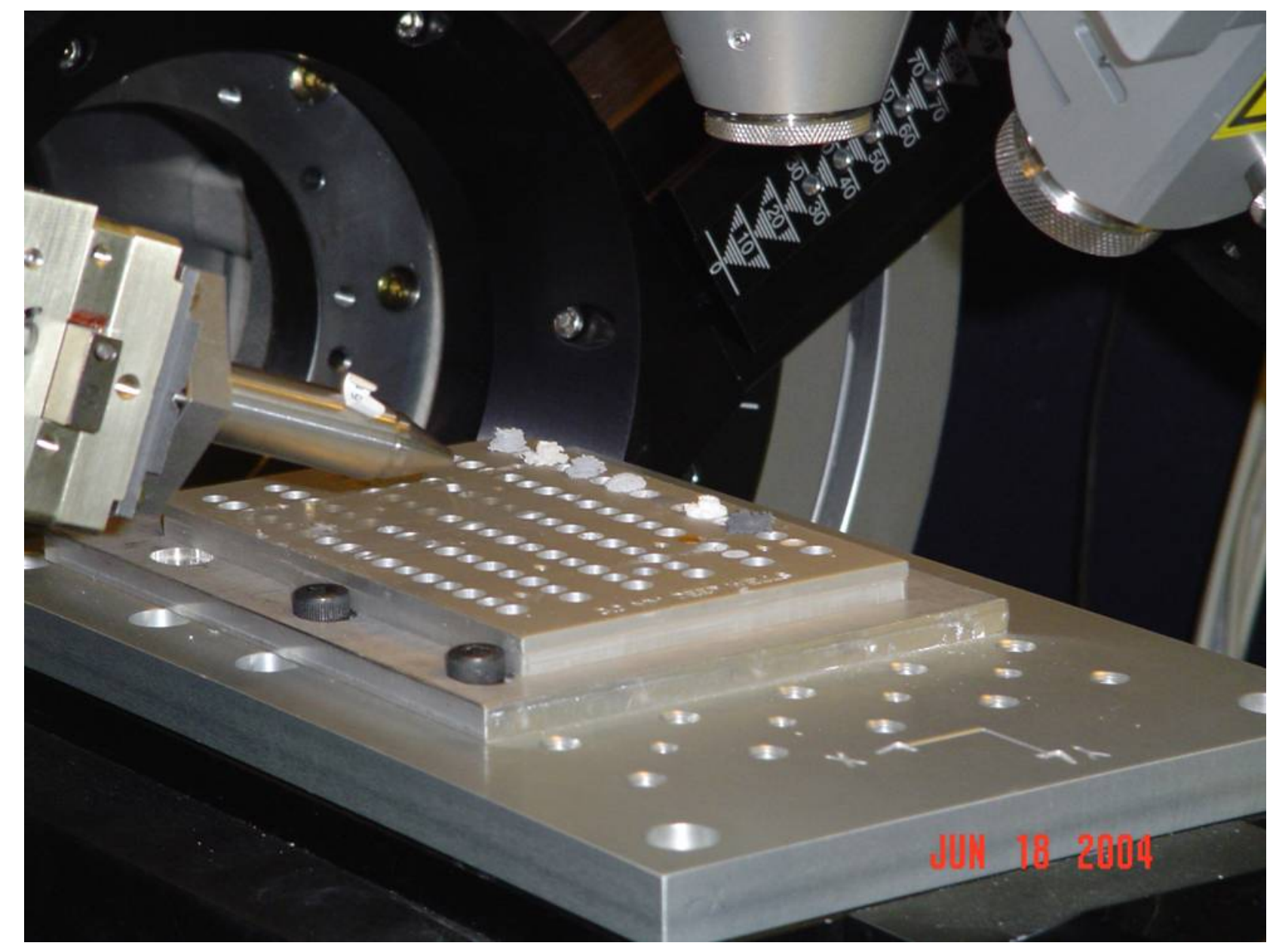

48 sample array, automated XYZ stage, GADDS area detector, Samples bound by parafilm on plate bottom, polycarbonate on top to protect from environment; Collected $2 \Theta=19-54.5^{\circ} ; 60$ second scan/sample ${ }^{130}$ 


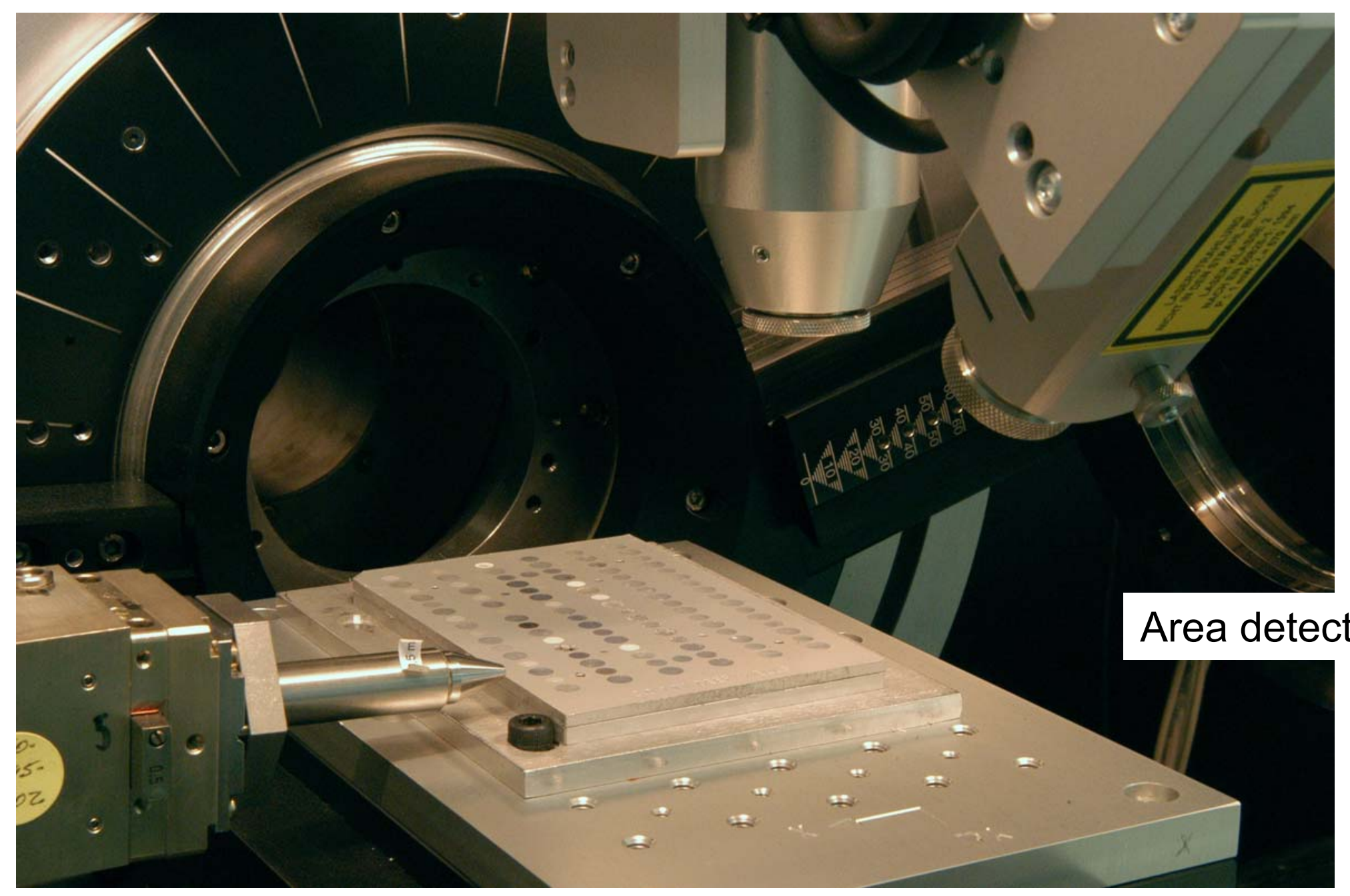


Equipment: HT Synthesis System in custom glovebox

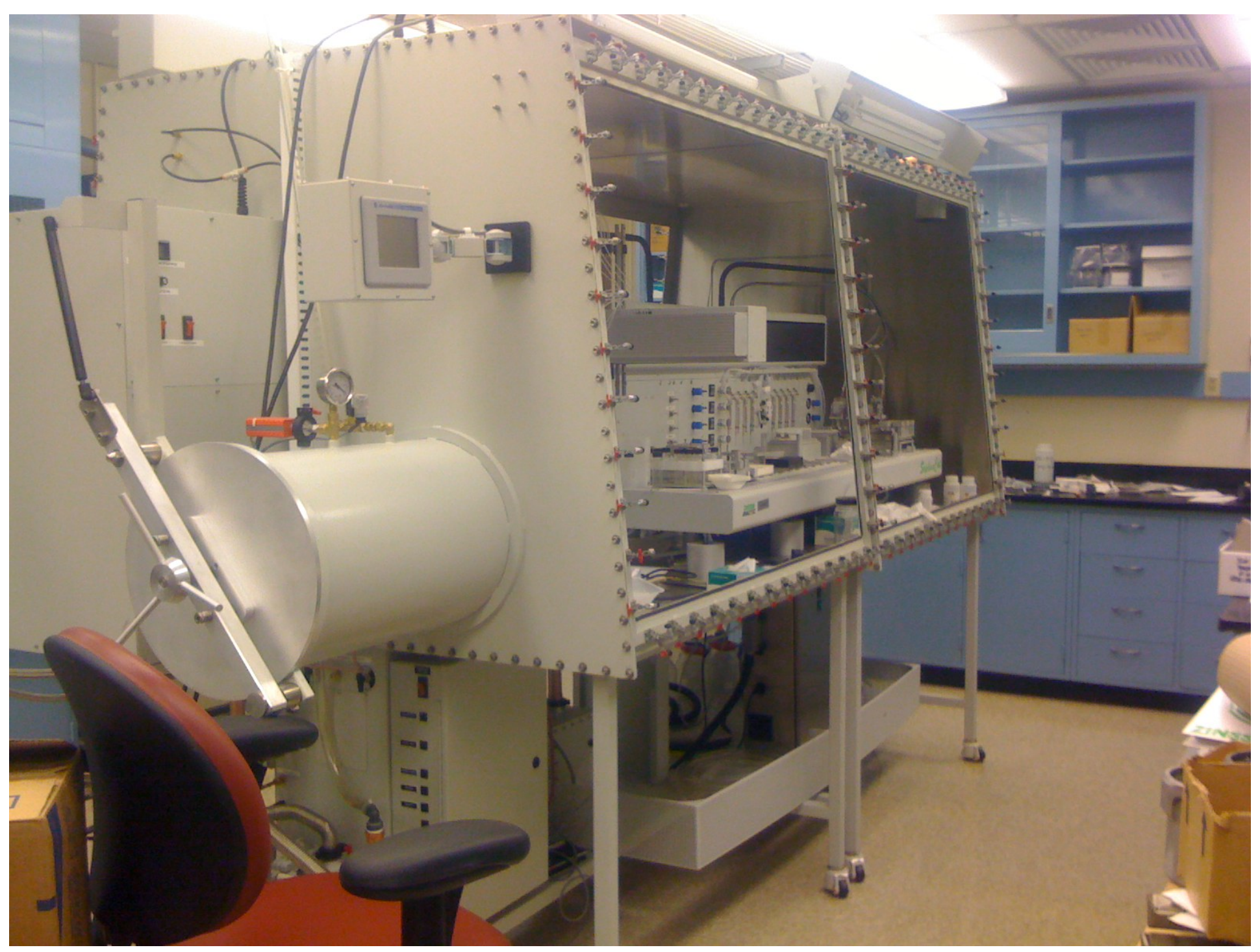




\section{Equipment: HT Synthesis System}

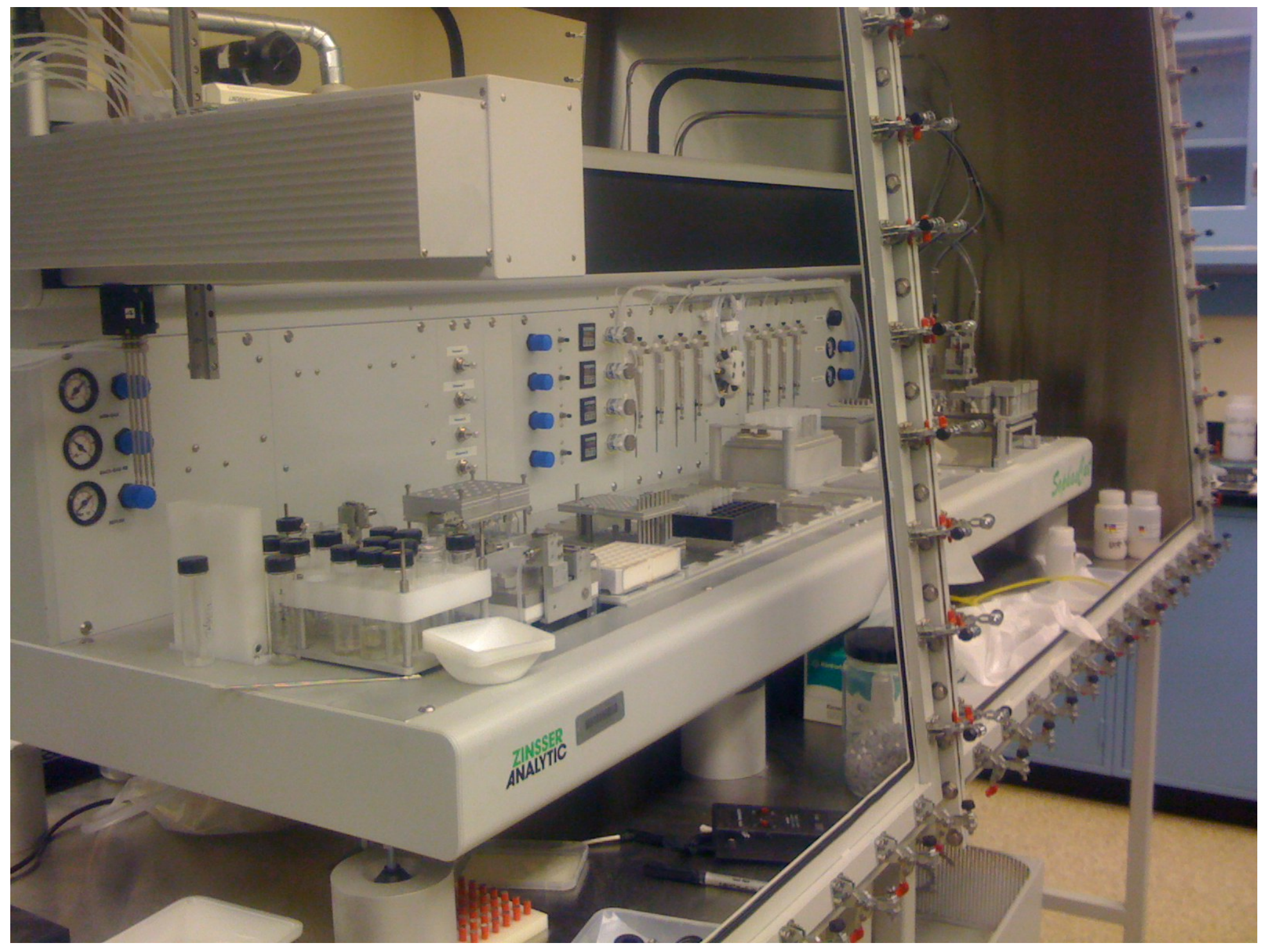




\section{Equipment: HT Synthesis System}

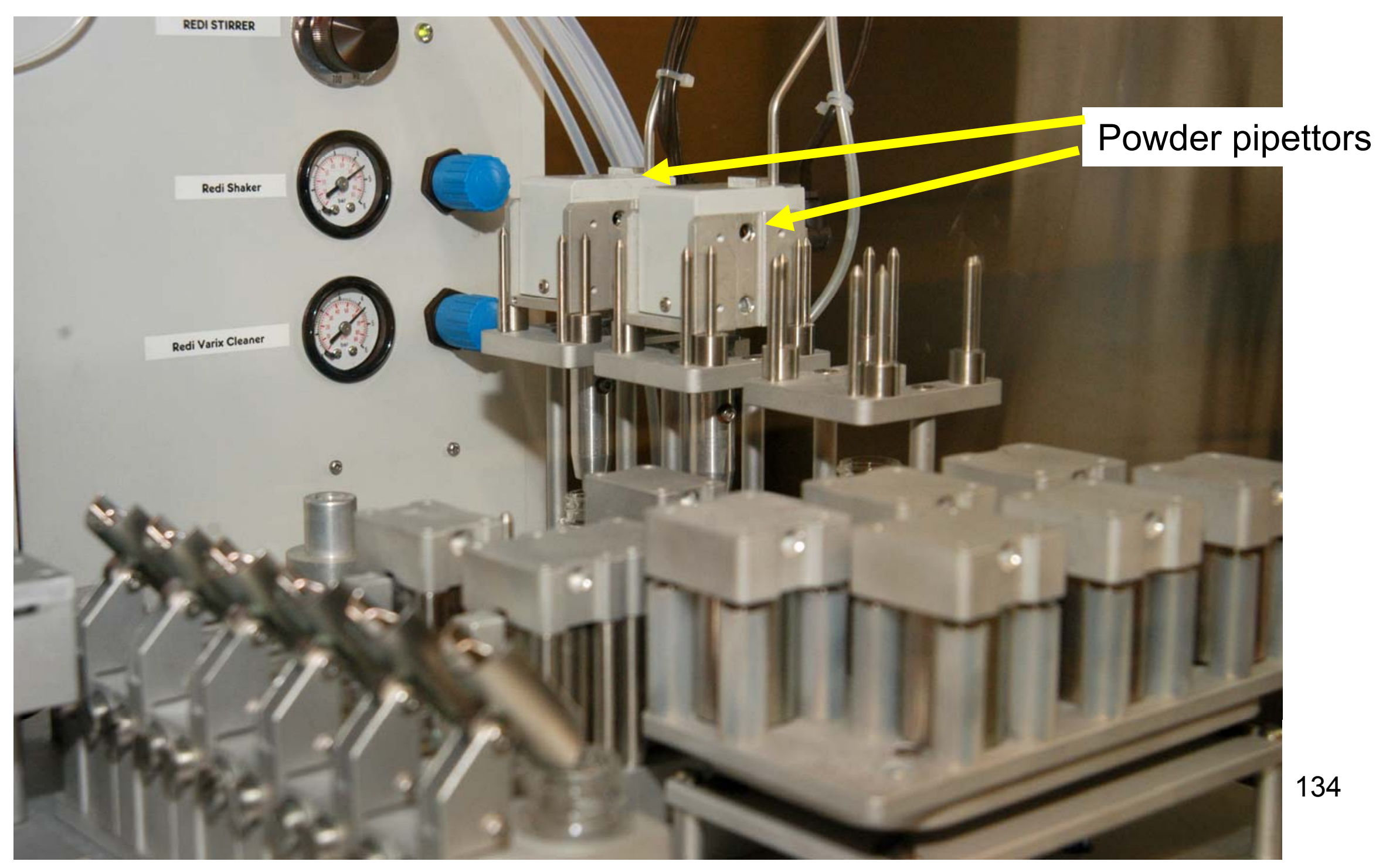




\section{Equipment: HT Synthesis System}

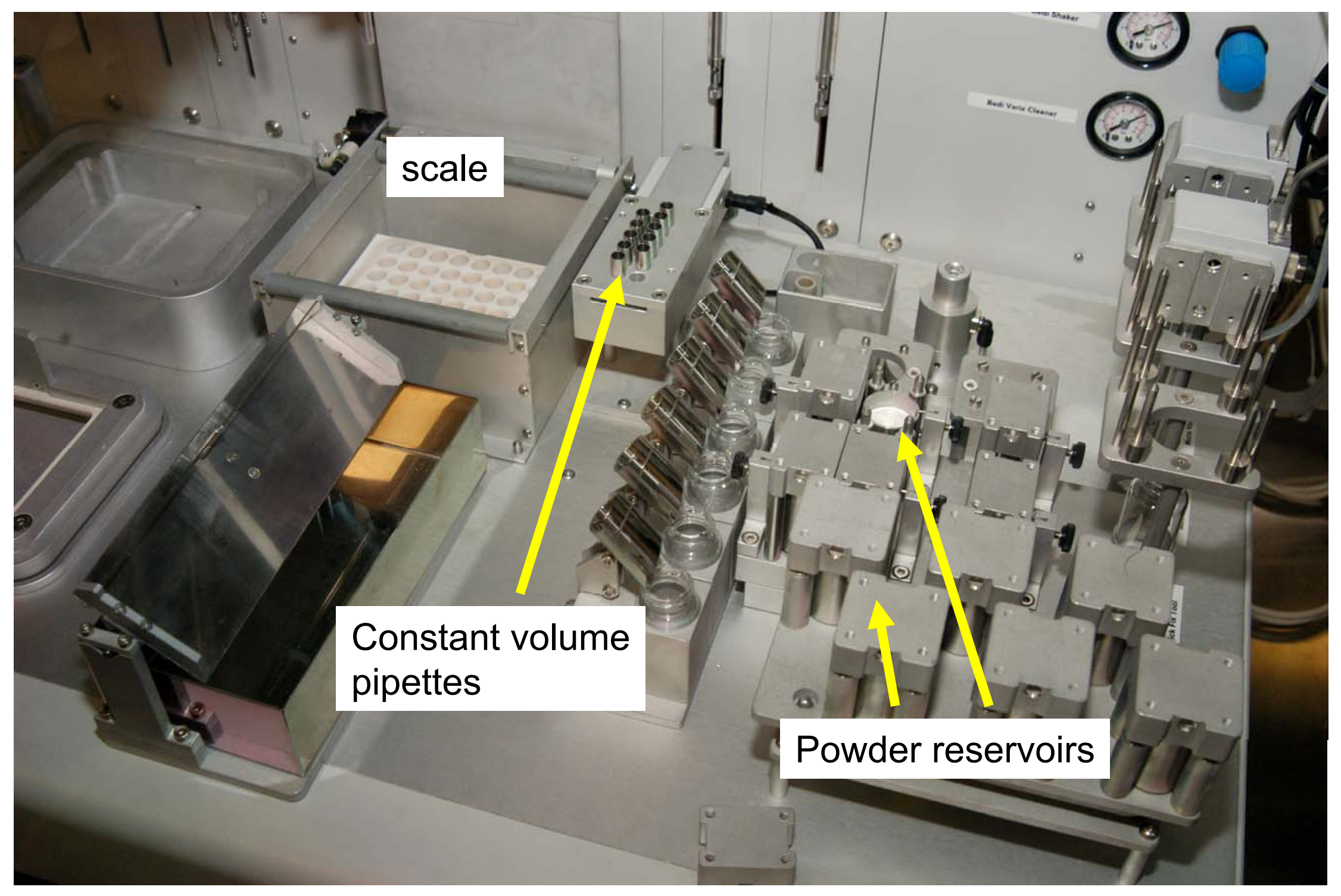




\section{High Throughput Synthesis System}

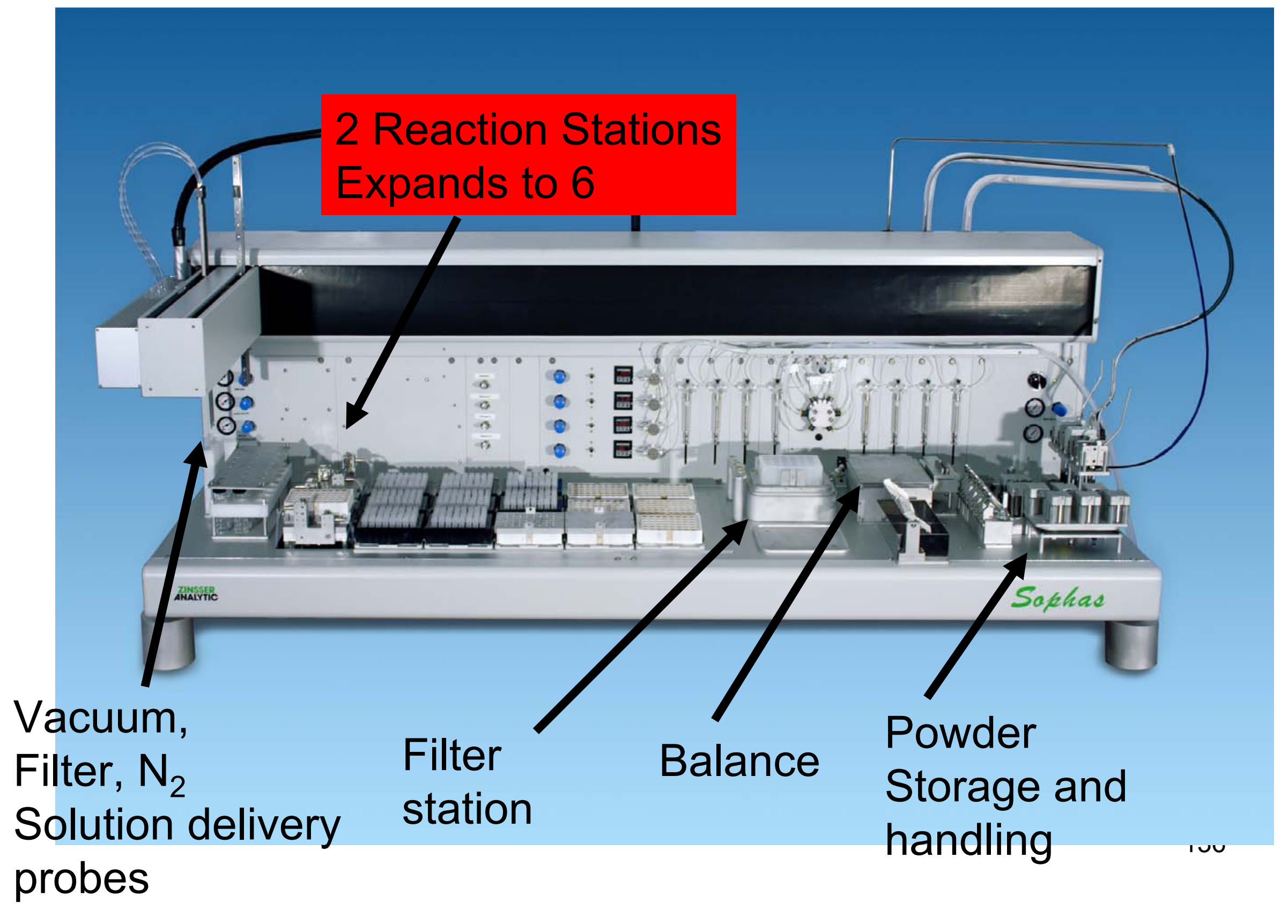




\section{Three types of powder tips for transferring powders}

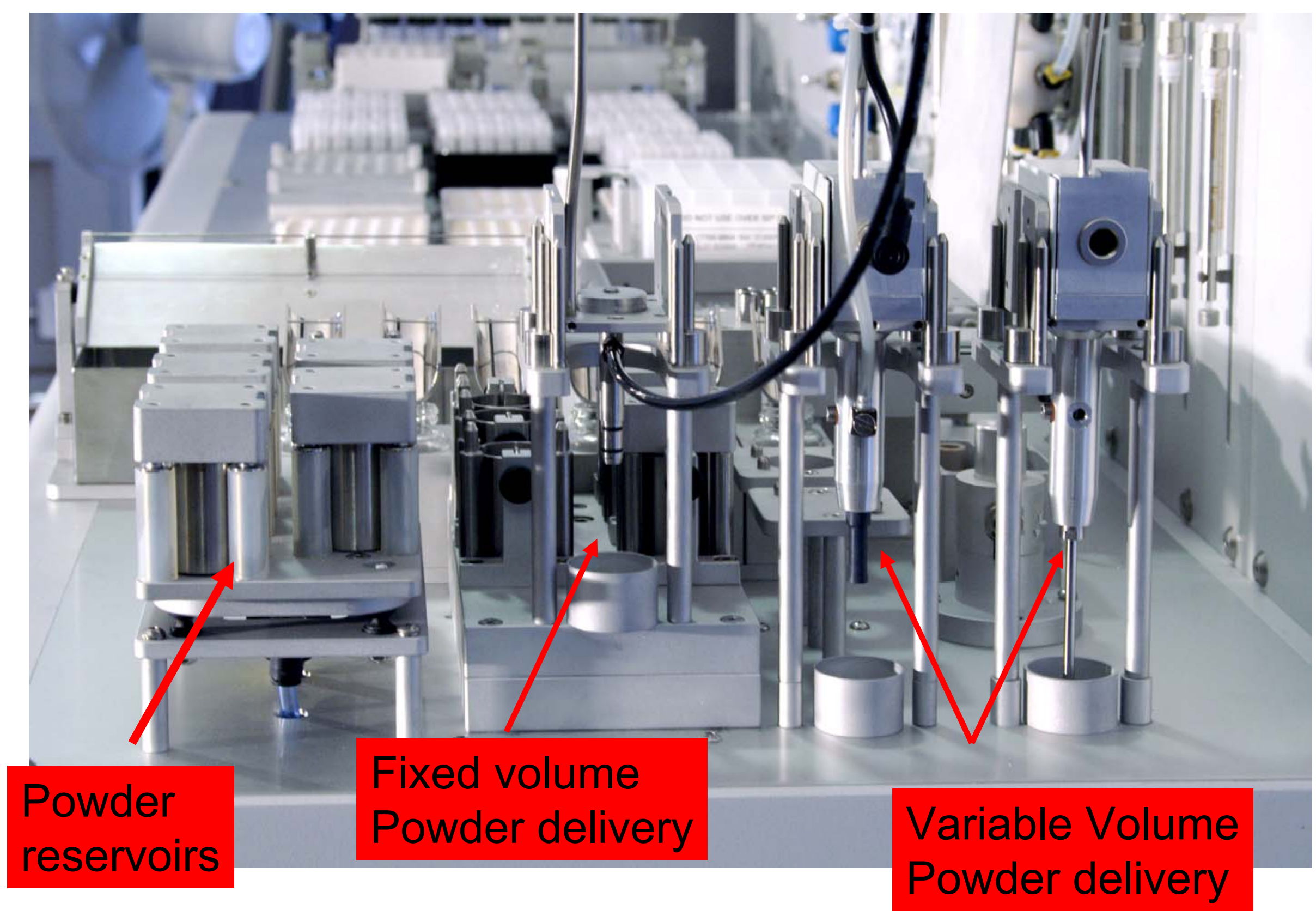




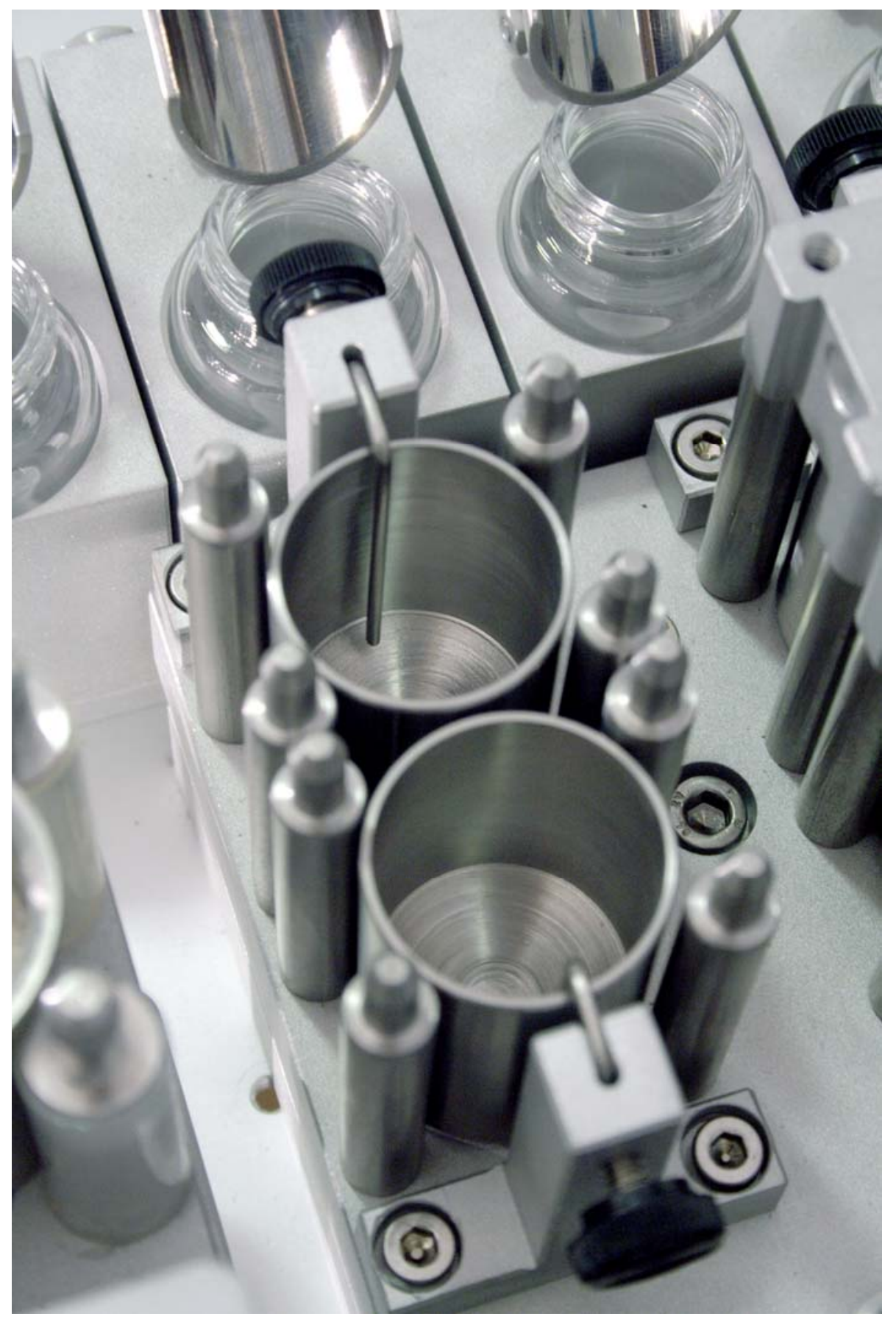

Powder Stirrer:

A new item developed for this apparatus 


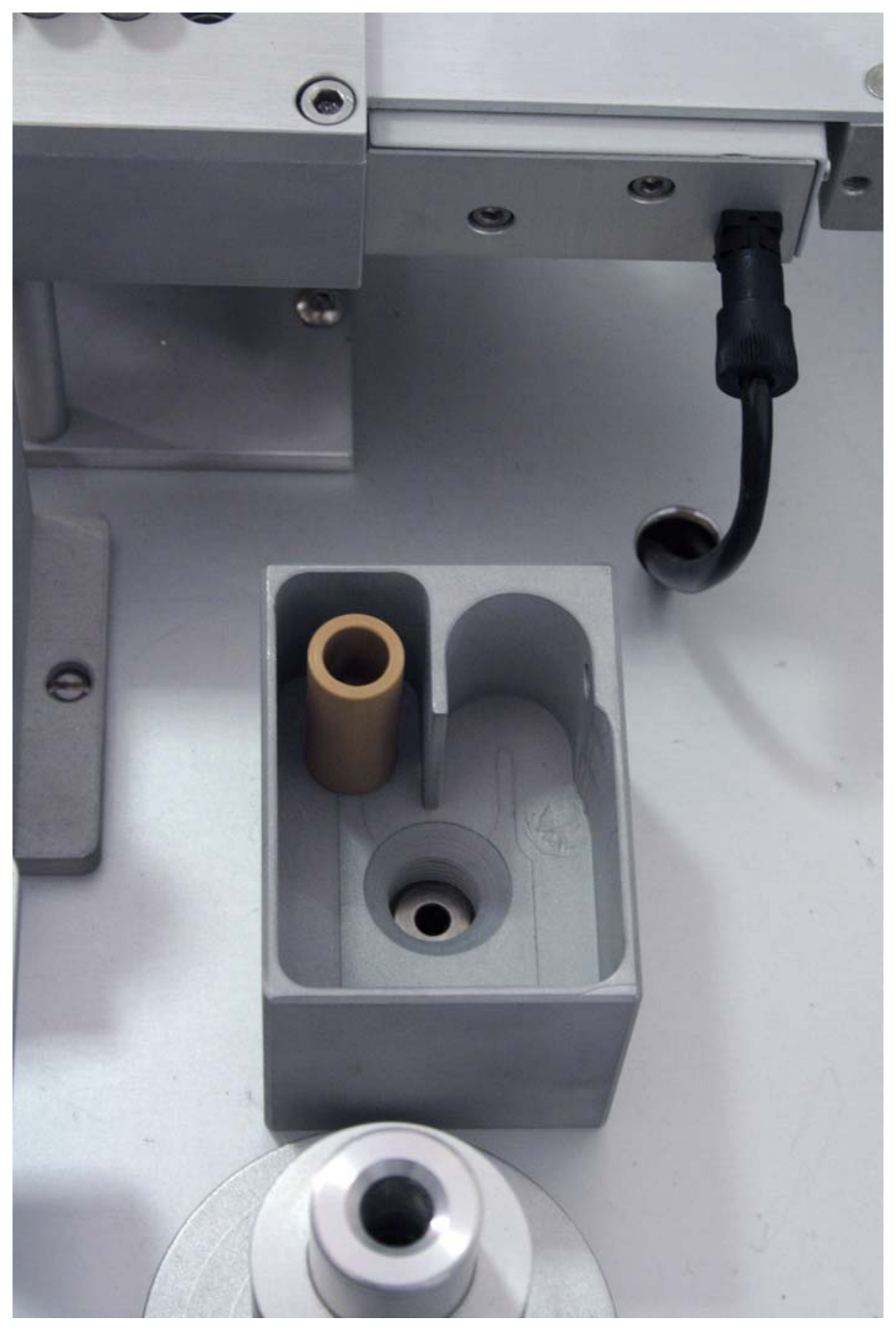
A new wash station was developed to clean the Varix (variable volume) tool. This was a critical step allowing the Varix to work with our milled powders. 
Syringes for liquid handling
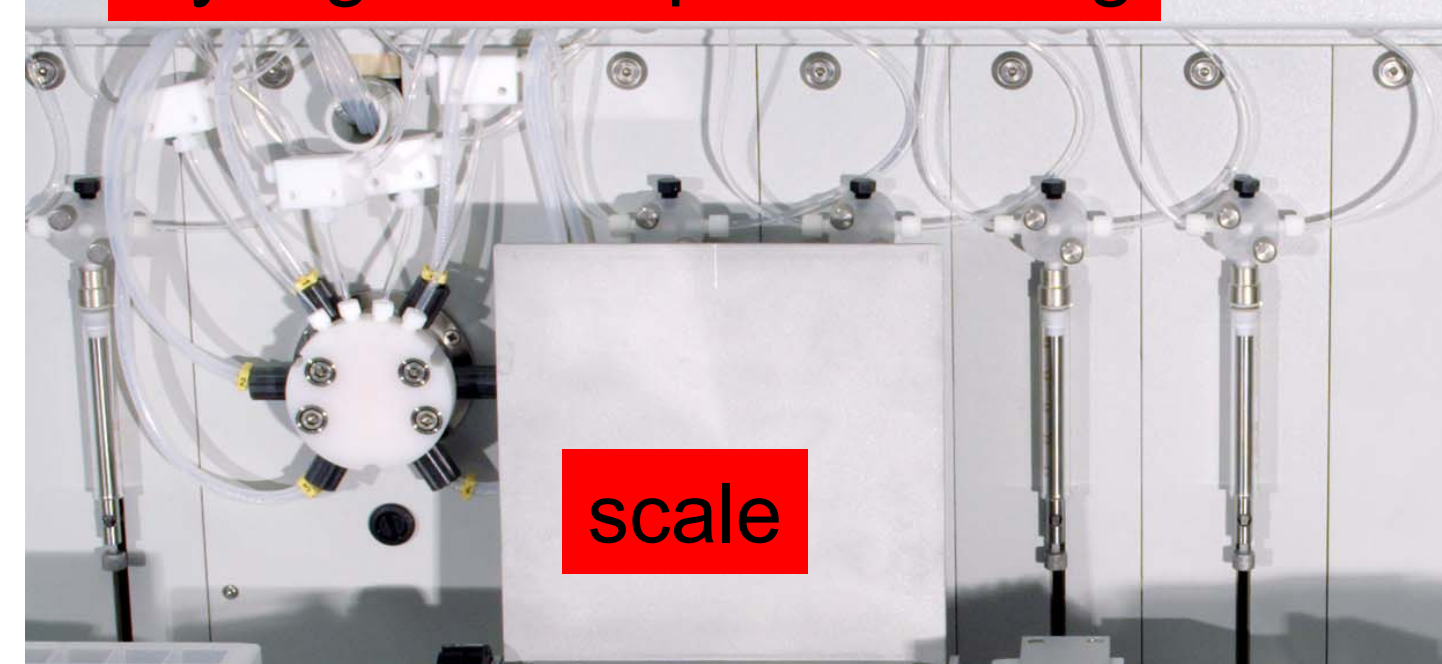

- scale
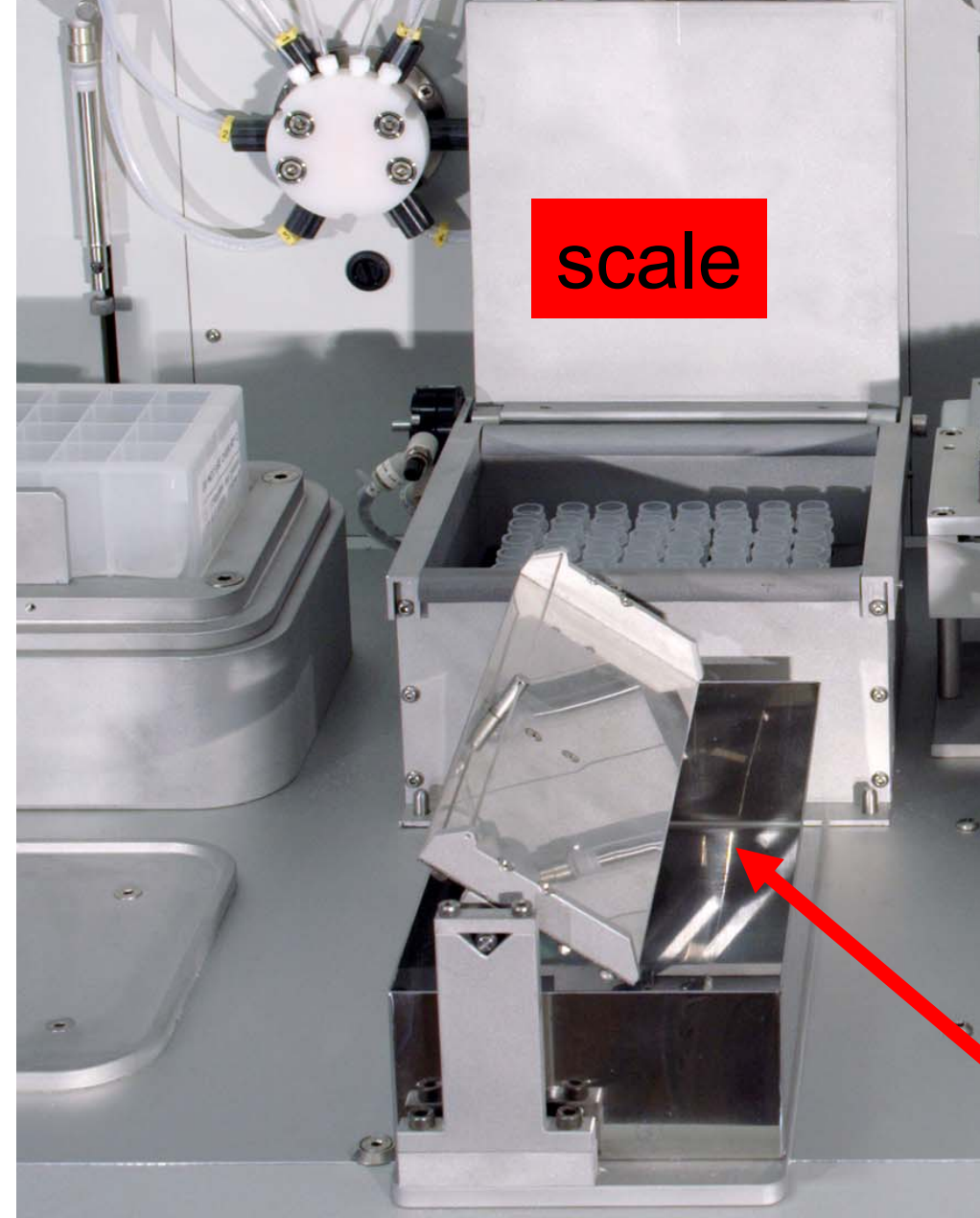

Wi

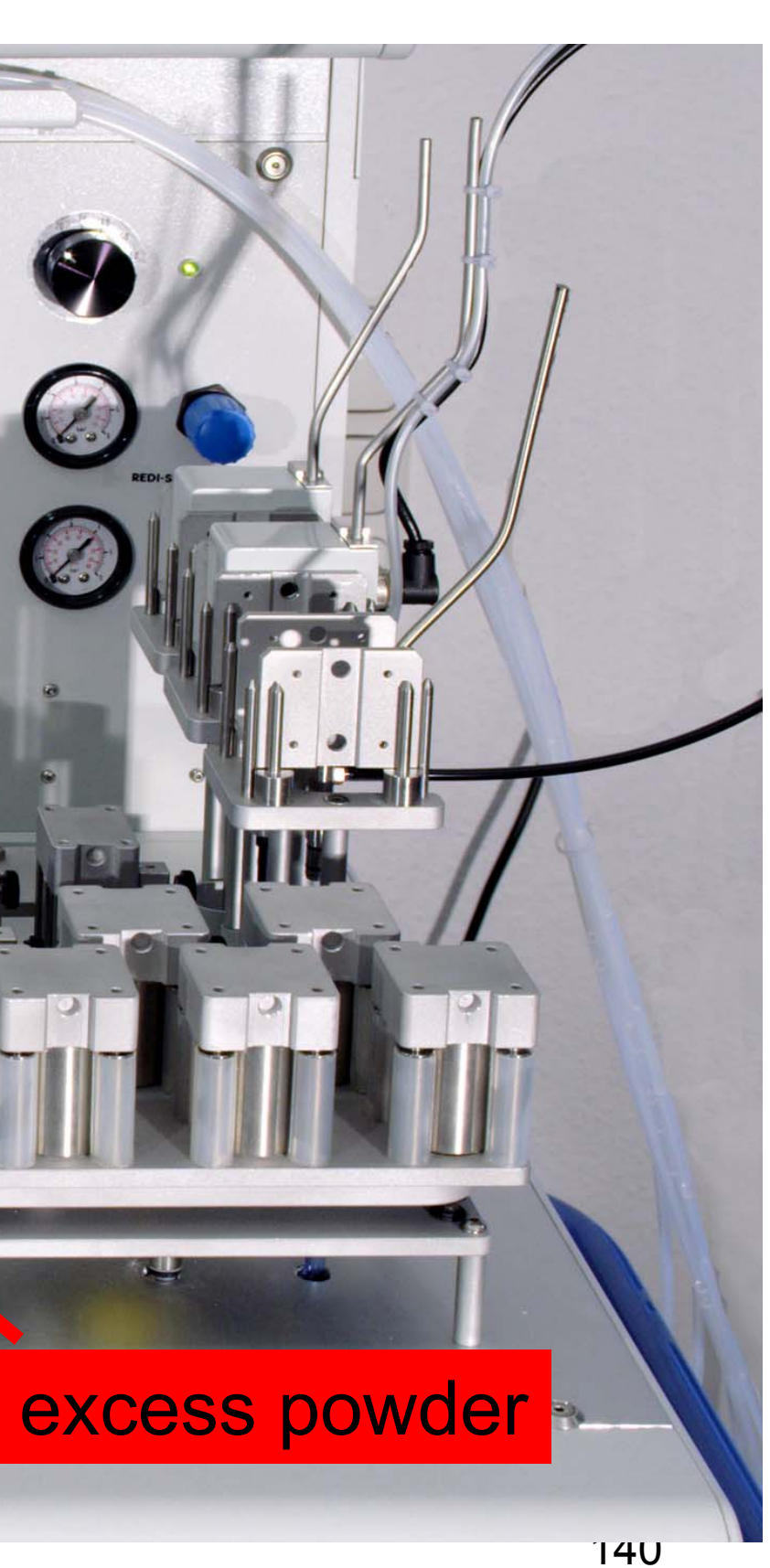


Tri-functional pipettes - solution delivery, vacuum, $\mathrm{N}_{2}$ pressure, filtration 


\section{Synthesis deck}

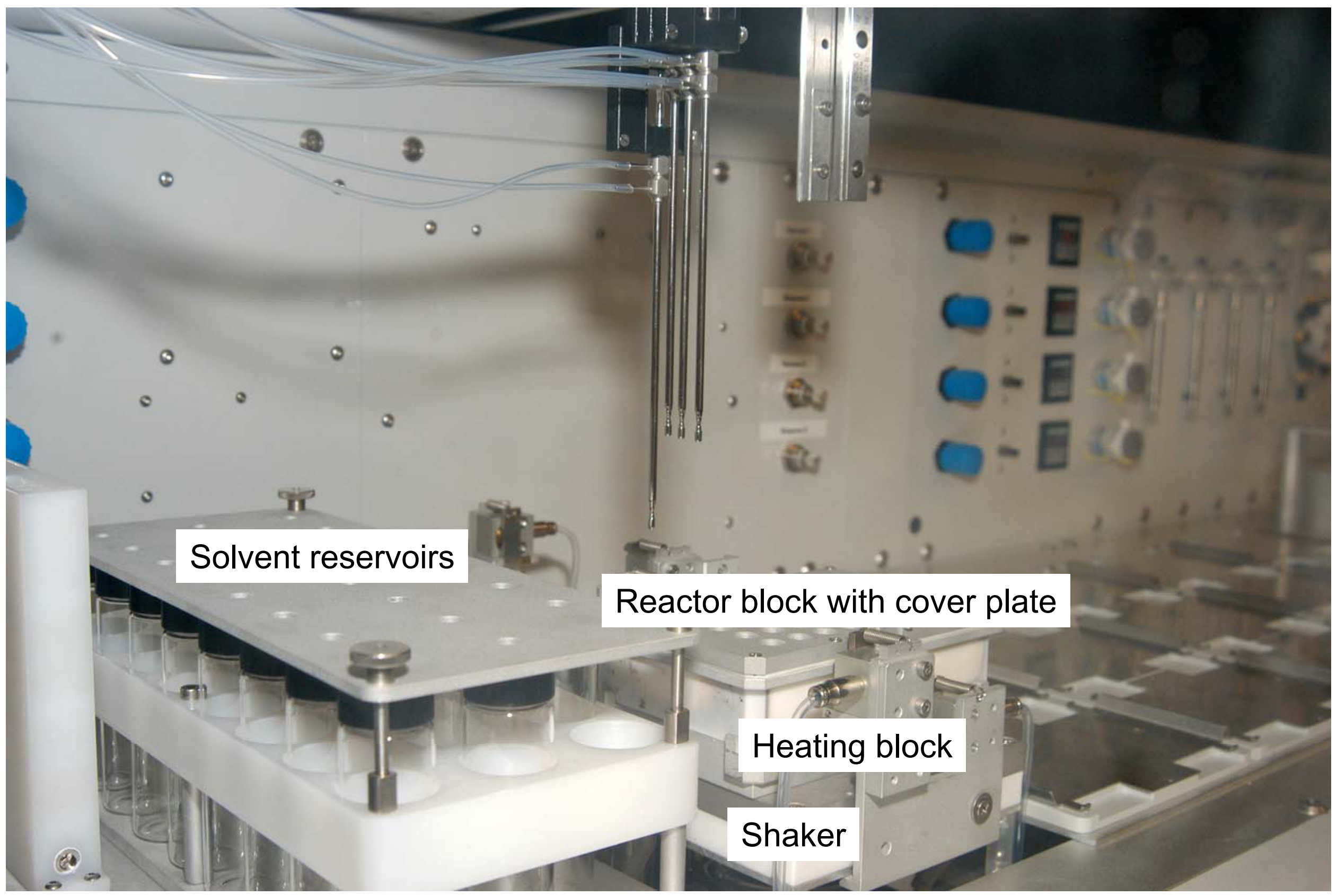


Reactor and top plate - pipettes pierce the rubber mat, prevents evaporation

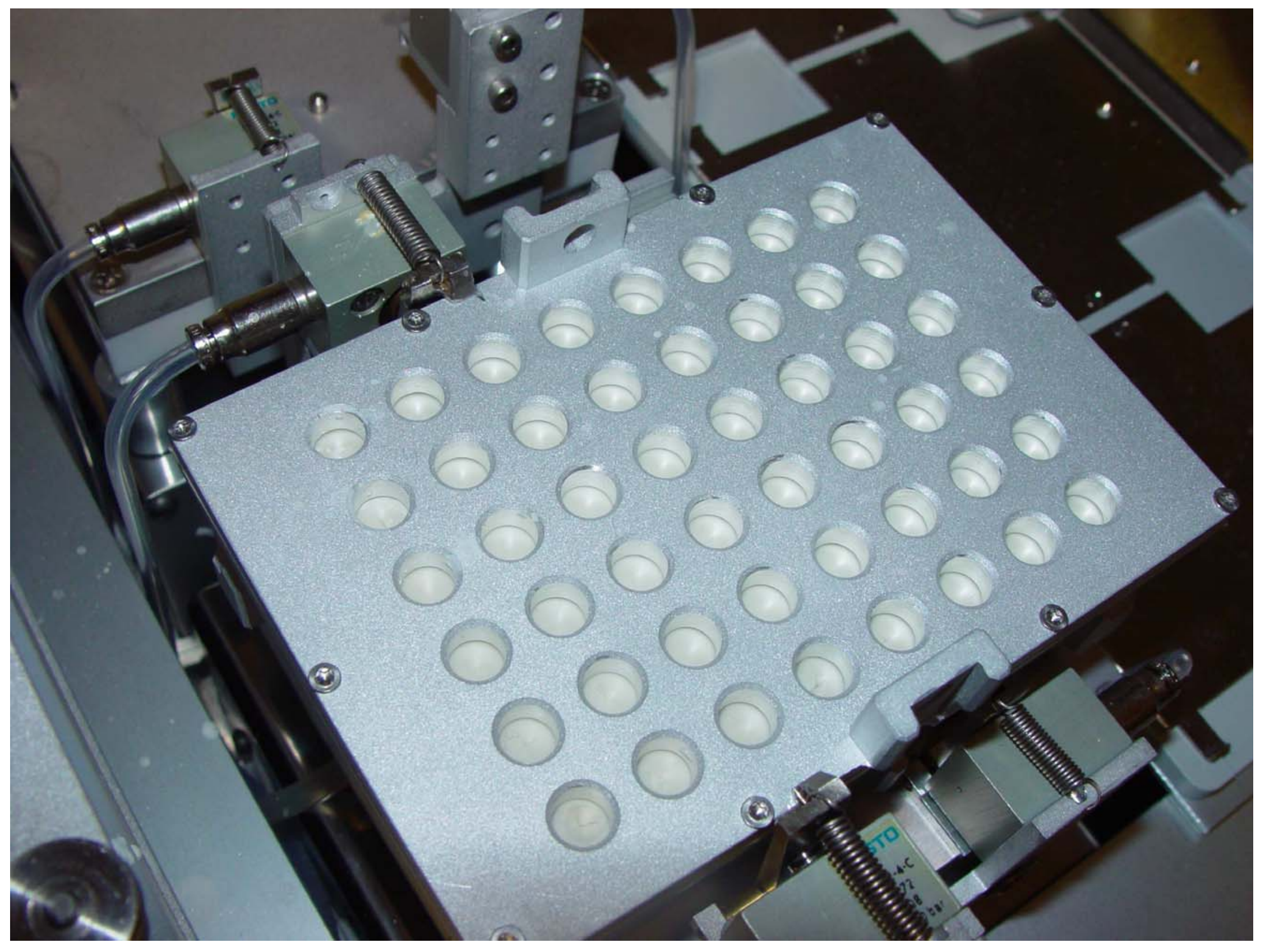


Reactor with top plate, sealed

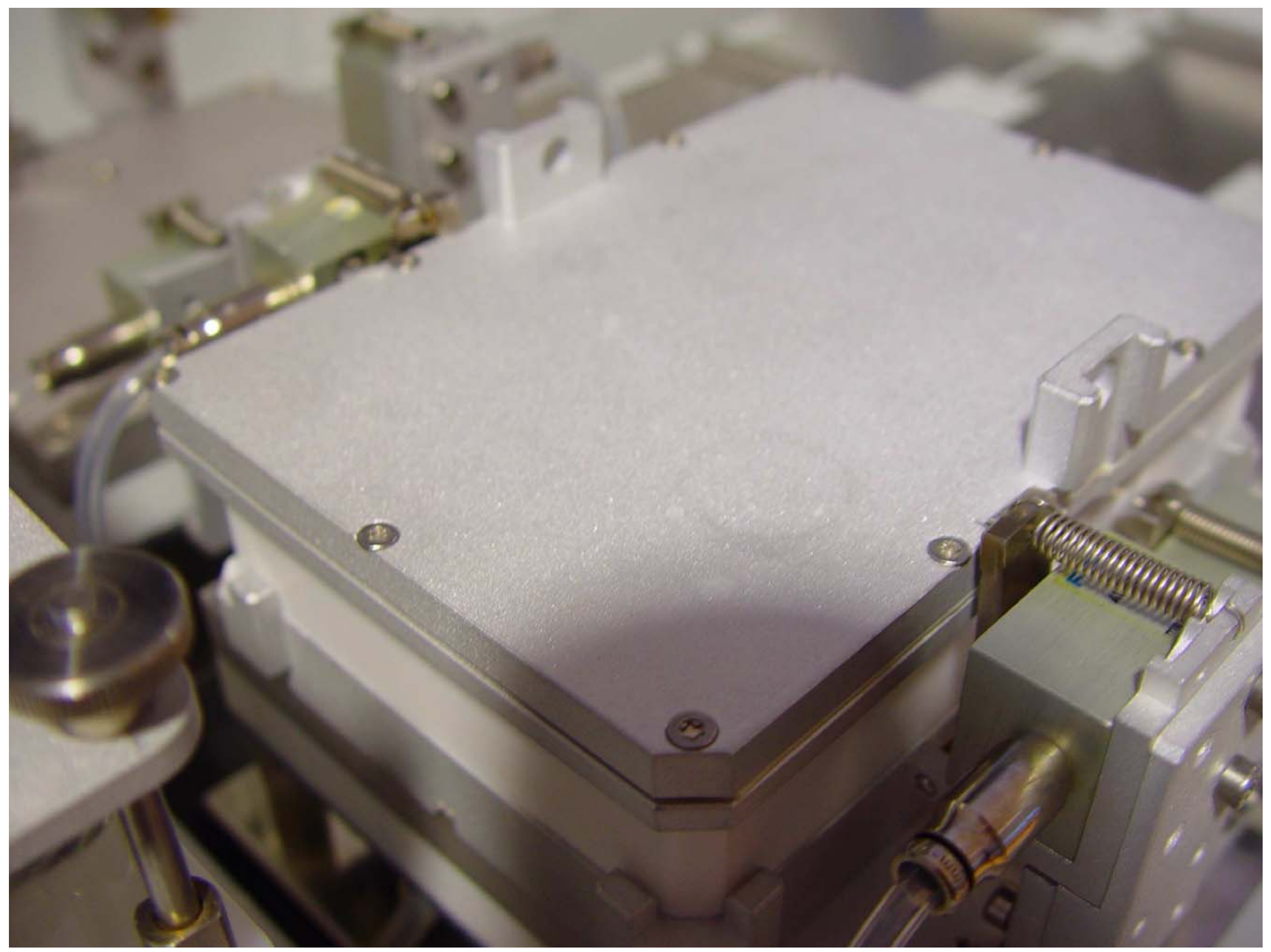




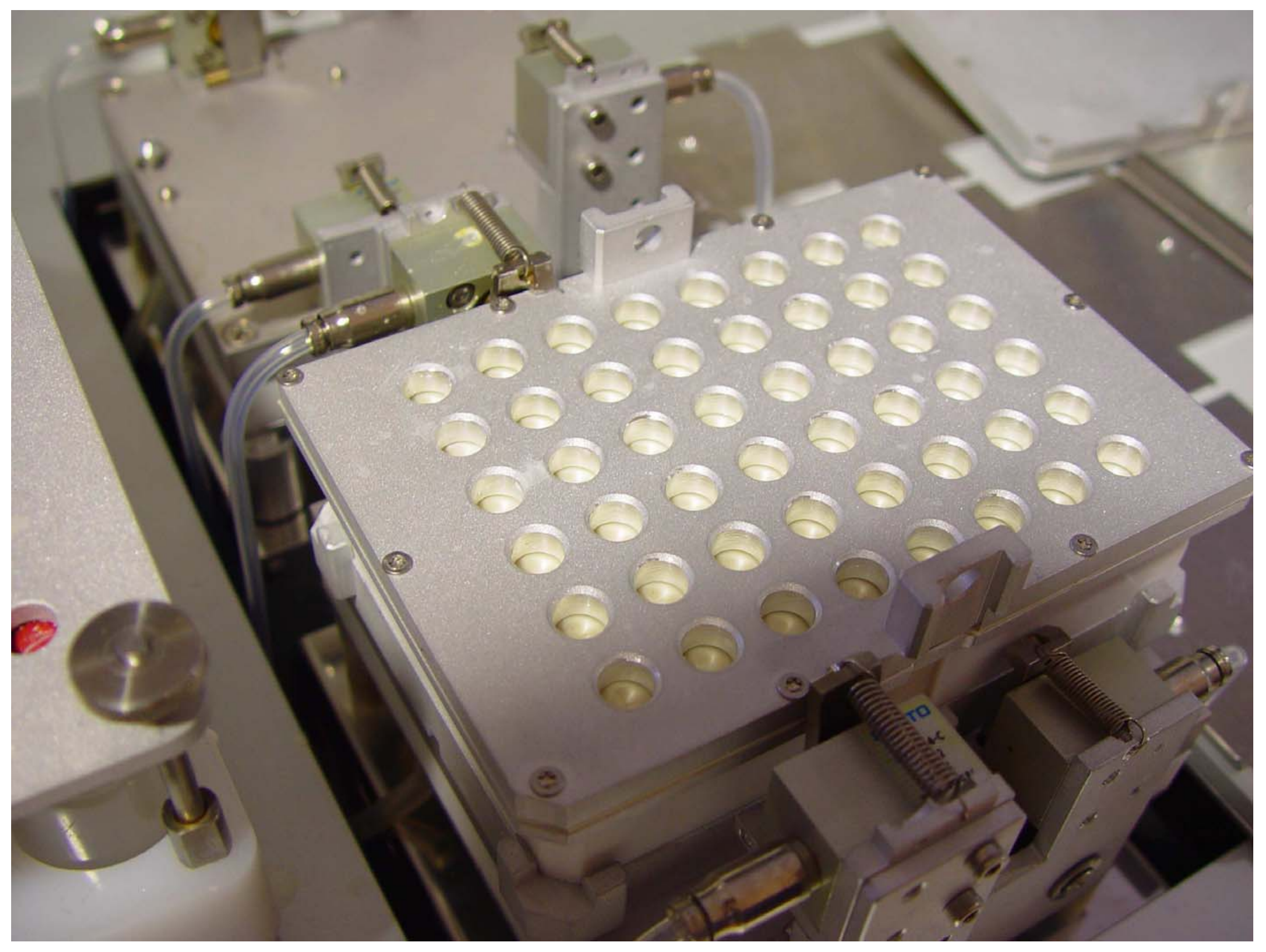




\section{Evaluation of Combi Milling}

- Objective: Determine if current planetary mill can be utilized for milling of 48 well plates

- Proof of Principle Experiment

- Weigh pre-milled solid into 48 well teflon plate

- Each well equipped with stainless steel balls

- Add solution of Ti-(OiPr $)_{4}$ in pentane

- Mill using standard milling conditions

- Remove pentane by evaporation 


\section{Combi Milling Experimental Details}

- Solids will be loaded into 32 wells with 8 unique positions

- All samples will receive the same amount of Ti/pentane solution

\begin{tabular}{|l|l|l|l|l|l|l|l|}
\hline A1 & A2 & A3 & A4 & A5 & A6 & A7 & A8 \\
\hline B1 & B2 & B3 & B4 & B5 & B6 & B7 & B8 \\
\hline C1 & C2 & C3 & C4 & C5 & C6 & C7 & C8 \\
\hline D1 & D2 & D3 & D4 & D5 & D6 & D7 & D8 \\
\hline E1 & E2 & E3 & E4 & E5 & E6 & E7 & E8 \\
\hline F1 & F2 & F3 & F4 & F5 & F6 & F7 & F8 \\
\hline
\end{tabular}

- Evaporation will be done under vacuum in the antechamber of the dry box

- Vacuum pump is equipped with a small trap 


\section{Combi Wet Milling Experiment}

- Objective: Determine if addition of THF will facilitate combi milled rxns

- Previous attempts to make $\mathrm{Mg}(\mathrm{AlH} 4) 2$ were not successful in either teflon or ceramic combi plates

- $2 \mathrm{NaAlH} 4+\mathrm{MgCl} 2 \rightarrow \mathrm{Mg}(\mathrm{AlH} 4) 2+2 \mathrm{NaCl}$

- Experimental Design

- 6 different rxns

- Within one plate rxns were run with and w/o THF

- Milled1h@350rpm

- $15 \mathrm{~min}$ forward/15min reverse, rest $15 \mathrm{~min}, 15 \mathrm{~min}$ for $/ 15 \mathrm{~min}$ rev

- Dried under vacuum $\sim 1 \mathrm{~h}$

\begin{tabular}{|l|l|l|l|l|l|l|l|}
\hline A1 & A2 & A3 & A4 & A5 & A6 & A7 & A8 \\
\hline B1 & B2 & B3 & B4 & B5 & B6 & B7 & B8 \\
\hline C1 & C2 & C3 & C4 & C5 & C6 & C7 & C8 \\
\hline D1 & D2 & D3 & D4 & D5 & D6 & D7 & D8 \\
\hline E1 & E2 2 & E3 3 & E4 & E5 5 & E6 6 & E7 & E8 8 \\
\hline F1 & F2 & F3 & F4 4 & F5 5 & F6 6 & F7 & F8 \\
\hline
\end{tabular}

1. $2 \mathrm{NaAlH} 4+\mathrm{MgCl} 2$

2. $\mathrm{NaAlH} 4+\mathrm{LiNH} 2$

3. $\mathrm{MgH} 2+\mathrm{LiNH} 2-->$

4. $\mathrm{LiBH} 4+\mathrm{MgCl} 2$

5. $\mathrm{LiBH} 4+\mathrm{LiNH} 2$

6. $\mathrm{MgCl} 2+2 \mathrm{LiNH} 2$ 


\section{Combi Wet Milling Reaction 1}

\section{$2 \mathrm{NaAlH} 4+\mathrm{MgCl} 2 \rightarrow$}

$\mathrm{NaAlH} 4+\mathrm{MgCl} 2$ (no reaction)

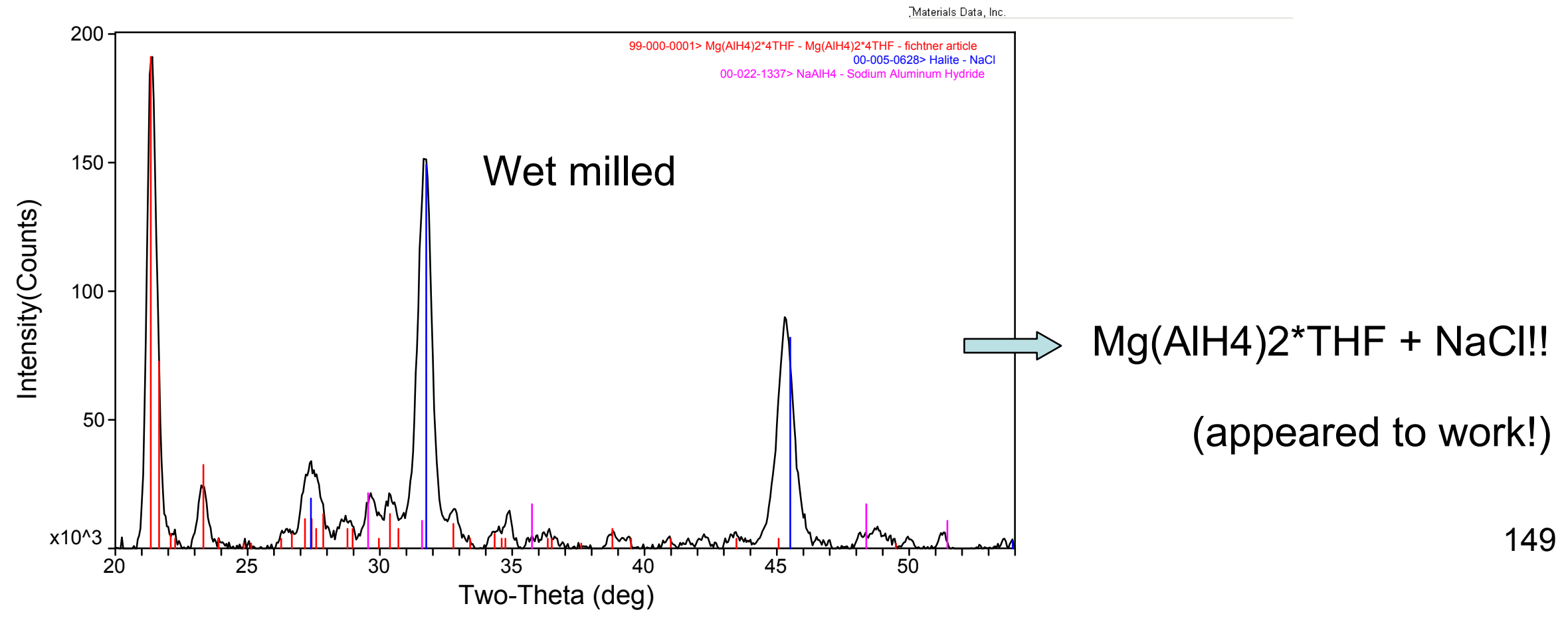

Dry milled 


\section{Combi Wet Milling Reaction 2}

- NaAlH4 + LiNH2 $\rightarrow$ no rxn with wet or dry combi milling

- Typical non-combi ball milling showed new phase along with starting materials

- AlH4LiNa2?

Non-combi ball-milled sample
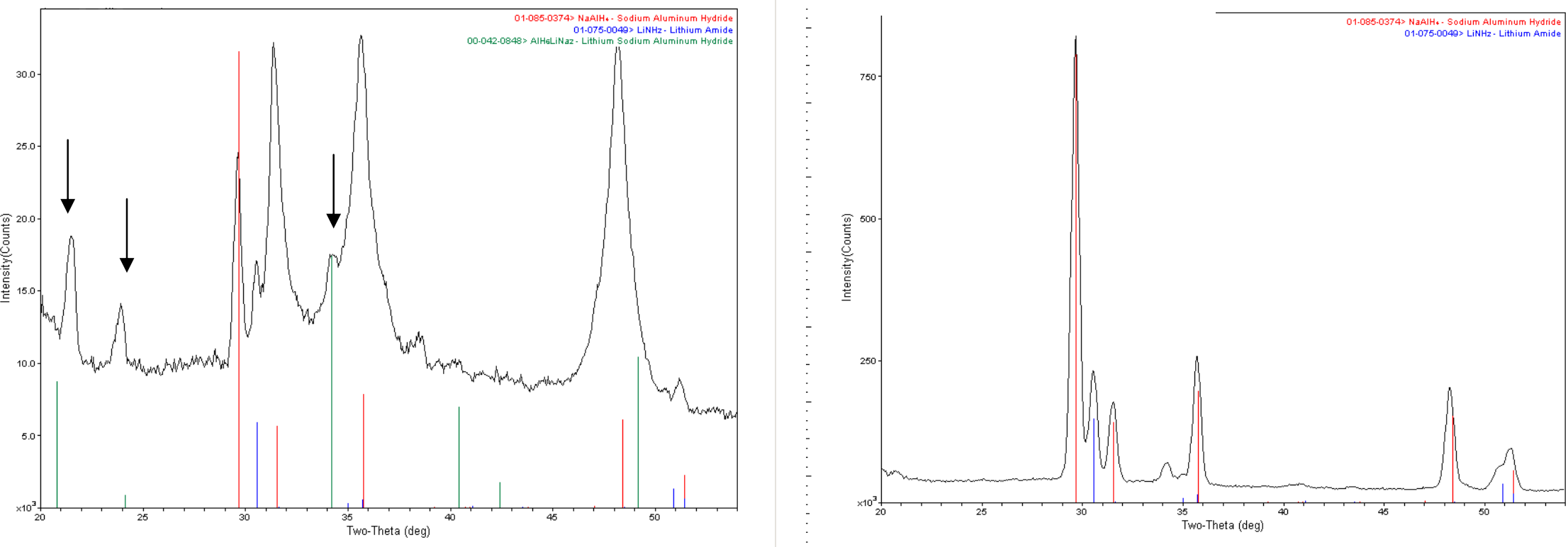

Wet-milled combi sample 


\section{Combi Wet Milling Reaction 3}

- $\mathrm{MgH} 2+\mathrm{LiNH} 2 \rightarrow$ no rxn with either wet or dry combi milling

Non-combi ball-milled sample

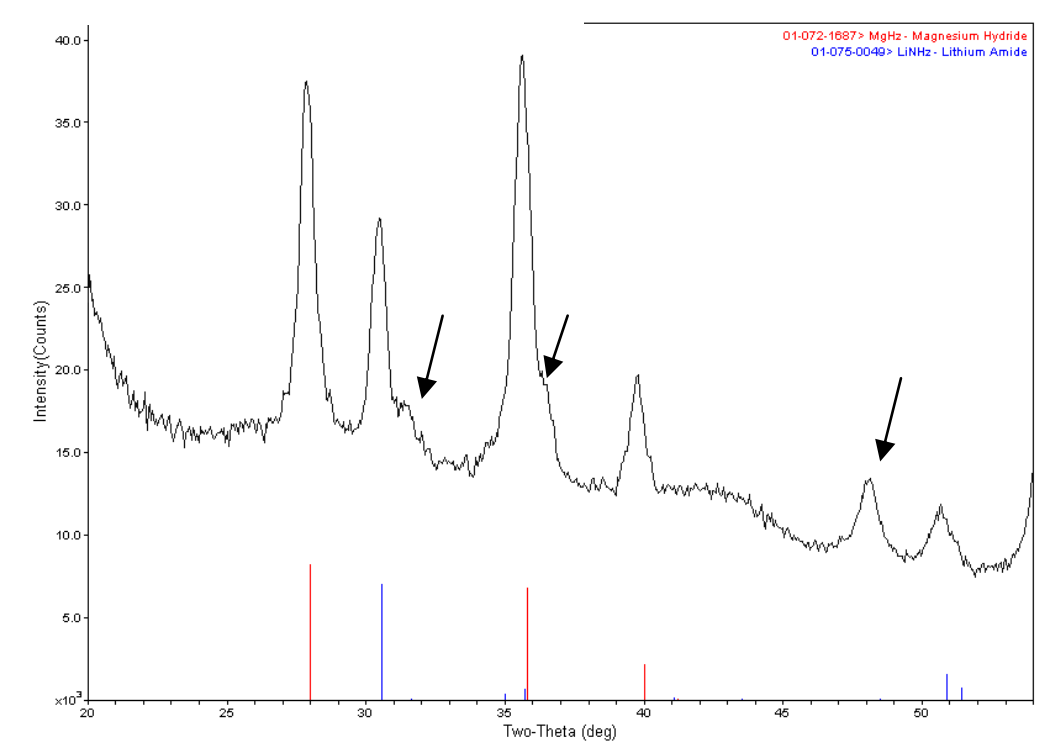

Wet milled combi sample

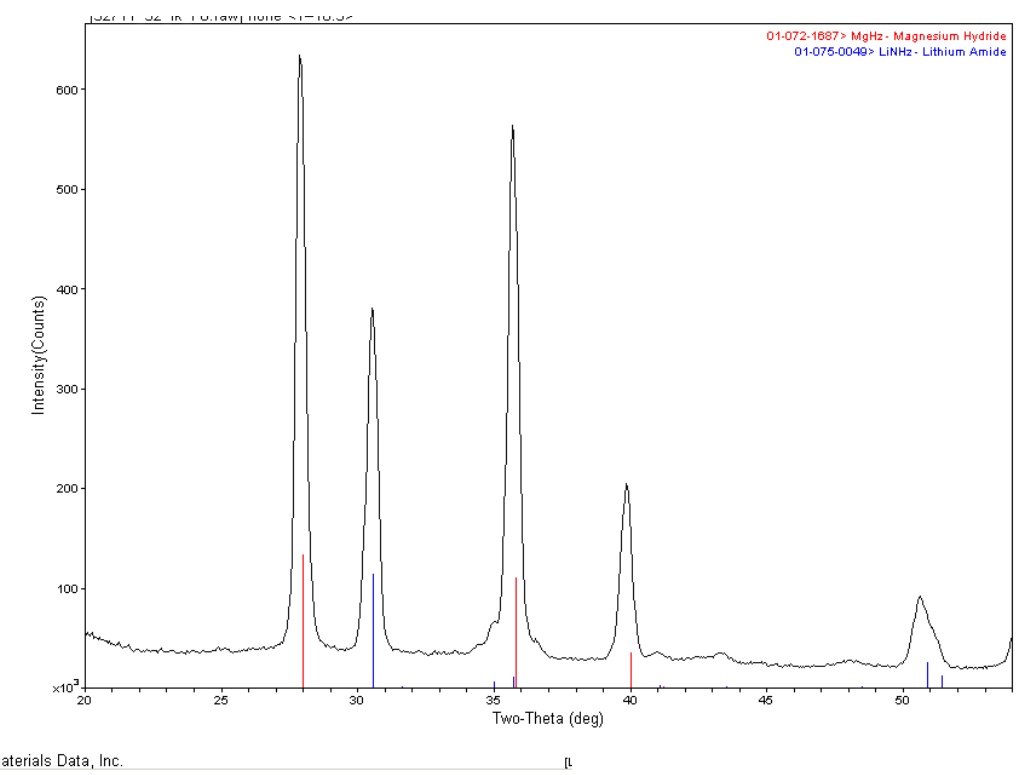




\section{Combi Wet Milling Reaction 4}

- $\mathrm{LiBH} 4+\mathrm{MgCl} 2 \rightarrow$ ?

Dry milled product: $\mathrm{MgCl} 2$

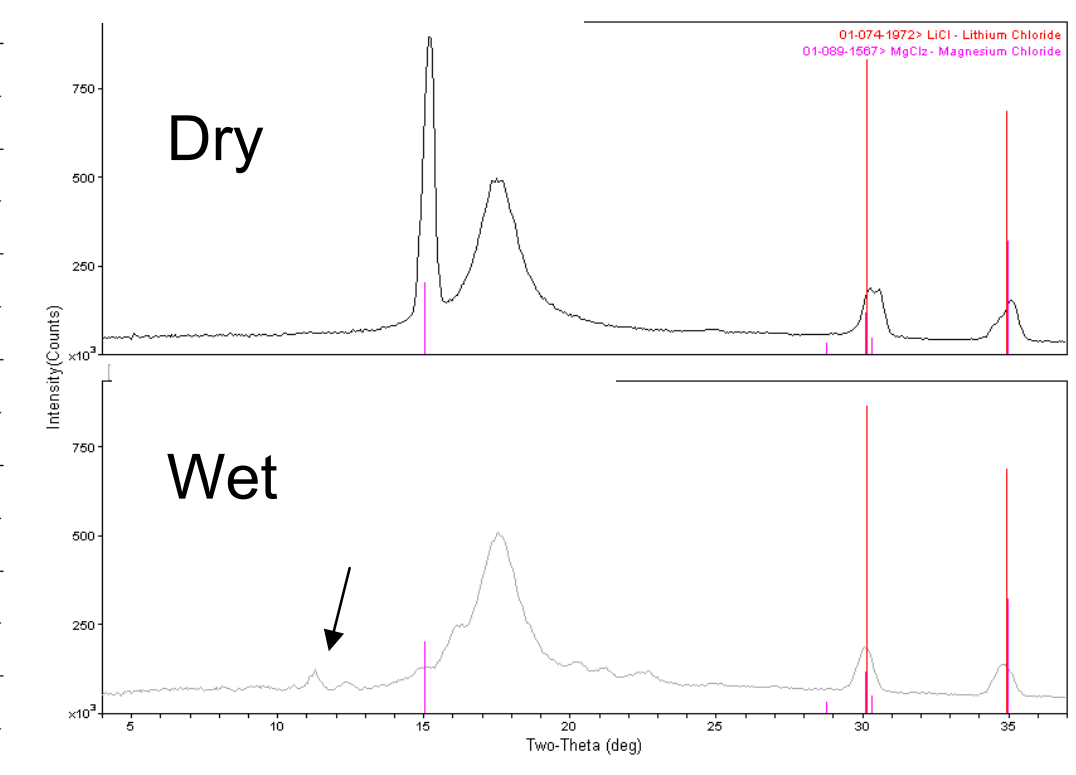

Wet milled product: $\mathrm{LiCl}+$ ?

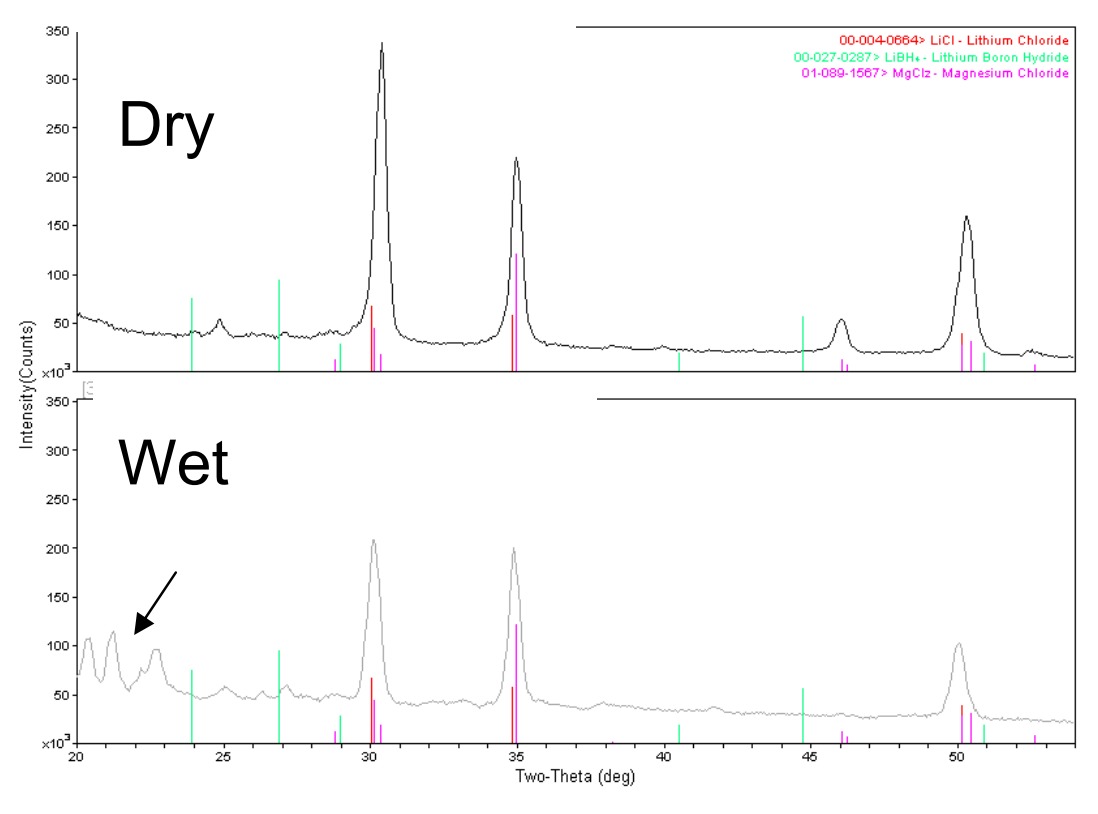




\section{Combi Wet Milling Reaction 5}

- $\mathrm{MgCl} 2+2 \mathrm{LiNH} 2 \rightarrow$ ?

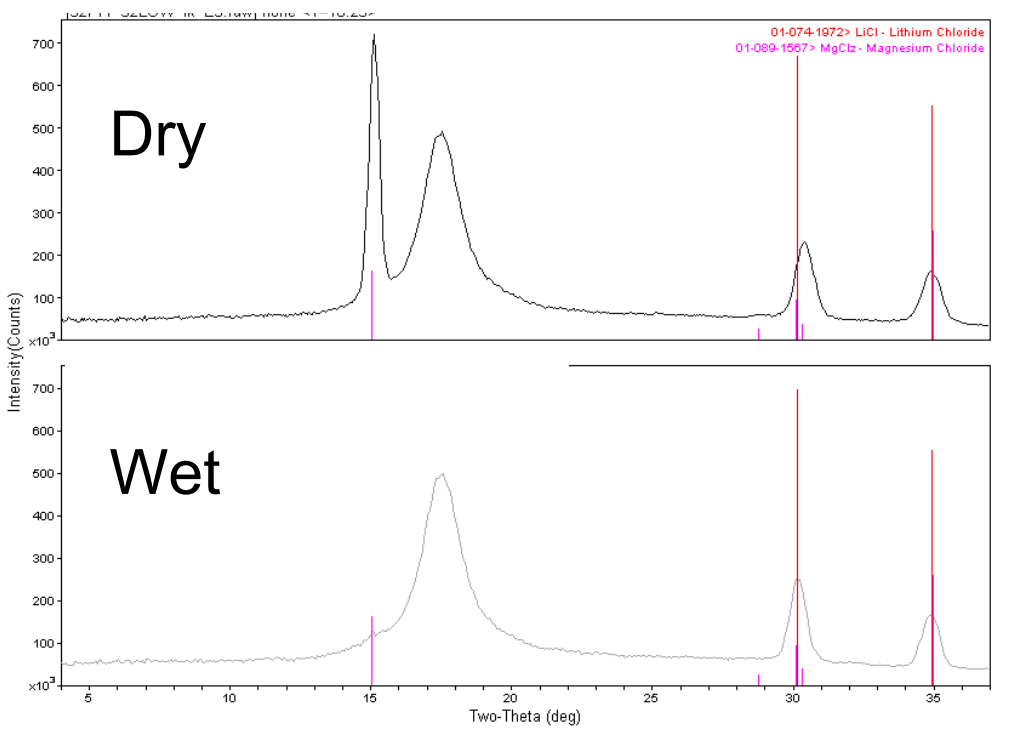

Dry product: $\mathrm{MgCl} 2$

Wet product: $\mathrm{LiCl}$

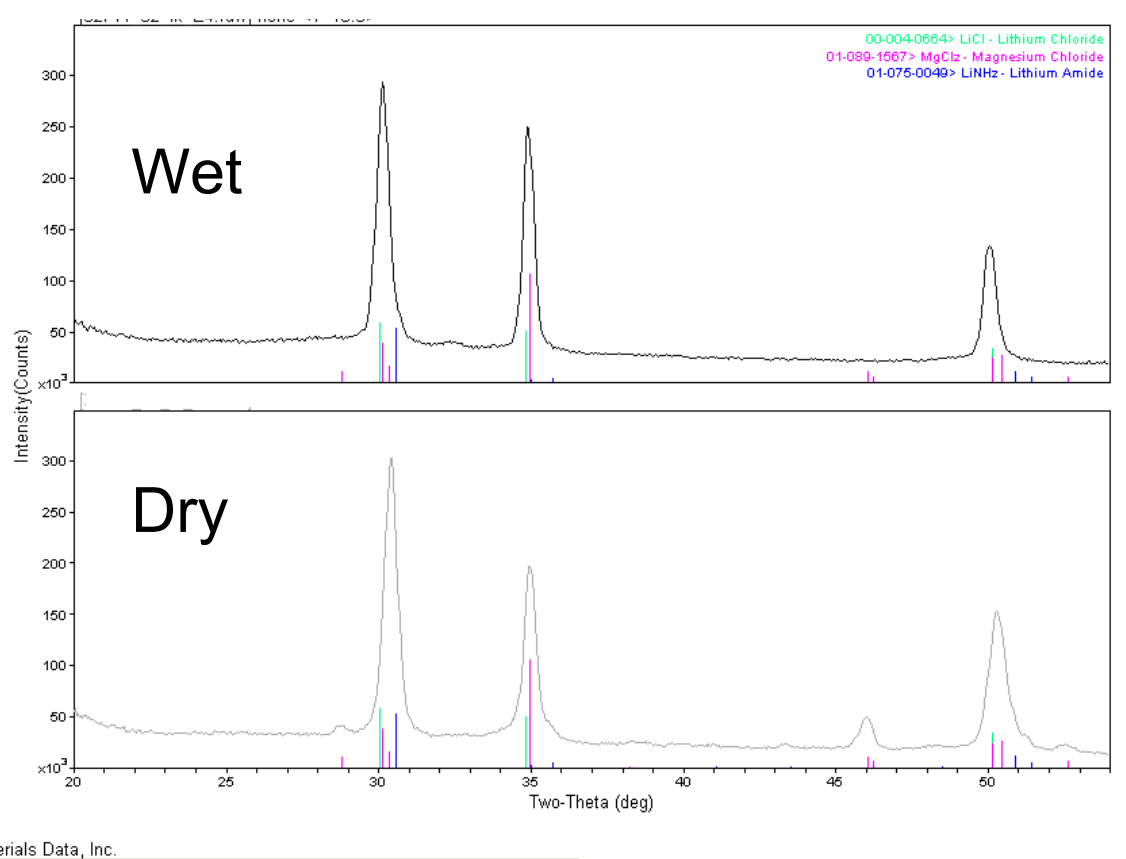




\section{Combi Wet Milling Reaction 6}

- $\mathrm{LiBH} 4+\mathrm{LiNH} 2 \rightarrow$ ?

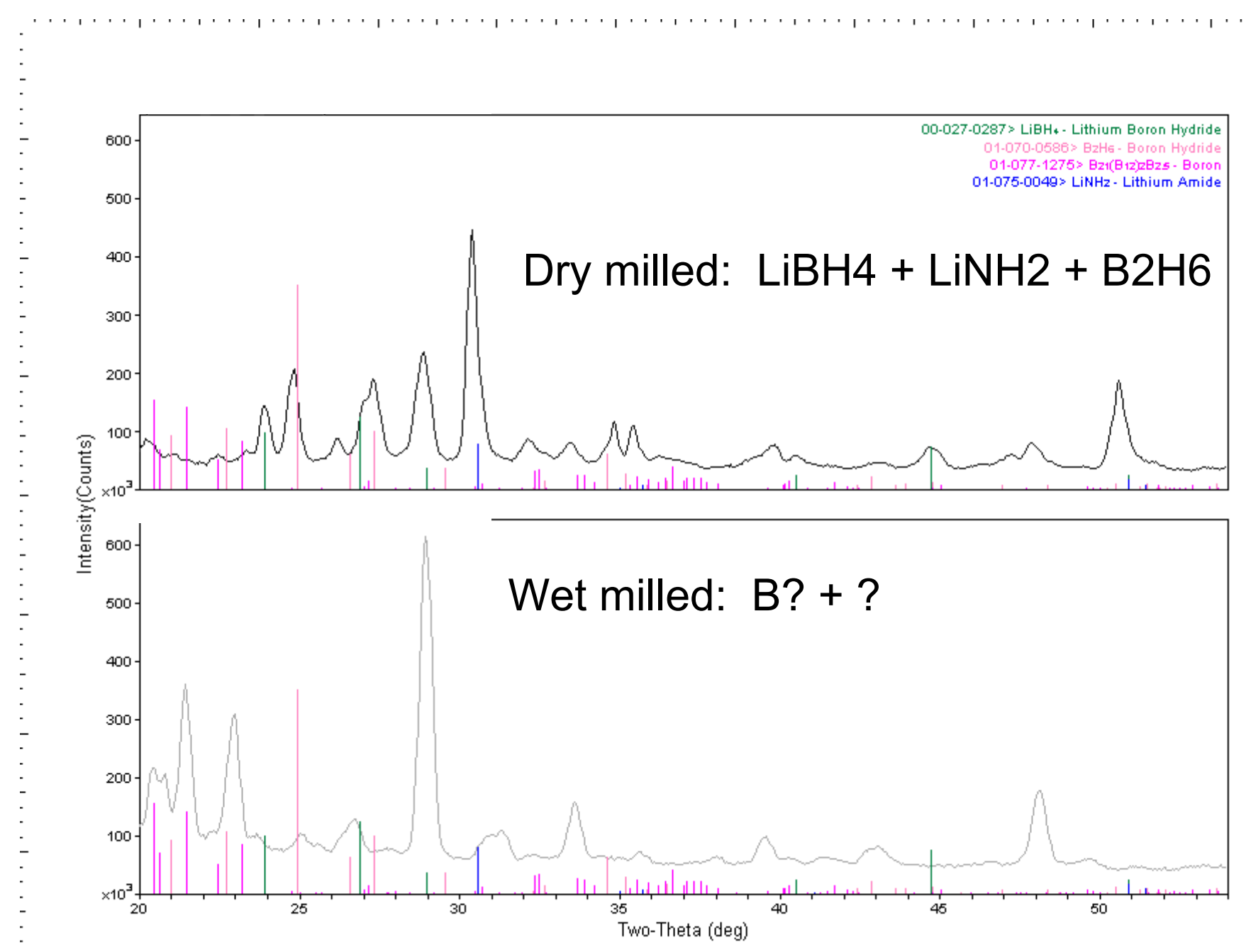




\section{Combi Milling Conclusions}

- THF did facilitate some, but not all of the desired reactions

- Did not seem to have any problems with THF leakage during milling

- Solids that were wet milled were more difficult to get out of plate

- Dried into very hard solids, hard to loosen ss balls 


\section{$\mathrm{NaNH}_{2}-\mathrm{NaBH}_{4}-\mathrm{MgH}_{2}$}

Phase diagram is covered in 41 reactions:

- $\mathrm{NaNH}_{2}: \mathrm{NaBH}_{4}=0.25,0.33,0.5,1,2,3,4$

- $\mathrm{MgH}_{2} /\left(\mathrm{NaNH}_{2}+\mathrm{NaBH}_{4}\right)=0,0.25-2$

- Theoretical capacities range from $6.22-9.47 \% \mathrm{H}$

Used integral stoichiometries vs. equal coverage

- $\mathrm{LiBH}_{4}-\mathrm{LiNH}_{2}-\mathrm{MgH}_{2}$ has complicated product dist.

- More direct hits rather than ending up with off-stoichiometry mixtures - may ease ID issues

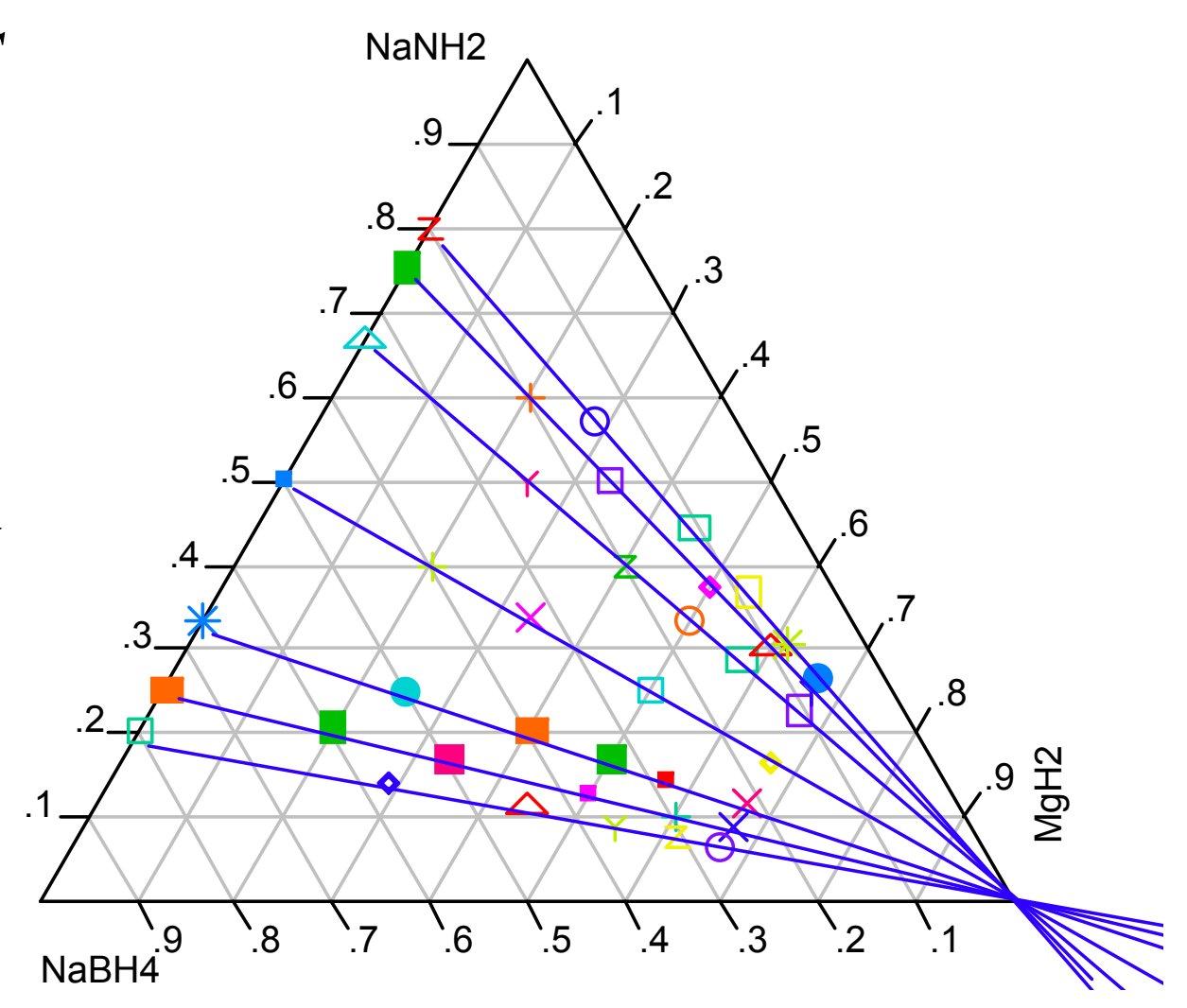




\section{APPENDIX B}

\section{Virtual High Throughput Screening of Mixed Complex Hydrides}

\section{Introduction}

The screening of materials for desired properties with computational methods can be an arduous task. An approximate model could screen many different compositions and elements in a time scale similar to the experimental high throughput screening of materials. We refer to this approach as virtual high throughput screening (VHTS). The approximate model developed here has the ability to screen the heats of mixing for different combinations of alanates and borohydrides The combination of the results from experimental screening of mixtures and predictions of an approximate model increases the confidence that the experimental effort did not miss any promising mixtures or compounds. An analysis of the results leads to qualitative concepts which lead to an understanding of these materials at a more fundamental level. This fundamental understanding leads to a rational approach to selecting mixture of complex hydrides which could be reversible under reasonable conditions.

Mixtures of alkali and alkaline earth aluminum tetrahydrides (alanates) and mixtures of transition metal, alkali and alkaline earth borohydrides are the focus of this work. Since $\mathrm{NaAlH}_{4}$ has $4 \mathrm{wt} \%$ reversible hydrogen capacity and is reversible at relatively high temperature, mixing less stable alanates with higher hydrogen capacities such as $\mathrm{LiAlH}_{4}$ and $\mathrm{Mg}\left(\mathrm{AlH}_{4}\right)_{2}$ with $\mathrm{NaAlH}_{4}$ could yield a less stable compound with higher capacities, which could meet the gravimetric and stability targets defined by DOE. Alkali and Alkaline Earth Borohydrides have high hydrogen capacity but are too stable to be reversible under reasonable conditions. Transition Metal Borohydrides also have high hydrogen capacity but are too unstable to be reversible under reasonable conditions. Compounds between transition metal borohydrides and alkali and alkaline earth borohydrides are also known to exist and appear to be more stable than transition metal borohydrides and have hydrogen capacities which will meet the DOE gravimetric density targets.

Classically, complex hydrides are ionic compounds where the cations are monatomic and the anions contain several atoms. The polyatomic nature of the anion is what defines these hydrides as "complex". Born, et al. have shown that the cohesive energy, structure and dynamics of ionic compounds could be modeled with a relatively simple Born model (Born \& Huang,1954). The Born model consists essentially of two terms. The first term is an electrostatic term between ions which gives rise to the cohesive energy of the salt. The second term is an overlap term which defines the distances between neighbors in the ionic lattice. We have extended the Born model to complex hydrides by assuming that the bonding between the cations and the complex anions is ionic and can be described by the Born model. The bonding between atoms within a complex anion is assumed to be essentially covalent. Although the Born model is a crude approximation of the bonding in complex hydrides, it gives a qualitatively correct description of the bonding in mixtures of complex hydrides (van Setten, de Wijs \& Brocks, 2006). See the Methods section below for more details about these calculations. Note that the most significant advantage of the Born model is that it several orders of magnitude less computationally intense than quantum mechanics and allows for screening of approximately a thousand different mixtures of complex hydrides in a month. However the rate determining step in VHTS is the determination of 
parameters that can predict the structure of materials containing several different elements including transition metals. The fitting of the potential parameters described in the methods section required approximately a month for each element included in the VHTS. Including the time required parameter fitting, the screening rate decreases to approximately one hundred phases per month. This screening rate is approximately the same as the rate that samples can be screened experimentally. The results of screening complex hydrides with this simple model can be used to find candidate materials for hydrogen storage and aids in the understanding of the properties of mixtures of complex hydrides.

\section{Virtual High Throughput Screening of the Heats of Mixing of Alanates}

We chose to focus first of the heats of mixing of the aluminum tetrahydrides (alanates) because these phases had the best chance of meeting DOE's gravimetric hydrogen capacity target $\left(>6 \mathrm{wt} \% \mathrm{H}_{2}\right)$. Although stable mixtures of alkali and alkaline earth aluminum hexahydrides are known these phases have gravimetric capacities less than 6 wt $\% \mathrm{H}_{2}$ ). Forming stable mixtures of hexahydrides would lead to materials which would not meet the density targets. Once stable mixtures of tetrahydrides are found then we would then consider their decomposition products, which may include mixed hexahydrides.

An $8 \times 8 \times 8 \times 8$ grid of compositions was selected to screen mixtures of $\mathrm{Li}, \mathrm{Na}, \mathrm{K}, \mathrm{Be}, \mathrm{Mg}$ and $\mathrm{Ca}$ alanates. The step size of the grid was 4 atoms of alkali metals and 2 atoms of alkaline earths. This generated a total of 1287 compositions. The simulated annealing algorithm was applied to each of the compositions and 1086 converged to minimum. Seven mixtures were found to have negative heats of mixing (Figure B1). These mixtures were $\mathrm{Be}_{2} \mathrm{Mg}_{6} \mathrm{Ca}_{4} \mathrm{~K}_{8}\left(\mathrm{AlH}_{4}\right)_{32}, \mathrm{Be}_{2} \mathrm{Mg}_{4} \mathrm{Ca}_{6} \mathrm{~K}_{8}\left(\mathrm{AlH}_{4}\right)_{32}, \mathrm{Li}_{24} \mathrm{Na}_{8}\left(\mathrm{AlH}_{4}\right)_{32}$, $\mathrm{Li}_{20} \mathrm{Na}_{12}(\mathrm{AlH} 4)_{32}, \mathrm{Be}_{2} \mathrm{~K}_{28}\left(\mathrm{AlH}_{4}\right)_{32}, \mathrm{Mg}_{2} \mathrm{Ca}_{14}\left(\mathrm{AlH}_{4}\right)_{32}$ and $\mathrm{Mg}_{4} \mathrm{Ca}_{12}\left(\mathrm{AlH}_{4}\right)_{32}$. The heats of mixing for these phases were consistently small $\left(\left|\Delta \mathrm{H}_{\text {mix }}\right|<2.25 \mathrm{~kJ} / \mathrm{mol}^{*} \mathrm{H}_{2}\right)$.

A stable mixture of $\mathrm{LiAlH}_{4}$ and $\mathrm{NaAlH}_{4}$ must have a heat of mixing large enough to make the decomposition to form $\mathrm{Li}_{3} \mathrm{AlH}_{6}$ unfavorable thermodynamically. For pure $\mathrm{LiAlH}_{4}$ the enthalpy for the decomposition reaction (3. $\mathrm{LiAlH}_{4} \rightarrow \mathrm{Li}_{3} \mathrm{AlH} \mathrm{H}_{6}+2 \cdot \mathrm{Al}+3 \cdot \mathrm{H}_{2}$ ) is $9 \mathrm{~kJ} / \mathrm{mol} \cdot \mathrm{H}_{2}$

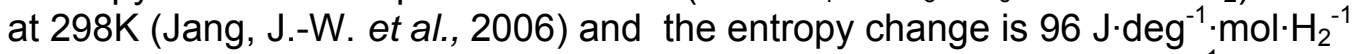
(Bonnetot, B., et al., 1979). The $\Delta \mathrm{G}$ for this reaction is $-19.7 \mathrm{~kJ} / \mathrm{mol} \cdot \mathrm{H}_{2}^{-1}$. A reaction with a free energy this large requires a hydrogen pressure larger than $2.8 \mathrm{Kbar}$ to reverse at 298K. A compound of $\mathrm{NaAlH}_{4}$ and $\mathrm{LiAlH}_{4}$ would need a heat of mixing of $-20 \mathrm{~kJ} / \mathrm{mol} \cdot \mathrm{Li}$ to prevent the decomposition of $\mathrm{LiAlH}_{4}$ in the compound. The heat of mixing for $\mathrm{Li}_{24} \mathrm{Na}_{8}\left(\mathrm{AlH}_{4}\right)_{32}$ and $\mathrm{Li}_{20} \mathrm{Na}_{12}\left(\mathrm{AlH}_{4}\right)_{32}$ predicted to be $-7 \mathrm{~kJ} / \mathrm{mol} \cdot \mathrm{Li}$ and $-5 \mathrm{~kJ} / \mathrm{mol} \cdot \mathrm{Li}$. Our model predicts that neither of these compounds will be stable with respect to decomposition of the $\mathrm{LiAlH}_{4}$ to $\mathrm{Li}_{3} \mathrm{AlH}$, $\mathrm{Al}$ and $\mathrm{H}_{2}$.

Claudy, et al reported the heat of formation $\left(\Delta \mathrm{H}_{\mathrm{f}}\right)$ of $\mathrm{Mg}\left(\mathrm{AlH}_{4}\right)_{2}$ to $-80.4 \mathrm{~kJ} / \mathrm{mol}$ (Claudy, P., Bonnetot, B. \& Letoffe, J.M., 1979). This leads to a heat of decomposition $\left[\mathrm{Mg}\left(\mathrm{AlH}_{4}\right)_{2}\right.$ $\left.\rightarrow \mathrm{MgH}_{2}+2 \cdot \mathrm{Al}+3 \cdot \mathrm{H}_{2}\right]$ of $1 \mathrm{~kJ} / \mathrm{mol} \cdot \mathrm{H}_{2}$. A recent high quality density functional prediction of $\Delta \mathrm{H}_{\mathrm{f}}(=-84 \mathrm{~kJ} / \mathrm{mol})$ (Lovvik \& Molin, 2005) is consistent with the Claudy's experimental

value. A stable alanate compound would require a heat of mixing of approximately -116 $\mathrm{kJ} / \mathrm{mol} \cdot \mathrm{Mg}$ to stabilize the $\mathrm{Mg}\left(\mathrm{AlH}_{4}\right)_{2}$ part of the compound enough to be reversible at 298K and 1 atmosphere $\mathrm{H}_{2}$. $\mathrm{Be}_{2} \mathrm{Mg}_{6} \mathrm{Ca}_{4} \mathrm{~K}_{8}\left(\mathrm{AlH}_{4}\right)_{32}, \mathrm{Be}_{2} \mathrm{Mg}_{4} \mathrm{Ca}_{6} \mathrm{~K}_{8}\left(\mathrm{AlH}_{4}\right)_{32}$, $\mathrm{Mg}_{2} \mathrm{Ca}_{14}\left(\mathrm{AlH}_{4}\right)_{32}$ and $\mathrm{Mg}_{4} \mathrm{Ca}_{12}\left(\mathrm{AlH}_{4}\right)_{32}$ have heats of mixing of $-23.8,-28.4,-36.6$ and -2.4 $\mathrm{kJ} / \mathrm{mol} \cdot \mathrm{Mg}$ respectively. Although these compounds would be stable with respect to 
mixing, they are not stable with respect to decomposition of the $\operatorname{Mg}\left(\mathrm{AlH}_{4}\right)_{2}$. These compounds will not reversibly desorb $\mathrm{H}_{2}$ under reasonable conditions.

After this work was completed, $\mathrm{LiMg}\left(\mathrm{AlH}_{4}\right)_{3}$ was synthesized (Mamatha, et al. 2006). The VHTS scan of the alanates did not find that $\mathrm{LiMg}\left(\mathrm{AlH}_{4}\right)_{3}$ had a negative heat of mixing. We carried out pseudopotential plane-wave calculations (Kresse \& Hafner,1996) $\mathrm{LiAlH}_{4}, \mathrm{Mg}\left(\mathrm{AlH}_{4}\right)_{2}$ and $\left.\mathrm{LiMg}(\mathrm{AlH})_{3}\right)_{3}$ to obtain an accurate prediction for the energy for the reaction $\mathrm{LiAlH}_{4}+\mathrm{Mg}\left(\mathrm{AlH}_{4}\right)_{2} \rightarrow \mathrm{LiMg}\left(\mathrm{AlH}_{4}\right)_{3}$ of $0.4 \mathrm{~kJ} / \mathrm{mol}$. Although this calculation predicts that this reaction is endothermic, the errors in the calculation $( \pm 10 \mathrm{KJ} / \mathrm{mol})$ leads to the conclusion that the calculation does not rule out $\mathrm{LiMg}\left(\mathrm{AlH}_{4}\right)_{3}$ as phase which could be stable with respect to $\mathrm{LiAlH}_{4}$ and $\mathrm{Mg}\left(\mathrm{AlH}_{4}\right)_{2}$. However it does rule out $\mathrm{LiMg}\left(\mathrm{AlH}_{4}\right)_{3}$ as a phase which would desorb hydrogen reversibly because the $\mathrm{Mg}\left(\mathrm{AlH} \mathrm{H}_{4}\right)_{2}$ requires 116 $\mathrm{kJ} / \mathrm{mol} \cdot \mathrm{Mg}$ of stabilization to decompose reversibly under reasonable conditions. $\mathrm{LiMg}\left(\mathrm{AlH}_{4}\right)_{3}$ has been to observed to decompose exothermically to $\mathrm{LiMgAlH}_{6}$. The formation of mixed hexahydride during decomposition further destabilizes $\operatorname{LiMg}\left(\mathrm{AlH}_{4}\right)_{3}$. The observed instability of $\mathrm{LiMg}\left(\mathrm{AlH}_{4}\right)_{3}$ and energies from plane-wave calculations supports the conclusion from VHTS and combinatorial chemistry that mixtures of alanates will not be reversible under reasonable conditions.

Small heats of mixing are a consequence of the ionic bonding in alanates. Kapustinskii has proposed an equation to estimate heats of formation for ionic materials which depends only on the size and charge of the ions (Kapustinkski, 1956). The Kapustinskii equation was shown to be fairly accurate to within $5 \%$ of the ionic lattice energy for a large range of systems including metal halides, oxide and chalcogenides. This corresponds to and error of about $40 \mathrm{~kJ} / \mathrm{mol}$. The reason that this approximation works is that the electrostatic energy dominates the cohesive energy of salts. The electrostatic energy is dominated by the interaction of nearest neighbors which is given by $z_{i} z_{j} n_{i} / r_{i j}$. The term $z_{i}$ is the charge of ion $\mathrm{i}$. The term $n_{i}$ is the coordination number of ion $\mathrm{i}$. An estimate for $n_{i}$ can be derived from Pauling's ratio rules. The term $r_{i j}$ is the distance between nearest neighbors which can be estimated as the sum of ionic radii. Although the Kapustinkskii equation is a crude method to estimate heats of formation, the approximation is valid because the nearest neighbor distances and coordination numbers between a pair of ions are approximately the same over a large range of materials. To first order $( \pm 40 \mathrm{~kJ} / \mathrm{mol})$ the lattice energy of many double salts is the weighted sum of the lattice energy of their components (Yoder \& Flora, 2005). This approximation is valid for a large number of double salts including oxides, (Driessens, 1968), halides (Driessens, 1968), carbonates (Driessens, 1968), sulfates (Glynn, 2000), and molten salt mixtures (Kleppa, 1987; J.Lumsden, 1966). The exceptions to this first order approximation are the reactions like that between $\mathrm{SiO}_{2}$ and alkali oxides (i.e $\mathrm{SiO}_{2}+$ $\mathrm{Na}_{2} \mathrm{O} \rightarrow \mathrm{Na}_{2} \mathrm{SiO}_{3} \Delta \mathrm{H}=-239 \mathrm{~kJ} / \mathrm{mol}$ ). In the silicate reaction the three dimensional $\mathrm{SiO} 2$ framework reacts with $\mathrm{Na}_{2} \mathrm{O}$ to form one dimensional chains of $\left[\mathrm{Si}_{2} \mathrm{O}_{6}\right]^{-4}$. The formation of new complex anions from the reactants is what increases the magnitude of the enthalpy change of this reaction. The upper bound of $40 \mathrm{~kJ} / \mathrm{mol}$ for a heat of mixing is a useful tool for surveying complex hydrides to determine which complex hydrides could form a mixture which would be reversible under reasonable conditions.

Alanate mixtures containing magnesium and will not be stable with respect to dehydrogenation because the heat of mixing can not be large enough to stabilize the mixture with respect to dehydriding. Although our estimate of the upper bound for the heat of mixing can not rule out that it may be possible to stabilize $\mathrm{LiAlH}_{4}$ with respect to dehydriding by mixing it with another alanate, experimental efforts, our VHTS and $a b$ 
initio models has not found any stable mixtures. Since $\mathrm{Be}\left(\mathrm{AlH} \mathrm{H}_{4}\right)_{4}$ is toxic and is less stable than $\mathrm{Mg}\left(\mathrm{AlH}_{4}\right)_{2}$ it also is not a good candidate for mixtures either. The small heats of mixing expected from ionic materials makes it unlikely that mixtures of alanates will lead materials to with a higher gravimetric capacity or more attractive thermodynamics for hydrogen storage. One needs to mix complex hydrides which have enthalpies of dehydriding between $20-30 \mathrm{~kJ} / \mathrm{mol} \cdot \mathrm{H}_{2}$ or react to form new complex ions.

\section{VHTS Screening of Mixtures of Alkali, Alkaline Earth and Zn Borohydrides}

Alkali and alkaline earth borohydrides are ionic materials which decompose at fairly high temperatures and have a low vapor pressure. Conversely transition metal borohydrides (TMB) have much more covalent character. The covalent nature of TMB leads to lower stability and higher vapor pressures. Several compounds of alkali and transition metal borohydrides have been reported in the literature. It appears that the reaction between alkali and transition borohydrides forms complex anions containing the transition metal and borotetrahydride. (Marks \& Kolb, 1977). The reaction between alkali (and alkaline earth) borohydrides and transition metal borohydrides could lead to large heats of because it involves a reaction of complex ions rather than simple mixing. The larger heat of reaction could lead to a compound which is reversible under reasonable conditions. This motivated a VHTS search of mixtures of alkali, alkaline earth and $\mathrm{Zn}$ borohydrides. Zn borohydride has been observed to be unstable. It has been observed to decompose at $85^{\circ} \mathrm{C}$ and to slowly lose hydrogen at room temperature (Jeon \& Cho, 2006). The product of the reaction of alkali borohydrides with $\mathrm{Zn}\left(\mathrm{BH}_{4}\right)_{2}$ forms a more stable compound which decomposes above $100{ }^{\circ} \mathrm{C}$. (Eliseo and Jenson, 2006). If we assume that the reaction between $\mathrm{Zn}\left(\mathrm{BH}_{4}\right)_{2}$ and alkali or alkaline earths borohydrides is not simple mixing but a reaction to form a complex anion containing $\mathrm{Zn}$ (i.e, $\mathrm{Zn}\left(\mathrm{BH}_{4}\right)_{4}^{-2}$ ), then these mixtures could lead to a material which is reversible at reasonable conditions.

In a manner similar to the alanates we used to the forcefield parameters derived above to perform virtual high throughput screening on mixtures of $\mathrm{LiBH}_{4}, \mathrm{NaBH}_{4}, \mathrm{Mg}\left(\mathrm{BH}_{4}\right)$, $\mathrm{Ca}\left(\mathrm{BH}_{4}\right)_{2}$ and $\mathrm{Zn}\left(\mathrm{BH}_{4}\right)_{2}$. Sixteen mixtures were found to have negative heats of mixing (Figure B2). $\mathrm{Li}_{4} \mathrm{Ca}_{5} \mathrm{Zn}\left(\mathrm{BH}_{4}\right)_{16}$ has a heat of mixing of $-7.5 \mathrm{~kJ} / \mathrm{mol} \cdot \mathrm{Zn}$. This compound has the largest heat of mixing per Zinc atom. Recent DFT calculations on $\mathrm{Zn}\left(\mathrm{BH}_{4}\right)_{2}$ (Nakamori, et al., 2006) has indicated that the decomposition of $\mathrm{Zn}\left(\mathrm{BH}_{4}\right)_{2}$ is exothermic by $7.5 \mathrm{~kJ} / \mathrm{mol} \cdot \mathrm{H}_{2}$. Assuming an entropy of $\mathrm{H}_{2}$ desorption of $130 \mathrm{~J} / \mathrm{deg} \cdot \mathrm{mol} \cdot \mathrm{H}_{2},($ Grochala \& Edwards, 2004) a material should have an enthalpy for $\mathrm{H}_{2}$ desorption at about 40 $\mathrm{KJ} / \mathrm{mol} \cdot \mathrm{H}_{2}$ to be reversible near $300 \mathrm{~K}$ and $1 \mathrm{~atm} \mathrm{H}_{2}$ pressure. The heats of mixing for $\mathrm{Li}_{4} \mathrm{Ca}_{5} \mathrm{Zn}\left(\mathrm{BH}_{4}\right)_{16}$ or any other mixture detected in the VHTS scan are not larger enough to stabilize $\mathrm{Zn}\left(\mathrm{BH}_{4}\right)_{2}$ to be reversible under reasonable condtions.

Recent DFT calculations (Nakamori, et al. 2006) has estimated the enthalpy of $\mathrm{H}_{2}$ desorption for $\mathrm{Zr}\left(\mathrm{BH}_{4}\right)_{4}$ and $\mathrm{Sc}\left(\mathrm{BH}_{3}\right)_{3}$ to be 3 and $4 \mathrm{~kJ} / \mathrm{mol}^{-} \mathrm{H}_{2}$ respectively. Neither of these compounds could be stabilized enough to be reversible under reasonable conditions, if these compounds have the heats of mixing of typical ionic compounds. The largest possible heat of mixing of $40 \mathrm{~kJ} / \mathrm{mol}$ would have to be spread over ten or hydrogen atoms, result in a stabilization of only $<5 \mathrm{~kJ} / \mathrm{mol} \cdot \mathrm{H}_{2}$. This would result in a possible enthalpy of decomposition of less than $10 \mathrm{~kJ} / \mathrm{mol} \cdot \mathrm{H} 2$. However these compounds are not very ionic and could have larger heats of mixing with other borohydrides because of reactions to form new complex anions (i.e. $\mathrm{Zr}\left(\mathrm{BH}_{4}\right)_{6}{ }^{-2}$ or $\left.\mathrm{Sc}\left(\mathrm{BH}_{4}\right)_{4}{ }^{-}\right)$. This reaction would be analogous to the reaction of alkali oxides with silica which has a large $(\Delta \mathrm{H}=-239 \mathrm{~kJ} / \mathrm{mol})$ reaction enthalpy. Mixtures of borohydrides 
containing transition metals could lead to a reversible material with high gravimetric capacity. More estimates of the enthalpy of binary transition metal borohydrides which could be used to select better candidates.

\section{Summary}

A VHTS method was implemented to screen mixtures of complex hydrides. This method was applied to mixtures of alanates and borohydrides. No mixture was found to have a heat of mixing large enough to stabilize the unstable component of the mixture. Small heats of mixing are a consequence of the ionic nature of complex hydrides. The prediction of small heats of mixing is consistent with ab initio results (Arroyo y de Dompablo \& Ceder, 2004), our combinatorial chemistry effort and the observed stability of the few mixtures of alanates or borohydrides which have been synthesized, such as, LiMg(AlH3)3 (Mamatha, et al. 2006) and alkali transition metal borohydrides (Eliseo \& Jenson, 2006). Assuming a upper bound of $40 \mathrm{KJ} / \mathrm{mol}$ on heats of mixing of complex hydrides, one should focus of mixtures of complex hydrides with heats of dehydriding between 40 and $20 \mathrm{~kJ} / \mathrm{mol} \cdot \mathrm{H}_{2}$. Very few complex hydrides have dehydriding enthalpies that fall into this range and gravimetric densities above $6 \mathrm{wt} \% \mathrm{H}_{2}$. Further work should be done to synthesize and characterize alkali and alkaline earth transition metal borohydrides. The compounds could contain novel complex anions which could be more stable than transition metal borohydride.

\section{Methods}

The major limitation of the Born model is the parameters used to describe the interatomic interactions. We have chosen to parameterize this model by fitting the parameters to the total energies from quantum mechanical calculations. The program DMOL3 from Accelrys (Delly, 1990; Delly, 2000; DMOL3, 2007) was used to generate quantum mechanical energies (QME). The program GULP was used to fit parameters to the QME (Gale, 2007; Gale, 1997). The fitting process involved several steps. The first step was to define the atomic charges. The charges of the cations were assigned to their formal charges (i.e. +1 for alkali, +2 for alkaline earths). The atomic charges for atoms in the complex anions were fit to QME of reference compounds with their lattice constants increased to larger values with the internal coordinates and orientation of the complex anion held fixed. The simple scan isolated the electrostatic energy of the solid and simplified the fitting of the electrostatic terms.

In Figure B3, we show a comparison of the QME and electrostatic energy from the Born Model of the primitive cell of $\mathrm{NaAlH}_{4}$ as a function of the lattice constant. The fractional coordinates of the $\mathrm{Na}$ and $\mathrm{Al}$ atoms in this lattice and the internal coordinates and orientation of the $\mathrm{AlH}_{4}{ }^{-}$complex anions were held fixed. An acceptable fit of the electrostatic energy to the QME for was obtained by setting the charges of $\mathrm{H}$ to $-0.5 \mathrm{e}^{-}$, the charge of $\mathrm{Al}$ to $1.0 \mathrm{e}^{-}$and the charge of $\mathrm{Na}$ to $1.0 \mathrm{e}^{-}$. A constant term of $133.975 \mathrm{eV}$ was added to the electrostatic energy in this fit. This constant term represents the difference between the DMOL3 cohesive energy and the electrostatic energy of separated sodium cations and alanate $\left(\mathrm{AlH}_{4}{ }^{-}\right)$anions for this particular choice of atomic charges. These charges were used in all subsequent calculations involving alanates.

The $\mathrm{AlH}_{4}{ }^{-}$groups were treated as isolated molecules. The intramolecular parameters for the bond stretching and angle bending terms of $\mathrm{AlH}_{4}{ }^{-}$were fit to the geometry and vibrational frequencies of the isolated $\mathrm{AlH}_{4}{ }^{-}$anion as calculated by DMOL3. A Morse 
potential was used to describe the $\mathrm{Al}-\mathrm{H}$ bond $\left(\mathrm{D}=5.6427 \mathrm{eV}, \mathrm{a}=1.1728 \AA^{-2}\right.$ and $\left.1.589 \AA\right)$. A quartic polynomial was used to describe the $\mathrm{H}-\mathrm{Al}-\mathrm{H}$ bond angle potential $\left(\theta_{0}=109.47\right.$ degrees, $\mathrm{k}_{2}=1.5533 \mathrm{eV}$ radians $^{-2}, \mathrm{k}_{3}=0.0$ and $\mathrm{k}_{4}=1.0023 \mathrm{eV}$ radian $^{-4}$ ). See $(\mathrm{Gale}$, 2007) for a description of functional forms.

An intermolecular potential was fitted to the fitted to the atomic positions and vibrational frequencies predicted by DMOL3 at the experimental lattice constants for $\mathrm{NaAlH}_{4}$ (Bel'skii, V. K., Bulych'ev, B. M. \& Golubeva, A.V.,1983) and $\mathrm{LiAlH}_{4}$ (Sklar, N. \& Post, B., 1967; Hauback, et al, (2003). It was found that a shell model (Dick, B.G. \& Overhauser, A. W., 1958) for hydrogen was required to predict the experimental structure of $\mathrm{LiAlH}_{4}$ as a minimum. The charge of the hydrogen shell is $-1.5 \mathrm{e}^{-}$and the charge on the hydrogen core is $1.0 \mathrm{e}^{-}$. The spring constant for the core-shell interaction is $76.5697 \mathrm{eV} \AA^{-2}$. A Born-Mayer intermolecular potential (Born, M. \& Mayer, J.E., 1932) was used to describe interaction between hydrogen shell and the metal atoms. The functional form for this interaction $(\Phi(r) B M)$ is given by $\Phi(r) B M=A \exp (-r / \rho)$, where $r$ is the internuclear distance, $A$ and $p$ are parameters fit to QME or extrapolated from other elements. The metal-hydrogen parameters used for the results reported in this work are shown in Table B1.

A comparison of the experimental and predicted structures for $\mathrm{LiAlH}_{4}, \mathrm{NaAlH}_{4}$, and $\mathrm{Mg}\left(\mathrm{AlH}_{4}\right)_{2}$ are shown in Table B2. Note that almost all predicted lattice constants for alanates are with $10 \%$ of the experimental crystal structures. The only exception is the $c$ lattice constant for $\mathrm{Mg}\left(\mathrm{AlH}_{4}\right)_{2}$, which is off by $20 \%$. This error is most likely due to the poor description of the Van de Waals forces by the DMOL3 calculations use to parameterize the forcefield. The $c$ parameter in $\mathrm{Mg}(\mathrm{AlH} 4)_{2}$ is determined by the spacing between neutral layers of $\mathrm{Mg}\left(\mathrm{AlH}_{4}\right)_{2}$, the interlayer is very sensitive to the Van de Waals forces.

Another test of this forcefield is to compare the heats of solution predicted by the forcefield and quantum mechanical calculations. Cedar has predicted the energy of mixing with quantum mechanics for $\mathrm{LiAlH}_{4}$ and $\mathrm{NaAlH}_{4}$ (Arroyo y de Dompablo, M. E. \& Ceder, 2004). We compare the predictions of the forcefield with the quantum mechanical results in Figure B4. Note that the results from the forcefield and quantum mechanics are in qualitatively agreement. Both methods predict that the heats of mixing are always predicted to be positive and small (less than $10 \mathrm{~kJ} \cdot \mathrm{mol}^{-1}$ ).

Heat capacities provide yet another validation of the forcefield parameters. Heat capacities for $\mathrm{NaAlH}_{4}$ and $\mathrm{LiAlH}_{4}$ were calculated from their predicted phonon bands. The phonon bands were integrated over $5 \times 5 \times 5$ grid in k-space to compute the heat capacities. A comparison of the heat capacities derived from the forcefield and from experiment is shown in Figure B5. Note that the force field predicts heat capacities which are within $15 \mathrm{~J} \cdot \mathrm{mol}^{-1} \cdot \mathrm{deg}^{-1}$ which demonstrates that the forcefield is capturing the shape of the potential surface near the experimental structure.

Predicting the lowest energy crystal structure from first principles for an arbitrary mixture is a very difficult. A completely rigorous method to predict crystal structures with ForceField methods is currently not possible (Maddox, 1988). However, our experience indicates that is possible to get close in energy (to within an $\mathrm{eV} \cdot \mathrm{cell}^{-1}$ ) to the lowest energy structure using simulated annealing techniques. Although an $\mathrm{eV}$ is large error, it should be remembered that this error is for a large cell containing 32 formula units (for alkali alanates). This reduces the error to approximately $32 \mathrm{meV}\left(3 \mathrm{KJ} \cdot \mathrm{mole}^{-1}\right)$ per 
alanate $\left(\mathrm{AlH}_{4}{ }^{-}\right)$. This level of error is useful for estimating heats of mixing and predicting which mixtures of complex hydrides could be useful candidates for hydrogen storage.

The relative energies of different crystal structures for the same composition are difficult to predict exactly with force-field methods. However the errors associated with this error also appears to be largely cancelled out when comparing the energies of mixed phases with the energies of pure phases. Therefore the mixing energies should be qualitatively correct. The approximate model used in this work is predicting mixing energies for mixtures of complex hydrides containing the same anion with cations with different sizes and charges. Since the predicted lattice constants for alanates compare well to experimental lattice constants, the cations in our model have approximately the sizes corresponding to $\mathrm{Li}^{+}, \mathrm{Na}^{+}, \mathrm{K}^{+}, \mathrm{Be}^{+2}, \mathrm{Mg}^{+2}$ and $\mathrm{Ca}^{+2}$ cations and $\mathrm{AlH}_{4}{ }^{-}$anions. The qualitative results from this model have been also found to be consistent with the observations of our experimental effort. Although the model contains several approximations which cause quantitative errors in several properties, qualitatively the model correctly predict the mixing behavior of alanates.

Our procedure for estimating the heats of mixing for alanates starts with a tetragonal cell with a lattice constants of $a=b=13.8126 \AA$ and $c=13.4554 \AA$ at have a general composition $\mathrm{Li}_{(32-\mathrm{v}-\mathrm{w}-2 \mathrm{x}-2 \mathrm{y}-2 \mathrm{z})} \mathrm{Na}_{\mathrm{v}} \mathrm{K}_{\mathrm{w}} \mathrm{Be}_{\mathrm{x}} \mathrm{Mg}_{\mathrm{y}} \mathrm{Ca}_{\mathrm{z}}\left(\mathrm{AlH}_{4}\right)_{32}$. This cell is a $2 \times 2 \times 2$ supercell of a unit cell with I41/AMD symmetry and lattice constants $a=b=6.906$ and $c=6.723$. The fractional positions of this unit cell are tabulated in Table B3.

This cell was chosen because it contains pairs of layers of close packed alanate groups separated by pairs of layers of cations. The actual coordinates are the result of a high pressure (1 GigaPascal) minimization of $\mathrm{NaAlH}_{4}$. Paired layers of closed packed alanates groups are common in the crystal structures of compounds containing $\mathrm{AlH}_{4}^{-}$, $\mathrm{BH}_{4}^{-}, \mathrm{MoO}_{4}^{-2}$ and other tetrahedral complex anions with the $\mathrm{MX}_{4}$ stoichiometry. This type of anion packing is most obvious in the crystal structure of $\mathrm{Mg}\left(\mathrm{AlH}_{4}\right)_{2}$ and can be found in $\mathrm{NaAlH}_{4}$. The packing of anions in LiAlH4 could also be considered a distorted form of this type of packing. See Figure B6 for a comparison of the structures of $\mathrm{LiAlH}_{4}, \mathrm{NaAlH}_{4}$ and $\mathrm{Mg}\left(\mathrm{AlH}_{4}\right)_{2}$ with the paired layers of $\mathrm{AlH}_{4}{ }^{-}$groups highlighted. We found that this arrangement of $\mathrm{MX}_{4}{ }^{-}$anions were necessary in the starting guess to converge to lowest energy crystal structure.

The cations were distributed on the cation sites defined in Table B3 to minimize their electrostatic energy. A combinatorial procedure was used to find the lowest energy cation distribution (Low, 2005). Once the cations were distributed, the positions of all the atoms were relaxed to a local energy minimum with the program GULP(Gale, 2007). This minimum may not be the global minima because of the crude initial starting guess. Simulated annealing was used to allow the atoms move around and possibly find a lower energy structure. The structure was annealed by performing a molecular dynamics simulation at $200 \mathrm{~K}$ and $500 \mathrm{~K}$ with the program DL_POLY (Smith, Yong \& Rodger, 2002) with the parameters described above and starting with the GULP minimum energy structure. All the molecular dynamics reported has variable cell size and shape and used a Hoover thermostat and a zero pressure barostat. After allowing the MD simulation to run for 10 picoseconds (100,000 steps) the geometry was then quenched by allowing the atoms to relax to a local energy minimum. This low temperature run allowed the structure to break symmetry and possibly move to a lower energy minima. The new minimized structure was then annealed in high temperature (500K) molecular dynamics simulation which is identical the low temperature simulations in all parameters 
except for the temperature. The final geometry from the MD run was then energy minimized with program GULP. This run was intended to search for energy minima which might separate by large energy barriers from the initial starting geometry. This procedure was fairly efficient at finding low energy crystal structures which have energies to close to the lowest energy crystal structure.

Figure B7 demonstrates how well the above method works for predicting low energy structures for $\mathrm{NaAlH}_{4}$. Very little change occurs after the initial geometry optimization and low temperature molecular dynamics. However after high temperature molecular dynamics followed by optimization with GULP, the shape of the supercell changed significantly. The initial orthorhombic supercell changed to a monoclinic supercell. During this transformation the space group of the cell changed from the initial symmetry $\left(14_{1} /\right.$ amd $)$ of the supercell cell to $14_{1} / a$ with lattice constants $a=5.12$ and $c=10.84$, which is very close to the experimental crystal structure of $\mathrm{NaAlH}_{4}$.

The approximate approach taken in this effort will not always lead to a correct prediction of the experimental crystal structure. Several of the approximations in the method could easily lead to the incorrect relative energies of different crystal structures. The simulated procedure described above will not always lead to the lowest energy structure. The approximate model used in this work is predicting mixing energies for mixtures of complex ions containing the same anion with cations with different sizes and charges. The cations have approximately the sizes corresponding to $\mathrm{Li}, \mathrm{Na}, \mathrm{K}, \mathrm{Be}, \mathrm{Mg}$ and $\mathrm{Ca}$ cations. This model appears to qualitatively reproduce the observed mixing behavior of alanates.

The parameters used to model mixtures of borohydrides were derived in a similar manner to the alanates. The charges of the alkali, alkaline earths and $\mathrm{Zn}$ cations were assigned to their formal charges. The charges of the hydrogens in $\mathrm{BH}^{-}$groups were assigned to $-0.27 \mathrm{e}^{-}$. The charge assigned to $\mathrm{B}$ is $0.08 \mathrm{e}^{-}$. These charges were fit to the QME of $\mathrm{NaBH} 4$ where the lattice constants of $\mathrm{NaBH}_{4}$ were scaled to larger values and the internal coordinates of $\mathrm{BH}_{4}$ were held fixed. The Born-Mayer parameters (see Table B4) for the intermolecular potentials were derived to fits of the QME of DMOL3 calculations. We found it necessary to add three-body terms weighted by an exponential to favor $\eta^{2}$ coordination to $\mathrm{Mg}$ and $\mathrm{Zn}$ cations. The Born-Mayer potential favors $\eta^{3}$ bonding of the $\mathrm{BH} 4$ - group which maximizing the electrostatic interaction between the hydrides of $\mathrm{BH}_{4}{ }^{-}$and cations.

The $\mathrm{BH}_{4}^{-}$groups were treated as isolated molecules. The intramolecular parameters for the bond stretching and angle bending terms of $\mathrm{BH}_{4}{ }^{-}$were fit to the geometry and vibrational frequencies of the isolated $\mathrm{BH}_{4}{ }^{-}$anion as calculated by DMOL3. A harmonic potential was used to describe the $\mathrm{B}-\mathrm{H}$ bond $\left(\mathrm{k}_{2}=17.8797 \mathrm{eV} / \AA^{2}\right.$ and $\left.\mathrm{r}_{0}=1.589 \AA\right)$. $A$ harmonic potential was used to describe the $\mathrm{H}-\mathrm{B}-\mathrm{H}$ bond angle potential $\left(\theta_{0}=109.47\right.$ degrees, $\mathrm{k}_{2}=2.55 \mathrm{eV}$ radians $^{-2}$ ). See (Gale, 2007) for a description of functional forms. In Table B5 we compare the predicted versus experimental and density functional theory (DFT) structures for borohydrides using the parameters from Table B4. The force-field is predicting lattice constants which are within $10 \%$ of the experimental or DFT predicted structures. Experimental structures for $\mathrm{Mg}\left(\mathrm{BH}_{4}\right)_{2}$ and $\mathrm{Zn}\left(\mathrm{BH}_{4}\right)_{2}$ were not available when the VHTS work was performed. Ozolins and Mazoub have carried out data-mining of the ICSD structure database and have also applied Monte Carlo methods to estimate the lowest energy structures of alkaline earth borohydrides with DFT. Tables B6 and B7 compare the atomic coordinates predicted by the forcefield method with those predicted 
by DFT for $\mathrm{Mg}\left(\mathrm{BH}_{4}\right)_{2}$ and $\mathrm{Zn}\left(\mathrm{BH}_{4}\right)_{2}$ (Ozolins and Mazoub, 2006). The lowest energy structure they found for $\mathrm{Mg}\left(\mathrm{BH}_{4}\right)_{2}$ has $\mathrm{l}-4 \mathrm{~m} 2$ symmetry with atomic positions listed in Table B6. Since we performed this work an experimental structure for $\mathrm{Mg}\left(\mathrm{BH}_{4}\right)_{2}(\mathrm{Her}$, et al. 2007) has been disclosed. The experimental structure has a lower symmetry structure with a larger unit cell then the DFT structure predicted by Ozolins and Mazoub. The predicted structure is qualitatively similar to the experimental structure. The $\mathrm{BH}_{4}$ anions in both the theoretical and experimental structures bridge two Mg cations. The $\mathrm{Mg}$ cation in both structures are coordinated to four $\mathrm{BH}_{4}$ anions. The predicted structure should be within $20 \mathrm{~kJ} / \mathrm{mol} \cdot \mathrm{H}_{2}$ of the experimental structure and is good enough to derive force-field parameters. The atomic coordinates from the forcefield methods are within $10 \%$ of the coordinates predicted DFT. These results are adequate to derive parameters for the VHTS of these materials.

The initial cell for the search was a cubic cell with a lattice constant of $12.12 \AA$. This cell is the 2X2X2 supercell of the unit cell for the room temperature phase of $\mathrm{NaBH}_{4}$ (Davis and Kennard, 1985) with symmetry F-43m symmetry and a lattice constant of $6.06 \AA$. This cell has a general composition of $\mathrm{Li}_{(32-\mathrm{w}-2 x-2 y-2 z)} \mathrm{Na}_{w} \mathrm{Mg}_{x} \mathrm{Ca}_{y} \mathrm{Zn}_{z}\left(\mathrm{AlH}_{4}\right)_{32}$. Only one of the two $\mathrm{H}$ sites of the experimental structure was occupied to give an ordered structure with fully occupied sites. The atomic coordinates of the atoms in this lattice are shown in Table B8. Cations were distributed in the same manner as described for the VHTS of the alanates. An $8 \times 8 \times 8 \times 8 \times 8$ grid of compositions, consisting of 495 different compositions, were scanned for stable mixtures. 


\section{APPENDIX B References}

Arroyo y de Dompablo, M. E. \& Ceder, G. (2004) J. Alloys Comp. 364, 6.

Bel'skii, V. K., Bulych'ev, B. M. \& Golubeva, A.V. (1983) Zh. Neorg. Khim 28, 2694.

Blöchl, P.E., Jepsen, O. \& Andersen, O.K. (1994) Phys. Rev. B 49,16223.

Bonnetot, B., Claudy, P., Diot, M., \& Letoffe, J.M. (1979) J. Chem. Thermo. 11, 1197;

Entropies for $\mathrm{H} 2$ and Al taken from the NIST Chemistry WebBook,

http://webbook.nist.gov/chemistry/.

Born, M. \& Huang, K. (1954) "Dynamical Theory of Crystal Lattices”, Clarendon Press, 1954.

Born, M. \& Mayer, J.E. (1932) Z. Phys. 751.

Claudy, P., Bonnetot, B. \& Letoffe, J.M. (1979) J. Therm. Anal. 15, 119.

Davis, R. L. \& Kennard, C. H. L. (1985) J. Sol. State Chem. 59, 393.

Delley, B. (1990) J. Chem. Phys. 92, 508.

Delley, B. (2000) J. Chem. Phys. 113, 7756

Dick, B.G. \& Overhauser, A. W. (1958) Phys. Rev. 112, 90.

DMOL3 (2007) is available as part of Materials Studio from Accelrys Inc.

Driessens, F.C.M. (1968) Ber. Bunsen-Gesellschaft 72, 754.

Eliseo, J.R. \& Craig Jensen, C.M. (2006) "Developments in Advanced Borohydride Materials for Hydrogen Storage", International Symposium on Metal-Hydrogen Systems, Lahaina, Maui, Hawaii.

Gale, J.D. (2007) “User Manual for GULP: General Utility Lattice Program version 1.3”, Nanochemistry Research Institute, Curtin University of Technology, P.O. Box U1987, Perth 6845, Western Australia.

Gale, J.D. (1997) J. Chem. Soc., Faraday Trans. 93, 629.

Grochala, W. \& Edwards, P. P. (2004) Chem. Rev. 104, 1283.

Glynn, P. (2000) Rev. Mineral. Geochem. 40, 481.

Hauback, et al, (2003) J. Alloys Comp. 351, 222.

Her, J.-H., Stephens, P., Gao, Y., Soloveichik, G., Rijssenbeek, Andrus, J., M. \& Zhao, J.-C. (2007) Acta Cryst. B, accepted for publication, as cited by P. Stephens, http://www.nsls.bnl.gov/newsroom/news/2007/05-BN X16C.htm. 
Jang, J.-W., Shim, J.-H., Cho, Y.W. \& Lee, B.-J. (2006) J. Alloy Comp. 420, 286.

Jeon, e. \& Cho, Y. (2006) J. Alloys Comp. 422, 273.

Kapustinskii, A. F. (1956) Q. Rev. Chem. Soc., 10, 283.

Kleppa, O.J. (1987) NATO ASI Series, Series C: Mathematical and Physical Sciences, 202, 79.

Kresse G. \& Hafner, J. (1996) Phys. Rev. B, 54, 11169. The PAW-PBE potentials were used in these calculations (Kresse \& Joubert, 1999). The cell volume and shape were optimized in these calculations starting with their experimental structures. A planewave cutoff of $500 \mathrm{eV}$ was used. The k-points integration mesh was $5 \times 3 \times 3$ for $\mathrm{LiAlH}_{4}, 3 \times 3 \times 3$ for $\mathrm{Mg}\left(\mathrm{AlH}_{4}\right)_{2}$ and $3 \times 3 \times 3$ for $\mathrm{LiMg}\left(\mathrm{AlH}_{4}\right)_{3}$. The linear-tetrahedron method with Bloechl corrections to the energy was used in the k-space integration. (Blöchl, Jepsen \& Andersen, 1994).

Kresse, G. \& Joubert, J. (1999) Phys. Rev. B 59, 1758.

Lovvik, O.M. \& Molin, P.N. (2005) Phys.Rev. B 72, 073201.

Low, J.J. (2005) U.S. Patent 6845329.

Lumsden, J. (1966) "Thermodynamics of Molten Salt Mixtures", Academic Press, New York.

Maddox, J. (1988) Nature (London), 335, 201.

Mamatha M., Weidenthaler, C., Pommerin, A., Felderhoff, M. \& Schuth, F. (2006) J. Alloys Compd. 416, 303.

Marks, T. J. \& Kolb, J. R. (1977) Chem. Rev. 77, 263.

Nakamori, Y., Miwa, K., Ninomiya, A., Li, H., Ohba, N., Towata, S., Züttel, A. \& Orimo, S. (2006) Phys. Rev. B 74, 045126.

Ozolins, V. and Mazoub, E. (2006) Personal Communications.

Sklar, N. \& Post, B. (1967) Inorg. Chem. 6, 669.

Smith, W., Yong, C.W. \& Rodger, P.M. (2002) Mol. Simul. 28, 385.

van Setten, J.M., de Wijs, G. A. \& Brocks, G. (2006) Los Alamos Nat. Lab., Preprint Arch. Cond. Matter.1-3; http://aps.arxiv.org/PS cache/cond-mat/pdf/0611/0611665.pdf.

Yoder, C.H. \& Flora, N.J. (2005) Am. Mineral. 90, 488. 


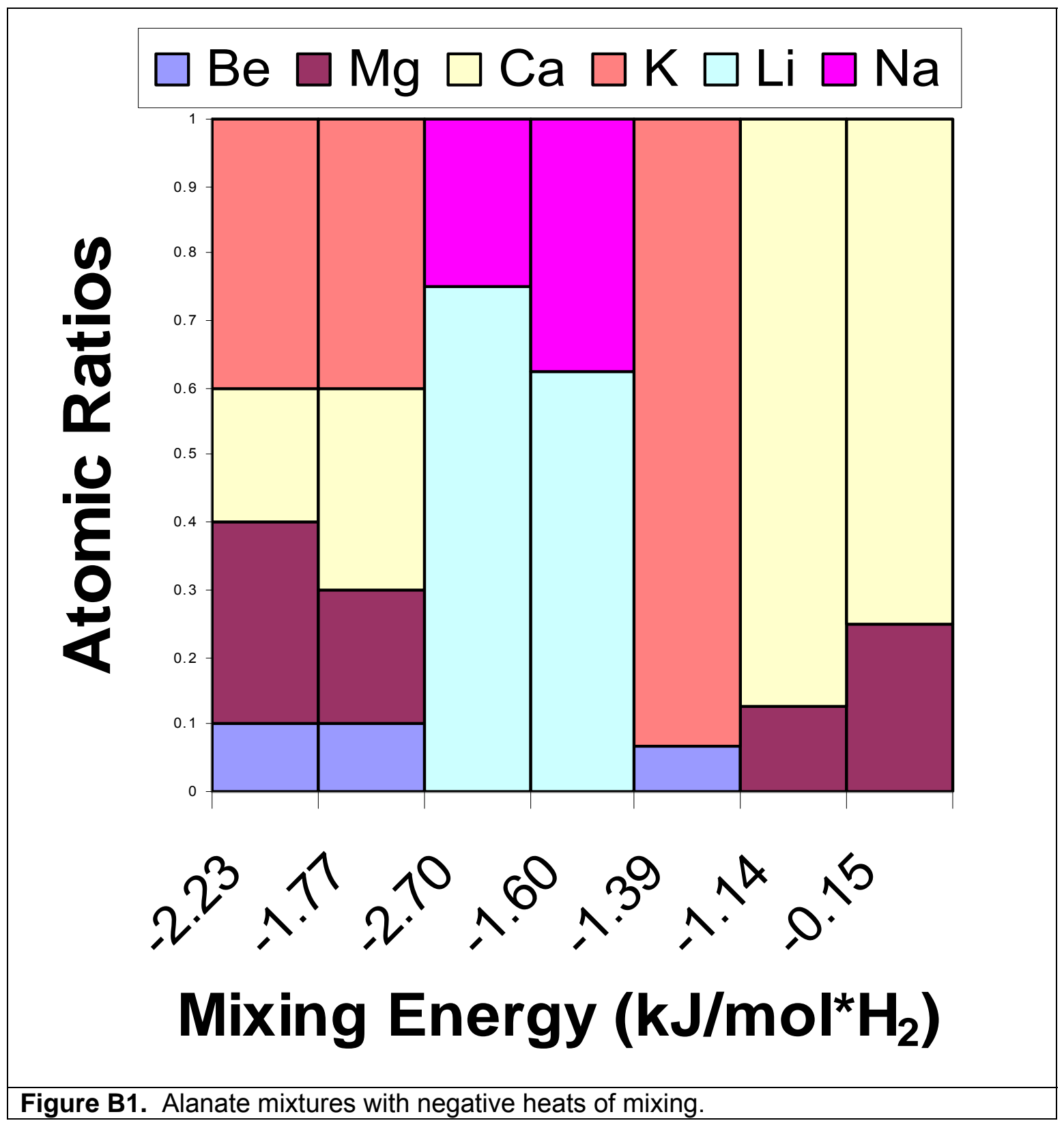




\section{Composition of mixed borohydrides}

with negative heats of mixing

$\square \mathrm{Li} \square \mathrm{Na} \square \mathrm{Mg} \square \mathrm{Ca} \quad \square \mathrm{Zn}$

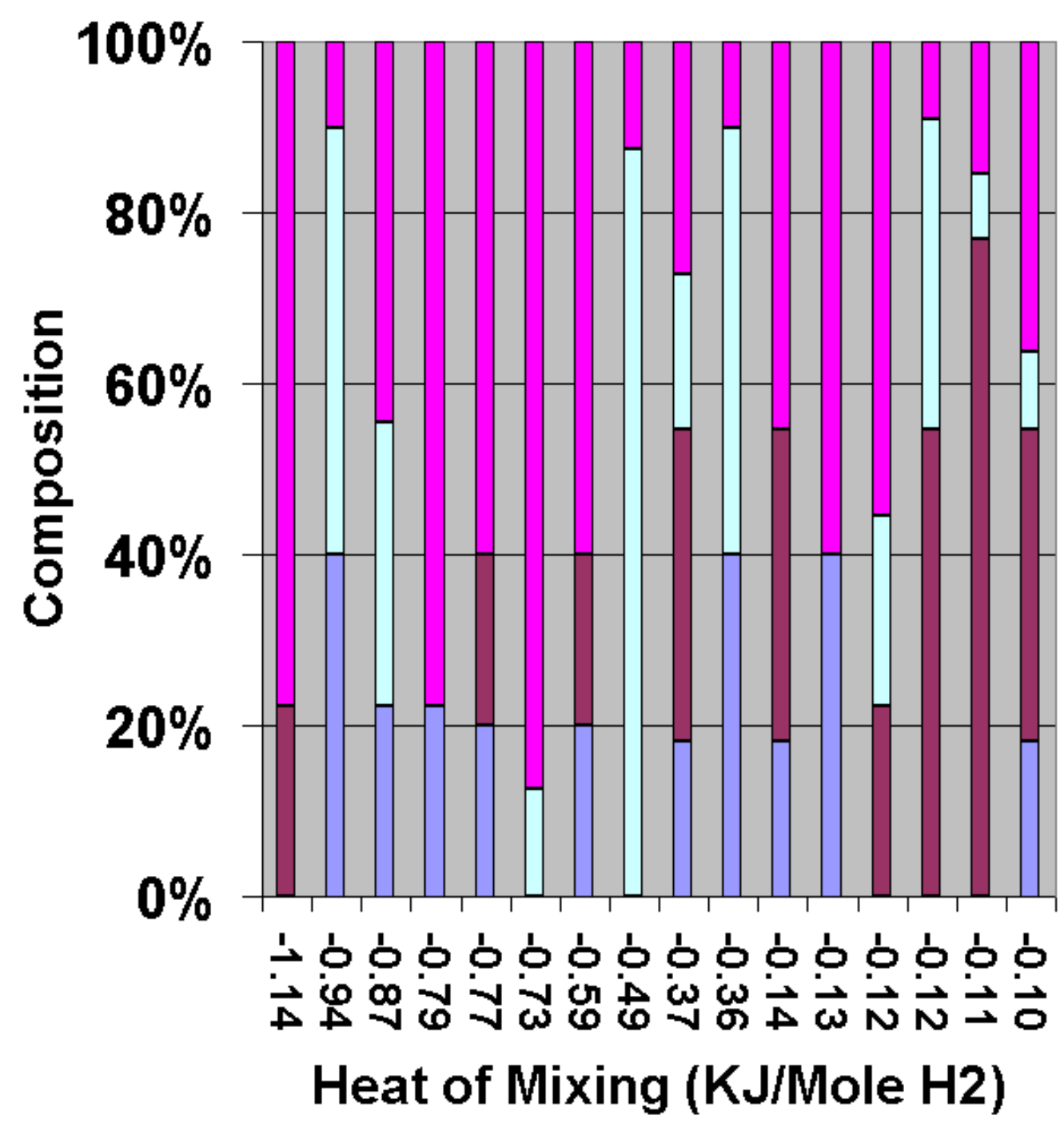

Figure B2. Borohydride mixtures with negative heats of mixing. 


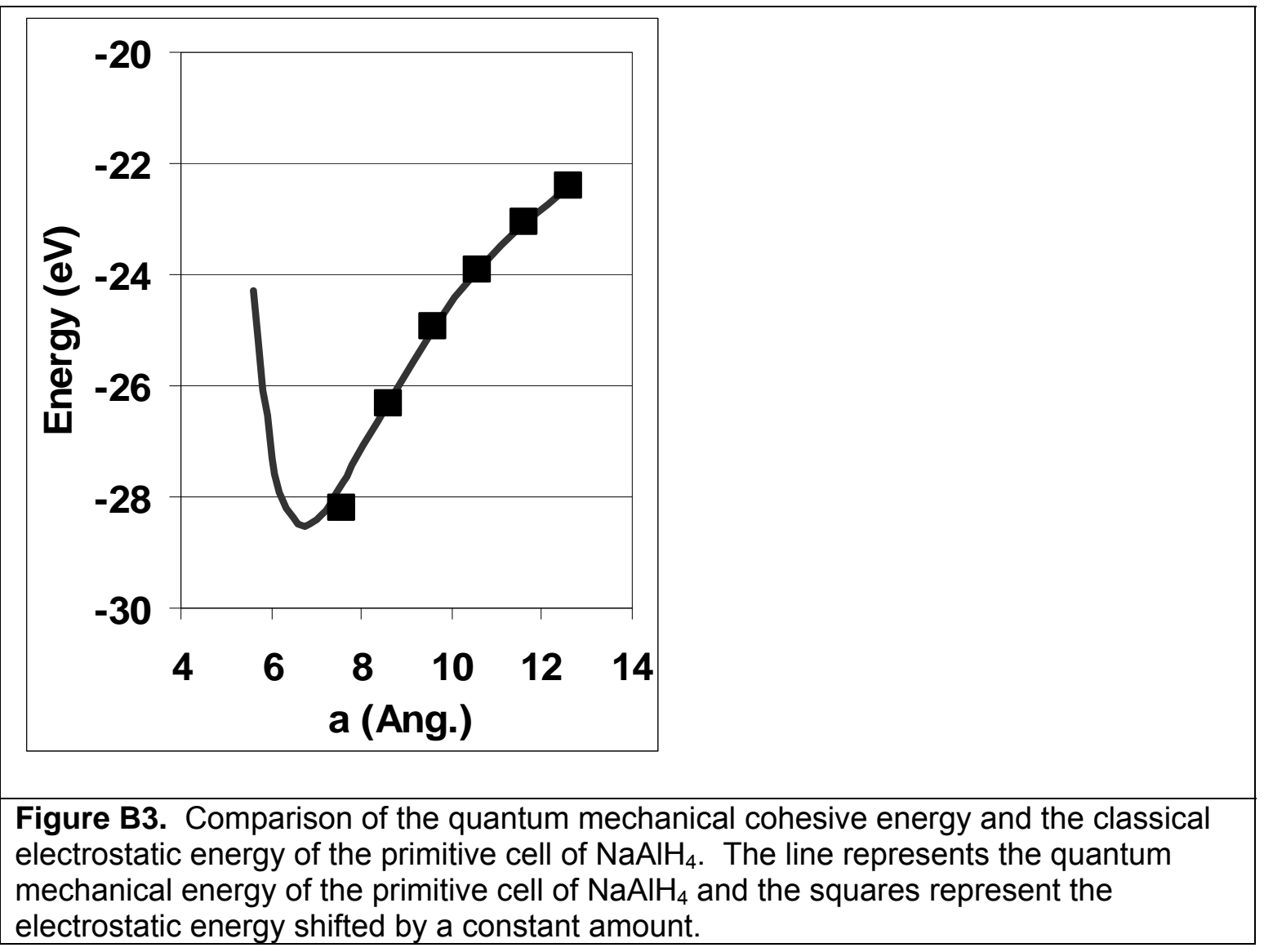




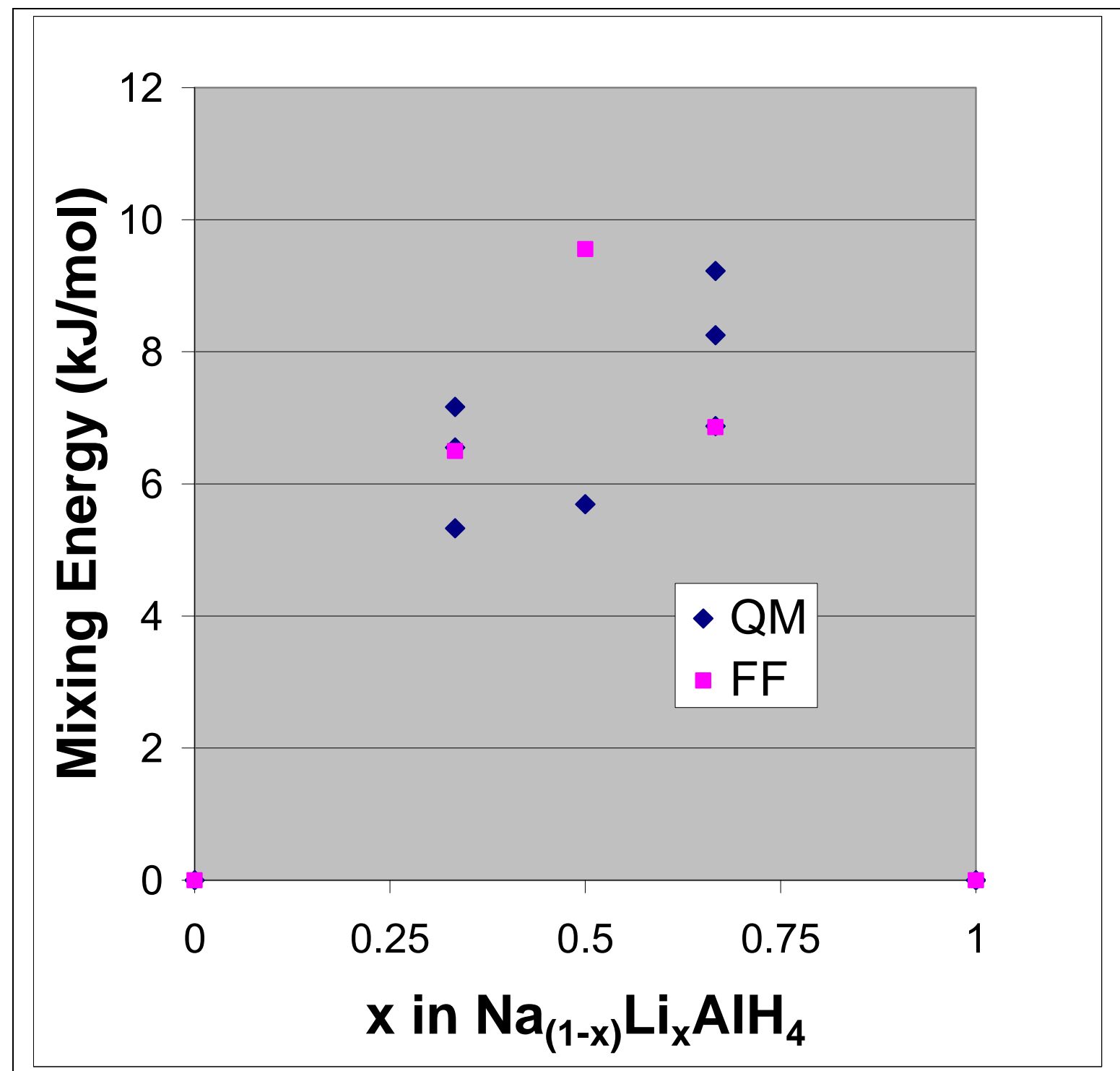

Figure B4. Comparison of Mixing Energies Predicted from Quantum Mechanical (QM) and Forcefield (FF) methods. 


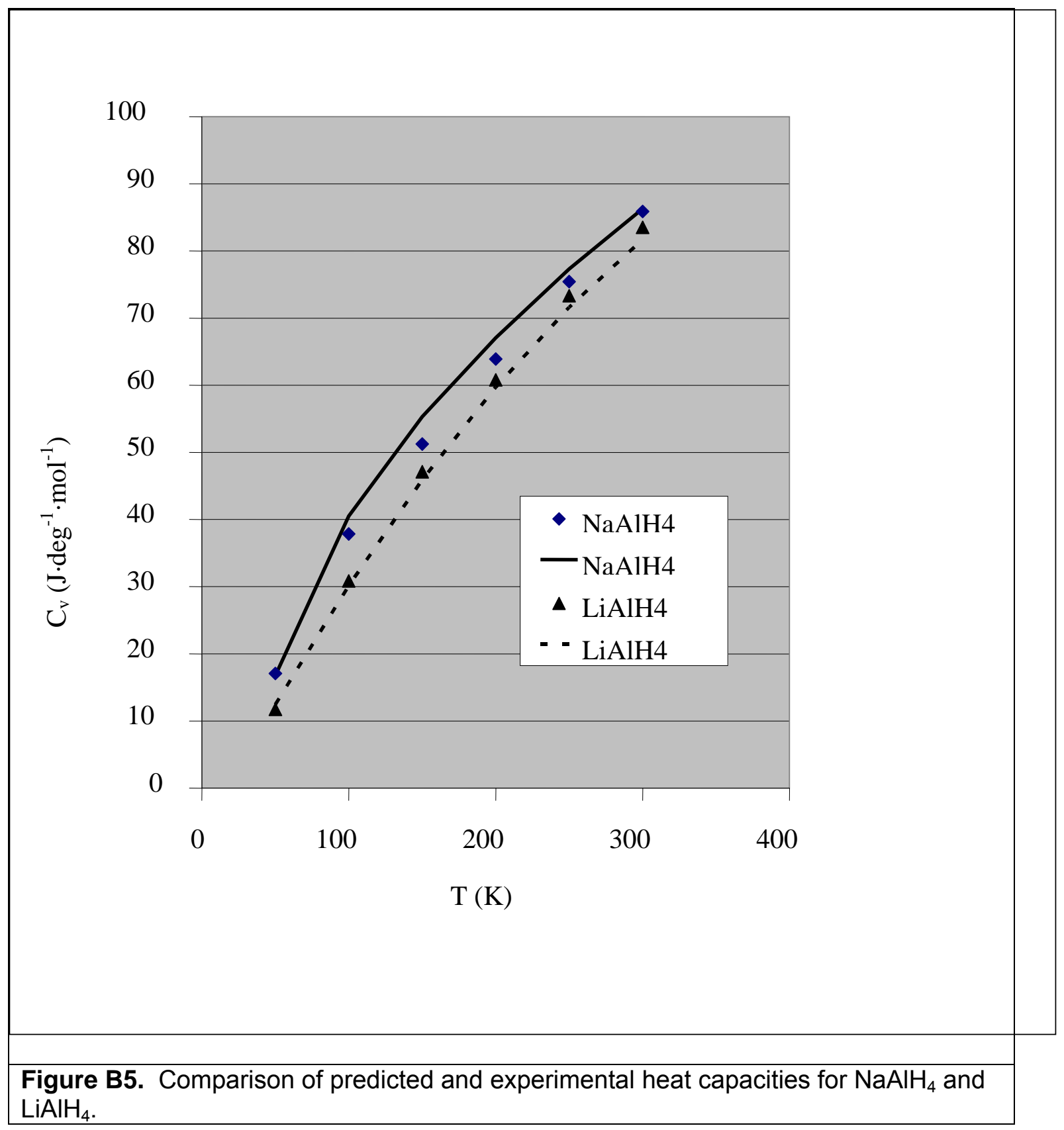




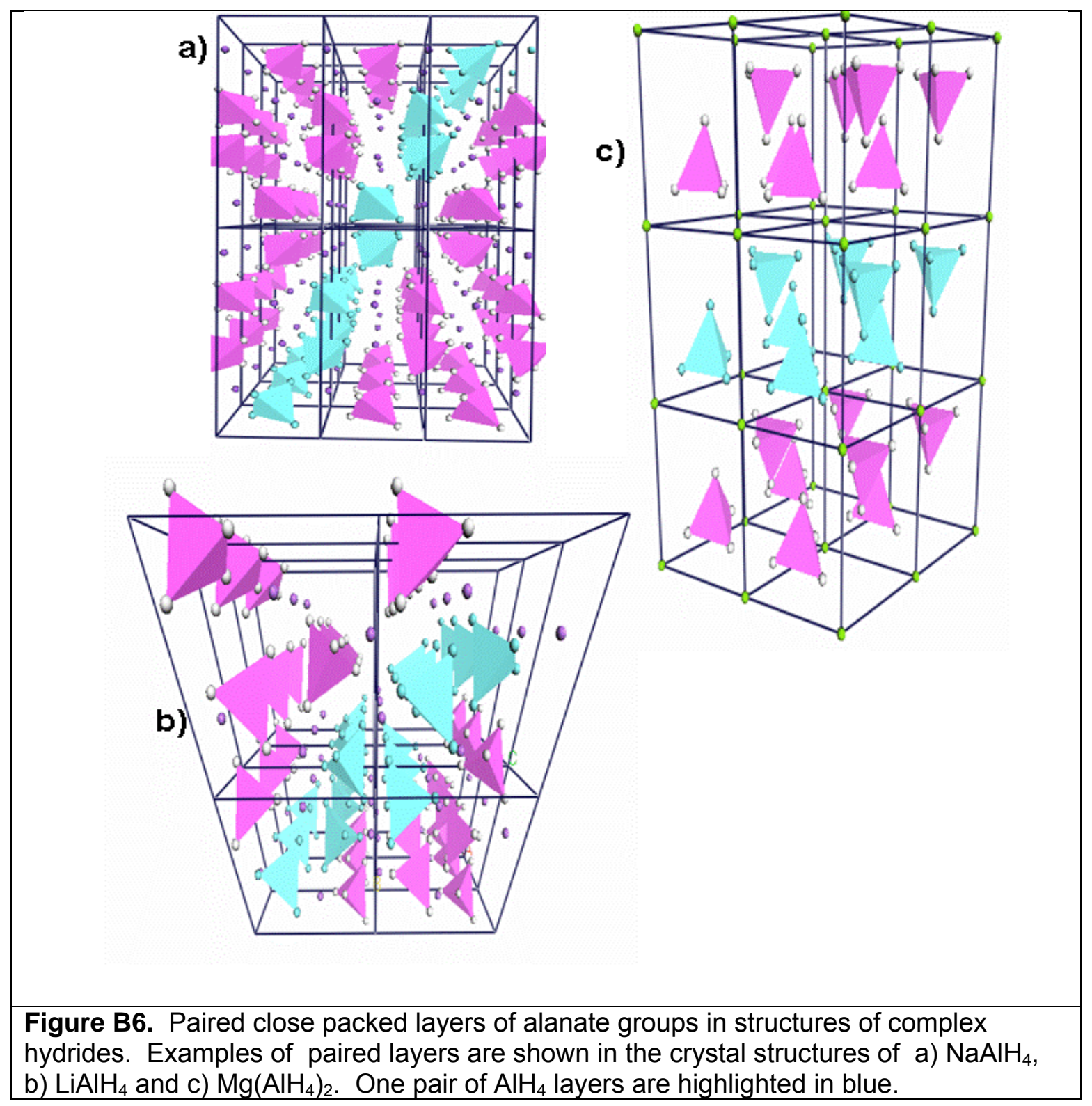




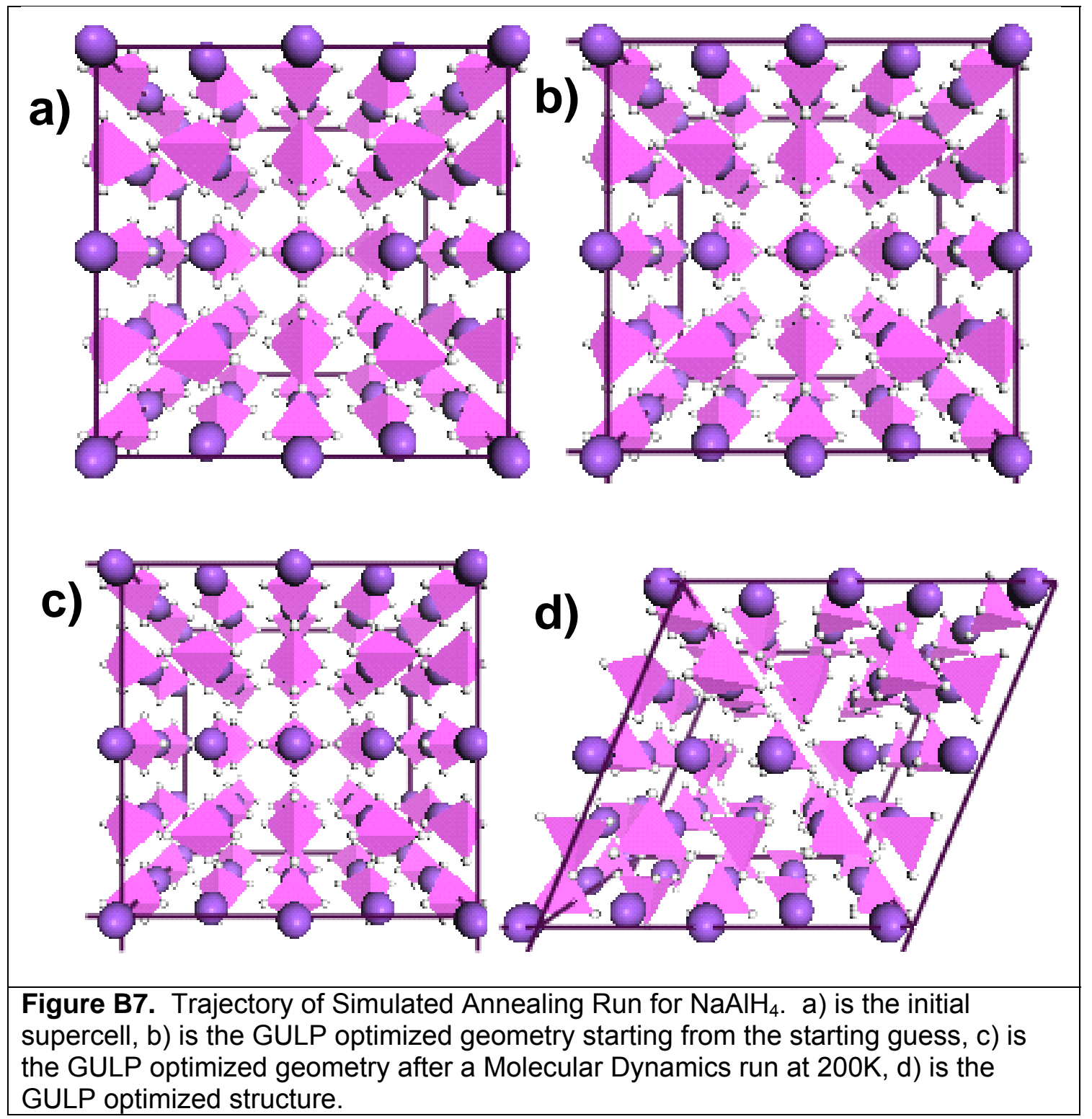




\begin{tabular}{|c|c|c|}
\hline Interaction & $A(e V)$ & $\rho(\AA)$ \\
\hline Li-Ha & 200.0 & 0.2969 \\
\hline $\mathrm{Na}-\mathrm{Ha}$ & 416.196 & 0.2967 \\
\hline $\mathrm{K}-\mathrm{H}^{b}$ & 1500.0 & 0.2967 \\
\hline $\mathrm{Be}-\mathrm{H}^{\mathrm{c}}$ & 200.0 & 0.2877 \\
\hline $\mathrm{Mg}-\mathrm{H}^{\mathrm{a}}$ & 564.698 & 0.2877 \\
\hline $\mathrm{Ca}-\mathrm{H}^{\mathrm{c}}$ & 1840.0 & 0.2877 \\
\hline $\mathrm{Al}-\mathrm{H}^{\mathrm{a}}$ & 416.1956 & 0.2726 \\
\hline \multicolumn{3}{|c|}{$\begin{array}{l}{ }^{a} \text { Fitted to structures, total energies and vibrational frequencies from DMOL3 } \\
\text { calculations. } \\
\text { b Extrapolated from the Na parameters by keeping the same } \rho \text { multiplying the } A \\
\text { parameter from Na by exp }\left(R_{k} / R_{N a}\right) \text {, where } R_{K} \text { and } R_{N a} \text { is the Pauling ionic radii of } K \text { and } \\
\text { Na respectively. } \\
\text { bExtrapolated from } M g \text { parameters by holding } \rho \text { fixed and multiplying the } A \text { parameter } \\
\text { for } M g \text { by exp }\left(R_{i} / R_{M g}\right) \text { where } R_{i} \text { is the Pauling ionic radius of the metal. }\end{array}$} \\
\hline
\end{tabular}

Table B2. Comparison of crystal structure predicted from parameters in Table B1 and Experimental Neutron Diffraction.

\begin{tabular}{|c|c|c|c|c|c|c|}
\hline \multirow{2}{*}{$\begin{array}{l}\text { Lattice } \\
\text { Parameter }\end{array}$} & \multicolumn{2}{|l|}{$\mathrm{LiAlH}_{4}$} & \multicolumn{2}{|l|}{$\mathrm{NaAlH}_{4}$} & \multicolumn{2}{|l|}{$\mathrm{Mg}\left(\mathrm{AlH}_{4}\right)_{2}$} \\
\hline & Predicted & Exp. $^{a}$ & Predicted & Exp. ${ }^{b}$ & Predicted & Exp. ${ }^{c}$ \\
\hline A & 4.93 & 4.81 & 5.11 & 4.98 & 5.53 & 5.21 \\
\hline$B$ & 7.75 & 7.80 & 5.11 & 4.98 & 5.53 & 5.21 \\
\hline C & 8.15 & 7.82 & 10.89 & 11.15 & 4.99 & 5.84 \\
\hline A & 90.0 & 90.0 & 90.0 & 90.0 & 90.0 & 90.0 \\
\hline$B$ & 111.5 & 112.2 & 90.0 & 90.0 & 90.0 & 90.0 \\
\hline$\Gamma$ & 90.0 & 90.0 & 90.0 & 90.0 & 120.0 & 120.0 \\
\hline
\end{tabular}

${ }^{a}$ O. M. Lovvik, S.M. Opalka, H.W. Brinks, B.C. Hauback, Phys. Rev. B 69(2004)134117.

${ }^{\mathrm{b}}$ H.W. Brinks, C.M. Jensen, S.S. Srinivasan, B.C. Hauback, D. Blanchard, K. Murphy, J. Alloys Comp. 376(2004) 215.

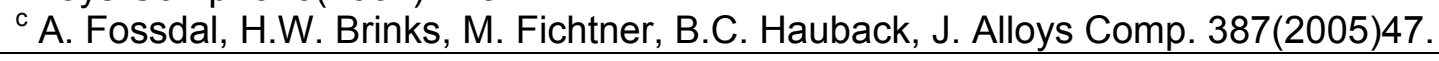

Table B3. Structural parameters for the unit cell for the initial geometry for VHTS simulations

\begin{tabular}{l|l|l|l|}
\hline Atom & $\mathrm{X}$ & $\mathrm{y}$ & $\mathrm{z}$ \\
\hline $\begin{array}{l}\text { Cation }(\mathrm{Li}, \mathrm{Na}, \mathrm{K}, \\
\mathrm{Be}, \mathrm{Mg}, \text { or } \mathrm{Ca})\end{array}$ & 0.0 & 0.0 & 0.0 \\
\hline $\mathrm{Al}$ & 0.5 & 0.5 & 0.5 \\
\hline $\mathrm{H}$ & 0.312 & 0.0 & 0.099 \\
\hline $\begin{array}{l}\text { The space group is } \mathrm{I}_{1} / \mathrm{amd}, 141, \text { and the unit cell dimensions are } \mathrm{a}=6.90628 \AA \text { and } \\
\mathrm{c}=6.72272 \AA .\end{array}$ \\
\hline
\end{tabular}




\begin{tabular}{|c|c|c|}
\hline Interaction & $A(e V)$ & $\rho(\AA)$ \\
\hline $\mathrm{Li}-\mathrm{H}$ & 44.0 & 0.3 \\
\hline $\mathrm{Na}-\mathrm{H}$ & 892.79013 & 0.256909 \\
\hline $\mathrm{Mg}-\mathrm{H}^{\mathrm{a}}$ & 757.22934 & 0.219185 \\
\hline $\mathrm{Ca}-\mathrm{H}$ & 811.03140 & 0.286686 \\
\hline $\mathrm{Zn}-\mathrm{H}^{\mathrm{b}}$ & 274.80464 & 0.318708 \\
\hline $\mathrm{B}-\mathrm{H}$ & 161.29 & 0.2726 \\
\hline $\mathrm{H}-\mathrm{H}^{\mathrm{c}}$ & 487.52 & 0.2178 \\
\hline \multicolumn{3}{|c|}{$\begin{array}{l}\text { Three-body-exponential term for } \mathrm{H}-\mathrm{Mg}-\mathrm{H} \text { and } \mathrm{B}-\mathrm{H}-\mathrm{Mg} \text { bending was added to the } \mathrm{Mg}-\mathrm{H} \\
\text { interaction. The parameters for the } \mathrm{H}-\mathrm{Mg}-\mathrm{H} \text { bend are } \mathrm{k}_{2}=777.591 \mathrm{eV} \cdot \mathrm{radian}^{2}, \mathrm{q}_{0}=129.5 \\
\text { degrees, and } \rho 1=\rho_{2}=0.5 \AA \text {. The parameters for the } \mathrm{B}-\mathrm{H}-\mathrm{Mg} \text { bend are } \mathrm{k}_{2}=186.556, \mathrm{q}_{0} \\
=95.39 \text { degrees and } \rho 1=\rho_{2}=0.6 \AA \text {. } \\
{ }^{\mathrm{b}} \text { Three-body-exponential terms for } \mathrm{H}-\mathrm{Zn}-\mathrm{H} \text { bending and } \mathrm{B}-\mathrm{H}-\mathrm{Zn} \text { bending were added to } \\
\text { the } \mathrm{Zn}-\mathrm{H} \text { interaction. The parameters for the } \mathrm{H}-\mathrm{Zn}-\mathrm{H} \text { term are } \mathrm{k} 2=54.8 \mathrm{eV} \cdot \mathrm{radian}^{2} \text {, } \\
\mathrm{q}_{0}=120.0 \text { degrees, and } \rho_{1}=\rho_{2}=0.5 \AA \text {. The parameters for } \mathrm{B}-\mathrm{H}-\mathrm{Zn} \text { term are } \\
{ }^{c} \text { An additional term of }-0.852 \mathrm{eV} \cdot \AA^{6} / \mathrm{r}^{6} \text { was added to the } \mathrm{H}-\mathrm{H} \text { intermolecular potential to } \\
\text { account for dispersion between hydride ions. }\end{array}$} \\
\hline
\end{tabular}

\begin{tabular}{|c|c|c|c|c|c|c|c|c|c|c|}
\hline \multirow{2}{*}{$\begin{array}{l}\text { Lattice } \\
\text { Paramete } \\
r\end{array}$} & \multicolumn{2}{|l|}{$\mathrm{LiBH}_{4}$} & \multicolumn{2}{|c|}{$\mathrm{NaBH}_{4}$} & \multicolumn{2}{|c|}{$\mathrm{Mg}\left(\mathrm{BH}_{4}\right)_{2}$} & \multicolumn{2}{|c|}{$\mathrm{Ca}\left(\mathrm{BH}_{4}\right)_{2}$} & \multicolumn{2}{|c|}{$\mathrm{Zn}\left(\mathrm{BH}_{4}\right)_{2}$} \\
\hline & Pred. & $\underset{\mathrm{a}}{\mathrm{Exp} .}$ & Pred & Exp. & Pred. & DFT. $^{\mathrm{c}}$ & Pred & Exp. $^{d}$ & Pred. & ${ }_{\mathrm{e}}^{\mathrm{DFT}}$ \\
\hline $\mathrm{a}$ & 7.60 & 7.18 & 4.31 & 4.33 & 8.86 & 8.26 & 9.26 & 8.79 & 8.87 & 7.97 \\
\hline$b$ & 4.40 & 4.44 & 4.31 & 4.33 & 8.86 & 8.26 & 13.78 & 13.13 & 8.87 & 7.97 \\
\hline $\mathrm{C}$ & 6.16 & 6.60 & 5.91 & 5.87 & 10.01 & 9.60 & 6.90 & 7.50 & 10.30 & 9.30 \\
\hline$\alpha$ & 90 & 90 & 90 & 90 & 90 & 90 & 90 & 90 & 90 & 90 \\
\hline$\beta$ & 90 & 90 & 90 & 90 & 90 & 90 & 90 & 90 & 90 & 90 \\
\hline Y & 90 & 90 & 90 & 90 & 90 & 90 & 90 & 90 & 90 & 90 \\
\hline $\begin{array}{l}\text { a J-Ph. Sou } \\
200-205 . \\
\text { b P. Fische } \\
{ }^{c} \text { Structures } \\
{ }^{d} \text { T.Noritake } \\
\text { 74,(2006)1 } \\
{ }^{\mathrm{e}} \text { Structures }\end{array}$ & $\begin{array}{l}\text { r, A. Züt } \\
\text { s Predic } \\
\text { e, N.Oh } \\
55122 \\
\text { s Predic }\end{array}$ & $\begin{array}{l}\text { I, Mat } \\
\text { d by } \\
\text {, Y.N. }\end{array}$ & $\begin{array}{l}\text { Sci. } \\
\text { Ozoli } \\
\text { amor }\end{array}$ & $\begin{array}{l}\text { ny, K. } \\
\text { orum } \\
\text { and } \\
\text { S.Ton }\end{array}$ & $\begin{array}{l}37(200 \\
. \text { Mazc } \\
\text { ta, A.Z }\end{array}$ & $\begin{array}{l}\text { rnal of } \\
43 . \\
\text { Persc } \\
\text { el, S.O }\end{array}$ & $\begin{array}{l}\text { l Com } \\
\text { רo, } \mathrm{Ph}\end{array}$ & $\begin{array}{l}\text { unicatic } \\
\text { Rev. }\end{array}$ & ds 34 & \\
\hline
\end{tabular}




\begin{tabular}{|c|c|c|c|}
\hline \multicolumn{4}{|c|}{$\begin{array}{l}\text { Table B6. Predicted atomic positions for } \mathrm{Mg}\left(\mathrm{BH}_{4}\right)_{2} \\
\text { calculations (Space Group }=\mathrm{I}-4 \mathrm{~m} 2)^{\mathrm{a}}\end{array}$} \\
\hline & $a$ & $\mathrm{~b}$ & C \\
\hline $\mathrm{Mg}$ & 0.0 & 0.0 & 0.5 \\
\hline $\mathrm{Mg}$ & 0.5 & 0.0 & 0.75 \\
\hline B & $0.270 \quad(0.271)$ & 0.0 & $0.593(0.595)$ \\
\hline $\mathrm{H}$ & $0.737 \quad(0.748)$ & 0.5 & $0.973(0.969)$ \\
\hline $\mathrm{H}$ & $0.649 \quad(0.648)$ & 0.5 & $0.156(0.168)$ \\
\hline $\mathrm{H}$ & $0.843 \quad(0.843)$ & $0.389(0.375)$ & $0.121(0.130)$ \\
\hline
\end{tabular}

Table B7. Predicted atomic positions for the predicted structure for $\mathrm{Zn}(\mathrm{BH} 4) 2$ from DFT calculations (Space Group $\mathrm{I}-4 \mathrm{~m} 2$ )

\begin{tabular}{|c|c|c|c|}
\hline & $a$ & B & c \\
\hline $\mathrm{Zn}$ & 0.0 & 0.5 & 0.25 \\
\hline $\mathrm{Zn}$ & 0.0 & 0.0 & 0.0 \\
\hline$B$ & $0.270(0.273)$ & 0.5 & $0.346(0.342)$ \\
\hline $\mathrm{H}$ & $0.344(0.343)$ & $0.385(0.368)$ & $0.372(0.373)$ \\
\hline $\mathrm{H}$ & $0.239(0.263)$ & 0.5 & $0.288(0.311)$ \\
\hline $\mathrm{H}$ & $0.155(0.142)$ & 0.5 & $0.414(0.413)$ \\
\hline
\end{tabular}

Table B8. Structural parameters for the unit cell for the initial geometry for VHTS simulations of mixtures of borohydrides.

\begin{tabular}{|l|l|l|l|}
\hline Atom & $\mathrm{X}$ & $\mathrm{Y}$ & $\mathrm{Z}$ \\
\hline $\begin{array}{l}\text { Cation }(\mathrm{Li}, \mathrm{Na}, \mathrm{K}, \\
\mathrm{Be}, \mathrm{Mg}, \text { or } \mathrm{Ca})\end{array}$ & 0.0 & 0.0 & 0.0 \\
\hline $\mathrm{B}$ & 0.5 & 0.5 & 0.5 \\
\hline $\mathrm{H}$ & 0.378 & 0.378 & 0.378 \\
\hline \multicolumn{2}{|l|}{ The space group is $\mathrm{F}-43 \mathrm{~m}$, and the lattice parameter is a=6.06 $\AA$} \\
\hline
\end{tabular}




\section{APPENDIX C}

\section{Informatics Summary}

Informatics support for the Hydrogen Storage project focused on development of three workflows:

(1) Workflow to store hydrogen storage material synthesis data in an existing Oracle database

(2) Workflow to process medium throughput hydrogen storage assay data

(3) Workflow to process high throughput hydrogen storage assay data

Each workflow was implemented in one or more software tools that exchange data through files. Because the high throughput assay processing workflow was developed as an extension to the tools initially developed for the medium throughput workflow, the hydrogen storage assay workflow will be discussed in the context of the high throughput system only.

The workflow to store hydrogen storage material synthesis information was implemented in a single Java application named "Hydrogen Storage Material Synthesis Interface" or H2SMI. H2SMI contained separate modules to collect and store the information required to describe each step, or "unit operation" in material synthesis, including Milling,

Evaporation, Extraction, and Drying. The details of raw materials were stored in existing tables in the Oracle database and then brought into H2SMI through queries. Tables to store the details of the unit operations were defined and then automatically populated with the information gathered from either input files or through a graphical user interface (GUI).

The workflows to process the hydrogen storage assay data were created as a series of tools operating on raw or processed data from desorption experiments in order to create a comprehensive database of desorption results that could be correlated with storage material properties. Each tool calculated and/or aggregated the data to enable processing at the subsequent stage. Figure $\mathrm{C} 1$ summarizes the final hydrogen desorption data process workflow. 


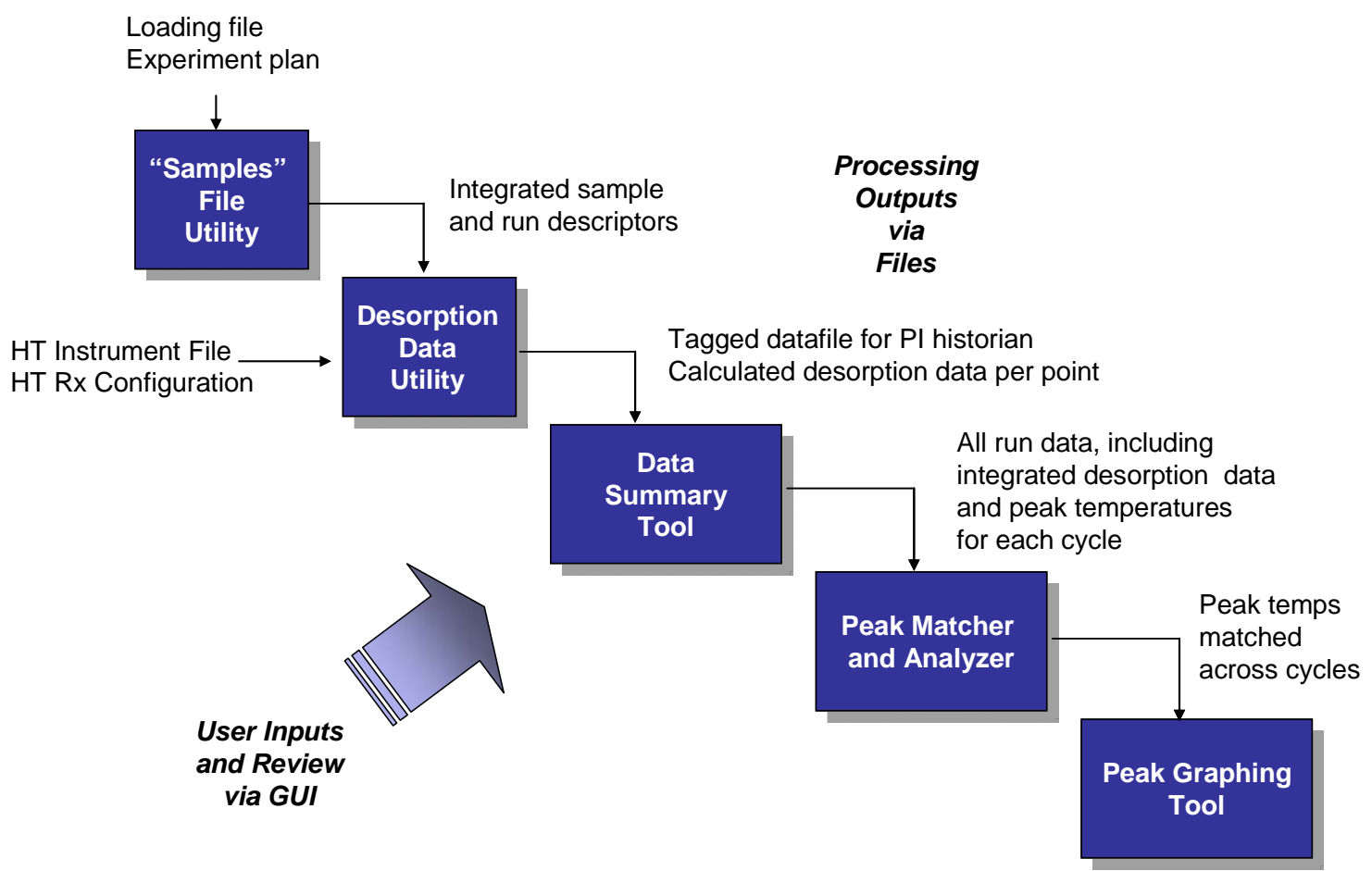

Figure C1. Summary of Hydrogen Desorption Data Processing Workflow

The initial suite of tools was developed to operate on the medium-throughput (ChemScan) assay data. Ad hoc tools were developed to expedite batch processing of the ChemScan runs, extracting the temperatures of maximum $\mathrm{H}_{2}$ desorption (peaks) and assigning weight percent $\mathrm{H}_{2}$ desorbed to individual peaks. These tools were extended to new data formats and requirements of the high throughput assay system and new tools were added to automate processing of the large volume of information associated with high throughput runs.

The first tool, the Samples utility, creates a composite summary of the run parameters ("Samples" file), including sample information and the sequence of planned experimental steps. The Data Desorption Utility (DDU) tool reads the Samples file as well as the instrument output file and an XML description of the test unit configuration. The DDU then is used to compute and visualize primary data such as $w \mathrm{t} \% \mathrm{H}_{2}$ and desorption descriptors derived from the experimental results. Figure $\mathrm{C} 2$ shows screenshots from the DDU user interface. In order to accurately quantify desorption as a function of temperature in the high throughput data, methods were developed to analytically fit and differentiate the desorption profiles; thresholds for desorption peak detection were refined based on initial results so that nearly all runs could be processed without manual intervention. Figure C3 shows an example of a desorption curve with peak data generated by the DDU. The DDU also translates the process data into a format suitable for storage in the OSI PISoft PI historian database. 


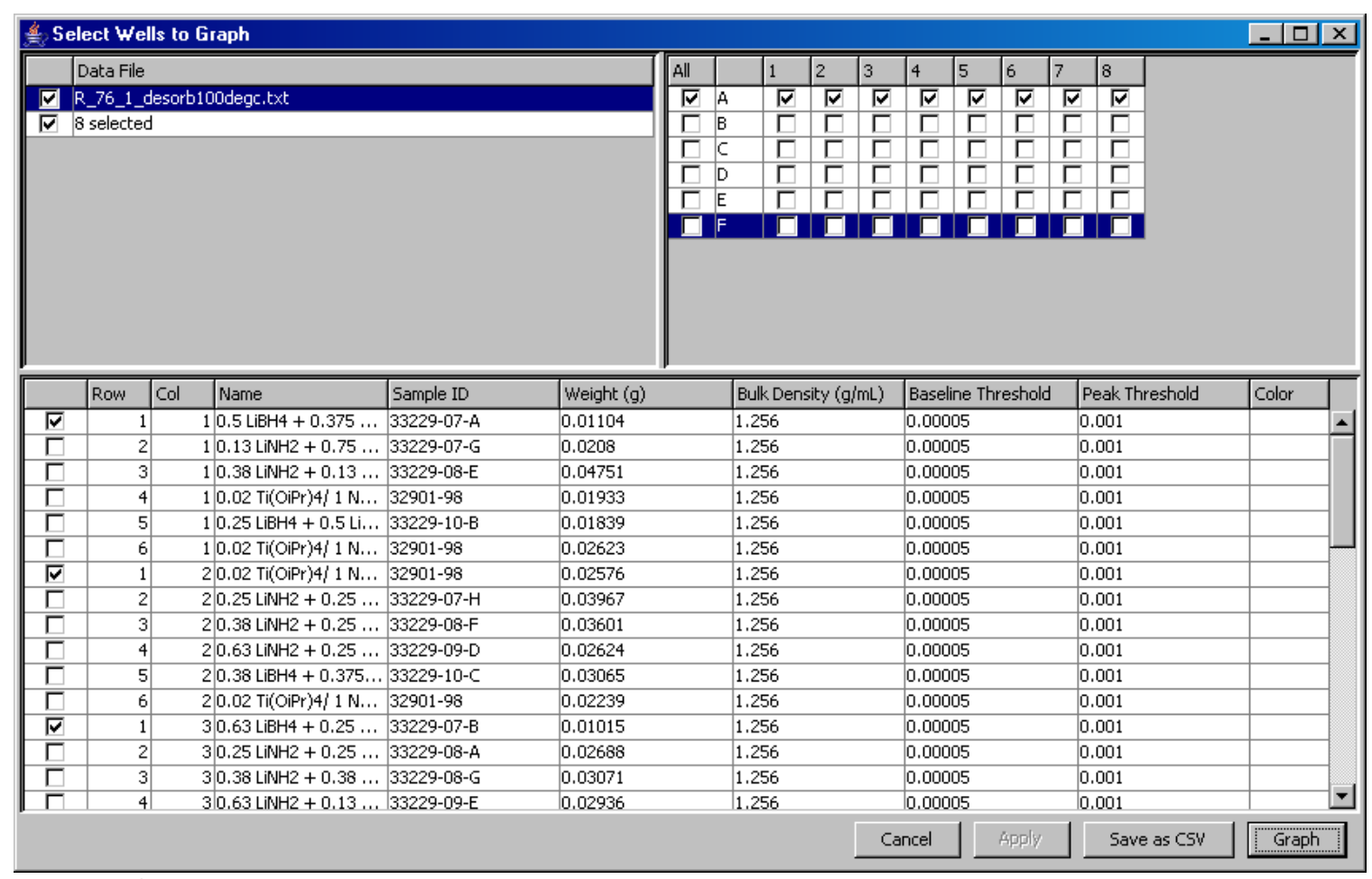

Figure C2. Data selection in the DDU interface.
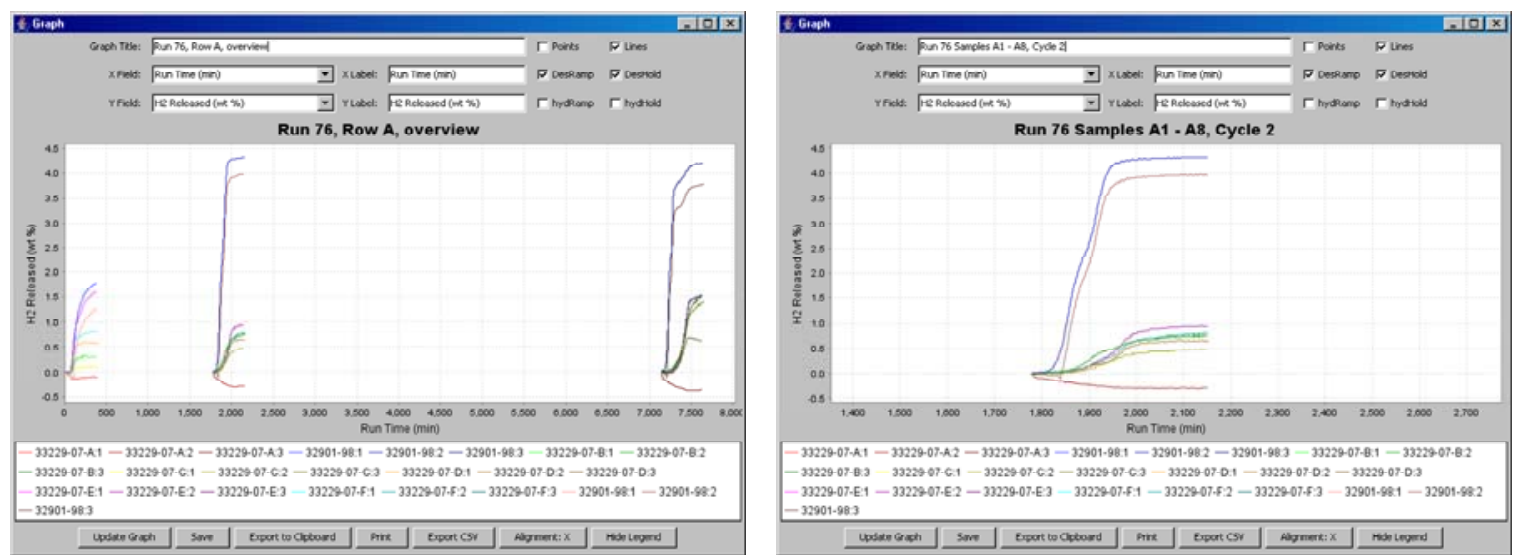

Figure C3. Graphing of desorption profiles in the DDU.

After aggregation of the Samples information and the output of the DDU in the Data Summary Tool, the PeakMatcher tool was developed to support the search for samples with reproducible desorption behavior across cycles. PeakMatcher is a post-processor of the peak data from one or more $\mathrm{H}_{2}$ assay runs (either Medium Throughput or High Throughput). The Peak Grapher application was used to review and edit the desorption peak descriptors, either before or after PeakMatcher (Figure C4).

The output of the hydrogen storage assay processing was a flat file database integrating sample, run, desorption and computed hydrogen storage parameters suitable for subsequent data mining by the research team. 


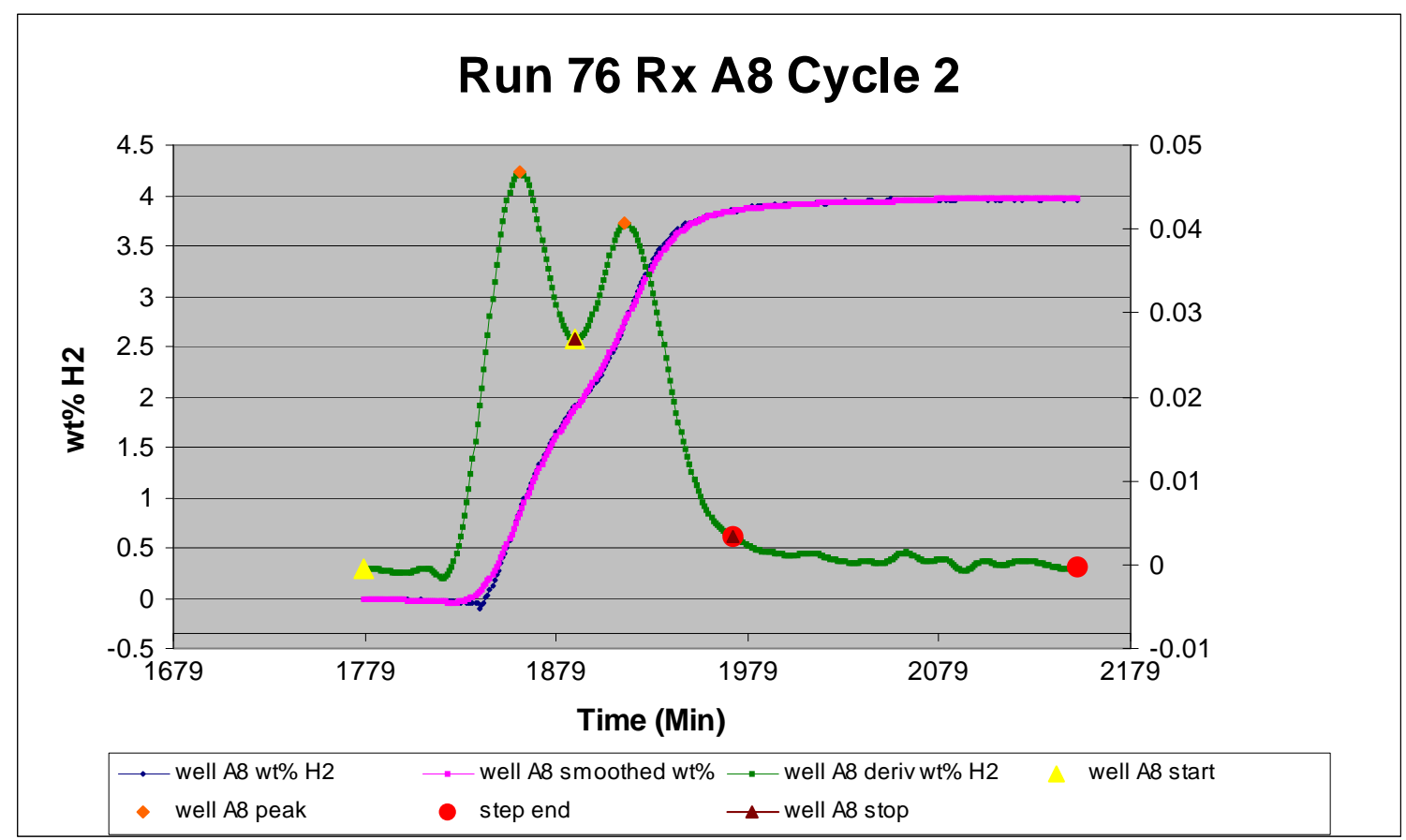

Figure C4. Graph of desorption data showing extracted peak parameters. 


\section{Appendix D}

\section{Synthesis and Hydrogen Storage Assay Data Tables}

Appendix D contains the Synthesis and Hydrogen Storage Assay Data Tables. The tables are organized by compositions synthesized and follow the text. Included in the data tables are

1) Compositions Synthesized. The format used for describing the compositions is the tabulation of the molar ratios of the starting materials used to make the composition. Dopants are also listed in molar ratios except where weight percents are specifically denoted.

2) XRD results. The tables may include $X R D$ results on as-synthesized materials, spent materials (materials recovered after the hydrogen storage assay evaluation from either the medium throughput unit or the high throughput unit) or both. The compounds identified in the table are in the order of the abundance in which they occur in that particular pattern as determined by the most intense peaks. The phases are assigned with chemical formula. If some of the lines cannot be assigned to any phase, they are assigned as unk, $\mathbf{d}=\ldots$... This means the lines are unknown and the $d$-spacings are given in $\AA$. If there are too many lines to fit into the table, they are assigned a bold letter such as $\mathbf{C}$ or $\mathbf{U} \mathbf{1}$ and the lines corresponding to $\mathrm{C}$ are listed at the bottom of the table.

3) Hydrogen Storage Capacity Results. These are given for both Medium Throughput (MT) and High Throughput (HT) assays. The MT assay has two desorption cycles and it is understood that desorption is ramped to $220^{\circ} \mathrm{C}$. Thus the heading for MT results are Des1 and Des 2, referring to the first and second desorptions. The HT unit uses a variety of desorption cycle

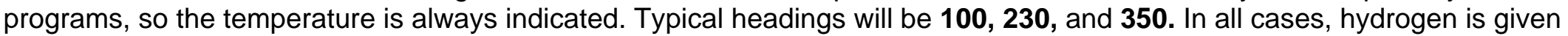
as weight percent hydrogen evolved from the sample, wt. $\% \mathbf{H}_{2}$.

4) Notations. A number of notations are used in the tables; they are defined below and typically in the very bottom line of each table.

$\mathbf{N}=$ not measured

$\mathbf{B}=$ bad measurement

${ }^{*},{ }^{\mathbf{a}}, \mathbf{b}=$ substitution or special property, see bottom of table

$\mathbf{M}=$ Metal

$X=$ general anionic group, such amide, hydride or chloride

Unk. $d=\ldots, C$, U1 = unknown materials identified in the XRD patterns. $d$-spacings are given in $\AA$ in the table or at the bottom 


\begin{tabular}{|c|c|c|c|c|c|c|c|c|c|c|c|}
\hline \multicolumn{12}{|c|}{ Table 1. $\mathrm{NaAlH}_{4}-\mathrm{LiAlH}_{4}-\mathrm{Mg}\left(\mathrm{AlH}_{4}\right)_{2}$ phase diagram. Standard milling, desorption at $220^{\circ} \mathrm{C}}$. \\
\hline \multicolumn{3}{|c|}{$\begin{array}{c}\text { Mole fraction } \\
\mathrm{AlH}_{4}^{-}\end{array}$} & \multicolumn{3}{|c|}{ As-Synthesized XRD } & \multicolumn{4}{|c|}{ Spent XRD } & \multicolumn{2}{|c|}{$\begin{array}{c}\text { Hydrogen } \\
\text { Capacity (wt. \%) }\end{array}$} \\
\hline $\mathrm{Na}$ & Li & Mg & XRD-1 & XRD-2 & XRD-3 & XRD-1 & XRD-2 & XRD-3 & XRD-4 & Des 1 & Des 2 \\
\hline 0.8 & 0.2 & 0 & $\mathrm{NaAlH}_{4}$ & $\mathrm{Al}$ & & Al & $\mathrm{NaH}$ & $\mathrm{LiNa}_{2} \mathrm{AlH}_{6}$ & $\mathrm{Na}_{3} \mathrm{AlH}_{6}$ & 4.14 & 3.29 \\
\hline 0.6 & 0.4 & 0 & $\mathrm{NaAlH}_{4}$ & Al & & Al & $\mathrm{Na}_{3} \mathrm{AlH}_{6}$ & $\mathrm{NaH}$ & $\mathrm{LiNa}_{2} \mathrm{AlH}_{6}$ & 4.45 & 1.87 \\
\hline 0.4 & 0.6 & 0 & $\mathrm{NaAlH}_{4}(\mathrm{tr})$ & & & $\mathrm{Al}$ & $\mathrm{LiNa}_{2} \mathrm{AlH}_{6}$ & $\mathrm{NaH}$ & $\mathrm{Na}_{3} \mathrm{AlH}_{6}$ & 4.12 & 1.34 \\
\hline 0.2 & 0.8 & 0 & $\mathrm{Al}$ & $\mathrm{Li}_{3} \mathrm{AlH}_{6}$ & $\mathrm{NaAlH}_{4}$ & $\mathrm{Al}$ & $\mathrm{NaH}$ & $\mathrm{LiNa}_{2} \mathrm{AlH}_{6}$ & $\mathrm{Na}_{3} \mathrm{AlH}_{6}$ & 3.31 & 0.71 \\
\hline 0 & 1 & 0 & $\mathrm{Al}$ & $\mathrm{Li}_{3} \mathrm{AlH} 6$ & 2.97 & $\mathrm{LiH}$ & $\mathrm{Al}$ & & & 7.38 & 0.16 \\
\hline 0.8 & 0 & 0.1 & $\mathrm{NaAlH}_{4}$ & $\mathrm{Al}$ & $2.23,2.08$ & $\mathrm{Al}$ & $\mathrm{Na}_{3} \mathrm{AlH}_{6}$ & $\mathrm{NaH}$ & $\mathrm{NaAlH}_{4}$ & 5.06 & 3.92 \\
\hline 1 & 0 & 0 & $\mathrm{NaAlH}_{4}$ & & & $\mathrm{Al}$ & $\mathrm{Na}_{3} \mathrm{AlH}_{6}$ & $\mathrm{NaH}$ & $\mathrm{NaAlH} 4$ & 5.48 & 4.42 \\
\hline 0.6 & 0.2 & 0.1 & $\mathrm{NaAlH}_{4}$ & $\mathrm{Al}$ & & $\mathrm{Al} / \mathrm{LiH}$ & $\mathrm{NaH}$ & $\mathrm{LiNa}_{2} \mathrm{AlH}_{6}$ & $\mathrm{NaMgH}_{3}$ & 3.55 & 2.04 \\
\hline 0.4 & 0.4 & 0.1 & $\mathrm{NaAlH}_{4}$ & $\mathrm{Al}$ & $2.23,2.08$ & $\mathrm{Al} / \mathrm{LiH}$ & $\mathrm{NaH}$ & $\mathrm{NaMgH}_{3}$ & $\mathrm{LiNa} \mathrm{AlH}_{6}$ (tr) & 3.79 & 1.12 \\
\hline 0.2 & 0.6 & 0.1 & Al & $\mathrm{NaAlH}_{4}$ & & $\mathrm{Al} / \mathrm{LiH}$ & $\mathrm{NaMgH}_{3}$ & $\mathrm{Na}_{3} \mathrm{AlH}_{6}$ & $\mathrm{NaH}$ & 2.92 & 0.48 \\
\hline 0 & 0.8 & 0.1 & $\mathrm{Al}$ & $\mathrm{Li}_{3} \mathrm{AlH}_{6}$ & & $\mathrm{Al} / \mathrm{LiH}$ & & & & 2.88 & 0.33 \\
\hline 0.6 & 0 & 0.2 & $\mathrm{NaAlH}_{4}$ & $\mathrm{Al}(\mathrm{tr})$ & & $\mathrm{NaMgH}_{3}$ & $\mathrm{Al}$ & $\mathrm{Na}_{3} \mathrm{AlH}_{6}$ & $\mathrm{NaH}$ & 4.68 & 3.53 \\
\hline 0.4 & 0.2 & 0.2 & $\mathrm{NaAlH}_{4}$ & $\mathrm{Al}$ & & $\mathrm{Al} / \mathrm{LiH}$ & $\mathrm{NaMgH}_{3}$ & $\mathrm{NaH}$ & unk d = 2.63 & 3.21 & 0.66 \\
\hline 0.2 & 0.4 & 0.2 & $\mathrm{Al}$ & $\mathrm{NaAlH}_{4}$ & $\mathrm{Li}_{3} \mathrm{AlH}_{6}$ & $\mathrm{Al} / \mathrm{LiH}$ & $\mathrm{NaMgH}_{3}$ & $\mathrm{NaH}$ & & 2.97 & 0.16 \\
\hline 0 & 0.6 & 0.2 & $\mathrm{Al}$ & $\mathrm{NaAlH}_{4}$ & $\mathrm{MgH}_{2}$ & $\mathrm{Al}$ & $\mathrm{MgH}_{2}$ & Unk. $d=2.82$ & & 6.65 & 0.29 \\
\hline 0.4 & 0 & 0.3 & $\mathrm{NaAlH}_{4}$ & $\mathrm{NaH}$ & $\mathrm{d}=2.63,2.34,2.23$ & $\mathrm{LiNa}_{2} \mathrm{AlH}_{6}$ & $\mathrm{NaMgH}_{3}$ & $\mathrm{NaAlH}_{4}$ & Unk. $d=2.34,2.08,2.03$ & 3.51 & 1.81 \\
\hline 0.2 & 0.2 & 0.3 & $\mathrm{Al}$ & $\mathrm{NaAlH}_{4}$ & $\mathrm{MgH}_{2}$ & $\mathrm{Al}$ & $\mathrm{NaMgH}_{3}$ & $\mathrm{NaAlH}_{4}$ & Unk. $d=2.24,2.089$ & 3.08 & 0.25 \\
\hline 0 & 0.4 & 0.3 & $\mathrm{Al}$ & $\mathrm{NaAlH}_{4}$ & $\mathrm{MgH}_{2}$ & $\mathrm{Al}$ & $\mathrm{MgH}_{2}$ & Unk. $d=2.82$ & & 2.78 & 0.31 \\
\hline 0.2 & 0 & 0.4 & $\mathrm{Al}$ & $\mathrm{NaAlH}_{4}$ & $\mathrm{MgH}_{2}$ & $\mathrm{Al}$ & $\mathrm{NaMgH}_{3}$ & $\mathrm{MgH}_{2}$ & $\mathrm{NaH}$ & 1.77 & 0.17 \\
\hline 0 & 0.2 & 0.4 & $\mathrm{Al}$ & $\mathrm{NaAlH}_{4}$ & $\mathrm{MgH}_{2}$ & $\mathrm{Al}$ & $\mathrm{MgH}_{2}$ & Unk. $d=2.82$ & & 1.95 & 0.21 \\
\hline 0 & 0 & 0.5 & $\mathrm{Al}$ & $\mathrm{NaAlH}_{4}$ & $\mathrm{MgH}_{2}$ & $\mathrm{Al}$ & $\mathrm{NaAlH}_{4}$ & $\mathrm{MgH}_{2}$ & & 1.29 & 0.22 \\
\hline 1 & 0 & 0 & $\mathrm{NaAlH}_{4}$ & $\mathrm{Na}_{3} \mathrm{AlH}_{6}$ & $\mathrm{Al}$ & $\mathrm{NaAlH}_{4}$ & $\mathrm{Na}_{3} \mathrm{AlH}_{6}$ & $\mathrm{Al}$ & & 5.44 & 4.29 \\
\hline
\end{tabular}




\begin{tabular}{|c|c|c|c|c|c|c|c|c|c|c|c|c|}
\hline & & & able & $\mathrm{NaAlH}_{4}$ & $\mathrm{H}_{4}-\mathrm{IVI} \mathrm{g}(\mathrm{AII}$ & ohas & diagr & m. 2-step "m & IIIIIng, & sorption at $220^{\circ}$ & & \\
\hline & $\begin{array}{l}\text { Mole } \\
\text { racti } \\
\mathrm{AlH}_{4}\end{array}$ & & & As-Syn & sized XRD & & & & ent XRD & & $\begin{array}{r}\text { Hyd } \\
\text { Cap } \\
\text { (w }\end{array}$ & $\begin{array}{l}\text { ogen } \\
\text { acity } \\
\%)\end{array}$ \\
\hline $\mathbf{N a}$ & $\mathrm{Li}$ & $\mathrm{Mg}$ & xrd 1 & xrd 2 & xrd 3 & $\operatorname{xrd} 4$ & xrd 1 & xrd 2 & xrd 3 & xrd 4 & Des1 & Des2 \\
\hline 0.8 & 0 & 0.1 & $\mathrm{NaAlH}_{4}$ & $\mathrm{Al}$ & $\mathrm{Na}_{3} \mathrm{AlH}_{6}$ & & $\mathrm{Al}$ & $\mathrm{NaMqH}_{3}$ & $\mathrm{NaH}$ & $\mathrm{NaAlH}_{4}$ & 4.62 & 3.73 \\
\hline 0.6 & 0.2 & 0.1 & $\mathrm{NaAlH}_{4}$ & $\mathrm{Al}$ & $\mathrm{LiNa}_{2} \mathrm{AlH}_{6}$ & & $\mathrm{Al} / \mathrm{LiH}$ & $\mathrm{NaMgH}_{3}$ & $\mathrm{NaH}$ & $\mathrm{LiNa}_{2} \mathrm{AlH}_{6}$ & 4.38 & 2.00 \\
\hline 0.4 & 0.4 & 0.1 & $\mathrm{Al}$ & $\mathrm{LiNa}_{2} \mathrm{AlH}_{6}$ & $\mathrm{NaAlH}_{4}$ & & $\mathrm{Al} / \mathrm{LiH}$ & $\mathrm{NaMgH}_{3}$ & $\mathrm{NaH}$ & $\mathrm{LiNa}_{2} \mathrm{AlH}_{6}$ & 3.72 & 1.03 \\
\hline 0.2 & 0.6 & 0.1 & $\mathrm{Bad}$ XRD & & & & $\mathrm{Al} / \mathrm{LiH}$ & $\mathrm{NaMgH}_{3}$ & $\mathrm{NaH}$ & $\mathrm{LiNa}_{2} \mathrm{AlH}_{6}$ & 3.10 & 0.42 \\
\hline 0.8 & 0.2 & 0 & $\mathrm{NaAlH}_{4}$ & $\mathrm{Al}$ & $\mathrm{LiNa}_{2} \mathrm{AlH}_{6}$ & $\mathrm{Na}_{3} \mathrm{AlH}_{6}$ & $\mathrm{Al} / \mathrm{LiH}$ & $\mathrm{LiNa}_{2} \mathrm{AlH}_{6}$ & $\mathrm{Na}_{3} \mathrm{AlH}_{6}$ & $\mathrm{NaH}$ & 4.32 & 3.50 \\
\hline 0.6 & 0.4 & 0 & Bad XRD & & & & $\mathrm{Al} / \mathrm{LiH}$ & $\mathrm{NaH}$ & $\mathrm{LiNa}_{2} \mathrm{AlH}_{6}$ & $\mathrm{Na}_{3} \mathrm{AlH}_{6}$ & 4.63 & 1.86 \\
\hline 0.4 & 0.6 & 0 & $\mathrm{Al}$ & $\mathrm{NaAlH}_{4}$ & $\mathrm{LiNa}_{2} \mathrm{AlH}_{6}$ & & $\mathrm{Al} / \mathrm{LiH}$ & $\mathrm{NaH}$ & $\mathrm{LiNa}_{2} \mathrm{AlH}_{6}$ & & 3.82 & 1.24 \\
\hline 0.2 & 0.8 & 0 & $\mathrm{Al}$ & $\mathrm{NaAlH}_{4}$ & $\mathrm{LiNa}_{2} \mathrm{AlH}_{6}$ & $\mathrm{Li}_{3} \mathrm{AlH}_{6}$ & $\mathrm{Al}$ & $\mathrm{NaH}$ & $\mathrm{LiNa}_{2} \mathrm{AlH}_{6}$ & & 3.32 & 0.69 \\
\hline 1 & 0 & 0 & $\mathrm{NaAlH}_{4}$ & & & & $\mathrm{NaAlH}_{4}$ & $\mathrm{Na}_{3} \mathrm{AlH}_{6}$ & $\mathrm{Al}$ & & 5.52 & 3.79 \\
\hline 0 & 1 & 0 & $\mathrm{Al}$ & $\mathrm{Li}_{3} \mathrm{AlH}_{6}$ & $\begin{array}{l}\mathrm{d}=3.00,2.23 \\
1.889\end{array}$ & & $\mathrm{Al}$ & $\begin{array}{l}\text { Unk. } d=2.98,2.82, \\
2.50,2.23\end{array}$ & & & 3.56 & 0.12 \\
\hline 0 & 0.8 & 0.1 & $\mathrm{Al}$ & $\mathrm{Li}_{3} \mathrm{AlH}_{6}$ & $\mathrm{NaAlH}_{4}$ & & $\mathrm{Al}$ & $\begin{array}{l}\text { Unk. } d=2.99,2.82, \\
2.50,2.23\end{array}$ & & & 3.45 & 0.20 \\
\hline 0.6 & 0 & 0.2 & $\mathrm{Al}$ & $\mathrm{NaAlH}_{4}$ & $\mathrm{Li}_{3} \mathrm{AlH}_{6}$ & & $\mathrm{Al}$ & $\mathrm{NaAlH}_{4}$ & $\mathrm{NaMgH}_{3}$ & & 3.82 & 2.09 \\
\hline 0.4 & 0.2 & 0.2 & $\mathrm{NaAlH}_{4}$ & $\mathrm{Al}$ & $U . d=2.23,2.08$ & & $\mathrm{Al}$ & $\mathrm{NaMgH}_{3}$ & $\mathrm{LiNa}_{2} \mathrm{AlH}_{6}$ & $\mathrm{NaAlH}_{4}$ & 4.05 & 0.64 \\
\hline 0.2 & 0.4 & 0.2 & $\mathrm{Al}$ & $\mathrm{NaAlH}_{4}$ & Unk. $d=2.24$ & & $\mathrm{Al}$ & $\mathrm{LiH}$ & $\mathrm{NaMgH}_{3}$ & $\mathrm{NaH}$ & 3.71 & 0.10 \\
\hline 1 & 0 & 0 & $\mathrm{NaAlH}_{4}$ & $\mathrm{Al}(\mathrm{tr})$ & & & $\mathrm{NaAlH}_{4}$ & $\mathrm{Na}_{3} \mathrm{AlH}_{6}$ & $\mathrm{Al}$ & & 5.39 & 3.63 \\
\hline 0 & 0.6 & 0.2 & $\mathrm{Al}$ & $\mathrm{Li}_{3} \mathrm{AlH}_{6}$ & $\mathrm{NaAlH}_{4}(\mathrm{tr})$ & & $\mathrm{Al}$ & $\mathrm{MgH}_{2}$ & Unk. $d=2.82$ & & 3.74 & 0.25 \\
\hline 1 & 0 & 0 & $\mathrm{NaAlH}_{4}$ & & & & $\mathrm{NaAlH}_{4}$ & $\mathrm{Na}_{3} \mathrm{AlH}_{6}$ & $\mathrm{Al}$ & & 5.17 & 3.07 \\
\hline 0.4 & 0 & 0.3 & $\mathrm{Al}$ & $\mathrm{NaAlH}_{4}$ & Unk. $\mathrm{D}=2.23$ & & $\mathrm{Al}$ & $\mathrm{NaMgH}_{3}$ & $\mathrm{NaAlH}_{4}$ & Unk. $d=2.24$ & 3.38 & 0.54 \\
\hline 0.2 & 0.2 & 0.3 & $\mathrm{Al}$ & $\mathrm{NaAlH}_{4}$ & $\mathrm{MgH}_{2}$ & & $\mathrm{Al}$ & $\mathrm{NaMgH}_{3}$ & $\begin{array}{l}\text { U. } d=2.82, \\
2.00\end{array}$ & $\mathrm{MgH}_{2}(\mathrm{tr})$ & 2.77 & 0.13 \\
\hline 0 & 0.4 & 0.3 & $\mathrm{Al}$ & $\mathrm{NaAlH}_{4}$ & $\mathrm{MgH}_{2}$ & U. $d=2.24$ & $\mathrm{Al}$ & $\mathrm{MgH}_{2}$ & $\begin{array}{l}\text { U. } d=2.82, \\
2.00\end{array}$ & & 3.42 & 0.27 \\
\hline 0.2 & 0 & 0.4 & $\mathrm{Al}$ & $\mathrm{NaAlH}_{4}$ & Unk. $d=2.24$ & & $\mathrm{Al}$ & $\mathrm{NaMgH}_{3}$ & $\mathrm{MgH}_{2}$ & $\mathrm{NaAlH}_{4}$ ? & 4.47 & 0.11 \\
\hline 0 & 0.2 & 0.4 & $\mathrm{Mg}\left(\mathrm{AlH}_{4}\right)_{2}$ & $\mathrm{LiAlH}_{4}$ & $\mathrm{NaAlH}_{4}$ & $\mathrm{Al}$ & $\mathrm{Al}$ & $\mathrm{MgH}_{2}$ & & & 6.73 & 0.12 \\
\hline 0 & 0 & 0.5 & $\mathrm{NaAlH}_{4}$ & & & & $\mathrm{NaAlH}_{4}$ & $\mathrm{Na}_{3} \mathrm{AlH}_{6}$ & $\mathrm{Al}$ & $\begin{array}{l}\text { unk. } d=3.44,3.17,2.60 \text {, } \\
2.24\end{array}$ & 4.39 & 3.35 \\
\hline 1 & 0 & 0 & $\mathrm{NaAlH}_{4}$ & $\begin{array}{l}\text { U. } d=3.08 \\
2.19\end{array}$ & $\mathrm{Al}$ & $\mathrm{Mg}\left(\mathrm{AlH}_{4}\right)_{2}$ & $\mathrm{Al}$ & $\mathrm{MgH}_{2}$ & Unk. $d=2.82$ & & 5.34 & 0.21 \\
\hline
\end{tabular}




\begin{tabular}{|c|c|c|c|c|c|c|c|c|c|c|c|c|c|c|c|}
\hline \multicolumn{6}{|c|}{ Composition } & \multicolumn{4}{|c|}{ As-Synthesized XRD } & \multicolumn{4}{|c|}{ Spent XRD } & \multicolumn{2}{|c|}{$\begin{array}{c}\text { Hydrogen } \\
\text { Capacity } \\
\text { (Wt.\%) }\end{array}$} \\
\hline Al & LiH & $\mathrm{NaH}$ & KH & $\mathrm{MgH}_{2}$ & $\mathrm{CaH}_{2}$ & xrd 1 & xrd 2 & xrd 3 & xrd 4 & xrd 1 & xrd 2 & xrd 3 & xrd 4 & Des 1 & Des 2 \\
\hline 1 & 0 & 1 & 0 & 0 & 0 & $\mathrm{Al}$ & $\mathrm{NaH}$ & & & & & & & 1.40 & 1.24 \\
\hline 1 & 0 & 2 & 0 & 0 & 0 & $\mathrm{NaH}$ & $\mathrm{Al}$ & & & & & & & 0.94 & 0.86 \\
\hline 1 & 0 & 3 & 0 & 0 & 0 & $\mathrm{NaH}$ & $\mathrm{Al}$ & & & & & & & 0.56 & 0.45 \\
\hline $\mathrm{Ni}_{0.51} \mathrm{Al}$ & 0 & 1 & 0 & 0 & 0 & $\mathrm{Al}_{3} \mathrm{Ni}_{2}$ & $\mathrm{Al}_{3} \mathrm{Ni}$ & $\mathrm{NaH}$ & & & & & & 0.13 & 0.05 \\
\hline $\mathrm{Ni}_{0.51} \mathrm{Al}$ & 0 & 2 & 0 & 0 & 0 & $\mathrm{Al}_{3} \mathrm{Ni}_{2}$ & $\mathrm{NaH}$ & $\mathrm{Al}_{3} \mathrm{Ni}$ & & & & & & 0.08 & 0.03 \\
\hline $\mathrm{Ni}_{0.51} \mathrm{Al}$ & 0 & 3 & 0 & 0 & 0 & $\mathrm{NaH}$ & $\mathrm{Al}_{3} \mathrm{Ni}_{2}$ & $\mathrm{Al}_{3} \mathrm{Ni}$ & & & & & & 0.11 & 0.06 \\
\hline $\mathrm{Li}_{0.92} \mathrm{Al}$ & 0 & 1 & 0 & 0 & 0 & $\mathrm{Al}$ & Unknown & $\mathrm{NaH}$ & $\mathrm{NaAlH}_{4}$ & & & & & 2.21 & 2.17 \\
\hline $\mathrm{Li}_{0.92} \mathrm{Al}$ & 0 & 2 & 0 & 0 & 0 & $\mathrm{NaH}$ & $\mathrm{NaAlH}_{4}$ & Unknown & $\mathrm{Al}$ & & & & & 3.85 & 3.90 \\
\hline 1 & 1 & 0 & 0 & 0 & 0 & $\mathrm{LiH}$ & $\mathrm{Al}$ & & & $\mathrm{Al} / \mathrm{LiH}$ & $\begin{array}{l}\text { unk. } d= \\
2.83,2.69 \\
2.50,1.88\end{array}$ & & & 0.27 & 0.06 \\
\hline 1 & 0.2 & 0.8 & 0 & 0 & 0 & $\mathrm{Al}$ & $\mathrm{NaH}$ & $\mathrm{LiH}$ & & $\mathrm{Al} / \mathrm{LiH}$ & $\mathrm{NaH}$ & $\mathrm{Na}_{3} \mathrm{AlH}_{6}$ & $\mathrm{LiNa}_{2} \mathrm{AlH}_{6}$ & 3.10 & 2.72 \\
\hline 1 & 0.4 & 0.6 & 0 & 0 & 0 & $\mathrm{Al}$ & $\mathrm{LiH}$ & $\mathrm{NaH}$ & & $\mathrm{Al} / \mathrm{LiH}$ & $\mathrm{NaH}$ & $\mathrm{Na}_{3} \mathrm{AlH}_{6}$ & $\mathrm{LiNa}_{2} \mathrm{AlH}_{6}$ & 1.68 & 2.49 \\
\hline 1 & 0.6 & 0.4 & 0 & 0 & 0 & $\mathrm{Al}$ & $\mathrm{LiH}$ & $\mathrm{NaH}$ & & $\mathrm{Al} / \mathrm{LiH}$ & $\mathrm{NaH}$ & $\mathrm{LiNa}_{2} \mathrm{AlH}_{6}$ & $\mathrm{Na}_{3} \mathrm{AlH}_{6}$ & 1.43 & 1.57 \\
\hline 1 & 0.8 & 0.2 & 0 & 0 & 0 & $\mathrm{Al}$ & $\mathrm{LiH}$ & $\mathrm{NaH}$ & & $\mathrm{Al} / \mathrm{LiH}$ & $\mathrm{LiNa}_{2} \mathrm{AlH}_{6}$ & $\mathrm{NaH}$ & $\mathrm{Na}_{3} \mathrm{AlH}_{6}$ & 0.82 & 0.68 \\
\hline 1 & 0 & 1 & 0 & 0 & 0 & $\mathrm{Al}$ & $\mathrm{NaH}$ & & & $\mathrm{Al}$ & $\mathrm{NaH}$ & $\mathrm{Na}_{3} \mathrm{AlH}_{6}$ & $\mathrm{Na}_{3} \mathrm{AlH}_{6}$ & 3.80 & 2.74 \\
\hline 1 & 0 & 0.6 & 0.4 & 0 & 0 & $\mathrm{Al}$ & $\mathrm{KH}$ & $\mathrm{NaH}$ & & $\mathrm{K}_{2} \mathrm{NaAlH}_{6}$ & $\mathrm{KAlH}_{4}$ & $\mathrm{NaH}$ & $\mathrm{Na}_{3} \mathrm{AlH}_{6}$ & 1.52 & 1.37 \\
\hline 1 & 0 & 0.8 & 0.2 & 0 & 0 & $\mathrm{Al}$ & $\mathrm{NaH}$ & $\mathrm{KH}$ & & $\mathrm{Al}$ & $\mathrm{Na}_{3} \mathrm{AlH}_{6}$ & $\mathrm{KAIH}_{4}$ & $\mathrm{NaH}$ & 1.86 & 1.59 \\
\hline 1 & 0.2 & 0.6 & 0.2 & 0 & 0 & $\mathrm{Al}$ & $\mathrm{NaH}$ & $\mathrm{KH}$ & $\mathrm{LiH}$ & & & & & 2.43 & 0.00 \\
\hline 1 & 0.2 & 0.6 & 0 & 0 & 0.1 & $\mathrm{Al}$ & $\mathrm{NaH}$ & $\mathrm{CaH}_{2}$ & $\mathrm{LiH}$ & & & & & 2.71 & 0.00 \\
\hline 1 & 0 & 0.6 & 0.2 & 0 & 0 & $\mathrm{Al}$ & $\mathrm{NaH}$ & $\mathrm{KH}$ & $\mathrm{CaH}_{2}$ & & & & & 2.65 & 0.00 \\
\hline 1 & 0 & 0.4 & 0.6 & 0 & 0 & $\mathrm{Al}$ & $\mathrm{KH}$ & $\mathrm{NaH}$ & & & & & & 1.34 & 0.00 \\
\hline 1 & 0 & 0.4 & 0 & 0 & 0.3 & & & & & & & & & 1.58 & 0.00 \\
\hline 1 & 0 & 0.4 & 0.4 & 0 & 0.1 & $\mathrm{Al}$ & $\mathrm{NaH}$ & $\mathrm{KH}$ & $\mathrm{CaH}_{2}$ & & & & & 1.36 & 0.00 \\
\hline 1 & 0 & 0.4 & 0.2 & 0 & 0.2 & $\mathrm{Al}$ & $\mathrm{NaH}$ & $\mathrm{KH}$ & $\mathrm{CaH}_{2}$ & & & & & 1.66 & 0.00 \\
\hline 1 & 0.4 & 0.4 & 0.2 & 0 & 0 & $\mathrm{Al}$ & $\mathrm{LiH}$ & $\mathrm{NaH}$ & $\mathrm{KH}$ & & & & & 1.69 & 0.00 \\
\hline 1 & 0 & 0.8 & 0 & 0 & 0.1 & $\mathrm{Al}$ & $\mathrm{NaH}$ & $\mathrm{CaH}_{2}$ & & $\mathrm{Al}$ & $\mathrm{NaH}$ & $\mathrm{Na}_{3} \mathrm{AlH}_{6}$ & $\mathrm{CaH}_{2}$ & 2.89 & 2.16 \\
\hline 1 & 0 & 0.6 & 0 & 0 & 0.2 & $\mathrm{Al}$ & $\mathrm{NaH}$ & $\mathrm{CaH}_{2}$ & $\begin{array}{l}\mathrm{d}=2.54 \\
2.24,2.09\end{array}$ & $\mathrm{Al}$ & $\mathrm{CaH}_{2}$ & $\mathrm{NaH}$ & $\mathrm{Na}_{3} \mathrm{AlH}_{6}$ & 2.10 & 1.77 \\
\hline 1 & 0.2 & 0.4 & 0.4 & 0 & 0 & $\mathrm{LiH}$ & Al & $\mathrm{NaH}$ & $\mathrm{KH}$ & $\mathrm{K}_{2} \mathrm{NaAlH}_{6}$ & $\mathrm{KAlH}_{4}$ & $\mathrm{Al}$ & $\mathrm{Na}_{3} \mathrm{AlH}_{6}$ & 1.39 & 1.35 \\
\hline 1 & 0.2 & 0.4 & 0 & 0 & 0.2 & $\mathrm{Al}$ & $\mathrm{CaH}_{2}$ & $\mathrm{LiH}$ & & $\mathrm{Al}$ & $\mathrm{CaH}_{2}$ & $\mathrm{NaH}$ & $\mathrm{Na}_{3} \mathrm{AlH}_{6}$ & 1.90 & 1.78 \\
\hline$\frac{ \pm}{1}$ & 0.4 & 0.4 & 0 & 0 & 0.1 & $\mathrm{LiH}$ & $\mathrm{Al}$ & $\mathrm{CaH}_{2}$ & $\mathrm{NaH}$ & $\mathrm{LiH} / \mathrm{Al}$ & $\mathrm{CaH}_{2}$ & $\mathrm{Na}_{3} \mathrm{AlH}_{6}$ & $\mathrm{NaH}$ & 1.66 & 1.72 \\
\hline 1 & 0.8 & 0 & 0.2 & 0 & 0 & $\mathrm{Al}$ & $\mathrm{LiH}$ & $\mathrm{KH}$ & $\mathrm{KOH}^{\star} \mathrm{H}_{2} \mathrm{O}$ & $\mathrm{Al} / \mathrm{LiH}$ & $\mathrm{KH}$ & Unknown & & 0.19 & 0.36 \\
\hline 1 & 0.8 & 0 & 0 & 0 & 0.1 & $\mathrm{Al}$ & $\mathrm{LiH}$ & $\mathrm{CaH}_{2}$ & & $\mathrm{Al} / \mathrm{LiH}$ & $\mathrm{CaH}_{2}$ & & & 0.24 & 0.08 \\
\hline 1 & 0.6 & 0 & 0.4 & 0 & 0 & $\mathrm{Al}$ & $\mathrm{LiH}$ & $\mathrm{KH}$ & $d=3.00$ & $\mathrm{Al} / \mathrm{LiH}$ & $\mathrm{KAlH}_{4}$ & & & 0.09 & 0.35 \\
\hline 1 & 0 & 0 & 0 & 1 & 0 & $\mathrm{Al}$ & $\mathrm{MgH}_{2}$ & & & $\mathrm{Al}$ & $\mathrm{MgH}_{2}$ & & & 0.33 & 0.00 \\
\hline 1 & 0.2 & 0 & 0 & 0.4 & 0 & $\mathrm{Al}$ & $\mathrm{LiH}$ & $\mathrm{MgH}_{2}$ & & $\mathrm{Al}$ & $\mathrm{LiH}$ & $\mathrm{MgH}_{2}$ & & 0.24 & 0.00 \\
\hline
\end{tabular}




\begin{tabular}{|c|c|c|c|c|c|c|c|c|c|c|c|c|c|c|c|}
\hline \multicolumn{6}{|c|}{ Composition } & \multicolumn{4}{|c|}{ As-Synthesized XRD } & \multicolumn{4}{|c|}{ Spent XRD } & \multicolumn{2}{|c|}{$\begin{array}{c}\text { Hydrogen } \\
\text { Capacity } \\
\text { (Wt.\%) }\end{array}$} \\
\hline Al & LiH & $\mathrm{NaH}$ & $\mathrm{KH}$ & $\mathrm{MgH}_{2}$ & $\mathrm{CaH}_{2}$ & xrd 1 & xrd 2 & xrd 3 & xrd 4 & xrd 1 & xrd 2 & xrd 3 & xrd 4 & Des 1 & Des 2 \\
\hline 1 & 0.4 & 0 & 0 & 0.3 & 0 & $\mathrm{Al}$ & $\mathrm{LiH}$ & $\mathrm{MgH}_{2}$ & & $\mathrm{Al}$ & $\mathrm{LiH}$ & $\mathrm{MgH}_{2}$ & & 0.18 & 0.00 \\
\hline 1 & 0.6 & 0 & 0 & 0.2 & 0 & $\mathrm{Al}$ & $\mathrm{LiH}$ & $\mathrm{MgH}_{2}$ & & $\mathrm{Al}$ & $\mathrm{LiH}$ & $\mathrm{MgH}_{2}$ & $\mathrm{~d}=1.88$ & 0.24 & 0.00 \\
\hline 1 & 0.8 & 0 & 0 & 0.1 & 0 & $\mathrm{Al}$ & $\mathrm{LiH}$ & $\mathrm{MgH} 2$ & & $\mathrm{Al}$ & $\mathrm{LiH}$ & $\mathrm{MgH} 2$ & $\begin{array}{l}\mathrm{d}=3.13 \\
2.74,2.69\end{array}$ & 0.20 & 0.00 \\
\hline 1 & 0 & 0.2 & 0 & 0.4 & 0 & $\mathrm{Al}$ & $\mathrm{MgH}_{2}$ & $\mathrm{NaH}$ & & $\mathrm{Al}$ & $\mathrm{MgH}_{2}$ & $\mathrm{NaMgH}_{3}$ & & 1.05 & 0.00 \\
\hline 1 & 0 & 0.4 & 0 & 0.3 & 0 & $\mathrm{Al}$ & $\mathrm{MgH}_{2}$ & $\mathrm{NaH}$ & & $\mathrm{Al}$ & $\mathrm{NaMgH}_{3}$ & $\mathrm{NaAlH}_{4}$ & & 1.78 & 0.00 \\
\hline 1 & 0 & 0.6 & 0 & 0.2 & 0 & $\mathrm{Al}$ & $\mathrm{NaH}$ & $\mathrm{MgH}_{2}$ & & $\mathrm{Al}$ & $\mathrm{NaAlH}_{4}$ & $\mathrm{NaMgH}_{3}$ & & 2.69 & 0.00 \\
\hline 1 & 0 & 0.8 & 0 & 0.1 & 0 & $\mathrm{Al}$ & $\mathrm{NaH}$ & $\mathrm{MgH}_{2}$ & & $\mathrm{Al}$ & $\mathrm{NaAlH} 4$ & & & 2.58 & 1.91 \\
\hline 1 & 0.2 & 0.2 & 0 & 0.3 & 0 & $\mathrm{Al}$ & $\mathrm{MgH}_{2}$ & $\mathrm{LiH}$ & $\mathrm{NaH}$ & $\mathrm{Al} / \mathrm{LiH}$ & $\mathrm{NaMgH}_{3}(\mathrm{tr})$ & $\mathrm{MgH}_{2}(\mathrm{tr})$ & $\mathrm{NaH}(\mathrm{tr})$ & 0.98 & 0.14 \\
\hline 1 & 0.2 & 0.4 & 0 & 0.2 & 0 & $\mathrm{Al}$ & $\mathrm{NaH}$ & $\mathrm{MgH}_{2}$ & $\mathrm{LiH}$ & $\mathrm{Al} / \mathrm{LiH}$ & $\mathrm{NaAlH}_{4}$ & $\mathrm{LiNa}_{2} \mathrm{AlH}_{6}$ & $\mathrm{NaMgH}_{3}$ & 1.69 & 1.41 \\
\hline 1 & 0.2 & 0.6 & 0 & 0.1 & 0 & $\mathrm{Al}$ & $\mathrm{NaH}$ & $\mathrm{LiH}$ & $\mathrm{MgH}_{2}$ & $\mathrm{Al}$ & $\mathrm{Na}_{3} \mathrm{AlH}_{6}$ & $\mathrm{NaAlH}_{4}$ & $\mathrm{MgH}_{2}$ & 2.73 & 2.56 \\
\hline$\frac{1}{1}$ & 0.4 & 0.2 & 0 & 0.2 & 0 & $\mathrm{Al}$ & $\mathrm{LiH}$ & $\mathrm{MgH}_{2}$ & $\mathrm{NaH}$ & $\mathrm{Al} / \mathrm{LiH}$ & $\mathrm{LiNa}_{2} \mathrm{AlH}_{6}$ & $\mathrm{NaMgH}_{3}$ & $\mathrm{NaAlH}_{4}$ & 0.78 & 0.36 \\
\hline 1 & 0.4 & 0.4 & 0 & 0.1 & 0 & $\mathrm{Al}$ & $\mathrm{LiH}$ & $\mathrm{NaH}$ & $\mathrm{MgH}_{2}$ & $\mathrm{Al} / \mathrm{LiH}$ & $\mathrm{NaAlH}_{4}$ & $\mathrm{LiNa}_{2} \mathrm{AlH}_{6}$ & $\mathrm{NaMgH}_{3}$ & 1.68 & 1.63 \\
\hline 1 & 0.6 & 0.2 & 0 & 0.1 & 0 & $\mathrm{Al}$ & $\mathrm{LiH}$ & $\mathrm{MgH}_{2}$ & $\mathrm{NaH}$ & $\mathrm{Al} / \mathrm{LiH}$ & $\begin{array}{l}\text { Unk d = } \\
3.36,2.74, \\
2.50,2.46 \\
1.82,1.77\end{array}$ & $\mathrm{LiNa}_{2} \mathrm{AlH}_{6}$ & & 0.74 & 0.55 \\
\hline 1 & 0.4 & 0.1 & 0 & 0.2 & 0 & $\mathrm{Al}$ & $\mathrm{CaH}_{2}$ & $\mathrm{NaH}$ & $\mathrm{MgH}_{2}$ & $\mathrm{Al}$ & $\mathrm{CaH}_{2}$ & $\mathrm{NaAlH}_{4}$ & & 1.19 & 1.06 \\
\hline 1 & 0.4 & 0 & 0 & 0.2 & 0.1 & $\mathrm{Al}$ & $\mathrm{CaH}_{2}$ & $\mathrm{MgH}_{2}$ & $\mathrm{NaH}$ & $\mathrm{Al}$ & $\mathrm{NaMgH}_{3}$ & $\mathrm{CaH}_{2}$ & $\mathrm{MgH}_{2}$ & 1.63 & 0.95 \\
\hline 1 & 0.6 & 0 & 0 & 0 & 0.2 & $\mathrm{Al}$ & $\mathrm{LiH}$ & $\mathrm{CaH}_{2}$ & & $\mathrm{Al} / \mathrm{LiH}$ & $\mathrm{CaH}_{2}$ & & & 0.26 & 0.06 \\
\hline 1 & 0.6 & 0 & 0 & 0.1 & 0.1 & $\mathrm{Al}$ & $\mathrm{LiH}$ & $\mathrm{CaH}_{2}$ & $\mathrm{MgH}_{2}$ & $\mathrm{Al} / \mathrm{LiH}$ & $\mathrm{CaH}_{2}$ & $\mathrm{MgH}_{2}$ & & 0.15 & 0.02 \\
\hline 1 & 0 & 0 & 0 & 0.4 & 0.1 & $\mathrm{Al}$ & $\mathrm{MgH}_{2}$ & $\mathrm{CaH}_{2}$ & & $\mathrm{Al}$ & $\mathrm{MgH}_{2}$ & $\mathrm{CaH}_{2}$ & & 0.21 & 0.05 \\
\hline 1 & 0 & 0 & 0.2 & 0 & 0.4 & $\mathrm{Al}$ & $\mathrm{CaH}_{2}$ & $\mathrm{MgH}_{2}$ & & $\mathrm{Al}$ & $\mathrm{MgH}_{2}$ & $\mathrm{CaH}_{2}$ & & 0.15 & 0.04 \\
\hline 1 & 0 & 0.2 & 0 & 0.3 & 0.1 & $\mathrm{Al}$ & $\mathrm{CaH}_{2}$ & $\mathrm{MgH}_{2}$ & $\mathrm{NaH}$ & $\mathrm{Al}$ & $\mathrm{CaH}_{2}$ & $\mathrm{NaMgH}_{3}$ & $\mathrm{MgH}_{2}$ & 0.90 & 0.10 \\
\hline 1 & 0 & 0 & 0 & 0.3 & 0.2 & $\mathrm{Al}$ & $\mathrm{CaH}_{2}$ & $\mathrm{MgH}_{2}$ & & $\mathrm{Al}$ & $\mathrm{CaH}_{2}$ & $\mathrm{MgH}_{2}$ & & 0.25 & 0.08 \\
\hline 1 & 0 & 0 & 0 & 0 & 0.5 & $\mathrm{Al}$ & $\mathrm{CaH}_{2}$ & & & $\mathrm{Al}$ & $\mathrm{CaH}_{2}$ & & & 0.14 & 0.05 \\
\hline 1 & 0 & 0 & 0 & 0.1 & 0.4 & & & & & $\mathrm{Al}$ & $\mathrm{CaH}_{2}$ & $\mathrm{MgH}_{2}$ & & 0.07 & 0.00 \\
\hline 1 & 0 & 0 & 0.2 & 0 & 0.4 & & & & & $\mathrm{Al}$ & $\mathrm{CaH}_{2}$ & $\mathrm{MgH}_{2}$ & & 0.45 & 0.62 \\
\hline 1 & 0.2 & 0 & 0 & 0 & 0.4 & & & & & $\mathrm{Al} / \mathrm{LiH}$ & $\mathrm{CaH}_{2}$ & & & 0.15 & 0.03 \\
\hline 1 & 0 & 0.6 & 0.2 & 0.1 & 0 & $\mathrm{Al}$ & $\mathrm{NaH}$ & $\mathrm{KOH}^{\star} \mathrm{H}_{2} \mathrm{O}$ & & $\mathrm{NaAlH}_{4}$ & $\mathrm{KAlH}_{4}$ & $\mathrm{Al}$ & $\mathrm{NaMgH}_{3}$ & 2.85 & 2.46 \\
\hline 1 & 0 & 0.4 & 0.2 & 0.2 & 0 & $\mathrm{Al}$ & $\mathrm{KOH}^{*} \mathrm{H}_{2} \mathrm{O}$ & $\mathrm{NaH}$ & $\mathrm{MgH}_{2}$ & $\mathrm{Al}$ & $\mathrm{NaAlH}_{4}$ & $\mathrm{KAlH}_{4}$ & $\mathrm{NaMgH}_{3}$ & 1.75 & 1.59 \\
\hline 1 & 0.6 & 0 & 0.4 & 0 & 0 & $\mathrm{Al}$ & $\mathrm{LiH}$ & $\mathrm{LiOH}$ & wax & $\mathrm{Al} / \mathrm{LiH}$ & $\mathrm{KAlH}_{4}$ & & & 0.35 & 0.37 \\
\hline 1 & 0.6 & 0 & 0.2 & 0 & 0.1 & $\mathrm{Al}$ & $\mathrm{LiH}$ & $\mathrm{CaH}_{2}$ & $\mathrm{KOH}^{*} \mathrm{H}_{2} \mathrm{O}$ & $\mathrm{Al} / \mathrm{LiH}$ & $\mathrm{KAlH}_{4}$ & $\mathrm{CaH}_{2}$ & & 0.51 & 0.45 \\
\hline 1 & 0.6 & 0.2 & 0.2 & 0 & 0 & $\mathrm{Al}$ & $\mathrm{LiH}$ & $\mathrm{KH}$ & $\mathrm{NaH}$ & $\mathrm{Al} / \mathrm{LiH}$ & $\mathrm{LiNa}_{2} \mathrm{AlH}_{6}$ & $\mathrm{KAIH}_{4}$ & $\begin{array}{l}\mathrm{NaAlH}_{4} \\
\text { (tr) }\end{array}$ & 1.13 & 0.87 \\
\hline
\end{tabular}


Table 3 (cont.). Reverse alanate reactions; compositions, structural analysis and storage capacities based on desorption at $220^{\circ} \mathrm{C}$.

\begin{tabular}{|c|c|c|c|c|c|c|c|c|c|c|c|c|c|c|c|}
\hline \multicolumn{6}{|c|}{ Composition } & \multicolumn{4}{|c|}{ As-Synthesized XRD } & \multicolumn{4}{|c|}{ Spent XRD } & \multicolumn{2}{|c|}{$\begin{array}{c}\text { Hydrogen } \\
\text { Capacity } \\
\text { (Wt.\%) }\end{array}$} \\
\hline Al & LiH & $\mathrm{NaH}$ & $\mathbf{K H}$ & $\mathrm{MgH}_{2}$ & $\mathrm{CaH}_{2}$ & xrd 1 & xrd 2 & xrd 3 & xrd 4 & xrd 1 & xrd 2 & xrd 3 & xrd 4 & Des 1 & Des 2 \\
\hline 1 & 0.6 & 0 & 0.2 & 0.1 & 0 & $\mathrm{Al}$ & $\mathrm{LiH}$ & $\mathrm{KOH}^{*} \mathrm{H}_{2} \mathrm{O}$ & $\mathrm{MgH}_{2}$ & $\mathrm{Al} / \mathrm{LiH}$ & $\mathrm{KAIH}_{4}$ & $\mathrm{MgH}_{2}$ & & 0.48 & 0.45 \\
\hline 1 & 0 & 0 & 0.2 & 0.4 & 0 & $\mathrm{Al}$ & $\mathrm{MgH}_{2}$ & $\mathrm{KOH}^{*} \mathrm{H}_{2} \mathrm{O}$ & & $\mathrm{Al}$ & $\mathrm{MgH}_{2}$ & $\mathrm{MgH}_{2}$ & & 1.12 & 0.27 \\
\hline 1 & 0 & 0 & 0.4 & 0.3 & 0 & $\mathrm{Al}$ & $\mathrm{MgH}_{2}$ & $\mathrm{KOH}^{*} \mathrm{H}_{2} \mathrm{O}$ & & $\mathrm{Al}$ & $\mathrm{MgH}_{2}$ & $\mathrm{MgH}_{2}$ & $\mathrm{KAlH}_{4}(\mathrm{tr})$ & -0.09 & 0.41 \\
\hline 1 & 0.2 & 0.8 & 0 & 0 & 0 & & & & & $\mathrm{NaAlH}_{4}$ & $\mathrm{LiNa}_{2} \mathrm{AlH}_{6}$ & $\mathrm{Al} / \mathrm{LiH}$ & $\mathrm{Na}_{3} \mathrm{AlH}_{6}$ & 3.56 & 3.39 \\
\hline 1 & 0 & 0 & 0.2 & 0.3 & 0.1 & $\mathrm{Al}$ & $\mathrm{CaH}_{2}$ & $\mathrm{MgH}_{2}$ & $\mathrm{KOH}^{*} \mathrm{H}_{2} \mathrm{O}$ & $\mathrm{Al}$ & $\mathrm{KMgH}_{3}$ & $\mathrm{CaH}_{2}$ & $\mathrm{MgH}_{2}$ & 1.04 & 0.33 \\
\hline 1 & 0 & 0.2 & 0.2 & 0.3 & 0 & $\mathrm{Al}$ & $\mathrm{MgH}_{2}$ & $\mathrm{NaH}$ & $\mathrm{KOH}^{*} \mathrm{H}_{2} \mathrm{O}$ & $\mathrm{Al}$ & $\mathrm{MgH}_{2}$ & $\begin{array}{l}\text { Unk d = } \\
2.96,2.81 \text {, } \\
2.17\end{array}$ & & 1.20 & 0.64 \\
\hline 1 & 0.2 & 0 & 0.2 & 0.3 & 0 & $\mathrm{Al}$ & $\mathrm{LiH}$ & $\mathrm{MgH}_{2}$ & $\mathrm{KOH}^{*} \mathrm{H}_{2} \mathrm{O}$ & $\mathrm{Al}$ & $\mathrm{MgH}_{2}$ & $\mathrm{KAIH}_{4}$ & & 1.14 & 0.69 \\
\hline 1 & 0 & 0 & 1 & 0 & 0 & $\mathrm{KOH}^{*} \mathrm{H}_{2} \mathrm{O}$ & $\mathrm{Al}$ & $\mathrm{KH}$ & & $\mathrm{KAIH}_{4}$ & $\mathrm{KOH}^{\star} \mathrm{H}_{2} \mathrm{O}$ & & & 1.00 & 0.06 \\
\hline 1 & 0 & 0.2 & 0.8 & 0 & 0 & $\mathrm{Al}$ & $\mathrm{KOH}^{*} \mathrm{H}_{2} \mathrm{O}$ & $\mathrm{NaH}$ & $\mathrm{KH}$ & $\mathrm{KAlH}_{4}$ & & & & 0.70 & 0.65 \\
\hline 1 & 0.2 & 0 & 0.8 & 0 & 0 & $\begin{array}{l}\text { Unk d = } \\
2.99,2.89\end{array}$ & $\begin{array}{l}2.66,2.49,2.36, \\
2.32,2.27,2.23,\end{array}$ & $\begin{array}{l}2.12,2.08 \\
2.01,1.96 \\
\end{array}$ & $\begin{array}{l}1.87,1.76 \\
1.75,1.73 \\
\end{array}$ & $\mathrm{KAIH}_{4}$ & & & & 0.34 & 0.27 \\
\hline 1 & 0 & 0 & 0.8 & 0.1 & 0 & $\mathrm{Al}$ & $\mathrm{KOH}^{*} \mathrm{H}_{2} \mathrm{O}$ & $\mathrm{KH}$ & $\mathrm{MgH}_{2}$ & $\mathrm{KAlH}_{4}$ & $\mathrm{Al}$ & & & 0.42 & 0.29 \\
\hline 1 & 0 & 0 & 0.8 & 0 & 0.1 & $\mathrm{Al}$ & $\mathrm{KOH}^{*} \mathrm{H}_{2} \mathrm{O}$ & $\mathrm{CaH}_{2}$ & $\mathrm{KH}$ & $\mathrm{KAIH}_{4}$ & $\mathrm{CaH}_{2}$ & $\mathrm{Al}$ & & 0.62 & 0.18 \\
\hline
\end{tabular}




\begin{tabular}{|c|c|c|}
\hline \multirow[t]{2}{*}{ Composition } & \multicolumn{2}{|c|}{$\begin{array}{l}\text { Hydrogen Storage } \\
\text { Capacities (wt. \%) }\end{array}$} \\
\hline & Des 1 & Des 2 \\
\hline $2 \mathrm{Ti}\left[\mathrm{OCH}\left(\mathrm{CH}_{3}\right)_{2}\right]_{4} / 100 \mathrm{NaAlH}_{4}+10 \mathrm{NaH}$ & 4.88 & 3.74 \\
\hline $2 \mathrm{Ti}\left[\mathrm{OCH}\left(\mathrm{CH}_{3}\right)_{2}\right]_{4} / 100 \mathrm{NaAlH}_{4}+25 \mathrm{NaH}$ & 4.74 & 3.70 \\
\hline $2 \mathrm{Ti}\left[\mathrm{OCH}\left(\mathrm{CH}_{3}\right)_{2}\right]_{4} / 100 \mathrm{LiAlH}_{4}+10 \mathrm{NaH}$ & 2.78 & 0.32 \\
\hline $2 \mathrm{Ti}\left[\mathrm{OCH}\left(\mathrm{CH}_{3}\right)_{2}\right]_{4} / 100 \mathrm{LiAlH}_{4}+25 \mathrm{NaH}$ & 2.91 & 0.80 \\
\hline $2 \mathrm{Ti}\left[\mathrm{OCH}\left(\mathrm{CH}_{3}\right)_{2}\right]_{4} / 100 \mathrm{NaAlH}_{4}$ & 5.39 & 3.39 \\
\hline $2 \mathrm{Ti}\left[\mathrm{OCH}\left(\mathrm{CH}_{3}\right)_{2}\right]_{4} / 100 \mathrm{NaAlH}_{4}+5 \mathrm{NaH}$ & 5.38 & 3.28 \\
\hline $2 \mathrm{Ti}\left[\mathrm{OCH}\left(\mathrm{CH}_{3}\right)_{2}\right]_{4} / 100 \mathrm{NaAlH}_{4}+10 \mathrm{NaH}$ & 5.15 & 3.09 \\
\hline $2 \mathrm{Ti}\left[\mathrm{OCH}\left(\mathrm{CH}_{3}\right)_{2}\right]_{4} / 100 \mathrm{NaAlH}_{4}$ & 5.34 & 3.30 \\
\hline $2 \mathrm{Ti}\left[\mathrm{OCH}\left(\mathrm{CH}_{3}\right)_{2}\right]_{4} / 100 \mathrm{NaAlH}_{4}+5 \mathrm{NaH}$ & 5.41 & 3.27 \\
\hline $2 \mathrm{Ti}\left[\mathrm{OCH}\left(\mathrm{CH}_{3}\right)_{2}\right]_{4} / 100 \mathrm{NaAlH}_{4}+10 \mathrm{NaH}$ & 5.68 & 3.43 \\
\hline $0.02 \mathrm{Ti}(\mathrm{OiPr})_{4}(97 \%) / 1 \mathrm{Na}_{3} \mathrm{AlH}_{6}$ & 2.54 & 1.74 \\
\hline $0.06 \mathrm{Ti}(\mathrm{OiPr})_{4}(97 \%) / 3 \mathrm{NaAlH}_{4}+1 \mathrm{MgCl}_{2}, 98 \%$ & 1.15 & 0.08 \\
\hline $0.04 \mathrm{Ti}(\mathrm{OiPr})_{4}(97 \%) / 2 \mathrm{NaAlH}_{4}+1 \mathrm{CaH}_{2}, 99.9 \%$ & 3.60 & 1.58 \\
\hline $0.02 \mathrm{Ti}(\mathrm{OiPr})_{4}(97 \%) / 1 \mathrm{NaAlH}_{4}+2 \mathrm{LIH}, 98 \%$ & 3.29 & 2.04 \\
\hline $0.02 \mathrm{Ti}(\mathrm{OiPr})_{4}(97 \%) / 1 \mathrm{NaAlH}_{4}+2 \mathrm{KH}$ & 0.32 & 0.02 \\
\hline $0.02 \mathrm{Ti}(\mathrm{OiPr})_{4}(97 \%) / 1 \mathrm{NaAlH}_{4}+2 \mathrm{NaH}, 95 \%$ & 2.87 & 2.35 \\
\hline $0.02 \mathrm{Ti}(\mathrm{OiPr})_{4}(97 \%) / 1 \mathrm{NaAlH}_{4}+1 \mathrm{NaH}, 95 \%+1 \mathrm{LiH}$ & 3.33 & 2.79 \\
\hline $0.02 \mathrm{Ti}(\mathrm{OiPr})_{4}(97 \%) / 1 \mathrm{LiAlH}_{4}+2 \mathrm{KH}$ & 0.28 & 0.12 \\
\hline $0.02 \mathrm{Ti}(\mathrm{OiPr})_{4}(97 \%) / 1 \mathrm{LiAlH}_{4}+2 \mathrm{NaH}(95 \%)$ & 3.24 & 2.96 \\
\hline $0.02 \mathrm{Ti}(\mathrm{OiPr})_{4}(97 \%) / 1 \mathrm{LiAlH}_{4}+1 \mathrm{MgH}_{2}(82.3 \%)$ & 3.68 & 0.06 \\
\hline $0.02 \mathrm{Ti}(\mathrm{OiPr})_{4}(97 \%) / 1 \mathrm{LiAlH}_{4}+1 \mathrm{CaH}_{2}, 99.9 \%$ & 3.41 & 0.26 \\
\hline $0.02 \mathrm{Ti}(\mathrm{OiPr})_{4}(97 \%) / 1 \mathrm{LiAlH}_{4}+1 \mathrm{KH}+1 \mathrm{NaH}(95 \%)$ & 0.94 & 1.02 \\
\hline $0.02 \mathrm{Ti}(\mathrm{OiPr})_{4}(97 \%) / 1 \mathrm{LiAlH}_{4}+0.5 \mathrm{MgH}_{2}(82.3 \%)+0.5 \mathrm{CaH}_{2}, 99.9 \%$ & 3.90 & 0.19 \\
\hline $0.02 \mathrm{Ti}(\mathrm{OiPr})_{4}(97 \%) / 1 \mathrm{LiAlH}_{4}+1 \mathrm{KH}+0.5 \mathrm{MgH}_{2}(82.3 \%)$ & 0.87 & 0.70 \\
\hline $0.02 \mathrm{Ti}(\mathrm{OiPr})_{4}(97 \%) / 1 \mathrm{LiAlH}_{4}+1 \mathrm{NaH}(95 \%)+0.5 \mathrm{MgH}_{2}(82.3 \%)$ & 3.44 & 1.06 \\
\hline $0.02 \mathrm{Ti}(\mathrm{OiPr})_{4}(99.999 \%) / 1 \mathrm{Mg}\left(\mathrm{AlH}_{4}\right)_{2}+2 \mathrm{MgH}_{2}$ & 0.29 & 0.12 \\
\hline $0.02 \mathrm{Ti}(\mathrm{OiPr})_{4}(99.999 \%) / 1 \mathrm{Mg}\left(\mathrm{AlH}_{4}\right)_{2}+2 \mathrm{NaH}+1 \mathrm{MgH}_{2}$ & 1.44 & 0.07 \\
\hline $0.02 \mathrm{Ti}(\mathrm{OiPr})_{4}(99.999 \%) / 1 \mathrm{Mg}\left(\mathrm{AlH}_{4}\right)_{2}+2 \mathrm{LiH}+1 \mathrm{MgH}_{2}$ & 0.47 & 0.19 \\
\hline $0.02 \mathrm{Ti}(\mathrm{OiPr})_{4}(99.999 \%) / 1 \mathrm{NaAlH}_{4}+1 \mathrm{MgH}_{2}$ & 3.12 & 0.07 \\
\hline $0.02 \mathrm{Ti}(\mathrm{OiPr})_{4}(99.999 \%) / 2 \mathrm{NaAlH}_{4}+2 \mathrm{NaH}+1 \mathrm{MgH}_{2}$ & 3.07 & 2.44 \\
\hline $0.02 \mathrm{Ti}(\mathrm{OiPr})_{4}(99.999 \%) / 2 \mathrm{NaAlH}_{4}+1 \mathrm{NaH}+1.5 \mathrm{MgH}_{2}$ & 3.32 & 2.26 \\
\hline $0.02 \mathrm{Ti}(\mathrm{OiPr})_{4}(99.999 \%) / 2 \mathrm{NaAlH}_{4}+2 \mathrm{LiH}+1 \mathrm{MgH}_{2}$ & 2.42 & 1.07 \\
\hline $0.02 \mathrm{Ti}(\mathrm{OiPr})_{4}(99.999 \%) / 1 \mathrm{NaAlH}_{4}+1.5 \mathrm{LiH}+0.5 \mathrm{NaH}$ & 3.32 & 2.71 \\
\hline
\end{tabular}




\begin{tabular}{|c|c|c|c|c|c|c|c|c|c|c|c|c|}
\hline \multirow{2}{*}{\multicolumn{3}{|c|}{ Composition }} & \multirow{2}{*}{\multicolumn{4}{|c|}{ Spent XRD in order of abundance }} & \multicolumn{6}{|c|}{ Hydrogen Storage Capacity (wt.\%) } \\
\hline & & & & & & & \multicolumn{2}{|c|}{ MT $\left(220^{\circ} \mathrm{C}\right)$} & \multicolumn{4}{|c|}{ HT Des T $\left({ }^{\circ} \mathrm{C}\right)$} \\
\hline $\mathrm{LiNH}_{2}$ & $\mathrm{LiBH}_{4}$ & $\mathrm{MgH}_{2}$ & xrd 1 & xrd 2 & xrd 3 & xrd 4 & Des 1 & Des 2 & 220 & 285 & 350 & 350 \\
\hline 0.8 & 0.2 & 1.0 & $\mathrm{MgH}_{2}$ & Unk., $d=2.17$ (br) & & & 1.52 & 0.38 & $\mathrm{~N}$ & $\mathrm{~N}$ & $\mathrm{~N}$ & $\mathrm{~N}$ \\
\hline 0.2 & 0.8 & 1.0 & $\mathrm{MgH}_{2}$ & Unk., $d=2.17$ (br) & WC & & 0.28 & 0.02 & $\mathrm{~N}$ & $\mathrm{~N}$ & $\mathrm{~N}$ & $\mathrm{~N}$ \\
\hline 0.5 & 0.5 & 0.5 & $\mathrm{MgH}_{2}$ & $\mathrm{Mg}_{3} \mathrm{~N}_{2}$ & $\mathrm{MgB}_{2}$ & $\mathrm{Mg}$ & 1.74 & 0.45 & $\mathrm{~N}$ & $\mathrm{~N}$ & $\mathrm{~N}$ & $\mathrm{~N}$ \\
\hline 0.3 & 0.7 & 0.5 & $\mathrm{MgH}_{2}$ & $\mathrm{Mg}$ & $\begin{array}{l}\text { unk., } d=3.84,3.63,2.86 \\
2.18(b r), 2.00\end{array}$ & & 1.12 & 0.33 & $\mathrm{~N}$ & $\mathrm{~N}$ & $\mathrm{~N}$ & $\mathrm{~N}$ \\
\hline 0.7 & 0.3 & 0.5 & $\mathrm{Mg}_{3} \mathrm{~N}_{2}$ & $\mathrm{MgH}_{2}$ & WC & & 2.52 & 0.64 & $\mathrm{~N}$ & $\mathrm{~N}$ & $\mathrm{~N}$ & $\mathrm{~N}$ \\
\hline 0.8 & 0.2 & 0.5 & & & & & $\mathrm{~N}$ & $\mathrm{~N}$ & $\mathrm{~N}$ & $\mathrm{~N}$ & $\mathrm{~N}$ & $\mathrm{~N}$ \\
\hline 0.2 & 0.8 & 0.5 & & & & & $\mathrm{~N}$ & $\mathrm{~N}$ & $\mathrm{~N}$ & $\mathrm{~N}$ & $\mathrm{~N}$ & $\mathrm{~N}$ \\
\hline 0.5 & 0.5 & 2.0 & & & & & $\mathrm{~N}$ & $\mathrm{~N}$ & $\mathrm{~N}$ & $\mathrm{~N}$ & $\mathrm{~N}$ & $\mathrm{~N}$ \\
\hline 2.0 & 0.0 & 1.1 & $\mathrm{Li}_{2} \mathrm{Mg}(\mathrm{NH})_{2}$ & BN & & & 3.83 & 2.31 & $\mathrm{~N}$ & $\mathrm{~N}$ & $\mathrm{~N}$ & $\mathrm{~N}$ \\
\hline 5.0 & 1.0 & 2.2 & $\mathrm{Mg}\left(\mathrm{NH}_{2}\right)_{2}$ & $\mathrm{Li}_{4}\left(\mathrm{NH}_{2}\right)_{3} \mathrm{BH}_{4}$ & $\mathrm{Li}_{2} \mathrm{Mg}(\mathrm{NH})_{2}$ & & 3.89 & 3.41 & $\mathrm{~N}$ & $\mathrm{~N}$ & $\mathrm{~N}$ & $\mathrm{~N}$ \\
\hline 4.0 & 1.0 & 2.2 & $\mathrm{Mg}\left(\mathrm{NH}_{2}\right)_{2}$ & $\mathrm{Li}_{4}\left(\mathrm{NH}_{2}\right)_{3} \mathrm{BH}_{4}$ & $\mathrm{Li}_{2} \mathrm{Mg}(\mathrm{NH})_{2}$ & & 3.68 & 2.99 & $\mathrm{~N}$ & $\mathrm{~N}$ & $\mathrm{~N}$ & $\mathrm{~N}$ \\
\hline 5.0 & 1.0 & 2.2 & & & & & 3.53 & 3.12 & $\mathrm{~N}$ & $\mathrm{~N}$ & $\mathrm{~N}$ & $\mathrm{~N}$ \\
\hline 5.0 & 0.0 & 2.2 & $\mathrm{Li}_{2} \mathrm{NH}$ & $\mathrm{Li}_{2} \mathrm{Mg}(\mathrm{NH})_{2}$ & $\mathrm{MgH}_{2}$ & $\mathrm{LiH}$ & 1.10 & 0.43 & $\mathrm{~N}$ & $\mathrm{~N}$ & $\mathrm{~N}$ & $\mathrm{~N}$ \\
\hline 6.0 & 1.0 & 2.2 & $\mathrm{Li}_{4}\left(\mathrm{NH}_{2}\right)_{3} \mathrm{BH}_{4}$ & $\mathrm{Mg}\left(\mathrm{NH}_{2}\right)_{2}$ & & & 3.20 & 3.00 & $\mathrm{~N}$ & $\mathrm{~N}$ & $\mathrm{~N}$ & $\mathrm{~N}$ \\
\hline 0.2 & 0.8 & 0.0 & & & & & 0.26 & 0.19 & 0.54 & 3.34 & 0.32 & 0.11 \\
\hline 0.3 & 0.7 & 0.0 & $\mathrm{Li}_{4}\left(\mathrm{NH}_{2}\right)_{3} \mathrm{BH}_{4}$ & Li-N-B-H\#2 & $\mathrm{LiBH}_{4}$ & & 0.35 & 0.27 & 0.55 & 4.60 & 0.31 & 0.12 \\
\hline 0.4 & 0.6 & 0.0 & & & & & 0.52 & 0.19 & 1.50 & 5.76 & 0.18 & 0.12 \\
\hline 0.5 & 0.5 & 0.0 & $\mathrm{Li}_{2} \mathrm{O}$ & $\mathrm{Li}_{4}\left(\mathrm{NH}_{2}\right)_{3} \mathrm{BH}_{4}$ & Li-N-B-H\#2 & $\mathrm{LiBH}_{4}$ & 1.27 & 0.67 & 2.07 & 6.27 & 0.97 & 0.20 \\
\hline 0.6 & 0.4 & 0.0 & WC & $\mathrm{Li}_{4}\left(\mathrm{NH}_{2}\right)_{3} \mathrm{BH}_{4}$ & Li-N-B-H\#2 & unk. $d=3.48,3.35,3.21$ & 1.08 & 0.61 & 2.12 & 8.20 & 0.10 & 0.03 \\
\hline 0.7 & 0.3 & 0.0 & $\mathrm{Li}_{4}\left(\mathrm{NH}_{2}\right)_{3} \mathrm{BH}_{4}$ & WC & unk., $d=3.33,2.93,2.73$ & & 0.84 & 0.39 & 3.18 & 7.85 & 0.15 & 0.05 \\
\hline 0.8 & 0.2 & 0.0 & $\mathrm{Li}_{4}\left(\mathrm{NH}_{2}\right)_{3} \mathrm{BH}_{4}$ & WC & $\mathrm{Li}_{2} \mathrm{NH}$ & unk. $d=2.76$ & 0.65 & 0.31 & 0.93 & 5.94 & 0.12 & 0.03 \\
\hline 0.9 & 0.1 & 0.0 & $\mathrm{Li}_{2} \mathrm{NH}$ & $\mathrm{Li}_{4}\left(\mathrm{NH}_{2}\right)_{3} \mathrm{BH}_{4}$ & unk., $d=2.77,2.57$ & & 0.12 & 0.06 & $\mathrm{~B}$ & 1.51 & 2.48 & 0.20 \\
\hline 0.1 & 0.8 & 0.1 & $\mathrm{LiBH}_{4}$ & $\mathrm{MgH}_{2}$ & $\mathrm{Mg}_{3} \mathrm{~N}_{2}$ & $\mathrm{Li}_{4}\left(\mathrm{NH}_{2}\right)_{3} \mathrm{BH}_{4}$ & 0.92 & 0.33 & 1.40 & 1.15 & 0.70 & 0.48 \\
\hline 0.2 & 0.7 & 0.1 & Li-N-B-H\#2 & $\mathrm{LiBH} 4$ & $\begin{array}{l}\text { unk., } d=3.41,3.32,2.98 \\
2.35\end{array}$ & & 1.12 & 0.95 & B & B & 0.42 & 0.29 \\
\hline 0.3 & 0.6 & 0.1 & $\mathrm{BN}$ & Li-N-B-H\#2 & $\mathrm{Li}_{4}\left(\mathrm{NH}_{2}\right)_{3} \mathrm{BH}_{4}$ & $\mathrm{MgH} 2$ & 1.24 & 0.96 & 2.41 & 3.60 & 0.49 & 0.35 \\
\hline 0.4 & 0.5 & 0.1 & Li-N-B-H\#2 & $\mathrm{MgH}_{2}$ & $\mathrm{Li}_{4}\left(\mathrm{NH}_{2}\right)_{3} \mathrm{BH}_{4}$ & $\mathrm{BN}$ & 1.30 & 0.97 & 1.77 & 5.23 & 0.77 & 0.49 \\
\hline 0.5 & 0.4 & 0.1 & Li-N-B-H\#2 & $\mathrm{Li}_{4}\left(\mathrm{NH}_{2}\right)_{3} \mathrm{BH}_{4}$ & $\left(\mathrm{BH}_{2} \mathrm{NH}_{2}\right)_{5}$ & $\mathrm{LiH}$ & 1.27 & 1.09 & 3.05 & 4.46 & 0.87 & 0.20 \\
\hline 0.6 & 0.3 & 0.1 & $\mathrm{Li}_{4}\left(\mathrm{NH}_{2}\right)_{3} \mathrm{BH}_{4}$ & $\begin{array}{l}\text { unk., } d=3.81,2.97,2.35 \\
1.89,1.82\end{array}$ & WC & & 1.53 & 1.36 & 3.33 & 5.74 & 1.39 & 0.32 \\
\hline 0.7 & 0.2 & 0.1 & $\mathrm{Li}_{4}\left(\mathrm{NH}_{2}\right)_{3} \mathrm{BH}_{4}$ & WC & $\mathrm{LiNH}_{2}$ & $\mathrm{MgH}_{2}$ & 2.02 & 1.72 & 3.52 & 4.75 & 2.01 & 0.73 \\
\hline 5.0 & 1.0 & 2.2 & $\mathrm{Li}_{2} \mathrm{Mg}(\mathrm{NH})_{2}$ & $\mathrm{LiNH}_{2}$ & $\mathrm{Mg}_{3} \mathrm{~N}_{2}$ & $\mathrm{Mg}_{3} \mathrm{BN}_{3}$ & $\mathrm{~N}$ & $\mathrm{~N}$ & B & B & 0.00 & 0.00 \\
\hline 4.0 & 1.0 & 2.2 & & & & & 3.67 & 3.13 & $\mathrm{~N}$ & $\mathrm{~N}$ & $\mathrm{~N}$ & $\mathrm{~N}$ \\
\hline 0.8 & 0.1 & 0.1 & & & & & 1.39 & 1.05 & 2.51 & 2.00 & 3.13 & 0.48 \\
\hline 0.9 & 0.0 & 0.1 & & & & & 0.25 & 0.11 & 0.90 & 1.65 & 0.87 & 0.26 \\
\hline
\end{tabular}




\begin{tabular}{|c|c|c|c|c|c|c|c|c|c|c|c|c|}
\hline \multirow{2}{*}{\multicolumn{3}{|c|}{ Composition }} & \multirow{2}{*}{\multicolumn{4}{|c|}{ Spent XRD in order of abundance }} & \multicolumn{6}{|c|}{ Hydrogen Storage Capacity (wt.\%) } \\
\hline & & & & & & & \multicolumn{2}{|c|}{ MT $\left(220^{\circ} \mathrm{C}\right)$} & \multicolumn{4}{|c|}{$\begin{array}{c}\text { HT (Des. } \\
\text { Temperature) }\end{array}$} \\
\hline $\mathrm{LiNH}_{2}$ & $\mathrm{LiBH}_{4}$ & $\mathrm{MgH}_{2}$ & xrd 1 & xrd 2 & xrd 3 & xrd 4 & Des 1 & Des 2 & 220 & 285 & 350 & 350 \\
\hline 0.1 & 0.7 & 0.2 & $\mathrm{MgH}_{2}$ & $\mathrm{LiBH}_{4}$ & unk., $d=3.60,3.40$ & $\mathrm{Mg}_{3} \mathrm{~N}_{2}$ & 1.41 & 0.46 & 2.19 & 0.74 & 1.04 & 0.64 \\
\hline 0.2 & 0.6 & 0.2 & $\mathrm{MgH}_{2}$ & $\mathrm{LiBH}_{4}$ & unk., $d=3.60,3.40$ & $\mathrm{Mg}_{3} \mathrm{~N}_{2}$ & 1.48 & 0.14 & 2.05 & 0.99 & 0.62 & 0.43 \\
\hline 0.3 & 0.5 & 0.2 & LiMgNBH\#1 & $\mathrm{LiBH}_{4}$ & $\mathrm{MgH}_{2}$ & unk., $d=3.60,3.40$ & 2.06 & 1.35 & 2.37 & 3.37 & 0.32 & 0.22 \\
\hline 0.4 & 0.4 & 0.2 & LiMgNBH\#1 & $\mathrm{LiBH}_{4}$ & LiMgNBH\#2 & & 2.39 & 2.10 & 2.44 & 5.13 & 0.85 & 0.08 \\
\hline 0.5 & 0.3 & 0.2 & LiMgNBH\#1 & $\mathrm{Li}_{4}\left(\mathrm{NH}_{2}\right)_{3} \mathrm{BH}_{4}$ & LiMgNBH\#2 & & 2.69 & 2.08 & 3.30 & 4.84 & 1.35 & 0.06 \\
\hline 0.6 & 0.2 & 0.2 & $\mathrm{Li}_{4}\left(\mathrm{NH}_{2}\right)_{3} \mathrm{BH}_{4}$ & LiMgNBH\#1 & LiMgNBH\#2 & & 2.78 & 2.59 & 3.16 & 5.61 & 2.22 & 0.25 \\
\hline 0.7 & 0.1 & 0.2 & $\mathrm{LiOH}$ & $\mathrm{Li}_{2} \mathrm{NH} / \mathrm{LiNH}_{2}$ & $\mathrm{Li}_{2} \mathrm{Mg}(\mathrm{NH})_{2}$ & & 2.85 & 2.18 & 2.78 & 2.11 & 1.73 & 0.10 \\
\hline 0.8 & 0.0 & 0.2 & $\mathrm{Li}_{2} \mathrm{Mg}(\mathrm{NH})_{2}$ & $\mathrm{Li}_{2} \mathrm{NH} / \mathrm{LiNH}_{2}$ & $\mathrm{LiOH}$ & & 0.27 & 0.12 & 0.84 & 1.89 & 0.70 & 0.17 \\
\hline 0.1 & 0.6 & 0.3 & $\mathrm{MgH}_{2}$ & $\mathrm{LiBH}_{4}$ & $\mathrm{Mg}_{3} \mathrm{~N}_{2}$ & & 1.23 & 0.30 & 1.30 & 0.83 & 1.11 & 0.69 \\
\hline 0.2 & 0.5 & 0.3 & $\mathrm{Mg}_{3} \mathrm{~N}_{2}$ & $\mathrm{MgH}_{2}$ & $\mathrm{LiBH}_{4}$ & unk., $d=3.60,3.40$ & 2.27 & 0.69 & 1.72 & 1.37 & 0.65 & 0.47 \\
\hline 0.3 & 0.4 & 0.3 & $\mathrm{MgH}_{2}$ & Li-N-B-H\#2 & & & 2.63 & 0.40 & 2.67 & 2.87 & 0.61 & 0.71 \\
\hline 0.4 & 0.3 & 0.3 & LiMgNBH\#1 & LiMgN & $\mathrm{LiBH}_{4}$ & $\mathrm{Li}_{3} \mathrm{~N}$ & 2.89 & 1.43 & 3.43 & 4.49 & 0.60 & 0.33 \\
\hline 0.5 & 0.2 & 0.3 & LiMgNBH\#1 & $\mathrm{Li}_{2} \mathrm{Mg}(\mathrm{NH})_{2}$ & LiMgNBH\#2 & $\mathrm{MgH}_{2}$ & 3.54 & 2.64 & 3.89 & 6.61 & 0.49 & 0.10 \\
\hline 0.6 & 0.1 & 0.3 & & & & & 3.75 & 3.38 & 4.77 & 6.08 & 1.49 & 0.53 \\
\hline 0.7 & 0.0 & 0.3 & & & & & 0.54 & 0.23 & 0.95 & 3.37 & 0.74 & 0.14 \\
\hline 0.1 & 0.5 & 0.4 & & & & & 1.25 & 0.17 & 1.41 & 0.58 & 2.24 & 1.26 \\
\hline 0.2 & 0.4 & 0.4 & & & & & 2.49 & 0.62 & 2.04 & 1.41 & 0.84 & 0.40 \\
\hline 0.3 & 0.3 & 0.4 & & & & & 2.52 & 0.33 & 2.63 & 2.37 & 0.55 & 0.25 \\
\hline 0.4 & 0.2 & 0.4 & & & & & 3.47 & 0.47 & 3.60 & 3.70 & 0.58 & 0.24 \\
\hline 0.5 & 0.1 & 0.4 & & & & & 4.16 & 1.23 & 4.11 & 3.96 & 2.13 & 0.33 \\
\hline 0.6 & 0.0 & 0.4 & & & & & 1.26 & 0.46 & 1.43 & 3.44 & 1.16 & 0.72 \\
\hline 0.1 & 0.4 & 0.5 & & & & & 1.44 & 0.08 & 1.60 & 0.40 & 2.27 & 1.16 \\
\hline 0.2 & 0.3 & 0.5 & & & & & 2.96 & 0.21 & 2.61 & 0.86 & 1.42 & 0.74 \\
\hline 0.3 & 0.2 & 0.5 & & & & & 2.81 & 1.13 & $\mathrm{~B}$ & 1.92 & 0.14 & 0.13 \\
\hline 0.4 & 0.1 & 0.5 & & & & & 3.35 & 0.56 & 3.44 & 3.22 & 0.60 & 0.14 \\
\hline 0.5 & 0.0 & 0.5 & & & & & 1.29 & 0.44 & 2.36 & 2.28 & 1.92 & 0.44 \\
\hline 0.1 & 0.3 & 0.6 & & & & & 1.44 & 0.14 & 1.90 & 0.56 & 3.42 & 2.48 \\
\hline 0.2 & 0.2 & 0.6 & & & & & 2.96 & 0.15 & 2.52 & 0.68 & 2.09 & 1.11 \\
\hline 0.3 & 0.1 & 0.6 & & & & & 3.94 & 0.28 & 3.70 & 1.04 & 0.65 & 0.38 \\
\hline 0.4 & 0.0 & 0.6 & & & & & 2.01 & 0.47 & 2.15 & 2.40 & 1.83 & 0.23 \\
\hline 0.1 & 0.2 & 0.7 & & & & & 1.38 & 0.06 & 1.46 & 0.12 & 3.49 & 2.67 \\
\hline 0.2 & 0.1 & 0.7 & & & & & 2.84 & 0.07 & 2.47 & 0.50 & 1.98 & 0.72 \\
\hline
\end{tabular}




\begin{tabular}{|c|c|c|c|c|c|c|c|c|c|c|c|c|}
\hline \multicolumn{13}{|c|}{ 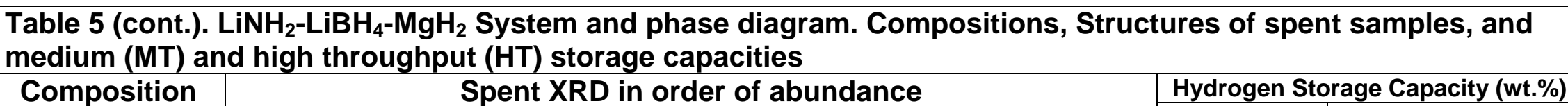 } \\
\hline \multicolumn{3}{|c|}{ Compositıon } & \multicolumn{4}{|c|}{ 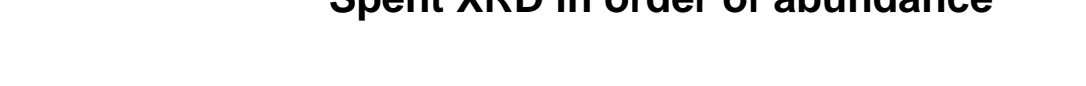 } & \multicolumn{2}{|c|}{$\mathrm{MT}\left(220^{\circ} \mathrm{C}\right)$} & \multicolumn{4}{|c|}{$\begin{array}{c}\text { HT (Des. } \\
\text { Temperature) }\end{array}$} \\
\hline $\mathrm{LiNH}_{2}$ & $\mathrm{LiBH}_{4}$ & $\mathrm{MgH}_{2}$ & xrd 1 & xrd 2 & xrd 3 & xrd 4 & Des 1 & Des 2 & 220 & 285 & 350 & 350 \\
\hline 0.3 & 0.0 & 0.7 & & & & & 1.81 & 0.36 & 1.84 & 1.79 & 0.73 & 0.02 \\
\hline 0.1 & 0.1 & 0.8 & & & & & 0.36 & 0.04 & 1.76 & 0.66 & 2.72 & 1.81 \\
\hline 0.2 & 0.0 & 0.8 & & & & & 1.18 & 0.26 & 1.16 & 1.33 & 1.71 & 0.52 \\
\hline 0.1 & 0.0 & 0.9 & & & & & 0.75 & 0.09 & 0.89 & 0.58 & 3.64 & 0.66 \\
\hline 0.0 & 0.1 & 0.9 & & & & & 0.01 & -0.02 & 0.07 & 0.08 & 5.61 & 3.62 \\
\hline 0.0 & 0.2 & 0.8 & & & & & 0.06 & 0.03 & 0.20 & 0.26 & 5.25 & 4.05 \\
\hline 0.0 & 0.3 & 0.7 & & & & & 0.05 & 0.02 & $\mathrm{~N}$ & $\mathrm{~N}$ & $\mathrm{~N}$ & $\mathrm{~N}$ \\
\hline 0.0 & 0.4 & 0.6 & & & & & 0.04 & 0.01 & $\mathrm{~N}$ & $\mathrm{~N}$ & $\mathrm{~N}$ & $\mathrm{~N}$ \\
\hline 0.0 & 0.5 & 0.5 & & & & & 0.03 & 0.01 & $\mathrm{~N}$ & $\mathrm{~N}$ & $\mathrm{~N}$ & $\mathrm{~N}$ \\
\hline 0.0 & 0.6 & 0.4 & & & & & 0.01 & -0.01 & $\mathrm{~N}$ & $\mathrm{~N}$ & $\mathrm{~N}$ & $\mathrm{~N}$ \\
\hline 0.0 & 0.7 & 0.3 & & & & & 0.02 & 0.00 & $\mathrm{~N}$ & $\mathrm{~N}$ & $\mathrm{~N}$ & $\mathrm{~N}$ \\
\hline 0.0 & 0.8 & 0.2 & & & & & 0.00 & -0.02 & $\mathrm{~N}$ & $\mathrm{~N}$ & $\mathrm{~N}$ & $\mathrm{~N}$ \\
\hline 0.0 & 0.9 & 0.1 & & & & & $\mathrm{~N}$ & $\mathrm{~N}$ & $\mathrm{~N}$ & $\mathrm{~N}$ & $\mathrm{~N}$ & $\mathrm{~N}$ \\
\hline 5.0 & 1.0 & 2.2 & & & & & 3.43 & 3.04 & $\mathrm{~N}$ & $\mathrm{~N}$ & $\mathrm{~N}$ & $\mathrm{~N}$ \\
\hline 0.6 & 0.1 & 0.3 & & & & & $\mathrm{~N}$ & $\mathrm{~N}$ & $\mathrm{~N}$ & $\mathrm{~N}$ & $\mathrm{~N}$ & $\mathrm{~N}$ \\
\hline 2.0 & 1.0 & 1.0 & & & & & $\mathrm{~N}$ & $\mathrm{~N}$ & $\mathrm{~N}$ & $\mathrm{~N}$ & $\mathrm{~N}$ & $\mathrm{~N}$ \\
\hline 5.0 & 1.0 & 2.2 & & & & & 3.62 & $\mathrm{~N}$ & $\mathrm{~N}$ & $\mathrm{~N}$ & $\mathrm{~N}$ & $\mathrm{~N}$ \\
\hline 5.0 & 1.0 & 2.2 & & & & & 0.78 & 0.11 & $\mathrm{~N}$ & $\mathrm{~N}$ & $\mathrm{~N}$ & $\mathrm{~N}$ \\
\hline 5.0 & 1.0 & 2.2 & & & & & 0.93 & 0.09 & $\mathrm{~N}$ & $\mathrm{~N}$ & $\mathrm{~N}$ & $\mathrm{~N}$ \\
\hline 5.0 & 1.0 & 2.2 & & & & & 2.28 & 1.12 & $\mathrm{~N}$ & $\mathrm{~N}$ & $\mathrm{~N}$ & $\mathrm{~N}$ \\
\hline
\end{tabular}




\begin{tabular}{|c|c|c|c|c|c|c|}
\hline Doped $\mathrm{LiNH}_{2}-\mathrm{MgH}_{2}-\mathrm{LiBH}_{4}$ Compositions & MT Des1 & MT Des2 & $\begin{array}{l}\text { HT Des1 } \\
\left(230^{\circ} \mathrm{C}\right)\end{array}$ & $\begin{array}{c}\text { HT Des } 2 \\
\left(230^{\circ} \mathrm{C}\right)\end{array}$ & $\begin{array}{c}\text { HT Des } 3 \\
\left(350^{\circ} \mathrm{C}\right)\end{array}$ & $\begin{array}{c}\text { HT Des } 4 \\
\left(350^{\circ} \mathrm{C}\right)\end{array}$ \\
\hline $0.02 \mathrm{NiCl} 2 / 5 \mathrm{LiNH} 2+2.2 \mathrm{MgH} 2+1 \mathrm{LiBH} 4$ & 5.21 & 1.48 & $\mathrm{~N}$ & $\mathrm{~N}$ & $\mathrm{~N}$ & $\mathrm{~N}$ \\
\hline $0.05 \mathrm{NiCl} 2 / 5 \mathrm{LiNH} 2+2.2 \mathrm{MgH} 2+1 \mathrm{LiBH} 4$ & 4.49 & 0.99 & $\mathrm{~N}$ & $\mathrm{~N}$ & $\mathrm{~N}$ & $\mathrm{~N}$ \\
\hline $0.01 \mathrm{NiCl} 2 / 5 \mathrm{LiNH} 2+2.2 \mathrm{MgH} 2+1 \mathrm{LiBH} 4$ & 4.22 & 2.71 & $\mathrm{~N}$ & $\mathrm{~N}$ & $\mathrm{~N}$ & $\mathrm{~N}$ \\
\hline $0.01 \mathrm{NiCl} 2+0.01 \% \mathrm{TiF} 3 / 0.6 \mathrm{LiNH} 2+0.1 \mathrm{LiBH} 4+0.3 \mathrm{MgH} 2$ & 4.71 & 0.93 & $\mathrm{~N}$ & $\mathrm{~N}$ & $\mathrm{~N}$ & $\mathrm{~N}$ \\
\hline $0.015 \mathrm{NiCl} 2+0.015 \% \mathrm{TiF} 3 / 0.6 \mathrm{LiNH} 2+0.1 \mathrm{LiBH} 4+0.3 \mathrm{MgH} 2$ & 4.22 & 0.77 & $\mathrm{~N}$ & $\mathrm{~N}$ & $\mathrm{~N}$ & $\mathrm{~N}$ \\
\hline $0.02 \mathrm{NiCl} 2+0.01 \% \mathrm{TiF} / 0.6 \mathrm{LiNH} 2+0.1 \mathrm{LiBH} 4$ + $0.3 \mathrm{MgH} 2$ & 4.02 & 0.98 & $\mathrm{~N}$ & $\mathrm{~N}$ & $\mathrm{~N}$ & $\mathrm{~N}$ \\
\hline $0.02 \mathrm{NiCl} 2+0.015 \% \mathrm{TiF} 3 / 0.6 \mathrm{LiNH} 2+0.1 \mathrm{LiBH} 4+0.3 \mathrm{MgH} 2$ & 3.84 & 0.92 & $\mathrm{~N}$ & $\mathrm{~N}$ & $\mathrm{~N}$ & $\mathrm{~N}$ \\
\hline $0.02 \mathrm{NiCl} 2+0.02 \% \mathrm{TiF} / 0.6 \mathrm{LiNH} 2+0.1 \mathrm{LiBH} 4+0.3 \mathrm{MgH} 2$ & 5.25 & 1.21 & $\mathrm{~N}$ & $\mathrm{~N}$ & $\mathrm{~N}$ & $\mathrm{~N}$ \\
\hline $0.015 \mathrm{NiCl} 2+0.02 \% \mathrm{TiF} 3 / 0.6 \mathrm{LiNH} 2+0.1 \mathrm{LiBH} 4+0.3 \mathrm{MgH} 2$ & 3.34 & 0.88 & $\mathrm{~N}$ & $\mathrm{~N}$ & $\mathrm{~N}$ & $\mathrm{~N}$ \\
\hline $0.02 \mathrm{NiCl} 2 / 0.6 \mathrm{LiNH} 2+0.1 \mathrm{LiBH} 4+0.3 \mathrm{MgH} 2$ & 4.49 & 1.42 & $\mathrm{~N}$ & $\mathrm{~N}$ & $\mathrm{~N}$ & $\mathrm{~N}$ \\
\hline $0.02 \mathrm{CrF} / 5 \mathrm{LiNH} 2+1 \mathrm{LiBH} 4+2.2 \mathrm{MgH} 2$ & 3.89 & 0.75 & $\mathrm{~N}$ & $\mathrm{~N}$ & $\mathrm{~N}$ & $\mathrm{~N}$ \\
\hline $0.02 \mathrm{CrF} 3+0.02 \% \mathrm{Ti}(\mathrm{OiPr}) 4 / 5 \mathrm{LiNH} 2+1 \mathrm{LiBH} 4+2.2 \mathrm{MgH} 2$ & 3.80 & 0.95 & $\mathrm{~N}$ & $\mathrm{~N}$ & $\mathrm{~N}$ & $\mathrm{~N}$ \\
\hline $0.02 \mathrm{NiCl} 2+0.02 \% \mathrm{CrF} 3 / 5 \mathrm{LiNH} 2$ + $1 \mathrm{LiBH} 4$ + $2.2 \mathrm{MgH} 2$ & 3.63 & 0.92 & $\mathrm{~N}$ & $\mathrm{~N}$ & $\mathrm{~N}$ & $\mathrm{~N}$ \\
\hline $0.01 \mathrm{NiCl} 2+0.01 \% \mathrm{Ti}(\mathrm{OiPr}) 4 / 5 \mathrm{LiNH} 2+1 \mathrm{LiBH} 4+2.2 \mathrm{MgH} 2$ & 4.16 & 0.99 & $\mathrm{~N}$ & $\mathrm{~N}$ & $\mathrm{~N}$ & $\mathrm{~N}$ \\
\hline $0.02 \mathrm{NiCl} 2+0.02 \% \mathrm{YbCl} 3 / 0.6 \mathrm{LiNH} 2+0.3 \mathrm{MgH} 2+0.1 \mathrm{LiBH} 4$ & 3.63 & 3.23 & 4.82 & 0.39 & $\mathrm{~N}$ & $\mathrm{~N}$ \\
\hline $0.02 \mathrm{NiCl} 2+0.02 \% Z r F 4 / 0.6 \mathrm{LiNH} 2+0.3 \mathrm{MgH} 2+0.1 \mathrm{LiBH} 4$ & 0.67 & 0.27 & 4.97 & 0.21 & $\mathrm{~N}$ & $\mathrm{~N}$ \\
\hline $0.02 \mathrm{NiCl} 2+0.02 \% \mathrm{CrF} 3 / 0.65 \mathrm{LiNH} 2+0.24 \mathrm{MgH} 2+0.11 \mathrm{LiBH} 4$ & 4.05 & 3.49 & 5.63 & 0.23 & $\mathrm{~N}$ & $\mathrm{~N}$ \\
\hline $0.02 \mathrm{NiCl} 2+0.02 \% \mathrm{CrF} 3 / 0.65 \mathrm{LiNH} 2+0.19 \mathrm{MgH} 2+0.16 \mathrm{LiBH} 4$ & $\mathrm{~N}$ & $\mathrm{~N}$ & 6.37 & 0.14 & $\mathrm{~N}$ & $\mathrm{~N}$ \\
\hline $0.02 \mathrm{NiCl} 2+0.02 \% \mathrm{YbCl} 3 / 0.6 \mathrm{LiNH} 2+0.3 \mathrm{MgH} 2+0.1 \mathrm{LiBH} 4$ & $\mathrm{~N}$ & $\mathrm{~N}$ & 4.43 & 0.18 & $\mathrm{~N}$ & $\mathrm{~N}$ \\
\hline $0.02 \mathrm{NiCl} 2+0.02 \% \mathrm{ZrF} 4 / 0.6 \mathrm{LiNH} 2+0.3 \mathrm{MgH} 2+0.1 \mathrm{LiBH} 4$ & $\mathrm{~N}$ & $\mathrm{~N}$ & 3.47 & 0.23 & $\mathrm{~N}$ & $\mathrm{~N}$ \\
\hline $0.02 \mathrm{PdCl} 2+1 \% \mathrm{C} / 5 \mathrm{LiNH} 2+2.2 \mathrm{MgH} 2+1 \mathrm{LiBH} 4$ & 3.44 & 2.55 & 4.19 & 3.50 & 5.05 & 2.28 \\
\hline $0.02 \mathrm{PdCl} 2 / 5 \mathrm{LiNH} 2+2.2 \mathrm{MgH} 2+1 \mathrm{LiBH} 4$ & 3.29 & 2.37 & 5.33 & 0.33 & 0.48 & 2.05 \\
\hline $0.02 \mathrm{PdCl} 2+0.02 \% \mathrm{NiCl} 2 / 5 \mathrm{LiNH} 2+2.2 \mathrm{MgH} 2+1 \mathrm{LiBH} 4$ & 5.29 & 3.39 & 6.27 & 0.31 & 0.78 & 2.19 \\
\hline $0.02 \mathrm{NiCl} 2+1 \% \mathrm{Cl} 5 \mathrm{LiNH} 2+2.2 \mathrm{MgH} 2+1 \mathrm{LiBH} 4$ & 4.45 & 3.51 & 5.75 & 1.13 & 1.61 & 1.91 \\
\hline $0.02 \mathrm{PdCl} 2+0.02 \% \mathrm{NiCl} 2 / 6 \mathrm{LiNH} 2+2.2 \mathrm{MgH} 2+1.1 \mathrm{LiBH} 4$ & 4.65 & 3.57 & 5.91 & 0.32 & 0.77 & 2.52 \\
\hline $0.02 \mathrm{PdCl} 2+0.02 \% \mathrm{NiCl} 2 / 2 \mathrm{LiNH} 2+1 \mathrm{LiBH} 4$ & 3.66 & 2.67 & $\mathrm{~N}$ & $\mathrm{~N}$ & $\mathrm{~N}$ & $\mathrm{~N}$ \\
\hline $0.02 \mathrm{PdCl} 2+1 \% \mathrm{C} / 2 \mathrm{LiNH} 2+1 \mathrm{LiBH} 4$ & 1.86 & 0.72 & $\mathrm{~N}$ & $\mathrm{~N}$ & $\mathrm{~N}$ & $\mathrm{~N}$ \\
\hline 0.02 PdCl2/ 2 LiNH2 + 1 LiBH4 & 1.32 & 1.00 & $\mathrm{~N}$ & $\mathrm{~N}$ & $\mathrm{~N}$ & $\mathrm{~N}$ \\
\hline $0.02 \mathrm{Cr} 2 \mathrm{O} 3 / 5 \mathrm{LiNH} 2+1 \mathrm{LiBH} 4+1.1 \mathrm{MgH} 2$ & 2.38 & 1.98 & $\mathrm{~N}$ & $\mathrm{~N}$ & $\mathrm{~N}$ & $\mathrm{~N}$ \\
\hline
\end{tabular}




\begin{tabular}{|c|c|c|c|c|c|c|c|c|c|c|c|c|}
\hline \multirow{2}{*}{\multicolumn{3}{|c|}{ Composition }} & \multirow{2}{*}{\multicolumn{4}{|c|}{ XRD of spent materials }} & \multicolumn{6}{|c|}{ Hydrogen Storage Capacity (wt.\%) } \\
\hline & & & & & & & \multicolumn{2}{|c|}{$\begin{array}{c}\text { Medium } \\
\text { Throughput }\end{array}$} & \multicolumn{4}{|c|}{$\begin{array}{c}\text { High Throughput (Des } \\
\left.{ }^{\circ} \mathrm{C}\right)\end{array}$} \\
\hline $\mathrm{LiNH}_{2}$ & $\mathrm{LiBH}_{4}$ & $\mathrm{CaH}_{2}$ & Xrd 1 & Xrd 2 & Xrd 3 & Xrd 4 & Des 1 & Des 2 & 230 & 230 & 350 & 350 \\
\hline 0.125 & 0.75 & 0.125 & & & & & 0.79 & 0.30 & 1.46 & 0.52 & 2.01 & 0.96 \\
\hline 0.25 & 0.625 & 0.125 & Li-B-N-H\#2 & $\mathrm{CaH}_{2}$ & $\mathrm{Ca}_{2} \mathrm{~N}_{2}$ & & 1.02 & 0.65 & 1.25 & 0.87 & 2.62 & 0.30 \\
\hline 0.375 & 0.5 & 0.125 & $\mathrm{BN}$ & $\mathrm{Li}_{4}\left(\mathrm{NH}_{2}\right)_{3} \mathrm{BH}_{4}$ & $\mathrm{Li}_{3} \mathrm{BN}_{2}$ & Li-B-N-H\#2 & 1.09 & 0.59 & 1.38 & 0.71 & 4.55 & 0.19 \\
\hline 0.125 & 0.625 & 0.25 & & & & & 0.58 & 0.27 & 1.10 & 0.57 & 1.87 & 0.77 \\
\hline 0.25 & 0.5 & 0.25 & & & & & $\mathrm{~N}$ & $\mathrm{~N}$ & 0.14 & 0.11 & 3.15 & 1.26 \\
\hline 0.5 & 0.375 & 0.125 & & & & & $\mathrm{~N}$ & $\mathrm{~N}$ & 0.28 & 0.09 & 1.94 & 1.33 \\
\hline 0.375 & 0.375 & 0.25 & & & & & $\mathrm{~N}$ & $\mathrm{~N}$ & 0.18 & 0.08 & 1.32 & 1.04 \\
\hline 0.625 & 0.25 & 0.125 & & & & & $\mathrm{~N}$ & $\mathrm{~N}$ & 0.91 & 0.61 & 1.74 & 0.51 \\
\hline 0 & 0.875 & 0.125 & $\begin{array}{l}\text { unk., } d=4.34,3.56,3.32,3.19,2.94 \\
2.54,2.45,2.27,2.16,2.12,1.80\end{array}$ & $\mathrm{LiBH}_{4}$ & $\mathrm{Ca}\left(\mathrm{BH}_{4}\right)_{2}$ & $\mathrm{LiH}$ & 1.33 & 0.63 & & & & \\
\hline 0 & 0.75 & 0.25 & WC & $\begin{array}{l}\text { unk., } d=4.40,3.60,3.09 \\
2.91,2.52,2.27,2.09,2.05 \\
1.89\end{array}$ & & & 0.93 & 0.50 & & & & \\
\hline 0 & 0.625 & 0.375 & $\begin{array}{l}\text { unk., } d=4.39,3.59,3.30,3.08,3.02, \\
2.70,2.54,2.38,2.26,2.01,1.94 \\
1.87,1.85\end{array}$ & & & & 1.32 & 1.01 & & & & \\
\hline 0.125 & 0.5 & 0.375 & unk., $d=3.55,2.90,2.51,2.05,1.78$ & $\mathrm{Li}_{4}\left(\mathrm{NH}_{2}\right)_{3} \mathrm{BH}_{4}$ & & & 0.57 & 0.35 & & & & \\
\hline 0 & 0.5 & 0.5 & $\mathrm{CaH}_{2}$ & $\mathrm{LiBH}_{4}$ & & & 0.05 & 0.03 & & & & \\
\hline 0.25 & 0.375 & 0.375 & $\mathrm{CaH}_{2}$ & $\mathrm{CaNH}$ & $\mathrm{Li}_{4}\left(\mathrm{NH}_{2}\right)_{3} \mathrm{BH}_{4}$ & & 1.40 & 0.76 & & & & \\
\hline 0.5 & 0.25 & 0.25 & $\mathrm{CaNH}$ & $\mathrm{Ca}_{6} \mathrm{BN}_{5}$ & $\mathrm{Li}_{4}\left(\mathrm{NH}_{2}\right)_{3} \mathrm{BH}_{4}$ & & 1.11 & 0.46 & & & & \\
\hline 0.75 & 0.125 & 0.125 & & & & & 0.65 & 0.17 & & & & \\
\hline 0.125 & 0.375 & 0.5 & $\mathrm{CaH}_{2}$ & $\mathrm{Li}_{2} \mathrm{NH}$ & $\mathrm{LiBH}_{4}$ & $\mathrm{CaNH}$ & 1.18 & 0.42 & & & & \\
\hline 0.375 & 0.25 & 0.375 & $\begin{array}{l}\text { unk., } d=4.39,3.59,3.30,3.08,3.02, \\
2.70,2.54,2.38,2.26,2.01,1.94 \\
1.87,1.85\end{array}$ & & & & 1.30 & 1.05 & & & & \\
\hline 0.625 & 0.125 & 0.25 & $\mathrm{Ca}_{6} \mathrm{BN}_{5}$ & WC & $\mathrm{Li}_{2} \mathrm{NH}$ & $\mathrm{Li}_{4}\left(\mathrm{NH}_{2}\right)_{3} \mathrm{BH}_{4}$ & 0.83 & 0.23 & & & & \\
\hline 0 & 0.375 & 0.625 & & & & & 0.02 & -0.01 & & & & \\
\hline 0.61 & 0.122 & 0.268 & & & & & 1.32 & 0.29 & & & & \\
\hline 0.652 & 0.109 & 0.239 & & & & & 0.77 & 0.20 & & & & \\
\hline 0.686 & 0.098 & 0.216 & & & & & 0.72 & 0.17 & & & & \\
\hline 0.875 & 0 & 0.125 & & & & & 0.36 & 0.05 & & & & \\
\hline
\end{tabular}




\begin{tabular}{|c|c|c|c|c|c|c|c|c|c|c|c|c|}
\hline \multicolumn{4}{|c|}{ Composition } & \multicolumn{3}{|c|}{ As synthesized XRD ${ }^{1}$} & \multicolumn{4}{|c|}{ Spent XRD ${ }^{2}$} & \multicolumn{2}{|c|}{$\begin{array}{l}\text { Hydrogen } \\
\text { Storage Cap- } \\
\text { acity (wt. \%) }\end{array}$} \\
\hline $\mathrm{LiNH}_{2}$ & $\mathrm{NaNH}_{2}$ & MH & $\mathrm{mol}$ & xrd 1 & xrd 2 & xrd 3 & xrd 1 & xrd 2 & xrd 3 & xrd 4 & Des 1 & Des 2 \\
\hline 1 & 0 & $\mathrm{NaH}$ & 0.5 & $\mathrm{NaH}$ & $\mathrm{Li}_{2} \mathrm{NH}$ & $\mathrm{Ti}$ & $\mathrm{NaH}$ & $\mathrm{Li}_{3} \mathrm{Na}\left(\mathrm{NH}_{2}\right)_{2}$ & $\mathrm{LiNH}_{2} / \mathrm{Li}_{2} \mathrm{NH}$ & unk., $d=3.35,2.69$ & 0.96 & 0.14 \\
\hline 1 & 0 & $\mathrm{NaH}$ & 2 & $\mathrm{NaH}$ & $\mathrm{Li}_{2} \mathrm{NH}$ & $\mathrm{Ti}$ & $\mathrm{NaH}$ & $\mathrm{Li}_{3} \mathrm{Na}\left(\mathrm{NH}_{2}\right)_{2}$ & & & 0.65 & 0.11 \\
\hline 0.5 & 0.5 & $\mathrm{NaH}$ & 0 & $\mathrm{NaNH}_{2}$ & $\mathrm{NaNH}_{2}$ & & A & $\mathrm{NaH}$ & & & 1.23 & 0.09 \\
\hline 0.5 & 0.5 & $\mathrm{NaH}$ & 1 & $\mathrm{NaH}$ & $\mathrm{NaNH}_{2}$ & $\begin{array}{l}\text { unk., } d= \\
4.17,2.72 \text {, } \\
2.52\end{array}$ & $\mathrm{NaH}$ & $\mathrm{NaNH}_{2}$ & $\mathrm{NaNH}_{2}$ & WC & 0.75 & 0.09 \\
\hline 0.5 & 0.5 & $\mathrm{NaH}$ & 0.5 & $\mathrm{NaH}$ & $\mathrm{NaNH}_{2}$ & $\begin{array}{l}\text { unk., } d= \\
2.72,2.52\end{array}$ & $\mathrm{NaH}$ & $\mathrm{NaNH}_{2}$ & $\mathrm{NaNH}_{2}$ & & 0.75 & 0.07 \\
\hline 0.5 & 0.5 & $\mathrm{NaH}$ & 2 & $\mathrm{NaH}$ & $\mathrm{NaNH}_{2}$ & $\begin{array}{l}\text { unk., } d= \\
2.72,2.52\end{array}$ & $\mathrm{NaH}$ & $\mathrm{NaNH}_{2}$ & & & 0.59 & 0.09 \\
\hline 0.25 & 0.75 & $\mathrm{NaH}$ & 0 & $\mathrm{NaNH}_{2}$ & $\mathrm{NaNH}_{2}$ & $\mathrm{Li}_{3} \mathrm{Na}\left(\mathrm{NH}_{2}\right)_{4}$ & $\mathrm{NaH}$ & $\mathrm{NaNH}_{2}$ & Unk., $d=2.60,2.36$ & & 1.44 & 0.28 \\
\hline 0.75 & 0.25 & $\mathrm{NaH}$ & 0 & $\mathrm{LiNH}_{2}$ & $\begin{array}{l}\mathrm{Li}_{3} \mathrm{Na} \\
\left(\mathrm{NH}_{2}\right)_{4}\end{array}$ & $\mathrm{NaNH}_{2}$ & $\mathrm{Li}_{3} \mathrm{Na}\left(\mathrm{NH}_{2}\right)_{4}$ & $\mathrm{NaOH}$ & $\mathrm{LiOH}$ & $\mathrm{LiOH}^{\star} \mathrm{H}_{2} \mathrm{O}(?)$ & 1.02 & 0.11 \\
\hline 1 & 0 & $\mathrm{NaH}$ & 0 & $\mathrm{LiNH}_{2}$ & $\begin{array}{l}\text { unk., } d= \\
2.76,2.58\end{array}$ & & $\mathrm{Li}_{2} \mathrm{NH}$ & $\mathrm{LiNH}_{2}$ & $\mathrm{LiOH}$ & unk., $d=2.68,2.57$ & 0.29 & 0.07 \\
\hline 1 & 0 & $\mathrm{NaH}$ & 0 & $\mathrm{LiNH}_{2}$ & $\mathrm{TiH}_{1.9}$ & & $\mathrm{Li}_{2} \mathrm{NH}$ & $\mathrm{LiNH}_{2}$ & $\mathrm{LiOH}$ & unk., $d=2.68,2.57$ & 0.38 & 0.27 \\
\hline $0^{*}$ & 1 & $\mathrm{NaH}$ & 0 & $\mathrm{NaNH}_{2}$ & $\mathrm{NaNH}_{2}$ & & $\mathrm{NaNH}_{2}$ & $\mathrm{NaH}$ & $\mathrm{NaOH}^{\star} \mathrm{H}_{2} \mathrm{O}$ & & 0.57 & 0.09 \\
\hline $0 *$ & 1 & $\mathrm{NaH}$ & 0 & $\mathrm{NaNH}_{2}$ & $\mathrm{NaNH}_{2}$ & & & & & & 1.17 & 0.25 \\
\hline 0 & 1 & $\mathrm{NaH}$ & 1 & $\mathrm{NaH}$ & $\mathrm{NaNH}_{2}$ & $\mathrm{NaNH}_{2}$ & $\mathrm{NaNH} 2$ & $\mathrm{NaH}$ & $\mathrm{d}=2.58,2.56$ & & 0.52 & 0.04 \\
\hline 0 & 1 & $\mathrm{NaH}$ & 0.5 & $\mathrm{NaNH}_{2}$ & $\mathrm{NaH}$ & & $\mathrm{NaNH}_{2}$ & $\mathrm{NaH}$ & & & 0.92 & 0.19 \\
\hline 0 & 1 & $\mathrm{NaH}$ & 2 & $\mathrm{NaH}$ & $\mathrm{NaNH}_{2}$ & & $\mathrm{NaNH}_{2}$ & $\mathrm{NaH}$ & & & 0.41 & 0.07 \\
\hline 1 & 0 & $\mathrm{NaH}$ & 1 & $\mathrm{NaH}$ & $\mathrm{Li}_{2} \mathrm{NH}$ & $\mathrm{Li}_{3} \mathrm{Na}\left(\mathrm{NH}_{2}\right)_{4}$ & $\mathrm{NaOH}$ & $\mathrm{LiOH}$ & $\mathrm{Li}_{3} \mathrm{Na}\left(\mathrm{NH}_{2}\right)_{4}$ & $\mathrm{TiO}_{2}$ & 0.77 & 0.11 \\
\hline 0.25 & 0.75 & $\mathrm{NaH}$ & 1 & $\mathrm{NaH}$ & $\mathrm{NaNH}_{2}$ & $\mathrm{NaNH}_{2}$ & $\mathrm{NaH}$ & $\mathrm{NaNH}_{2}$ & $\begin{array}{l}\text { unk., } d=2.56,2.51, \\
2.11,2.08\end{array}$ & & 0.69 & 0.09 \\
\hline 0.25 & 0.75 & $\mathrm{NaH}$ & 0.5 & $\mathrm{NaH}$ & $\mathrm{NaNH}_{2}$ & $\mathrm{NaNH}_{2}$ & $\mathrm{NaNH}_{2}$ & $\mathrm{NaH}$ & unk., $d=2.55,2.11$ & & 0.77 & 0.12 \\
\hline 0.25 & 0.75 & $\mathrm{NaH}$ & 2 & $\mathrm{NaH}$ & $\mathrm{NaNH}_{2}$ & $\mathrm{NaNH}_{2}$ & $\mathrm{NaNH}_{2}$ & $\mathrm{NaH}$ & unk., $d=2.55,2.11$ & & 0.52 & 0.03 \\
\hline 0.75 & 0.25 & $\mathrm{NaH}$ & 1 & $\mathrm{NaH}$ & $\mathrm{Li}_{3} \mathrm{Na}\left(\mathrm{NH}_{2}\right)_{4}$ & $\mathrm{NaNH}_{2}$ & $\mathrm{NaH}$ & $\mathrm{NaOH} / \mathrm{NaOH}^{\star} \mathrm{H}_{2} \mathrm{O}$ & $\mathrm{LiOH} / \mathrm{LiOH}^{*} \mathrm{H}_{2} \mathrm{O}$ & $\mathrm{NaNH}_{2}$ & 0.78 & 0.13 \\
\hline 0.75 & 0.25 & $\mathrm{NaH}$ & 0.5 & $\mathrm{NaH}$ & $\mathrm{Li}_{3} \mathrm{Na}\left(\mathrm{NH}_{2}\right)_{4}$ & $\mathrm{LiNH}_{2}$ & $\mathrm{NaOH}$ & $\mathrm{NaH}$ & $\mathrm{NaNH}_{2}$ & $\mathrm{Li}_{2} \mathrm{Na}(\mathrm{OH})_{3} / \mathrm{LiOH}$ & 0.99 & 0.18 \\
\hline 0.75 & 0.25 & $\mathrm{NaH}$ & 2 & $\mathrm{NaH}$ & $\mathrm{Li}_{3} \mathrm{Na}\left(\mathrm{NH}_{2}\right)_{4}$ & $\mathrm{NaNH}_{2}$ & $\mathrm{NaOH}$ & $\mathrm{NaH}$ & $\begin{array}{l}\text { unk., } d=2.55,2.23 \\
2.10\end{array}$ & & 0.60 & 0.10 \\
\hline 0 & 1 & $\mathrm{LiH}$ & 1 & $\mathrm{NaH}$ & $\mathrm{NaNH}_{2}$ & $\mathrm{NaNH}_{2}$ & $\mathrm{NaOH}$ & $\mathrm{NaH}$ & $\mathrm{Li}_{2} \mathrm{Na}(\mathrm{OH})_{3}$ & $\mathrm{NaNH}_{2}$ & 0.88 & 0.17 \\
\hline 0 & 1 & $\mathrm{LiH}$ & 0.5 & $\mathrm{NaNH}_{2}$ & $\mathrm{NaH}$ & $\mathrm{NaNH}_{2}$ & $\mathrm{NaNH}_{2}$ & $\mathrm{NaH}$ & $\mathrm{Li}_{2} \mathrm{Na}(\mathrm{OH})_{3}$ & $\mathrm{NaOH}$ & 0.89 & 0.18 \\
\hline 0 & 1 & $\mathrm{LiH}$ & 2 & $\mathrm{NaH}$ & $\mathrm{NaNH}_{2}$ & $\begin{array}{l}\text { unk., } d= \\
2.51\end{array}$ & $\mathrm{NaH}$ & $\mathrm{Li}_{2} \mathrm{NH}$ & $\mathrm{LiH}$ & $\begin{array}{l}\text { Unk., } d=3.35 \\
2.70,2.57\end{array}$ & 0.67 & 0.12 \\
\hline 1 & 0 & $\mathrm{LiH}$ & 1 & $\mathrm{Li}_{2} \mathrm{NH}$ & $\mathrm{LiH}$ & $\mathrm{LiH}$ & $\mathrm{Li}_{2} \mathrm{NH}$ & $\mathrm{LiH}$ & $\begin{array}{l}\text { unk., } d=3.35,2.70 \text {, } \\
2.57,2.25\end{array}$ & $\mathrm{LiNH}_{2}$ & 0.85 & 0.16 \\
\hline
\end{tabular}




\begin{tabular}{|c|c|c|c|c|c|c|c|c|c|c|c|c|}
\hline \multicolumn{4}{|c|}{ Composition } & \multicolumn{3}{|c|}{$\begin{array}{l}\text { As synthesized } \\
\text { XRD }^{1}\end{array}$} & \multicolumn{4}{|c|}{ Spent XRD ${ }^{2}$} & \multicolumn{2}{|c|}{$\begin{array}{l}\text { Hydrogen } \\
\text { Storage Cap- } \\
\text { acity (wt. \%) }\end{array}$} \\
\hline $\mathrm{LiNH}_{2}$ & $\mathrm{NaNH}_{2}$ & MH & $\mathrm{mol}$ & xrd 1 & xrd 2 & xrd 3 & xrd 1 & xrd 2 & $x$ xrd 3 & xrd 4 & Des 1 & Des 2 \\
\hline 1 & 0 & $\mathrm{LiH}$ & 0.5 & $\mathrm{LiNH}_{2}$ & $\mathrm{Li}_{2} \mathrm{NH}$ & $\mathrm{LiH}$ & $\mathrm{Li}_{2} \mathrm{NH}$ & $\mathrm{LiNH}_{2}$ & $\mathrm{LiH}$ & unk., $d=2.70,2.57$ & 1.08 & 0.13 \\
\hline 1 & 0 & $\mathrm{LiH}$ & 2 & $\mathrm{Li}_{2} \mathrm{NH}$ & $\mathrm{LiH}$ & $\mathrm{Ti}$ & $\mathrm{Li}_{2} \mathrm{NH}$ & $\mathrm{LiNH}_{2}$ & $\mathrm{LiH}$ & $\begin{array}{l}\text { unk., } d=2.70 \\
2.57,2.25\end{array}$ & 0.87 & 0.14 \\
\hline 0.5 & 0.5 & $\mathrm{LiH}$ & 1 & $\mathrm{NaH}$ & $\mathrm{LiNH}_{2}$ & $\mathrm{Li}_{3} \mathrm{Na}\left(\mathrm{NH}_{2}\right)_{4}$ & $\mathrm{NaH}$ & $\mathrm{Li}_{2} \mathrm{NH}$ & $\mathrm{LiNH}_{2}$ & unk., $d=2.70,2.57$ & 0.77 & 0.12 \\
\hline 0.5 & 0.5 & $\mathrm{LiH}$ & 0.5 & $\begin{array}{l}\text { Unk., } \\
d= \\
2.76 \\
2.37\end{array}$ & $\mathrm{Li}_{2} \mathrm{NH}$ & $\mathrm{NaH}$ & $\mathrm{Li}_{3} \mathrm{Na}\left(\mathrm{NH}_{2}\right)_{4}$ & $\mathrm{NaH}$ & $\mathrm{Li}_{2} \mathrm{NH}$ & unk., $d=2.70,2.57$ & 0.96 & 0.19 \\
\hline 0.5 & 0.5 & $\mathrm{LiH}$ & 2 & $\mathrm{NaH}$ & $\mathrm{Li}_{2} \mathrm{NH}$ & $\mathrm{LiNH}_{2}$ & $\mathrm{NaH}$ & $\mathrm{Li}_{2} \mathrm{NH}$ & $\mathrm{LiNH}_{2}$ & unk., $d=2.70,2.57$ & 0.79 & 0.13 \\
\hline 0.25 & 0.75 & $\mathrm{LiH}$ & 1 & $\mathrm{NaNH}_{2}$ & $\mathrm{NaNH}_{2}$ & $\mathrm{NaH}$ & $\mathrm{NaH}$ & $\mathrm{Li}_{2} \mathrm{NH}$ & $\mathrm{LiNH}_{2}$ & unk., $d=2.70,2.57$ & 0.71 & 0.19 \\
\hline 0.25 & 0.75 & $\mathrm{LiH}$ & 0.5 & $\mathrm{NaH}$ & $\begin{array}{l}\text { unk - } \\
\text { Shifted } \\
\mathrm{NaNH}_{2}\end{array}$ & & $\mathrm{NaH}$ & $\mathrm{Li}{ }_{3} \mathrm{Na}\left(\mathrm{NH}_{2}\right)_{4}$ & $\mathrm{NaNH}_{2}$ & & $\mathrm{~N}$ & $\mathrm{~N}$ \\
\hline 0.25 & 0.75 & $\mathrm{LiH}$ & 2 & $\mathrm{NaH}$ & $\mathrm{Li}_{2} \mathrm{NH}$ & $\mathrm{LiH}$ & $\mathrm{NaH}$ & $\mathrm{Li}_{2} \mathrm{NH}$ & $\mathrm{LiH}$ & unk., $d=3.35,2.70$ & $\mathrm{~N}$ & $\mathrm{~N}$ \\
\hline 0.75 & 0.25 & $\mathrm{LiH}$ & 1 & B & & & $\mathrm{NaH}$ & $\mathrm{LiNH}_{2}$ & $\mathrm{Li}_{2} \mathrm{NH}$ & $\mathrm{LiH}$ & $\mathrm{N}$ & $\mathrm{N}$ \\
\hline 0.75 & 0.25 & $\mathrm{LiH}$ & 0.5 & $\mathrm{Li}_{2} \mathrm{NH}$ & $\mathrm{NaH}$ & $\mathrm{Li}_{3} \mathrm{Na}\left(\mathrm{NH}_{2}\right)_{4}$ & $\mathrm{LiNH}_{2}$ & $\mathrm{Li}_{2} \mathrm{NH}$ & $\mathrm{NaH}$ & Unk., $d=2.71,2.57$ & $\mathrm{~N}$ & $\mathrm{~N}$ \\
\hline 0.75 & 0.25 & $\mathrm{LiH}$ & 2 & $\mathrm{Li}_{2} \mathrm{NH}$ & $\mathrm{NaH}$ & $\mathrm{LiH}$ & $\mathrm{Li}_{2} \mathrm{NH}$ & $\mathrm{LiNH}_{2}$ & $\mathrm{NaH}$ & $\mathrm{LiH}$ & $\mathrm{N}$ & $\mathrm{N}$ \\
\hline 0 & 1 & $\mathrm{KH}$ & 1 & $\mathrm{NaH}$ & $\mathrm{KH}$ & $\begin{array}{l}\text { Unk., } d= \\
3.90,3.57, \\
3.08,2.52, \\
1.78\end{array}$ & $\mathrm{NaH}$ & $\mathrm{KH}$ & $\mathrm{KNH}_{2}$ & $\mathrm{NaNH}_{2}$ & $\mathrm{~N}$ & $\mathrm{~N}$ \\
\hline 0 & 1 & $\mathrm{KH}$ & 0.5 & $\mathrm{KNH}_{2}$ & $\mathrm{NaH}$ & $\mathrm{NaNH}_{2}$ & $\mathrm{NaH}$ & C & & & $\mathrm{N}$ & $\mathrm{N}$ \\
\hline 0 & 1 & $\mathrm{KH}$ & 2 & $\mathrm{KH}$ & $\mathrm{NaH}$ & $\mathrm{NaNH}_{2}$ & $\mathrm{KH}$ & $\mathrm{NaH}$ & D & & 0.25 & 0.12 \\
\hline 1 & 0 & $\mathrm{MgH}_{2}$ & 0.25 & $\mathrm{Li}_{2} \mathrm{NH}$ & $\mathrm{MgH}_{2}$ & $\mathrm{LiNH}_{2}$ & $\mathrm{Li}_{2} \mathrm{NH}$ & $\mathrm{Ca}\left(\mathrm{NH}_{2}\right)_{2}$ & & & 1.68 & 0.37 \\
\hline 1 & 0 & $\mathrm{MgH}_{2}$ & 1 & $\mathrm{Li}_{2} \mathrm{NH}$ & $\mathrm{MgH}_{2}$ & $\mathrm{LiNH}_{2}$ & $\mathrm{Li}_{2} \mathrm{Mg}(\mathrm{NH})_{2}$ & $\mathrm{MgH}_{2}$ & & & 2.95 & 0.48 \\
\hline 0.5 & 0.5 & $\mathrm{MgH}_{2}$ & 0.5 & $\mathrm{MgH}_{2}$ & $\mathrm{NaH}$ & $\mathrm{Li}_{3} \mathrm{Na}\left(\mathrm{NH}_{2}\right)_{4}$ & $\mathrm{NaH}$ & $\mathrm{Li}_{2} \mathrm{Mg}(\mathrm{NH})_{2}$ & $\mathrm{Li}_{2} \mathrm{NH}$ & & 1.78 & 0.54 \\
\hline 0.5 & 0.5 & $\mathrm{MgH}_{2}$ & 0.25 & $\mathrm{MgH}_{2}$ & $\mathrm{NaNH}_{2}$ & $\mathrm{Li}_{3} \mathrm{Na}\left(\mathrm{NH}_{2}\right)_{4}$ & $\mathrm{Li}_{3} \mathrm{Na}\left(\mathrm{NH}_{2}\right)_{4}$ & $\mathrm{NaH}$ & Unk., $d=3.82,2.96$ & & 0.94 & 0.22 \\
\hline 0.5 & 0.5 & $\mathrm{MgH}_{2}$ & 1 & $\mathrm{MgH}_{2}$ & $\mathrm{NaH}$ & $\mathrm{Li}_{2} \mathrm{NH}$ & $\mathrm{NaH}$ & $\mathrm{NaMgH}_{2.72}$ & $\mathrm{Li}_{2} \mathrm{Mg}(\mathrm{NH})_{2}$ & $\mathrm{MgH}_{2}$ & 2.74 & 0.44 \\
\hline 0.25 & 0.75 & $\mathrm{MgH}_{2}$ & 0.5 & $\mathrm{MgH}_{2}$ & $\mathrm{NaH}$ & $\mathrm{NaNH}_{2}$ & $\mathrm{NaH}$ & $\mathrm{Mg}\left(\mathrm{NH}_{2}\right)_{2}$ & & & 1.09 & 0.50 \\
\hline 0.25 & 0.75 & $\mathrm{MgH}_{2}$ & 0.25 & $\mathrm{MgH}_{2}$ & $\mathrm{NaNH}_{2}$ & $\begin{array}{l}\text { unk d = } \\
2.72,1.89- \\
\mathrm{Na}_{2} \mathrm{NH}\end{array}$ & $\mathrm{NaH}$ & $\mathrm{E}$ & & & 0.94 & 0.19 \\
\hline 0.25 & 0.75 & $\mathrm{MgH}_{2}$ & 1 & $\mathrm{NaH}$ & $\mathrm{MgH}_{2}$ & $\begin{array}{l}\text { unk d = } \\
2.72,1.89- \\
\mathrm{Na}_{2} \mathrm{NH}\end{array}$ & $\mathrm{NaH}$ & $\mathrm{NaMgH}_{2.72}$ & $\mathrm{MgH}_{2}$ & WC & $\mathrm{N}$ & $\mathrm{N}$ \\
\hline 0.75 & 0.25 & $\mathrm{MgH}_{2}$ & 0.5 & $\mathrm{Li}_{2} \mathrm{NH}$ & $\mathrm{MgH}_{2}$ & $\mathrm{NaH}$ & $\mathrm{Li}_{2} \mathrm{Mg}(\mathrm{NH})_{2}$ & $\mathrm{NaH}$ & & & 2.37 & 0.64 \\
\hline 0.75 & 0.25 & $\mathrm{MgH}_{2}$ & 0.25 & $\mathrm{MgH}_{2}$ & $\begin{array}{l}\mathrm{Li}_{3} \mathrm{Na}( \\
\left.\mathrm{NH}_{2}\right)_{4}\end{array}$ & $\mathrm{Li}_{2} \mathrm{NH}$ & $\mathrm{Li}_{2} \mathrm{Mg}(\mathrm{NH})_{2}$ & $\mathrm{LiNH}_{2} / \mathrm{Li}_{2} \mathrm{NH}$ & $\mathrm{NaH}$ & $\mathrm{NaMgH}_{2.72}$ & 1.09 & 0.28 \\
\hline 0.75 & 0.25 & $\mathrm{MgH}_{2}$ & 1 & $\mathrm{MgH}_{2}$ & $\mathrm{NaH}$ & $\mathrm{NaNH}_{2}$ & $\mathrm{NaH}$ & $\mathrm{NaMgH}_{2.72}$ & WC & $\mathrm{Li}_{2} \mathrm{Mg}(\mathrm{NH})_{2}$ & 2.02 & 0.76 \\
\hline
\end{tabular}


Table 8a (cont). Metal Amide System. Compositions, structure before and after testing, and hydrogen storage capacities (MT, 220 $\mathrm{C})$.

\begin{tabular}{|c|c|c|c|c|c|c|c|c|c|c|c|c|}
\hline \multicolumn{4}{|c|}{ Composition } & \multicolumn{3}{|c|}{$\begin{array}{l}\text { As synthesized } \\
\text { XRD }^{1}\end{array}$} & \multicolumn{4}{|c|}{ Spent XRD ${ }^{2}$} & \multicolumn{2}{|c|}{$\begin{array}{l}\text { Hydrogen } \\
\text { Storage Cap- } \\
\text { acity (wt. \%) }\end{array}$} \\
\hline $\mathrm{LiNH}_{2}$ & $\mathrm{NaNH}_{2}$ & MH & $\mathrm{mol}$ & xrd 1 & xrd 2 & xrd 3 & xrd 1 & xrd 2 & xrd 3 & xrd 4 & Des 1 & Des 2 \\
\hline 0 & 1 & $\mathrm{CaH}_{2}$ & 0.25 & $\mathrm{CaH}_{2}$ & $\mathrm{NaNH}_{2}$ & CaNH & $\mathrm{NaH}$ & $\mathrm{NaCa}\left(\mathrm{NH}_{2}\right)_{3}$ & $\mathrm{NaNH}_{2}$ & & 0.82 & 0.16 \\
\hline 0 & 1 & $\mathrm{CaH}_{2}$ & .125 & $\mathrm{CaH}_{2}$ & $\mathrm{NaNH}_{2}$ & $\mathrm{CaNH}$ & $\mathrm{NaH}$ & $\mathrm{NaNH}_{2}$ & $\mathrm{CaH}_{2}$ & & 0.60 & 0.28 \\
\hline 0 & 1 & $\mathrm{CaH}_{2}$ & 0.5 & $\mathrm{CaH}_{2}$ & $\mathrm{NaNH}_{2}$ & $\mathrm{CaNH}$ & $\mathrm{NaH}$ & $\mathrm{NaCa}\left(\mathrm{NH}_{2}\right)_{3}$ & & & 0.77 & 0.12 \\
\hline 1 & 0 & $\mathrm{CaH}_{2}$ & 0.25 & $\mathrm{CaH}_{2}$ & $\mathrm{Li}_{2} \mathrm{NH}$ & & $\mathrm{Li}_{2} \mathrm{NH}$ & $\mathrm{CaH}_{2}$ & & & 0.78 & 0.20 \\
\hline 1 & 0 & $\mathrm{CaH}_{2}$ & .125 & $\mathrm{Li}_{2} \mathrm{NH}$ & $\mathrm{CaH}_{2}$ & $\mathrm{CaNH}$ & $\mathrm{Li}_{2} \mathrm{NH} / \mathrm{LiNH}_{2}$ & $\mathrm{CaH}_{2}$ & & & 1.11 & 0.22 \\
\hline 1 & 0 & $\mathrm{MgH}_{2}$ & 1.2 & & & & & & & & 0.64 & 0.49 \\
\hline $2^{*}$ & 0 & $\mathrm{MgH}_{2}$ & 1.1 & & & & & & & & 3.47 & 2.55 \\
\hline $2^{*}$ & 0 & $\mathrm{TiH}_{2}$ & 1 & & & & & & & & 0.12 & 0.05 \\
\hline
\end{tabular}

All formulations treated with 0.02 moles $\mathrm{Ti}(\mathrm{OiPr})_{4}$ dopant. * = formulations with no dopant. 1 . Three most abundant products as-synthesized in order from greatest to least. 2 .

The top 4 products seen in spent materials seen by xrd. $\mathbf{A}$ is unk., $\mathrm{d}=4.18,3.82,3.46,3.18,3.05,2.72,2.55,2.52,2.35,2.24,2.10,1.97,1.86,1.83,1.75$. $\mathbf{B}$ is unk $\mathrm{d}=2.99,2.91$

$2.75,2.50,2.36,2.24,2.12,2.05,1.95,1.89 \ldots$ data is very weak. $\mathbf{C}$ is unk., $d=3.90,3.58,3.17,3.07,2.65,2.51,2.35,2.21,2.08,2.05,1.97,1.88,1.82,1.77 . \mathbf{D}$ is unk., $d=3.90$,

$3.58,3.17,3.07,2.65,2.51,2.35,2.21,1.82$. E is unk., $\mathrm{d}=4.18,3.80,2.96,2.72,2.51,2.36,2.22,2.07,1.97,1.89,1.83,1.75 ; \mathrm{N}=$ not measured.

\section{Table 8b. Metal Amide System. Compositions, structures after testing, and hydrogen storage capacities (MT, $220^{\circ} \mathrm{C}$ ).}

\section{Composition}

\section{Spent material XRD}

Hydrogen

\begin{tabular}{|c|c|c|c|c|c|c|c|c|c|c|c|c|}
\hline & & & & & & & & & & & acity & vt. \%) \\
\hline $\mathrm{LiNH}_{2}$ & $\mathrm{Mg}\left(\mathrm{NH}_{2}\right)_{2}$ & LiH & $\mathrm{NaH}$ & $\mathrm{MgH}_{2}$ & dopant & level & xrd-1 & xrd-2 & xrd-3 & xrd-4 & Des1 & Des2 \\
\hline 0 & $\cdots,-1-2, k$ & 1.1 & 0 & 0 & & & $\mathrm{Li}_{2} \mathrm{Mg}(\mathrm{NH})_{2}$ & LiMgN & $\mathrm{MgH}_{2}$ & unk., $d=2.14(b r)$ & 3.91 & 0.59 \\
\hline 0 & 1 & 0 & 1.1 & 0 & & & WC & $\mathrm{NaNH}_{2}$ & $\mathrm{NaOH}$ & $\mathrm{Mg}\left(\mathrm{NH}_{2}\right)_{2} \operatorname{tr}$ & 0.59 & 0.37 \\
\hline 0 & 1 & 0 & 0 & 1.1 & & & WC & $\mathrm{MgH}_{2}$ & & & 0.45 & 0.09 \\
\hline 0 & 3 & 5 & 0 & 0 & & & $\mathrm{Li}_{2} \mathrm{Mg}(\mathrm{NH})_{2}$ & $\mathrm{Mg}\left(\mathrm{NH}_{2}\right)_{2}$ & $\mathrm{MgH}_{2}$ & & 3.07 & 1.53 \\
\hline 0 & 3 & 6 & 0 & 0 & & & & & & & 3.02 & 1.41 \\
\hline 0 & 2.2 & 5 & 0 & 0 & & & & & & & 2.78 & 1.42 \\
\hline 2 & 3 & 4 & 0 & 0 & & & & & & & $\mathrm{~N}$ & $\mathrm{~N}$ \\
\hline 2 & 3 & 6 & 0 & 0 & & & & & & & $\mathrm{~N}$ & $\mathrm{~N}$ \\
\hline 5 & 2.2 & 1 & 0 & 0 & & & & & & & $\mathrm{~N}$ & $\mathrm{~N}$ \\
\hline 2 & 0 & 0 & 0 & 1 & & & & & & & 0.49 & 0.50 \\
\hline 2 & 0 & 2 & 0 & 1 & & & & & & & 2.13 & 1.21 \\
\hline 2 & 0 & 2 & 0 & 1 & $\mathrm{NiCl}_{2}$ & 0.02 & & & & & 1.83 & 1.13 \\
\hline 2 & 0 & 2 & 0 & 1 & $\mathrm{TiF}_{3}$ & 0.02 & & & & & 2.16 & 1.36 \\
\hline 2 & 0 & 2 & 0 & 1 & $\mathrm{NiCl}_{2} / \mathrm{TiF}_{3}$ & 0.01 & & & & & 2.25 & 1.26 \\
\hline
\end{tabular}




\begin{tabular}{|c|c|c|c|c|c|c|c|c|c|c|}
\hline \multicolumn{11}{|c|}{ Table 9. Metal Borohydride Materials: Composition and Hydrogen Storage Capacities } \\
\hline & & & & & & \multicolumn{5}{|c|}{ Hydrogen Storage Capacity (wt. \%) } \\
\hline \multicolumn{6}{|c|}{ Composition } & \multicolumn{2}{|c|}{ Medium Throughput } & \multicolumn{3}{|c|}{ High Throughput } \\
\hline A-BH4 & mol & M-Cl & mol & Dopant & mol & Des 1 & Des 2 & 100 & 230 & 350 \\
\hline $\mathrm{NaBH}_{4}$ & 4 & $\mathrm{ZnCl}_{2}$ & 1 & & & $\mathrm{~N}$ & $\mathrm{~N}$ & 0.73 & $0.02^{\star}$ & $0.02^{\mathrm{a}}$ \\
\hline $\mathrm{LiBH}_{4}$ & 3 & $\mathrm{ZnCl}_{2}$ & 1 & & & $\mathrm{~N}$ & $\mathrm{~N}$ & 2.36 & $-0.02^{\star}$ & $0.04^{\mathrm{a}}$ \\
\hline $\mathrm{NaBH}_{4}$ & 3 & $\mathrm{ZnCl}_{2}$ & 1 & & & $\mathrm{~N}$ & $\mathrm{~N}$ & 1.22 & $0.01 *$ & $0.02^{a}$ \\
\hline $\mathrm{KBH}_{4}$ & 3 & $\mathrm{ZnCl}_{2}$ & 1 & & & $\mathrm{~N}$ & $\mathrm{~N}$ & 0.35 & $0.00 *$ & $0.08^{a}$ \\
\hline $\mathrm{KBH}_{4}$ & 4 & $\mathrm{ZnCl}_{2}$ & 1 & & & $\mathrm{~N}$ & $\mathrm{~N}$ & 0.35 & $-0.01^{*}$ & $0.07^{a}$ \\
\hline $\mathrm{LiBH}_{4}$ & 6 & $\mathrm{TiCl}_{3}$ & 1 & & & 1.24 & 0.19 & 0.49 & 1.08 & 1.33 \\
\hline $\mathrm{LiBH}_{4}$ & 6 & $\mathrm{TiCl}_{4}$ & 1 & & & 1.39 & 0.26 & 0.67 & 1.10 & 1.20 \\
\hline $\mathrm{LiBH}_{4}$ & 6 & $\mathrm{CoCl}_{2}$ & 1 & & & 1.03 & 0.03 & 0.32 & 0.64 & 1.28 \\
\hline $\mathrm{LiBH}_{4}$ & 4 & $\mathrm{CuCl}_{2}$ & 1 & & & 0.48 & 0.06 & -0.02 & 0.26 & 1.06 \\
\hline $\mathrm{LiBH}_{4}$ & 6 & $\mathrm{CrCl}_{3}$ & 1 & & & 1.89 & 0.12 & 1.04 & 0.34 & 0.65 \\
\hline $\mathrm{LiBH}_{4}$ & 6 & $\mathrm{FeCl}_{3}$ & 1 & & & 0.70 & 0.08 & 0.67 & 0.79 & 1.08 \\
\hline $\mathrm{LiBH}_{4}$ & 4 & $\mathrm{NiCl}_{2}$ & 1 & & & 2.47 & 0.11 & 0.21 & 2.25 & 1.36 \\
\hline $\mathrm{NaBH}_{4}$ & 6 & $\mathrm{TiCl}_{4}$ & 1 & & & 1.91 & 0.21 & 1.28 & 0.68 & 0.72 \\
\hline $\mathrm{NaBH}_{4}$ & 6 & $\mathrm{TiCl}_{4}$ & 1 & & & B & B & 0.61 & 0.64 & 0.44 \\
\hline $\mathrm{NaBH}_{4}$ & 6 & $\mathrm{TiCl}_{3}$ & 1 & & & 2.77 & 0.10 & 1.33 & 0.68 & 0.38 \\
\hline $\mathrm{NaBH}_{4}$ & 6 & $\mathrm{TiCl}_{3}$ & 1 & & & 1.14 & 0.17 & 0.64 & 0.72 & 0.59 \\
\hline $\mathrm{NaBH}_{4}$ & 6 & $\mathrm{CrCl}_{3}$ & 1 & & & 1.90 & 0.00 & 1.01 & 0.35 & 0.17 \\
\hline $\mathrm{NaBH}_{4}$ & 6 & $\mathrm{CoCl}_{2}$ & 1 & & & 2.12 & 0.08 & 0.10 & 1.65 & 0.16 \\
\hline $\mathrm{NaBH}_{4}$ & 6 & $\mathrm{FeCl}_{3}$ & 1 & & & 2.06 & 0.06 & -0.04 & 1.55 & 0.24 \\
\hline $\mathrm{NaBH}_{4}$ & 4 & $\mathrm{NiCl}_{2}$ & 1 & & & 2.93 & 0.04 & 0.10 & 2.10 & 0.33 \\
\hline $\mathrm{NaBH}_{4}$ & 4 & $\mathrm{CuCl}_{2}$ & 1 & & & $\mathrm{~B}$ & $B$ & -0.13 & 0.27 & -0.14 \\
\hline $\mathrm{KBH}_{4}$ & 6 & $\mathrm{TiCl}_{3}$ & 1 & & & $\mathrm{~N}$ & $\mathrm{~N}$ & 0.49 & 1.39 & $\mathrm{~N}$ \\
\hline $\mathrm{KBH}_{4}$ & 6 & $\mathrm{TiCl}_{4}$ & 1 & & & $\mathrm{~N}$ & $\mathrm{~N}$ & 0.12 & 1.50 & $\mathrm{~N}$ \\
\hline $\mathrm{KBH}_{4}$ & 4 & $\mathrm{NiCl}_{2}$ & 1 & & & $\mathrm{~N}$ & $\mathrm{~N}$ & 0.07 & 1.26 & $\mathrm{~N}$ \\
\hline $\mathrm{KBH}_{4}$ & 4 & $\mathrm{CuCl}_{2}$ & 1 & & & $\mathrm{~N}$ & $\mathrm{~N}$ & 0.06 & 0.32 & $\mathrm{~N}$ \\
\hline $\mathrm{KBH}_{4}$ & 4 & $\mathrm{CuCl}_{2}$ & 1 & & & $\mathrm{~N}$ & $\mathrm{~N}$ & 0.10 & 0.40 & $\mathrm{~N}$ \\
\hline $\mathrm{KBH}_{4}$ & 6 & $\mathrm{FeCl}_{3}$ & 1 & & & $\mathrm{~N}$ & $\mathrm{~N}$ & -0.06 & $\mathrm{~B}$ & $\mathrm{~N}$ \\
\hline $\mathrm{KBH}_{4}$ & 6 & $\mathrm{CrCl}_{3}$ & 1 & & & $\mathrm{~N}$ & $\mathrm{~N}$ & 0.16 & 0.72 & $\mathrm{~N}$ \\
\hline $\mathrm{KBH}_{4}$ & 6 & $\mathrm{VCl}_{3}$ & 1 & & & $\mathrm{~N}$ & $\mathrm{~N}$ & 0.41 & 0.68 & $\mathrm{~N}$ \\
\hline $\mathrm{NaBH}_{4}$ & 6 & $\mathrm{VCl}_{3}$ & 1 & & & $\mathrm{~N}$ & $\mathrm{~N}$ & 1.38 & 0.53 & $\mathrm{~N}$ \\
\hline $\mathrm{LiBH}_{4}$ & 4 & $\mathrm{CuCl}$ & 1 & & & $\mathrm{~N}$ & $\mathrm{~N}$ & 0.49 & 1.31 & $\mathrm{~N}$ \\
\hline $\mathrm{NaBH}_{4}$ & 4 & $\mathrm{CuCl}$ & 1 & & & $\mathrm{~N}$ & $\mathrm{~N}$ & 0.15 & 0.28 & $\mathrm{~N}$ \\
\hline
\end{tabular}




\begin{tabular}{|c|c|c|c|c|c|c|c|c|c|c|}
\hline \multicolumn{11}{|c|}{ Table 9 (cont). Metal Borohydride Materials: Composition and Hydrogen Storage Capacities } \\
\hline & & & & & & \multicolumn{5}{|c|}{ Hydrogen Storage Capacity (wt. \%) } \\
\hline \multicolumn{6}{|c|}{ Composition } & \multicolumn{2}{|c|}{ Medium Throughput } & \multicolumn{3}{|c|}{ High Throughput } \\
\hline A-BH4 & mol & $\mathrm{M}-\mathrm{Cl}$ & mol & Dopant & mol & Des 1 & Des 2 & 100 & 230 & 350 \\
\hline $\mathrm{LiBH}_{4}$ & 6 & $\mathrm{ScCl}_{3}$ & 1 & & & $\mathrm{~N}$ & $\mathrm{~N}$ & 0.45 & 2.02 & $\mathrm{~N}$ \\
\hline $\mathrm{NaBH}_{4}$ & 6 & $\mathrm{ScCl}_{3}$ & 1 & & & $\mathrm{~N}$ & $\mathrm{~N}$ & 0.14 & 2.00 & $\mathrm{~N}$ \\
\hline $\mathrm{KBH}_{4}$ & 4 & $\mathrm{CuCl}$ & 1 & & & $\mathrm{~N}$ & $\mathrm{~N}$ & 0.27 & 0.17 & $\mathrm{~N}$ \\
\hline $\mathrm{KBH}_{4}$ & 4 & $\mathrm{CuCl}$ & 1 & & & $\mathrm{~N}$ & $\mathrm{~N}$ & 0.19 & 0.18 & $\mathrm{~N}$ \\
\hline $\mathrm{KBH}_{4}$ & 6 & $\mathrm{VCl}_{3}$ & 1 & & & $\mathrm{~N}$ & $\mathrm{~N}$ & 0.43 & 1.70 & $\mathrm{~N}$ \\
\hline $\mathrm{KBH}_{4}$ & 6 & $\mathrm{VCl}_{3}$ & 1 & & & $\mathrm{~N}$ & $\mathrm{~N}$ & 0.61 & 1.29 & $\mathrm{~N}$ \\
\hline $\mathrm{KBH}_{4}$ & 6 & $\mathrm{ScCl}_{3}$ & 1 & & & $\mathrm{~N}$ & $\mathrm{~N}$ & -0.06 & 1.10 & $\mathrm{~N}$ \\
\hline $\mathrm{LiBH}_{4}$ & 3 & $\mathrm{MnCl}_{2}$ & 1 & & & $\mathrm{~N}$ & $\mathrm{~N}$ & 2.75 & 0.13 & $\mathrm{~N}$ \\
\hline $\mathrm{KBH}_{4}$ & 6 & $\mathrm{FeCl}_{3}$ & 1 & & & $\mathrm{~N}$ & $\mathrm{~N}$ & 0.13 & 1.24 & $\mathrm{~N}$ \\
\hline $\mathrm{LiBH}_{4}$ & 6 & $\mathrm{FeCl}_{3}$ & 1 & & & $\mathrm{~N}$ & $\mathrm{~N}$ & 0.47 & 0.49 & $\mathrm{~N}$ \\
\hline $\mathrm{NaBH}_{4}$ & 3 & $\mathrm{MnCl}_{2}$ & 1 & & & $\mathrm{~N}$ & $\mathrm{~N}$ & 1.40 & 1.64 & $\mathrm{~N}$ \\
\hline $\mathrm{NaBH}_{4}$ & 3 & $\mathrm{MnCl}_{2}$ & 1 & & & $\mathrm{~N}$ & $\mathrm{~N}$ & 2.19 & 1.44 & $\mathrm{~N}$ \\
\hline $\mathrm{NaBH}_{4}$ & 3 & $\mathrm{MnCl}_{2}$ & 1 & & & $\mathrm{~N}$ & $\mathrm{~N}$ & 2.01 & 0.46 & $\mathrm{~N}$ \\
\hline $\mathrm{KBH}_{4}$ & 6 & $\mathrm{CoCl}_{2}$ & 1 & & & $\mathrm{~N}$ & $\mathrm{~N}$ & 0.36 & -0.23 & $\mathrm{~N}$ \\
\hline $\mathrm{LiBH}_{4}$ & 6 & $\mathrm{TiCl}_{3}$ & 1 & & & $\mathrm{~N}$ & $\mathrm{~N}$ & 0.48 & 0.89 & 1.19 \\
\hline $\mathrm{NaBH}_{4}$ & 6 & $\mathrm{TiCl}_{3}$ & 1 & & & $\mathrm{~N}$ & $\mathrm{~N}$ & -0.25 & 0.06 & 0.67 \\
\hline $\mathrm{KBH} 4$ & 6 & $\mathrm{TiCl}_{3}$ & 1 & & & $\mathrm{~N}$ & $\mathrm{~N}$ & 0.44 & 1.43 & 0.64 \\
\hline $\mathrm{LiBH}_{4}$ & 6 & $\mathrm{VCl}_{3}$ & 1 & & & $\mathrm{~N}$ & $\mathrm{~N}$ & 0.21 & 0.77 & 1.19 \\
\hline $\mathrm{NaBH}_{4}$ & 6 & $\mathrm{VCl}_{3}$ & 1 & & & $\mathrm{~N}$ & $\mathrm{~N}$ & 0.62 & 0.58 & 0.41 \\
\hline $\mathrm{LiBH}_{4}$ & 6 & $\mathrm{CoCl}_{2}$ & 1 & & & $\mathrm{~N}$ & $\mathrm{~N}$ & 0.65 & 1.32 & 0.95 \\
\hline $\mathrm{NaBH}_{4}$ & 6 & $\mathrm{CoCl}_{2}$ & 1 & & & $\mathrm{~N}$ & $\mathrm{~N}$ & 0.16 & 0.43 & 0.22 \\
\hline $\mathrm{KBH}_{4}$ & 6 & $\mathrm{CoCl}_{2}$ & 1 & & & $\mathrm{~N}$ & $\mathrm{~N}$ & 0.17 & 0.25 & 0.16 \\
\hline $\mathrm{LiBH}_{4}$ & 6 & $\mathrm{CrCl}_{3}$ & 1 & & & $\mathrm{~N}$ & $\mathrm{~N}$ & 0.26 & 0.56 & 0.75 \\
\hline $\mathrm{NaBH}_{4}$ & 6 & $\mathrm{CrCl}_{3}$ & 1 & & & $\mathrm{~N}$ & $\mathrm{~N}$ & 0.57 & 0.71 & -0.15 \\
\hline $\mathrm{KBH}_{4}$ & 6 & $\mathrm{CrCl}_{3}$ & 1 & & & $\mathrm{~N}$ & $\mathrm{~N}$ & 0.35 & 1.28 & 0.33 \\
\hline $\mathrm{LiBH}_{4}$ & 4 & $\mathrm{CuCl}_{2}$ & 1 & & & $\mathrm{~N}$ & $\mathrm{~N}$ & 0.36 & 1.95 & 1.82 \\
\hline $\mathrm{NaBH}_{4}$ & 4 & $\mathrm{CuCl}_{2}$ & 1 & & & $\mathrm{~N}$ & $\mathrm{~N}$ & 0.16 & 0.69 & 0.36 \\
\hline $\mathrm{KBH}_{4}$ & 4 & $\mathrm{CuCl}_{2}$ & 1 & & & $\mathrm{~N}$ & $\mathrm{~N}$ & 0.12 & 0.21 & 0.17 \\
\hline $\mathrm{LiBH}_{4}$ & 4 & $\mathrm{CuCl}$ & 1 & & & $\mathrm{~N}$ & $\mathrm{~N}$ & 0.06 & 0.35 & 2.43 \\
\hline $\mathrm{NaBH} 4$ & 4 & $\mathrm{CuCl}$ & 1 & & & $\mathrm{~N}$ & $\mathrm{~N}$ & 0.12 & 0.91 & 0.24 \\
\hline $\mathrm{LiBH}_{4}$ & 4 & $\mathrm{NiCl}_{2}$ & 1 & & & $\mathrm{~N}$ & $\mathrm{~N}$ & 0.21 & 1.60 & 1.74 \\
\hline $\mathrm{NaBH}_{4}$ & 4 & $\mathrm{NiCl}_{2}$ & 1 & & & $\mathrm{~N}$ & $\mathrm{~N}$ & -0.01 & 2.08 & 0.26 \\
\hline
\end{tabular}




\begin{tabular}{|c|c|c|c|c|c|c|c|c|c|c|}
\hline \multicolumn{11}{|c|}{ Table 9 (cont). Metal Borohydride Materials: Composition and Hydrogen Storage Capacities } \\
\hline & & & & & & \multicolumn{5}{|c|}{ Hydrogen Storage Capacity (wt. \%) } \\
\hline \multicolumn{6}{|c|}{ Composition } & \multicolumn{2}{|c|}{ Medium Throughput } & \multicolumn{3}{|c|}{ High Throughput } \\
\hline A-BH4 & mol & $\mathrm{M}-\mathrm{Cl}$ & $\mathrm{mol}$ & Dopant & mol & Des 1 & Des 2 & $100^{\circ} \mathrm{C}$ & $230^{\circ} \mathrm{C}$ & $350^{\circ} \mathrm{C}$ \\
\hline $\mathrm{KBH}_{4}$ & 4 & $\mathrm{NiCl}_{2}$ & 1 & & & $\mathrm{~N}$ & $\mathrm{~N}$ & 0.01 & 0.26 & 1.40 \\
\hline $\mathrm{LiBH}_{4}$ & 6 & $\mathrm{CrCl} 2$ & 1 & & & $\mathrm{~N}$ & $\mathrm{~N}$ & 0.09 & 0.44 & 0.95 \\
\hline $\mathrm{Zn}\left(\mathrm{BH}_{4}\right)_{2}$ & 1 & & & $\mathrm{Ti}(\mathrm{OiPr})_{4}$ & 0.02 & 0.05 & 0.01 & & & \\
\hline $\mathrm{LiBH}_{4}$ & 2 & $\mathrm{MgH}_{2}$ & 1 & & & -0.01 & -0.01 & & & \\
\hline $\mathrm{LiBH}_{4}$ & 3 & $\mathrm{NiCl}_{2}$ & 1 & & & 0.42 & 0.14 & & & \\
\hline $\mathrm{LiBH}_{4}$ & 4 & $\mathrm{NiCl}_{2}$ & 1 & & & 0.28 & 0.12 & & & \\
\hline $\mathrm{LiBH}_{4}$ & 2 & $\mathrm{NiCl}_{2}$ & 1 & & & 0.59 & 0.09 & & & \\
\hline $\mathrm{LiBH}_{4}$ & 2 & $\mathrm{MgH}_{2}$ & 1 & $\mathrm{ZnCl}_{2}$ & 0.06 & 0.11 & 0.03 & & & \\
\hline $\mathrm{LiBH}_{4}$ & 2 & $\mathrm{MgH}_{2}$ & 1 & $\mathrm{ZnCl}_{2}$ & 0.08 & 0.22 & 0.07 & & & \\
\hline $\mathrm{LiBH}_{4}$ & 2 & $\mathrm{MgH}_{2}$ & 1 & $\mathrm{ZnCl}_{2}$ & 0.1 & 0.20 & 0.04 & & & \\
\hline $\mathrm{KBH}_{4}$ & 2 & $\mathrm{MgH}_{2}$ & 1 & $\mathrm{ZnCl}_{2}$ & 0.08 & 0.16 & 0.03 & & & \\
\hline
\end{tabular}




\begin{tabular}{|c|c|c|c|c|c|c|c|c|c|c|}
\hline \multicolumn{9}{|c|}{ Composition } & \multirow{2}{*}{\multicolumn{2}{|c|}{$\begin{array}{l}\text { Hydrogen storage } \\
\text { Capacity (wt. \%) }\end{array}$}} \\
\hline \multicolumn{4}{|c|}{ Metal borides/metal nitrides } & \multicolumn{2}{|c|}{ Metal Hydride } & \multicolumn{2}{|c|}{ Metal amidelalanate } & \multirow{2}{*}{$\begin{array}{r}\text { dopant } \\
\mathrm{Ti}(\mathrm{OiPr})_{4}\end{array}$} & & \\
\hline MB/MN-1 & mol & $\mathrm{MB} / \mathrm{MN}-2$ & mol & MH & mol & MAIH/MNH & mol & & Des 1 & Des 2 \\
\hline $\mathrm{AlB}_{2}$ & 1.00 & & & $\mathrm{LiH}$ & 3.00 & & & 0.06 & 0.28 & 0.11 \\
\hline $\mathrm{AlB}_{2}$ & 1.00 & & & $\mathrm{NaH}$ & 3.00 & & & 0.06 & 0.24 & 0.09 \\
\hline $\mathrm{AlB}_{2}$ & 1.00 & & & $\mathrm{KH}$ & 3.00 & & & 0.06 & 0.29 & 0.04 \\
\hline $\mathrm{AlB}_{2}$ & 1.00 & & & $\mathrm{MgH}_{2}$ & 1.50 & & & 0.06 & 0.47 & 0.07 \\
\hline $\mathrm{AlB}_{2}$ & 1.00 & & & $\mathrm{CaH}_{2}$ & 1.50 & & & 0.06 & 0.25 & 0.02 \\
\hline $\mathrm{AlB}_{2}$ & 1.00 & & & $\mathrm{LiH}$ & 6.00 & & & 0.06 & 0.24 & 0.08 \\
\hline $\mathrm{AlB}_{2}$ & 1.00 & & & $\mathrm{NaH}$ & 6.00 & & & 0.06 & 0.23 & 0.10 \\
\hline $\mathrm{AlB}_{2}$ & 1.00 & & & $\mathrm{KH}$ & 6.00 & & & 0.06 & 0.38 & 0.14 \\
\hline $\mathrm{AlB}_{2}$ & 1.00 & & & $\mathrm{MgH}_{2}$ & 3.00 & & & 0.06 & 0.35 & 0.07 \\
\hline $\mathrm{AlB}_{2}$ & 1.00 & & & $\mathrm{CaH}_{2}$ & 3.00 & & & 0.06 & 0.19 & 0.03 \\
\hline $\mathrm{AlB}_{2}$ & 1.00 & $\mathrm{MgB}_{2}$ & 1.00 & $\mathrm{LiH}$ & 2.00 & & & 0.04 & 0.17 & 0.04 \\
\hline $\mathrm{AlB}_{2}$ & 1.00 & $\mathrm{MgB}_{2}$ & 1.00 & $\mathrm{NaH}$ & 2.00 & & & 0.04 & 0.19 & 0.05 \\
\hline $\mathrm{AlB}_{2}$ & 1.00 & $\mathrm{MgB}_{2}$ & 1.00 & $\mathrm{KH}$ & 2.00 & & & 0.04 & 0.31 & 0.03 \\
\hline $\mathrm{AlB}_{2}$ & 1.00 & $\mathrm{MgB}_{2}$ & 1.00 & $\mathrm{MgH}_{2}$ & 1.00 & & & 0.04 & 0.31 & 0.09 \\
\hline $\mathrm{AlB}_{2}$ & 1.00 & $\mathrm{MgB}_{2}$ & 1.00 & $\mathrm{CaH}_{2}$ & 1.00 & & & 0.04 & 0.21 & 0.02 \\
\hline $\mathrm{AlB}_{2}$ & 1.00 & $\mathrm{MgB}_{2}$ & 1.00 & $\mathrm{LiH}$ & 4.00 & & & 0.04 & 0.22 & 0.06 \\
\hline $\mathrm{AlB}_{2}$ & 1.00 & $\mathrm{MgB}_{2}$ & 1.00 & $\mathrm{NaH}$ & 4.00 & & & 0.04 & 0.19 & 0.06 \\
\hline $\mathrm{AlB}_{2}$ & 1.00 & $\mathrm{MgB}_{2}$ & 1.00 & $\mathrm{KH}$ & 4.00 & & & 0.04 & 0.30 & 0.07 \\
\hline $\mathrm{AlB}_{2}$ & 1.00 & $\mathrm{MgB}_{2}$ & 1.00 & $\mathrm{MgH}_{2}$ & 2.00 & & & 0.04 & 0.30 & 0.08 \\
\hline $\mathrm{AlB}_{2}$ & 1.00 & $\mathrm{MgB}_{2}$ & 1.00 & $\mathrm{CaH}_{2}$ & 2.00 & & & 0.04 & 0.54 & 0.24 \\
\hline AIN & 1.00 & & & $\mathrm{LiH}$ & 2.00 & & & 0.04 & 0.29 & 0.08 \\
\hline AIN & 1.00 & & & $\mathrm{NaH}$ & 2.00 & & & 0.04 & 0.12 & 0.05 \\
\hline AIN & 1.00 & & & $\mathrm{KH}$ & 2.00 & & & 0.04 & 0.24 & 0.12 \\
\hline AIN & 1.00 & & & $\mathrm{MgH}_{2}$ & 1.00 & & & 0.04 & 0.41 & 0.09 \\
\hline AIN & 1.00 & & & $\mathrm{CaH}_{2}$ & 1.00 & & & 0.04 & 0.22 & 0.06 \\
\hline AIN & 1.00 & & & $\mathrm{LiH}$ & 4.00 & & & 0.04 & 0.34 & 0.09 \\
\hline AIN & 1.00 & & & $\mathrm{NaH}$ & 4.00 & & & 0.04 & 0.14 & 0.05 \\
\hline AIN & 1.00 & & & $\mathrm{KH}$ & 4.00 & & & 0.04 & 0.23 & 0.12 \\
\hline AIN & 1.00 & & & $\mathrm{MgH}_{2}$ & 2.00 & & & 0.04 & 0.35 & 0.10 \\
\hline $\mathrm{CrB}$ & 1.00 & & & $\mathrm{LiH}$ & 1.00 & & & 0.02 & 0.10 & 0.04 \\
\hline $\mathrm{CrB}$ & 1.00 & & & $\mathrm{NaH}$ & 1.00 & & & 0.02 & 0.13 & 0.05 \\
\hline $\mathrm{CrB}$ & 1.00 & & & $\mathrm{MgH}_{2}$ & 0.50 & & & 0.02 & 0.12 & 0.04 \\
\hline $\mathrm{CrB}$ & 1.00 & & & $\mathrm{CaH}_{2}$ & 0.50 & & & 0.02 & 0.13 & -0.01 \\
\hline $\mathrm{CrB}$ & 1.00 & & & $\mathrm{LiH}$ & 2.00 & & & 0.02 & 0.11 & 0.05 \\
\hline CrB & 1.00 & & & $\mathrm{NaH}$ & 2.00 & & & 0.02 & 0.11 & 0.05 \\
\hline $\mathrm{CrB}$ & 1.00 & & & $\mathrm{MgH}_{2}$ & 1.00 & & & 0.02 & 0.11 & 0.03 \\
\hline
\end{tabular}




\begin{tabular}{|c|c|c|c|c|c|c|c|c|c|c|}
\hline \multicolumn{9}{|c|}{ Composition } & \multirow{2}{*}{\multicolumn{2}{|c|}{$\begin{array}{l}\text { Hydrogen storage } \\
\text { Capacity (wt. \%) }\end{array}$}} \\
\hline \multicolumn{4}{|c|}{ Metal borides/metal nitrides } & \multicolumn{2}{|c|}{ Metal Hydride } & \multicolumn{2}{|c|}{ Metal amide/alanate } & \multirow{2}{*}{$\begin{array}{r}\text { dopant } \\
\mathrm{Ti}(\mathrm{OiPr})_{4}\end{array}$} & & \\
\hline MB/MN-1 & mol & MB/MN-2 & mol & MH & mol & MAIH/MNH & mol & & Des 1 & Des 2 \\
\hline $\mathrm{CrB}$ & 1.00 & & & $\mathrm{CaH}_{2}$ & 1.00 & & & 0.02 & 0.12 & 0.00 \\
\hline $\mathrm{CrB}$ & 0.50 & $\mathrm{MgB}_{2}$ & 0.25 & $\mathrm{LiH}$ & 1.00 & & & 0.02 & 0.14 & 0.03 \\
\hline $\mathrm{CrB}$ & 0.50 & $\mathrm{MgB}_{2}$ & 0.25 & $\mathrm{NaH}$ & 1.00 & & & 0.02 & 0.15 & 0.06 \\
\hline $\mathrm{CrB}$ & 0.50 & $\mathrm{MgB}_{2}$ & 0.25 & $\mathrm{MgH}_{2}$ & 0.50 & & & 0.02 & 0.14 & 0.02 \\
\hline $\mathrm{CrB}$ & 0.50 & $\mathrm{MgB}_{2}$ & 0.25 & $\mathrm{CaH}_{2}$ & 0.50 & & & 0.02 & 0.22 & 0.01 \\
\hline $\mathrm{CrB}$ & 0.50 & $\mathrm{MgB}_{2}$ & 0.25 & $\mathrm{LiH}$ & 1.75 & & & 0.02 & 0.08 & 0.00 \\
\hline $\mathrm{CrB}$ & 0.50 & $\mathrm{MgB}_{2}$ & 0.25 & $\mathrm{NaH}$ & 1.75 & & & 0.02 & 0.09 & 0.05 \\
\hline $\mathrm{CrB}$ & 0.50 & $\mathrm{MgB}_{2}$ & 0.25 & $\mathrm{MgH}_{2}$ & 0.88 & & & 0.02 & 0.24 & 0.06 \\
\hline $\mathrm{CrB}$ & 0.50 & $\mathrm{MgB}_{2}$ & 0.25 & $\mathrm{CaH}_{2}$ & 0.88 & & & 0.02 & 0.24 & 0.02 \\
\hline $\mathrm{CrB}$ & 0.50 & $\mathrm{AlB}_{2}$ & 0.25 & $\mathrm{LiH}$ & 1.00 & & & 0.02 & 0.19 & 0.07 \\
\hline $\mathrm{CrB}$ & 0.50 & $\mathrm{AlB}_{2}$ & 0.25 & $\mathrm{NaH}$ & 1.00 & & & 0.02 & 0.08 & 0.03 \\
\hline $\mathrm{CrB}$ & 0.50 & $\mathrm{AlB}_{2}$ & 0.25 & $\mathrm{MgH}_{2}$ & 0.50 & & & 0.02 & 0.12 & 0.01 \\
\hline $\mathrm{CrB}$ & 0.50 & $\mathrm{AlB}_{2}$ & 0.25 & $\mathrm{CaH}_{2}$ & 0.50 & & & 0.02 & 0.19 & 0.03 \\
\hline $\mathrm{CrB}$ & 0.50 & $\mathrm{AlB}_{2}$ & 0.25 & $\mathrm{LiH}$ & 1.75 & & & 0.02 & 0.24 & 0.07 \\
\hline $\mathrm{CrB}$ & 0.50 & $\mathrm{AlB}_{2}$ & 0.25 & $\mathrm{NaH}$ & 1.75 & & & 0.02 & 0.08 & 0.04 \\
\hline $\mathrm{CrB}$ & 0.50 & $\mathrm{AlB}_{2}$ & 0.25 & $\mathrm{MgH}_{2}$ & 0.88 & & & 0.02 & 0.19 & 0.06 \\
\hline CrB & 0.50 & $\mathrm{AlB}_{2}$ & 0.25 & $\mathrm{CaH}_{2}$ & 0.88 & & & 0.02 & 0.18 & 0.01 \\
\hline $\mathrm{MgB}_{2}$ & 1.00 & & & & & & & 0.04 & 0.08 & 0.03 \\
\hline $\mathrm{MgB}_{2}$ & 0.00 & $B$ & 2.00 & $\mathrm{MgH}_{2}$ & 1.00 & & & 0.04 & 0.19 & 0.05 \\
\hline $\mathrm{MgB}_{2}$ & 1.00 & & & $\mathrm{LiAlH}_{4}$ & 1.00 & $\mathrm{Mg}\left(\mathrm{AlH}_{4}\right)_{2}$ & 1.00 & 0.06 & 0.75 & 0.14 \\
\hline $\mathrm{MgB}_{2}$ & 1.00 & & & $\mathrm{LiAlH}_{4}$ & 1.00 & $\mathrm{Mg}\left(\mathrm{AlH}_{4}\right)_{2}$ & 1.00 & 0 & 0.46 & 0.15 \\
\hline $\mathrm{MgB}_{2}$ & 1.00 & & & $\mathrm{MgH}_{2}$ & 1.00 & & & 0.04 & 0.32 & 0.09 \\
\hline $\mathrm{MgB}_{2}$ & 1.00 & & & & & $\mathrm{LiAlH}_{4}$ & 2.00 & 0 & 0.28 & 0.03 \\
\hline $\mathrm{MgB}_{2}$ & 1.00 & & & & & & & 0.08 & $\mathrm{~N}$ & $\mathrm{~N}$ \\
\hline $\mathrm{MgB}_{2}$ & 1.00 & & & $\mathrm{MgH}_{2}$ & 1.00 & & & 0.08 & 0.12 & 0.04 \\
\hline $\mathrm{VB}_{2}$ & 1.00 & & & $\mathrm{LiH}$ & 2.00 & & & & $\mathrm{~N}$ & $\mathrm{~N}$ \\
\hline $\mathrm{VB}_{2}$ & 1.00 & & & $\mathrm{NaH}$ & 2.00 & & & & $\mathrm{~N}$ & $\mathrm{~N}$ \\
\hline $\mathrm{VB}_{2}$ & 1.00 & & & $\mathrm{KH}$ & 2.00 & & & & $\mathrm{~N}$ & $\mathrm{~N}$ \\
\hline $\mathrm{VB}_{2}$ & 1.00 & & & $\mathrm{MgH}_{2}$ & 1.00 & & & & $\mathrm{~N}$ & $\mathrm{~N}$ \\
\hline $\mathrm{VB}_{2}$ & 1.00 & & & $\mathrm{CaH}_{2}$ & 1.00 & & & & $\mathrm{~N}$ & $\mathrm{~N}$ \\
\hline $\mathrm{VB}_{2}$ & 1.00 & & & & & $\mathrm{LiNH}_{2}$ & 2.00 & & $\mathrm{~N}$ & $\mathrm{~N}$ \\
\hline $\mathrm{VB}_{2}$ & 1.00 & & & & & $\mathrm{NaNH}_{2}$ & 2.00 & & $\mathrm{~N}$ & $\mathrm{~N}$ \\
\hline $\mathrm{VB}_{2}$ & 1.00 & & & & & $\mathrm{LiNH}_{2}$ & 4.00 & & $\mathrm{~N}$ & $\mathrm{~N}$ \\
\hline $\mathrm{VB}_{2}$ & 1.00 & & & & & $\mathrm{NaNH}_{2}$ & 4.00 & & $\mathrm{~N}$ & $\mathrm{~N}$ \\
\hline
\end{tabular}




\begin{tabular}{|c|c|c|c|c|c|c|c|c|c|c|}
\hline \multicolumn{9}{|c|}{ Composition } & \multirow{2}{*}{\multicolumn{2}{|c|}{$\begin{array}{l}\text { Hydrogen storag } \\
\text { Capacity (wt. \%) }\end{array}$}} \\
\hline \multicolumn{4}{|c|}{ Metal borides/metal nitrides } & \multicolumn{2}{|c|}{ Metal Hydride } & \multicolumn{2}{|c|}{ Metal amidelalanate } & \multirow{2}{*}{$\begin{array}{r}\text { dopant } \\
\mathrm{Ti}(\mathrm{OiPr})_{4}\end{array}$} & & \\
\hline MB/MN-1 & mol & MB/MN-2 & mol & MH & mol & MAIH/MNH & mol & & Des 1 & Des 2 \\
\hline $\mathrm{VB}_{2}$ & 1.00 & & & $\mathrm{LiH}$ & 2.00 & & & 0.04 & $\mathrm{~N}$ & $\mathrm{~N}$ \\
\hline $\mathrm{VB}_{2}$ & 1.00 & & & $\mathrm{NaH}$ & 2.00 & & & 0.04 & $\mathrm{~N}$ & $\mathrm{~N}$ \\
\hline $\mathrm{VB}_{2}$ & 1.00 & & & $\mathrm{KH}$ & 2.00 & & & 0.04 & $\mathrm{~N}$ & $\mathrm{~N}$ \\
\hline $\mathrm{VB}_{2}$ & 1.00 & & & $\mathrm{MgH}_{2}$ & 1.00 & & & 0.04 & $\mathrm{~N}$ & $\mathrm{~N}$ \\
\hline $\mathrm{VB}_{2}$ & 1.00 & & & $\mathrm{CaH}_{2}$ & 1.00 & & & 0.04 & $\mathrm{~N}$ & $\mathrm{~N}$ \\
\hline $\mathrm{VB}_{2}$ & 1.00 & & & & & $\mathrm{LiNH}_{2}$ & 2.00 & 0.04 & $\mathrm{~N}$ & $\mathrm{~N}$ \\
\hline $\mathrm{VB}_{2}$ & 1.00 & & & & & $\mathrm{NaNH}_{2}$ & 2.00 & 0.04 & $\mathrm{~N}$ & $\mathrm{~N}$ \\
\hline $\mathrm{Li}_{3} \mathrm{~N}$ & 0.25 & $\mathrm{Mg}_{3} \mathrm{~N}_{2}$ & 0.25 & $\mathrm{LiH}$ & 0.50 & & & 0.02 & 0.94 & 0.84 \\
\hline $\mathrm{Mg}_{3} \mathrm{~N}_{2}$ & 0.20 & & & $\mathrm{LiH}$ & 0.40 & $\mathrm{LiNH}_{2}$ & 0.40 & 0.02 & 0.38 & 0.34 \\
\hline $\mathrm{Mg}_{3} \mathrm{~N}_{2}$ & 0.24 & & & $\mathrm{MgH}_{2}$ & 0.27 & $\mathrm{LiNH}_{2}$ & 0.49 & 0.02 & 1.81 & 1.13 \\
\hline $\mathrm{Mg}_{3} \mathrm{~N}_{2}$ & 0.20 & & & $\mathrm{LiH}$ & 0.40 & $\mathrm{LiNH}_{2}$ & 0.20 & 0.02 & 1.24 & 0.85 \\
\hline $\mathrm{Li}_{3} \mathrm{~N}$ & 0.27 & $\mathrm{Mg}_{3} \mathrm{~N}_{2}$ & 0.13 & $\mathrm{LiH}$ & 0.27 & $\mathrm{LiNH}_{2}$ & 0.13 & 0.02 & 1.28 & 0.93 \\
\hline $\mathrm{Li}_{3} \mathrm{~N}$ & 0.12 & AIN & 0.12 & $\mathrm{MgH}_{2}$ & 0.27 & $\mathrm{LiNH}_{2}$ & 0.49 & 0.02 & 1.63 & 1.31 \\
\hline
\end{tabular}




\begin{tabular}{|c|c|c|c|c|c|c|c|c|c|c|c|}
\hline \multicolumn{12}{|c|}{ Table 11a. Metal Alanate - M } \\
\hline \multicolumn{7}{|c|}{ Composition } & \multirow{2}{*}{\multicolumn{5}{|c|}{ XRD of as-synthesized materials }} \\
\hline \multicolumn{2}{|c|}{ Metal alanates } & \multicolumn{2}{|c|}{ Metal amides } & \multicolumn{2}{|c|}{ Metal hydrides } & \multirow{2}{*}{$\begin{array}{l}\text { dopant } \\
\text { TiP }^{\mathrm{d}}\end{array}$} & & & & & \\
\hline $\mathrm{MAlH}_{4}$ & mol & $\mathrm{MNH}_{2}$ & mol & MH 1 & mol & & xrd 1 & xrd 2 & xrd 3 & xrd 4 & xrd 5 \\
\hline $\mathrm{LiAlH}_{4}$ & 1 & $\mathrm{LiNH}_{2}$ & 1 & & & 0.02 & $\mathrm{Li}_{2} \mathrm{NH}$ & $\mathrm{LiNH}_{2}$ & $\mathrm{Li}_{3} \mathrm{AlH}_{6}$ & $\mathrm{Al}$ & \\
\hline $\mathrm{LiAlH}_{4}$ & 2 & $\mathrm{LiNH}_{2}$ & 1 & & & 0.04 & $\mathrm{Al}$ & $\mathrm{Li}_{2} \mathrm{NH}$ & $\mathrm{Li}_{3} \mathrm{AlH} \mathrm{H}_{6}$ & & \\
\hline $\mathrm{NaAlH}_{4}$ & 1 & $\mathrm{LiNH}_{2}$ & 1 & & & 0.02 & $\mathrm{LiNa}_{2} \mathrm{AlH}_{6}$ & $\mathrm{Li}_{2} \mathrm{NH}$ & $\mathrm{Na}_{3} \mathrm{AlH}_{6}$ & $\mathrm{NaAlH}_{4}$ & \\
\hline $\mathrm{NaAlH}_{4}$ & 2 & $\mathrm{LiNH}_{2}$ & 1 & & & 0.04 & $\mathrm{NaAlH}_{4}$ & $\mathrm{Li}_{2} \mathrm{NH}$ & $\mathrm{Na}_{3} \mathrm{AlH}_{6}$ & $\mathrm{Al}$ & $\mathrm{LiNa}_{2} \mathrm{AlH}_{6}$ \\
\hline $\mathrm{LiAlH}_{4}$ & 1 & $\mathrm{NaNH}_{2}$ & 1 & & & 0.02 & $\mathrm{NaH}$ & $\mathrm{LiNa}_{2} \mathrm{AlH}_{6}$ & $\mathrm{NaNH}_{2}$ & & \\
\hline $\mathrm{LiAlH}_{4}$ & 2 & $\mathrm{NaNH}_{2}$ & 1 & & & 0.04 & $\mathrm{NaAlH}_{4}$ & $\mathrm{Al}$ & $\mathrm{NaNH}_{2}$ & $\mathrm{Li}_{2} \mathrm{NH}$ & \\
\hline $\mathrm{NaAlH}_{4}$ & 1 & $\mathrm{NaNH}_{2}$ & 1 & & & 0.02 & $\mathrm{NaH}$ & $\mathrm{NaAlH}_{4}$ & $\mathrm{NaNH}_{2}(\mathrm{tr})$ & & \\
\hline $\mathrm{NaAlH}_{4}$ & 2 & $\mathrm{NaNH}_{2}$ & 1 & & & 0.04 & $\mathrm{Na}_{3} \mathrm{AlH}_{6}$ & $\mathrm{NaAlH}_{4}$ & & & \\
\hline $\mathrm{LiAlH}_{4}$ & 1 & $\mathrm{LiNH}_{2}$ & 2 & & & 0.02 & $\mathrm{Li}_{2} \mathrm{NH} / \mathrm{LiNH}_{2}$ & $\mathrm{LiAlH}_{4}$ & & & \\
\hline $\mathrm{NaAlH}_{4}$ & 1 & $\mathrm{NaNH}_{2}$ & 2 & & & 0.02 & $\mathrm{NaH}$ & $\mathrm{WC} / \mathrm{NaAlH}_{4}$ & $\mathrm{NaNH}_{2}$ & & \\
\hline $\mathrm{LiAlH}_{4}$ & 1 & $\mathrm{LiNH}_{2}$ & 4 & & & & & & & & \\
\hline $\mathrm{LiAlH}_{4}$ & 1 & $\mathrm{LiNH}_{2}$ & 1 & & & 0.02 & & & & & \\
\hline $\mathrm{NaAlH}_{4}$ & 1 & $\mathrm{LiNH}_{2}$ & 4 & & & 0.02 & & & & & \\
\hline $\mathrm{NaAlH}_{4}$ & 1 & $\mathrm{LiNH}_{2}$ & 1 & & & 0.02 & & & & & \\
\hline $\mathrm{Mg}\left(\mathrm{AlH}_{4}\right)_{2}$ & 1 & $\mathrm{LiNH}_{2}$ & 2 & & & & & & & & \\
\hline $\mathrm{Mg}\left(\mathrm{AlH}_{4}\right)_{2}$ & 1 & $\mathrm{LiNH}_{2}$ & 2 & $\mathrm{KH}$ & 1 & & & & & & \\
\hline $\mathrm{NaAlH}_{4}$ & 1 & $\mathrm{LiNH}_{2}$ & 1 & & & 0.02 & $\mathrm{LiNa}_{2} \mathrm{AlH}_{6}$ & $\mathrm{Li}_{2} \mathrm{NH}$ & $\mathrm{NaH}$ & & \\
\hline $\mathrm{NaAlH}_{4}$ & 1 & $\mathrm{LiNH}_{2}$ & 2 & & & 0.02 & $\mathrm{Li}_{2} \mathrm{NH}$ & $\mathrm{NaH}$ & $\mathrm{Na}_{3} \mathrm{AlH}_{6}$ & $\mathrm{LiNa}_{2} \mathrm{AlH}_{6}$ & $\mathrm{NaAlH}_{4}$ \\
\hline $\mathrm{NaAlH}_{4}$ & 1 & $\mathrm{LiNH}_{2}$ & 4 & & & 0.02 & $\mathrm{Li}_{2} \mathrm{NH}$ & $\mathrm{NaH}$ & $\mathrm{NaAlH}_{4}$ & $\mathrm{LiNa}_{2} \mathrm{AlH}_{6}$ & \\
\hline $\mathrm{NaAlH}_{4}$ & 1 & $\mathrm{LiNH}_{2}$ & 0.5 & & & 0.02 & $\mathrm{NaAlH}_{4}$ & $\mathrm{LiNa}_{2} \mathrm{AlH}_{6}$ & $\mathrm{Li}_{2} \mathrm{NH}$ & $\mathrm{Na}_{3} \mathrm{AlH}_{6}$ & \\
\hline $\mathrm{NaAlH}_{4}$ & 1 & $\mathrm{LiNH}_{2}$ & 1 & & & & $\mathrm{NaAlH}_{4}$ & $\mathrm{Li}_{2} \mathrm{NH}$ & $\mathrm{LiNa}_{2} \mathrm{AlH}_{6}$ & & \\
\hline $\mathrm{NaAlH}_{4}$ & 1 & $\mathrm{LiNH}_{2}$ & 2 & & & & $\mathrm{Li}_{2} \mathrm{NH}$ & $\mathrm{LiNa}_{2} \mathrm{AlH}_{6}$ & WC & $\mathrm{NaH}$ & $\mathrm{Na}_{3} \mathrm{AlH}_{6}$ \\
\hline $\mathrm{NaAlH}_{4}$ & 1 & $\mathrm{LiNH}_{2}$ & 4 & & & & $\mathrm{Li}_{2} \mathrm{NH}$ & $\mathrm{LiNa}_{2} \mathrm{AlH}_{6}$ & WC & $\mathrm{NaH}$ & $\mathrm{Na}_{3} \mathrm{AlH}_{6}$ \\
\hline $\mathrm{NaAlH}_{4}$ & 1 & $\mathrm{LiNH}_{2}$ & 0.5 & & & & $\mathrm{NaAlH}_{4}$ & $\mathrm{LiNa}_{2} \mathrm{AlH}_{6}$ & $\mathrm{Li}_{2} \mathrm{NH}$ & $\mathrm{Na}_{3} \mathrm{AlH}_{6}$ & \\
\hline $\mathrm{NaAlH}_{4}$ & 1 & $\mathrm{NaNH}_{2}$ & 1 & & & 0.02 & $\mathrm{NaH}$ & $\mathrm{NaNH}_{2}$ & unk., $d=2.58$ & & \\
\hline $\mathrm{NaAlH}_{4}$ & 1 & $\mathrm{NaNH}_{2}$ & 2 & & & 0.02 & $\mathrm{NaNH}_{2}$ & $\mathrm{NaH}$ & unk., $d=2.58$ & & \\
\hline $\mathrm{NaAlH}_{4}$ & 1 & $\mathrm{NaNH}_{2}$ & 4 & & & 0.02 & $\mathrm{NaNH}_{2}$ & WC & & & \\
\hline $\mathrm{NaAlH}_{4}$ & 1 & $\mathrm{NaNH}_{2}$ & 0.5 & & & 0.02 & $\mathrm{NaNH}_{2}$ & $\mathrm{Na}_{3} \mathrm{AlH}_{6}$ & WC & & \\
\hline $\mathrm{NaAlH}_{4}$ & 1 & $\mathrm{LiNH}_{2}$ & 1 & $\mathrm{NaH}$ & 1 & 0.02 & $\mathrm{Na}_{3} \mathrm{AlH}_{6}$ & $\mathrm{NaH}$ & unk., $d=3.01,2.56$ & & \\
\hline $\mathrm{NaAlH}_{4}$ & 1 & $\mathrm{LiNH}_{2}$ & 1 & $\mathrm{LiH}$ & 1 & 0.02 & $\mathrm{LiNa}_{2} \mathrm{AlH}_{6}$ & $\mathrm{NaAlH}_{4}$ & $\mathrm{Na}_{3} \mathrm{AlH}_{6}$ & $\mathrm{Li}_{2} \mathrm{NH}$ & \\
\hline $\mathrm{NaAlH}_{4}$ & 1 & $\mathrm{LiNH}_{2}$ & 2 & $\mathrm{LiH}$ & 1 & 0.02 & WC & & & & \\
\hline $\mathrm{NaAlH}_{4}$ & 1 & $\mathrm{LiNH}_{2}$ & 2 & $\mathrm{NaH}$ & 1 & 0.02 & $\mathrm{NaH}$ & WC & $\mathrm{Na}_{3} \mathrm{AlH}_{6}$ & $\mathrm{NaAlH}_{4}$ & $\mathrm{Li}_{2} \mathrm{NH}$ \\
\hline $\mathrm{Mg}\left(\mathrm{AlH}_{4}\right)_{2}$ & 1 & $\mathrm{LiNH}_{2}$ & 1 & & & & $\mathrm{Al}$ & $\mathrm{MgH}_{2}$ & $\mathrm{Li}_{2} \mathrm{NH}$ & & \\
\hline $\mathrm{Mg}\left(\mathrm{AlH}_{4}\right)_{2}$ & 1 & $\mathrm{LiNH}_{2}$ & 2 & & & & $\mathrm{Al}$ & $\mathrm{Li}_{2} \mathrm{NH}$ & $\mathrm{MgH}_{2}$ & unk., $d=2.82$ & \\
\hline $\mathrm{Mg}\left(\mathrm{AlH}_{4}\right)_{2}$ & 1 & $\mathrm{LiNH}_{2}$ & 4 & & & & $\mathrm{Al}$ & $\mathrm{Li}_{2} \mathrm{NH}$ & $\mathrm{MgH}_{2}$ & unk., $d=1.99$ & \\
\hline $\mathrm{Mg}\left(\mathrm{AlH}_{4}\right)_{2}$ & 1 & $\mathrm{LiNH}_{2}$ & 8 & & & & AM & $\mathrm{Al}$ & $\mathrm{Li}_{2} \mathrm{NH}$ & & \\
\hline $\mathrm{Mg}\left(\mathrm{AlH}_{4}\right)_{2}$ & 1 & $\mathrm{NaNH}_{2}$ & 1 & & & & $\mathrm{Al}$ & $\mathrm{NaMgH}_{3}$ & $\mathrm{NaH}$ & $\mathrm{MgH}_{2}$ & \\
\hline $\mathrm{Mg}\left(\mathrm{AlH}_{4}\right)_{2}$ & 1 & $\mathrm{NaNH}_{2}$ & 2 & & & & $\mathrm{Al}$ & $\mathrm{NaH}$ & $\mathrm{NaMgH}_{3}$ & $\mathrm{MgH}_{2}$ & \\
\hline $\mathrm{Mg}\left(\mathrm{AlH}_{4}\right)_{2}$ & 1 & $\mathrm{NaNH}_{2}$ & 4 & & & & $\mathrm{Al}$ & $\mathrm{NaH}$ & WC & $\mathrm{NaMgH}_{3}(\mathrm{tr})$ & \\
\hline $\mathrm{Mg}\left(\mathrm{AlH}_{4}\right)_{2}$ & 1 & $\mathrm{NaNH}_{2}$ & 8 & & & & $\mathrm{Al}$ & $\mathrm{NaNH}_{2}$ & $\mathrm{NaH}$ & $\mathrm{MgH}_{2}$ & $\mathrm{NaMgH}_{3}$ \\
\hline
\end{tabular}




\begin{tabular}{|c|c|c|c|c|c|c|c|c|c|c|c|}
\hline \multicolumn{7}{|c|}{ Composition } & \multirow{2}{*}{\multicolumn{5}{|c|}{ XRD of as-synthesized materials }} \\
\hline \multicolumn{2}{|c|}{ Metal alanates } & \multicolumn{2}{|c|}{ Metal amides } & \multicolumn{2}{|c|}{ Metal hydrides } & \multirow{2}{*}{$\begin{array}{l}\text { dopant } \\
\text { TiP }^{\mathrm{d}} \\
\end{array}$} & & & & & \\
\hline $\mathrm{MAIH}_{4}$ & mol & $\mathrm{MNH}_{2}$ & mol & MH 1 & mol & & xrd 1 & xrd 2 & xrd 3 & xrd 4 & xrd 5 \\
\hline $\mathrm{NaAlH}_{4}$ & 1 & $\mathrm{LiNH}_{2}$ & 4 & $\mathrm{MgH}_{2}$ & 2.2 & $0.02^{\mathrm{a}}$ & $\mathrm{MgH}_{2}$ & $\mathrm{Li}_{2} \mathrm{NH}$ & $\mathrm{NaH}$ & & \\
\hline Al-NP & 1 & $\mathrm{LiNH}_{2}$ & 4 & $\mathrm{MgH}_{2} / \mathrm{NaH}$ & $2.2 / 1$ & 0.02 & $\mathrm{Li}_{2} \mathrm{NH}$ & $\mathrm{MgH}_{2}$ & $\mathrm{Al}$ & $\mathrm{NaH}$ & \\
\hline $\mathrm{NaAlH}_{4}$ & 1 & $\mathrm{NaNH}_{2}$ & 4 & $\mathrm{MgH}_{2}$ & 2.2 & $0.02^{\mathrm{a}}$ & $\mathrm{MgH}_{2}$ & $\mathrm{NaH}$ & WC & $\mathrm{NaNH}_{2}$ & \\
\hline Al-NP & 1 & $\mathrm{NaNH}_{2}$ & 4 & $\mathrm{MgH}_{2} / \mathrm{NaH}$ & $2.2 / 1$ & 0.02 & $\mathrm{MgH}_{2}$ & $\mathrm{NaH}$ & $\mathrm{NaNH}_{2}$ & $\mathrm{Al}$ & \\
\hline Al-NP & 1 & $\mathrm{LiNH}_{2}$ & 4 & $\mathrm{MgH}_{2} / \mathrm{KH}$ & $2.2 / 1$ & 0.02 & WC & $\mathrm{MgH}_{2}$ & $\mathrm{KH}$ & $\mathrm{Al}$ & $\mathrm{Li}_{2} \mathrm{NH}$ \\
\hline $\mathrm{LiAlH}_{4}$ & 0.5 & $\mathrm{NaNH}_{2}$ & 0.5 & & & 0.02 & & & & & \\
\hline $\mathrm{LiAlH}_{4}$ & 0.67 & $\mathrm{NaNH}_{2}$ & 0.33 & & & 0.02 & & & & & \\
\hline $\mathrm{LiAlH}_{4}$ & 0.33 & $\mathrm{NaNH}_{2}$ & 0.67 & & & 0.02 & & & & & \\
\hline $\mathrm{LiAlH}_{4}$ & 2 & $\mathrm{Mg}\left(\mathrm{NH}_{2}\right)_{2}$ & 1 & & & & & & & & \\
\hline $\mathrm{NaAlH}_{4}$ & 1 & $\mathrm{Mg}\left(\mathrm{NH}_{2}\right)_{2}$ & 0.5 & $\mathrm{LiNH}_{2} / \mathrm{MgH}_{2}$ & $1 / 0.55$ & 0.02 & & & & & \\
\hline $\mathrm{LiAlH}_{4}$ & 2 & $\mathrm{Mg}\left(\mathrm{NH}_{2}\right)_{2}$ & 2.2 & $\mathrm{LiH}$ & 4 & & & & & & \\
\hline $\mathrm{LiAlH}_{4}$ & 1 & $\mathrm{Mg}\left(\mathrm{NH}_{2}\right)_{2}$ & 2.2 & $\mathrm{LiH}$ & 5 & & & & & & \\
\hline $\mathrm{LiAlH}_{4}$ & 1 & $\mathrm{LiNH}_{2}$ & 1 & & & 0.02 & & & & & \\
\hline $\mathrm{LiAlH}_{4}$ & 1 & $\mathrm{LiNH}_{2}$ & 4 & & & & & & & & \\
\hline $\mathrm{LiAlH}_{4}$ & 1 & $\mathrm{LiNH}_{2}$ & 4 & & & 0.02 & & & & & \\
\hline $\mathrm{LiAlH}_{4}$ & 1 & $\mathrm{LiNH}_{2}$ & 6 & $\mathrm{MgH}_{2}$ & 1.1 & 0.02 & & & & & \\
\hline $\mathrm{LiAlH}_{4}$ & 1 & $\mathrm{LiNH}_{2}$ & 5 & $\mathrm{NaAlH}_{4}$ & 1 & 0.02 & & & & & \\
\hline $\mathrm{LiAlH}_{4}$ & 1 & $\mathrm{LiNH}_{2}$ & 6 & & & 0.02 & & & & & \\
\hline $\mathrm{NaAlH}_{4}$ & 0.875 & $\mathrm{LiNH}_{2}$ & 0.125 & & & $0.02^{b}$ & & & & & \\
\hline $\mathrm{NaAlH}_{4}$ & 0.875 & $\mathrm{LiNH}_{2}$ & 0.125 & & & $0.02^{c}$ & & & & & \\
\hline $\mathrm{NaAlH}_{4}$ & 0.875 & $\mathrm{LiNH}_{2}$ & 0.125 & & & $0.02^{b}$ & & & & & \\
\hline $\mathrm{NaAlH}_{4}$ & 0.875 & $\mathrm{LiNH}_{2}$ & 0.25 & & & $0.02^{\mathrm{C}}$ & & & & & \\
\hline $\mathrm{NaAlH}_{4}$ & 0.25 & $\mathrm{LiNH}_{2}$ & 0.62 & & & $0.02^{b}$ & & & & & \\
\hline $\mathrm{NaAlH}_{4}$ & 0.25 & $\mathrm{LiNH}_{2}$ & 0.62 & & & $0.02^{\mathrm{C}}$ & & & & & \\
\hline $\mathrm{NaAlH}_{4}$ & 0.25 & $\mathrm{LiNH}_{2}$ & 0.62 & & & $0.02^{c}$ & & & & & \\
\hline $\mathrm{NaAlH}_{4}$ & 0.4 & $\mathrm{LiNH}_{2}$ & 0.5 & & & $0.02^{b}$ & & & & & \\
\hline $\mathrm{NaAlH}_{4}$ & 0.25 & $\mathrm{LiNH}_{2}$ & 0.62 & $\mathrm{MgH}_{2}$ & 0.14 & $0.02^{b}$ & & & & & \\
\hline $\mathrm{NaAlH}_{4}$ & 0.25 & $\mathrm{LiNH}_{2}$ & 0.62 & $\mathrm{MgH}_{2}$ & 0.14 & $0.02^{c}$ & & & & & \\
\hline $\mathrm{NaAlH}_{4}$ & 0.25 & $\mathrm{LiNH}_{2}$ & 0.62 & $\mathrm{MgH}_{2}$ & 0.14 & $0.02^{\mathrm{C}}$ & & & & & \\
\hline $\mathrm{NaAlH}_{4}$ & 0.4 & $\mathrm{LiNH}_{2}$ & 0.5 & $\mathrm{MgH}_{2}$ & 0.2 & $0.02^{b}$ & & & & & \\
\hline
\end{tabular}




\begin{tabular}{|c|c|c|c|c|c|c|c|c|c|c|c|}
\hline \multicolumn{12}{|c|}{ Table 11b. Metal Alanate - Metal Amide - Metal hydride System: Compositions and spent structures } \\
\hline \multicolumn{7}{|c|}{ Composition } & \multirow{2}{*}{\multicolumn{5}{|c|}{ XRD of spent materials }} \\
\hline \multicolumn{2}{|c|}{ Metal alanates } & \multicolumn{2}{|c|}{ Metal amides } & \multicolumn{2}{|c|}{ Metal hydrides } & \multirow{2}{*}{$\begin{array}{l}\text { dopant } \\
\text { TiP }^{\mathrm{d}}\end{array}$} & & & & & \\
\hline $\mathrm{MAlH}_{4}$ & mol & $\mathrm{MNH}_{2}$ & mol & MH 1 & mol & & xrd 1 & xrd 2 & xrd 3 & xrd 4 & $\operatorname{xrd} 5$ \\
\hline $\mathrm{LiAlH}_{4}$ & 1 & $\mathrm{LiNH}_{2}$ & 1 & & & 0.02 & WC & $\mathrm{Al}$ & & & \\
\hline $\mathrm{LiAlH}_{4}$ & 2 & $\mathrm{LiNH}_{2}$ & 1 & & & 0.04 & $\mathrm{Al}$ & $\mathrm{AM}$ & & & \\
\hline $\mathrm{NaAlH}_{4}$ & 1 & $\mathrm{LiNH}_{2}$ & 1 & & & 0.02 & $\mathrm{NaH}$ & $\mathrm{LiH}$ & $\mathrm{Al}$ & & \\
\hline $\mathrm{NaAlH}_{4}$ & 2 & $\mathrm{LiNH}_{2}$ & 1 & & & 0.04 & $\mathrm{LiNa}_{2} \mathrm{AlH}_{6}$ & $\mathrm{NaH}$ & $\mathrm{LiH}$ & $\mathrm{NaAlH}_{4}$ & \\
\hline $\mathrm{LiAlH}_{4}$ & 1 & $\mathrm{NaNH}_{2}$ & 1 & & & 0.02 & $\mathrm{NaH}$ & $\mathrm{NaAlH}_{4}$ & & & \\
\hline $\mathrm{LiAlH}_{4}$ & 2 & $\mathrm{NaNH}_{2}$ & 1 & & & 0.04 & $\mathrm{LiNa}_{2} \mathrm{AlH}_{6}$ & WC & LiNH2 & $\mathrm{NaAlH}_{4}$ & \\
\hline $\mathrm{NaAlH}_{4}$ & 1 & $\mathrm{NaNH}_{2}$ & 1 & & & 0.02 & $\mathrm{NaH}$ & $\mathrm{Al}$ & & & \\
\hline $\mathrm{NaAlH}_{4}$ & 2 & $\mathrm{NaNH}_{2}$ & 1 & & & 0.04 & $\mathrm{NaH}$ & $\mathrm{Al}$ & & & \\
\hline $\mathrm{LiAlH}_{4}$ & 1 & $\mathrm{LiNH}_{2}$ & 2 & & & 0.02 & $\mathrm{LiNH}_{2}$ & $\mathrm{Li}_{2} \mathrm{NH}$ & Al & & \\
\hline $\mathrm{NaAlH}_{4}$ & 1 & $\mathrm{NaNH}_{2}$ & 2 & & & 0.02 & $\mathrm{NaH}$ & $\mathrm{NaAlH}_{4} / \mathrm{WC}$ & Unk., $d=3.34,2.35$ & & \\
\hline $\mathrm{LiAlH}_{4}$ & 1 & $\mathrm{LiNH}_{2}$ & 4 & & & & & & & & \\
\hline $\mathrm{LiAlH}_{4}$ & 1 & $\mathrm{LiNH}_{2}$ & 1 & & & 0.02 & & & & & \\
\hline $\mathrm{NaAlH}_{4}$ & 1 & $\mathrm{LiNH}_{2}$ & 4 & & & 0.02 & & & & & \\
\hline $\mathrm{NaAlH}_{4}$ & 1 & $\mathrm{LiNH}_{2}$ & 1 & & & 0.02 & & & & & \\
\hline $\mathrm{Mg}\left(\mathrm{AlH}_{4}\right)_{2}$ & 1 & $\mathrm{LiNH}_{2}$ & 2 & & & & & & & & \\
\hline $\mathrm{Mg}\left(\mathrm{AlH}_{4}\right)_{2}$ & 1 & $\mathrm{LiNH}_{2}$ & 2 & $\mathrm{KH}$ & 1 & & & & & & \\
\hline $\mathrm{NaAlH}_{4}$ & 1 & $\mathrm{LiNH}_{2}$ & 1 & & & 0.02 & $\mathrm{NaH}$ & $\mathrm{LiH}$ & $\mathrm{Al}$ & & \\
\hline $\mathrm{NaAlH}_{4}$ & 1 & $\mathrm{LiNH}_{2}$ & 2 & & & 0.02 & $\mathrm{NaH}$ & $\mathrm{Li}_{2} \mathrm{NH}$ & $\mathrm{Al}$ & unk., $d=3.33,3.17,2.67$ & \\
\hline $\mathrm{NaAlH}_{4}$ & 1 & $\mathrm{LiNH}_{2}$ & 4 & & & 0.02 & $\mathrm{Li}_{2} \mathrm{NH}$ & $\mathrm{LiNH}_{2}$ & $\mathrm{NaH}$ & $\mathrm{LiNa}_{2} \mathrm{AlH}_{6}$ & $\mathrm{Al}$ \\
\hline $\mathrm{NaAlH}_{4}$ & 1 & $\mathrm{LiNH}_{2}$ & 0.5 & & & 0.02 & $\mathrm{LiNa}_{2} \mathrm{AlH}_{6}$ & WC & $\mathrm{Na}_{3} \mathrm{AlH}_{6}$ & $\mathrm{Li}_{2} \mathrm{NH}$ & $\mathrm{Al}$ \\
\hline $\mathrm{NaAlH}_{4}$ & 1 & $\mathrm{LiNH}_{2}$ & 1 & & & & WC & $\mathrm{NaH}$ & $\mathrm{LiNa}_{2} \mathrm{AlH}_{6}$ & & \\
\hline $\mathrm{NaAlH}_{4}$ & 1 & $\mathrm{LiNH}_{2}$ & 2 & & & & $\mathrm{NaH}$ & WC & $\mathrm{Li}_{2} \mathrm{NH}$ & $\mathrm{LiOH}^{*} \mathrm{H}_{2} \mathrm{O}$ & $\mathrm{LiNa}_{2} \mathrm{AlH}_{6}$ \\
\hline $\mathrm{NaAlH}_{4}$ & 1 & $\mathrm{LiNH}_{2}$ & 4 & & & & $\mathrm{Li}_{2} \mathrm{NH}$ & $\mathrm{NaH}$ & WC & & \\
\hline $\mathrm{NaAlH}_{4}$ & 1 & $\mathrm{LiNH}_{2}$ & 0.5 & & & & $\mathrm{LiNa}_{2} \mathrm{AlH}_{6}$ & $\mathrm{NaH}$ & $\mathrm{Na}_{3} \mathrm{AlH}_{6}$ & $\mathrm{Al}$ & $\mathrm{Li}_{2} \mathrm{NH}$ \\
\hline $\mathrm{NaAlH}_{4}$ & 1 & $\mathrm{NaNH}_{2}$ & 1 & & & 0.02 & $\mathrm{NaNH}_{2} / \mathrm{Na}_{2} \mathrm{NH}$ & $\mathrm{NaH}$ & & & \\
\hline $\mathrm{NaAlH}_{4}$ & 1 & $\mathrm{NaNH}_{2}$ & 2 & & & 0.02 & $\mathrm{NaNH}_{2} / \mathrm{Na}_{2} \mathrm{NH}$ & $\mathrm{NaH}$ & & & \\
\hline $\mathrm{NaAlH}_{4}$ & 1 & $\mathrm{NaNH}_{2}$ & 4 & & & 0.02 & $\mathrm{NaH}$ & $\mathrm{NaNH}_{2}$ & WC & & \\
\hline $\mathrm{NaAlH}_{4}$ & 1 & $\mathrm{NaNH}_{2}$ & 0.5 & & & 0.02 & $\mathrm{NaNH}_{2} / \mathrm{Na}_{2} \mathrm{NH}$ & $\mathrm{NaH}$ & WC & & \\
\hline $\mathrm{NaAlH}_{4}$ & 1 & $\mathrm{LiNH}_{2}$ & 1 & $\mathrm{NaH}$ & 1 & 0.02 & $\mathrm{NaH}$ & $\begin{array}{l}\text { unk., } d=2.55,2.35 \\
2.10,1.92\end{array}$ & & & \\
\hline $\mathrm{NaAlH}_{4}$ & 1 & $\mathrm{LiNH}_{2}$ & 1 & $\mathrm{LiH}$ & 1 & 0.02 & $\mathrm{NaH}$ & $\mathrm{Na}_{3} \mathrm{AlH}_{6}$ & $\mathrm{LiNa}_{2} \mathrm{AlH}_{6}$ & unk., $d=2.55,2.35,2.10,2.05$ & \\
\hline $\mathrm{NaAlH}_{4}$ & 1 & $\mathrm{LiNH}_{2}$ & 2 & $\mathrm{LiH}$ & 1 & 0.02 & WC & $\mathrm{NaH}$ & $\mathrm{Na}_{3} \mathrm{AlH}_{6}$ & $\mathrm{LiNa}_{2} \mathrm{AlH}_{6}$ & \\
\hline $\mathrm{NaAlH}_{4}$ & 1 & $\mathrm{LiNH}_{2}$ & 2 & $\mathrm{NaH}$ & 1 & 0.02 & $\mathrm{NaH}$ & WC & $\mathrm{Na}_{3} \mathrm{AlH}_{6}$ & $\mathrm{LiNa}_{2} \mathrm{AlH}_{6}$ & \\
\hline $\mathrm{Mg}\left(\mathrm{AlH}_{4}\right)_{2}$ & 1 & $\mathrm{LiNH}_{2}$ & 1 & & & & $\mathrm{Al}$ & $\mathrm{MgH}_{2}$ & $\mathrm{NaCl}$ & & \\
\hline $\mathrm{Mg}\left(\mathrm{AlH}_{4}\right)_{2}$ & 1 & $\mathrm{LiNH}_{2}$ & 2 & & & & $\mathrm{Al}$ & $\mathrm{NaCl}$ & & & \\
\hline $\mathrm{Mg}\left(\mathrm{AlH}_{4}\right)_{2}$ & 1 & $\mathrm{LiNH}_{2}$ & 4 & & & & $\mathrm{Al}$ & $\mathrm{Li}_{2} \mathrm{NH}$ & WC & & \\
\hline $\mathrm{Mg}\left(\mathrm{AlH}_{4}\right)_{2}$ & 1 & $\mathrm{LiNH}_{2}$ & 8 & & & & $\mathrm{Li}_{2} \mathrm{NH}$ & $\mathrm{LiNH}_{2}$ & $\mathrm{Al}$ & $\mathrm{MgH}_{2}(\mathrm{tr})$ & \\
\hline $\mathrm{Mg}\left(\mathrm{AlH}_{4}\right)_{2}$ & 1 & $\mathrm{NaNH}_{2}$ & 1 & & & & $\mathrm{Al}$ & $\mathrm{NaMgH}_{3}$ & $\mathrm{NaCl}$ & & \\
\hline $\mathrm{Mg}\left(\mathrm{AlH}_{4}\right)_{2}$ & 1 & $\mathrm{NaNH}_{2}$ & 2 & & & & $\mathrm{NaMgH}_{3}$ & $\mathrm{Na}_{3} \mathrm{AlH}_{6}$ & $\mathrm{NaCl}$ & & \\
\hline $\mathrm{Mg}\left(\mathrm{AlH}_{4}\right)_{2}$ & 1 & $\mathrm{NaNH}_{2}$ & 4 & & & & $\mathrm{NaH}$ & $\mathrm{Al}$ & $\mathrm{NaMgH}_{3}$ & $\mathrm{NaCl}$ & $\mathrm{Na}_{3} \mathrm{AlH}_{6}$ \\
\hline $\mathrm{Mg}\left(\mathrm{AlH}_{4}\right)_{2}$ & 1 & $\mathrm{NaNH}_{2}$ & 8 & & & & $\mathrm{NaH}$ & $\mathrm{Al}$ & WC & $\mathrm{NaCl}$ & \\
\hline
\end{tabular}




\begin{tabular}{|c|c|c|c|c|c|c|c|c|c|c|c|}
\hline \multicolumn{7}{|c|}{ Composition } & \multirow{2}{*}{\multicolumn{5}{|c|}{ XRD of spent materials }} \\
\hline \multicolumn{2}{|c|}{ Metal alanates } & \multicolumn{2}{|c|}{ Metal amides } & \multicolumn{2}{|c|}{ Metal hydrides } & \multirow{2}{*}{$\begin{array}{l}\text { dopant } \\
\mathrm{TiP}^{\mathrm{d}}\end{array}$} & & & & & \\
\hline $\mathrm{MAIH}_{4}$ & $\mathrm{~mol}$ & $\mathrm{MNH}_{2}$ & $\mathrm{~mol}$ & MH 1 & mol & & xrd 1 & xrd 2 & xrd 3 & xrd 4 & xrd 5 \\
\hline $\mathrm{NaAlH}_{4}$ & 1 & $\mathrm{LiNH}_{2}$ & 4 & $\mathrm{MgH}_{2}$ & 2.2 & $0.02^{\mathrm{a}}$ & $\mathrm{Li}_{2} \mathrm{Mg}(\mathrm{NH})_{2}$ & $\mathrm{NaH}$ & $\mathrm{NaMgH}_{3}$ & $\mathrm{Na}_{3} \mathrm{AlH}_{6}$ & $\mathrm{MgH}_{2}$ \\
\hline Al-NP & 1 & $\mathrm{LiNH}_{2}$ & 4 & $\mathrm{MgH}_{2} / \mathrm{NaH}$ & $2.2 / 1$ & 0.02 & $\mathrm{Li}_{2} \mathrm{Mg}(\mathrm{NH})_{2}$ & $\mathrm{NaH}$ & $\mathrm{Al}$ & $\mathrm{NaMgH}_{3}$ & \\
\hline $\mathrm{NaAlH}_{4}$ & 1 & $\mathrm{NaNH}_{2}$ & 4 & $\mathrm{MgH}_{2}$ & 2.2 & $0.02^{\mathrm{a}}$ & $\mathrm{NaH}$ & WC & $\mathrm{NaMgH}_{3}$ & $\mathrm{Na3AlH}_{6}$ & \\
\hline Al-NP & 1 & $\mathrm{NaNH}_{2}$ & 4 & $\mathrm{MgH}_{2} / \mathrm{NaH}$ & $2.2 / 1$ & 0.02 & $\mathrm{NaH}$ & $\mathrm{NaNH}_{2}$ & $\mathrm{NaMgH}_{3}$ & $\mathrm{Al}$ & \\
\hline Al-NP & 1 & $\mathrm{LiNH}_{2}$ & 4 & $\mathrm{MgH}_{2} / \mathrm{KH}$ & $2.2 / 1$ & 0.02 & & & & & \\
\hline $\mathrm{LiAlH}_{4}$ & 0.5 & $\mathrm{NaNH}_{2}$ & 0.5 & & & 0.02 & $\mathrm{NaH}$ & & & & \\
\hline $\mathrm{LiAlH}_{4}$ & 0.67 & $\mathrm{NaNH}_{2}$ & 0.33 & & & 0.02 & $\mathrm{LiNa}_{2} \mathrm{AlH}_{6}$ & $\mathrm{NaH}$ & $\mathrm{Al}$ & $\mathrm{Li}_{2} \mathrm{NH}$ & \\
\hline $\mathrm{LiAlH}_{4}$ & 0.33 & $\mathrm{NaNH}_{2}$ & 0.67 & & & 0.02 & $\mathrm{NaBH}_{4}$ & $\mathrm{NaH}$ & WC & & \\
\hline $\mathrm{LiAlH}_{4}$ & 2 & $\mathrm{Mg}\left(\mathrm{NH}_{2}\right)_{2}$ & 1 & & & & $\mathrm{Al}$ & WC & $\mathrm{Li}_{3} \mathrm{AIN}_{2}$ & $\mathrm{MgH}_{2}$ & \\
\hline $\mathrm{NaAlH}_{4}$ & 1 & $\mathrm{Mg}\left(\mathrm{NH}_{2}\right)_{2}$ & 0.5 & $\mathrm{LiNH}_{2} / \mathrm{MgH}_{2}$ & $1 / 0.55$ & 0.02 & WC & $\mathrm{NaH}$ & $\mathrm{Na3AlH}_{6}$ & $\mathrm{NaMgH}_{3}$ & \\
\hline $\mathrm{LiAlH}_{4}$ & 2 & $\mathrm{Mg}\left(\mathrm{NH}_{2}\right)_{2}$ & 2.2 & $\mathrm{LiH}$ & 4 & & & & & & \\
\hline $\mathrm{LiAlH}_{4}$ & 1 & $\mathrm{Mg}\left(\mathrm{NH}_{2}\right)_{2}$ & 2.2 & $\mathrm{LiH}$ & 5 & & & & & & \\
\hline $\mathrm{LiAlH}_{4}$ & 1 & $\mathrm{LiNH}_{2}$ & 1 & & & 0.02 & $\mathrm{Al}$ & $\mathrm{Li}_{2} \mathrm{NH}$ & & & \\
\hline $\mathrm{LiAlH}_{4}$ & 1 & $\mathrm{LiNH}_{2}$ & 4 & & & & $\mathrm{Li}_{2} \mathrm{NH}$ & $\mathrm{Al}$ & $\mathrm{Li}_{3} \mathrm{AlH}_{6}$ & & \\
\hline $\mathrm{LiAlH}_{4}$ & 1 & $\mathrm{LiNH}_{2}$ & 4 & & & 0.02 & $\mathrm{Li}_{2} \mathrm{NH}$ & $\mathrm{Al}$ & $\mathrm{Li}_{3} \mathrm{AlH}{ }_{6}$ & & \\
\hline $\mathrm{LiAlH}_{4}$ & 1 & $\mathrm{LiNH}_{2}$ & 6 & $\mathrm{MgH}_{2}$ & 1.1 & 0.02 & $\mathrm{Li}_{2} \mathrm{NH}$ & $\mathrm{MgH}_{2}$ & $\mathrm{Li}_{2} \mathrm{Mg}(\mathrm{NH})_{2}$ & & \\
\hline $\mathrm{LiAlH}_{4}$ & 1 & $\mathrm{LiNH}_{2}$ & 5 & $\mathrm{NaAlH}_{4}$ & 1 & 0.02 & $\mathrm{Li}_{2} \mathrm{NH}$ & $\mathrm{LiNH}_{2}$ & $\mathrm{Li}_{3} \mathrm{Na}\left(\mathrm{NH}_{2}\right)_{4}$ & $\mathrm{Na}_{3} \mathrm{AlH}_{6}$ & \\
\hline $\mathrm{LiAlH}_{4}$ & 1 & $\mathrm{LiNH}_{2}$ & 6 & & & 0.02 & $\mathrm{Li}_{2} \mathrm{NH}$ & $\mathrm{MgH}_{2}$ & $\mathrm{TiH}_{2}$ & $\mathrm{Al}$ & \\
\hline $\mathrm{NaAlH}_{4}$ & 0.875 & $\mathrm{LiNH}_{2}$ & 0.125 & & & $0.02^{b}$ & & & & & \\
\hline $\mathrm{NaAlH}_{4}$ & 0.875 & $\mathrm{LiNH}_{2}$ & 0.125 & & & $0.02^{c}$ & & & & & \\
\hline $\mathrm{NaAlH}_{4}$ & 0.875 & $\mathrm{LiNH}_{2}$ & 0.125 & & & $0.02^{b}$ & & & & & \\
\hline $\mathrm{NaAlH}_{4}$ & 0.875 & $\mathrm{LiNH}_{2}$ & 0.25 & & & $0.02^{\mathrm{c}}$ & & & & & \\
\hline $\mathrm{NaAlH}_{4}$ & 0.25 & $\mathrm{LiNH}_{2}$ & 0.62 & & & $0.02^{b}$ & & & & & \\
\hline $\mathrm{NaAlH}_{4}$ & 0.25 & $\mathrm{LiNH}_{2}$ & 0.62 & & & $0.02^{\mathrm{C}}$ & & & & & \\
\hline $\mathrm{NaAlH}_{4}$ & 0.25 & $\mathrm{LiNH}_{2}$ & 0.62 & & & $0.02^{\mathrm{C}}$ & & & & & \\
\hline $\mathrm{NaAlH}_{4}$ & 0.4 & $\mathrm{LiNH}_{2}$ & 0.5 & & & $0.02^{b}$ & & & & & \\
\hline $\mathrm{NaAlH}_{4}$ & 0.25 & $\mathrm{LiNH}_{2}$ & 0.62 & $\mathrm{MgH}_{2}$ & 0.14 & $0.02^{b}$ & & & & & \\
\hline $\mathrm{NaAlH}_{4}$ & 0.25 & $\mathrm{LiNH}_{2}$ & 0.62 & $\mathrm{MgH}_{2}$ & 0.14 & $0.02^{\mathrm{C}}$ & & & & & \\
\hline $\mathrm{NaAlH}_{4}$ & 0.25 & $\mathrm{LiNH}_{2}$ & 0.62 & $\mathrm{MgH}_{2}$ & 0.14 & $0.02^{\mathrm{C}}$ & & & & & \\
\hline $\mathrm{NaAlH}_{4}$ & 0.4 & $\mathrm{LiNH}_{2}$ & 0.5 & $\mathrm{MgH}_{2}$ & 0.2 & $0.02^{b}$ & & & & & \\
\hline
\end{tabular}




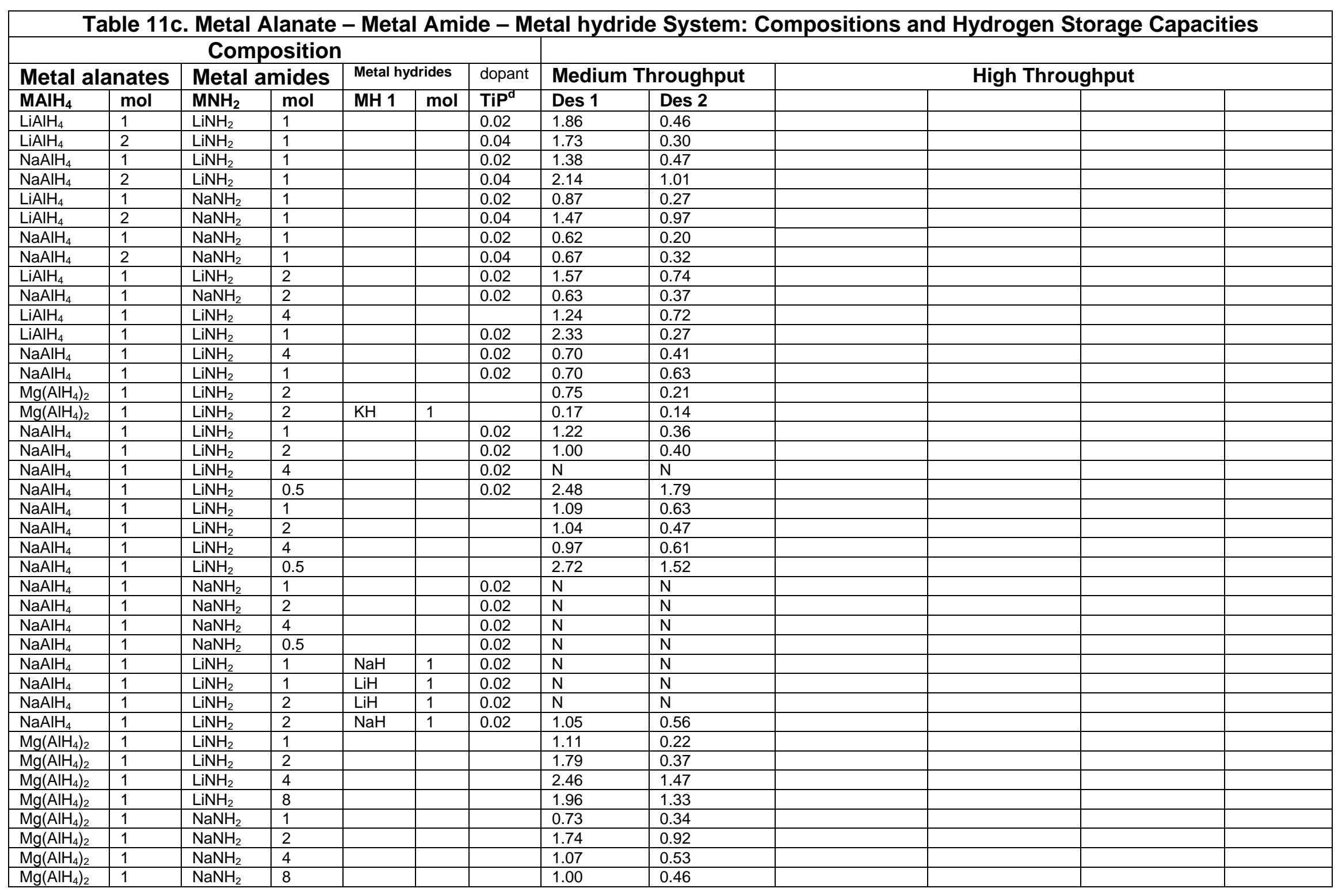




\begin{tabular}{|c|c|c|c|c|c|c|c|c|c|c|c|c|}
\hline \multicolumn{7}{|c|}{ Composition } & \multicolumn{6}{|c|}{ Hydrogen Storage Capacity (wt. \%) } \\
\hline \multicolumn{2}{|c|}{ Metal alanates } & \multicolumn{2}{|c|}{ Metal amides } & \multicolumn{2}{|c|}{ Metal hydrides } & \multirow{2}{*}{$\begin{array}{l}\text { dopant } \\
\text { TiP }^{\mathrm{d}}\end{array}$} & \multicolumn{2}{|c|}{ Medium Throughput } & \multicolumn{4}{|c|}{ High Throughput (Des T) } \\
\hline $\mathrm{MAIH}_{4}$ & mol & $\mathrm{MNH}_{2}$ & mol & MH 1 & mol & & Des 1 & Des 2 & $230^{\circ} \mathrm{C}$ & $230^{\circ} \mathrm{C}$ & $350^{\circ} \mathrm{C}$ & $350^{\circ} \mathrm{C}$ \\
\hline $\mathrm{NaAlH}_{4}$ & 1 & $\mathrm{LiNH}_{2}$ & 4 & $\mathrm{MgH}_{2}$ & 2.2 & $0.02^{\mathrm{a}}$ & 2.69 & 1.08 & & & & \\
\hline Al-NP & 1 & $\mathrm{LiNH}_{2}$ & 4 & $\mathrm{MgH}_{2} / \mathrm{NaH}$ & $2.2 / 1$ & 0.02 & 3.45 & 1.49 & & & & \\
\hline $\mathrm{NaAlH}_{4}$ & 1 & $\mathrm{NaNH}_{2}$ & 4 & $\mathrm{MgH}_{2}$ & 2.2 & $0.02^{\mathrm{a}}$ & 1.00 & 0.41 & & & & \\
\hline Al-NP & 1 & $\mathrm{NaNH}_{2}$ & 4 & $\mathrm{MgH}_{2} / \mathrm{NaH}$ & $2.2 / 1$ & 0.02 & 0.88 & 0.37 & & & & \\
\hline Al-NP & 1 & $\mathrm{LiNH}_{2}$ & 4 & $\mathrm{MgH}_{2} / \mathrm{KH}$ & $2.2 / 1$ & 0.02 & 3.16 & 1.40 & & & & \\
\hline $\mathrm{LiAlH}_{4}$ & 0.5 & $\mathrm{NaNH}_{2}$ & 0.5 & & & 0.02 & 1.26 & 0.26 & & & & \\
\hline $\mathrm{LiAlH}_{4}$ & 0.67 & $\mathrm{NaNH}_{2}$ & 0.33 & & & 0.02 & 1.68 & 0.95 & & & & \\
\hline $\mathrm{LiAlH}_{4}$ & 0.33 & $\mathrm{NaNH}_{2}$ & 0.67 & & & 0.02 & 0.94 & 0.38 & & & & \\
\hline $\mathrm{LiAlH}_{4}$ & 2 & $\mathrm{Mg}\left(\mathrm{NH}_{2}\right)_{2}$ & 1 & & & & 0.86 & 0.24 & & & & \\
\hline $\mathrm{NaAlH}_{4}$ & 1 & $\mathrm{Mg}\left(\mathrm{NH}_{2}\right)_{2}$ & 0.5 & $\mathrm{LiNH}_{2} / \mathrm{MgH}_{2}$ & $1 / 0.55$ & 0.02 & 1.28 & 0.35 & & & & \\
\hline $\mathrm{LiAlH}_{4}$ & 2 & $\mathrm{Mg}\left(\mathrm{NH}_{2}\right)_{2}$ & 2.2 & $\mathrm{LiH}$ & 4 & & 0.61 & 0.07 & & & & \\
\hline $\mathrm{LiAlH}_{4}$ & 1 & $\mathrm{Mg}\left(\mathrm{NH}_{2}\right)_{2}$ & 2.2 & $\mathrm{LiH}$ & 5 & & $\mathrm{~N}$ & $\mathrm{~N}$ & & & & \\
\hline $\mathrm{LiAlH}_{4}$ & 1 & $\mathrm{LiNH}_{2}$ & 1 & & & 0.02 & 2.15 & 0.45 & & & & \\
\hline $\mathrm{LiAlH}_{4}$ & 1 & $\mathrm{LiNH}_{2}$ & 4 & & & & 1.29 & 0.52 & & & & \\
\hline $\mathrm{LiAlH}_{4}$ & 1 & $\mathrm{LiNH}_{2}$ & 4 & & & 0.02 & 1.04 & 0.49 & & & & \\
\hline $\mathrm{LiAlH}_{4}$ & 1 & $\mathrm{LiNH}_{2}$ & 6 & $\mathrm{MgH}_{2}$ & 1.1 & 0.02 & 1.61 & 0.92 & & & & \\
\hline $\mathrm{LiAlH}_{4}$ & 1 & $\mathrm{LiNH}_{2}$ & 5 & $\mathrm{NaAlH}_{4}$ & 1 & 0.02 & 1.48 & 0.81 & & & & \\
\hline $\mathrm{LiAlH}_{4}$ & 1 & $\mathrm{LiNH}_{2}$ & 6 & & & 0.02 & 1.43 & 0.74 & & & & \\
\hline $\mathrm{NaAlH}_{4}$ & 0.875 & $\mathrm{LiNH}_{2}$ & 0.125 & & & $0.02^{b}$ & $\mathrm{~N}$ & $\mathrm{~N}$ & 4.51 & 3.31 & 3.31 & 3.00 \\
\hline $\mathrm{NaAlH}_{4}$ & 0.875 & $\mathrm{LiNH}_{2}$ & 0.125 & & & $0.02^{\mathrm{C}}$ & $\mathrm{N}$ & $\mathrm{N}$ & 3.65 & 2.93 & 3.05 & B \\
\hline $\mathrm{NaAlH}_{4}$ & 0.875 & $\mathrm{LiNH}_{2}$ & 0.125 & & & $0.02^{b}$ & $\mathrm{~N}$ & $\mathrm{~N}$ & 4.00 & 2.99 & 3.15 & 2.47 \\
\hline $\mathrm{NaAlH}_{4}$ & 0.875 & $\mathrm{LiNH}_{2}$ & 0.25 & & & $0.02^{\mathrm{C}}$ & $\mathrm{N}$ & $\mathrm{N}$ & 3.48 & 3.12 & 3.61 & 2.54 \\
\hline $\mathrm{NaAlH}_{4}$ & 0.25 & $\mathrm{LiNH}_{2}$ & 0.62 & & & $0.02^{b}$ & $\mathrm{~N}$ & $\mathrm{~N}$ & 0.35 & 1.88 & 2.46 & $\mathrm{~N}$ \\
\hline $\mathrm{NaAlH}_{4}$ & 0.25 & $\mathrm{LiNH}_{2}$ & 0.62 & & & $0.02^{C}$ & $\mathrm{~N}$ & $\mathrm{~N}$ & 0.97 & 0.31 & 2.00 & 0.34 \\
\hline $\mathrm{NaAlH}_{4}$ & 0.25 & $\mathrm{LiNH}_{2}$ & 0.62 & & & $0.02^{\mathrm{C}}$ & $\mathrm{N}$ & $\mathrm{N}$ & 1.95 & 1.00 & 2.02 & 0.82 \\
\hline $\mathrm{NaAlH}_{4}$ & 0.4 & $\mathrm{LiNH}_{2}$ & 0.5 & & & $0.02^{b}$ & $\mathrm{~N}$ & $\mathrm{~N}$ & 2.19 & 0.76 & 1.32 & 0.34 \\
\hline $\mathrm{NaAlH}_{4}$ & 0.25 & $\mathrm{LiNH}_{2}$ & 0.62 & $\mathrm{MgH}_{2}$ & 0.14 & $0.02^{b}$ & $\mathrm{~N}$ & $\mathrm{~N}$ & 2.36 & 0.88 & 1.69 & 0.63 \\
\hline $\mathrm{NaAlH}_{4}$ & 0.25 & $\mathrm{LiNH}_{2}$ & 0.62 & $\mathrm{MgH}_{2}$ & 0.14 & $0.02^{\mathrm{C}}$ & $\mathrm{N}$ & $\mathrm{N}$ & 1.80 & 0.72 & 2.24 & 0.94 \\
\hline $\mathrm{NaAlH}_{4}$ & 0.25 & $\mathrm{LiNH}_{2}$ & 0.62 & $\mathrm{MgH}_{2}$ & 0.14 & $0.02^{\mathrm{C}}$ & $\mathrm{N}$ & $\mathrm{N}$ & 1.72 & 0.75 & 2.22 & 0.79 \\
\hline $\mathrm{NaAlH}_{4}$ & 0.4 & $\mathrm{LiNH}_{2}$ & 0.5 & $\mathrm{MgH}_{2}$ & 0.2 & $0.02^{b}$ & $\mathrm{~N}$ & $\mathrm{~N}$ & 1.63 & 0.52 & 1.48 & 0.26 \\
\hline
\end{tabular}




\begin{tabular}{|c|c|c|c|c|c|c|c|c|c|c|c|c|c|c|}
\hline \multicolumn{4}{|c|}{ Composition } & \multicolumn{4}{|c|}{ As-synthesized XRD } & \multicolumn{5}{|c|}{ Spent material XRD } & \multicolumn{2}{|c|}{$\begin{array}{c}\text { Hydrogen } \\
\text { Storage } \\
\text { Capacity (wt. } \\
\% \text { ) }\end{array}$} \\
\hline $\mathrm{NaAlH}_{4}$ & $\mathrm{MBH}_{4}$ & mol & $\mathrm{Ti}(\mathrm{OiPr})_{4}$ & xrd 1 & $\operatorname{xrd} 2$ & xrd 3 & $\operatorname{xrd} 4$ & xrd 1 & xrd 2 & xrd 3 & $\operatorname{xrd} 4$ & xrd 5 & Des 1 & Des 2 \\
\hline 0 & $\mathrm{LiBH}_{4}$ & 1 & 0.02 & $\mathrm{LiBH}_{4}$ & B & & & $\mathrm{LiBH}_{4}$ & C & & & & 0.56 & 0.07 \\
\hline 0.2 & $\mathrm{LiBH}_{4}$ & 0.8 & 0.02 & $\mathrm{NaBH}_{4}$ & $\mathrm{NaAlH}_{4}$ & $\mathrm{Al}$ & $\mathrm{LiBH}_{4}$ & $\mathrm{NaAlH}_{4}$ & $\mathrm{NaBH}_{4}$ & $\mathrm{LiBH}_{4}$ & $\mathrm{Al}$ & $\mathrm{Li}_{3} \mathrm{AlH}_{6}$ & 1.57 & 0.17 \\
\hline 0.33 & $\mathrm{LiBH}_{4}$ & 0.67 & 0.02 & $\mathrm{NaAlH}_{4}$ & $\mathrm{NaBH}_{4}$ & $\mathrm{Al}$ & $\mathrm{LiBH}_{4}$ & $\mathrm{NaAlH}_{4}$ & $\mathrm{NaBH}_{4}$ & $\mathrm{Al}$ & $\mathrm{LiBH}_{4}$ & $\mathrm{Li}_{3} \mathrm{AlH}_{6}$ & 2.31 & 0.03 \\
\hline 0.4 & $\mathrm{LiBH}_{4}$ & 0.6 & 0.02 & $\mathrm{NaAlH}_{4}$ & $\mathrm{NaBH}_{4}$ & $\mathrm{Al}$ & $\mathrm{LiBH}_{4}$ & $\mathrm{NaAlH}_{4}$ & $\mathrm{NaBH}_{4}$ & $\mathrm{Al}$ & $\mathrm{LiBH}_{4}$ & $\mathrm{Li}_{3} \mathrm{AlH}_{6}$ & 2.53 & 0.07 \\
\hline 0.5 & $\mathrm{LiBH}_{4}$ & 0.5 & 0.02 & $\mathrm{NaBH}_{4}$ & $\mathrm{Al}$ & $\mathrm{NaAlH}_{4}$ & $\mathrm{Li}_{3} \mathrm{AlH}_{6}$ & $\mathrm{D}$ & $\mathrm{Al}$ & $\mathrm{NaBH}_{4}$ & $\mathrm{NaAlH}_{4}$ & & 1.86 & 0.05 \\
\hline 0.6 & $\mathrm{LiBH}_{4}$ & 0.4 & 0.02 & $\mathrm{~B}$ & & & & $\mathrm{NaAlH}_{4}$ & $\mathrm{NaBH}_{4}$ & $\mathrm{Al}$ & $\mathrm{E}$ & $\mathrm{Li}_{3} \mathrm{AlH}_{6}$ (tr) & 2.52 & 0.61 \\
\hline 0.67 & $\mathrm{LiBH}_{4}$ & 0.33 & 0.02 & $\mathrm{NaAlH}_{4}$ & $\mathrm{NaBH}_{4}$ & $\mathrm{Al}$ & $\mathrm{LiNa}_{2} \mathrm{AlH}_{6}$ & $\mathrm{NaAlH}_{4}$ & $\mathrm{NaBH}_{4}$ & $\mathrm{Al}$ & $\mathrm{Li}_{3} \mathrm{AlH}_{6}$ & & 2.98 & 0.99 \\
\hline 0.8 & $\mathrm{LiBH}_{4}$ & 0.2 & 0.02 & $\mathrm{Al}$ & $\mathrm{AlB}_{2}$ & $\mathrm{NaAlH}_{4}$ & $\mathrm{NaBH}_{4}$ & $\mathrm{Al}$ & $\mathrm{Mg}\left(\mathrm{AlH}_{4}\right)_{2}$ & $\mathrm{NaAlH}_{4}$ & $\mathrm{~F}$ & & 3.73 & 2.09 \\
\hline 0 & $\mathrm{NaBH}_{4}$ & 1 & 0.02 & & & & & & & & & & 0.21 & 0.06 \\
\hline 0.2 & $\mathrm{NaBH}_{4}$ & 0.8 & 0.02 & & & & & & & & & & 0.98 & 0.32 \\
\hline 0.4 & $\mathrm{NaBH}_{4}$ & 0.6 & 0.02 & & & & & & & & & & 2.01 & 0.66 \\
\hline 0.6 & $\mathrm{NaBH}_{4}$ & 0.4 & 0.02 & & & & & & & & & & 3.02 & 1.22 \\
\hline 0.8 & $\mathrm{NaBH}_{4}$ & 0.2 & 0.02 & $\mathrm{NaAlH}_{4}$ & $\mathrm{Na}_{3} \mathrm{AlH}_{6}$ & $\mathrm{NaBH}_{4}$ & $\mathrm{Al}$ & & & & & & 3.30 & 2.64 \\
\hline 0.33 & $\mathrm{NaBH}_{4}$ & 0.67 & 0.02 & $\mathrm{NaBH}_{4}$ & $\mathrm{NaAlH}_{4}$ & $\mathrm{Na}_{3} \mathrm{AlH}_{6}$ & $\mathrm{Al}$ & & & & & & 1.70 & 0.61 \\
\hline $1^{\mathrm{a}}$ & $\mathrm{LiBH}_{4}$ & 1 & & & & & & & & & & & 0.27 & 0.09 \\
\hline
\end{tabular}




\begin{tabular}{|c|c|c|c|c|c|c|c|c|c|c|c|c|c|}
\hline \multicolumn{7}{|c|}{ Composition } & \multicolumn{5}{|c|}{ XRD of Spent Materials } & \multicolumn{2}{|c|}{$\begin{array}{c}\text { Hydrogen } \\
\text { Storage } \\
\text { Capacity } \\
\text { (Wt.\%) }\end{array}$} \\
\hline M-AlH 6 & mol & M-H 1 & mol & M-H 2 & mol & $\mathrm{Ti}(\mathrm{OiPr})_{4}$ & xrd 1 & xrd 2 & xrd 3 & xrd 4 & xrd 5 & Des 1 & Des 2 \\
\hline $\mathrm{Na}_{3} \mathrm{AlH}_{6}$ & 0.50 & $\mathrm{MgH}_{2}$ & 0.50 & & & 0 & $\mathrm{NaMgH}_{3}$ & $\mathrm{Na}_{3} \mathrm{AlH}_{6}$ & $\mathrm{Al}$ & $\mathrm{NaH}$ & WC & 2.10 & 1.33 \\
\hline $\mathrm{Na}_{3} \mathrm{AlH}_{6}$ & 0.50 & $\mathrm{LiNH}_{2}$ & 0.50 & & & 0 & $\mathrm{NaH}$ & WC & $\mathrm{Al}(\mathrm{tr})$ & & & 0.83 & 0.16 \\
\hline $\mathrm{Na}_{3} \mathrm{AlH}_{6}$ & 0.50 & $\mathrm{LiBH}_{4}$ & 0.50 & & & 0 & $\mathrm{LiNa}_{2} \mathrm{AlH}_{6}$ & $\mathrm{NaBH}_{4}$ & $\mathrm{NaH}$ & $\mathrm{Al}$ & WC & 2.27 & 2.04 \\
\hline $\mathrm{Na}_{3} \mathrm{AlH} \mathrm{H}_{6}$ & 0.50 & $\mathrm{LiAlH}_{4}$ & 0.50 & & & 0 & & & & & & 1.83 & 1.05 \\
\hline $\mathrm{Na}_{3} \mathrm{AlH}_{6}$ & 0.50 & $\mathrm{MgH}_{2}$ & 0.50 & & & 0.02 & & & & & & 2.01 & 1.43 \\
\hline $\mathrm{Na}_{3} \mathrm{AlH}_{6}$ & 0.25 & $\mathrm{MgH}_{2}$ & 0.75 & & & 0.02 & & & & & & 1.45 & 0.19 \\
\hline $\mathrm{Na}_{3} \mathrm{AlH}_{6}$ & 0.75 & $\mathrm{MgH}_{2}$ & 0.25 & & & 0.02 & & & & & & 2.53 & 2.03 \\
\hline $\mathrm{Na}_{3} \mathrm{AlH}_{6}$ & 0.50 & $\mathrm{LiNH}_{2}$ & 0.50 & & & 0.02 & & & & & & 1.04 & 0.19 \\
\hline $\mathrm{Na}_{3} \mathrm{AlH}_{6}$ & 0.25 & $\mathrm{LiNH}_{2}$ & 0.75 & & & 0.02 & $\mathrm{NaH}$ & $\mathrm{Li}_{2} \mathrm{NH}$ & $\mathrm{Al}(\mathrm{tr})$ & & & 0.96 & 0.30 \\
\hline $\mathrm{Na}_{3} \mathrm{AlH}_{6}$ & 0.75 & $\mathrm{LiNH}_{2}$ & 0.25 & & & 0.02 & $\mathrm{NaH}$ & $\mathrm{LiNa}_{2} \mathrm{AlH}_{6}$ & $\mathrm{Al}(\mathrm{tr})$ & WC & & 0.78 & 0.59 \\
\hline $\mathrm{Na}_{3} \mathrm{AlH}_{6}$ & 0.50 & $\mathrm{LiBH}_{4}$ & 0.50 & & & 0.02 & $\mathrm{LiNa}_{2} \mathrm{AlH}_{6}$ & $\mathrm{NaBH}_{4}$ & $\mathrm{NaH}$ & $\mathrm{Al}$ & WC & 2.05 & 1.55 \\
\hline $\mathrm{Na}_{3} \mathrm{AlH}{ }_{6}$ & 0.25 & $\mathrm{LiBH}_{4}$ & 0.75 & & & 0.02 & $\mathrm{NaBH}_{4}$ & $\mathrm{Al}$ & $\mathrm{NaH}$ & WC & & 0.22 & 0.17 \\
\hline $\mathrm{Na}_{3} \mathrm{AlH}$ & 0.75 & $\mathrm{LiBH}_{4}$ & 0.25 & & & 0.02 & $\mathrm{LiNa}_{2} \mathrm{AlH}_{6}$ & $\mathrm{Na}_{3} \mathrm{AlH}_{6}$ & $\mathrm{NaH}$ & $\mathrm{NaBH}_{4}$ & WC & 2.31 & 1.88 \\
\hline $\mathrm{Na}_{3} \mathrm{AlH}_{6}$ & 0.50 & $\mathrm{LiAlH}_{4}$ & 0.50 & & & 0.02 & $\mathrm{LiNa}_{2} \mathrm{AlH}_{6}$ & $\mathrm{Na}_{3} \mathrm{AlH}_{6}$ & $\mathrm{NaH}$ & $\mathrm{NaAlH}_{4}$ & & 3.81 & 2.82 \\
\hline $\mathrm{Na}_{3} \mathrm{AlH}_{6}$ & 0.25 & $\mathrm{LiAlH}_{4}$ & 0.75 & & & 0.02 & WC & $\mathrm{LiNa}_{2} \mathrm{AlH}_{6}$ & & & & $\mathrm{~N}$ & $\mathrm{~N}$ \\
\hline $\mathrm{Na}_{3} \mathrm{AlH}_{6}$ & 0.75 & $\mathrm{LiAlH}_{4}$ & 0.25 & & & 0.02 & $f$ & & & & & 2.90 & 2.50 \\
\hline $\mathrm{Na}_{2} \mathrm{LiAlH}_{6}$ & 0.50 & $\mathrm{MgH}_{2}$ & 0.50 & & & & $\mathrm{Na}_{3} \mathrm{AlH}_{6}$ & $\mathrm{LiNa}_{2} \mathrm{AlH}_{6}$ & $\mathrm{MgH}_{2}$ (tr) & & & 2.56 & 1.46 \\
\hline $\mathrm{Na}_{2} \mathrm{LiAlH}_{6}$ & 0.50 & $\mathrm{LiNH}_{2}$ & 0.50 & & & & $\mathrm{NaH}$ & $\mathrm{LiH}$ & WC & & & 0.75 & 0.24 \\
\hline $\mathrm{Na}_{2} \mathrm{LiAlH}_{6}$ & 0.50 & $\mathrm{LiBH}_{4}$ & 0.50 & & & & $\mathrm{LiNa}_{2} \mathrm{AlH}_{6}$ & $\mathrm{NaBH}_{4}$ & $\mathrm{Al}$ & WC & & 1.67 & 1.11 \\
\hline $\mathrm{Na}_{2} \mathrm{LiAlH}_{6}$ & 0.50 & $\mathrm{LiAlH}_{4}$ & 0.50 & & & & $\mathrm{LiNa}_{2} \mathrm{AlH}_{6}$ & $\mathrm{Al}$ & WC & & & 3.20 & 2.18 \\
\hline $\mathrm{Na}_{2} \mathrm{LiAlH}_{6}$ & 0.50 & $\mathrm{MgH}_{2}$ & 0.50 & & & 0.02 & $\mathrm{NaMgH}_{3}$ & WC & & & & 2.30 & 1.32 \\
\hline $\mathrm{Na}_{2} \mathrm{LiAlH}_{6}$ & 0.25 & $\mathrm{MgH}_{2}$ & 0.75 & & & 0.02 & $\mathrm{NaMgH}_{3}$ & $\mathrm{Al}$ & WC & & & 1.66 & 0.21 \\
\hline $\mathrm{Na}_{2} \mathrm{LiAlH}_{6}$ & 0.75 & $\mathrm{MgH}_{2}$ & 0.25 & & & 0.02 & $\mathrm{NaMgH}_{3}$ & $\mathrm{NaH}$ & $\mathrm{Al}$ & WC & & 2.77 & 2.25 \\
\hline $\mathrm{Na}_{2} \mathrm{LiAlH}_{6}$ & 0.50 & $\mathrm{LiNH}_{2}$ & 0.50 & & & 0.02 & WC & $\mathrm{NaH}$ & & & & 0.62 & 0.12 \\
\hline $\mathrm{Na}_{2} \mathrm{LiAlH}_{6}$ & 0.25 & $\mathrm{LiNH}_{2}$ & 0.75 & & & 0.02 & WC & $\mathrm{LiOH}$ & & & & 1.04 & 0.49 \\
\hline $\mathrm{Na}_{2} \mathrm{LiAlH}_{6}$ & 0.75 & $\mathrm{LiNH}_{2}$ & 0.25 & & & 0.02 & $\mathrm{LiNa}_{2} \mathrm{AlH}_{6}$ & $\mathrm{Na}_{3} \mathrm{AlH}_{6}$ & $\mathrm{NaH}$ & $\mathrm{NaNH}_{2}$ & WC & 1.45 & 1.09 \\
\hline $\mathrm{Na}_{2} \mathrm{LiAlH}_{6}$ & 0.33 & $\mathrm{LiNH}_{2}$ & 0.67 & & & 0.02 & $\mathrm{Al} / \mathrm{LiH}$ & WC & $\mathrm{Na}_{3} \mathrm{AlH}_{6}$ & & & 1.15 & 0.53 \\
\hline $\mathrm{Na}_{2} \mathrm{LiAlH}_{6}$ & 0.67 & $\mathrm{LiNH}_{2}$ & 0.33 & & & 0.02 & $\mathrm{NaH}$ & WC & $\mathrm{LiNa}_{2} \mathrm{AlH}_{6}$ & $\mathrm{Na}_{3} \mathrm{AlH}_{6}$ & & 1.05 & 0.50 \\
\hline $\mathrm{Na}_{2} \mathrm{LiAlH}_{6}$ & 0.86 & $\mathrm{LiNH}_{2}$ & 0.14 & & & 0.02 & $\mathrm{LiNa}_{2} \mathrm{AlH}_{6}$ & $\mathrm{Na}_{3} \mathrm{AlH}_{6}$ & $\mathrm{NaAlH}_{4}$ & & & 1.92 & 1.83 \\
\hline $\mathrm{Na}_{2} \mathrm{LiAlH}_{6}$ & 0.14 & $\mathrm{LiNH}_{2}$ & 0.86 & & & 0.02 & $\mathrm{Na}_{3} \mathrm{AlH}_{6}$ & $\mathrm{Li}_{2} \mathrm{NH}$ & $\mathrm{LiNH}_{2}$ & $\mathrm{LiNa}_{2} \mathrm{AlH}_{6}$ & & 1.07 & 0.36 \\
\hline $\mathrm{Na}_{2} \mathrm{LiAlH}_{6}$ & 0.50 & $\mathrm{LiBH}_{4}$ & 0.50 & & & 0.02 & $\mathrm{LiNa}_{2} \mathrm{AlH}_{6}$ & $\mathrm{NaBH}_{4}$ & WC & $\mathrm{NaAlH}_{4}$ & $\mathrm{Al}$ & 1.27 & 1.15 \\
\hline $\mathrm{Na}_{2} \mathrm{LiAlH}_{6}$ & 0.25 & $\mathrm{LiBH}_{4}$ & 0.75 & & & 0.02 & $\mathrm{NaBH}_{4}$ & WC & $\mathrm{Al}$ & $\mathrm{LiNa}_{2} \mathrm{AlH}_{6}$ & & 0.22 & 0.13 \\
\hline
\end{tabular}


Table 13 (cont). Augmented Aluminum Hexahydride Reactions. Compositions, XRD of spent materials and Hydrogen Storage Capacities (MT, Des T = $\left.220^{\circ} \mathrm{C}\right)$

\begin{tabular}{|c|c|c|c|c|c|c|c|c|c|c|c|c|c|}
\hline \multicolumn{7}{|c|}{ Composition } & \multicolumn{5}{|c|}{ XRD of Spent Materials } & \multicolumn{2}{|c|}{$\begin{array}{c}\text { Hydrogen } \\
\text { Storage } \\
\text { Capacity } \\
\text { (Wt.\%) }\end{array}$} \\
\hline M-AlH 6 & mol & M-H 1 & mol & M-H 2 & mol & $\mathrm{Ti}(\mathrm{OiPr})_{4}$ & xrd 1 & xrd 2 & xrd 3 & xrd 4 & xrd 5 & Des 1 & Des 2 \\
\hline $\mathrm{K}_{2} \mathrm{NaAlH}_{6}$ & 1.00 & & & & & & $\mathrm{KOH}^{\star} \mathrm{H}_{2} \mathrm{O}$ & $\mathrm{Al}$ & & & & 0.02 & 0.01 \\
\hline $\mathrm{K}_{2} \mathrm{NaAlH}_{6}$ & 1.00 & & & & & 0.02 & $\mathrm{KOH}^{\star} \mathrm{H}_{2} \mathrm{O}$ & $\mathrm{Al}$ & & & & 0.22 & 0.02 \\
\hline $\mathrm{K}_{2} \mathrm{NaAlH}_{6}$ & 2.00 & $\mathrm{MgH}_{2}$ & 1.00 & & & 0.02 & $\mathrm{~K}_{2} \mathrm{NaAlH}_{6}$ & $\mathrm{KMgH}_{3}$ & $\mathrm{NaMgH}_{3}$ & $\mathrm{MgH}_{2}$ & WC & 0.23 & 0.20 \\
\hline $\mathrm{K}_{2} \mathrm{NaAlH}_{6}$ & 1.00 & $\mathrm{MgH}_{2}$ & 2.20 & $\mathrm{LiNH}_{2}$ & 5 & & $\mathrm{~K}_{2} \mathrm{Mg}(\mathrm{NH})_{2}$ & $\mathrm{~K}_{2} \mathrm{NaAlH}_{6}$ & $\mathrm{Al} / \mathrm{LiH}$ & WC & & 2.44 & 2.04 \\
\hline $\mathrm{Na}_{2} \mathrm{LiAlH}_{6}$ & 2.00 & $\mathrm{Mg}\left(\mathrm{NH}_{2}\right)_{2}$ & 1.00 & & & & $\mathrm{LiNa}_{2} \mathrm{AlH}_{6}$ & WC & $\mathrm{NaMgH}_{3}$ & $\mathrm{NaH}$ & $\mathrm{Na}_{3} \mathrm{AlH}_{6}$ & 1.62 & 1.31 \\
\hline $\mathrm{Na}_{2} \mathrm{LiAlH}_{6}$ & 0.50 & $\mathrm{NaAlH}_{4}$ & 1.00 & & & $\mathrm{a}$ & & & & & & $\mathrm{N}$ & $\mathrm{N}$ \\
\hline $\mathrm{Na}_{2} \mathrm{LiAlH}_{6}$ & 0.50 & $\mathrm{NaAlH}_{4}$ & 1.00 & & & 0.02 & & & & & & 4.38 & 2.99 \\
\hline $\mathrm{Na}_{2} \mathrm{LiAlH}_{6}$ & 0.50 & $\mathrm{NaAlH}_{4}$ & 1.00 & & & $\mathrm{~b}$ & $\mathrm{Al}$ & $\mathrm{Na}_{2} \mathrm{LiAlH}_{6}$ & $" \mathrm{Cr}_{2} \mathrm{O}_{3} "$ & $\mathrm{NaCl}$ & & 3.54 & 2.75 \\
\hline $\mathrm{Na}_{2} \mathrm{LiAlH}_{6}$ & 0.50 & $\mathrm{NaAlH}_{4}$ & 1.00 & & & $\mathrm{C}$ & $\mathrm{LiH}$ & $\mathrm{NaCl}$ & unk., $d=3.06,2.65$ & & & 3.92 & 2.42 \\
\hline $\mathrm{K}_{2} \mathrm{NaAlH}_{6}$ & 0.25 & $\mathrm{LiNH}_{2}$ & 0.75 & & & $d$ & $\mathrm{KCl}$ & $\mathrm{NaH}$ & $\mathrm{K}_{2} \mathrm{NaAlH}_{6}$ & $\mathrm{Li}_{2} \mathrm{NH}$ & $\mathrm{LiH}$ & 0.66 & 0.30 \\
\hline $\mathrm{K}_{2} \mathrm{NaAlH}_{6}$ & 0.25 & $\mathrm{LiNH}_{2}$ & 0.75 & & & $\mathrm{e}$ & $\mathrm{NaBH}_{4} / \mathrm{KCl}$ & $\mathrm{NaH}$ & $\mathrm{K}_{2} \mathrm{NaAlH}_{6}$ & $\mathrm{Li}_{2} \mathrm{NH}$ & & 0.77 & 0.26 \\
\hline $\mathrm{Na}_{2} \mathrm{LiAlH}_{6}$ & 0.25 & $\mathrm{LiNH}_{2}$ & 0.75 & & & $d$ & $\mathrm{NaH}$ & $\mathrm{Li}_{2} \mathrm{NH}$ & $\mathrm{NaCl}$ & $\mathrm{Al}$ & $\mathrm{LiNa}_{2} \mathrm{AlH}_{6}$ & 0.96 & 0.47 \\
\hline $\mathrm{Na}_{2} \mathrm{LiAlH}_{6}$ & 0.25 & $\mathrm{LiNH}_{2}$ & 0.75 & & & $\mathrm{e}$ & $\mathrm{NaH}$ & $\mathrm{Li}_{2} \mathrm{NH}$ & $\mathrm{NaCl}$ & $\mathrm{Al}$ & $\mathrm{Ti}$ & 1.05 & 0.50 \\
\hline $\mathrm{Na}_{3} \mathrm{AlH}_{6}$ & 0.25 & $\mathrm{LiNH}_{2}$ & 0.75 & & & d & $\mathrm{NaH}$ & $\mathrm{Li}_{2} \mathrm{NH}$ & $\mathrm{LiNa}_{2} \mathrm{AlH}_{6}$ & $\mathrm{NaCl}$ & $\mathrm{Al}, \mathrm{Ti}$ & 0.77 & 0.38 \\
\hline $\mathrm{Na}_{3} \mathrm{AlH}_{6}$ & 0.25 & $\mathrm{LiNH}_{2}$ & 0.75 & & & $\mathrm{e}$ & $\mathrm{NaH}$ & $\mathrm{Li}_{2} \mathrm{NH}$ & Unk., $d=1.88$ & $\mathrm{LiNa}_{2} \mathrm{AlH}_{6}$ & $\mathrm{Al}$ & 0.90 & 0.43 \\
\hline $\mathrm{K}_{2} \mathrm{NaAlH}_{6}$ & 0.25 & $\mathrm{LiNH}_{2}$ & 0.75 & $\mathrm{LiBH}_{4}$ & .05 & $d$ & & & & & & 0.69 & 0.38 \\
\hline $\mathrm{Na}_{2} \mathrm{LiAlH}_{6}$ & 0.25 & $\mathrm{LiNH}_{2}$ & 0.75 & $\mathrm{LiBH}_{4}$ & .05 & $\mathrm{e}$ & & & & & & 0.88 & $\mathrm{~N}$ \\
\hline
\end{tabular}

$\mathrm{a}=0.02 \mathrm{Ti}(0) \mathrm{THF}$ complex; $\mathrm{b}=0.02 \mathrm{Ti}(0)+0.02 \mathrm{ZrCl}_{4} ; \mathrm{c}=0.02 \mathrm{Ti}(\mathrm{OiPr})_{4}+0.02 \mathrm{ZrCl}_{4} ; \mathrm{d}=\left(\mathrm{TiCl}_{3}+\mathrm{AlCl}_{3}\right), 4 \mathrm{wt} . \% ; \mathrm{e}=\left(\mathrm{TiF}{ }_{3}+\mathrm{AlF}\right)_{3}, 4 \mathrm{wt} . \% ; f=u n k ., \mathrm{d}=2.75$,

$2.73,2.63,2.62,2.54,2.52,1.96,1.90,1.87 ; \mathrm{N}=$ not measured 


\begin{tabular}{|c|c|c|c|c|c|c|c|c|c|c|c|c|c|}
\hline \multicolumn{12}{|c|}{ Composition } & \multirow{2}{*}{\multicolumn{2}{|c|}{$\begin{array}{c}\text { Hydrogen } \\
\text { Storage } \\
\text { Capacity } \\
\text { (wt. \%) }\end{array}$}} \\
\hline \multicolumn{2}{|c|}{ Metal borohydrides } & \multicolumn{2}{|c|}{ Metal amides } & \multicolumn{4}{|c|}{$\begin{array}{l}\text { Metal amides - hydrides - } \\
\text { chlorides }\end{array}$} & \multicolumn{4}{|c|}{ Dopants } & & \\
\hline $\mathrm{M}-\mathrm{BH}_{4}$ & mol & $\mathrm{M}-\mathrm{NH}_{2}$ & mol & MX-1 & mol & MX-2 & mol & Dop 1 & mol & Dop 2 & mol & Des 1 & Des 2 \\
\hline $\mathrm{LiBH}_{4}$ & 0.50 & $\mathrm{LiNH}_{2}$ & 0.50 & & 0 & & & $\mathrm{Ti}(\mathrm{OiPr})_{4}$ & 0.02 & & & 0.62 & 0.41 \\
\hline $\mathrm{LiBH}_{4}$ & 0.67 & $\mathrm{LiNH}_{2}$ & 0.33 & & 0 & & & $\mathrm{Ti}(\mathrm{OiPr})_{4}$ & 0.02 & & & 0.86 & 0.60 \\
\hline $\mathrm{LiBH}_{4}$ & 0.33 & $\mathrm{LiNH}_{2}$ & 0.67 & & 0 & & & $\mathrm{Ti}(\mathrm{OiPr})_{4}$ & 0.02 & & & 2.47 & 0.60 \\
\hline $\mathrm{LiBH}_{4}$ & 0.20 & $\mathrm{LiNH}_{2}$ & 0.80 & & 0 & & & $\mathrm{Ti}(\mathrm{OiPr})_{4}$ & 0.02 & & & 1.33 & 0.52 \\
\hline $\mathrm{LiBH}_{4}$ & 0.80 & $\mathrm{LiNH}_{2}$ & 0.20 & & 0 & & & $\mathrm{Ti}(\mathrm{OiPr})_{4}$ & 0.02 & & & 0.59 & 0.36 \\
\hline $\mathrm{LiBH}_{4}$ & 0.50 & $\mathrm{LiNH}_{2}$ & 0.50 & $\mathrm{MgH}_{2}$ & 1.00 & & & $\mathrm{Ti}(\mathrm{OiPr})_{4}$ & 0.02 & & & 1.04 & 0.08 \\
\hline $\mathrm{LiBH}_{4}$ & 0.67 & $\mathrm{LiNH}_{2}$ & 0.33 & $\mathrm{MgH}_{2}$ & 1.00 & & & $\mathrm{Ti}(\mathrm{OiPr})_{4}$ & 0.02 & & & 0.50 & 0.07 \\
\hline $\mathrm{LiBH}_{4}$ & 0.33 & $\mathrm{LiNH}_{2}$ & 0.67 & $\mathrm{MgH}_{2}$ & 1.00 & & & $\mathrm{Ti}(\mathrm{OiPr})_{4}$ & 0.02 & & & 1.17 & 0.24 \\
\hline $\mathrm{Zn}\left(\mathrm{BH}_{4}\right)_{2}$ & 1.00 & $\mathrm{LiNH}_{2}$ & 2.00 & & 0 & & & $\mathrm{Ti}(\mathrm{OiPr})_{4}$ & 0.01 & & & 0.98 & 0.59 \\
\hline $\mathrm{LiBH}_{4}$ & 0.50 & $\mathrm{NaNH}_{2}$ & 0.50 & & 0 & & & $\mathrm{Ti}(\mathrm{OiPr})_{4}$ & 0.02 & & & 0.94 & 0.24 \\
\hline $\mathrm{NaBH}_{4}$ & 0.50 & $\mathrm{NaNH}_{2}$ & 0.50 & & 0 & & & $\mathrm{Ti}(\mathrm{OiPr})_{4}$ & 0.02 & & & 1.31 & 0.13 \\
\hline $\mathrm{LiBH}_{4}$ & 0.67 & $\mathrm{NaNH}_{2}$ & 0.33 & & 0 & & & $\mathrm{Ti}(\mathrm{OiPr})_{4}$ & 0.02 & & & 0.34 & 0.27 \\
\hline $\mathrm{NaBH}_{4}$ & 0.67 & $\mathrm{NaNH}_{2}$ & 0.33 & & 0 & & & $\mathrm{Ti}(\mathrm{OiPr})_{4}$ & 0.02 & & & 1.13 & 0.04 \\
\hline $\mathrm{LiBH}_{4}$ & 0.33 & $\mathrm{NaNH}_{2}$ & 0.67 & & 0 & & & $\mathrm{Ti}(\mathrm{OiPr})_{4}$ & 0.02 & & & 0.82 & 0.07 \\
\hline $\mathrm{LiBH}_{4}$ & 1.00 & $\mathrm{LiNH}_{2}$ & 6.00 & $\mathrm{MgH}_{2}$ & 2.20 & $\mathrm{NaH}$ & 1.00 & & & & & 2.10 & 1.93 \\
\hline $\mathrm{LiBH}_{4}$ & 2.00 & $\mathrm{Mg}\left(\mathrm{NH}_{2}\right)_{2}$ & 1.00 & & 0 & & & & & & & 0.64 & 0.14 \\
\hline $\mathrm{LiBH}_{4}$ & 1.00 & $\mathrm{Mg}\left(\mathrm{NH}_{2}\right)_{2}$ & 1.00 & $\mathrm{LiNH}_{2}$ & 2.00 & $\mathrm{MgH}_{2}$ & 1.10 & & & & & 3.24 & 2.30 \\
\hline $\mathrm{LiBH}_{4}$ & 1.00 & $\mathrm{Mg}\left(\mathrm{NH}_{2}\right)_{2}$ & 1.00 & $\mathrm{LiNH}_{2}$ & 1.00 & $\mathrm{MgH}_{2}$ & 0.55 & & & & & 2.63 & 1.57 \\
\hline $\mathrm{LiBH}_{4}$ & 1.00 & $\mathrm{Mg}\left(\mathrm{NH}_{2}\right)_{2}$ & 1.00 & $\mathrm{LiNH}_{2}$ & 2.00 & & & & & & & 1.71 & 1.60 \\
\hline $\mathrm{LiBH}_{4}$ & 1.00 & $\mathrm{LiNH}_{2}$ & 1.00 & $\mathrm{MgH}_{2}$ & 0.00 & & & $\mathrm{NiCl}_{2}$ & 0.02 & & & 6.02 & 1.67 \\
\hline $\mathrm{LiBH}_{4}$ & 1.00 & $\mathrm{LiNH}_{2}$ & 1.00 & $\mathrm{MgH}_{2}$ & 0.00 & & & $\mathrm{NiCl}_{2}$ & 0.01 & & & 5.50 & 1.95 \\
\hline $\mathrm{LiBH}_{4}$ & 1.00 & $\mathrm{LiNH}_{2}$ & 1.00 & $\mathrm{MgH}_{2}$ & 0.00 & & & $\mathrm{NiCl}_{2}$ & 0.05 & & & 6.03 & 0.52 \\
\hline $\mathrm{LiBH}_{4}$ & 1.00 & $\mathrm{LiNH}_{2}$ & 2.00 & $\mathrm{MgH}_{2}$ & 0.00 & & & $\mathrm{NiCl}_{2}$ & 0.02 & & & 7.00 & 3.03 \\
\hline $\mathrm{LiBH}_{4}$ & 1.00 & $\mathrm{Mg}\left(\mathrm{NH}_{2}\right)_{2}$ & 1.00 & & 0 & & & & & & & 1.60 & 0.66 \\
\hline $\mathrm{LiBH}_{4}$ & 1.00 & $\mathrm{Mg}\left(\mathrm{NH}_{2}\right)_{2}$ & 2.00 & & 0 & & & & & & & 1.88 & 0.41 \\
\hline $\mathrm{LiBH}_{4}$ & 1.00 & $\mathrm{Mg}\left(\mathrm{NH}_{2}\right)_{2}$ & 1.00 & $\mathrm{LiNH}_{2}$ & 1.00 & & & & & & & 2.79 & 0.76 \\
\hline $\mathrm{LiBH}_{4}$ & 2.00 & $\mathrm{Mg}\left(\mathrm{NH}_{2}\right)_{2}$ & 1.00 & $\mathrm{LiNH}_{2}$ & 2.00 & & & & & & & 3.14 & 1.59 \\
\hline $\mathrm{LiBH}_{4}$ & 4.00 & $\mathrm{Mg}\left(\mathrm{NH}_{2}\right)_{2}$ & 1.00 & $\mathrm{LiNH}_{2}$ & 2.00 & & & & & & & 1.95 & 0.84 \\
\hline $\mathrm{LiBH}_{4}$ & 4.00 & $\mathrm{Mg}\left(\mathrm{NH}_{2}\right)_{2}$ & 1.00 & $\mathrm{LiNH}_{2}$ & 2.00 & $\mathrm{MgH}_{2}$ & 1.00 & & & & & 1.80 & 0.65 \\
\hline $\mathrm{LiBH}_{4}$ & 4.00 & $\mathrm{Mg}\left(\mathrm{NH}_{2}\right)_{2}$ & 1.00 & $\mathrm{LiNH}_{2}$ & 2.00 & $\mathrm{MgH}_{2}$ & 2.00 & & & & & 1.98 & 0.55 \\
\hline $\mathrm{LiBH}_{4}$ & 1.00 & $\mathrm{Mg}\left(\mathrm{NH}_{2}\right)_{2}$ & 2.00 & $\mathrm{LiNH}_{2}$ & 2.00 & & & & & & & $\mathrm{~N}$ & $\mathrm{~N}$ \\
\hline $\mathrm{LiBH}_{4}$ & 1.00 & $\mathrm{LiNH}_{2}$ & 2.00 & & 0 & & & $\mathrm{CrF}_{3}$ & 0.02 & & & $\mathrm{~N}$ & $\mathrm{~N}$ \\
\hline $\mathrm{LiBH}_{4}$ & 1.00 & $\mathrm{LiNH}_{2}$ & 2.00 & & 0 & & & $\mathrm{CrF}_{3}$ & 0.02 & $\mathrm{Ti}(\mathrm{OiPr})_{4}$ & 0.02 & 0.46 & 0.32 \\
\hline $\mathrm{LiBH}_{4}$ & 1.00 & $\mathrm{LiNH}_{2}$ & 2.00 & & 0 & & & $\mathrm{CrF}_{3}$ & 0.03 & & & 0.48 & 0.30 \\
\hline
\end{tabular}




\begin{tabular}{|c|c|c|c|c|c|c|c|c|c|c|c|c|c|}
\hline \multicolumn{12}{|c|}{ Composition } & \multirow{2}{*}{\multicolumn{2}{|c|}{$\begin{array}{c}\text { Hydrogen } \\
\text { Storage } \\
\text { Capacity } \\
\text { (wt. \%) }\end{array}$}} \\
\hline \multicolumn{2}{|c|}{ Metal borohydrides } & \multicolumn{2}{|c|}{ Metal amides } & \multicolumn{4}{|c|}{$\begin{array}{c}\text { Metal amides - hydrides - } \\
\text { chlorides }\end{array}$} & \multicolumn{4}{|c|}{ Dopants } & & \\
\hline $\mathrm{M}-\mathrm{BH}_{4}$ & $\mathrm{~mol}$ & $\mathrm{M}-\mathrm{NH}_{2}$ & mol & MX-1 & mol & MX-2 & mol & Dop 1 & mol & Dop 2 & mol & Des 1 & Des 2 \\
\hline $\mathrm{LiBH}_{4}$ & 1.00 & $\mathrm{LiNH}_{2}$ & 2.00 & & & & & $\mathrm{NiCl}_{2}$ & 0.02 & $\mathrm{CrF}_{3}$ & 0.02 & 3.87 & 3.34 \\
\hline $\mathrm{KBH}_{4}$ & 1.00 & $\mathrm{LiNH}_{2}$ & 5.00 & $\mathrm{MgH}_{2}$ & 2.20 & & & & & & & 0.94 & 0.65 \\
\hline $\mathrm{KBH}_{4}$ & 2.00 & $\mathrm{Mg}\left(\mathrm{NH}_{2}\right)_{2}$ & 1.00 & & & & & & & & & 0.05 & 0.00 \\
\hline $\mathrm{KBH}_{4}$ & 1.00 & $\mathrm{LiNH}_{2}$ & 5.00 & $\mathrm{MgH}_{2}$ & 2.20 & & & $\mathrm{TiCl} 3$ & 0.02 & & & 0.62 & 0.36 \\
\hline $\mathrm{KBH}_{4}$ & 2.00 & $\mathrm{Mg}\left(\mathrm{NH}_{2}\right)_{2}$ & 1.00 & & & & & $\mathrm{CrF}_{3}$ & 0.02 & $\mathrm{NiCl}_{2}$ & 0.02 & 0.09 & 0.01 \\
\hline $\mathrm{KBH}_{4}$ & 1.00 & $\mathrm{LiNH}_{2}$ & 5.00 & $\mathrm{MgH}_{2}$ & 2.20 & & & & & & & 0.50 & 0.29 \\
\hline $\mathrm{KBH}_{4}$ & 1.00 & $\mathrm{Mg}\left(\mathrm{NH}_{2}\right)_{2}$ & 1.00 & $\mathrm{LiH}$ & 2.20 & & & & & & & 0.47 & 0.17 \\
\hline $\mathrm{KBH}_{4}$ & 1.00 & $\mathrm{LiNH}_{2}$ & 5.00 & $\mathrm{MgH}_{2}$ & 2.20 & & & $\mathrm{CrF}_{3}$ & 0.01 & $\mathrm{TiCl}_{3}$ & 0.01 & 0.43 & 0.25 \\
\hline $\mathrm{KBH}_{4}$ & 1.00 & $\mathrm{LiNH}_{2}$ & 5.00 & $\mathrm{MgH}_{2}$ & 2.20 & $\mathrm{LiAlH}_{4}$ & 2.00 & & & & & 0.84 & 0.51 \\
\hline $\mathrm{LiBH}_{4}$ & 1.00 & $\mathrm{LiNH}_{2}$ & 2.00 & & & & & & & & & 0.23 & 0.20 \\
\hline $\mathrm{LiBH}_{4}$ & 1.00 & $\mathrm{NaNH}_{2}$ & 5.00 & $\mathrm{MgH}_{2}$ & 2.20 & & & & & & & 0.39 & 0.38 \\
\hline $\mathrm{NaBH}_{4}$ & 1.00 & $\mathrm{NaNH}_{2}$ & 5.00 & $\mathrm{MgH}_{2}$ & 2.20 & & & & & & & 0.15 & 0.12 \\
\hline $\mathrm{NaBH}_{4}$ & 1.00 & $\mathrm{LiNH}_{2}$ & 5.00 & $\mathrm{MgH}_{2}$ & 2.20 & & & & & & & 0.65 & 0.64 \\
\hline $\mathrm{NaBH}_{4}$ & 0.10 & $\mathrm{NaNH}_{2}$ & 0.60 & $\mathrm{MgH}_{2}$ & 0.30 & & & & & & & 0.21 & 0.18 \\
\hline $\mathrm{LiBH}_{4}$ & 1.00 & $\mathrm{LiNH}_{2}$ & 2.00 & & & & & $\mathrm{NiCl}_{2}$ & 0.02 & $\mathrm{CrF}_{3}$ & 0.01 & 6.09 & 5.09 \\
\hline $\mathrm{LiBH}_{4}$ & 0.50 & $\mathrm{LiNH}_{2}$ & 1.00 & & & & & $\mathrm{NiCl}_{2}$ & 0.02 & $\mathrm{CrF}_{3}$ & 0.01 & 6.70 & 3.31 \\
\hline $\mathrm{LiBH}_{4}$ & 1.50 & $\mathrm{LiNH}_{2}$ & 3.00 & & & & & $\mathrm{NiCl}_{2}$ & 0.02 & $\mathrm{CrF}_{3}$ & 0.01 & 5.91 & 5.65 \\
\hline $\mathrm{LiBH}_{4}$ & 2.00 & $\mathrm{LiNH}_{2}$ & 4.00 & & & & & $\mathrm{NiCl}_{2}$ & 0.02 & $\mathrm{CrF}_{3}$ & 0.01 & 3.59 & 5.88 \\
\hline $\mathrm{Ca}\left(\mathrm{BH}_{4}\right)_{2} * 2 \mathrm{THF}$ & 1.00 & $\mathrm{LiNH}_{2}$ & 5.00 & $\mathrm{CaH}_{2}$ & 1.00 & & & & & & & 1.27 & 0.61 \\
\hline $\left.\mathrm{Ca}\left(\mathrm{BH}_{4}\right)_{2}\right)^{*} \mathrm{THF}$ & 1.00 & $\mathrm{LiNH}_{2}$ & 5.00 & $\mathrm{CaH}_{2}$ & 1.10 & & & & & & & 1.21 & 0.42 \\
\hline $\left.\mathrm{Ca}\left(\mathrm{BH}_{4}\right)_{2}\right)^{*} \mathrm{THF}$ & 1.00 & $\mathrm{LiNH}_{2}$ & 3.00 & & & & & & & & & $\mathrm{~N}$ & $\mathrm{~N}$ \\
\hline $\mathrm{Ca}\left(\mathrm{BH}_{4}\right)_{2}{ }^{*} 2 \mathrm{THF}$ & 1.00 & $\mathrm{LiNH}_{2}$ & 3.00 & & & & & $\mathrm{NiCl} 2$ & 0.02 & & & $\mathrm{~N}$ & $\mathrm{~N}$ \\
\hline $\left.\mathrm{Ca}\left(\mathrm{BH}_{4}\right)_{2}\right)^{*} \mathrm{THF}$ & 1.00 & $\mathrm{LiNH}_{2}$ & 3.00 & & & & & $\mathrm{NiCl} 2$ & 0.02 & $\mathrm{CrF}_{3}$ & 0.02 & $\mathrm{~N}$ & $\mathrm{~N}$ \\
\hline $\left.\mathrm{Ca}\left(\mathrm{BH}_{4}\right)_{2}\right)^{*} \mathrm{THF}$ & 1.00 & $\mathrm{LiNH}_{2}$ & 3.00 & $\mathrm{LiH}$ & 1.00 & & & & & & & $\mathrm{~N}$ & $\mathrm{~N}$ \\
\hline $\left.\mathrm{Ca}\left(\mathrm{BH}_{4}\right)_{2}\right)^{*} \mathrm{THF}$ & 1.00 & & & & & & & & & & & 0.52 & 0.29 \\
\hline $\mathrm{LiBH}_{4}$ & 1.00 & $\mathrm{LiNH}_{2}$ & 3.00 & & & & & $\mathrm{Cr}_{2} \mathrm{O}_{3}$ & 0.02 & & & 0.90 & 0.47 \\
\hline $\mathrm{LiBH}_{4}$ & 1.00 & $\mathrm{LiNH}_{2}$ & 3.00 & & & & & $\mathrm{Cr}_{2} \mathrm{O}_{3}$ & 0.02 & $\mathrm{NiCl}_{2}$ & 0.02 & 6.41 & 2.00 \\
\hline $\mathrm{LiBH}_{4}$ & 1.00 & $\mathrm{LiNH}_{2}$ & 3.00 & $\mathrm{MgH}_{2}$ & 1.00 & & & & & & & 2.57 & 2.53 \\
\hline $\mathrm{NaBH}_{4}$ & 1.00 & $\mathrm{LiNH}_{2}$ & 2.00 & $\mathrm{NaNH}_{2}$ & 1.00 & & & $\mathrm{NiCl}_{2}$ & 0.02 & & & 0.16 & 0.07 \\
\hline $\mathrm{NaBH}_{4}$ & 1.00 & $\mathrm{LiNH}_{2}$ & 3.00 & & & & & $\mathrm{NiCl}_{2}$ & 0.02 & & & 0.32 & 0.08 \\
\hline $\mathrm{KBH}_{4}$ & 1.00 & $\mathrm{LiNH}_{2}$ & 4.00 & $\mathrm{NaNH}_{2}$ & 1.00 & $\mathrm{MgH}_{2}$ & 1.20 & $\mathrm{NiCl}_{2}$ & 0.04 & & & 2.99 & 1.25 \\
\hline $\mathrm{KBH}_{4}$ & 1.00 & $\mathrm{LiNH}_{2}$ & 5.00 & & & $\mathrm{MgH}_{2}$ & 1.20 & $\mathrm{NiCl}_{2}$ & 0.04 & & & 0.73 & 0.30 \\
\hline $\mathrm{KBH}_{4}$ & 1.00 & $\mathrm{LiNH}_{2}$ & 0.00 & $\mathrm{NaNH}_{2}$ & 5.00 & $\mathrm{MgH}_{2}$ & 1.20 & $\mathrm{NiCl}_{2}$ & 0.04 & & & 0.18 & 0.16 \\
\hline $\mathrm{Ca}\left(\mathrm{BH}_{4}\right)_{2}{ }^{*} 2 \mathrm{THF}$ & 1.00 & $\mathrm{LiNH}_{2}$ & 6.00 & $\mathrm{MgH}_{2}$ & 1.20 & & & $\mathrm{NiCl}_{2}$ & 0.04 & & & 1.75 & 0.31 \\
\hline $\mathrm{Ca}\left(\mathrm{BH}_{4}\right)_{2}{ }^{\star} 2 \mathrm{THF}$ & 1.00 & $\mathrm{LiNH}_{2}$ & 5.00 & $\mathrm{NaNH}_{2}$ & 1.00 & $\mathrm{MgH}_{2}$ & 1.20 & $\mathrm{NiCl}_{2}$ & 0.04 & & & 4.62 & 3.11 \\
\hline $\left.\mathrm{Ca}\left(\mathrm{BH}_{4}\right)_{2}\right)^{*} \mathrm{THF}$ & 1.00 & $\mathrm{LiNH}_{2}$ & 5.00 & $\mathrm{NaNH}_{2}$ & 1.00 & $\mathrm{MgH}_{2}$ & 1.20 & $\mathrm{NiCl}_{2}$ & 0.04 & & & 3.20 & 1.34 \\
\hline
\end{tabular}




\begin{tabular}{|c|c|c|c|c|c|c|c|c|c|c|c|c|c|}
\hline \multicolumn{12}{|c|}{ Composition } & \multirow{2}{*}{\multicolumn{2}{|c|}{$\begin{array}{c}\text { Hydrogen } \\
\text { Storage } \\
\text { Capacity } \\
\text { (wt. \%) }\end{array}$}} \\
\hline \multicolumn{2}{|c|}{ Metal borohydrides } & \multicolumn{2}{|c|}{ Metal amides } & \multicolumn{4}{|c|}{$\begin{array}{c}\text { Metal amides - hydrides - } \\
\text { chlorides }\end{array}$} & \multicolumn{4}{|c|}{ Dopants } & & \\
\hline $\mathrm{M}-\mathrm{BH}_{4}$ & $\mathrm{~mol}$ & $\mathrm{M}-\mathrm{NH}_{2}$ & mol & MX-1 & mol & MX-2 & mol & Dop 1 & mol & Dop 2 & mol & Des 1 & Des 2 \\
\hline $\mathrm{Ca}\left(\mathrm{BH}_{4}\right)_{2} * 2 \mathrm{THF}$ & 1.00 & $\mathrm{LiNH}_{2}$ & 5.00 & $\mathrm{NaNH}_{2}$ & 1.00 & $\mathrm{MgH}_{2}$ & 1.20 & & & & & 1.60 & 0.34 \\
\hline $\mathrm{LiBH}_{4}$ & 1.00 & $\mathrm{LiNH}_{2}$ & 5.00 & & & $\mathrm{MgCl}_{2}$ & 2.20 & & & & & 0.18 & 0.20 \\
\hline $\mathrm{LiBH}_{4}$ & 1.00 & $\mathrm{LiNH}_{2}$ & 5.00 & $\mathrm{LiH}$ & 1.00 & $\mathrm{MgCl}_{2}$ & 2.20 & & & & & 0.34 & 0.23 \\
\hline $\mathrm{LiBH}_{4}$ & 0.00 & $\mathrm{LiNH}_{2}$ & 4.00 & $\mathrm{NiC}_{12}$ & 1.00 & & & & & & & $\mathrm{~N}$ & $\mathrm{~N}$ \\
\hline $\mathrm{LiBH}_{4}$ & 0.33 & $\mathrm{LiNH}_{2}$ & 0.42 & $\mathrm{MgH}_{2}$ & 0.08 & $\mathrm{MgCl}_{2}$ & 0.17 & & & & & 3.77 & 0.67 \\
\hline $\mathrm{LiBH}_{4}$ & 0.33 & $\mathrm{LiNH}_{2}$ & 0.42 & $\mathrm{MgH}_{2}$ & 0.08 & $\mathrm{NiCl}_{2}$ & 0.17 & & & & & 3.62 & 0.71 \\
\hline $\mathrm{LiBH}_{4}$ & 0.33 & $\mathrm{LiNH}_{2}$ & 0.42 & $\mathrm{MgH}_{2}$ & 0.08 & $\mathrm{ZnCl}_{2}$ & 0.17 & & & & & 0.77 & 0.29 \\
\hline $\mathrm{LiBH}_{4}$ & 0.35 & $\mathrm{LiNH}_{2}$ & 0.47 & $\mathrm{MgH}_{2}$ & 0.06 & $\mathrm{VCl}_{3}$ & 0.12 & & & & & 1.78 & 0.52 \\
\hline $\mathrm{LiBH}_{4}$ & 0.43 & $\mathrm{LiNH}_{2}$ & 0.36 & $\mathrm{MgH}_{2}$ & 0.07 & $\mathrm{CuCl}_{2}$ & 0.07 & & & & & 1.61 & 0.51 \\
\hline $\mathrm{LiBH}_{4}$ & 0.31 & $\mathrm{LiNH}_{2}$ & 0.50 & $\mathrm{MgH}_{2}$ & 0.06 & $\mathrm{CaCl}_{2}$ & 0.06 & & & & & 0.69 & 0.32 \\
\hline $\mathrm{LiBH}_{4}$ & 0.17 & $\mathrm{LiNH}_{2}$ & 0.67 & $\mathrm{MgH}_{2}$ & 0.08 & $\mathrm{MnCl}_{2}$ & 0.08 & & & & & 0.98 & 1.00 \\
\hline $\mathrm{LiBH}_{4}$ & 0.17 & $\mathrm{LiNH}_{2}$ & 0.67 & $\mathrm{MgH}_{2}$ & 0.08 & $\mathrm{NiCl}_{2}$ & 0.08 & & & & & 2.23 & 0.26 \\
\hline $\mathrm{LiBH}_{4}$ & 1.00 & $\mathrm{LiNH}_{2}$ & 3.00 & $\mathrm{LiH}$ & 1.00 & & & & & & & 0.73 & 0.49 \\
\hline $\mathrm{LiBH}_{4}$ & 1.00 & $\mathrm{LiNH}_{2}$ & 3.00 & $\mathrm{LiH}$ & 2.00 & & & & & & & 0.98 & 0.56 \\
\hline $\mathrm{LiBH}_{4}$ & 1.00 & $\mathrm{LiNH}_{2}$ & 3.00 & $\mathrm{LiH}$ & 3.00 & & & & & & & 1.05 & 0.65 \\
\hline $\mathrm{LiBH}_{4}$ & 1.00 & $\mathrm{LiNH}_{2}$ & 3.00 & $\mathrm{LiH}$ & 1.00 & & & $\mathrm{NiCl}_{2}$ & 0.02 & $\mathrm{CrF}_{3}$ & 0.02 & 6.01 & 2.20 \\
\hline $\mathrm{LiBH}_{4}$ & 1.00 & $\mathrm{LiNH}_{2}$ & 3.00 & $\mathrm{LiH}$ & 2.00 & & & $\mathrm{NiCl}_{2}$ & 0.02 & $\mathrm{CrF}_{3}$ & 0.02 & 3.86 & 2.64 \\
\hline $\mathrm{LiBH}_{4}$ & 1.00 & $\mathrm{LiNH}_{2}$ & 3.00 & $\mathrm{LiH}$ & 3.00 & & & $\mathrm{NiCl}_{2}$ & 0.02 & $\mathrm{CrF}_{3}$ & 0.02 & 4.55 & 2.72 \\
\hline $\mathrm{LiBH}_{4}$ & 0.00 & $\mathrm{LiNH}_{2}$ & 1.00 & $\mathrm{LiH}$ & 1.00 & & & $\mathrm{NiCl}_{2}$ & 0.02 & $\mathrm{CrF}_{3}$ & 0.02 & 0.17 & 0.01 \\
\hline $\mathrm{LiBH}_{4}$ & 0.00 & $\mathrm{LiNH}_{2}$ & 1.00 & $\mathrm{LiH}$ & 2.00 & & & $\mathrm{NiCl}_{2}$ & 0.02 & $\mathrm{CrF}_{3}$ & 0.02 & 1.50 & 1.16 \\
\hline $\mathrm{LiBH}_{4}$ & 1.00 & $\mathrm{LiNH}_{2}$ & 1.00 & $\mathrm{LiH}$ & 1.00 & & & & & & & 1.40 & 0.92 \\
\hline $\mathrm{LiBH}_{4}$ & 0.50 & $\mathrm{LiNH}_{2}$ & 1.00 & $\mathrm{LiH}$ & 1.00 & & & & & & & 0.63 & 0.57 \\
\hline $\mathrm{LiBH}_{4}$ & 0.25 & $\mathrm{LiNH}_{2}$ & 1.00 & $\mathrm{LiH}$ & 1.00 & & & & & & & $\mathrm{~N}$ & $\mathrm{~N}$ \\
\hline $\mathrm{LiBH}_{4}$ & 0.10 & $\mathrm{LiNH}_{2}$ & 1.00 & $\mathrm{LiH}$ & 1.00 & & & & & & & 0.46 & 0.23 \\
\hline $\mathrm{LiBH}_{4}$ & 1.00 & $\mathrm{LiNH}_{2}$ & 1.00 & $\mathrm{LiH}$ & 2.00 & & & & & & & 0.84 & 0.62 \\
\hline $\mathrm{LiBH}_{4}$ & 0.50 & $\mathrm{LiNH}_{2}$ & 1.00 & $\mathrm{LiH}$ & 2.00 & & & & & & & 0.27 & 0.22 \\
\hline $\mathrm{LiBH}_{4}$ & 0.25 & $\mathrm{LiNH}_{2}$ & 1.00 & $\mathrm{LiH}$ & 2.00 & & & & & & & 0.73 & 0.29 \\
\hline $\mathrm{LiBH}_{4}$ & 0.10 & $\mathrm{LiNH}_{2}$ & 1.00 & $\mathrm{LiH}$ & 2.00 & & & & & & & 0.33 & 0.25 \\
\hline $\mathrm{KBH}_{4}$ & 1.00 & $\mathrm{LiNH}_{2}$ & 4.00 & $\mathrm{KH}$ & 1.10 & & & $\mathrm{MoO}_{3}$ & 0.04 & & & 0.35 & 0.14 \\
\hline $\mathrm{KBH}_{4}$ & 1.00 & $\mathrm{LiNH}_{2}$ & 5.00 & $\mathrm{CaH}_{2}$ & 1.10 & & & $\mathrm{MoO}_{3}$ & 0.04 & & & 0.48 & 0.15 \\
\hline $\mathrm{LiBH}_{4}$ & 1.00 & $\mathrm{LiNH}_{2}$ & 5.00 & $\mathrm{CaH}_{2}$ & 1.10 & & & $\mathrm{MoO}_{3}$ & 0.04 & & & 1.16 & 0.36 \\
\hline $\mathrm{KBH}_{4}$ & 1.00 & $\mathrm{LiNH}_{2}$ & 5.00 & $\mathrm{MgH}_{2}$ & 2.20 & & & $\mathrm{MoO}_{3}$ & 0.04 & & & 0.55 & 0.33 \\
\hline $\mathrm{LiBH}_{4}$ & 1.00 & $\mathrm{LiNH}_{2}$ & 5.00 & $\mathrm{MgH}_{2}$ & 2.20 & & & $\mathrm{MoO}_{3}$ & 0.1 & & & 3.30 & 2.90 \\
\hline $\mathrm{LiBH}_{4}$ & 1.00 & $\mathrm{LiNH}_{2}$ & 4.00 & $\mathrm{KH}$ & 1.00 & & & $\mathrm{MoO}_{3}$ & 0.05 & & & 0.30 & 0.13 \\
\hline $\mathrm{LiBH}_{4}$ & 1.00 & $\mathrm{LiNH}_{2}$ & 3.00 & & & & & $\mathrm{MoO}_{3}$ & 0.06 & & & 0.39 & 0.31 \\
\hline $\mathrm{LiBH}_{4}$ & 1.00 & $\mathrm{LiNH}_{2}$ & 5.00 & $\mathrm{TiH}_{2}$ & 2.10 & & & $\mathrm{MoO}_{3}$ & 0.1 & & & 2.07 & 1.22 \\
\hline
\end{tabular}




\begin{tabular}{|c|c|c|c|c|c|c|c|c|c|c|c|c|c|}
\hline \multicolumn{12}{|c|}{ Compositions } & \multirow{2}{*}{\multicolumn{2}{|c|}{$\begin{array}{c}\text { Hydrogen } \\
\text { Storage } \\
\text { Capacity } \\
\text { (wt. \%) }\end{array}$}} \\
\hline \multicolumn{2}{|c|}{ Metal borohydrides } & \multicolumn{2}{|c|}{ Metal amides } & \multicolumn{4}{|c|}{$\begin{array}{c}\text { Metal amides - hydrides - } \\
\text { chlorides }\end{array}$} & \multicolumn{4}{|c|}{ Dopants } & & \\
\hline $\mathrm{M}-\mathrm{BH}_{4}$ & $\mathrm{~mol}$ & $\mathrm{M}-\mathrm{NH}_{2}$ & $\mathrm{~mol}$ & MX-1 & mol & MX-2 & mol & Dop 1 & mol & Dop 2 & mol & Des 1 & Des 2 \\
\hline $\mathrm{LiBH}_{4}$ & 2.00 & $\mathrm{LiNH}_{2}$ & 4.00 & & & & & $\mathrm{NiCl}_{2}$ & 0.02 & $\mathrm{CrF}_{3}$ & 0.02 & 2.97 & 2.60 \\
\hline $\mathrm{LiBH}_{4}$ & 2.00 & $\mathrm{LiNH}_{2}$ & 4.00 & & & & & $\mathrm{NiCl}_{2}$ & 0.02 & $\mathrm{CrF}_{3}$ & 0.01 & 5.13 & 4.50 \\
\hline $\mathrm{LiBH}_{4}$ & 2.00 & $\mathrm{LiNH}_{2}$ & 4.00 & & & & & $\mathrm{NiCl}_{2}$ & 0.02 & $\mathrm{CrF}_{3}$ & 0.03 & 2.56 & 2.19 \\
\hline $\mathrm{LiBH}_{4}$ & 2.00 & $\mathrm{LiNH}_{2}$ & 4.00 & & & & & $\mathrm{NiCl}_{2}$ & 0.03 & $\mathrm{CrF}_{3}$ & 0.01 & 3.84 & 3.37 \\
\hline $\mathrm{LiBH}_{4}$ & 3.00 & $\mathrm{LiNH}_{2}$ & 6.00 & & & & & $\mathrm{NiCl}_{2}$ & 0.02 & $\mathrm{CrF}_{3}$ & 0.02 & 2.96 & 1.94 \\
\hline $\mathrm{LiBH}_{4}$ & 3.00 & $\mathrm{LiNH}_{2}$ & 6.00 & & & & & $\mathrm{NiCl}_{2}$ & 0.02 & $\mathrm{CrF}_{3}$ & 0.01 & 4.10 & 3.44 \\
\hline $\mathrm{LiBH}_{4}$ & 3.00 & $\mathrm{LiNH}_{2}$ & 6.00 & & & & & $\mathrm{NiCl}_{2}$ & 0.02 & $\mathrm{CrF}_{3}$ & 0.03 & 5.30 & 3.99 \\
\hline $\mathrm{LiBH}_{4}$ & 3.00 & $\mathrm{LiNH}_{2}$ & 6.00 & & & & & $\mathrm{NiCl}_{2}$ & 0.03 & $\mathrm{CrF}_{3}$ & 0.01 & 3.96 & 3.17 \\
\hline $\mathrm{LiBH}_{4}$ & 0.30 & $\mathrm{LiNH}_{2}$ & 0.60 & & & & & $\mathrm{NiCl}_{2}$ & 0.02 & $\mathrm{CrF}_{3}$ & 0.02 & 5.86 & 1.99 \\
\hline $\mathrm{LiBH}_{4}$ & 0.30 & $\mathrm{LiNH}_{2}$ & 0.60 & & & & & $\mathrm{NiCl}_{2}$ & 0.02 & $\mathrm{ZrF}_{4}$ & 0.02 & 5.65 & 0.91 \\
\hline $\mathrm{LiBH}_{4}$ & 0.30 & $\mathrm{LiNH}_{2}$ & 0.60 & & & & & $\mathrm{NiCl}_{2}$ & 0.02 & $\mathrm{YbCl}_{3}$ & 0.02 & 5.69 & 1.62 \\
\hline $\mathrm{LiBH}_{4}$ & 1.00 & $\mathrm{LiNH}_{2}$ & 2.00 & & & & & $\mathrm{NiCl}_{2}$ & 0.02 & $\mathrm{CrF}_{3}$ & 0.02 & 5.03 & 4.28 \\
\hline $\mathrm{LiBH}_{4}$ & 1.00 & $\mathrm{LiNH}_{2}$ & 2.00 & & & & & $\mathrm{NiCl}_{2}$ & 0.02 & $\mathrm{CrF}_{3}$ & 0.01 & 2.99 & 0.66 \\
\hline $\mathrm{LiBH}_{4}$ & 0.30 & $\mathrm{LiNH}_{2}$ & 0.60 & & & & & $\mathrm{NiCl}_{2}$ & 0.01 & $\mathrm{CrF}_{3}$ & 0.01 & 4.78 & 0.62 \\
\hline $\mathrm{LiBH}_{4}$ & 0.30 & $\mathrm{LiNH}_{2}$ & 0.60 & & & & & $\mathrm{NiCl}_{2}$ & 0.02 & $\mathrm{CrF}_{3}$ & 0.02 & 3.02 & 0.40 \\
\hline $\mathrm{LiBH}_{4}$ & 0.30 & $\mathrm{LiNH}_{2}$ & 0.60 & & & & & $\mathrm{NiCl}_{2}$ & 0.015 & $\mathrm{CrF}_{3}$ & 0.02 & 7.41 & 2.13 \\
\hline
\end{tabular}




\begin{tabular}{|c|c|c|c|c|c|c|c|c|c|c|c|c|c|}
\hline \multicolumn{10}{|c|}{ Compositions } & \multirow{2}{*}{\multicolumn{4}{|c|}{$\begin{array}{c}\text { Hydrogen Storage Capacity (wt. \%) } \\
\left.\text { (High Throughput Desorption T ( }{ }^{\circ} \mathrm{C}\right) \text { ) } \\
\mathrm{N}=\text { not measured }\end{array}$}} \\
\hline \multicolumn{2}{|c|}{$\begin{array}{c}\text { Metal } \\
\text { borohydrides }\end{array}$} & \multicolumn{2}{|c|}{ Metal amides } & \multicolumn{2}{|c|}{ Metal Hydrides } & \multicolumn{4}{|c|}{ Dopants } & & & & \\
\hline M-BH4 & mol & M-NH2 & mol & MX-1 & Mol & Dop 1 & mol & Dop 2 & mol & 230 & 230 & 350 & 350 \\
\hline $\mathrm{LiBH}_{4}$ & 1 & $\mathrm{LiNH}_{2}$ & 3 & $\mathrm{LiH}$ & 1.00 & & & & & 1.55 & 0.99 & 5.51 & 0.76 \\
\hline $\mathrm{LiBH}_{4}$ & 1 & $\mathrm{LiNH}_{2}$ & 3 & $\mathrm{LiH}$ & 2.00 & & & & & 1.76 & 1.04 & 6.33 & 1.38 \\
\hline $\mathrm{LiBH}_{4}$ & 1 & $\mathrm{LiNH}_{2}$ & 3 & $\mathrm{LiH}$ & 3.00 & & & & & 1.52 & 0.78 & 5.47 & 1.34 \\
\hline $\mathrm{LiBH}_{4}$ & 1 & $\mathrm{LiNH}_{2}$ & 3 & $\mathrm{LiH}$ & 1.00 & $\mathrm{NiCl}_{2}$ & 0.02 & $\mathrm{CrF}_{3}$ & 0.02 & 7.17 & 0.18 & 1.25 & 1.10 \\
\hline $\mathrm{LiBH}_{4}$ & 1 & $\mathrm{LiNH}_{2}$ & 3 & $\mathrm{LiH}$ & 2.00 & $\mathrm{NiCl}_{2}$ & 0.02 & $\mathrm{CrF}_{3}$ & 0.02 & 0.10 & 6.58 & 1.46 & $\mathrm{~N}$ \\
\hline $\mathrm{LiBH}_{4}$ & 1 & $\mathrm{LiNH}_{2}$ & 3 & $\mathrm{LiH}$ & 3.00 & $\mathrm{NiCl}_{2}$ & 0.02 & $\mathrm{CrF}_{3}$ & 0.02 & 4.12 & 0.80 & 1.66 & 0.58 \\
\hline $\mathrm{LiBH}_{4}$ & 0 & $\mathrm{LiNH}_{2}$ & 1 & $\mathrm{LiH}$ & 1.00 & $\mathrm{NiCl}_{2}$ & 0.02 & $\mathrm{CrF}_{3}$ & 0.02 & 0.35 & 0.13 & 3.89 & 2.35 \\
\hline $\mathrm{LiBH}_{4}$ & 0 & $\mathrm{LiNH}_{2}$ & 1 & $\mathrm{LiH}$ & 2.00 & $\mathrm{NiCl}_{2}$ & 0.02 & $\mathrm{CrF}_{3}$ & 0.02 & 0.41 & 0.14 & 3.79 & 3.19 \\
\hline $\mathrm{LiBH}_{4}$ & 1 & $\mathrm{LiNH}_{2}$ & 1 & $\mathrm{LiH}$ & 1.00 & & & & & $\mathrm{~N}$ & $\mathrm{~N}$ & $\mathrm{~N}$ & $\mathrm{~N}$ \\
\hline $\mathrm{LiBH}_{4}$ & 0.5 & $\mathrm{LiNH}_{2}$ & 1 & $\mathrm{LiH}$ & 1.00 & & & & & $\mathrm{~N}$ & $\mathrm{~N}$ & $\mathrm{~N}$ & $\mathrm{~N}$ \\
\hline $\mathrm{LiBH}_{4}$ & 0.25 & $\mathrm{LiNH}_{2}$ & 1 & $\mathrm{LiH}$ & 1.00 & & & & & 1.39 & 0.71 & 5.60 & 1.72 \\
\hline $\mathrm{LiBH}_{4}$ & 0.1 & $\mathrm{LiNH}_{2}$ & 1 & $\mathrm{LiH}$ & 1.00 & & & & & 0.75 & 0.35 & 3.98 & 1.26 \\
\hline $\mathrm{LiBH}_{4}$ & 1 & $\mathrm{LiNH}_{2}$ & 1 & $\mathrm{LiH}$ & 2.00 & & & & & $\mathrm{~N}$ & $\mathrm{~N}$ & $\mathrm{~N}$ & 0.84 \\
\hline $\mathrm{LiBH}_{4}$ & 0.5 & $\mathrm{LiNH}_{2}$ & 1 & $\mathrm{LiH}$ & 2.00 & & & & & 0.04 & 3.35 & 3.36 & $\mathrm{~N}$ \\
\hline $\mathrm{LiBH}_{4}$ & 0.25 & $\mathrm{LiNH}_{2}$ & 1 & $\mathrm{LiH}$ & 2.00 & & & & & 0.69 & 0.23 & 4.36 & 2.74 \\
\hline $\mathrm{LiBH}_{4}$ & 0.1 & $\mathrm{LiNH}_{2}$ & 1 & $\mathrm{LiH}$ & 2.00 & & & & & 0.43 & 0.22 & 5.48 & 1.08 \\
\hline $\mathrm{KBH}_{4}$ & 1 & $\mathrm{LiNH}_{2}$ & 4 & $\mathrm{KH}$ & 1.10 & $\mathrm{MoO}_{3}$ & 0.04 & & & 0.40 & 0.17 & 1.95 & 1.49 \\
\hline $\mathrm{KBH}_{4}$ & 1 & $\mathrm{LiNH}_{2}$ & 5 & $\mathrm{CaH}_{2}$ & 1.10 & $\mathrm{MoO}_{3}$ & 0.04 & & & 0.52 & 0.14 & 0.99 & 0.97 \\
\hline $\mathrm{LiBH}_{4}$ & 1 & $\mathrm{LiNH}_{2}$ & 5 & $\mathrm{CaH}_{2}$ & 1.10 & $\mathrm{MoO}_{3}$ & 0.04 & & & 1.56 & 0.53 & 3.90 & 1.36 \\
\hline $\mathrm{KBH}_{4}$ & 1 & $\mathrm{LiNH}_{2}$ & 5 & $\mathrm{MgH}_{2}$ & 2.20 & $\mathrm{MoO}_{3}$ & 0.04 & & & 0.57 & 0.28 & 2.46 & 2.68 \\
\hline $\mathrm{LiBH}_{4}$ & 1 & $\mathrm{LiNH}_{2}$ & 5 & $\mathrm{MgH}_{2}$ & 2.20 & $\mathrm{MoO}_{3}$ & 0.1 & & & 3.76 & 3.38 & 6.19 & 2.02 \\
\hline $\mathrm{LiBH}_{4}$ & 1 & $\mathrm{LiNH}_{2}$ & 4 & $\mathrm{KH}$ & 1.00 & $\mathrm{MoO}_{3}$ & 0.05 & & & 0.52 & 0.19 & 2.25 & 1.25 \\
\hline $\mathrm{LiBH}_{4}$ & 1 & $\mathrm{LiNH}_{2}$ & 3 & & & $\mathrm{MoO}_{3}$ & 0.06 & & & 0.61 & 0.29 & 3.84 & 0.31 \\
\hline $\mathrm{LiBH}_{4}$ & 1 & $\mathrm{LiNH}_{2}$ & 5 & $\mathrm{TiH}_{2}$ & 2.10 & $\mathrm{MoO}_{3}$ & 0.1 & & & 3.29 & 0.09 & 0.75 & 0.41 \\
\hline $\mathrm{LiBH}_{4}$ & 2 & $\mathrm{LiNH}_{2}$ & 4 & & & $\mathrm{NiCl}_{2}$ & 0.02 & $\mathrm{CrF}_{3}$ & 0.02 & 9.66 & 0.33 & 0.95 & 0.36 \\
\hline $\mathrm{LiBH}_{4}$ & 2 & $\mathrm{LiNH}_{2}$ & 4 & & & $\mathrm{NiCl}_{2}$ & 0.02 & $\mathrm{CrF}_{3}$ & 0.01 & 8.48 & 0.31 & 0.28 & 0.08 \\
\hline $\mathrm{LiBH}_{4}$ & 2 & $\mathrm{LiNH}_{2}$ & 4 & & & $\mathrm{NiCl}_{2}$ & 0.02 & $\mathrm{CrF}_{3}$ & 0.03 & 9.00 & 0.24 & 1.06 & 0.40 \\
\hline $\mathrm{LiBH}_{4}$ & 2 & $\mathrm{LiNH}_{2}$ & 4 & & & $\mathrm{NiCl}_{2}$ & 0.03 & $\mathrm{CrF}_{3}$ & 0.01 & 9.64 & 0.23 & 0.78 & 0.29 \\
\hline $\mathrm{LiBH}_{4}$ & 3 & $\mathrm{LiNH}_{2}$ & 6 & & & $\mathrm{NiCl}_{2}$ & 0.02 & $\mathrm{CrF}_{3}$ & 0.02 & 9.43 & 0.30 & 0.85 & 0.30 \\
\hline $\mathrm{LiBH}_{4}$ & 3 & $\mathrm{LiNH}_{2}$ & 6 & & & $\mathrm{NiCl}_{2}$ & 0.02 & $\mathrm{CrF}_{3}$ & 0.01 & 9.47 & 0.24 & 0.79 & 0.36 \\
\hline $\mathrm{LiBH}_{4}$ & 3 & $\mathrm{LiNH}_{2}$ & 6 & & & $\mathrm{NiCl}_{2}$ & 0.02 & $\mathrm{CrF}_{3}$ & 0.03 & 9.21 & 0.39 & 0.78 & 0.28 \\
\hline $\mathrm{LiBH}_{4}$ & 3 & $\mathrm{LiNH}_{2}$ & 6 & & & $\mathrm{NiCl}_{2}$ & 0.03 & $\mathrm{CrF}_{3}$ & 0.01 & 7.14 & 0.79 & 1.29 & 0.32 \\
\hline $\mathrm{LiBH}_{4}$ & 0.3 & $\mathrm{LiNH}_{2}$ & 0.6 & & & $\mathrm{NiCl}_{2}$ & 0.02 & $\mathrm{CrF}_{3}$ & 0.02 & $\mathrm{~N}$ & $\mathrm{~N}$ & 7.90 & 0.09 \\
\hline $\mathrm{LiBH}_{4}$ & 0.3 & $\mathrm{LiNH}_{2}$ & 0.6 & & & $\mathrm{NiCl}_{2}$ & 0.02 & $\mathrm{ZrF}_{4}$ & 0.02 & $\mathrm{~N}$ & $\mathrm{~N}$ & 6.88 & 0.06 \\
\hline $\mathrm{LiBH}_{4}$ & 0.3 & $\mathrm{LiNH}_{2}$ & 0.6 & & & $\mathrm{NiCl}_{2}$ & 0.02 & $\mathrm{YbCl}_{3}$ & 0.02 & $\mathrm{~N}$ & $\mathrm{~N}$ & $\mathrm{~N}$ & 0.04 \\
\hline $\mathrm{LiBH}_{4}$ & 1 & $\mathrm{LiNH}_{2}$ & 2 & & & $\mathrm{NiCl}_{2}$ & 0.02 & $\mathrm{CrF}_{3}$ & 0.02 & $\mathrm{~N}$ & $\mathrm{~N}$ & 10.10 & 0.13 \\
\hline $\mathrm{LiBH}_{4}$ & 1 & $\mathrm{LiNH}_{2}$ & 2 & & & $\mathrm{NiCl}_{2}$ & 0.02 & $\mathrm{CrF}_{3}$ & 0.01 & $\mathrm{~N}$ & $\mathrm{~N}$ & 8.50 & 0.18 \\
\hline $\mathrm{LiBH}_{4}$ & 0.3 & $\mathrm{LiNH}_{2}$ & 0.6 & & & $\mathrm{NiCl}_{2}$ & 0.01 & $\mathrm{CrF}_{3}$ & 0.01 & $\mathrm{~N}$ & $\mathrm{~N}$ & $\mathrm{~N}$ & 0.07 \\
\hline $\mathrm{LiBH}_{4}$ & 0.3 & $\mathrm{LiNH}_{2}$ & 0.6 & & & $\mathrm{NiCl}_{2}$ & 0.02 & $\mathrm{CrF}_{3}$ & 0.02 & $\mathrm{~N}$ & $\mathrm{~N}$ & 8.91 & 0.10 \\
\hline $\mathrm{LiBH}_{4}$ & 0.3 & $\mathrm{LiNH}_{2}$ & 0.6 & & & $\mathrm{NiCl}_{2}$ & 0.015 & $\mathrm{CrF}_{3}$ & 0.02 & $\mathrm{~N}$ & $\mathrm{~N}$ & $\mathrm{~N}$ & 0.01 \\
\hline
\end{tabular}




\begin{tabular}{|c|c|c|c|c|c|c|c|c|c|c|c|c|c|c|}
\hline \multicolumn{10}{|c|}{ Composition } & \multicolumn{5}{|c|}{ XRD of Spent Materials } \\
\hline $\mathrm{MNH}_{2}$ & mol & $\mathrm{MBH}_{4}$ & $\mathrm{~mol}$ & $\mathrm{MH}-1$ & $\mathrm{~mol}$ & MH-2 & Mol & Dopants & $\mathrm{mol}$ & xrd 1 & xrd 2 & xrd 3 & xrd 4 & xrd 5 \\
\hline $\mathrm{LiNH}_{2}$ & 0.8 & $\mathrm{LiBH}_{4}$ & 0.2 & & & & & $\mathrm{Ti}(\mathrm{OiPr})_{4}$ & 0.02 & $\mathrm{LiOH}$ & $\mathrm{Li}_{2} \mathrm{NH} / \mathrm{LiNH}_{2}$ & LiNB3-1 & & \\
\hline $\mathrm{LiNH}_{2}$ & 0.2 & $\mathrm{LiBH}_{4}$ & 0.8 & & & & & $\mathrm{Ti}(\mathrm{OiPr})_{4}$ & 0.02 & $\mathrm{~B}(\mathrm{OH})_{3}$ & $\mathrm{LiBH}_{4}$ & $\mathrm{Li}_{3} \mathrm{BN}_{2}$ & LiNB3-1 & \\
\hline $\mathrm{LiNH}_{2}$ & 0.5 & $\mathrm{LiBH}_{4}$ & 0.5 & $\mathrm{MgH}_{2}$ & 1 & & & $\mathrm{Ti}(\mathrm{OiPr})_{4}$ & 0.02 & $\mathrm{MgH}_{2}$ & LiNB3-1 & $\begin{array}{c}\text { unk., } d=2.17(b r) \\
2.02,1.97\end{array}$ & & \\
\hline $\mathrm{LiNH}_{2}$ & 0.33 & $\mathrm{LiBH}_{4}$ & 0.67 & $\mathrm{MgH}_{2}$ & 1 & & & $\mathrm{Ti}(\mathrm{OiPr})_{4}$ & 0.02 & $\mathrm{MgH}_{2}$ & $\begin{array}{c}\text { Unk., } d= \\
1.88\end{array}$ & & & \\
\hline $\mathrm{LiNH}_{2}$ & 2 & $\mathrm{Zn}\left(\mathrm{BH}_{4}\right)_{2}$ & 1 & & & & & $\mathrm{Ti}(\mathrm{OiPr})_{4}$ & 0.01 & $\mathrm{BN}$ & $\mathrm{Zn}$ & $\mathrm{NaCl}$ & $\mathrm{LiCl}$ & WC \\
\hline $\mathrm{NaNH}_{2}$ & 0.5 & $\mathrm{LiBH}_{4}$ & 0.5 & & & & & $\mathrm{Ti}(\mathrm{OiPr})_{4}$ & 0.02 & $\mathrm{NaBH}_{4}$ & $\mathrm{Li}_{2} \mathrm{NH}$ & & & \\
\hline $\mathrm{NaNH}_{2}$ & 0.5 & $\mathrm{NaBH}_{4}$ & 0.5 & & & & & $\mathrm{Ti}(\mathrm{OiPr})_{4}$ & 0.02 & $\mathrm{NaBH}_{4}$ & $\mathrm{NaNH}_{2}$ & WC & & \\
\hline $\mathrm{NaNH}_{2}$ & 0.33 & $\mathrm{LiBH}_{4}$ & 0.67 & & & & & $\mathrm{Ti}(\mathrm{OiPr})_{4}$ & 0.02 & $\mathrm{NaBH}_{4}$ & & & & \\
\hline $\mathrm{NaNH}_{2}$ & 0.33 & $\mathrm{NaBH}_{4}$ & 0.67 & & & & & $\mathrm{Ti}(\mathrm{OiPr})_{4}$ & 0.02 & $\mathrm{NaBH}_{4}$ & $\mathrm{NaH}$ & C & & \\
\hline $\mathrm{NaNH}_{2}$ & 0.67 & $\mathrm{LiBH}_{4}$ & 0.33 & & & & & $\mathrm{Ti}(\mathrm{OiPr})_{4}$ & 0.02 & $\mathrm{NaBH}_{4}$ & $\mathrm{Li}_{3} \mathrm{Na}\left(\mathrm{NH}_{2}\right)_{4}$ & $\mathrm{NaH}$ & $\mathrm{NaNH}_{2}$ & $\mathrm{LiNH}_{2}$ \\
\hline $\mathrm{LiNH}_{2}$ & 6 & $\mathrm{LiBH}_{4}$ & 1 & $\mathrm{MgH}_{2}$ & 2.2 & $\mathrm{NaH}$ & 1 & & & $\mathrm{Li}_{2} \mathrm{Mg}(\mathrm{NH})_{2}$ & $\mathrm{Li}_{2} \mathrm{NH}$ & $\mathrm{NaBH}_{4}$ & LiNB3-1 & $\mathrm{NaMgH}_{3}$ \\
\hline $\mathrm{Mg}\left(\mathrm{NH}_{2}\right)_{2}$ & 1 & $\mathrm{LiBH}_{4}$ & 2 & & & & & & & A & $\mathrm{MgH}_{2}$ & & & \\
\hline $\mathrm{Mg}\left(\mathrm{NH}_{2}\right)_{2}$ & 1 & $\mathrm{LiBH}_{4}$ & 1 & $\mathrm{LiNH}_{2}$ & 2 & $\mathrm{MgH}_{2}$ & 1.1 & & & $\mathrm{Mg}\left(\mathrm{NH}_{2}\right)_{2}$ & $\mathrm{Li}_{2} \mathrm{Mg}(\mathrm{NH})_{2}$ & & & \\
\hline $\mathrm{Mg}\left(\mathrm{NH}_{2}\right)_{2}$ & 1 & $\mathrm{LiBH}_{4}$ & 1 & $\mathrm{LiNH}_{2}$ & 1 & $\mathrm{MgH}_{2}$ & 0.55 & & & $\mathrm{Mg}\left(\mathrm{NH}_{2}\right)_{2}$ & LiNB3-1 & $\mathrm{LiBH}_{4}$ & & \\
\hline $\mathrm{Mg}\left(\mathrm{NH}_{2}\right)_{2}$ & 1 & $\mathrm{LiBH}_{4}$ & 1 & $\mathrm{LiNH}_{2}$ & 2 & & & & & $\mathrm{Mg}\left(\mathrm{NH}_{2}\right)_{2}$ & LiNB3-1 & $\mathrm{LiBH}_{4}$ & & \\
\hline $\mathrm{LiNH}_{2}$ & 2 & $\mathrm{LiBH}_{4}$ & 1 & & & & & $\mathrm{NiCl}_{2}$ & 0.02 & WC & $\mathrm{BN}$ & $\mathrm{Li}_{3} \mathrm{BN}_{2}$ & & \\
\hline $\mathrm{LiNH}_{2}$ & 0.6 & $\mathrm{LiBH}_{4}$ & 0.3 & & & & & $\mathrm{NiCl}_{2} / \mathrm{CrF}_{3}$ & $0.01 / 0.01$ & $\mathrm{LiOH}$ & $\mathrm{Na}_{2} \mathrm{CO}_{3}$ & & & \\
\hline $\mathrm{LiNH}_{2}$ & 0.6 & $\mathrm{LiBH}_{4}$ & 0.3 & & & & & $\mathrm{NiCl}_{2} / \mathrm{CrF}_{3}$ & $\begin{array}{c}0.02 / 0.01 \\
5\end{array}$ & WC & $\mathrm{NaAlO}_{2}{ }^{*} \mathrm{H}_{2} \mathrm{O}$ & & & \\
\hline $\mathrm{LiNH}_{2}$ & 0.6 & $\mathrm{LiBH}_{4}$ & 0.3 & & & & & $\mathrm{NiCl}_{2} / \mathrm{CrF}_{3}$ & $\begin{array}{c}0.015 / 0.0 \\
15\end{array}$ & $\mathrm{Na}_{2} \mathrm{CO}_{3}$ & & & & \\
\hline $\mathrm{LiNH}_{2}$ & 3 & $\mathrm{LiBH}_{4}$ & 1 & & & & & $\mathrm{Cr}_{2} \mathrm{O}_{3}$ & 0.02 & LiNB3-1 & $\mathrm{Cr}_{2} \mathrm{O}_{3}$ & unk., $d=2.94$ & & \\
\hline $\mathrm{LiNH}_{2}$ & 3 & $\mathrm{LiBH}_{4}$ & 1 & & & & & $\begin{array}{c}\mathrm{Cr}_{2} \mathrm{O}_{3} / \mathrm{Ni} \\
\mathrm{Cl}_{2}\end{array}$ & $0.02 / 0.02$ & $\mathrm{Li}_{2} \mathrm{NH}$ & $\mathrm{LiBO}_{2}$ & $\mathrm{Cr}_{2} \mathrm{O}_{3}$ & & \\
\hline $\mathrm{LiNH}_{2}$ & 4 & $\mathrm{KBH}_{4}$ & 1 & $\mathrm{KH}$ & 1.1 & & & $\mathrm{MoO}_{3}$ & 0.04 & $\mathrm{KBH}_{4}$ & $\mathrm{KH}$ & $\mathrm{KOH}^{\star} \mathrm{H}_{2} \mathrm{O}$ & $\mathrm{KLi}_{3}\left(\mathrm{NH}_{2}\right)_{4}$ & \\
\hline $\mathrm{LiNH}_{2}$ & 5 & $\mathrm{KBH}_{4}$ & 1 & $\mathrm{CaH}_{2}$ & 1.1 & & & $\mathrm{MoO}_{3}$ & 0.04 & $\mathrm{KBH}_{4}$ & $\mathrm{Li}_{2} \mathrm{NH}$ & $\mathrm{CaNH}$ & $\mathrm{CaH}_{2}$ & $\mathrm{KLi}_{3}\left(\mathrm{NH}_{2}\right)_{4}$ \\
\hline $\mathrm{LiNH}_{2}$ & 5 & $\mathrm{KBH}_{4}$ & 1 & $\mathrm{MgH}_{2}$ & 2.2 & & & $\mathrm{MoO}_{3}$ & 0.04 & LiMgBNH\#2 & $\mathrm{KBH}_{4}$ & $\mathrm{MgH}_{2}$ & & \\
\hline $\mathrm{LiNH}_{2}$ & 2 & $\mathrm{NaBH}_{4}$ & 1 & $\mathrm{NaNH}_{2}$ & 1 & & & $\mathrm{NiCl}_{2}$ & 0.02 & $\mathrm{KBH}_{4}$ & $\mathrm{Li}_{3} \mathrm{Na}\left(\mathrm{NH}_{2}\right)_{4}$ & $\mathrm{Li}_{2} \mathrm{NH}$ & WC & \\
\hline $\mathrm{LiNH}_{2}$ & 3 & $\mathrm{NaBH}_{4}$ & 1 & & & & & $\mathrm{NiCl}_{2}$ & 0.02 & $\mathrm{KBH}_{4}$ & $\mathrm{Li}_{2} \mathrm{NH}$ & & & \\
\hline $\mathrm{LiNH}_{2}$ & 4 & $\mathrm{KBH}_{4}$ & 1 & $\mathrm{NaNH}_{2}$ & 1 & $\mathrm{MgH}_{2}$ & 1.2 & $\mathrm{NiCl}_{2}$ & 0.04 & $\mathrm{KBH}_{4}$ & $\mathrm{Li}_{2} \mathrm{NH}$ & $\mathrm{Li}_{2} \mathrm{Mg}(\mathrm{NH})_{2}$ & $\mathrm{NaBH}_{4}$ & \\
\hline $\mathrm{LiNH}_{2}$ & 6 & $\mathrm{Ca}\left(\mathrm{BH}_{4}\right)_{2}{ }^{*}$ & 1 & $\mathrm{MgH}_{2}$ & 1.2 & & & $\mathrm{NiCl}_{2}$ & 0.04 & LiNB3-1 & $\mathrm{CaB}_{6}$ & B & & \\
\hline $\mathrm{LiNH}_{2}$ & 5 & $\mathrm{Ca}\left(\mathrm{BH}_{4}\right)_{2}{ }^{*}$ & 1 & $\mathrm{NaNH}_{2}$ & 1 & $\mathrm{MgH}_{2}$ & 1.2 & $\mathrm{NiCl}_{2}$ & 0.04 & $\mathrm{MgCl}_{2}$ & LiMgBNH\#2 & Li-Ca-B-N\#1 & & \\
\hline $\mathrm{LiNH}_{2}$ & 5 & $\mathrm{Ca}\left(\mathrm{BH}_{4}\right)_{2}{ }^{*}$ & 1 & $\mathrm{NaNH}_{2}$ & 1 & $\mathrm{MgH}_{2}$ & 1.2 & $\mathrm{NiCl}_{2}$ & 0.04 & $\mathrm{Li}_{2} \mathrm{NH}$ & $\mathrm{NaBH}_{4}$ & $\mathrm{Li}_{2} \mathrm{Mg}(\mathrm{NH})_{2}$ & $\mathrm{CaB}_{6}$ & $\mathrm{CaH}_{2}$ \\
\hline $\mathrm{LiNH}_{2}$ & 5 & $\mathrm{Ca}\left(\mathrm{BH}_{4}\right)_{2}{ }^{*}$ & 1 & $\mathrm{NaNH}_{2}$ & 1 & $\mathrm{MgH}_{2}$ & 1.2 & & & $\mathrm{NaBH}_{4}$ & LiNB3-1 & $\mathrm{Li}_{2} \mathrm{Mg}(\mathrm{NH})_{2}$ & $\mathrm{CaH}_{2}$ & $\mathrm{Ca}\left(\mathrm{NH}_{2}\right)_{2}$ \\
\hline $\mathrm{LiNH}_{2}$ & 5 & $\mathrm{LiBH}_{4}$ & 1 & $\mathrm{MgCl}_{2}$ & 2.2 & & & & & $\mathrm{LiCl}$ & $\mathrm{MgCl}_{2}$ & $\mathrm{Mg}\left(\mathrm{NH}_{2}\right)_{2}$ & LiMgNBH \#1 & \\
\hline $\mathrm{LiNH}_{2}$ & 5 & $\mathrm{LiBH}_{4}$ & 1 & $\mathrm{MgCl}_{2}$ & 2.2 & $\mathrm{LiH}$ & 1 & & & $\mathrm{LiCl}$ & $\mathrm{MgCl}_{2}$ & WC & LiMgNBH \#1 & \\
\hline
\end{tabular}




\begin{tabular}{|c|c|c|c|c|c|c|c|}
\hline \multicolumn{3}{|c|}{ Composition } & \multicolumn{3}{|c|}{ Spent XRD in order of abundance } & \multicolumn{2}{|c|}{$\begin{array}{c}\text { Hydrogen Storage } \\
\text { Capacity (Wt. \%) }\end{array}$} \\
\hline $\mathrm{LiNH}_{2}$ & $\mathrm{LiBH}_{4}$ & $\mathrm{LiAlH}_{4}$ & xrd 1 & xrd 2 & xrd 3 & $230^{\circ} \mathrm{C}$ & $230^{\circ} \mathrm{C}$ \\
\hline 0 & 0.125 & 0.875 & $\mathrm{Al} / \mathrm{LiH}$ & Unk., $d=2.59,1.83$ & & 5.63 & 0.12 \\
\hline 0 & 0.25 & 0.75 & $\mathrm{Al}$ & $\mathrm{NaBH}_{4}$ & & 4.71 & 0.18 \\
\hline 0 & 0.375 & 0.625 & Al & $\begin{array}{l}\text { Unk., } \mathrm{Ca}_{2} \mathrm{Ti}_{5} \mathrm{O}_{2} \text { structure?- } \mathrm{d}= \\
2.87,2.49,1.88,1.76\end{array}$ & Unk., $d=3.90,2.77$ & 3.33 & 0.26 \\
\hline 0 & 0.5 & 0.5 & $\begin{array}{l}\text { Unk., } d=3.92,2.89,2.77,2.56,2.46 \\
2.36,2.04,1.88,1.76,1.70\end{array}$ & & & 2.51 & 0.30 \\
\hline 0 & 0.625 & 0.375 & Al & unk., $d=3.08$ & & 4.71 & 0.21 \\
\hline 0 & 0.75 & 0.25 & $\mathrm{Al}$ & $\begin{array}{l}\text { unk., } d=3.58,3.10,2.70,2.19 \\
1.87,1.84,1.79\end{array}$ & & 3.90 & 0.10 \\
\hline 0 & 0.875 & 0.125 & $\mathrm{Al}$ & & & 6.26 & 0.13 \\
\hline 0.125 & 0 & 0.875 & $\mathrm{Al}$ & $\mathrm{LiBH}_{4}$ & $\begin{array}{l}\text { unk, } d=3.60,3.40,2.59 \\
2.54,2.47,2.26,1.96\end{array}$ & 1.65 & 0.10 \\
\hline 0.125 & 0.125 & 0.75 & $\mathrm{Al}$ & $\mathrm{LiH} / \mathrm{Al}$ & & 5.03 & 0.23 \\
\hline 0.125 & 0.25 & 0.625 & & & & 3.89 & 0.40 \\
\hline 0.125 & 0.375 & 0.5 & $\mathrm{Al}$ & $\mathrm{LiBH}_{4}$ & Unk., $d=3.60,2.18$ & 4.14 & 0.74 \\
\hline 0.125 & 0.5 & 0.375 & $\mathrm{Al} / \mathrm{LiH}$ & & & 3.38 & 0.36 \\
\hline 0.125 & 0.625 & 0.25 & $\mathrm{Al} / \mathrm{LiH}$ & & & 2.82 & 0.34 \\
\hline 0.125 & 0.75 & 0.125 & $\mathrm{AM}$ & & & 2.59 & 1.42 \\
\hline 0.25 & 0 & 0.75 & AM & $\mathrm{Al} / \mathrm{LiH}$ & & 5.32 & 0.28 \\
\hline 0.25 & 0.125 & 0.625 & $\mathrm{Al} / \mathrm{LiH}$ & $\mathrm{NaBH}_{4}$ & & 3.63 & 0.73 \\
\hline 0.25 & 0.25 & 0.5 & AM & $\mathrm{Al}$ & & 3.10 & 0.35 \\
\hline 0.25 & 0.375 & 0.375 & AM & $\mathrm{Al}$ & & 1.69 & 0.38 \\
\hline 0.25 & 0.5 & 0.25 & $\mathrm{Al} / \mathrm{LiH}$ & $\mathrm{NaBH}_{4}$ & & 3.14 & 0.59 \\
\hline 0.25 & 0.625 & 0.125 & AM & $\mathrm{NaBH}_{4}$ & & 0.35 & 2.04 \\
\hline 0.375 & 0 & 0.625 & $\mathrm{Al} / \mathrm{LiH}$ & $\mathrm{Li}_{3} \mathrm{AlN}_{2}$ & & 4.87 & 0.41 \\
\hline 0.375 & 0.125 & 0.5 & AM & $\mathrm{Al} / \mathrm{LiH}$ & & 4.56 & 0.73 \\
\hline 0.375 & 0.25 & 0.375 & $\mathrm{NaBH}_{4}$ & $\mathrm{Al} / \mathrm{LiH}$ & WC & 1.83 & 0.43 \\
\hline 0.375 & 0.375 & 0.25 & $\mathrm{Al}$ & $\mathrm{LiBH}_{4}$ & WC & 1.80 & 0.88 \\
\hline 0.375 & 0.5 & 0.125 & AM & $\mathrm{Li}_{4}\left(\mathrm{NH}_{2}\right)_{3} \mathrm{BH}_{4}$ & $\mathrm{Al}$ & 2.16 & 1.53 \\
\hline 0.5 & 0 & 0.5 & AM & $\mathrm{Al}$ & unk., $d=3.01,2.84$ & 3.34 & 0.58 \\
\hline 0.5 & 0.125 & 0.375 & AM & $\mathrm{Al}(\mathrm{tr})$ & & 4.31 & 1.12 \\
\hline 0.5 & 0.25 & 0.25 & $\mathrm{LiH} / \mathrm{Al}$ & unk., $d=1.90$ & & 3.51 & 1.30 \\
\hline 0.5 & 0.375 & 0.125 & $\begin{array}{l}\text { Unk., } d=3.26,3.13,3.08,3.01,2.96 \\
2.85,2.53,1.89\end{array}$ & $\mathrm{Al} / \mathrm{LiH}$ & & 2.57 & 1.26 \\
\hline 0.625 & 0 & 0.375 & $\mathrm{Al} / \mathrm{LiH}$ & WC & Unk., $d=3.91,2.77,1.76$ & 3.25 & 0.42 \\
\hline 0.625 & 0.125 & 0.25 & Unk., $d=2.27,1.97$ & & & 2.60 & 1.38 \\
\hline 0.625 & 0 & 0.125 & $\mathrm{Li}_{4}\left(\mathrm{NH}_{2}\right)_{3} \mathrm{BH}_{4}$ & & & 2.10 & 1.31 \\
\hline
\end{tabular}




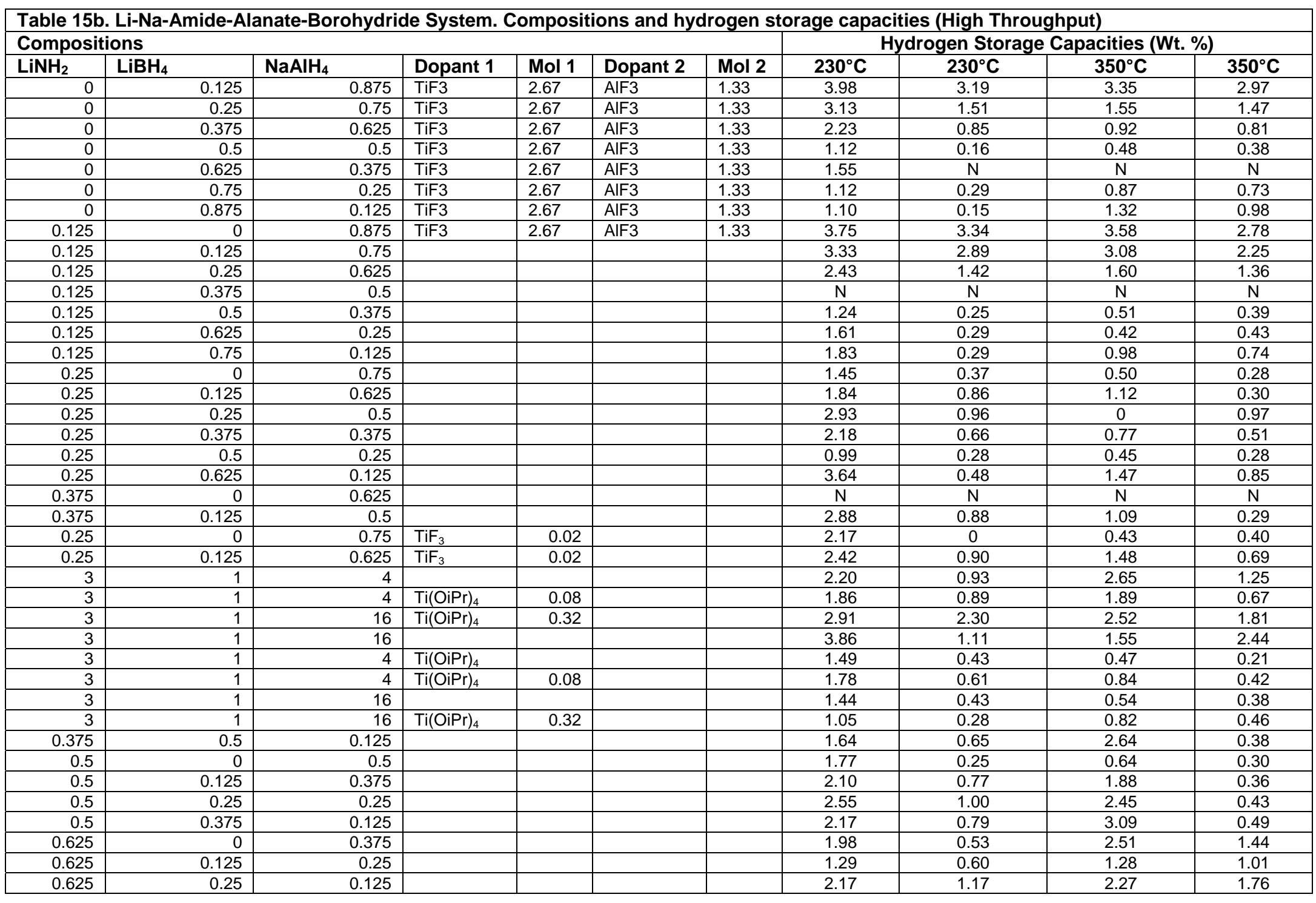




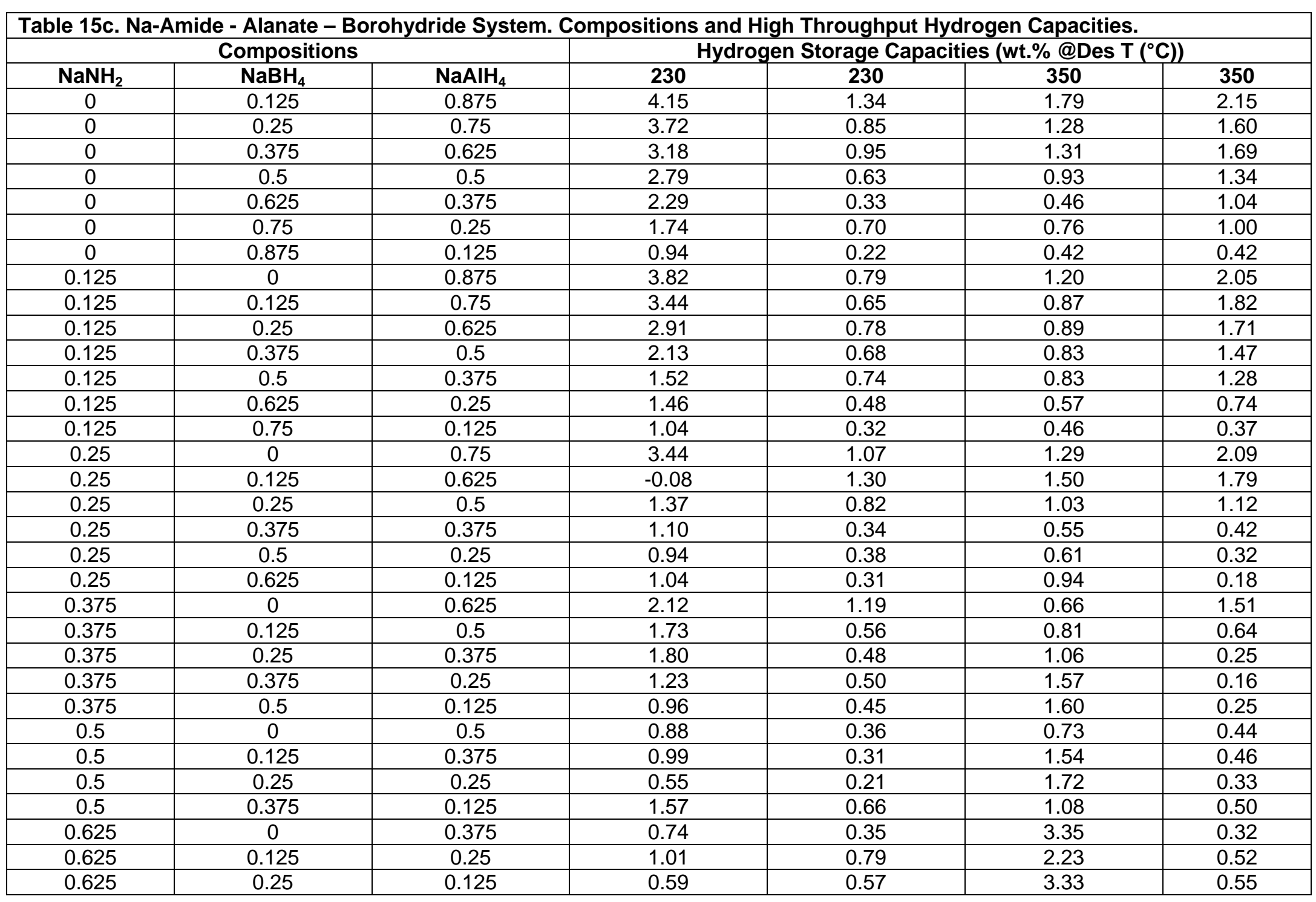




\begin{tabular}{|c|c|c|c|c|c|c|c|c|c|c|c|c|c|}
\hline \multicolumn{8}{|c|}{ Composition } & \multicolumn{2}{|c|}{$\begin{array}{l}\text { Medium Throughput } \\
\text { (wt. \%), Des } \mathrm{T}=220^{\circ} \mathrm{C}\end{array}$} & \multicolumn{4}{|c|}{ High Throughput (wt.\%), Des T $\left({ }^{\circ} \mathrm{C}\right)$} \\
\hline $\mathrm{LiNH}_{2}$ & $\mathrm{LiBH}_{4}$ & $\mathrm{NaAlH}_{4}^{*}$ & $\mathrm{MgH}_{2}$ & dop 1 & mol & dop 2 & mol & Des 1 & Des 2 & 230 & 230 & 350 & 350 \\
\hline 0.666 & 0.167 & $0.167^{*}$ & & $\mathrm{Ti}(\mathrm{OiPr})_{4}$ & 0.02 & $\mathrm{NiCl}_{2}$ & 0.02 & 3.78 & 1.58 & $\mathrm{~N}$ & $\mathrm{~N}$ & $\mathrm{~N}$ & $\mathrm{~N}$ \\
\hline 0.777 & 0.111 & $0.111^{\star}$ & & $\mathrm{Ti}(\mathrm{OiPr})_{4}$ & 0.02 & $\mathrm{NiCl}_{2}$ & 0.02 & 3.00 & 1.20 & $\mathrm{~N}$ & $\mathrm{~N}$ & $\mathrm{~N}$ & $\mathrm{~N}$ \\
\hline 0.777 & 0.111 & $0.111^{*}$ & & $\mathrm{Ti}(\mathrm{OiPr})_{4}$ & 0.02 & $\mathrm{NiCl}_{2}$ & 0.02 & 2.68 & 1.31 & $\mathrm{~N}$ & $\mathrm{~N}$ & $\mathrm{~N}$ & $\mathrm{~N}$ \\
\hline 0.777 & 0.111 & 0.111 & & $\mathrm{TiH}_{2}$ & 0.02 & $\mathrm{Cr}_{2} \mathrm{O}_{3}$ & 0.02 & 1.07 & 0.66 & $\mathrm{~N}$ & $\mathrm{~N}$ & $\mathrm{~N}$ & $\mathrm{~N}$ \\
\hline 0.666 & 0.167 & 0.167 & & $\mathrm{TiH}_{2}$ & 0.02 & $\mathrm{Cr}_{2} \mathrm{O}_{3}$ & 0.02 & 1.03 & 0.55 & $\mathrm{~N}$ & $\mathrm{~N}$ & $\mathrm{~N}$ & $\mathrm{~N}$ \\
\hline 0.777 & 0.111 & 0.111 & & $\mathrm{TiH}_{2}$ & 0.02 & $\mathrm{Cr}_{2} \mathrm{O}_{3}$ & 0.02 & 0.84 & 0.42 & $\mathrm{~N}$ & $\mathrm{~N}$ & $\mathrm{~N}$ & $\mathrm{~N}$ \\
\hline 0.125 & 0.125 & 0.75 & & $\mathrm{TiCl} 3$ & 0.02 & $\mathrm{AlCl}_{3}$ & 0.02 & $\mathrm{~N}$ & $\mathrm{~N}$ & 2.32 & 1.79 & 2.07 & 1.49 \\
\hline 0.125 & 0.125 & 0.75 & & $\mathrm{TiF}_{3}$ & 0.02 & $\mathrm{AlF}_{3}$ & 0.02 & 3.55 & 1.77 & 3.72 & 1.58 & 1.82 & 0.73 \\
\hline 0.125 & 0.125 & 0.75 & & $\mathrm{AlCl}_{3}$ & 0.02 & $\mathrm{CoCl}_{2}$ & 0.02 & 2.83 & 2.09 & 2.74 & 1.81 & 2.02 & 1.42 \\
\hline 0.125 & 0.125 & 0.75 & & $\mathrm{TiCl}_{3}$ & 0.02 & $\mathrm{NiCl}_{2}$ & 0.02 & 2.43 & 2.37 & 2.25 & 2.10 & 2.37 & 1.75 \\
\hline 0.125 & 0.125 & 0.75 & & $\mathrm{AlCl}_{3}$ & 0.02 & $\mathrm{TiF}_{3}$ & 0.02 & $\mathrm{~N}$ & $\mathrm{~N}$ & 3.33 & 1.30 & 1.59 & 0.38 \\
\hline 0.125 & 0.125 & 0.75 & & $\mathrm{TiCl}_{3}$ & 0.02 & $\mathrm{AlF}_{3}$ & 0.02 & 3.06 & 2.88 & 2.96 & 2.49 & 2.75 & 2.15 \\
\hline 0.125 & 0.125 & 0.75 & & $\mathrm{TiF}_{3}$ & 0.02 & $\mathrm{CoCl}_{2}$ & 0.02 & 3.33 & 3.11 & 3.17 & 2.47 & 2.72 & 2.09 \\
\hline 0.125 & 0.125 & 0.75 & & $\mathrm{TiF}_{3}$ & 0.02 & $\mathrm{NiCl}_{2}$ & 0.02 & 3.29 & 3.04 & 3.43 & 2.60 & 2.93 & 2.15 \\
\hline 0.125 & 0.25 & 0.625 & & $\mathrm{AlCl}_{3}$ & 0.02 & $\mathrm{TiCl}_{3}$ & 0.02 & $\mathrm{~N}$ & $\mathrm{~N}$ & 1.94 & 0.72 & 1.78 & 1.46 \\
\hline 0.125 & 0.25 & 0.625 & & $\mathrm{AlCl}_{3}$ & 0.02 & $\mathrm{CoCl}_{2}$ & 0.02 & $\mathrm{~N}$ & $\mathrm{~N}$ & 1.08 & 0.31 & 0.54 & 0.19 \\
\hline 0.125 & 0.25 & 0.625 & & $\mathrm{TiCl}_{3}$ & 0.02 & $\mathrm{NiCl}_{2}$ & 0.02 & $\mathrm{~N}$ & $\mathrm{~N}$ & 1.57 & 0.95 & 1.14 & 0.84 \\
\hline 0.125 & 0.25 & 0.625 & & $\mathrm{AlCl}_{3}$ & 0.02 & $\mathrm{NiCl}_{2}$ & 0.02 & $\mathrm{~N}$ & $\mathrm{~N}$ & 2.00 & 1.03 & 1.36 & 0.82 \\
\hline 0.125 & 0.25 & 0.625 & & $\mathrm{TiCl}_{3}$ & 0.02 & & & $\mathrm{~N}$ & $\mathrm{~N}$ & 2.15 & 1.35 & 1.69 & 1.06 \\
\hline 0.105 & 0.25 & 0.63 & & $\mathrm{TiF}_{3}$ & 0.02 & $\mathrm{CoCl}_{2}$ & 0.02 & $\mathrm{~N}$ & $\mathrm{~N}$ & 3.36 & 2.64 & 2.87 & 2.11 \\
\hline 0.105 & 0.25 & 0.63 & & $\mathrm{AlCl}_{3}$ & 0.02 & $\mathrm{NiCl}_{2}$ & 0.02 & $\mathrm{~N}$ & $\mathrm{~N}$ & 3.37 & 2.59 & 2.82 & 2.16 \\
\hline 0.25 & 0.25 & 0.5 & & $\mathrm{AlCl}_{3}$ & 0.02 & $\mathrm{TiCl}_{3}$ & 0.02 & $\mathrm{~N}$ & $\mathrm{~N}$ & 0.73 & 0.49 & 0.91 & 0.49 \\
\hline 0.25 & 0.25 & 0.5 & & $\mathrm{TiCl}_{3}$ & 0.02 & $\mathrm{CoCl}_{2}$ & 0.02 & $\mathrm{~N}$ & $\mathrm{~N}$ & 1.02 & 0.63 & 1.09 & 0.48 \\
\hline 0.25 & 0.25 & 0.5 & & $\mathrm{AlCl}_{3}$ & 0.02 & $\mathrm{CoCl}_{2}$ & 0.02 & $\mathrm{~N}$ & $\mathrm{~N}$ & 0.81 & 0.51 & 0.98 & 0.56 \\
\hline 0.25 & 0.25 & 0.5 & & $\mathrm{TiCl}_{3}$ & 0.02 & $\mathrm{NiCl}_{2}$ & 0.02 & $\mathrm{~N}$ & $\mathrm{~N}$ & 0.86 & 0.49 & 0.93 & 0.37 \\
\hline 0.526 & 0.066 & 0.263 & 0.145 & $\mathrm{AlCl}_{3}$ & 0.02 & $\mathrm{TiCl}_{3}$ & 0.02 & $\mathrm{~N}$ & $\mathrm{~N}$ & 1.41 & 0.61 & 2.00 & 0.20 \\
\hline 0.53 & 0.076 & 0.227 & 0.167 & $\mathrm{AlCl}_{3}$ & 0.02 & $\mathrm{TiCl}_{3}$ & 0.02 & $\mathrm{~N}$ & $\mathrm{~N}$ & 1.34 & 0.60 & 2.55 & 0.17 \\
\hline
\end{tabular}




\begin{tabular}{|c|c|c|c|c|c|c|c|c|c|c|c|c|c|c|c|}
\hline \multicolumn{7}{|c|}{ Composition } & \multicolumn{3}{|c|}{$\begin{array}{l}\text { As-Synthesized } \\
\text { Structures }\end{array}$} & \multicolumn{4}{|c|}{ Spent Structures } & \multicolumn{2}{|c|}{$\begin{array}{c}\text { Hydrogen } \\
\text { Storage } \\
\text { Capacity (wt. \%) }\end{array}$} \\
\hline MX & $\mathrm{mol}$ & M1* & $\mathrm{mol}$ & M2* & $\mathrm{mol}$ & $\mathrm{Ti}(\mathrm{OiPr})_{4}$ & xrd 1 & xrd 2 & xrd 3 & xrd 1 & xrd 2 & xrd 3 & xrd 4 & Des 1 & Des 2 \\
\hline $\mathrm{LiBH}_{4}$ & 1 & $\mathrm{Si}^{*}$ & 1 & & & 0.02 & $\mathrm{Si}$ & $\mathrm{LiBH}_{4}$ & A & $\mathrm{Si}$ & $\mathrm{LiBH}_{4}$ & & & 0.27 & 0.06 \\
\hline $\mathrm{LiBH}_{4}$ & $\frac{1}{2}$ & $\mathrm{Si}^{*}$ & 1 & & & 0.04 & $\mathrm{Si}$ & $\mathrm{LiBH}_{4}$ & $A$ & $\mathrm{Si}$ & $\mathrm{LiBH}_{4}$ & & & 0.24 & 0.02 \\
\hline $\mathrm{LiBH}_{4}$ & 4 & $\mathrm{Si}^{\star}$ & 1 & & & 0.08 & $\mathrm{Si}$ & $\mathrm{LiBH}_{4}$ & $A$ & $\mathrm{Si}$ & A & $\mathrm{LiBH}_{4}$ & & 0.21 & 0.00 \\
\hline $\mathrm{LiBH}_{4}$ & 6 & $\mathrm{Si}^{*}$ & 1 & & & 0.12 & $\mathrm{Si}$ & $\mathrm{LiBH}_{4}$ & $A$ & $\mathrm{Si}$ & A & $\mathrm{LiBH}_{4}$ & & 0.28 & 0.09 \\
\hline $\mathrm{NaBH}_{4}$ & 1 & $\mathrm{Si}^{\star}$ & 1 & & & 0.02 & $\mathrm{Si}$ & $\mathrm{NaBH}_{4}$ & & $\mathrm{Si}$ & $\mathrm{NaBH}_{4}$ & $\mathrm{Si}$ & & 0.04 & -0.01 \\
\hline $\mathrm{NaBH}_{4}$ & 2 & $\mathrm{Si}^{\star}$ & 1 & & & 0.02 & $\mathrm{NaBH}_{4}$ & $\mathrm{Si}$ & & $\mathrm{NaBH}_{4}$ & $\mathrm{Si}$ & & & 0.08 & 0.03 \\
\hline $\mathrm{NaBH}_{4}$ & 4 & Si* & 1 & & & 0.08 & $\mathrm{NaBH}_{4}$ & $\mathrm{Si}$ & & $\mathrm{NaBH}_{4}$ & $\mathrm{Si}$ & & & 0.12 & 0.03 \\
\hline $\mathrm{NaBH}_{4}$ & 6 & $\mathrm{Si}^{*}$ & 1 & & & 0.12 & $\mathrm{NaBH}_{4}$ & $\mathrm{Si}$ & & $\mathrm{NaBH}_{4}$ & $\mathrm{Si}$ & & & 0.07 & 0.02 \\
\hline $\mathrm{LiAlH}_{4}$ & 1 & $\mathrm{Si}^{*}$ & 1 & & & 0.02 & $\mathrm{Si}$ & Al & $\mathrm{Li}_{3} \mathrm{AlH}_{6}$ & & & & & 0.43 & 0.11 \\
\hline $\mathrm{LiAlH}_{4}$ & 2 & $\mathrm{Si}^{\star}$ & 1 & & & 0.04 & $\mathrm{Si}$ & $\mathrm{Al}$ & $\mathrm{Li}_{3} \mathrm{AlH}_{6}$ & $\mathrm{Al}$ & $\mathrm{Si}$ & & & 0.33 & 0.14 \\
\hline $\mathrm{LiAlH}_{4}$ & 4 & $\mathrm{Si}^{*}$ & 1 & & & 0.08 & $\mathrm{Al}$ & Si & $\mathrm{Li}_{3} \mathrm{AlH}_{6}$ & $\mathrm{Al}$ & $\mathrm{Si}$ & & & 1.02 & 0.11 \\
\hline $\mathrm{NaAlH}_{4}$ & 1 & $\mathrm{Si}^{\star}$ & 1 & & & 0.02 & $\mathrm{Si}$ & $\mathrm{NaAlH}_{4}$ & & $\mathrm{Si}$ & $\mathrm{NaAlH}_{4}$ & $\mathrm{Na}_{3} \mathrm{AlH}_{6}$ & $\mathrm{Al}$ & 3.61 & 3.05 \\
\hline $\mathrm{NaAlH}_{4}$ & 2 & $\mathrm{Si}^{*}$ & 1 & & & 0.04 & $\mathrm{NaAlH}_{4}$ & $\mathrm{Si}$ & & $\mathrm{NaAlH}_{4}$ & $\mathrm{Si}$ & $\mathrm{Na}_{3} \mathrm{AlH}_{6}$ & $\mathrm{Al}$ & 4.21 & 3.52 \\
\hline $\mathrm{NaAlH}_{4}$ & 4 & $\mathrm{Si}^{\star}$ & 1 & & & 0.08 & $\mathrm{NaAlH}_{4}$ & $\mathrm{Si}$ & & $\mathrm{NaAlH}_{4}$ & $\mathrm{Si}$ & $\mathrm{Na}_{3} \mathrm{AlH}_{6}$ & $\mathrm{Al}$ & 4.78 & 3.99 \\
\hline $\mathrm{NaBH}_{4}$ & 4 & $\mathrm{Si}^{*}$ & 1 & $\mathrm{NaAlH}_{4}$ & 1 & 0.1 & $\mathrm{NaBH}_{4}$ & $\mathrm{Si}$ & $\mathrm{NaAlH}_{4}$ & $\mathrm{NaBH}_{4}$ & $\mathrm{Si}$ & $\mathrm{Na}_{3} \mathrm{AlH}_{6}$ & $\mathrm{~B}_{4} \mathrm{Si}$ & 1.03 & 0.38 \\
\hline $\mathrm{LiBH}_{4}$ & 4 & $\mathrm{Si}^{*}$ & 1 & $\mathrm{LiAlH}_{4}$ & 1 & 0.1 & $\mathrm{Si}$ & $\mathrm{Al}$ & B & $\mathrm{Si}$ & Al & $\mathrm{LiBH}_{4}$ & A & 0.31 & 0.16 \\
\hline $\mathrm{NaH}$ & 1 & $\mathrm{Si}^{*}$ & 1 & & & 0.02 & $\mathrm{Si}$ & $\mathrm{NaH}$ & $\mathrm{E}$ & $\mathrm{Si}$ & $\mathrm{NaH}$ & $\mathrm{E}$ & & 0.15 & 0.05 \\
\hline $\mathrm{NaH}$ & 2 & $\mathrm{Si}^{\star}$ & 1 & & & 0.02 & & & & & & & & 0.10 & 0.04 \\
\hline $\mathrm{NaH}$ & 4 & $\mathrm{Si}^{\star}$ & 1 & & & 0.02 & $\mathrm{NaH}$ & $\mathrm{Si}$ & $\mathrm{NaOH}$ & $\mathrm{NaH}$ & $\mathrm{Si}$ & $\mathrm{NaOH}$ & & 0.07 & 0.01 \\
\hline $\mathrm{NaH}$ & 1 & Si* & 0.5 & $\mathrm{Al}^{\prime}$ & 0.5 & 0.02 & $\mathrm{NaH}$ & $\mathrm{Si}$ & $\mathrm{Al}$ & $\mathrm{Na}_{3} \mathrm{AlH}_{6}$ & $\mathrm{Si}$ & $\mathrm{NaH}$ & WC & 1.80 & 1.44 \\
\hline $\mathrm{NaH}$ & 2 & $\mathrm{Si}^{\star}$ & 0.5 & $\mathrm{Al}^{\prime}$ & 0.5 & 0.02 & $\mathrm{NaH}$ & $\mathrm{Si}$ & $\mathrm{Al}$ & & & & & 1.03 & 0.98 \\
\hline $\mathrm{NaH}$ & 4 & $\mathrm{Si}^{*}$ & 0.5 & $\mathrm{Al}^{\prime}$ & 0.5 & 0.02 & $\mathrm{NaH}$ & $\mathrm{Si}$ & $\mathrm{Al}$ & $\mathrm{NaH}$ & $\mathrm{Si}$ & $\mathrm{Na}_{3} \mathrm{AlH}_{6}$ & WC & 0.53 & 0.54 \\
\hline $\mathrm{LiH}$ & 1 & $\mathrm{Si}^{\star}$ & 1 & & & 0.02 & $\mathrm{Si}$ & WC & $\mathrm{LiH}$ & $\mathrm{Si}$ & WC & $\mathrm{LiH}$ & & 0.21 & 0.07 \\
\hline $\mathrm{LiH}$ & 2 & $\mathrm{Si}^{*}$ & 1 & & & 0.02 & $\mathrm{Si}$ & WC & $\mathrm{LiH}$ & $\mathrm{Si}$ & WC & $\mathrm{LiH}$ & & 0.15 & 0.08 \\
\hline $\mathrm{LiH}$ & 4 & $\mathrm{Si}^{\star}$ & 1 & & & 0.02 & $\mathrm{Si}$ & $\mathrm{LiH}$ & & & & & & 0.18 & 0.07 \\
\hline $\mathrm{MgH}_{2}$ & 1 & $\mathrm{Si}^{*}$ & 1 & & & 0.02 & $\mathrm{Si}$ & $\mathrm{MgH}_{2}$ & & & & & & 0.34 & 0.09 \\
\hline $\mathrm{MgH}_{2}$ & 2 & $\mathrm{Si}^{\star}$ & 1 & & & 0.02 & $\mathrm{Si}$ & $\mathrm{MgH}_{2}$ & WC & & & & & 0.21 & 0.04 \\
\hline $\mathrm{CaH}_{2}$ & 1 & $\mathrm{Si}^{\star}$ & 1 & & & 0.02 & $\mathrm{Si}$ & $\mathrm{CaH}_{2}$ & WC & $\mathrm{Si}$ & $\mathrm{CaH}_{2}$ & WC & & 0.17 & 0.01 \\
\hline $\mathrm{CaH}_{2}$ & 2 & $\mathrm{Si}^{*}$ & 1 & & & 0.02 & $\mathrm{CaH}_{2}$ & $\mathrm{Si}$ & & & & & & 0.12 & -0.02 \\
\hline $\mathrm{KH}$ & 1 & $\mathrm{Si}^{*}$ & 1 & & & 0.02 & $\mathrm{Si}$ & $\mathrm{KOH}^{\star} \mathrm{H}_{2} \mathrm{O}$ & $\mathrm{KH}$ & & & & & 0.21 & 0.07 \\
\hline $\mathrm{LiBH}_{4}$ & 4 & $\mathrm{Al}^{\prime}$ & 2 & & & 0.08 & & & & $\mathrm{Al}$ & $\mathrm{LiBH}_{4}$ & $\mathrm{C}$ & & 0.20 & 0.01 \\
\hline $\mathrm{LiBH}_{4}$ & 2 & $\mathrm{TiH}_{2}$ & 1 & & & 0.04 & & & & $\mathrm{TiH}_{2}$ & WC & $\mathrm{D}$ & & 0.14 & $\mathrm{~N}$ \\
\hline $\mathrm{LiBH}_{4}$ & 1 & $\mathrm{TiH}_{2}$ & 1 & & & 0.02 & & & & $\mathrm{TiH}_{2}$ & & & & 0.24 & 0.04 \\
\hline $\mathrm{LiBH}_{4}$ & 2 & $\mathrm{~V}^{*}$ & $\frac{1}{1}$ & & & 0.04 & & & & $\mathrm{VH}_{0.81}$ & $\mathrm{Ti}$ & $\mathrm{V}$ & $\mathrm{V}_{2} \mathrm{~T}_{\mathrm{i} 3} \mathrm{O}_{9}$ & 0.23 & 0.06 \\
\hline $\mathrm{LiBH}_{4}$ & 2 & $\mathrm{Cr}^{*}$ & 1 & & & 0.04 & & & & $\mathrm{Cr}$ & & & & 0.19 & 0.04 \\
\hline $\mathrm{LiBH}_{4}$ & 1 & $\mathrm{Cr}^{*}$ & 1 & & & 0.02 & & & & $\mathrm{Cr}$ & & & & 0.18 & 0.04 \\
\hline $\mathrm{LiBH}_{4}$ & 2 & $\mathrm{Mg}^{*}$ & 1 & & & 0.04 & & & & $\mathrm{Mg}$ & & & & 0.30 & 0.03 \\
\hline
\end{tabular}




\begin{tabular}{|c|c|c|c|c|c|c|c|c|c|c|c|}
\hline \multicolumn{3}{|c|}{ Composition } & \multicolumn{5}{|c|}{ As-Synthesized Structures } & \multicolumn{4}{|c|}{ Hydrogen Storage Capacities (wt. \% @ DesT) } \\
\hline $\mathrm{LiNH}_{2}$ & $\mathrm{LiBH}_{4}$ & $\mathrm{CoCl}_{2}$ & XRD 1 & XRD 2 & XRD 3 & XRD 4 & XRD 5 & 100 & 230 & $\operatorname{Des} 3\left({ }^{\circ} \mathrm{C}\right)$ & Des 3 (wt. \%) \\
\hline 0 & 0.4 & 0.6 & $\mathrm{AM}$ & $\mathrm{LiCl}$ & $\mathrm{CoCl}_{2}$ & & & 0.18 & 0.10 & 230 & 0.02 \\
\hline 0 & 0.5 & 0.5 & AM & $\mathrm{LiCl}$ & $\mathrm{CoCl}_{2}$ & & & 0.46 & 0.12 & 230 & 0.01 \\
\hline 0 & 0.6 & 0.4 & AM & $\mathrm{LiCl}$ & $\mathrm{CoCl}_{2}$ & & & 0.48 & 1.25 & 230 & -0.02 \\
\hline 0 & 0.7 & 0.3 & AM & $\mathrm{LiCl}$ & $\mathrm{CoCl}_{2}$ & & & 0.63 & 1.68 & 230 & 0.06 \\
\hline 0 & 0.8 & 0.2 & AM & $\mathrm{LiCl}$ & U1 & $\mathrm{CoCl}_{2}$ & $\mathrm{LiBH}_{4}$ & B & B & 230 & B \\
\hline 0 & 0.9 & 0.1 & AM & $\mathrm{LiCl}$ & U1 & $\mathrm{LiBH}_{4}$ & $\mathrm{CoCl}_{2}$ & 0.51 & 0.65 & 230 & 0.11 \\
\hline 0.1 & 0.4 & 0.5 & AM & $\mathrm{CoCl}_{2}$ & $\mathrm{LiCl}$ & & & 0.35 & 1.54 & 230 & 0.03 \\
\hline 0.1 & 0.5 & 0.4 & AM & $\mathrm{CoCl}_{2}$ & $\mathrm{LiCl}$ & & & 0.24 & 2.28 & 230 & 0.02 \\
\hline 0.1 & 0.6 & 0.3 & AM & $\mathrm{CoCl}_{2}$ & $\mathrm{LiCl}$ & & & 0.99 & 1.42 & 230 & 0.14 \\
\hline 0.1 & 0.7 & 0.2 & AM & $\mathrm{LiCl}$ & $\mathrm{LiBH}_{4}$ & & & 0.79 & 0.69 & 230 & 0.38 \\
\hline 0.1 & 0.8 & 0.1 & AM & $\mathrm{LiCl}$ & U1 & $\mathrm{LiBH}_{4}$ & $\mathrm{Li}_{2} \mathrm{NH}$ & 0.80 & 0.62 & 230 & 0.29 \\
\hline 0.2 & 0.3 & 0.5 & AM & $\mathrm{CoCl}_{2}$ & $\mathrm{Li}_{2} \mathrm{NH}$ & $\mathrm{LiBH}_{4}$ & & 0.31 & 0.94 & 230 & 0.09 \\
\hline 0.2 & 0.4 & 0.4 & AM & $\mathrm{CoCl}_{2}$ & $\mathrm{LiBH}_{4}$ & $\mathrm{Li}_{2} \mathrm{NH}$ & & 0.33 & 1.45 & 230 & 0.14 \\
\hline 0.2 & 0.5 & 0.3 & AM & $\mathrm{LiCl}$ & & & & 0.13 & 0.42 & 230 & 0.08 \\
\hline 0.2 & 0.6 & 0.2 & $\mathrm{AM}$ & $\mathrm{LiCl}$ & & & & 0.42 & 0.97 & 230 & 0.30 \\
\hline 0.2 & 0.7 & 0.1 & AM & $\mathrm{LiCl}$ & $\mathrm{LiNH}_{2}$ & $\mathrm{LiBH}_{4}$ & U2 & 1.20 & 1.17 & 230 & 0.30 \\
\hline 0.2 & 0.3 & 0.4 & AM & $\mathrm{LiCl}$ & Co & & & 0.31 & 0.86 & 230 & 0.10 \\
\hline 0.3 & 0.4 & 0.3 & AM & $\mathrm{LiCl}$ & Co & & & $\mathrm{B}$ & 0.18 & 230 & 0.06 \\
\hline 0.3 & 0.5 & 0.2 & AM & $\mathrm{Li}_{2} \mathrm{NH}$ & $\mathrm{LiCl}$ & $\mathrm{CoCl}_{2}$ & & 0.77 & 2.87 & 230 & 0.21 \\
\hline 0.3 & 0.6 & 0.1 & $\mathrm{Li}_{2} \mathrm{NH}$ & $\mathrm{LiCl}$ & $\mathrm{LiBH}_{4}$ & $\mathrm{Li}_{4}\left(\mathrm{NH}_{2}\right)_{3}\left(\mathrm{BH}_{4}\right)$ & & 0.69 & 1.38 & 230 & -0.10 \\
\hline 0.4 & 0.2 & 0.4 & AM & $\mathrm{CoCl}_{2}$ & $\mathrm{LiNH}_{2}$ & $\mathrm{Li}_{2} \mathrm{NH}$ & & 0.19 & 2.59 & 230 & 0.01 \\
\hline 0.4 & 0.3 & 0.3 & AM & $\mathrm{CoCl}_{2}$ & $\mathrm{LiNH}_{2}$ & $\mathrm{LiBH}_{4}$ & & 0.11 & 0.51 & 230 & 0.53 \\
\hline 0.4 & 0.4 & 0.2 & U2 & & & & & 0.19 & 3.39 & 230 & 0.42 \\
\hline 0.4 & 0.5 & 0.1 & $\mathrm{LiCl}$ & $\mathrm{Li}_{2} \mathrm{NH}$ & & & & 0.40 & 4.52 & 230 & 0.22 \\
\hline 0.5 & 0.1 & 0.4 & Co $? d=2.06,1.78$ & $\mathrm{LiCl}$ & & & & -0.03 & 0.20 & 350 & 0.36 \\
\hline 0.5 & 0.2 & 0.3 & Co & $\mathrm{LiCl}$ & & & & 0.00 & 0.08 & 350 & 0.18 \\
\hline 0.5 & 0.3 & 0.2 & $\mathrm{LiNH}_{2}$ & $\mathrm{CoCl}_{2}$ & & & & 0.21 & 1.80 & 350 & 2.34 \\
\hline 0.5 & 0.4 & 0.1 & $\mathrm{LiNH}_{2}$ & $\mathrm{CoCl}_{2}$ & & & & 0.27 & 5.56 & 350 & 0.38 \\
\hline 0.6 & 0.1 & 0.3 & $\mathrm{LiNH}_{2}$ & $\mathrm{CoCl}_{2}$ & & & & -0.01 & 1.26 & 350 & 0.43 \\
\hline 0.6 & 0.2 & 0.2 & $\mathrm{Li}_{2} \mathrm{NH} / \mathrm{LiNH}_{2}$ & $\mathrm{CoCl}_{2}$ & & & & 0.01 & 1.13 & 350 & 2.62 \\
\hline 0.6 & 0.3 & 0.1 & $\mathrm{U} 2$ & & & & & 0.13 & 5.07 & 350 & 1.35 \\
\hline 0.7 & 0 & 0.3 & $\mathrm{CoCl}_{2}$ & & & & & 0.01 & $\mathrm{~B}$ & 350 & 0.89 \\
\hline
\end{tabular}




\begin{tabular}{|c|c|c|c|c|c|c|c|c|c|c|c|}
\hline \multicolumn{12}{|c|}{$\begin{array}{c}\text { Table 18. } \mathrm{LiNH}_{2}-\mathrm{LiBH}_{4}-\mathrm{CuCl}_{2}-\mathrm{LiH} \text { Pha } \\
\text { Composition }\end{array}$} \\
\hline $\mathrm{LiNH}_{2}$ & $\mathrm{LiBH}_{4}$ & $\mathrm{CuCl}_{2}$ & LiH & Des T1 & Des 1 & Des T2 & Des 2 & Des T3 & Des 3 & Des T4 & Des 4 \\
\hline 0 & 0 & 0.125 & 0.875 & 230 & 0.85 & 230 & 0.26 & 350 & 0.35 & 350 & 0.11 \\
\hline 0 & 0.125 & 0.125 & 0.75 & 230 & 0.09 & 230 & 0.05 & 350 & 0.37 & 350 & 0.23 \\
\hline 0 & 0.25 & 0.125 & 0.625 & 230 & 0.15 & 230 & 0.03 & 350 & 0.39 & 350 & 0.18 \\
\hline 0 & 0.375 & 0.125 & 0.5 & 230 & 0.10 & 230 & 0.02 & 350 & 0.44 & 350 & 0.20 \\
\hline 0 & 0.5 & 0.125 & 0.375 & 230 & 0.19 & 230 & 0.07 & 350 & 0.85 & 350 & 0.41 \\
\hline 0 & 0.625 & 0.125 & 0.25 & 230 & 0.15 & 230 & 0.01 & 350 & 1.08 & 350 & 0.55 \\
\hline 0 & 0.75 & 0.125 & 0.125 & 230 & 0.30 & 230 & 0.06 & 350 & 2.72 & 350 & 0.59 \\
\hline 0 & 0.875 & 0.125 & 0 & 230 & -0.01 & 230 & -0.04 & 350 & 2.13 & 350 & 0.53 \\
\hline 0 & 0.5 & 0.125 & 0.375 & 100 & 0.03 & 100 & 0.03 & 230 & 0.12 & 230 & 0.04 \\
\hline 0 & 0.625 & 0.125 & 0.25 & 100 & -0.07 & 100 & -0.04 & 230 & 0.02 & 230 & -0.08 \\
\hline 0 & 0.75 & 0.125 & 0.125 & 100 & 0.01 & 100 & -0.05 & 230 & 0.10 & 230 & 0.01 \\
\hline 0.125 & 0.375 & 0.125 & 0.375 & 100 & 0.13 & 230 & 1.10 & 350 & $\mathrm{~B}$ & $\mathrm{~N}$ & $\mathrm{~N}$ \\
\hline 0.125 & 0.5 & 0.125 & 0.25 & 100 & -0.05 & 100 & -0.04 & 230 & 0.00 & 230 & -0.06 \\
\hline 0.125 & 0.625 & 0.125 & 0.125 & 100 & 0.09 & 100 & 0.01 & 230 & 0.15 & 230 & 0.02 \\
\hline 0.125 & 0.75 & 0.125 & 0 & 100 & 0.33 & 100 & -0.03 & 230 & 1.57 & 230 & 0.69 \\
\hline 0.25 & 0.25 & 0.125 & 0.375 & 100 & 0.45 & 100 & -0.03 & 230 & 0.74 & 230 & 0.17 \\
\hline 0.25 & 0.375 & 0.125 & 0.25 & 100 & 0.62 & 100 & 0.06 & 230 & 1.94 & 230 & 0.77 \\
\hline 0.25 & 0.5 & 0.125 & 0.125 & 100 & 0.12 & 100 & 0.02 & 230 & 0.94 & 230 & 0.30 \\
\hline 0.25 & 0.625 & 0.125 & 0 & 100 & 0.74 & 100 & -0.03 & 230 & 1.19 & 230 & 0.33 \\
\hline 0.375 & 0.125 & 0.125 & 0.375 & 100 & 0.05 & 100 & 0.03 & 230 & 0.42 & 230 & 0.20 \\
\hline 0.375 & 0.25 & 0.125 & 0.25 & 100 & 0.02 & 230 & 0.87 & 350 & 2.29 & $\mathrm{~N}$ & $\mathrm{~N}$ \\
\hline 0.375 & 0.375 & 0.125 & 0.125 & 100 & 0.07 & 230 & 1.30 & 350 & 3.42 & $\mathrm{~N}$ & $\mathrm{~N}$ \\
\hline 0.375 & 0.5 & 0.125 & 0 & 100 & 0.22 & 230 & 2.04 & 350 & 1.99 & $\mathrm{~N}$ & $\mathrm{~N}$ \\
\hline 0.5 & 0 & 0.125 & 0.375 & 100 & 0.02 & 230 & 0.19 & 350 & 1.20 & $\mathrm{~N}$ & $\mathrm{~N}$ \\
\hline 0.125 & 0.625 & 0.25 & 0 & 100 & 0.08 & 230 & 0.91 & 350 & 0.57 & $\mathrm{~N}$ & $\mathrm{~N}$ \\
\hline 0.25 & 0.125 & 0.25 & 0.375 & 100 & 0.02 & 230 & 0.23 & 350 & 0.24 & $\mathrm{~N}$ & $\mathrm{~N}$ \\
\hline 0.25 & 0.25 & 0.25 & 0.25 & 100 & 0.01 & 230 & -0.05 & 350 & -0.08 & $\mathrm{~N}$ & $\mathrm{~N}$ \\
\hline 0.25 & 0.375 & 0.25 & 0.125 & 100 & 0.10 & 230 & 0.33 & 350 & 0.26 & $\mathrm{~N}$ & $\mathrm{~N}$ \\
\hline 0.25 & 0.5 & 0.25 & 0 & 100 & 0.00 & 230 & 2.33 & 350 & 1.03 & $\mathrm{~N}$ & $\mathrm{~N}$ \\
\hline
\end{tabular}




\begin{tabular}{|c|c|c|c|c|c|c|c|c|c|c|c|}
\hline \multicolumn{4}{|c|}{ Composition } & \multicolumn{8}{|c|}{ Hydrogen Storage Capacities (Desorption temperatures and wt. \%) } \\
\hline $\mathrm{LiNH}_{2}$ & $\mathrm{LiBH}_{4}$ & $\mathrm{CuCl}_{2}$ & LiH & Des T1 & Des 1 & Des T2 & Des 2 & Des T3 & Des 3 & Des T4 & Des 4 \\
\hline 0.375 & 0.125 & 0.25 & 0.25 & 100 & 0.05 & 230 & 0.26 & 350 & 0.46 & $\mathrm{~N}$ & $\mathrm{~N}$ \\
\hline 0.375 & 0.25 & 0.25 & 0.125 & 100 & 0.13 & 230 & 0.35 & 350 & 0.80 & $\mathrm{~N}$ & $\mathrm{~N}$ \\
\hline 0.375 & 0.375 & 0.25 & 0 & 100 & -0.04 & 230 & 0 & 350 & 0 & $\mathrm{~N}$ & $\mathrm{~N}$ \\
\hline 0.5 & 0 & 0.125 & 0.375 & 100 & 0.02 & 230 & 0.26 & 350 & 1.66 & $\mathrm{~N}$ & $\mathrm{~N}$ \\
\hline 0.5 & 0.125 & 0.125 & 0.25 & 100 & -0.07 & 230 & 0.43 & 350 & 1.93 & $\mathrm{~N}$ & $\mathrm{~N}$ \\
\hline 0.5 & 0.25 & 0.125 & 0.125 & 100 & -0.04 & 230 & 0.82 & 350 & 1.61 & $\mathrm{~N}$ & $\mathrm{~N}$ \\
\hline 0.5 & 0.375 & 0.125 & 0 & 100 & -0.03 & 230 & 0.05 & 350 & 0.80 & $\mathrm{~N}$ & $\mathrm{~N}$ \\
\hline 0 & 0.75 & 0.25 & 0 & 100 & 0.06 & 230 & 1.75 & 350 & 2.33 & $\mathrm{~N}$ & $\mathrm{~N}$ \\
\hline 0.125 & 0.25 & 0.25 & 0.375 & 100 & 0.43 & 230 & 1.40 & 350 & 2.80 & $\mathrm{~N}$ & $\mathrm{~N}$ \\
\hline 0.125 & 0.375 & 0.25 & 0.25 & 100 & 0.00 & 230 & 0.90 & 350 & 0.33 & $\mathrm{~N}$ & $\mathrm{~N}$ \\
\hline 0.125 & 0.5 & 0.25 & 0.125 & 100 & 0.17 & 230 & 1.45 & 350 & 1.95 & $\mathrm{~N}$ & $\mathrm{~N}$ \\
\hline 0.125 & 0.625 & 0.25 & 0 & 100 & -0.03 & 230 & 3.38 & 350 & -0.06 & $\mathrm{~N}$ & $\mathrm{~N}$ \\
\hline 0.25 & 0.125 & 0.25 & 0.375 & 100 & 0.01 & 230 & 0.94 & 350 & 1.11 & $\mathrm{~N}$ & $\mathrm{~N}$ \\
\hline 0.25 & 0.25 & 0.25 & 0.25 & 100 & 0.03 & 230 & 1.20 & 350 & 1.61 & $\mathrm{~N}$ & $\mathrm{~N}$ \\
\hline 0.25 & 0.375 & 0.25 & 0.125 & 100 & -0.01 & 230 & 1.84 & 350 & -0.06 & $\mathrm{~N}$ & $\mathrm{~N}$ \\
\hline 0.25 & 0.5 & 0.25 & 0 & 100 & 0.03 & 230 & 0.97 & 350 & 0.82 & $\mathrm{~N}$ & $\mathrm{~N}$ \\
\hline 0.375 & 0.125 & 0.25 & 0.25 & 100 & -0.21 & 230 & 0.25 & 350 & 0.05 & $\mathrm{~N}$ & $\mathrm{~N}$ \\
\hline 0.375 & 0.25 & 0.25 & 0.125 & 100 & 0.09 & 230 & 0.34 & 350 & 0.29 & $\mathrm{~N}$ & $\mathrm{~N}$ \\
\hline 0.375 & 0.375 & 0.25 & 0 & 100 & 0.13 & 230 & 0.56 & 350 & 0.52 & $\mathrm{~N}$ & $\mathrm{~N}$ \\
\hline 0.5 & 0.125 & 0.25 & 0.125 & 100 & 0.11 & 230 & 0.68 & 350 & 0.82 & $\mathrm{~N}$ & $\mathrm{~N}$ \\
\hline 0.5 & 0.25 & 0.25 & 0 & 100 & 0.10 & 230 & 0.52 & 350 & 0.41 & $\mathrm{~N}$ & $\mathrm{~N}$ \\
\hline 0.625 & 0.125 & 0.25 & 0 & 100 & 0.05 & 230 & 0.46 & 350 & 0.47 & $\mathrm{~N}$ & $\mathrm{~N}$ \\
\hline 0 & 0.5 & 0.375 & 0.125 & 100 & -0.08 & 230 & 0.12 & 350 & 0.06 & $\mathrm{~N}$ & $\mathrm{~N}$ \\
\hline 0 & 0.625 & 0.375 & 0 & 100 & -0.03 & 230 & 0.11 & 350 & 0.51 & $\mathrm{~N}$ & $\mathrm{~N}$ \\
\hline 0.125 & 0.375 & 0.375 & 0.125 & 100 & 0.02 & 230 & 0.49 & 350 & 0.11 & $\mathrm{~N}$ & $\mathrm{~N}$ \\
\hline 0.125 & 0.5 & 0.375 & 0 & 100 & 0.00 & 230 & 0.10 & 350 & 0.24 & $\mathrm{~N}$ & $\mathrm{~N}$ \\
\hline 0.25 & 0.375 & 0.375 & 0 & 100 & 0.05 & 230 & 3.04 & 350 & 0.31 & $\mathrm{~N}$ & $\mathrm{~N}$ \\
\hline
\end{tabular}


Table 19. $\mathrm{LiNH}_{2}-\mathrm{LiBH}_{4}-\mathrm{MnCl}_{2}-\mathrm{LiH}$ Phase Diagram. Compositions, spent material structures, and MT and HT hydrogen storage capacities.

\begin{tabular}{|c|c|c|c|c|c|c|c|c|c|c|c|c|c|c|}
\hline \multirow{2}{*}{\multicolumn{4}{|c|}{ Composition }} & \multirow{2}{*}{\multicolumn{5}{|c|}{ Spent Material Structures }} & \multicolumn{6}{|c|}{ Hydrogen Storage Capacities (wt. \%) } \\
\hline & & & & & & & & & \multicolumn{2}{|c|}{$\begin{array}{c}\text { Medium } \\
\text { Throughput }\end{array}$} & \multicolumn{4}{|c|}{ High Throughput (Des $\left.\mathrm{T}-{ }^{\circ} \mathrm{C}\right)$} \\
\hline $\mathrm{LiNH}_{2}$ & $\mathrm{LiBH}_{4}$ & $\mathrm{MnCl}_{2}$ & $\mathrm{LiH}$ & xrd 1 & xrd 2 & xrd 3 & xrd 4 & xrd 5 & Des 1 & Des 2 & 230 & 230 & 350 & 350 \\
\hline 2 & 0 & 1 & 0 & & & & & & 1.68 & 0.70 & 0.92 & 0.05 & 0.07 & 0.08 \\
\hline 2 & 1 & 1 & 0 & & & & & & $\mathrm{~N}$ & $\mathrm{~N}$ & 0.24 & 0.11 & 0.25 & 0.21 \\
\hline 2 & 0 & 1 & 0 & & & & & & $\mathrm{~N}$ & $\mathrm{~N}$ & 0.56 & 0.07 & 0.38 & 0.22 \\
\hline 0 & 3 & 1 & 0 & & & & & & $\mathrm{~N}$ & $\mathrm{~N}$ & 0.22 & 0.07 & 0.43 & 0.35 \\
\hline 2 & 1 & 1 & 0 & & & & & & $\mathrm{~N}$ & $\mathrm{~N}$ & 2.00 & 0.23 & 0.46 & 0.18 \\
\hline 1 & 2 & 1 & 0 & & & & & & $\mathrm{~N}$ & $\mathrm{~N}$ & -0.07 & -0.07 & -0.08 & 0.52 \\
\hline 1.5 & 1.5 & 1 & 0 & & & & & & $\mathrm{~N}$ & $\mathrm{~N}$ & B & B & B & B \\
\hline 4 & 0 & 1 & 0 & & & & & & $\mathrm{~N}$ & $\mathrm{~N}$ & 0.33 & 0.09 & 0.50 & 0.31 \\
\hline 0 & 4 & 1 & 0 & & & & & & $\mathrm{~N}$ & $\mathrm{~N}$ & 1.01 & 0.83 & 1.20 & 1.48 \\
\hline 3 & 1 & 1 & 0 & & & & & & $\mathrm{~N}$ & $\mathrm{~N}$ & 2.95 & 0.19 & 0.21 & 0.26 \\
\hline 1 & 3 & 1 & 0 & & & & & & $\mathrm{~N}$ & $\mathrm{~N}$ & 1.52 & 0.15 & 0.77 & 0.68 \\
\hline 2 & 2 & 1 & 0 & & & & & & $\mathrm{~N}$ & $\mathrm{~N}$ & 2.91 & 0.28 & 1.06 & 0.38 \\
\hline 1 & 0 & 1 & 1 & & & & & & $\mathrm{~N}$ & $\mathrm{~N}$ & $\mathrm{~N}$ & $\mathrm{~N}$ & $\mathrm{~N}$ & $\mathrm{~N}$ \\
\hline 0 & 1 & 1 & 1 & & & & & & $\mathrm{~N}$ & $\mathrm{~N}$ & $\mathrm{~N}$ & $\mathrm{~N}$ & $\mathrm{~N}$ & $\mathrm{~N}$ \\
\hline 1 & 0 & 1 & 2 & & & & & & $\mathrm{~N}$ & $\mathrm{~N}$ & $\mathrm{~N}$ & $\mathrm{~N}$ & $\mathrm{~N}$ & $\mathrm{~N}$ \\
\hline 0 & 1 & 1 & 2 & & & & & & $\mathrm{~N}$ & $\mathrm{~N}$ & $\mathrm{~N}$ & $\mathrm{~N}$ & $\mathrm{~N}$ & $\mathrm{~N}$ \\
\hline 2 & 0 & 1 & 1 & $\mathrm{LiCl}$ & $\mathrm{Mn}_{3} \mathrm{~N}_{2}$ & unk., $d=3.02$ & & & 0.49 & 0.08 & 0.27 & 0.09 & 0.38 & 0.24 \\
\hline 0 & 2 & 1 & 1 & $\mathrm{LiCl}$ & WC & & & & 0.09 & 0.00 & 0.16 & 0.07 & 0.50 & 0.48 \\
\hline 2 & 0 & 1 & 2 & $\mathrm{LiCl}$ & unk., $d=3.02,2.61$ & & & & 0.27 & 0.11 & 0.31 & 0.14 & 0.60 & 0.49 \\
\hline 0 & 2 & 1 & 2 & & & & & & 0.14 & 0.12 & 0.15 & 0.12 & 0.70 & 0.59 \\
\hline 1 & 1 & 1 & 1 & $\mathrm{LiCl}$ & AM & & & & 2.70 & 0.23 & 2.01 & 0.18 & 0.39 & 0.19 \\
\hline 1 & 1 & 1 & 2 & $\begin{array}{l}\text { unk., } d=2.73 \text {, } \\
2.04,2.02\end{array}$ & $\mathrm{LiCl}$ & $\mathrm{Li}_{3} \mathrm{~N}$ & $\mathrm{MnCl}_{2}$ & & 2.31 & 0.29 & 2.26 & 0.12 & 0.07 & 0.13 \\
\hline 2 & 1 & 1 & 1 & $\mathrm{LiCl}$ & AM & & & & 1.39 & 1.01 & 2.78 & 0.16 & 0.16 & 0.25 \\
\hline 1 & 2 & 1 & 1 & $\mathrm{LiCl}$ & AM & & & & 2.62 & 0.21 & 2.32 & 0.22 & 1.29 & 0.57 \\
\hline 0 & 4 & 1 & 0 & $\mathrm{LiCl}$ & $\mathrm{AM}$ & & & & 0.05 & 0.00 & 0.14 & 0.07 & 1.07 & 0.64 \\
\hline 3 & 1 & 1 & 0 & $\mathrm{LiCl}$ & $\mathrm{Mn}_{3} \mathrm{~N}_{2}$ & $\mathrm{Li}_{4}\left(\mathrm{NH}_{2}\right)_{3} \mathrm{BH}_{4}$ & $\mathrm{MnH}_{0.8}$ & $\mathrm{MnN}$ & 1.42 & 0.87 & 2.90 & 0.25 & 0.28 & 0.33 \\
\hline 1 & 3 & 1 & 0 & $\mathrm{LiCl}$ & & & & & 1.80 & 0.16 & 1.36 & 0.13 & 0.74 & 0.61 \\
\hline 2 & 2 & 1 & 0 & $\mathrm{LiCl}$ & WC & $\mathrm{Mn}_{3} \mathrm{~N}_{2}$ & & & 1.60 & 0.56 & 1.69 & 0.89 & 1.23 & 0.22 \\
\hline 1 & 0 & 1 & 1 & $\mathrm{LiCl}$ & $\mathrm{Mn}_{3} \mathrm{~N}_{2}$ & & & & 1.53 & 0.26 & 0.05 & 1.55 & 0.57 & $\mathrm{~N}$ \\
\hline 0 & 1 & 1 & 1 & $\mathrm{LiCl}$ & $\mathrm{Mn}_{3} \mathrm{~N}_{2}$ & & & & 0.45 & 0.08 & 0.47 & 0.03 & 0.15 & 0.17 \\
\hline 1 & 0 & 1 & 2 & $\mathrm{LiCl}$ & unk., $d=2.13$ & & & & 0.27 & 0.09 & 0.31 & 0.08 & 0.50 & 0.47 \\
\hline 0 & 1 & 1 & 2 & $\mathrm{LiCl}$ & unk., $d=2.23,2.15$ & & & & 0.16 & 0.16 & 0.21 & 0.20 & 0.63 & 0.44 \\
\hline
\end{tabular}


Table 20. $\mathrm{LiNH}_{2}-\mathrm{LiBH}_{4}-\mathrm{NiCl}_{2}-\mathrm{LiH}$. Compositions and High Throughput

Hydrogen Storage Capacities

\begin{tabular}{|c|c|c|c|c|c|c|c|}
\hline \multicolumn{4}{|c|}{ Composition } & \multicolumn{4}{|c|}{ Hydrogen Storage Capacity (wt. \%) } \\
\hline $\mathrm{LiNH}_{2}$ & $\mathrm{LiBH}_{4}$ & $\mathrm{NiCl}_{2}$ & LiH & $230^{\circ} \mathrm{C}$ & $230^{\circ} \mathrm{C}$ & $350^{\circ} \mathrm{C}$ & $350^{\circ} \mathrm{C}$ \\
\hline 0 & 0 & 0.125 & 0.875 & 0.43 & 0.13 & 0.34 & 0.17 \\
\hline 0 & 0.125 & 0.125 & 0.75 & 0.38 & 0.13 & 0.76 & 0.35 \\
\hline 0 & 0.25 & 0.125 & 0.625 & 0.44 & 0.24 & 1.63 & 0.68 \\
\hline 0 & 0.375 & 0.125 & 0.5 & 0.34 & 0.21 & 1.97 & 0.93 \\
\hline 0 & 0.5 & 0.125 & 0.375 & 0.40 & 0.25 & 2.37 & 1.27 \\
\hline 0 & 0.625 & 0.125 & 0.25 & 0.33 & 0.23 & 2.29 & 1.28 \\
\hline 0 & 0.75 & 0.125 & 0.125 & 0.30 & 0.18 & 2.86 & 1.24 \\
\hline 0 & 0.875 & 0.125 & 0 & 0.52 & 0.16 & 2.47 & 1.16 \\
\hline 0.125 & 0 & 0.125 & 0.75 & 1.06 & 0.14 & 0.73 & 0.22 \\
\hline 0.125 & 0.125 & 0.125 & 0.625 & 1.60 & 0.11 & 0.42 & 0.15 \\
\hline 0.125 & 0.25 & 0.125 & 0.5 & 1.43 & 0.21 & 0.67 & 0.39 \\
\hline 0.125 & 0.375 & 0.125 & 0.375 & 1.55 & 0.25 & 1.45 & 0.63 \\
\hline 0.125 & 0.5 & 0.125 & 0.25 & 0.07 & 0.19 & 2.00 & 1.12 \\
\hline 0.125 & 0.625 & 0.125 & 0.125 & 1.19 & 0.11 & 1.73 & 1.06 \\
\hline 0.125 & 0.75 & 0.125 & 0 & 1.58 & 0.21 & 1.90 & 1.21 \\
\hline 0.25 & 0 & 0.125 & 0.625 & 2.88 & 0.20 & 0.97 & 0.35 \\
\hline 0.25 & 0.125 & 0.125 & 0.5 & 2.57 & 0.13 & 0.71 & 0.13 \\
\hline 0.25 & 0.25 & 0.125 & 0.375 & 3.33 & 0.18 & 0.36 & -0.06 \\
\hline 0.25 & 0.375 & 0.125 & 0.25 & 2.95 & 0.27 & 0.96 & 0.46 \\
\hline 0.25 & 0.5 & 0.125 & 0.125 & 2.49 & 0.27 & 1.38 & 0.95 \\
\hline 0.25 & 0.625 & 0.125 & 0 & 2.16 & 0.18 & 1.71 & 0.86 \\
\hline 0.375 & 0 & 0.125 & 0.5 & 1.75 & 0.08 & 1.85 & 1.26 \\
\hline 0.375 & 0.125 & 0.125 & 0.375 & 2.23 & 0.17 & 1.28 & 0.77 \\
\hline 0.375 & 0.25 & 0.125 & 0.25 & 4.62 & 0.14 & 0.36 & 0.09 \\
\hline 0.375 & 0.375 & 0.125 & 0.125 & 4.04 & 0.24 & 0.57 & 0.21 \\
\hline 0.375 & 0.5 & 0.125 & 0 & 3.82 & 0.35 & 1.29 & 0.51 \\
\hline 0.5 & 0 & 0.125 & 0.375 & 0.28 & 0.12 & 1.94 & 1.40 \\
\hline 0.5 & 0.125 & 0.125 & 0.25 & 2.65 & 0.03 & 0.84 & 0.12 \\
\hline 0.5 & 0.25 & 0.125 & 0.125 & 0.35 & 3.96 & 1.13 & $\mathrm{~N}$ \\
\hline 0.5 & 0.375 & 0.125 & 0 & 5.07 & 0.15 & 0.57 & 0.11 \\
\hline 0.625 & 0 & 0.125 & 0.25 & 0.26 & 0.11 & 1.25 & 0.78 \\
\hline 0.625 & 0.125 & 0.125 & 0.125 & 2.06 & 0.21 & 1.44 & 0.22 \\
\hline 0.625 & 0.25 & 0.125 & 0 & 3.73 & 0.13 & 1.89 & 0.23 \\
\hline 0.75 & 0 & 0.125 & 0.125 & 0.36 & 0.15 & 0.94 & 0.43 \\
\hline 0.75 & 0.125 & 0.125 & 0 & 0.92 & 0.09 & 1.73 & 0.30 \\
\hline 0.875 & 0 & 0.125 & 0 & 0.37 & 0.11 & 1.11 & 0.54 \\
\hline
\end{tabular}


Table 20 (cont.). $\mathrm{LiNH}_{2}-\mathrm{LiBH}_{4}-\mathrm{NiCl}_{2}-\mathrm{LiH}$. Compositions and High Throughput Hydrogen Storage Capacities

\begin{tabular}{|c|c|c|c|c|c|c|c|}
\hline \multicolumn{4}{|c|}{ Composition } & \multicolumn{4}{|c|}{ Hydrogen Storage Capacity (wt. \%) } \\
\hline $\mathrm{LiNH}_{2}$ & $\mathrm{LiBH}_{4}$ & $\mathrm{NiCl}_{2}$ & LiH & $230^{\circ} \mathrm{C}$ & $230^{\circ} \mathrm{C}$ & $350^{\circ} \mathrm{C}$ & $350^{\circ} \mathrm{C}$ \\
\hline 0 & 0.25 & 0.25 & 0.5 & 0.57 & 0.30 & 0.78 & 0.53 \\
\hline 0 & 0.375 & 0.25 & 0.375 & 0.56 & 0.27 & 0.83 & 0.53 \\
\hline 0 & 0.5 & 0.25 & 0.25 & 0.40 & 0.27 & 1.67 & 0.71 \\
\hline 0 & 0.625 & 0.25 & 0.125 & 0.19 & 0.18 & 1.71 & 0.84 \\
\hline 0 & 0.75 & 0.25 & 0 & 0.53 & -0.15 & 2.35 & 0.26 \\
\hline 0.125 & 0.125 & 0.25 & 0.5 & 1.15 & 0.18 & 0.47 & 0.18 \\
\hline 0.125 & 0.25 & 0.25 & 0.375 & 1.11 & 0.23 & 0.49 & 0.33 \\
\hline 0.125 & 0.375 & 0.25 & 0.25 & 0.98 & 0.23 & 1.14 & 0.50 \\
\hline 0.125 & 0.5 & 0.25 & 0.125 & 1.07 & 0.26 & 0.82 & 0.57 \\
\hline 0.125 & 0.625 & 0.25 & 0 & 1.05 & 0.27 & 1.69 & 0.69 \\
\hline 0.25 & 0.125 & 0.25 & 0.375 & 1.04 & 0.16 & 0.59 & 0.24 \\
\hline 0.25 & 0.25 & 0.25 & 0.25 & 1.46 & 0.10 & 0.55 & 0.20 \\
\hline 0.25 & 0.375 & 0.25 & 0.125 & 2.35 & 0.18 & 0.53 & 0.33 \\
\hline 0.25 & 0.5 & 0.25 & 0 & 1.76 & 0.31 & 0.86 & 0.60 \\
\hline 0.375 & 0.125 & 0.25 & 0.25 & 0.13 & 0.04 & 0.25 & 0.13 \\
\hline 0.375 & 0.25 & 0.25 & 0.125 & 2.01 & 0.15 & 0.76 & 0.30 \\
\hline 0.375 & 0.375 & 0.25 & 0 & 0.84 & 0.08 & 0.23 & 0.14 \\
\hline 0.5 & 0.125 & 0.25 & 0.125 & 1.41 & 0.32 & 1.63 & 0.35 \\
\hline 0.5 & 0.25 & 0.25 & 0 & 0.45 & 0.09 & 0.57 & 0.26 \\
\hline 0.625 & 0.125 & 0.25 & 0 & 0.44 & 0.17 & 1.62 & 0.34 \\
\hline 0.75 & 0 & 0.25 & 0 & 0.63 & 0.04 & 0.61 & 0.20 \\
\hline 0 & 0.375 & 0.375 & 0.25 & 1.03 & 0.19 & 0.84 & 0.40 \\
\hline 0 & 0.5 & 0.375 & 0.125 & 0.80 & 0.19 & 0.78 & 0.50 \\
\hline 0 & 0.625 & 0.375 & 0 & 0.53 & 0.25 & 1.28 & 0.61 \\
\hline 0.125 & 0.375 & 0.375 & 0.125 & 1.09 & 0.11 & 0.49 & 0.37 \\
\hline 0.125 & 0.5 & 0.375 & 0 & 1.30 & 0.18 & 0.74 & 0.54 \\
\hline 0.25 & 0.375 & 0.375 & 0 & 1.38 & 0.09 & 0.56 & 0.12 \\
\hline 0.25 & 0.375 & 0.125 & 0.25 & 2.34 & 0.61 & 1.49 & 0.66 \\
\hline
\end{tabular}




\begin{tabular}{|c|c|c|c|c|c|c|}
\hline \multicolumn{4}{|c|}{ Compositions } & \multicolumn{3}{|c|}{ Hydrogen Storage Capacities (wt. \%) } \\
\hline $\mathrm{LiNH}_{2}$ & $\mathrm{LiBH}_{4}$ & $\mathrm{VCl}_{3}$ & LiH & $100^{\circ} \mathrm{C}$ & $230^{\circ} \mathrm{C}$ & $350^{\circ} \mathrm{C}$ \\
\hline 0 & 0.5 & 0.125 & 0.375 & $\mathrm{~B}$ & $\mathrm{~B}$ & $\mathrm{~B}$ \\
\hline 0 & 0.63 & 0.125 & 0.25 & 0.30 & 0.76 & 1.53 \\
\hline 0 & 0.75 & 0.125 & 0.125 & 0.11 & 0.47 & 1.38 \\
\hline 0.13 & 0.38 & 0.125 & 0.38 & 0.59 & 0.65 & 0.61 \\
\hline 0.13 & 0.5 & 0.125 & 0.25 & 1.62 & 0.94 & 1.49 \\
\hline 0.13 & 0.63 & 0.125 & 0.125 & 0.81 & 0.80 & 1.54 \\
\hline 0.13 & 0.75 & 0.125 & 0 & 0.54 & 0.71 & 1.63 \\
\hline 0.25 & 0.25 & 0.125 & 0.375 & 0.12 & 0.51 & 0.36 \\
\hline 0.25 & 0.25 & 0.125 & 0.375 & 0.17 & 0.85 & 1.61 \\
\hline 0.25 & 0.38 & 0.125 & 0.25 & 0.20 & 1.17 & 2.18 \\
\hline 0.25 & 0.5 & 0.125 & 0.125 & 0.15 & 1.13 & 2.36 \\
\hline 0.38 & 0.63 & 0.125 & 0 & 0.19 & 0.90 & 0.57 \\
\hline 0.38 & 0.13 & 0.125 & 0.375 & 0.16 & 0.88 & 0.33 \\
\hline 0.38 & 0.25 & 0.125 & 0.25 & 0.27 & 1.55 & 1.53 \\
\hline 0.38 & 0.38 & 0.125 & 0.125 & 0.05 & 1.97 & 1.64 \\
\hline 0.5 & 0 & 0.125 & 0.375 & -0.06 & 1.25 & 1.39 \\
\hline 0.5 & 0.13 & 0.125 & 0.25 & 0.33 & 1.31 & 1.46 \\
\hline 0.5 & 0.25 & 0.125 & 0.125 & 0.09 & 1.32 & 1.79 \\
\hline 0.5 & 0.38 & 0.125 & 0 & 0.23 & 2.97 & 1.61 \\
\hline 0.63 & 0 & 0.125 & 0.25 & 0.41 & 1.27 & 0.76 \\
\hline 0.63 & 0.13 & 0.125 & 0.125 & 0.11 & 0.90 & 1.79 \\
\hline 0.63 & 0.25 & 0.125 & 0 & 0.16 & 1.50 & 1.92 \\
\hline 0.75 & 0 & 0.125 & 0.125 & 0.49 & 0.80 & 1.25 \\
\hline 0.75 & 0.13 & 0.125 & 0 & 0.18 & 1.15 & 1.69 \\
\hline 0 & 0.13 & 0.25 & 0.625 & 0.18 & 0.58 & 0.68 \\
\hline 0 & 0.25 & 0.25 & 0.5 & 0.32 & 0.61 & 0.57 \\
\hline 0 & 0.38 & 0.25 & 0.375 & 0.26 & 0.77 & 0.34 \\
\hline 0 & 0.5 & 0.25 & 0.25 & -0.11 & 0.70 & 0.47 \\
\hline 0 & 0.63 & 0.25 & 0.125 & 0.66 & 1.52 & 0.41 \\
\hline 0 & 0.75 & 0.25 & 0 & 0.63 & 2.30 & 0.55 \\
\hline 0.125 & 0.13 & 0.25 & 0.5 & 0.39 & 1.00 & 0.45 \\
\hline 0.125 & 0.25 & 0.25 & 0.375 & 0.43 & 0.70 & 0.47 \\
\hline 0.125 & 0.375 & 0.25 & 0.25 & 0.75 & 1.45 & 0.71 \\
\hline 0.125 & 0.5 & 0.25 & 0.125 & 0.17 & 0.67 & 0.18 \\
\hline 0.125 & 0.63 & 0.25 & 0 & 0.28 & 0.78 & 0.35 \\
\hline 0.25 & 0 & 0.25 & 0.5 & 0.01 & 0.12 & B \\
\hline 0.25 & 0.125 & 0.25 & 0.375 & -0.05 & 1.01 & 0.51 \\
\hline 0.25 & 0.25 & 0.25 & 0.25 & 0.19 & 1.62 & 0.43 \\
\hline 0.25 & 0.375 & 0.25 & 0.125 & 0.39 & 1.43 & 0.15 \\
\hline 0.25 & 0.5 & 0.25 & 0 & 0.62 & 1.76 & 0.12 \\
\hline
\end{tabular}




\begin{tabular}{|c|c|c|c|c|c|c|}
\hline \multicolumn{4}{|c|}{ Compositions } & \multicolumn{3}{|c|}{ Hydrogen Storage Capacities (wt. \%) } \\
\hline $\mathrm{LiNH}_{2}$ & $\mathrm{LiBH}_{4}$ & $\mathrm{VCl}_{3}$ & LiH & $100^{\circ} \mathrm{C}$ & $230^{\circ} \mathrm{C}$ & $350^{\circ} \mathrm{C}$ \\
\hline 0.375 & 0 & 0.25 & 0.375 & 0.29 & 1.68 & 0.43 \\
\hline 0.375 & 0.125 & 0.25 & 0.25 & 0.31 & 1.47 & 0.45 \\
\hline 0.375 & 0.25 & 0.25 & 0.125 & 0.04 & 0.20 & 0.14 \\
\hline 0.375 & 0.375 & 0.25 & 0 & 0.04 & 0.18 & 0.15 \\
\hline 0.5 & 0 & 0.25 & 0.25 & 0.07 & 0.35 & 0.20 \\
\hline 0.5 & 0.125 & 0.25 & 0.13 & 0.12 & 0.22 & $\mathrm{~B}$ \\
\hline 0.5 & 0.25 & 0.25 & 0 & 0.05 & 0.61 & 1.27 \\
\hline 0.625 & 0 & 0.25 & 0.125 & -0.05 & 0.85 & B \\
\hline
\end{tabular}




\begin{tabular}{|c|c|c|c|c|c|c|c|c|}
\hline \multirow{2}{*}{\multicolumn{4}{|c|}{ Composition }} & \multicolumn{5}{|c|}{ Hydrogen Storage Capacity (wt. \%) } \\
\hline & & & & \multicolumn{2}{|c|}{ Medium Throughput } & \multicolumn{3}{|c|}{ High Throughput (Des $\left.\mathrm{T},{ }^{\circ} \mathrm{C}\right)$} \\
\hline $\mathrm{LiNH}_{2}$ & $\mathrm{LiBH}_{4}$ & $\mathrm{TiCl}_{3}$ & $\mathrm{VCl}_{3}$ & Des 1 & Des 2 & 100 & 230 & 350 \\
\hline 0.7 & 0.2 & 0.05 & 0.05 & 1.50 & 0.67 & 0.39 & 1.48 & 2.30 \\
\hline 0.5 & 0.4 & 0.05 & 0.05 & 2.05 & 0.96 & 0.95 & 2.16 & 2.57 \\
\hline 0.3 & 0.6 & 0.05 & 0.05 & 1.59 & 0.61 & 1.04 & 2.02 & 1.85 \\
\hline 0.1 & 0.8 & 0.05 & 0.05 & 1.08 & 0.36 & 0.47 & 1.14 & 1.41 \\
\hline 0.65 & 0.2 & 0.1 & 0.05 & 3.06 & 0.70 & 0.00 & 2.18 & 0.75 \\
\hline 0.45 & 0.4 & 0.1 & 0.05 & 3.26 & 0.49 & 1.76 & 1.85 & 0.61 \\
\hline 0.25 & 0.6 & 0.1 & 0.05 & 3.58 & 0.16 & 2.09 & 1.42 & 1.12 \\
\hline 0.05 & 0.8 & 0.1 & 0.05 & 1.00 & 0.38 & 0.28 & 1.24 & 1.51 \\
\hline 0.8 & 0 & 0.15 & 0.05 & $\mathrm{~N}$ & $\mathrm{~N}$ & -0.08 & -0.12 & 0.27 \\
\hline 0.6 & 0.2 & 0.15 & 0.05 & 1.96 & 0.17 & 0.12 & 1.52 & 0.13 \\
\hline 0.4 & 0.4 & 0.15 & 0.05 & $\mathrm{~N}$ & $\mathrm{~N}$ & -0.05 & 0.42 & 0.18 \\
\hline 0.2 & 0.6 & 0.15 & 0.05 & 1.66 & 0.28 & 0.59 & 1.08 & 0.41 \\
\hline 0 & 0.8 & 0.15 & 0.05 & $\mathrm{~N}$ & $\mathrm{~N}$ & 0.00 & 0.20 & 0.12 \\
\hline 0.75 & 0 & 0.2 & 0.05 & $\mathrm{~N}$ & $\mathrm{~N}$ & -0.02 & 0.63 & 0.34 \\
\hline 0.55 & 0.2 & 0.2 & 0.05 & $\mathrm{~N}$ & $\mathrm{~N}$ & 0.67 & 1.51 & 0.26 \\
\hline 0.35 & 0.4 & 0.2 & 0.05 & $\mathrm{~N}$ & $\mathrm{~N}$ & 0.44 & 0.90 & 0.23 \\
\hline 0.15 & 0.6 & 0.2 & 0.05 & $\mathrm{~N}$ & $\mathrm{~N}$ & 0.31 & 0.59 & 0.32 \\
\hline 0.65 & 0.2 & 0.05 & 0.1 & 1.10 & 0.86 & 0.04 & 1.24 & 0.87 \\
\hline 0.45 & 0.4 & 0.05 & 0.1 & $\mathrm{~N}$ & $\mathrm{~N}$ & 0.79 & 1.96 & 0.92 \\
\hline 0.25 & 0.6 & 0.05 & 0.1 & 2.03 & 0.22 & 0.54 & 1.24 & 1.84 \\
\hline 0.05 & 0.8 & 0.05 & 0.1 & $\mathrm{~N}$ & $N$ & 0.28 & 0.57 & 1.25 \\
\hline 0.8 & 0 & 0.1 & 0.1 & $\mathrm{~N}$ & $\mathrm{~N}$ & 0.35 & 0.40 & 0.28 \\
\hline 0.6 & 0.2 & 0.1 & 0.1 & 2.31 & 0.23 & 0.15 & 1.48 & 0.37 \\
\hline 0.4 & 0.4 & 0.1 & 0.1 & $\mathrm{~N}$ & $\mathrm{~N}$ & -0.01 & 0.30 & 0.25 \\
\hline 0.2 & 0.6 & 0.1 & 0.05 & $\mathrm{~N}$ & $\mathrm{~N}$ & 0.33 & 1.00 & 0.26 \\
\hline 0 & 0.8 & 0.1 & 0.1 & $\mathrm{~N}$ & $\mathrm{~N}$ & 0.28 & 0.83 & 0.27 \\
\hline 0.75 & 0 & 0.1 & 0.1 & $\mathrm{~N}$ & $\mathrm{~N}$ & 0.05 & 0.17 & -0.12 \\
\hline 0.55 & 0.2 & 0.1 & 0.1 & $\mathrm{~N}$ & $\mathrm{~N}$ & -0.03 & 0.51 & 0.34 \\
\hline 0.35 & 0.4 & 0.1 & 0.1 & 1.98 & 0.23 & 0.70 & 1.22 & 0.47 \\
\hline 0.15 & 0.6 & 0.1 & 0.1 & 2.29 & 0.15 & 1.18 & 1.11 & 0.43 \\
\hline 0.8 & 0 & 0.15 & 0.1 & 1.31 & 0.83 & 0.02 & 1.26 & 1.03 \\
\hline 0.6 & 0.2 & 0.15 & 0.1 & 2.16 & 0.41 & 0.19 & 1.91 & 1.24 \\
\hline 0.4 & 0.4 & 0.05 & 0.15 & $\mathrm{~N}$ & $\mathrm{~N}$ & 0.12 & 0.84 & 0.29 \\
\hline 0.2 & 0.6 & 0.05 & 0.15 & $B$ & $B$ & 1.43 & 1.49 & 0.65 \\
\hline 0 & 0.8 & 0.05 & 0.15 & $\mathrm{~N}$ & $\mathrm{~N}$ & -0.05 & 0.90 & -0.19 \\
\hline 0.75 & 0 & 0.1 & 0.15 & $\mathrm{~N}$ & $\mathrm{~N}$ & 0.02 & 0.25 & 0.12 \\
\hline 0.55 & 0.2 & 0.1 & 0.15 & $\mathrm{~N}$ & $\mathrm{~N}$ & 0.05 & 0.36 & 0.19 \\
\hline 0.35 & 0.4 & 0.1 & 0.15 & $\mathrm{~N}$ & $\mathrm{~N}$ & 0.35 & 0.51 & 0.30 \\
\hline 0.15 & 0.6 & 0.1 & 0.15 & $\mathrm{~N}$ & $\mathrm{~N}$ & 0.68 & 0.77 & 0.21 \\
\hline 0.75 & 0 & 0.05 & 0.2 & $\mathrm{~N}$ & $\mathrm{~N}$ & 0.07 & 0.07 & -0.11 \\
\hline
\end{tabular}


Table 23. $\mathrm{LiNH}_{2}-\mathrm{LiBH}_{4}-\mathrm{ZnCl}_{2}$ Phase Diagram. Compositions and High Throughput Hydrogen Storage Capacities.

\begin{tabular}{|c|c|c|c|c|c|c|c|}
\hline \multicolumn{4}{|c|}{ Composition } & \multicolumn{4}{|c|}{ Hydrogen Storage Capacity (wt. \%) } \\
\hline $\mathrm{LiNH}_{2}$ & $\mathrm{LiBH}_{4}$ & $\mathrm{ZnCl}_{2}$ & $\mathrm{Zn}(\mathrm{BH} 4)_{2}$ & 100 & 100 & 120 & 120 \\
\hline 0 & 0.6 & 0.4 & 0 & 2.19 & -0.04 & -0.04 & -0.01 \\
\hline 0 & 0.7 & 0.3 & 0 & 2.35 & -0.07 & 0.04 & 0.00 \\
\hline 0 & 0.8 & 0.2 & 0 & 2.03 & 0.11 & 0.10 & 0.11 \\
\hline 0 & 0.9 & 0.1 & 0 & 1.23 & -0.02 & 0.12 & 0.02 \\
\hline 0.1 & 0.5 & 0.4 & 0 & 2.43 & -0.01 & 0.02 & 0.03 \\
\hline 0.1 & 0.6 & 0.3 & 0 & 2.23 & 0.02 & 0.05 & 0.04 \\
\hline 0.1 & 0.7 & 0.2 & 0 & 1.74 & -0.02 & 0.04 & 0.01 \\
\hline 0.1 & 0.8 & 0.1 & 0 & 1.24 & 0.01 & -0.06 & -0.08 \\
\hline 0.2 & 0.4 & 0.4 & 0 & 1.72 & 0.02 & 0.07 & 0.06 \\
\hline 0.2 & 0.5 & 0.3 & 0 & 1.48 & -0.01 & 0.03 & 0.01 \\
\hline 0.2 & 0.6 & 0.2 & 0 & 1.75 & -0.01 & 0.03 & 0.00 \\
\hline 0.2 & 0.7 & 0.1 & 0 & 0.08 & 0.04 & -0.01 & 0.08 \\
\hline 0.3 & 0.4 & 0.3 & 0 & 2.16 & -0.03 & 0.04 & 0.00 \\
\hline 0.3 & 0.5 & 0.2 & 0 & 0.20 & -0.02 & 0.02 & 0.01 \\
\hline 0.3 & 0.6 & 0.1 & 0 & 0.02 & -0.02 & -0.06 & -0.01 \\
\hline 0.4 & 0.3 & 0.3 & 0 & 0.87 & 0.04 & 0.06 & 0.05 \\
\hline 0.4 & 0.4 & 0.2 & 0 & 0.02 & -0.03 & -0.05 & 0.06 \\
\hline 0.4 & 0.5 & 0.1 & 0 & 0.11 & 0.00 & 0.02 & 0.08 \\
\hline 0.5 & 0.2 & 0.3 & 0 & 0.07 & 0.07 & 0.05 & 0.12 \\
\hline 0.5 & 0.3 & 0.2 & 0 & 0.03 & 0.06 & 0.08 & 0.08 \\
\hline 0.5 & 0.4 & 0.1 & 0 & 0.10 & 0.06 & -0.02 & 0.04 \\
\hline 0.6 & 0.2 & 0.2 & 0 & 0.02 & 0.08 & 0.09 & 0.10 \\
\hline 0.6 & 0.3 & 0.1 & 0 & 0.01 & -0.01 & 0.00 & 0.05 \\
\hline 0.7 & 0.1 & 0.2 & 0 & 0.07 & 0.07 & 0.06 & 0.22 \\
\hline 0.7 & 0.2 & 0.1 & 0 & 0.03 & 0.01 & 0.02 & 0.08 \\
\hline 0.8 & 0 & 0.2 & 0 & 0.02 & 0.04 & 0.02 & 0.04 \\
\hline 0.8 & 0.1 & 0.1 & 0 & 0.04 & 0.06 & 0.07 & 0.11 \\
\hline 0.9 & 0 & 0.1 & 0 & 0.01 & 0.14 & 0.03 & 0.14 \\
\hline 0.57 & 0.29 & 0.14 & 0 & 0.06 & 0.04 & 0.07 & 0.07 \\
\hline 0 & 0.86 & 0.14 & 0 & 1.28 & 0.03 & 0.15 & 0.09 \\
\hline 0.666 & 0.167 & 0 & 0.167 & 0.09 & 0.02 & 0.02 & 0.03 \\
\hline 0.5 & 0.25 & 0 & 0.25 & 0.26 & 0.02 & 0.00 & 0.08 \\
\hline
\end{tabular}




\begin{tabular}{|c|c|c|c|c|c|c|c|c|c|}
\hline \multicolumn{4}{|c|}{ Compositions } & \multicolumn{6}{|c|}{ High Throughput Hydrogen Storage Capacities (wt. \%) } \\
\hline $\mathrm{LiNH}_{2}$ & $\mathrm{LiBH}_{4}$ & $\mathrm{ZrCl}_{4}$ & LiH & Des $1\left(100^{\circ} \mathrm{C}\right)$ & Des $2 \mathrm{~T}\left({ }^{\circ} \mathrm{C}\right)$ & Des 2 & Des $3 \mathrm{~T}\left({ }^{\circ} \mathrm{C}\right)$ & Des 3 & Des $4\left(230^{\circ} \mathrm{C}\right)$ \\
\hline 0.375 & 0.25 & 0.125 & 0.25 & 0.13 & 100 & 0.05 & 230 & 0.85 & 0.44 \\
\hline 0.375 & 0.375 & 0.125 & 0.125 & 0.13 & 100 & -0.04 & 230 & 1.14 & 0.20 \\
\hline 0.375 & 0.5 & 0.125 & 0 & 0.50 & 100 & 0.01 & 230 & 0.96 & 0.38 \\
\hline 0.5 & 0 & 0.125 & 0.375 & 0.25 & 100 & 0.03 & 230 & 0.49 & 0.15 \\
\hline 0.125 & 0.625 & 0.25 & 0 & B & 100 & B & 230 & B & B \\
\hline 0.25 & 0.125 & 0.25 & 0.375 & 0.62 & 100 & 0.02 & 230 & 0.95 & 0.54 \\
\hline 0.25 & 0.25 & 0.25 & 0.25 & 0.34 & 100 & -0.02 & 230 & 0.86 & 0.02 \\
\hline 0.25 & 0.375 & 0.25 & 0.125 & 0.23 & 100 & -0.03 & 230 & 0.94 & 0.04 \\
\hline 0.25 & 0.5 & 0.25 & 0 & 0.30 & 100 & -0.02 & 230 & 0.83 & 0.03 \\
\hline 0.375 & 0.125 & 0.25 & 0.25 & 0.17 & 100 & 0.06 & 230 & 0.40 & 0.08 \\
\hline 0.375 & 0.25 & 0.25 & 0.125 & 0.26 & 100 & -0.02 & 230 & 0.67 & 0.05 \\
\hline 0.375 & 0.375 & 0.25 & 0 & 0.13 & 100 & -0.02 & 230 & 0.82 & 0.02 \\
\hline 0.5 & 0 & 0.125 & 0.375 & 0.07 & 100 & -0.01 & 230 & 0.37 & 0.08 \\
\hline 0.5 & 0.125 & 0.125 & 0.25 & B & 100 & B & 230 & B & B \\
\hline 0.5 & 0.25 & 0.125 & 0.125 & 0.31 & 100 & -0.02 & 230 & 1.01 & 0.14 \\
\hline 0.5 & 0.375 & 0.125 & 0 & 0.53 & 100 & 0.05 & 230 & 0.59 & 0.20 \\
\hline 0.625 & 0 & 0.125 & 0.25 & 0.13 & 100 & 0.03 & 230 & 0.31 & 0.10 \\
\hline 0.625 & 0.125 & 0.125 & 0.125 & $B$ & 100 & B & 230 & $\mathrm{~B}$ & $B$ \\
\hline 0.625 & 0.25 & 0.125 & 0 & 0.24 & 100 & 0.02 & 230 & 0.98 & 0.24 \\
\hline 0.75 & 0 & 0.125 & 0.125 & -0.07 & 100 & -0.03 & 230 & 0.37 & 0.13 \\
\hline 0.75 & 0.125 & 0.125 & 0 & 0.22 & 100 & 0.00 & 230 & 0.66 & 0.13 \\
\hline 0 & 0.25 & 0.25 & 0.5 & 0.67 & 100 & 0.10 & 230 & 0.51 & 0.03 \\
\hline 0 & 0.375 & 0.25 & 0.375 & 0.49 & 100 & 0.05 & 230 & 0.52 & 0.04 \\
\hline 0 & 0.5 & 0.25 & 0.25 & 0.43 & 100 & 0.06 & 230 & 0.63 & 0.06 \\
\hline 0 & 0.625 & 0.25 & 0.125 & 0.48 & 100 & 0.05 & 230 & 0.57 & 0.01 \\
\hline 0 & 0.75 & 0.25 & 0 & 0.36 & 100 & -0.01 & 230 & 0.66 & -0.02 \\
\hline 0.125 & 0.25 & 0.25 & 0.375 & B & 100 & B & 230 & B & B \\
\hline 0.125 & 0.375 & 0.25 & 0.25 & 0.62 & 100 & 0.04 & 230 & 0.61 & 0.08 \\
\hline 0.375 & 0.375 & 0.25 & 0 & 0.20 & 100 & 0.02 & 230 & 0.93 & 0.08 \\
\hline 0.5 & 0.125 & 0.25 & 0.125 & $\mathrm{~N}$ & $\mathrm{~N}$ & $\mathrm{~N}$ & $\mathrm{~N}$ & $\mathrm{~N}$ & $\mathrm{~N}$ \\
\hline 0.5 & 0.25 & 0.25 & 0 & $\mathrm{~N}$ & $\mathrm{~N}$ & $\mathrm{~N}$ & $\mathrm{~N}$ & $\mathrm{~N}$ & $\mathrm{~N}$ \\
\hline 0.625 & 0.125 & 0.25 & 0 & $\mathrm{~N}$ & $\mathrm{~N}$ & $\mathrm{~N}$ & $\mathrm{~N}$ & $\mathrm{~N}$ & $\mathrm{~N}$ \\
\hline 0 & 0.5 & 0.375 & 0.125 & $\mathrm{~N}$ & $\mathrm{~N}$ & $\mathrm{~N}$ & $\mathrm{~N}$ & $\mathrm{~N}$ & $\mathrm{~N}$ \\
\hline 0 & 0.625 & 0.375 & 0 & $\mathrm{~N}$ & $\mathrm{~N}$ & $\mathrm{~N}$ & $\mathrm{~N}$ & $\mathrm{~N}$ & $\mathrm{~N}$ \\
\hline 0.125 & 0.375 & 0.375 & 0.125 & $\mathrm{~N}$ & $\mathrm{~N}$ & $\mathrm{~N}$ & $\mathrm{~N}$ & $\mathrm{~N}$ & $\mathrm{~N}$ \\
\hline
\end{tabular}




\begin{tabular}{|c|c|c|c|c|c|c|c|c|c|}
\hline \multicolumn{4}{|c|}{ Compositions } & \multicolumn{6}{|c|}{ High Throughput Hydrogen Storage Capacities (wt. \%) } \\
\hline $\mathrm{LiNH}_{2}$ & $\mathrm{LiBH}_{4}$ & $\mathrm{ZrCl}_{4}$ & $\mathrm{LiH}$ & Des $1\left(100^{\circ} \mathrm{C}\right)$ & Des $2 \mathrm{~T}\left({ }^{\circ} \mathrm{C}\right)$ & Des 2 & Des $3 \mathrm{~T}\left({ }^{\circ} \mathrm{C}\right)$ & Des 3 & Des $4\left(230^{\circ} \mathrm{C}\right)$ \\
\hline 0.125 & 0.5 & 0.375 & 0 & $\mathrm{~N}$ & $\mathrm{~N}$ & $\mathrm{~N}$ & $\mathrm{~N}$ & $\mathrm{~N}$ & $\mathrm{~N}$ \\
\hline 0 & 0.833 & 0.167 & 0 & 0.30 & 100 & 0.04 & 230 & 1.05 & 0.21 \\
\hline 0.571 & 0.143 & 0.143 & 0.143 & 0.13 & 100 & 0.06 & 230 & 0.27 & 0.04 \\
\hline 0.5 & 0 & 0.125 & 0.375 & 0.01 & 229 & 0.20 & 350 & 0.23 & $\mathrm{~N}$ \\
\hline 0.625 & 0 & 0.125 & 0.25 & 0.15 & 229 & 0.56 & 350 & 0.50 & $\mathrm{~N}$ \\
\hline 0.75 & 0 & 0.125 & 0.125 & -0.06 & 229 & 0.26 & 350 & -0.14 & $\mathrm{~N}$ \\
\hline 0.375 & 0.125 & 0.125 & 0.375 & 0.14 & 229 & 0.70 & 350 & 0.66 & $\mathrm{~N}$ \\
\hline 0.625 & 0.125 & 0.125 & 0.125 & 0.41 & 229 & 1.63 & 350 & 0.53 & $\mathrm{~N}$ \\
\hline 0.75 & 0.125 & 0.125 & 0 & 0.09 & 230 & 0.61 & 350 & 0.73 & $\mathrm{~N}$ \\
\hline 0.25 & 0.125 & 0.125 & 0.375 & 0.60 & 230 & 1.01 & 350 & 0.43 & $\mathrm{~N}$ \\
\hline 0.375 & 0.25 & 0.125 & 0.25 & 0.49 & 230 & 1.64 & 350 & 0.56 & $\mathrm{~N}$ \\
\hline 0.5 & 0.25 & 0.125 & 0.125 & 0.50 & 230 & 1.40 & 350 & 0.45 & $\mathrm{~N}$ \\
\hline 0.625 & 0.25 & 0.125 & 0 & 0.00 & 230 & 1.09 & 350 & 1.24 & $\mathrm{~N}$ \\
\hline 0.125 & 0.375 & 0.125 & 0.375 & 0.26 & 230 & 0.36 & 350 & 0.89 & $\mathrm{~N}$ \\
\hline 0.25 & 0.375 & 0.125 & 0.25 & 0.81 & 230 & 0.92 & 350 & 0.62 & $\mathrm{~N}$ \\
\hline 0.375 & 0.375 & 0.125 & 0.125 & 0.31 & 230 & 1.23 & 350 & 0.61 & $\mathrm{~N}$ \\
\hline 0.5 & 0.375 & 0.125 & 0 & 0.49 & 230 & 0.93 & 350 & 0.62 & $\mathrm{~N}$ \\
\hline 0 & 0.5 & 0.125 & 0.375 & 0.12 & 230 & 0.38 & 350 & 1.22 & $\mathrm{~N}$ \\
\hline 0 & 0.5 & 0.25 & 0.25 & 0.36 & 230 & 0.50 & 350 & 0.13 & $\mathrm{~N}$ \\
\hline 0.125 & 0.5 & 0.25 & 0.125 & 0.45 & 230 & 0.89 & 350 & 0.26 & $\mathrm{~N}$ \\
\hline 0.25 & 0.5 & 0.25 & 0 & 0.18 & 230 & 0.90 & 350 & 0.18 & $\mathrm{~N}$ \\
\hline 0 & 0.625 & 0.25 & 0.125 & 0.20 & 230 & 0.56 & 350 & 0.06 & B \\
\hline 0.125 & 0.625 & 0.25 & 0 & 0.40 & 230 & 0.97 & 350 & 0.30 & $\mathrm{~N}$ \\
\hline 0 & 0.75 & 0.25 & 0 & 0.41 & 230 & 0.88 & 350 & 0.13 & $\mathrm{~N}$ \\
\hline 0.25 & 0.375 & 0.25 & 0.125 & 0.41 & 230 & 1.38 & 350 & 0.25 & $\mathrm{~N}$ \\
\hline 0.375 & 0.375 & 0.25 & 0 & -0.03 & 230 & 1.35 & 350 & 0.42 & $\mathrm{~N}$ \\
\hline 0.125 & 0.5 & 0.125 & 0.25 & 0.54 & 230 & 1.00 & 350 & 0.63 & $\mathrm{~N}$ \\
\hline 0.25 & 0.5 & 0.125 & 0.125 & -0.06 & 230 & 0.87 & 350 & 1.27 & $\mathrm{~N}$ \\
\hline 0.375 & 0.5 & 0.125 & 0 & 0.82 & 230 & 1.88 & 350 & 1.42 & $\mathrm{~N}$ \\
\hline 0 & 0.625 & 0.125 & 0.25 & -0.06 & 230 & $\mathrm{~B}$ & 350 & $\mathrm{~B}$ & $\mathrm{~N}$ \\
\hline 0.125 & 0.625 & 0.125 & 0.125 & 0.48 & 230 & 0.65 & 350 & 0.83 & $\mathrm{~N}$ \\
\hline 0 & 0.75 & 0.125 & 0.125 & 0.11 & 230 & 0.24 & 350 & 0.56 & $\mathrm{~N}$ \\
\hline 0.125 & 0.75 & 0.125 & 0 & 0.26 & 230 & 0.62 & 350 & 0.97 & $\mathrm{~N}$ \\
\hline 0.375 & 0 & 0.25 & 0.375 & -0.02 & 230 & 0.19 & 350 & 0.24 & $\mathrm{~N}$ \\
\hline 0.5 & 0 & 0.25 & 0.25 & 0.08 & 230 & 0.39 & 350 & 0.36 & $\mathrm{~N}$ \\
\hline
\end{tabular}




\begin{tabular}{|c|c|c|c|c|c|c|c|c|c|}
\hline \multicolumn{4}{|c|}{ Compositions } & \multicolumn{6}{|c|}{ High Throughput Hydrogen Storage Capacities (wt. \%) } \\
\hline $\mathrm{LiNH}_{2}$ & $\mathrm{LiBH}_{4}$ & $\mathrm{ZrCl}_{4}$ & LiH & Des $1\left(100^{\circ} \mathrm{C}\right)$ & Des $2 \mathrm{~T}\left({ }^{\circ} \mathrm{C}\right)$ & Des 2 & Des $3 \mathrm{~T}\left({ }^{\circ} \mathrm{C}\right)$ & Des 3 & Des $4\left(230^{\circ} \mathrm{C}\right)$ \\
\hline 0.625 & 0 & 0.25 & 0.125 & 0.11 & 230 & 0.53 & 350 & 0.38 & $\mathrm{~N}$ \\
\hline 0.75 & 0 & 0.25 & 0 & 0.04 & 230 & 0.43 & 350 & 0.25 & $\mathrm{~N}$ \\
\hline 0.25 & 0.125 & 0.25 & 0.375 & 0.41 & 230 & 0.50 & 350 & 0.16 & $\mathrm{~N}$ \\
\hline 0.375 & 0.125 & 0.25 & 0.25 & 0.01 & 230 & 0.18 & 350 & 0.04 & $\mathrm{~N}$ \\
\hline 0.5 & 0.125 & 0.25 & 0.125 & 0.12 & 230 & 0.29 & 350 & 0.16 & $\mathrm{~N}$ \\
\hline 0.625 & 0.125 & 0.25 & 0 & 0.15 & 230 & 0.36 & 350 & 0.33 & $\mathrm{~N}$ \\
\hline 0.125 & 0.25 & 0.25 & 0.375 & 0.37 & 230 & 0.69 & 350 & 0.22 & $\mathrm{~N}$ \\
\hline 0.25 & 0.25 & 0.25 & 0.25 & 0.85 & 230 & 1.37 & 350 & 0.49 & $\mathrm{~N}$ \\
\hline 0.375 & 0.25 & 0.25 & 0.125 & 0.56 & 230 & 1.52 & 350 & 0.64 & $\mathrm{~N}$ \\
\hline 0.5 & 0.25 & 0.25 & 0 & 0.64 & 230 & 1.44 & 350 & 0.54 & $\mathrm{~N}$ \\
\hline 0 & 0.375 & 0.25 & 0.375 & 0.54 & 230 & 0.42 & 350 & 0.19 & $\mathrm{~N}$ \\
\hline 0.125 & 0.375 & 0.25 & 0.25 & 0.46 & 230 & 0.95 & 350 & 0.27 & $\mathrm{~N}$ \\
\hline
\end{tabular}




\begin{tabular}{|c|c|c|c|c|c|c|c|c|c|}
\hline \multirow{2}{*}{\multicolumn{5}{|c|}{ Composition }} & \multicolumn{5}{|c|}{ Hydrogen Storage Capacities (wt. \%) } \\
\hline & & & & & \multicolumn{2}{|c|}{ Medium Throughput } & \multicolumn{3}{|c|}{ High Throughput } \\
\hline $\mathrm{LiNH}_{2}$ & $\mathrm{LiBH}_{4}$ & $\mathrm{MgH}_{2}$ & $\mathrm{NiCl}_{2}$ & LiH & Des 1 & Des 2 & $100^{\circ} \mathrm{C}$ & $230^{\circ} \mathrm{C}$ & $350^{\circ} \mathrm{C}$ \\
\hline 0.8 & 0 & 0.1 & 0.1 & 0 & $\mathrm{~N}$ & $\mathrm{~N}$ & 0.43 & 0.37 & 1.02 \\
\hline 0.7 & 0.1 & 0.1 & 0.1 & 0 & $\mathrm{~N}$ & $\mathrm{~N}$ & 0.19 & 0.90 & 1.98 \\
\hline 0.6 & 0.2 & 0.1 & 0.1 & 0 & 2.88 & 0.58 & 0.29 & 2.45 & 1.65 \\
\hline 0.5 & 0.3 & 0.1 & 0.1 & 0 & 4.50 & 0.79 & 0.50 & 3.44 & 0.82 \\
\hline 0.4 & 0.4 & 0.1 & 0.1 & 0 & $\mathrm{~N}$ & $\mathrm{~N}$ & 0.57 & 3.54 & 0.43 \\
\hline 0.3 & 0.5 & 0.1 & 0.1 & 0 & 2.94 & 0.33 & 0.38 & 2.48 & 0.31 \\
\hline 0.2 & 0.6 & 0.1 & 0.1 & 0 & 2.17 & 0.31 & $B$ & $B$ & 1.14 \\
\hline 0.1 & 0.7 & 0.1 & 0.1 & 0 & 1.14 & 0.20 & 0.47 & 1.09 & 1.95 \\
\hline 0 & 0.8 & 0.1 & 0.1 & 0 & $\mathrm{~N}$ & $\mathrm{~N}$ & 0.09 & 0.78 & 1.16 \\
\hline 0.7 & 0 & 0.1 & 0.2 & 0 & $\mathrm{~N}$ & $\mathrm{~N}$ & 0.31 & 0.19 & 0.50 \\
\hline 0.6 & 0.1 & 0.1 & 0.2 & 0 & $\mathrm{~N}$ & $\mathrm{~N}$ & 0.25 & 0.54 & 1.19 \\
\hline 0.5 & 0.2 & 0.1 & 0.2 & 0 & $\mathrm{~N}$ & $\mathrm{~N}$ & 0.08 & 0.79 & 0.72 \\
\hline 0.4 & 0.3 & 0.1 & 0.2 & 0 & 3.16 & 0.37 & 0.34 & 2.45 & -0.11 \\
\hline 0.3 & 0.4 & 0.1 & 0.2 & 0 & 3.73 & 0.52 & 0.44 & 3.17 & 0.61 \\
\hline 0.2 & 0.5 & 0.1 & 0.2 & 0 & 3.35 & 0.27 & 0.45 & 2.01 & 0.68 \\
\hline 0.1 & 0.6 & 0.1 & 0.2 & 0 & 2.47 & 0.17 & 0.73 & 1.42 & 1.15 \\
\hline 0 & 0.7 & 0.1 & 0.2 & 0 & $\mathrm{~N}$ & $\mathrm{~N}$ & 0.57 & 0.94 & 1.38 \\
\hline 0.6 & 0 & 0.1 & 0.3 & 0 & $\mathrm{~N}$ & $\mathrm{~N}$ & -0.03 & 0.97 & 0.58 \\
\hline 0.5 & 0.1 & 0.1 & 0.3 & 0 & $B$ & $\mathrm{~B}$ & 0.03 & 0.22 & 0.27 \\
\hline 0.4 & 0.2 & 0.1 & 0.3 & 0 & 1.44 & 0.17 & 0.37 & 1.03 & 0.93 \\
\hline 0.3 & 0.3 & 0.1 & 0.3 & 0 & 2.30 & 0.23 & 0.58 & 1.73 & 0.88 \\
\hline 0.2 & 0.4 & 0.1 & 0.3 & 0 & 2.58 & 0.28 & 0.51 & 1.50 & 0.61 \\
\hline 0.1 & 0.5 & 0.1 & 0.3 & 0 & 3.09 & 0.14 & -0.02 & 1.35 & -0.08 \\
\hline 0 & 0.6 & 0.1 & 0.3 & 0 & 3.46 & 0.09 & 0.77 & 1.34 & 0.31 \\
\hline 0.5 & 0 & 0.1 & 0.4 & 0.3 & 1.22 & 0.80 & 0.20 & 1.56 & 0.67 \\
\hline 0.4 & 0.1 & 0.1 & 0.4 & 0.3 & 1.14 & 0.41 & 0.11 & 1.19 & 0.76 \\
\hline 0.3 & 0.2 & 0.1 & 0.4 & 0.3 & 2.29 & 0.16 & 0.44 & 0.84 & 0.75 \\
\hline 0.2 & 0.3 & 0.1 & 0.4 & 0.3 & $\mathrm{~N}$ & $\mathrm{~N}$ & 0.53 & 0.66 & 0.48 \\
\hline 0.1 & 0.4 & 0.1 & 0.4 & 0.3 & $\mathrm{~N}$ & $\mathrm{~N}$ & 0.50 & 1.31 & 0.46 \\
\hline 0 & 0.5 & 0.1 & 0.4 & 0.3 & $\mathrm{~N}$ & $\mathrm{~N}$ & B & $\mathrm{B}$ & 0.14 \\
\hline 0.7 & 0 & 0.2 & 0.1 & 0 & $\mathrm{~N}$ & $\mathrm{~N}$ & 0.14 & 1.13 & $\mathrm{~N}$ \\
\hline 0.6 & 0.1 & 0.2 & 0.1 & 0 & $\mathrm{~N}$ & $\mathrm{~N}$ & -0.02 & 1.05 & $\mathrm{~N}$ \\
\hline 0.5 & 0.2 & 0.2 & 0.1 & 0 & $\mathrm{~N}$ & $\mathrm{~N}$ & 0.31 & 1.04 & $\mathrm{~N}$ \\
\hline 0.4 & 0.3 & 0.2 & 0.1 & 0 & $\mathrm{~N}$ & $\mathrm{~N}$ & -0.04 & 0.94 & $\mathrm{~N}$ \\
\hline
\end{tabular}


Table 25 (cont.). $\mathrm{LiNH}_{2}-\mathrm{LiBH}_{4}-\mathrm{MgH}_{2}-\mathrm{NiCl}_{2}-\mathrm{LiH}$ Phase Diagram. Compositions and Hydrogen Storage Capacities

\begin{tabular}{|c|c|c|c|c|c|c|c|c|c|}
\hline \multirow{2}{*}{\multicolumn{5}{|c|}{ Composition }} & \multicolumn{5}{|c|}{ Hydrogen Storage Capacities (wt. \%) } \\
\hline & & & & & \multicolumn{2}{|c|}{ Medium Throughput } & \multicolumn{3}{|c|}{ High Throughput } \\
\hline $\mathrm{LiNH}_{2}$ & $\mathrm{LiBH}_{4}$ & $\mathrm{MgH}_{2}$ & $\mathrm{NiCl}_{2}$ & LiH & Des 1 & Des 2 & $100^{\circ} \mathrm{C}$ & $230^{\circ} \mathrm{C}$ & $350^{\circ} \mathrm{C}$ \\
\hline 0.3 & 0.4 & 0.2 & 0.1 & 0 & $\mathrm{~N}$ & $\mathrm{~N}$ & 0.34 & 0.48 & $\mathrm{~N}$ \\
\hline 0.2 & 0.5 & 0.2 & 0.1 & 0 & $\mathrm{~N}$ & $\mathrm{~N}$ & 0.45 & 0.98 & $\mathrm{~N}$ \\
\hline 0.1 & 0.6 & 0.2 & 0.1 & 0 & $\mathrm{~N}$ & $\mathrm{~N}$ & 0.26 & 1.67 & $\mathrm{~N}$ \\
\hline 0 & 0.7 & 0.2 & 0.1 & 0 & $\mathrm{~N}$ & $\mathrm{~N}$ & 0.27 & 2.68 & $\mathrm{~N}$ \\
\hline 0.6 & 0 & 0.2 & 0.2 & 0 & $\mathrm{~N}$ & $\mathrm{~N}$ & 0.27 & 3.38 & $\mathrm{~N}$ \\
\hline 0.5 & 0.1 & 0.2 & 0.2 & 0 & $\mathrm{~N}$ & $\mathrm{~N}$ & 0.03 & 3.15 & $\mathrm{~N}$ \\
\hline 0.5 & 0.2 & 0.2 & 0.1 & 0 & $\mathrm{~N}$ & $\mathrm{~N}$ & 0.61 & 2.57 & 1.34 \\
\hline 0.4 & 0.3 & 0.2 & 0.1 & 0 & $\mathrm{~N}$ & $\mathrm{~N}$ & 0.33 & 3.90 & 0.38 \\
\hline 0.3 & 0.4 & 0.2 & 0.1 & 0 & $\mathrm{~N}$ & $\mathrm{~N}$ & 0.27 & 3.09 & 0.86 \\
\hline 0.2 & 0.5 & 0.2 & 0.1 & 0 & $\mathrm{~N}$ & $\mathrm{~N}$ & 0.45 & 1.96 & 1.07 \\
\hline 0.1 & 0.6 & 0.2 & 0.1 & 0 & $\mathrm{~N}$ & $\mathrm{~N}$ & 0.47 & 0.99 & 1.67 \\
\hline 0 & 0.7 & 0.2 & 0.1 & 0 & $\mathrm{~N}$ & $\mathrm{~N}$ & 0.20 & 0.54 & 2.01 \\
\hline 0.6 & 0 & 0.2 & 0.2 & 0 & $\mathrm{~N}$ & $\mathrm{~N}$ & 0.08 & 1.45 & 1.30 \\
\hline
\end{tabular}




\begin{tabular}{|c|c|c|c|c|c|c|c|c|c|c|}
\hline \multicolumn{4}{|c|}{ Composition } & \multicolumn{5}{|c|}{ Medium Throughput Spent Structures } & \multicolumn{2}{|c|}{$\begin{array}{c}\text { Hydrogen Storage } \\
\text { Capacity (wt.\%) }\end{array}$} \\
\hline $\mathrm{LiNH}_{2}$ & $\mathrm{LiBH}_{4}$ & $\mathrm{ZrH}_{2}$ & $\mathrm{TiH}_{2}$ & xrd 1 & xrd 2 & xrd 3 & xrd4 & xrd 5 & Des 1 & Des 2 \\
\hline 0 & 0.8 & 0.2 & 0 & $\mathrm{ZrH}_{2}$ & $\mathrm{Zr}\left(\mathrm{IO}_{3}\right)_{4}$ str.(?) & & & & 0.05 & 0.02 \\
\hline 0.2 & 0.6 & 0.2 & 0 & WC & $\mathrm{LiB}(\mathrm{OH})_{4}$ & $\mathrm{LiOH}^{*} \mathrm{H}_{2} \mathrm{O}$ & $\mathrm{ZrO}_{2}$ & & 0.63 & 0.38 \\
\hline 0.4 & 0.4 & 0.2 & 0 & $\mathrm{ZrH}_{2}$ & WC & $\mathrm{Li}_{4}\left(\mathrm{NH}_{2}\right)_{3} \mathrm{BH}_{4}$ & & & 0.82 & 0.47 \\
\hline 0.6 & 0.2 & 0.2 & 0 & $\mathrm{ZrH}_{2}$ & WC & $\mathrm{Li}_{4}\left(\mathrm{NH}_{2}\right)_{3} \mathrm{BH}_{4}$ & & & 1.48 & 0.79 \\
\hline 0 & 0.6 & 0.4 & 0 & $\mathrm{LiOH}$ & $\mathrm{Zr}_{2} \mathrm{C}_{3} ?$ & $\mathrm{LiOH}^{*} \mathrm{H}_{2} \mathrm{O}$ & unk., $d=2.81,2.34$ & & 0.02 & -0.01 \\
\hline 0.2 & 0.4 & 0.4 & 0 & $\mathrm{LiOH}$ & $\mathrm{ZrH}_{2}$ & $\mathrm{Li}_{4} \mathrm{~B}_{2} \mathrm{O}_{5}$ & unk., $d=3.88,2.68$ & & 0.27 & 0.20 \\
\hline 0 & 0.2 & 0.8 & 0 & $\mathrm{LiOH}$ & $\mathrm{LiOH}^{\star} \mathrm{H}_{2} \mathrm{O}$ & $\mathrm{Li}_{4} \mathrm{~B}_{2} \mathrm{O}_{5}$ & $\mathrm{ZrH}_{2}, \mathrm{ZrO}_{2}$ & $\mathrm{Li}_{2} \mathrm{ZrO}_{3}, \mathrm{H}_{3} \mathrm{BO}_{3}$ & 0.11 & 0.03 \\
\hline 0.8 & 0 & 0.2 & 0 & $\mathrm{ZrH2}$ & WC & $\mathrm{Li}_{2} \mathrm{NH}$ & & & 0.06 & 0.04 \\
\hline 0 & 0.2 & 0 & 0.8 & $\mathrm{Na}_{2} \mathrm{CO}_{3}{ }^{*} 1.25 \mathrm{H}_{2} \mathrm{O}$ & $\mathrm{LiOH}$ & & & & 0.12 & 0.03 \\
\hline 0 & 0.4 & 0 & 0.6 & Unk., $d=2.27,1.97$ & & & & & 0.11 & 0.05 \\
\hline 0 & 0.6 & 0 & 0.4 & Unk., $d=2.30,1.99$ & & & & & 0.09 & 0.03 \\
\hline 0 & 0.8 & 0 & 0.2 & $\mathrm{Na}_{2} \mathrm{CO}_{3}{ }^{*} 1.25 \mathrm{H}_{2} \mathrm{O}$ & WC & & & & 0.06 & 0.04 \\
\hline 0.2 & 0.2 & 0 & 0.6 & & & & & & 0.24 & 0.14 \\
\hline 0.2 & 0.4 & 0 & 0.4 & & & & & & 1.35 & 0.88 \\
\hline 0.2 & 0.6 & 0 & 0.2 & & & & & & 0.46 & 0.36 \\
\hline 0.4 & 0 & 0 & 0.6 & $\mathrm{TiH}_{2}$ & unk., $d=2.96,1.90$ & & & & 0.08 & 0.03 \\
\hline
\end{tabular}

\begin{tabular}{|c|c|c|c|c|c|c|c|c|c|c|c|c|}
\hline \multicolumn{4}{|c|}{ Composition } & \multicolumn{4}{|c|}{ High Throughput Spent Structures } & \multicolumn{5}{|c|}{ Hydrogen Storage Capacities (wt. \%) } \\
\hline $\mathrm{LiNH}_{2}$ & $\mathrm{LiBH}_{4}$ & $\mathrm{ZrH}_{2}$ & $\mathrm{TiH}_{2}$ & xrd 1 & xrd 2 & xrd 3 & xrd 4 & Des 1, $\mathrm{T}\left({ }^{\circ} \mathrm{C}\right)$ & Des 1 & 230 & 350 & 350 \\
\hline 0 & 0.8 & 0.2 & 0 & $\mathrm{LiB}(\mathrm{OH})_{4}$ & $\mathrm{ZrO}_{2}$ & $\mathrm{LiOH}^{*} \mathrm{H}_{2} \mathrm{O}$ & & 100 & 0.01 & $\mathrm{~B}$ & 2.50 & $\mathrm{~N}$ \\
\hline 0.2 & 0.6 & 0.2 & 0 & & & & & 230 & 1.05 & 0.35 & 1.83 & 0.51 \\
\hline 0.4 & 0.4 & 0.2 & 0 & WC & $\mathrm{LiB}(\mathrm{OH})_{4}$ & & & 230 & 0.63 & 0.27 & 2.70 & 0.17 \\
\hline 0.6 & 0.2 & 0.2 & 0 & $\mathrm{ZrH}_{2}$ & $\mathrm{ZrH}_{1.81}$ & $\mathrm{LiOH}$ & unk., $d=2.05,1.91$ & 230 & 2.70 & 1.04 & 0.83 & 0.17 \\
\hline 0 & 0.6 & 0.4 & 0 & $\mathrm{NaBH}_{4}(?)$ & $\mathrm{ZrH}_{2}$ & $\mathrm{ZrB}_{2}$ & & 230 & 0.06 & $\mathrm{~B}$ & $\mathrm{~B}$ & 0.50 \\
\hline 0.2 & 0.4 & 0.4 & 0 & & & & & 230 & 0.32 & 0.15 & 1.31 & 0.18 \\
\hline 0 & 0.2 & 0.8 & 0 & & & & & 230 & 0.14 & 0.05 & 0.73 & 0.22 \\
\hline 0.8 & 0 & 0.2 & 0 & WC & $\mathrm{ZrH}_{2}$ & unk., $d=2.93$ & & 230 & 0.05 & 0.02 & 0.11 & 0.09 \\
\hline 0 & 0.2 & 0 & 0.8 & & & & & 230 & 0.11 & 0.05 & 0.41 & 0.25 \\
\hline 0 & 0.4 & 0 & 0.6 & & & & & 230 & 0.23 & 0.08 & 0.87 & 0.54 \\
\hline 0 & 0.6 & 0 & 0.4 & & & & & 230 & 0.09 & 0.04 & 1.04 & 0.44 \\
\hline 0 & 0.8 & 0 & 0.2 & & & & & 230 & 0.18 & 0.06 & 2.90 & 0.90 \\
\hline 0.2 & 0.2 & 0 & 0.6 & & & & & 230 & 0.39 & 0.22 & 2.16 & 0.31 \\
\hline 0.2 & 0.4 & 0 & 0.4 & & & & & 230 & 1.71 & 0.26 & 0.35 & 0.23 \\
\hline 0.2 & 0.6 & 0 & 0.2 & & & & & 100 & 0.13 & 1.84 & 0.38 & $\mathrm{~N}$ \\
\hline 0.4 & 0 & 0 & 0.6 & & & & & 230 & 0.09 & 0.04 & 0.28 & 0.18 \\
\hline
\end{tabular}




\begin{tabular}{|c|c|c|c|c|c|c|c|c|c|c|c|}
\hline \multirow{2}{*}{\multicolumn{3}{|c|}{$\frac{\text { Table 27. } \mathrm{LiNH}_{2}-\mathrm{LiBH}_{4}-\mathrm{Cr}_{2}}{\text { Composition }}$}} & \multirow{2}{*}{\multicolumn{3}{|c|}{ Spent Medium Throughput Structures }} & \multicolumn{6}{|c|}{ Hydrogen Storage Capacities (wt. \%) } \\
\hline & & & & & & \multicolumn{2}{|c|}{$\begin{array}{c}\text { Medium } \\
\text { Throughput }\end{array}$} & \multicolumn{4}{|c|}{ High Throughput, Des $\mathrm{T}\left({ }^{\circ} \mathrm{C}\right)$} \\
\hline $\mathrm{LiNH}_{2}$ & $\mathrm{LiBH}_{4}$ & $\mathrm{Cr}_{2} \mathrm{O}_{3}$ & xrd 1 & xrd 2 & xrd 3 & Des 1 & Des 2 & $230^{\circ} \mathrm{C}$ & $230^{\circ} \mathrm{C}$ & $350^{\circ} \mathrm{C}$ & $350^{\circ} \mathrm{C}$ \\
\hline 0 & 0.9 & 0.05 & $\mathrm{Cr}_{2} \mathrm{O}_{3}$ & $\mathrm{LiBH}_{4}$ & & 0.08 & 0.07 & 0.27 & 0.15 & 5.05 & 1.31 \\
\hline 0.1 & 0.8 & 0.05 & $\mathrm{Cr}_{2} \mathrm{O}_{3}$ & $\mathrm{LiBH}_{4}$ & $\mathrm{Li}_{4}\left(\mathrm{NH}_{2}\right)_{3} \mathrm{BH}_{4}$ & 0.63 & 0.41 & 0.53 & 0.41 & 3.70 & 1.20 \\
\hline 0.2 & 0.7 & 0.05 & $\mathrm{Cr}_{2} \mathrm{O}_{3}$ & unk., $d=3.16,1.88$ & & 0.90 & 0.77 & $\mathrm{~N}$ & $\mathrm{~N}$ & $\mathrm{~N}$ & $\mathrm{~N}$ \\
\hline 0.3 & 0.6 & 0.05 & & & & 0.44 & 0.37 & $\mathrm{~N}$ & $\mathrm{~N}$ & $\mathrm{~N}$ & $\mathrm{~N}$ \\
\hline 0.4 & 0.5 & 0.05 & $\mathrm{Cr}_{2} \mathrm{O}_{3}$ & $\mathrm{Li}_{4}\left(\mathrm{NH}_{2}\right)_{3} \mathrm{BH}_{4}$ & & 0.63 & 0.38 & $\mathrm{~N}$ & $\mathrm{~N}$ & $\mathrm{~N}$ & $\mathrm{~N}$ \\
\hline 0 & 0.8 & 0.1 & & & & $\mathrm{~N}$ & $\mathrm{~N}$ & $\mathrm{~N}$ & $\mathrm{~N}$ & $\mathrm{~N}$ & $\mathrm{~N}$ \\
\hline 0.5 & 0.4 & 0.05 & & & & $\mathrm{~N}$ & $\mathrm{~N}$ & $\mathrm{~N}$ & $\mathrm{~N}$ & $\mathrm{~N}$ & $\mathrm{~N}$ \\
\hline 0 & 0.6 & 0.2 & & & & 0.31 & 0.20 & 0.30 & $\mathrm{~B}$ & $\mathrm{~B}$ & 0.11 \\
\hline 0 & 0.7 & 0.15 & & & & 0.23 & 0.16 & 0.31 & 0.13 & 4.11 & 1.58 \\
\hline 0.1 & 0.5 & 0.2 & & & & 0.29 & 0.14 & 0.41 & 0.27 & 2.97 & 0.43 \\
\hline 0.1 & 0.6 & 0.15 & $\mathrm{Cr}_{2} \mathrm{O}_{3}$ & $\mathrm{LiBH}_{4}$ & unk., $d=2.97,2.61$ & 0.47 & 0.24 & 0.51 & 0.27 & 3.91 & 0.45 \\
\hline 0.1 & 0.7 & 0.1 & & & & 0.27 & 0.16 & 0.46 & 0.32 & 5.03 & 1.12 \\
\hline 0.2 & 0.5 & 0.15 & & & & 0.40 & 0.28 & 0.41 & 0.25 & 3.13 & 0.41 \\
\hline 0.2 & 0.6 & 0.1 & $\mathrm{Li}_{2} \mathrm{NH}$ & $\mathrm{Li}_{4}\left(\mathrm{NH}_{2}\right)_{3} \mathrm{BH}_{4}$ & unk., $d=2.88$ & 0.59 & 0.39 & 0.67 & 0.38 & 3.62 & 0.58 \\
\hline 0.3 & 0.5 & 0.1 & & & & 0.31 & 0.25 & 0.68 & 0.54 & 2.75 & 0.53 \\
\hline 0.4 & 0.3 & 0.15 & $\mathrm{Cr}_{2} \mathrm{O}_{3}$ & & & 0.32 & 0.24 & 0.42 & 0.34 & 2.07 & 0.23 \\
\hline 0.4 & 0.4 & 0.1 & & & & 0.25 & 0.16 & $\mathrm{~N}$ & $\mathrm{~N}$ & $\mathrm{~N}$ & $\mathrm{~N}$ \\
\hline 0.5 & 0.3 & 0.1 & & & & 0.34 & 0.23 & $\mathrm{~N}$ & $\mathrm{~N}$ & $\mathrm{~N}$ & $\mathrm{~N}$ \\
\hline 0.6 & 0.2 & 0.1 & $\mathrm{Cr}_{2} \mathrm{O}_{3}$ & $\mathrm{Li}_{4}\left(\mathrm{NH}_{2}\right)_{3} \mathrm{BH}_{4}$ & & 0.52 & 0.24 & $\mathrm{~N}$ & $\mathrm{~N}$ & $\mathrm{~N}$ & $\mathrm{~N}$ \\
\hline 0.6 & 0.3 & 0.05 & & & & 0.49 & 0.28 & $\mathrm{~N}$ & $\mathrm{~N}$ & $\mathrm{~N}$ & $\mathrm{~N}$ \\
\hline 0.7 & 0.1 & 0.1 & & & & 0.26 & 0.15 & $\mathrm{~N}$ & $\mathrm{~N}$ & $\mathrm{~N}$ & $\mathrm{~N}$ \\
\hline
\end{tabular}




\begin{tabular}{|c|c|c|c|c|c|c|c|c|c|c|c|c|c|c|}
\hline \multirow{2}{*}{\multicolumn{4}{|c|}{ Composition }} & \multirow{2}{*}{\multicolumn{4}{|c|}{ Medium Throughput Spent Structures }} & & & & & & & \\
\hline & & & & & & & & \multicolumn{2}{|c|}{$\begin{array}{c}\text { Medium } \\
\text { Throughput }\end{array}$} & \multicolumn{5}{|c|}{ High Throughput, Des $\mathrm{T}\left({ }^{\circ} \mathrm{C}\right)$} \\
\hline $\mathrm{LiNH}_{2}$ & $\mathrm{LiBH}_{4}$ & $\mathrm{~V}_{2} \mathrm{O}_{5}$ & $\mathrm{MoO}_{3}$ & xrd 1 & xrd 2 & xrd 3 & xrd 4 & Des 1 & Des2 & Des $1\left(T^{\circ} \mathrm{C}\right)$ & Des 1 & $230^{\circ} \mathrm{C}$ & $350^{\circ} \mathrm{C}$ & $350^{\circ} \mathrm{C}$ \\
\hline 0 & 0.9 & 0.05 & 0 & $\mathrm{LiV}_{2} \mathrm{O}_{4}$ & $\mathrm{LiBH}_{4}$ & & & 0.22 & 0.06 & 230 & 0.41 & 0.16 & 3.47 & 1.14 \\
\hline 0.1 & 0.8 & 0.05 & 0 & $\mathrm{LiV}_{2} \mathrm{O}_{4}$ & $\mathrm{LiBH}_{4}$ & $\mathrm{Li}_{3} \mathrm{BN}_{2}$ & $\mathrm{Li}_{4}\left(\mathrm{NH}_{2}\right)_{3} \mathrm{BH}_{4}$ & 1.09 & 0.09 & 230 & 1.10 & 0.23 & 4.99 & 1.64 \\
\hline 0.2 & 0.7 & 0.05 & 0 & WC & Li-N-B-H\#2 & $\mathrm{Li}_{2} \mathrm{~V}_{2} \mathrm{O}_{4}$ & & 1.05 & 0.61 & 230 & 1.40 & 0.68 & 4.55 & 0.86 \\
\hline 0.3 & 0.6 & 0.05 & 0 & $\mathrm{LiV}_{2} \mathrm{O}_{4}$ & Li-N-B-H\#2 & $\mathrm{LiBH}_{4}$ & & 0.86 & 0.59 & 230 & 1.12 & 0.67 & 5.11 & 0.50 \\
\hline 0.5 & 0.3 & 0.05 & 0 & & & & & $\mathrm{~N}$ & $\mathrm{~N}$ & 230 & 1.13 & 0.47 & 2.78 & 0.16 \\
\hline 0.6 & 0.3 & 0.05 & 0 & & & & & $\mathrm{~N}$ & $\mathrm{~N}$ & 230 & 1.06 & 0.64 & 4.45 & 0.21 \\
\hline 0.9 & 0 & 0.05 & 0 & & & & & $\mathrm{~N}$ & $\mathrm{~N}$ & 230 & 0.11 & 0.05 & 0.42 & 0.15 \\
\hline 0 & 0.7 & 0.15 & 0 & & & & & 1.42 & 0.31 & 230 & 1.99 & 0.24 & 1.42 & $B$ \\
\hline 0.1 & 0.6 & 0.15 & 0 & $\mathrm{LiV}_{2} \mathrm{O}_{4}$ & & & & 0.95 & 0.19 & 230 & 1.12 & 0.19 & 1.56 & 1.10 \\
\hline 0.2 & 0.5 & 0.15 & 0 & & & & & 0.16 & 0.04 & 230 & 0.33 & 0.14 & 0.43 & 0.21 \\
\hline 0.3 & 0.4 & 0.15 & 0 & & & & & 0.89 & 0.15 & 230 & 2.40 & B & B & 0.25 \\
\hline 0.4 & 0.4 & 0.1 & 0 & & & & & 0.66 & 0.48 & 230 & 1.05 & 0.80 & 3.19 & 0.28 \\
\hline 0.5 & 0.4 & 0.05 & 0 & & & & & 0.68 & 0.49 & 230 & 1.01 & 0.79 & 3.21 & 0.48 \\
\hline 0.7 & 0.2 & 0.05 & 0 & & & & & 0.58 & 0.40 & 230 & 0.58 & 0.31 & 4.06 & 0.19 \\
\hline 0 & 0.8 & 0.1 & 0 & $\mathrm{LiV}_{2} \mathrm{O}_{4}$ & C & & & 1.11 & 0.26 & 100 & 0.07 & 1.26 & 1.69 & $\mathrm{~N}$ \\
\hline 0.1 & 0.7 & 0.1 & 0 & & & & & 0.45 & 0.12 & 230 & 0.64 & 0.14 & 4.75 & 0.83 \\
\hline 0.2 & 0.6 & 0.1 & 0 & & & & & 1.79 & 0.11 & 230 & 1.67 & 0.24 & 3.81 & 0.51 \\
\hline 0.3 & 0.5 & 0.1 & 0 & & & & & 1.69 & 0.66 & 230 & -0.11 & $\mathrm{~B}$ & $\mathrm{~B}$ & 0.32 \\
\hline 0.4 & 0.5 & 0.05 & 0 & & & & & $\mathrm{~N}$ & $\mathrm{~N}$ & $\mathrm{~N}$ & $\mathrm{~N}$ & $\mathrm{~N}$ & $\mathrm{~N}$ & $\mathrm{~N}$ \\
\hline 0.6 & 0.2 & 0.1 & 0 & & & & & $\mathrm{~N}$ & $\mathrm{~N}$ & $\mathrm{~N}$ & $\mathrm{~N}$ & $\mathrm{~N}$ & $\mathrm{~N}$ & $\mathrm{~N}$ \\
\hline 0.8 & 0.1 & 0.05 & 0 & & & & & $\mathrm{~N}$ & $\mathrm{~N}$ & $\mathrm{~N}$ & $\mathrm{~N}$ & $\mathrm{~N}$ & $\mathrm{~N}$ & $\mathrm{~N}$ \\
\hline 0 & 0.7 & 0 & 0.3 & & & & & $\mathrm{~N}$ & $\mathrm{~N}$ & 230 & 0.22 & 0.05 & 0.25 & 0.13 \\
\hline 0 & 0.8 & 0 & 0.2 & & & & & 1.28 & 0.07 & 230 & 1.02 & -0.03 & 3.07 & 0.61 \\
\hline 0 & 0.9 & 0 & 0.1 & $A$ & Mo & & & 0.44 & 0.03 & 230 & 0.82 & -0.08 & 2.77 & 1.09 \\
\hline 0.1 & 0.7 & 0 & 0.2 & $\mathrm{Li}_{4} \mathrm{MoO}_{5}$ & D & $\mathrm{LiBH}_{4}$ & & 0.47 & 0.17 & 230 & 0.61 & 0.13 & 2.66 & 0.50 \\
\hline
\end{tabular}




\section{APPENDIX E}

Open literature report: a detailed study of the $2 \mathrm{LiNH}_{2}-\mathrm{LiBH}_{4}-\mathrm{MgH}_{2}$ system

See Section 6.2.1

Angewante Chemie International Edition 2008, 47, 882 - 887. 


\title{
A Self-Catalyzing Hydrogen-Storage Material**
}

\author{
Jun Yang, * Andrea Sudik, Donald J. Siegel, Devin Halliday, Andrew Drews, \\ Roscoe O. Carter, III, Christopher Wolverton, Gregory J. Lewis, J. W. Adriaan Sachtler, \\ John J. Low, Syed A. Faheem, David A. Lesch, and Vidvuds Ozolinš
}

Conventional (e.g. $\mathrm{MgH}_{2}$ ) and complex hydrides (e.g. alanates, borohydrides, and amides) are the two primary classes of solid-state hydrogen-storage materials. ${ }^{[1-3]}$ Many of these "high-density" hydrides have the potential to store large amounts of hydrogen by weight (up to $18.5 \mathrm{wt} \%$ for $\mathrm{LiBH}_{4}$ ) and/or volume (up to $112 \mathrm{gL}^{-1}$ for $\mathrm{MgH}_{2}$ ), values that are comparable to the hydrogen content of gasoline $(15.8 \mathrm{wt} \%$, $\left.112 \mathrm{~g} \mathrm{~L}^{-1}\right)$. However, all known hydrides are inadequate for mobile storage applications due to one or more of the following limitations: a) unfavorable thermodynamics (they require high temperatures to release hydrogen ${ }^{[4]}$ ), b) poor kinetics (low rates of hydrogen release and uptake), c) decomposition pathways involving the release of undesirable by-products (e.g. ammonia), and/or d) an inability to reabsorb hydrogen at modest temperatures and pressures (i.e. "irreversibility").

In spite of these drawbacks, renewed interest in complex hydrides has been stimulated recently by substantial improvements in their kinetics and reversibility ${ }^{[5,6]}$ provided by catalytic doping (e.g. $\mathrm{TiCl}_{3}$-doped $\mathrm{NaAlH}_{4}$ ), ${ }^{[7,8]}$ and by thermodynamic enhancements achieved through reactive binary mixtures ${ }^{[9]}$ such as $\mathrm{LiNH}_{2} / \mathrm{MgH}_{2},{ }^{[10,11]} \mathrm{LiBH}_{4} / \mathrm{MgH}_{2},{ }^{[12]}$ and $\mathrm{LiNH}_{2} / \mathrm{LiBH}_{4} \cdot{ }^{[13,14]}$ These compositions, previously termed "reactive hydride composites", ${ }^{[15]}$ represent the state-of-the-art in hydrogen-storage materials; compared to their constituent compounds, they exhibit improved thermodynamic properties, higher hydrogen purity, and, in some cases, reversibility. The desorption behavior of these previ-

[*] Dr. J. Yang, Dr. A. Sudik, Dr. D. J. Siegel, D. Halliday, Dr. A. Drews, Dr. R. O. Carter, III, Dr. C. Wolverton ${ }^{[+]}$

Ford Motor Company, Research and Advanced Engineering MD 1170/RIC, P.O. Box 2053, Dearborn, MI 48121 (USA)

Fax: $(+1)$ 313-594-2963

E-mail: jyang27@ford.com

Dr. G. J. Lewis, Dr. J. W. A. Sachtler, Dr. J. J. Low, S. A. Faheem,

Dr. D. A. Lesch

UOP LLC

25 East Algonquin Road, Des Plaines, IL 60017-5017 (USA)

Dr. V. Ozolinš

Department of Materials Science and Engineering

University of California, Los Angeles, CA 90095-1595 (USA)

$\left.{ }^{+}\right]$Current address: Department of Materials Science and Engineering, Northwestern University

2220 Campus Drive, Evanston, IL 60208 (USA)

$[\cdots *$ The authors are grateful to one of the referees for suggesting the inclusion of the reaction scheme flowchart shown in Figure S10 in the Supporting Information.

$\square$ Supporting information for this article is available on the WWWW under http://www.angewandte.org or from the authors. ously studied composites is illustrated in Figure $1 \mathrm{a}$. It is evident from the hydrogen desorption profile (top panel) that the composites generally desorb hydrogen at significantly lower temperatures than their individual components. For example, the lowest temperature reaction, which involves a

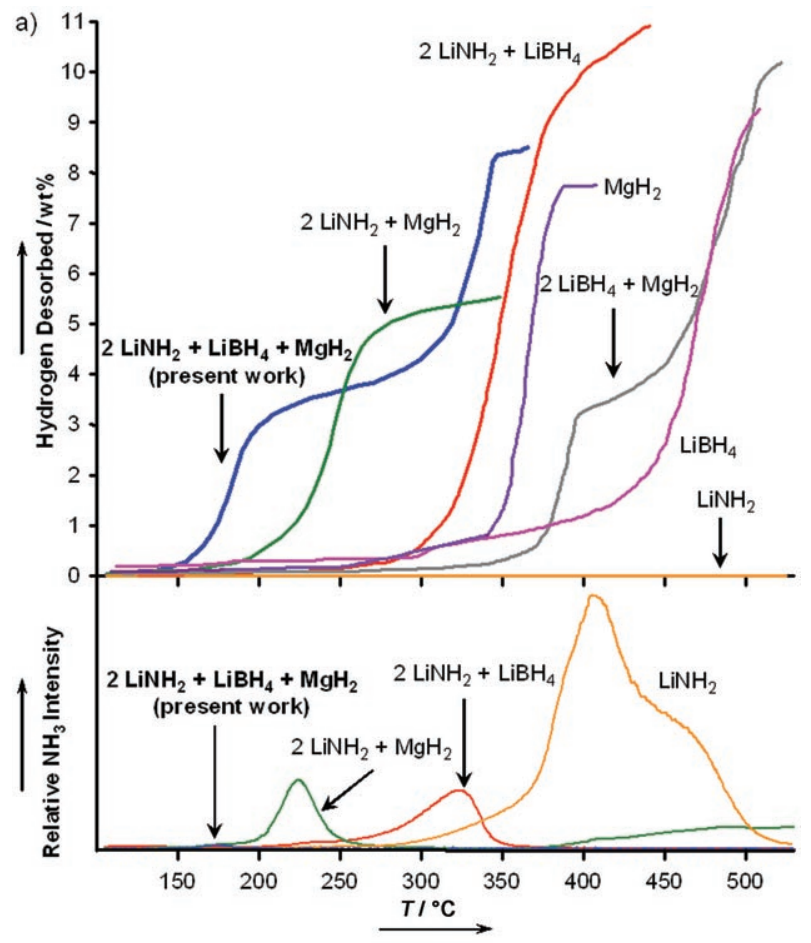

b)

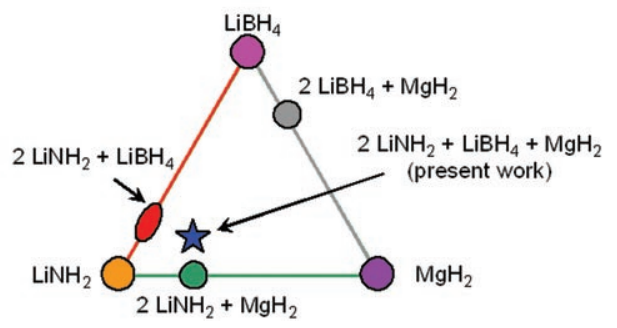

Figure 1. a) Hydrogen (top) and ammonia (bottom) kinetic desorption data as a function of temperature $\left(5^{\circ} \mathrm{Cmin}^{-1}\right.$ to $\left.550^{\circ} \mathrm{C}\right)$ for the ternary composition (blue trace) and its unary and binary constituents. Hydrogen desorption is measured in weight percent (wt \%) to 1 bar whereas relative ammonia release is measured as partial pressure (torr) in a flow-through set-up (100 sccm Ar). b) Ternary phase space defined by unary compounds (nodes), $\mathrm{LiBH}_{4}$ (pink), $\mathrm{MgH}_{2}$ (purple), and $\mathrm{LiNH}_{2}$ (orange) and the binary mixtures (edges), $\mathrm{LiBH}_{4} / \mathrm{MgH}_{2}$ (gray), $\mathrm{MgH}_{2} /$ $\mathrm{LiNH}_{2}$ (green), and $\mathrm{LiNH}_{2} / \mathrm{LiBH}_{4}$ (red). The present ternary composition, which is a 2:1:1 mixture of $\mathrm{LiNH}_{2}, \mathrm{LiBH}_{4}$, and $\mathrm{MgH}_{2}$, and previously investigated binaries, are identified. 
2:1 mixture of $\mathrm{LiNH}_{2}$ and $\mathrm{MgH}_{2}$, has a desorption temperature more than $100^{\circ} \mathrm{C}$ lower than that of either $\mathrm{MgH}_{2}$ (approx. $350^{\circ} \mathrm{C}$ ) or $\mathrm{LiNH}_{2}$ (which releases only $\mathrm{NH}_{3}$ ) alone. Although these binary reactions present significant benefits, they all have well-known disadvantages: a) their lowered desorption temperatures are still too high, b) the reaction involving $\mathrm{LiNH}_{2}$ and $\mathrm{LiBH}_{4}$ is irreversible, c) the nitrogencontaining binaries $\mathrm{LiNH}_{2} / \mathrm{MgH}_{2}$ and $\mathrm{LiNH}_{2} / \mathrm{LiBH}_{4}$ emit a significant amount of ammonia (a proton-exchange membrane fuel cell (PEM-FC) poison) together with the hydrogen (Figure $1 \mathrm{a}$, bottom panel), and, most significantly, d) hydrogen desorption/uptake in all of these binary composites is too slow. Therefore, further improvement in these areas is highly desirable.

Herein we present a strategy for enhancing the properties of binary composites through the creation of a multicomponent composite of three hydride compounds $\left(2 \mathrm{LiNH}_{2} / \mathrm{LiBH}_{4} / \mathrm{MgH}_{2}\right)$. The improved properties of this system arise almost entirely from a "self-catalyzing" reaction pathway that results in faster kinetics and lower desorption temperatures than for the binary composites and almost complete suppression of ammonia release. The key elements that contribute to the enhanced properties are the incorporation of a low melting temperature ionic liquid $\left(\mathrm{Li}_{4} \mathrm{BH}_{3} \mathrm{H}_{10}\right)$ and a mechanism for seeding the products of a reversible hydrogen desorption reaction. ${ }^{[16]}$

The choice of the $2 \mathrm{LiNH}_{2} / \mathrm{LiBH}_{4} / \mathrm{MgH}_{2}$ stoichiometry is based on several factors: a) the constituent hydrides all possess high gravimetric/volumetric capacities, b) binary mixtures of these hydrides are among the best known hydrogen-storage materials (see Figure 1 a, top panel), c) mixtures containing $\mathrm{MgH}_{2}$ are known to suppress ammonia release from nitrogen-containing hydrides such as $\mathrm{LiNH}_{2}$ (Figure 1 a, bottom panel), and d) a stable, lightweight compound, namely lithium magnesium boron nitride $\left(\mathrm{LiMgBN}_{2}\right)$, which contains $\mathrm{N}, \mathrm{B}$, and $\mathrm{Mg}$ in a 2:1:1 ratio (the same as our stoichiometric composite), is known which could serve as a potential dehydrogenated product phase. The compositional phase space of the ternary composite is shown in the Gibbs triangle in Figure $1 \mathrm{~b}$ and information regarding the sample synthesis and preparation conditions is given in the Experimental Section.

We begin our discussion of this system by summarizing its principal hydrogen-storage attributes in relation to those of the unary and binary components. Employing a wide range of experimental phase analyses and first-principles evaluation of reaction thermodynamics, we subsequently identify a complex, "cascading" sequence of reactions that explain the observed properties. We conclude with a more detailed discussion of the proposed "self-catalyzing" mechanism.

Lowered desorption temperatures: The measured kinetic desorption behavior $\left(5^{\circ} \mathrm{Cmin}^{-1}, 1\right.$ bar $)$ of the ternary composite is compared with the constituent unary and binary components in the upper panel of Figure $1 \mathrm{a}$. The ternary system rapidly releases hydrogen in a process that begins at $150^{\circ} \mathrm{C}$ (top panel), which is about $50-200^{\circ} \mathrm{C}$ lower than the binary composites, thereby indicating significantly improved kinetics and/or thermodynamics. The total capacity of the ternary composite is $8.2 \mathrm{wt} \%$.
Improved hydrogen purity: The composition of the gas released from the ternary composite while heating at $5^{\circ} \mathrm{Cmin}^{-1}$ in a flow of $100 \mathrm{sccm}$ argon is plotted in comparison with the binary composites in the lower panel of Figure $1 \mathrm{a}$. The ammonia released by the ternary composite is less than the $100 \mathrm{ppm}$ detection limit of our instrument; the ammonia released from the nitrogen-containing binaries was found to be more than an order of magnitude larger. No other volatile boron- and/or nitrogen-containing by-products were detected throughout the desorption process.

Reversibility: The reversible storage capacity and response to cycling were determined from a series of charge/discharge experiments performed with a Sievert-type PCT apparatus at $160^{\circ} \mathrm{C}$ and charging (discharging) at 100 (1) bar. The results for five charge/discharge cycles (Figure 2a) show that the as-prepared material rapidly releases approximately $3.0 \mathrm{wt} \%$ of hydrogen within 20 minutes. After recharging, the second through fifth
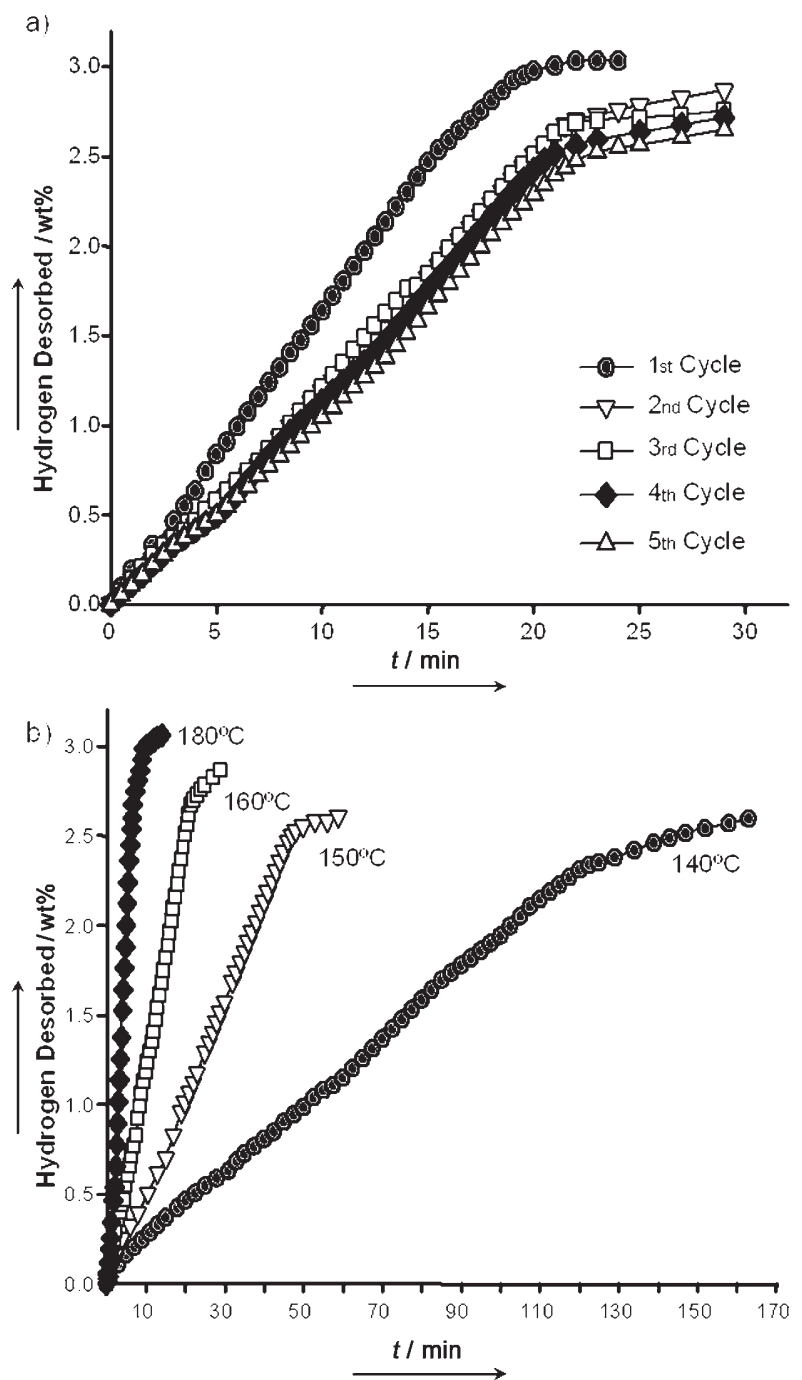

Figure 2. a) Hydrogen desorption kinetics at $160^{\circ} \mathrm{C}$ and 1 bar over five cycles after subsequent charging $\left(160^{\circ} \mathrm{C}\right.$ and 100 bar hydrogen). b) Reversible isothermal kinetic hydrogen desorption data (to 1 bar) for the ternary composition based on the second desorption cycle at $140(\bullet), 150(\nabla), 160(\square)$, and $180^{\circ} \mathrm{C}(\bullet)$ versus time. 
desorption cycles consistently liberate around $2.8 \mathrm{wt} \%$ of hydrogen, a reversible capacity at moderate temperature that is among the best for solid-state hydrogen storage. ${ }^{[5-8]}$

Kinetics: The reversible isothermal kinetic desorption profiles for the second desorption cycle (to $1 \mathrm{bar}$ ) were collected at $140,150,160$, and $180^{\circ} \mathrm{C}$ (Figure $2 \mathrm{~b}$ ). The ternary composite is capable of desorbing more than $2.5 \mathrm{wt} \%$ hydrogen in times ranging from $10 \mathrm{~min}\left(180^{\circ} \mathrm{C}\right)$ to $2.5 \mathrm{~h}\left(140^{\circ} \mathrm{C}\right)$ in this temperature range. The remaining hydrogen is liberated in a second step at higher temperatures for a total hydrogen capacity of $8.2 \mathrm{wt} \%$ (Figure 3 ). The initial release of hydrogen at both 260 and $320^{\circ} \mathrm{C}$ is dramatically accelerated, with $3.2 \mathrm{wt} \%$ released within minutes, while the subsequent desorption steps are more influenced by temperature, reaching full desorption after 1.5 and $14 \mathrm{~h}$ at 320 and $260^{\circ} \mathrm{C}$, respectively.

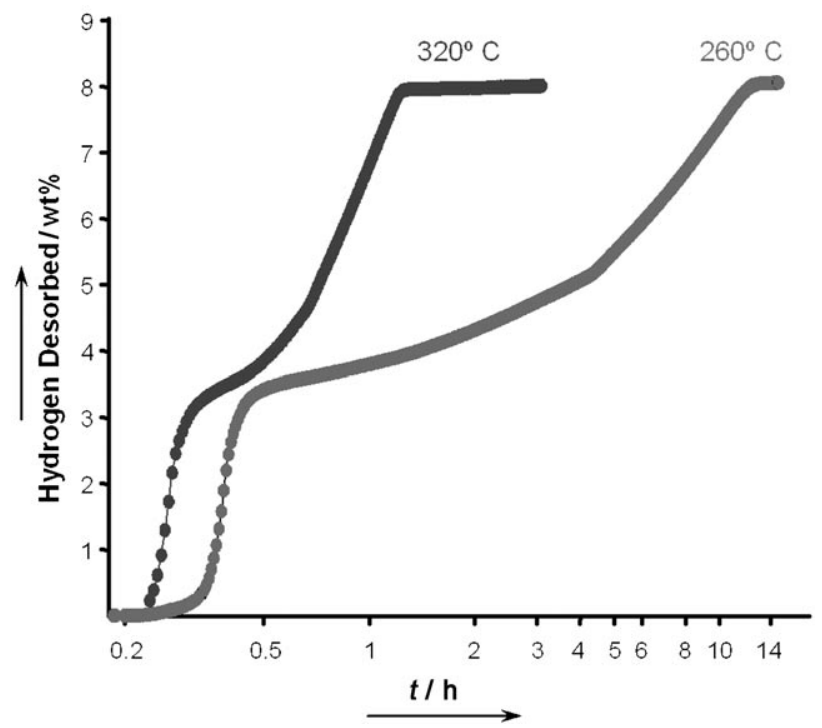

Figure 3. Isothermal kinetic hydrogen desorption to 1 bar for the ternary composition at 260 and $320^{\circ} \mathrm{C}$ versus time.

The unique desorption behavior described above strongly suggests that the reaction mechanism(s) of the ternary composite is not a simple superposition of the known binary reactions. To understand its hydrogen-release characteristics, we therefore collected temperature-programmed-desorption mass spectrometry (TPD-MS) data at a constant heating rate and carrier gas flow $\left(5^{\circ} \mathrm{Cmin}^{-1}, 100 \mathrm{sccm}\right.$ argon flow; Figure 4a). Four distinct hydrogen-release events occur (maxima at 180, 190 (shoulder), 310 , and $560^{\circ} \mathrm{C}$, respectively), with an initial desorption onset at $110^{\circ} \mathrm{C}^{[17]} \mathrm{TPD}-\mathrm{MS}$ data were also collected for the cycled/recharged material (See Supporting Information). These data clearly show that the first steep desorption step (at $180^{\circ} \mathrm{C}$ ) in the as-prepared sample is no longer observed in the recharged sample. Instead, the peak temperature for the recharged sample is now shifted to the shoulder region for the fresh material (approx. $190^{\circ} \mathrm{C}$ ), thus indicating that the reaction corresponding to the shoulder is reversible, which is consistent with the

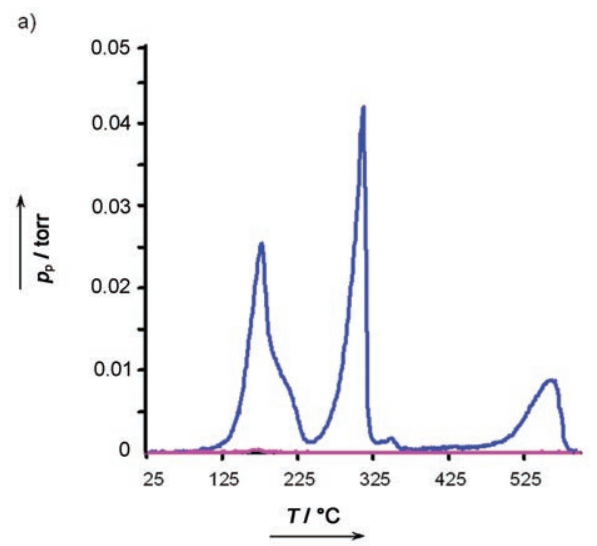

b)

\begin{tabular}{|c|c|c|c|c|c|c|c|c|}
\hline $11^{\circ} \mathrm{C}$ & $\frac{25}{0.0}$ & $\frac{140}{02}$ & $\frac{180}{20}$ & $\frac{255}{40}$ & $\frac{335}{73}$ & $\frac{375}{8.2}$ & $\frac{450}{8.2}$ & $\frac{500}{8.2}$ \\
\hline \multicolumn{9}{|l|}{$\mathrm{LiNH}_{2}$} \\
\hline \multicolumn{9}{|l|}{$\mathrm{LiBH}_{4}$} \\
\hline \multicolumn{9}{|l|}{$\mathrm{MgH}_{2}$} \\
\hline \multicolumn{9}{|l|}{$\mathrm{Mg}\left(\mathrm{NH}_{2}\right)_{2}$} \\
\hline \multicolumn{9}{|l|}{$\mathrm{Li}_{4} \mathrm{BN}_{3} \mathrm{H}_{10}$} \\
\hline \multicolumn{9}{|l|}{$\mathrm{Li}_{2} \mathrm{Mg}(\mathrm{NH})_{2}$} \\
\hline \multicolumn{9}{|l|}{$\mathrm{Li}_{3} \mathrm{BN}_{2}$} \\
\hline $\mathrm{Mg}_{3} \mathrm{~N}_{2}$ & & & & & & & & \\
\hline \multicolumn{9}{|l|}{$\mathrm{LiH}$} \\
\hline \multicolumn{9}{|l|}{ Phase $X$} \\
\hline $\mathrm{LiMgBN}_{2}$ & & & & & & & & \\
\hline
\end{tabular}

Figure 4. a) TPD-MS data for the ternary composition depicting hydrogen $(\mathrm{m} / \mathrm{z} 2$, blue) and ammonia $(\mathrm{m} / \mathrm{z} 17$, pink) as a function of temperature (heating at $5^{\circ} \mathrm{Cmin}^{-1}$ to $575^{\circ} \mathrm{C}$ ). b) Phase composition as a function of desorbed hydrogen amount (wt \%) and temperature $\left({ }^{\circ} \mathrm{C}\right.$ ) as determined from the static PXRD and IR data.

powder X-ray diffraction (PXRD) and IR spectroscopic analyses (discussed below).

Phase identification: Phase-composition studies were carried out for identically prepared samples, which were desorbed to varying degrees at 1 bar hydrogen by heating at $5^{\circ} \mathrm{Cmin}^{-1}$ in a water displacement apparatus (see Supporting Information) to identify the species involved in the various desorption reactions. Following desorption, each sample was quenched and analyzed by PXRD and IR spectroscopy. The results are summarized in Figure $4 \mathrm{~b}$, and raw data and phase assignments are provided as Supporting Information. The asprepared sample (ball milling $2 \mathrm{~g}$ of $\mathrm{LiNH}_{2}, \mathrm{LiBH}_{4}$, and $\mathrm{MgH}_{2}$ in a 2:1:1 ratio for $5 \mathrm{~h}$ ) contains two new species $\left(\mathrm{Mg}\left(\mathrm{NH}_{2}\right)_{2}\right.$ and $\mathrm{Li}_{4} \mathrm{BN}_{3} \mathrm{H}_{10}$ ) and no residual $\mathrm{LiNH}_{2}$, which is indicative of milling-induced transformations. Residual $\mathrm{MgH}_{2}$ and $\mathrm{LiBH}_{4}$ starting materials are also present. Growth of $\mathrm{Mg}\left(\mathrm{NH}_{2}\right)_{2}$ and (weakly crystalline) $\mathrm{LiH}$ is detected upon initial heating to $140^{\circ} \mathrm{C}$ before any appreciable amount of hydrogen is released. At the same time, the diffraction peaks for $\mathrm{Li}_{4} \mathrm{BN}_{3} \mathrm{H}_{10}$ disappear. As the characteristic symmetric and asymmetric amide $\mathrm{N}-\mathrm{H}$ IR frequencies (observed: 3301 and $3242 \mathrm{~cm}^{-1}$; literature: $:^{[18]} 3303$ and $3243 \mathrm{~cm}^{-1}$ ) persist, we conclude that $\mathrm{Li}_{4} \mathrm{BN}_{3} \mathrm{H}_{10}$ has melted. Further heating to $180^{\circ} \mathrm{C}$ results in the release of $2.0 \mathrm{wt} \%$ hydrogen (first low 
temperature event in Figure $4 \mathrm{a}$ ) and the formation of $\mathrm{Li}_{2} \mathrm{Mg}(\mathrm{NH})_{2}$, based on its three characteristic peaks at $30.7^{\circ}$, $51.3^{\circ}$, and $60.9^{\circ}$ in the PXRD pattern ${ }^{[19]}$ and the signature $\mathrm{N}-$ $\mathrm{H}$ stretch in the IR spectrum (observed: $3178 \mathrm{~cm}^{-1}$; literature: ${ }^{[20]} 3187 \mathrm{~cm}^{-1}$ ). This phase continues to grow in intensity until $255^{\circ} \mathrm{C}$, at which point $4.0 \mathrm{wt} \% \mathrm{H}_{2}$ has desorbed. At this stage, $\mathrm{MgH}_{2}$ and $\mathrm{Mg}\left(\mathrm{NH}_{2}\right)_{2}$ have been completely consumed while $\mathrm{Li}_{4} \mathrm{BN}_{3} \mathrm{H}_{10}$ is significantly depleted.

The second major hydrogen releasing event occurs between 255 and $375^{\circ} \mathrm{C}$ and corresponds to a total of $8.2 \mathrm{wt} \%$ desorbed hydrogen. $\mathrm{Li}_{2} \mathrm{Mg}(\mathrm{NH})_{2}$ and $\mathrm{LiBH}_{4}$ are consumed during this stage and $\mathrm{Mg}_{3} \mathrm{~N}_{2}$ and $\mathrm{Li}_{3} \mathrm{BN}_{2}$ are formed. Trace amounts of $\mathrm{LiH}$ and an unknown phase (denoted as "Phase X") are also detected by PXRD. ${ }^{[21]}$ Further heating to $500^{\circ} \mathrm{C}$ does not produce additional hydrogen but rather an observed phase transformation consistent with the consumption of $\mathrm{Li}_{3} \mathrm{BN}_{2}, \mathrm{Mg}_{3} \mathrm{~N}_{2}$, and $\mathrm{LiBH}_{4}$ and the production of $\mathrm{LiH}$ and $\mathrm{LiMgBN}_{2} \cdot{ }^{[22]}$ The final hydrogen releasing step $\left(>500^{\circ} \mathrm{C}\right)$ is attributed to decomposition of $\mathrm{LiH}$ (third major event in Figure $4 \mathrm{a}$ ).

Variable-temperature in situ PXRD was used to validate the above phase assignments and to provide phase transformation information (see the Supporting Information for instrument set-up and data collection protocol). Figure 5 a shows the raw PXRD data as a function of temperature (25$450^{\circ} \mathrm{C}$ ) and Figure $5 \mathrm{~b}$ shows the two-dimensional contour plot. The phase assemblage as a function of temperature is shown in Figure $5 \mathrm{c}$. The data reveal that the sequence and relative phase contributions are identical to those observed by static PXRD, thereby confirming the proposed reaction sequence. Furthermore, the in situ data reveal that the $\mathrm{Li}_{4} \mathrm{BN}_{3} \mathrm{H}_{10}$ and $\mathrm{MgH}_{2}$ phases disappear rapidly (by 100 and $150^{\circ} \mathrm{C}$, respectively) during initial heating of the as-prepared material and prior to any hydrogen release. The observed melting of $\mathrm{Li}_{4} \mathrm{BN}_{3} \mathrm{H}_{10}$ at $100^{\circ} \mathrm{C}$ occurs at a significantly lower temperature than previously reported $\left(150^{\circ} \mathrm{C}\right) .{ }^{[23]}$ This low temperature melt may serve as an effective mass transfer medium or homogenizing agent and aid in the distribution of $\mathrm{Li}_{2} \mathrm{Mg}(\mathrm{NH})_{2}$ (produced in the first desorption step reaction between $\mathrm{Li}_{4} \mathrm{BN}_{3} \mathrm{H}_{10}$ and $\mathrm{MgH}_{2}$ ), which would in turn serve as $\mathrm{Li}_{2} \mathrm{Mg}(\mathrm{NH})_{2}$ nucleation seeds for a second step reaction between $\mathrm{Mg}\left(\mathrm{NH}_{2}\right)_{2}$ and $\mathrm{LiH}$. The presence of the ionic liquid may therefore positively influence the desorption kinetics of the initial hydrogen release reactions.

Reaction pathway: A set of proposed reactions are summarized in Figure 6. Our assignment of reactions takes into account the observed and theoretical hydrogen capacity for each step, the reversible amount of stored hydrogen, and the phase compositions (obtained from both quenched/static and in situ PXRD and IR spectroscopy). A reaction scheme flowchart is included in the Supporting Information. The TPD-MS curve from Figure $4 \mathrm{a}$ is incorporated to indicate the temperature region under which each reaction occurs. The reaction enthalpies $\left(\Delta H_{\text {calcd }}\right)$ and free energies $\left(\Delta G_{\text {calcd }}\right)$ at $300 \mathrm{~K}$ obtained by density functional theory calculations are also included in this table. The fact that all the calculated free energies are negative suggests that the proposed reactions are thermodynamically reasonable. (The activation energies for reactions (2) and (4) are given as Supporting Information.)

During sample preparation, the starting materials $\mathrm{LiNH}_{2}$ and $\mathrm{LiBH}_{4}$ react to form $\mathrm{Li}_{4} \mathrm{BN}_{3} \mathrm{H}_{10} \cdot{ }^{[13]}$ Partial reaction of this quaternary phase with a portion of $\mathrm{MgH}_{2}$ then yields a small amount of $\mathrm{Mg}\left(\mathrm{NH}_{2}\right)_{2}$. As both reactions are exothermic (based on DFT calculations), it is likely that they occur under ball milling or upon moderate heating. After milling, the phases present include $\mathrm{Li}_{4} \mathrm{BN}_{3} \mathrm{H}_{10}, \mathrm{LiBH}_{4}, \mathrm{MgH}_{2}, \mathrm{Mg}\left(\mathrm{NH}_{2}\right)_{2}$, and $\mathrm{LiH}$. Upon subsequent heating, but before the onset of hydrogen release, production of $\mathrm{Mg}\left(\mathrm{NH}_{2}\right)_{2}$ continues according to reaction (1).

$2 \mathrm{Li}_{4} \mathrm{BN}_{3} \mathrm{H}_{10}+3 \mathrm{MgH}_{2} \rightarrow 3 \mathrm{Mg}\left(\mathrm{NH}_{2}\right)_{2}+2 \mathrm{LiBH}_{4}+6 \mathrm{LiH}$

Self-catalyzing mechanism: As the temperature reaches $100^{\circ} \mathrm{C}, \mathrm{Li}_{4} \mathrm{BN}_{3} \mathrm{H}_{10}$ melts and reacts with $\mathrm{MgH}_{2}$ to form $\mathrm{Li}_{2} \mathrm{Mg}(\mathrm{NH})_{2}$ and $\mathrm{LiBH}_{4}$ and releases $\mathrm{H}_{2}$ at the first low temperature desorption peak [reaction (2)]. This reaction only occurs during desorption of the as-prepared material and not in subsequent cycles (see Supporting Information). More importantly, reaction (2) serves to directly catalyze the subsequent reversible reaction between $\mathrm{Mg}\left(\mathrm{NH}_{2}\right)_{2}$ and $\mathrm{LiH}$ that occurs at the shoulder region (approx. $190-230^{\circ} \mathrm{C}$ ) [reaction (3)].
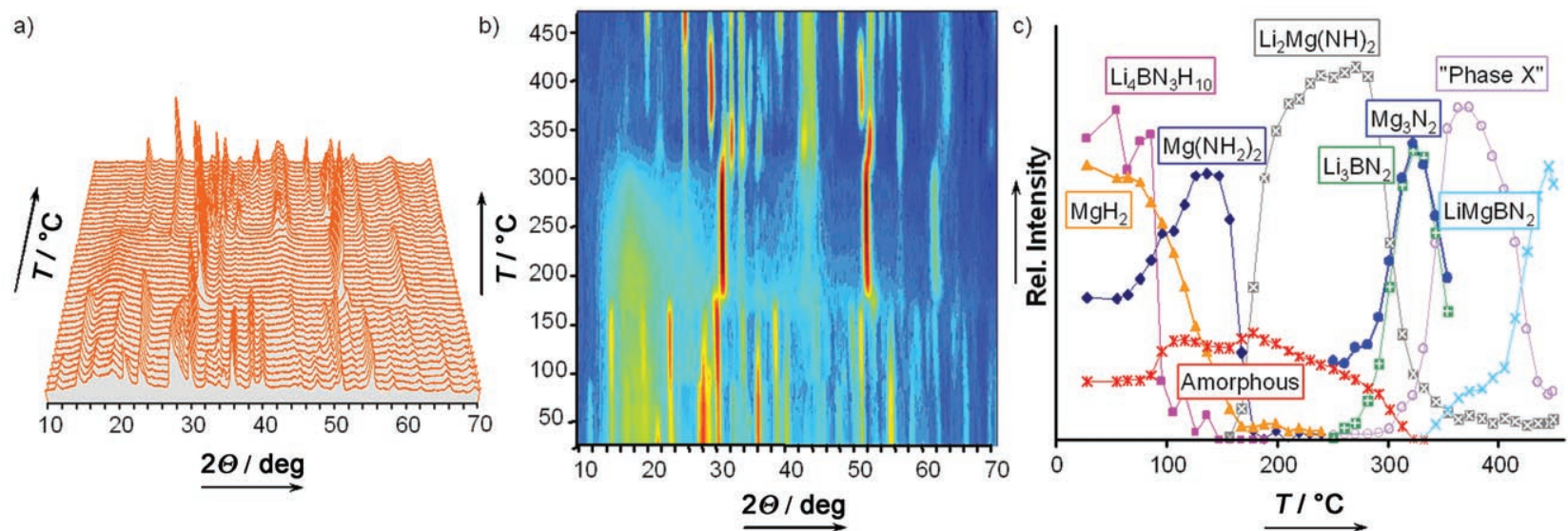

Figure 5. a) Raw PXRD data for the ternary composition as a function of temperature $\left(25-450^{\circ} \mathrm{C}\right)$. b) The corresponding two-dimensional contour plot derived from the raw patterns in (a). c) Plot of the relative amounts of individual phases as a function of temperature. 


\begin{tabular}{|c|c|c|c|c|c|c|c|c|}
\hline & & Step & $\begin{array}{l}\text { Rxn } \\
\text { No. }\end{array}$ & Reaction & Conversion & $\begin{array}{l}\text { Obs. (Theo.) } \mathrm{H}_{2} \\
\text { Release (wt.\%) }\end{array}$ & $\begin{array}{l}\Delta H_{\text {calcd }} \\
-\mathbf{k J} \mathrm{mol}^{-1}\end{array}$ & $\begin{array}{r}\Delta G_{\text {calld }} \\
-\mathrm{kJ} \mathrm{mol}^{-1}\end{array}$ \\
\hline & $P_{\mathrm{p}}$ & Milling & $\begin{array}{l}0 \\
1 \\
\end{array}$ & $\begin{array}{c}3 \mathrm{LiNH}_{2}+\mathrm{LiBH}_{4} \Rightarrow \mathrm{Li}_{4} \mathrm{BN}_{3} \mathrm{H}_{10} \\
2 \mathrm{Li}_{4} \mathrm{BN}_{3} \mathrm{H}_{10}+3 \mathrm{MgH}_{2} \Rightarrow 3 \mathrm{Mg}\left(\mathrm{NH}_{2}\right)_{2}+2 \mathrm{LiBH}_{4}+6 \mathrm{LiH}\end{array}$ & $\begin{array}{l}1 \\
x\end{array}$ & - & $\begin{array}{l}-12 \\
-207\end{array}$ & $\begin{array}{l}-10 \\
-206\end{array}$ \\
\hline & - Hydrogen $(m=2)$ & $\begin{array}{l}\text { Heating } \\
<110^{\circ} \mathrm{C}\end{array}$ & 1 & $2 \mathrm{Li}_{4} \mathrm{BN}_{3} \mathrm{H}_{10}+3 \mathrm{MgH}_{2} \Rightarrow 3 \mathrm{Mg}\left(\mathrm{NH}_{2}\right)_{2}+2 \mathrm{LiBH}_{4}+6 \mathrm{LiH}$ & $y$ & - & -207 & -206 \\
\hline & & $\begin{array}{l}\text { 1st Peak } \\
\text { Shoulder }\end{array}$ & 2 & $\begin{array}{c}2 \mathrm{Li}_{4} \mathrm{BN} \mathrm{N}_{3} \mathrm{H}_{10}+3 \mathrm{MgH}_{2} \Rightarrow 3 \mathrm{Li}_{2} \mathrm{Mg}(\mathrm{NH})_{2}+2 \mathrm{LiBH}_{4}+6 \mathrm{H}_{2} \\
\mathrm{Mg}\left(\mathrm{NH}_{2}\right)_{2}+2 \mathrm{LiH} \Leftrightarrow \mathrm{Li}_{2} \mathrm{Mg}(\mathrm{NH})_{2}+2 \mathrm{H}_{2}\end{array}$ & $\begin{array}{c}1-x-y \\
x+y\end{array}$ & $4.0(4.3)$ & $\begin{array}{l}80 \\
96\end{array}$ & $\begin{array}{l}-117 \\
-172\end{array}$ \\
\hline$F$ & & 2nd Peak & 4 & $3 \mathrm{Li}_{2} \mathrm{Mg}(\mathrm{NH})_{2}+2 \mathrm{LiBH}_{4} \Rightarrow 2 \mathrm{Li}_{3} \mathrm{BN}_{2}+\mathrm{Mg}_{3} \mathrm{~N}_{2}+2 \mathrm{LiH}+6 \mathrm{H}_{2}$ & 1 & $4.2(4.3)$ & -13 & -214 \\
\hline & & $\begin{array}{l}\text { Heating } \\
>400^{\circ} \mathrm{C}\end{array}$ & 6 & $\begin{array}{c}2 \mathrm{Li}_{3} \mathrm{BN}_{2}+\mathrm{Mg}_{3} \mathrm{~N}_{2}+\mathrm{LiBH}_{4} \Rightarrow 3 \mathrm{LiMgBN}_{2}(\text { Phase } X)+4 \mathrm{LiH} \\
\operatorname{LiMgBN}_{2}(\text { Phase } X) \Rightarrow \mathrm{LiMgBN}_{2}(\text { Tetragonal })\end{array}$ & 1 & - & -173 & - \\
\hline & & 3rdPeak & 7 & $2 \mathrm{LiH} \Rightarrow 2 \mathrm{Li}+\mathrm{H}_{2}$ & 1 & $2.1\{2.1\}$ & 84 & - \\
\hline
\end{tabular}

Figure 6. Proposed reaction pathway for the ternary composite, including the observed/theoretical hydrogen capacity, reaction enthalpy $(\Delta H)$, free energy $(\Delta G)$ (both in $\mathrm{kJ} \mathrm{mol}^{-1}$ for products at $300 \mathrm{~K}$ ), and the corresponding temperature range (coupled to the TPD-MS curve). The reaction numbers in this figure correspond to those used in the text.

$$
\begin{aligned}
& 2 \mathrm{Li}_{4} \mathrm{BN}_{3} \mathrm{H}_{10}+3 \mathrm{MgH}_{2} \rightarrow 3 \mathrm{Li}_{2} \mathrm{Mg}(\mathrm{NH})_{2}+2 \mathrm{LiBH}_{4}+6 \mathrm{H}_{2} \\
& \mathrm{Mg}\left(\mathrm{NH}_{2}\right)_{2}+2 \mathrm{LiH} \rightarrow \mathrm{Li}_{2} \mathrm{Mg}(\mathrm{NH})_{2}+2 \mathrm{H}_{2}
\end{aligned}
$$

We refer to the ternary composite as "self-catalyzed" in the sense that one reaction [reaction (2)] pre-forms the product nuclei $\left(\mathrm{Li}_{2} \mathrm{Mg}(\mathrm{NH})_{2}\right)$ for the subsequent reaction [reaction (3)], which results in an enhancement of the overall kinetic properties. A separate study has confirmed the beneficial effects of product seeding in improving the desorption kinetics of the $\mathrm{Mg}\left(\mathrm{NH}_{2}\right)_{2} / \mathrm{LiH}$ system. ${ }^{[24]}$

It should be emphasized that the thermodynamics of the binary reaction between $\mathrm{Mg}\left(\mathrm{NH}_{2}\right)_{2}$ and $\mathrm{LiH}$ [reaction (3)] indicate that it should proceed at a lower temperature than observed. Our results suggest a new rational route by which the kinetic properties of existing hydrogen-desorption reactions can be enhanced, namely by coupled self-catalyzing reactions.

Higher-temperature reactions: As the temperature is increased further, $\mathrm{Li}_{2} \mathrm{Mg}(\mathrm{NH})_{2}$ reacts with $\mathrm{LiBH}_{4}$ to form $\mathrm{Li}_{3} \mathrm{BN}_{2}, \mathrm{Mg}_{3} \mathrm{~N}_{2}$, and hydrogen (found: $4.2 \mathrm{wt} \%$; calcd: $4.3 \mathrm{wt} \%$ ), which corresponds to the second peak [reaction (4)]. This explains why the reversibility in this ternary system is sensitive to desorption temperature and desorbed hydrogen extent. When the sample is heated to above $350^{\circ} \mathrm{C}$, $\mathrm{Li}_{3} \mathrm{BN}_{2}, \mathrm{Mg}_{3} \mathrm{~N}_{2}$, and the remaining $\mathrm{LiBH}_{4}$ react to form "Phase $\mathrm{X}$ " and tetragonal $\mathrm{LiMgBN}_{2}$. On additional heating (to around $450^{\circ} \mathrm{C}$ ), "Phase $\mathrm{X}$ " is transformed completely into tetragonal $\mathrm{LiMgBN}_{2} \cdot{ }^{[22]}$ Finally, $\mathrm{LiH}$ decomposes in the last high-temperature hydrogen releasing step and liberates an additional $2.1 \mathrm{wt} \%$ hydrogen (calcd: $2.1 \mathrm{wt} \%$ ).

$3 \mathrm{Li}_{2} \mathrm{Mg}(\mathrm{NH})_{2}+2 \mathrm{LiBH}_{4} \rightarrow 2 \mathrm{Li}_{3} \mathrm{BN}_{2}+\mathrm{Mg}_{3} \mathrm{~N}_{2}+2 \mathrm{LiH}+6 \mathrm{H}_{2}$

In conclusion, our study of the ternary $\mathrm{LiBH}_{4} / 2 \mathrm{LiNH}_{2} /$ $\mathrm{MgH}_{2}$ composite has led to the discovery of a new "selfcatalyzing" strategy for enhancing the kinetics of hydrogen storage in complex hydride composites. We have demonstrated through a wide-ranging experimental and first-principle computational analysis that this self-catalyzing mechanism arises from a set of coupled, ancillary reactions that yield both a homogenizing ionic liquid phase and product nuclei for a subsequent reversible hydrogen-storage reaction. These effects combine to yield enhanced low-temperature desorption kinetics and a significant reduction in ammonia liberation relative to the state-of-the-art binary constituent composites. The strategy of utilizing built-in, ancillary reactions to catalyze a primary hydrogen-storage reaction suggests prospective routes for advancing existing and future storage materials.

\section{Experimental Section}

Sample Preparation: $\mathrm{LiNH}_{2}$ (95\% purity, Sigma-Aldrich), $\mathrm{MgH}_{2}$ ( $95 \%$ purity, Gelest), and $\mathrm{LiBH}_{4}$ ( $95 \%$ purity, Sigma-Aldrich) were used as received. All sample handling was performed in an MBraun Labmaster 130 glove box maintained under argon with less than $0.1 \mathrm{ppm} \mathrm{O}_{2}$ and $\mathrm{H}_{2} \mathrm{O}$ vapor. The binary composites $2 \mathrm{LiNH}_{2} / \mathrm{LiBH}_{4}$, $2 \mathrm{LiNH}_{2} / \mathrm{MgH}_{2}$, and $2 \mathrm{LiBH}_{4} / \mathrm{MgH}_{2}$ were prepared according to literature protocols. ${ }^{[10,12,13]}$ For the ternary composite, two grams of $\mathrm{LiNH}_{2}, \mathrm{LiBH}_{4}$, and $\mathrm{MgH}_{2}$ in a 2:1:1 molar ratio was loaded into a milling vial containing three stainless steel balls weighing $8.4 \mathrm{~g}$ each. Mechanical milling was carried out using a Spex 8000 high-energy mixer/mill for 1-20 h.

Characterization and Property Evaluation: All methods relating to sample characterization and property evaluation, including powder X-ray diffraction (PXRD), IR spectroscopy, kinetic hydrogen desorption/absorption studies (PCT, TPD-MS, and WDD), density functional theory (DFT) calculations, and activation energy calculations are described in detail in the Supporting Information.

Received: August 15, 2007

Revised: September 17, 2007

Published online: December 20, 2007 
Keywords: hydrides $\cdot$ hydrogen storage $\cdot$ kinetics . materials science $\cdot$ thermodynamics

[1] P. Dantzer, Hydrogen in Metals III: Topics in Applied Physics, Springer, Berlin, 1997.

[2] W. Grochala, P. P. Edwards, Chem. Rev. 2004, 104, 1283-1315.

[3] F. Schüth, B. Bodganović, M. Felderhoff, Chem. Commun. 2004, $2249-2258$.

[4] High desorption temperatures may also be a consequence of slow kinetics.

[5] B. Bogdanović, M. Schwickardi, J. Alloys Compd. 1997, 253-254, $1-9$.

[6] A. Züttel, P. Wegner, S. Rentsch, P. Sudan, P. Mauron, C. Emmenegger, J. Power Sources 2003, 118, 1-7.

[7] D. Sun, S. Srinivasan, T. Kiyobayashi, N. Kuriyama, C. M. Jensen, J. Phys. Chem. B 2003, 107, 10176-10179.

[8] T. Wang, J. Wang, A. D. Ebner, J. A. Ritter, J. Alloys Compd. 2007, DOI: 10.1016/j.jallcom.2006.10.072.

[9] P. Chen, Z. Xiong, J. Luo, J. Lin, K. Tan, Nature 2002, 420, $302-$ 304.

[10] W. Luo, J. Alloys Compd. 2004, 381, 284-287.

[11] H. Y. Leng, T. Ichikawa, S. Isobe, S. Hino, N. Hanada, H. Fujii, J. Phys. Chem. B 2004, 108, 8763-8765.

[12] J. Vajo, S. Skeith, J. Phys. Chem. B 2005, 109, 3719-3722.

[13] F. E. Pinkerton, G. P. Meisner, M. Meyer, M. Balogh, M. Kundrat, J. Phys. Chem. B 2005, 109, 6-8.

[14] M. Aoki, K. Miwa, T. Noritake, G. Kitahara, Y. Nakamori, S. Orimo, S. Towata, Appl. Phys. A 2005, 80, 1409-1413.
[15] M. Dornheim, S. Doppiu, G. Barkhordarian, U. Boesenberg, T. Klassen, O. Gutfleisch, R. Bormann, Scr. Mater. 2007, 56, $841-$ 846.

[16] Seeding refers to a process by which a small amount of reaction product is added to a chemical reaction in order to increase the nucleation rate of the product phase. Since nucleation can be a rate-limiting process, seeding can yield increased reaction rates.

[17] The difference in onset temperature between the TPD-MS data $\left(110^{\circ} \mathrm{C}\right)$ and the kinetic desorption data from Figure $1 \mathrm{a}\left(150^{\circ} \mathrm{C}\right)$ can be attributed to the pressure difference during data acquisition (100 sccm Ar flow for TPD-MS versus static 1 bar conditions for kinetic desorption experiments).

[18] Y. Filinchuk, K. Yvon, G. Meisner, F. E. Pinkerton, M. Balogh, Inorg. Chem. 2006, 45, 1433-1435.

[19] Z. Xiong, G. Wu, J. Hu, P. Chen, Adv. Mater. 2004, 16, $1522-$ 1525.

[20] P. Chen, Z. Xiong, L. Yang, G. Wu, W. Luo, J. Phys. Chem. B 2006, 110, $14221-14225$.

[21] Structural investigations on "Phase X" are on-going although, based on current data, it is thought to be a polymorph of $\mathrm{LiMgBN}_{2}$.

[22] U. Herterich, J. Curda, K. Peters, M. Somer, H. G. von Schnering, Z. Kristallogr. 1994, 209, 617.

[23] G. P. Meisner, M. Scullin, M. Balogh, F. E. Pinkerton, M. Meyer, J. Phys. Chem. B 2006, 110, 4186-4192.

[24] A. Sudik, J. Yang, D. Halliday, C. Wolverton, J. Phys. Chem. C 2007, 111, $6568-6573$. 


\section{APPENDIX F}

Open literature report: a detailed First Principles study of the Li-Mg-N-H system

See Section 6.3.1

Advanced Materials 2007, 19, 3233-3239. 


\author{
By Alireza R. Akbarzadeh, ${ }^{*}$ Vidvuds Ozolinšs,* and Christopher Wolverton*
}

Finding a material that can store hydrogen at high volumetric and gravimetric densities is one of the central challenges facing the introduction of hydrogen-fueled vehicles. Since none of the known simple hydrides can satisfy all the requirements for a practical on-board hydrogen storage system (e.g., low cost, high density, fast kinetics, favorable thermodynamics), the current research focus has shifted towards various multicomponent mixtures. Predicting thermodynamically favored hydrogen storage reactions in multinary systems is very difficult because of a large number of competing reaction pathways and end products. Here, we present a novel firstprinciples method which can systematically and automatically identify all thermodynamically allowed hydrogen storage reactions in multicomponent systems as functions of temperature and hydrogen pressure. When applied to the well-studied Li-Mg-N-H system, our method predicts all experimentallyobserved pathways in this system, as well as novel high-temperature decomposition pathways of $\mathrm{Li}_{2} \mathrm{Mg}(\mathrm{NH})_{2}$.

Demand for high-capacity hydrogen storage systems has fueled interest in studying novel multinary hydrides or multicomponent mixtures of hydrides with three or more elements, not counting hydrogen. ${ }^{[1-5]}$ In such systems one is faced with the challenge of identifying the thermodynamically stable phases and preferred reaction pathways as functions of the composition, temperature and hydrogen pressure. While the decomposition pathways of binary hydrides are usually simple to intuit, chemical intuition often ceases to be a sufficient guide in multicomponent systems, since the number of the possible end products and the associated decomposition reactions increases rapidly with the number of constituents. ${ }^{[5,6]}$ For instance, consider the recently discovered quaternary $\mathrm{Li}_{4} \mathrm{BN}_{3} \mathrm{H}_{10}$ compound. Using first-principles density-functional theory calculations, the authors of Ref. [5] calculated the free energies of as many as 17 candidate decomposition

[*] Dr. A. R. Akbarzadeh, Prof. V. Ozolinš̌ Department of Materials Science and Engineering University of California

Los Angeles, P.O. Box 951595, Los Angeles, CA 90095-1595 (USA)

E-mail: aakbarz@ucla.edu; vidvuds@ucla.edu

Prof. C. Wolverton

Department of Materials Science and Engineering

Northwestern University

Evanston, Illinois 60208 (USA)

E-mail: cwolvert@northwestern.edu

[**] The authors acknowledge financial support from the US DOE under grants DE-FG02-05ER46253 and DE-FC36-04G014013. reactions of $\mathrm{Li}_{4} \mathrm{BN}_{3} \mathrm{H}_{10}$. They found that only three of them emerged as "winners", corresponding to states with the lowest possible free energy in three different temperature intervals. However, this method of guessing decomposition pathways based on chemical intuition and enumeration will become increasingly difficult for complex multicomponent systems, and what is needed is a method to predict the lowest-energy pathway directly, without having to explicitly enumerate all possibilities. Also, we show below examples of reactions where chemical intuition breaks down qualitatively and can erroneously suggest that reactions are thermodynamically reasonable, when our method shows that in fact they are not.

The aim of the present article is to develop a theoretical framework which, given the overall chemical composition, can automatically predict thermodynamically favored reaction sequences, stable compounds and phase coexistence regions as functions of composition, temperature, and hydrogen pressure. We demonstrate that modern first-principles calculations of total energies and vibrational free energies can be used to systematically scan the composition space and identify those compositions which maximize the hydrogen storage capacity in a given temperature and pressure window. Our techniques are sufficiently simple and general to be immediately applicable to other multicomponent hydrides. Specifically, we present the application of our method to investigate the Li$\mathrm{Mg}-\mathrm{N}-\mathrm{H}$ system, which has emerged as a promising hydrogen storage material after Chen et al. ${ }^{[7]}$ reported reversible extraction of $\mathrm{H}_{2}$ from a mixture of $\mathrm{LiNH}_{2}$ and $\mathrm{LiH}$ above $570 \mathrm{~K}$. Although $\mathrm{LiNH}_{2}+\mathrm{LiH}$ can store hydrogen at reasonably high gravimetric densities, it cannot be used for on-board storage, as the temperatures required to extract $\mathrm{H}_{2}$ are too high. Studies of the pressure-composition isotherms for the $\mathrm{Li}$ amide reaction have shown that $\mathrm{LiNH}_{2}+\mathrm{LiH}$ is thermodynamically too stable, with a dehydriding enthalpy of $\sim 66 \mathrm{~kJ} / \mathrm{mol} \mathrm{H}_{2},{ }^{[7,8]}$ well above the $20-50 \mathrm{~kJ} / \mathrm{mol} \mathrm{H}_{2}$ range desired for reversible on-board storage. Many attempts have been made to effectively reduce the stability of the amide. One very promising avenue involves mixtures of $\mathrm{LiNH}_{2}$ with $\mathrm{MgH}_{2}$ (see Refs. $[2,3,9,10]$ and references therein) via reaction:

$2 \mathrm{LiNH}_{2}+\mathrm{MgH}_{2} \rightarrow 2 \mathrm{LiH}+\mathrm{Mg}\left(\mathrm{NH}_{2}\right)_{2} \leftrightarrow \mathrm{Li}_{2} \mathrm{Mg}(\mathrm{NH})_{2}+2 \mathrm{H}_{2}$

but reactions involving other compositions in the $\mathrm{Li}-\mathrm{Mg}$ $\mathrm{N}-\mathrm{H}$ system have also been proposed. For instance, Nakamori et al. ${ }^{[4]}$ have suggested that $\mathrm{Mg}\left(\mathrm{NH}_{2}\right)_{2}$ could store up to $9.1 \mathrm{wt} \% \mathrm{H}_{2}$ according to the following reaction: 
$\mathrm{Mg}\left(\mathrm{NH}_{2}\right)_{2}+4 \mathrm{LiH} \leftrightarrow \mathrm{Li}_{3} \mathrm{~N}+1 / 3 \mathrm{Mg}_{3} \mathrm{~N}_{2}+4 \mathrm{H}_{2}$

In a comprehensive study of destabilization reactions, Alapati et al. ${ }^{[1]}$ predicted that a 1:1 mixture of lithium amide and magnesium hydride could release $8.2 \mathrm{wt} \% \mathrm{H}_{2}$ :

$\mathrm{LiNH}_{2}+\mathrm{MgH}_{2} \leftrightarrow \mathrm{LiMgN}+2 \mathrm{H}_{2}$

Using first-principles DFT calculations, Alapati et al. estimated that Equation 3 has an enthalpy of $32 \mathrm{~kJ} / \mathrm{mol} \mathrm{H}_{2}$, excluding vibrational contributions, ${ }^{[1]}$ which is right in the middle of the range of enthalpies corresponding to reversible $\mathrm{H}_{2}$ storage reactions. These examples seem to suggest that new hydrogen storage reactions with improved properties might be obtained by simply tuning the molar ratios of the starting compounds in the Li-Mg-N-H system. In what follows, we will show that in general this is not possible, since the possible reaction pathways in multicomponent systems are tightly constrained by bulk thermodynamics, which favors a universal set of reactions determined only by the chemical identity of the constituents. For Equations 2 and 3 above, we find that instead of proceeding in one step, they happen via a series of intermediate reactions with sequentially increasing enthalpies.

Our approach to determining phase diagrams of multicomponent hydrides uses the grand-canonical Gibbs free energy for a system in contact with a gas-phase reservoir of hydrogen. The weight fraction of hydrogen in the solid phase varies with temperature and pressure and is determined from the minimization of the free energy. In particular, we consider a situation where the storage material, characterized by a certain ratio of non-hydrogen species can exchange hydrogen molecules with a reservoir of $\mathrm{H}_{2}$ gas at a given chemical potential, $\mu_{\mathrm{H}_{2}}(p, T)$, which is determined by the temperature, $T$, and pressure, $p$. Given the free energies of all possible phases in the given multicomponent hydride system (e.g., all phases constituted by $\mathrm{Li}, \mathrm{Mg}, \mathrm{N}$, and/or $\mathrm{H}$ ), the grand-canonical Gibbs free energy is given by the following expression:

$G(T, p)=\sum_{i} x_{i} F_{i}(T)-\frac{\mu_{\mathrm{H}_{2}}(T, p)}{2} \sum_{i} x_{i} n_{i}^{H}$

where $F_{\mathrm{i}}(T)$ is the free energy of phase " $i$ " (we neglect the pressure dependence of the free energies of solid phases), $n_{\mathrm{i}}^{\mathrm{H}}$ is the number of hydrogen ions in one formula unit of phase " $i$ ", and $x_{\mathrm{i}}$ are the (unknown) variable molar fractions of phases coexisting at a given composition, temperature, and pressure. The molar fractions are determined by minimizing Equation 4, subject to the following mass-conservation constraints for non-hydrogen species:

$f_{s}=\sum_{i} x_{i} n_{i}^{s}=$ const. for $\forall s \neq \mathrm{H}$

where $n_{\mathrm{i}}^{\mathrm{s}}$ is the number of ions of type " $s$ " in one formula unit of phase " $i$ ", and $f_{\mathrm{s}}$ represent given molar ratios of the non-hydrogen species (i.e., $\mathrm{Li}, \mathrm{Mg}$, and $\mathrm{N}$ ). Following standard con- ventions, the latter are be normalized to obey $\sum_{s \neq \mathrm{H}} f_{s}=1$. Equations 4 and 5 constitute a linear programming problem, where the unknown variables are molar fractions of the possible phases, $x_{\mathrm{i}}$. To obtain $x_{i}$ as functions of composition, pressure, and temperature, we minimize Equation 4 for a decreasing sequence of hydrogen chemical potentials $\mu_{\mathrm{H}_{2}}(T, p)$, starting from $T=0 \mathrm{~K}$, where $\mu_{\mathrm{H}_{2}}$ is given by the total energy of the $\mathrm{H}_{2}$ molecule. Since phase transformations and hydrogen release reactions manifest themselves as changes in the molar fractions $x_{\mathrm{i}}$, reactions are identified by comparing the computed molar fractions at two successive values of the chemical potential. If the chemical potential interval is chosen sufficiently small, each step involves no more than one reaction, and the reactants and reaction products are easily found by taking the difference between the two sets of $x_{\mathrm{i}}$. These reactions occur only at a few temperatures, corresponding to the thermodynamic equilibrium between the reactants and reaction products, reached when the change in the grand canonical Gibbs free energy becomes zero:

$\Delta G=\Delta H-T \Delta S+n_{\mathrm{H}_{2}} \mu_{\mathrm{H}_{2}}(p, T)=0$

where $\Delta H$ and $\Delta S$ are the total enthalpy and entropy change for all phases except $\mathrm{H}_{2}$, and $n_{\mathrm{H}_{2}}$ is the number of hydrogen molecules released or absorbed as a result of the reaction.

For each reaction, Equation 6 defines a relation between $p$ and $T$, which is usually well approximated by a line in the famous van't Hoff plot. Furthermore, our method can automatically identify solid-state reactions that do not lead to hydrogen release, such as those driven by the vibrational entropy, as well as determine the ground state stability of the solid-hydride phases at $T=0 \mathrm{~K}$. For instance, we show below that our method correctly identifies that the $\mathrm{LiNH}_{2}+\mathrm{MgH}_{2}$ mixture on the left side of Equation 3 is unstable with respect to the formation of $\mathrm{Mg}\left(\mathrm{NH}_{2}\right)_{2}$ and $\mathrm{LiH}$.

To apply the above formalism to the $\mathrm{Li}-\mathrm{Mg}-\mathrm{N}-\mathrm{H}$ system, we begin by identifying compounds with known crystal structures that have $\mathrm{Li}, \mathrm{Mg}, \mathrm{N}$, and $\mathrm{H}$ as their constituents. These 14 compounds are listed in Table 1. We have excluded a few known compounds from our list, which deserve comment: Our list does not include magnesium imide, $\mathrm{MgNH}$, which has been reported to exist, ${ }^{[1]}$ but its crystal structure is not known. We also leave out metallic alloys between $\mathrm{Li}$ and $\mathrm{Mg}$, since at the temperatures and pressures of interest for hydrogen storage they are expected to disproportionate into $\mathrm{LiH}$ and $\mathrm{MgH}_{2}$ (or $\mathrm{Mg}$ ). Finally, we have not included $\mathrm{N}_{2}$ in our calculations so as to prevent the thermodynamic decomposition of $\mathrm{NH}_{3}$, which is well-known to be a kinetically controlled reaction.

To obtain the free energies $F_{\mathrm{i}}(T)$, we have performed firstprinciples density-functional calculations of the total energies and phonon dispersions for all the compounds in Table 1. Our first-principles density functional calculations employed the projected augmented wave (PAW) approach. ${ }^{[12]}$ The method is implemented in the highly efficient ab-initio total-energy 
Table 1. All compounds in the Li-Mg-N-H system considered in this work. Shown are the firstprinciples calculated energies of formation $\Delta H_{f}$, zero-point energies (ZPE) at $\mathrm{T}=0 \mathrm{~K}, H_{\mathrm{vib}}^{\mathrm{T}=300}$ ${ }^{\mathrm{K}}$ vibrational energies $(\mathrm{kJ} / \mathrm{mol})$, and $S_{\mathrm{vib}}{ }^{\mathrm{T}}=300 \mathrm{~K}$ entropies $(\mathrm{J} / \mathrm{mol} \mathrm{K})$. Note that the energy of formation excludes the contribution due to ZPE.

\begin{tabular}{|c|c|c|c|c|c|c|}
\hline Compound & Space group & $\Delta \mathrm{H}_{\mathrm{f}}$ & ZPE & ZPE other & $H_{v i b}^{T=300 \mathrm{~K}}$ & $S_{v i b}^{T=300 \mathrm{~K}}$ \\
\hline $\mathrm{H}_{2}$ & & 0 & 25.9 & $25.7^{[5]}, 26.1^{[29]}$ & 25.9 & 0. \\
\hline $\mathrm{N}_{2}$ & & 0 & 15.0 & $14.0^{[5]}, 14.4^{[6]}$ & 14.0 & 0. \\
\hline $\mathrm{Li}$ & $\operatorname{lm} \overline{3} m(229)$ & 0 & 3.9 & $3.9^{[29]}$ & 8.2 & 27.4 \\
\hline$M g$ & $P 63 / m m c(194)$ & 0 & 2.9 & & 7.9 & 31.9 \\
\hline $\mathrm{NH}_{3}$ & & -98.4 & 87.7 & $87.8^{[5]}, 89.7^{[30]}$ & 87.8 & 0.4 \\
\hline $\mathrm{Mg}\left(\mathrm{NH}_{2}\right)_{2}$ & $14_{1} / \operatorname{acd}(142)$ & -363.7 & 134.8 & & 149.4 & 91.1 \\
\hline $\mathrm{Mg}_{3} \mathrm{~N}_{2}$ & $1 a \overline{3}(206)$ & -382.6 & 33.2 & & 46.8 & 72.2 \\
\hline $\mathrm{MgH}_{2}$ & $\mathrm{P} 42 / \mathrm{mmm}(136)$ & -62.7 & 39.1 & & 44.5 & 31.3 \\
\hline $\mathrm{LiH}$ & $F m \overline{3} m(225)$ & -83.9 & 21.5 & $21.7^{[5]}, 21.4^{[29]}$ & 25.2 & 19.7 \\
\hline $\mathrm{Li}_{3} \mathrm{~N}^{[\mathrm{a}]}$ & $P 6 / m m m(164)$ & -152.4 & 27.4 & $28.0^{[5]}, 28.6^{[31,32]}$ & 37.0 & 52.5 \\
\hline $\mathrm{LiNH}_{2}$ & $\overline{14}(82)$ & -197.4 & 69.3 & $\begin{array}{c}69.0^{[5]}, 69.1^{[31]} \\
69.5^{[32]}\end{array}$ & 77.6 & 46.6 \\
\hline $\mathrm{Li}_{2} \mathrm{NH}^{[\mathrm{b}]}$ & Pnma (62) & -198.2 & 46.8 & $46.7^{[6]}, 47.1^{[32]}$ & 56.2 & 50.8 \\
\hline $\mathrm{Li}_{2} \mathrm{Mg}(\mathrm{NH})_{2}{ }^{[c]}$ & Iba2 (45) & -411.0 & 86.9 & & 102.1 & 82.3 \\
\hline $\mathrm{LiMgH}$ & Pnma (62) & -194.9 & 19.9 & & 27.1 & 38.2 \\
\hline
\end{tabular}

[a] In agreement with Ref. [31] our calculations capture the weak instability at the $\Gamma$ point in $P 6 / \mathrm{mmm}$ symmetry. Soft-mode has $B_{2 g}$ symmetry and is $55 \mathrm{i} \mathrm{cm}{ }^{-1}$, ZPE stabilizes the structure in lower symmetry of $\mathrm{P} \overline{\mathrm{m}} \mathrm{l}$.

[b] Theoretically predicted structure from Ref. [32].

[c] Experimentally predicted structure from Ref. [23]. subject to the mass-conservation constraints for $\mathrm{Li}, \mathrm{Mg}$, and $\mathrm{N}$ species, Equation 5. We perform this minimization for each point in the ternary Li-Mg-N composition space, as a function of temperature and $\mathrm{H}_{2}$ pressure using the equation of state. This procedure yields the equilibrium molar fractions of all phases from Table 1 for all points in the ternary Li-Mg-N composition space.

We next describe the results from our calculations, in terms of the predicted composition-temperature phase diagrams. Figure 1 shows the calculated phase diagrams for the $\mathrm{Li}-\mathrm{Mg}-\mathrm{N}-\mathrm{H}$ system at atmospheric pressure. To represent various ratios of Li:Mg:N, we adopt the standard Gibbs triangle convention for drawing ternary phase diagrams. As shown in Figure 1a, at temperatures below $130 \mathrm{~K}$ the fully hydrided system exhibits $\mathrm{MgH}_{2}, \mathrm{Mg}\left(\mathrm{NH}_{2}\right)_{2}$, solid $\mathrm{NH}_{3}, \mathrm{LiNH}_{2}$, and $\mathrm{LiH}$ as stable compounds. Note that our results indicate that there is no equilibrium tie-line between $\mathrm{LiNH}_{2}$ and $\mathrm{MgH}_{2}$. This is in accord with experimental observations for this system: for instance, ball-milling a mixture of $\mathrm{LiNH}_{2}$ and $\mathrm{MgH}_{2}$ leads to the formation of $\mathrm{Mg}\left(\mathrm{NH}_{2}\right)_{2}$ and $\mathrm{LiH},{ }^{[2,3]}$ where in fact there is an equilibrium tie-line in our calculated phase diagram between the latter two phases (see Fig. 1a). The binary hydride phases $\mathrm{MgH}_{2}, \mathrm{LiH}$, and $\mathrm{NH}_{3}$ occupy the vertices of the Gibbs trianand molecular dynamics program VASP. ${ }^{[13-18]}$ The generalized gradient approximation (GGA) was used to represent the electronic exchange-correlation. ${ }^{[19]}$ The basis set for the electronic wavefunctions was defined by a plane wave cut off energy of $875 \mathrm{eV}$; the Brillouin zone was sampled using Monkhorst-Pack meshes ${ }^{[20]}$ with $256 k$ points per atom or better. The structures were fully relaxed in shape, volume and atomic positions until the forces were less than $10^{-2} \mathrm{eV}^{-1}$ and stresses were less than $0.1 \mathrm{GPa}$. The frozen phonon method was used to determine normal-mode frequencies of ionic vibrations within the harmonic approximation. The technical details of frozen phonon calculations are the same as in Ref. [21].

The results are summarized in Table 1 which gives the calculated energies of formation $\Delta H_{\mathrm{f}}$, vibrational zero-point energies (ZPE), and vibrational energies and entropies at $T=500 \mathrm{~K}$. Even though the desirable temperature range of operation of fuel cell vehicles is between -40 and $+80{ }^{\circ} \mathrm{C}(233$ to $353 \mathrm{~K}$ ), we have chosen to list the calculated enthalpies at this higher temperature because it more appropriately reflects the conditions commonly used in experimental measurements on the Li-Mg-N-H system. Using the calculated free energies, we minimize the grand-canonical free energy given by Equation 4 with respect to the unknown molar phase fractions $x_{\mathrm{i}}$, gle in Figure 1a, while the $\mathrm{Mg}$ amide and $\mathrm{Li}$ amide phases are represented by points on the $\mathrm{Mg}-\mathrm{N}$ and $\mathrm{Li}-\mathrm{N}$ edges of this triangle, respectively. Lines represent compositions where two phases coexist, while the triangular regions enclosed by these lines represent coexistence of the phases at the vertices of these triangles. We have found that, as a function of temperature, there are seven distinct reactions in the Li-Mg-N-H system, which involve a release of $\mathrm{H}_{2}$ (Table 2). We briefly discuss each of these starting from low temperature, where we show that our method correctly identifies experimentally-observed reactions. Then we turn to higher temperatures and demonstrate that our method is capable of predicting novel, as-yet-unobserved reactions.

Reaction (i): The first hydrogen release reaction occurs at $T=130 \mathrm{~K}$, when a mixture of $\mathrm{MgH}_{2}$ and $\mathrm{Mg}\left(\mathrm{NH}_{2}\right)_{2}$ decomposes according to rxn (i) from Table 2, releasing $7.41 \mathrm{wt} \%$ $\mathrm{H}_{2}$ and forming $\mathrm{Mg}_{3} \mathrm{~N}_{2}$. This reaction occurs for all ternary compositions where $\mathrm{MgH}_{2}$ and $\mathrm{Mg}\left(\mathrm{NH}_{2}\right)_{2}$ coexist, i.e., for all points within the triangle defined by the vertices corresponding to $\mathrm{MgH}_{2}, \mathrm{Mg}\left(\mathrm{NH}_{2}\right)_{2}$, and $\mathrm{LiH}$ in Figure 1a. The maximum weight fraction of hydrogen as a percentage of the starting material is released at the point corresponding to a $3: 2$ ratio of $\mathrm{Mg}$ and $\mathrm{N}$ (see Fig. 1b). Even though the amount of $\mathrm{H}_{2}$ released is quite high, the enthalpy of this reaction $\left(8 \mathrm{~kJ} \mathrm{~mol}^{-1}\right.$ 

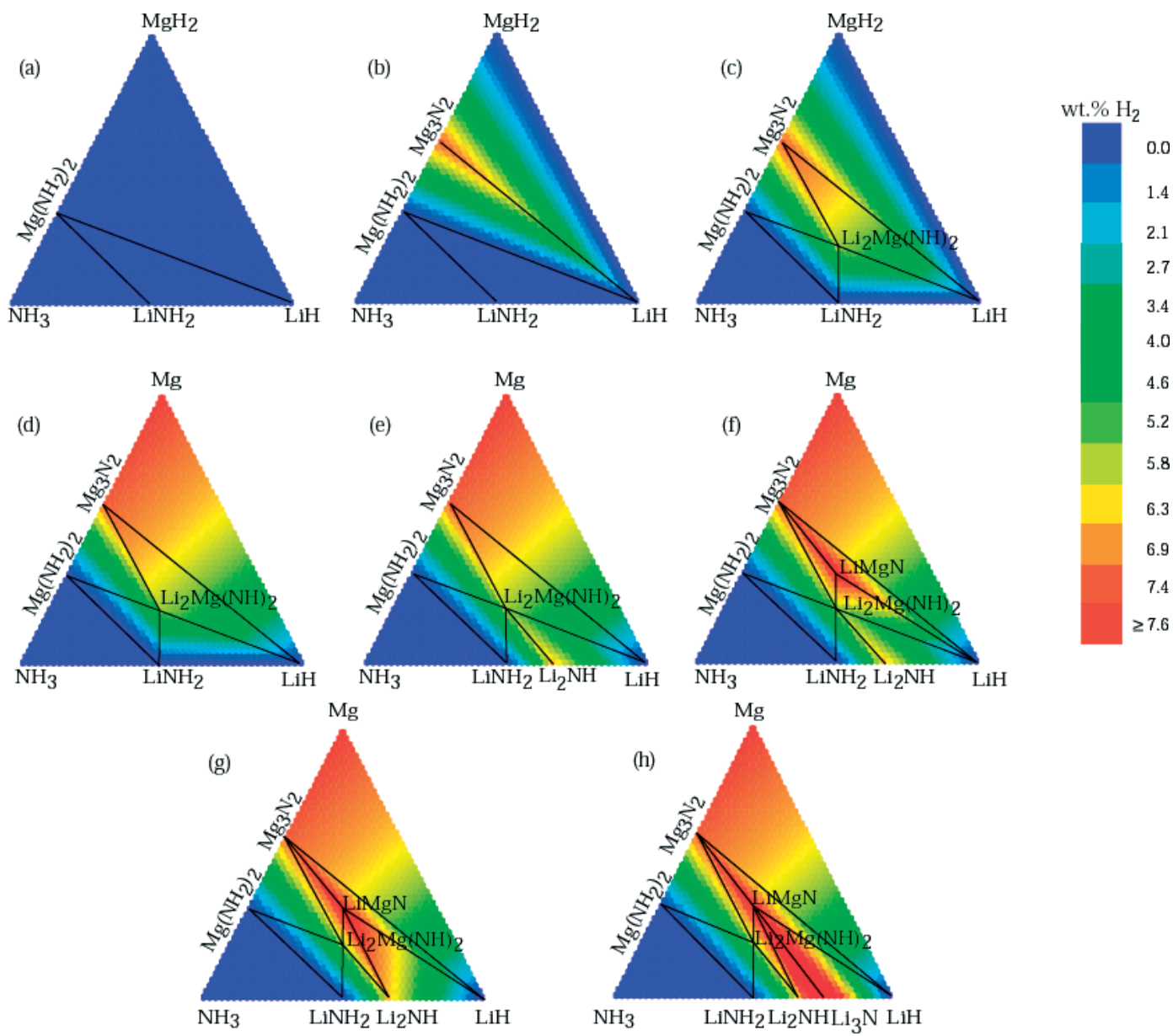

Figure 1. Phase diagrams of the Li-Mg-N-H system. Each Gibbs triangle refers to a specific temperature range: a) $T<130 \mathrm{~K}$, b) $130 \leq T<426 \mathrm{~K}$, c) $426 \leq T<458 \mathrm{~K}$, d) $458 \leq T<606 \mathrm{~K}$, e) $606 \leq T<734 \mathrm{~K}$, f) $734 \leq T<780 \mathrm{~K}, \mathrm{~g}) 780 \leq T<1077 \mathrm{~K}$, h) $1077 \leq T<1126 \mathrm{~K}$. Phases that coexist for each temperature interval are denoted. Color-coding indicates the amount of hydrogen released (in wt \% $\mathrm{H}_{2}$ ) relative to the starting mixture at $T=0 \mathrm{~K}$.

Table 2. Predicted sequence of thermodynamically favored decomposition reactions. For each reaction, we list the amount of $\mathrm{H}_{2}$ released (wt.\% $\mathrm{H}_{2}$ ), calculated and measured (when available) reaction enthalpies $\Delta \mathrm{H}\left(\mathrm{kJ} / \mathrm{mol} \mathrm{H}_{2}\right.$ ), calculated and measured (when available) reaction entropies $\Delta S$ $(\mathrm{J} / \mathrm{mol} \mathrm{K})$, and transition temperatures at atmospheric pressure $T_{\mathrm{atm}}(\mathrm{K}) . \Delta H_{\text {static }}{ }_{\mathrm{T}=0 \mathrm{~K}}, \Delta H_{Z P E+\text { static }}{ }_{\mathrm{T}=0 \mathrm{~K}}$ and are reaction enthalpies without and with ZPE contribution, respectively.

\begin{tabular}{|c|c|c|c|c|c|c|c|c|c|}
\hline No. & Reaction & wt. $\% \mathrm{H}_{2}$ & $\Delta H_{\text {static }}^{T=0 \mathrm{~K}}$ & $\Delta H_{\mathrm{ZPE}+\text { static }}^{T=0 \mathrm{~K}}$ & $\Delta H^{T=500 \mathrm{~K}}$ & $\Delta H^{\exp }$ & $\Delta S^{T=500 \mathrm{~K}}$ & $\Delta S^{\exp }$ & $T_{\mathrm{atm}}$ \\
\hline (i) & $\mathrm{Mg}\left(\mathrm{NH}_{2}\right)_{2}+2 \mathrm{MgH}_{2} \rightarrow \mathrm{Mg}_{3} \mathrm{~N}_{2}+4 \mathrm{H}_{2}$ & 7.41 & 27 & 8 & 15 & & 114 & & 130 \\
\hline (ii) & $\begin{array}{l}2 \mathrm{LiH}+\mathrm{Mg}\left(\mathrm{NH}_{2}\right)_{2} \\
\quad \rightarrow \mathrm{Li}_{2} \mathrm{Mg}(\mathrm{NH})_{2}+2 \mathrm{H}_{2}\end{array}$ & 5.59 & 60 & 40 & 47 & $39^{[2,3]}, 41.6^{[33]}$ & 110 & $116^{[33]}$ & 426 \\
\hline (iii) & $\mathrm{MgH}_{2} \rightarrow \mathrm{Mg}+\mathrm{H}_{2}$ & 7.67 & 62 & 53 & 63 & $74.6^{[34]}$ & 137 & $134.8^{[34]}$ & 458 \\
\hline (iv) & $\mathrm{LiH}+\mathrm{LiNH}_{2} \rightarrow \mathrm{Li}_{2} \mathrm{NH}+\mathrm{H}_{2}$ & 6.53 & 83 & 65 & 72 & $66.1^{[7]}, 66.6^{[8]}$ & 119 & $120^{[8]}$ & 606 \\
\hline (v) & $\begin{array}{l}2 \mathrm{LiH}+\mathrm{Li}_{2} \mathrm{Mg}(\mathrm{NH})_{2}+\mathrm{Mg}_{3} \mathrm{~N}_{2} \\
\quad \rightarrow 4 \mathrm{LiMgN}+2 \mathrm{H}_{2}\end{array}$ & 2.18 & 91 & 75 & 80 & & 109 & & 734 \\
\hline (vi) & $\begin{aligned} \mathrm{LiH} & +\mathrm{Li}_{2} \mathrm{Mg}(\mathrm{NH})_{2} \\
& \rightarrow \mathrm{Li}_{2} \mathrm{NH}+\mathrm{LiMgN}+\mathrm{H}_{2}\end{aligned}$ & 2.65 & 102 & 86 & 93 & & 120 & & 780 \\
\hline (vii) & $\mathrm{LiH}+\mathrm{Li}_{2} \mathrm{NH} \rightarrow \mathrm{Li}_{3} \mathrm{~N}+\mathrm{H}_{2}$ & 5.5 & 130 & 114 & 119 & & 112 & & 1077 \\
\hline
\end{tabular}


$\mathrm{H}_{2}$ at $T=0 \mathrm{~K}$ ) is too low for reversibility under practical recharging conditions. ${ }^{[22]}$

Reaction (ii): The next reaction is predicted to occur between $\mathrm{LiH}$ and $\mathrm{Mg}\left(\mathrm{NH}_{2}\right)_{2}$ at $T=426 \mathrm{~K}$, leading to the formation of the mixed ternary imide, $\mathrm{Li}_{2} \mathrm{Mg}(\mathrm{NH})_{2},{ }^{[23]}$ and releasing $5.6 \mathrm{wt} \%$ of hydrogen [see rxn. (ii) in Table 2]. Thus, our computational approach successfully predicts the experimentally observed reaction given by Equation 1. For reaction (ii), we obtain enthalpies of 40 and $47 \mathrm{~kJ} / \mathrm{mol} \mathrm{H}_{2}$ at $T=0$ and $500 \mathrm{~K}$, respectively. These results are in good agreement with the experimental enthalpy value of $39 \mathrm{~kJ} / \mathrm{mol} \mathrm{H}_{2}$ for temperatures between $473 \mathrm{~K}$ and $513 \mathrm{~K}$, given in Refs. [2,3]. This reaction takes place for all compositions within the quadrilateral region defined by the vertices representing $\mathrm{LiH}, \mathrm{LiNH}_{2}, \mathrm{Mg}\left(\mathrm{NH}_{2}\right)_{2}$, and $\mathrm{Mg}_{3} \mathrm{~N}_{2}$ in Figure 1b. Figure 1c shows the resulting phase diagram after the formation of the $\mathrm{Li}_{2} \mathrm{Mg}(\mathrm{NH})_{2}$ phase.

Reaction (iii): The next reaction is predicted to occur at $T=457 \mathrm{~K}$, where $\mathrm{MgH}_{2}$ decomposes via rxn. (iii) into $\mathrm{Mg}$ and $\mathrm{H}_{2}$ gas, releasing $7.67 \mathrm{wt} \% \mathrm{H}_{2}$ (see Fig. 1d). We calculate an enthalpy of $62 \mathrm{~kJ} / \mathrm{mol} \mathrm{H}_{2}$ for this well-studied hydrogen storage reaction, which is approximately $16 \%$ less than experimental measurements (Table 2). Although $\mathrm{MgH}_{2}$ has a rather high hydrogen storage capacity, slow kinetics and high hydrogenation temperatures make it an unfavorable material for on-board hydrogen storage. ${ }^{[24]}$

Reaction (iv): In the next step, at $T=606 \mathrm{~K}$, a 1:1 mixture of $\mathrm{LiH}$ and $\mathrm{LiNH}_{2}$ reacts to form $\mathrm{Li}$ imide, releasing $6.53 \mathrm{wt} \%$ $\mathrm{H}_{2}$ via reaction (iv) in Table 2. This reaction is the first step of the dehydrogenation process of $\mathrm{LiNH}_{2}$ proposed by Chen et al. ${ }^{[7]}$ We calculate an enthalpy value of $72 \mathrm{~kJ} / \mathrm{mol} \mathrm{H}_{2}$ and a harmonic entropy value of $119 \mathrm{~J} \mathrm{~mol}^{-1} \mathrm{~K}^{-1}$ at $T=500 \mathrm{~K}$, which compare well with the experimental values of $66 \mathrm{~kJ} / \mathrm{mol} \mathrm{H}_{2}{ }^{[7]}$ and $118-120 \mathrm{~J} \mathrm{~mol}^{-1} \mathrm{~K}^{-1}$, ${ }^{[8]}$ respectively. The resulting phase diagram is shown in Figure 1e.

Novel, Predicted High-Temperature Reactions (v) and (vi): Up to this point, our results have reproduced well-established experimental results in the Li-Mg-N-H system. At higher temperatures, we predict several new reactions that have not yet been observed experimentally and are offered as tests of the predictive power of the first-principles approach. In particular, we find two reactions that decompose the mixed $\mathrm{Li}-\mathrm{Mg}$ imide phase, leading to the formation of a ternary $\mathrm{LiMgN}$ compound. At $T=734 \mathrm{~K}$, rxn. (v) from Table 2 decomposes $\mathrm{Li}_{2} \mathrm{Mg}(\mathrm{NH})_{2}$ in a reaction with $\mathrm{LiH}$ and $\mathrm{Mg}_{3} \mathrm{~N}_{2}$, which releases $2.18 \mathrm{wt} \% \mathrm{H}_{2}$ and has an enthalpy of $80 \mathrm{~kJ} / \mathrm{mol} \mathrm{H}_{2}$. This reaction occurs in the coexistence region of the three phases on the left-hand side of the reaction, as shown in the resulting phase diagram in Figure 1f. At $780 \mathrm{~K}$ we obtain rxn. (vi) in Table 2, which involves equal fractions of $\mathrm{Li}_{2} \mathrm{Mg}(\mathrm{NH})_{2}$ and $\mathrm{LiH}$, leading to the formation of $\mathrm{LiMgN}$ and $\mathrm{Li}_{2} \mathrm{NH}$ and releasing $2.65 \mathrm{wt} \% \mathrm{H}_{2}$ with an enthalpy of $93 \mathrm{~kJ} / \mathrm{mol} \mathrm{H}_{2}$.

Reaction (vii): Finally, at $T=1076 \mathrm{~K}$, the Li imide phase is predicted to decompose according to rxn. (vii) Table 2, releasing $5.5 \mathrm{wt} \% \mathrm{H}_{2}$. This is the same reaction as the one proposed by Chen et al. in Ref. [7]. The resulting phase diagram is shown in Figure $1 \mathrm{~h}$.
Figure 2 shows the calculated van't Hoff plots for reactions (i)-(vii) from Table 2. As expected, we find that the logarithm of pressure versus the reciprocal of the absolute temperature yields a linear behavior for a wide range of temperatures: $200 \leq T \leq 850 \mathrm{~K}$. The desirable window of operating temperatures and pressures for on-board storage of $\mathrm{H}_{2}$ is shown as a dashed rectangle in Figure 2. We see that only reactions (i) and (ii) pass in the vicinity of this window, while all others miss it by a wide mark, corresponding to materials that are

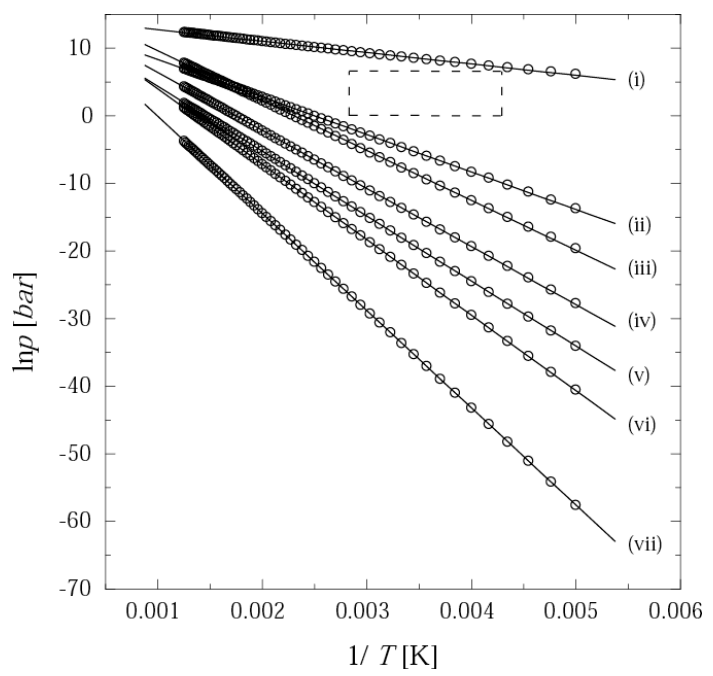

Figure 2. The calculated equilibrium pressure-temperature relations for all reactions from Table 2 in the $\mathrm{Li}-\mathrm{Mg}-\mathrm{N}-\mathrm{H}$ system. Points are the directly calculated equilibrium pressures, while lines are obtained from fits using the van't Hoff relation $\ln p=-\Delta H / R T+\Delta S / R$. Dashed rectangle indicates the practical temperature and pressure range of operation for fuel cell, i.e., $-40 \leq T \leq 80^{\circ} \mathrm{C}$ and $1 \leq p \leq 700$ bar, respectively.

too stable and will not release hydrogen at ambient temperatures. In particular, the $\mathrm{Li}_{2} \mathrm{Mg}(\mathrm{NH})_{2}$ phase is predicted to be very stable, ${ }^{[2]}$ and very high temperatures are required to decompose this compound according to the newly identified reactions (v) and (vi). It is also noteworthy that the van't Hoff lines for rxns. (ii) and (iii) intersect around $580 \mathrm{~K}$, which happens because the calculated entropies for rxns (ii) and (iii) are, respectively, significantly lower and higher than the standard molar entropy of $\mathrm{H}_{2}\left(130.6 \mathrm{~J} \mathrm{~mol}^{-1} \mathrm{~K}^{-1}\right.$ at $\left.T=300 \mathrm{~K}\right)$. Though the vast majority of the work on the thermodynamics of hydrogen storage materials is concentrated on reaction enthalpies, the large variation we have found here in the entropies of reactions indicates that there may be an additional route to tuning reaction thermodynamics: "entropy tailoring". In particular, if the entropy change in the reaction is smaller than the standard entropy of $\mathrm{H}_{2}$ gas, it may compensate for an enthalpy that would otherwise be too low. ${ }^{[25]}$

It is instructive to use the developed formalism to understand the thermodynamics of the reactions given by Equations 2 and 3 and illustrate how chemical intuition can fail for these two proposed reaction paths. The starting composition for Equation 2 falls on the tie-line connecting $\mathrm{LiH}$ and 
$\mathrm{Mg}\left(\mathrm{NH}_{2}\right)_{2}$ in the ternary phase diagram in Figure 1a. The first decomposition step for a 4:1 mixture of $\mathrm{LiH}$ and $\mathrm{Mg}\left(\mathrm{NH}_{2}\right)_{2}$ is the well-known lithium hydride-magnesium amide reaction. ${ }^{[10]}$ In the energy diagram shown in Figure 3, this reaction corresponds to going from point $\mathrm{A}$ to $\mathrm{B}$. The slope of the line connecting $\mathrm{A}$ and $\mathrm{B}$ is given by the enthalpy of reaction (ii) from Table $2\left(47 \mathrm{~kJ} / \mathrm{mol} \mathrm{H}_{2}\right)$. After this step we obtain a twophase mixture of $\mathrm{Li}_{2} \mathrm{Mg}(\mathrm{NH})_{2}$ and $\mathrm{LiH}$ in a $1: 2$ molar ratio. The second step (from B to C in Fig. 3) occurs at $T=780 \mathrm{~K}$

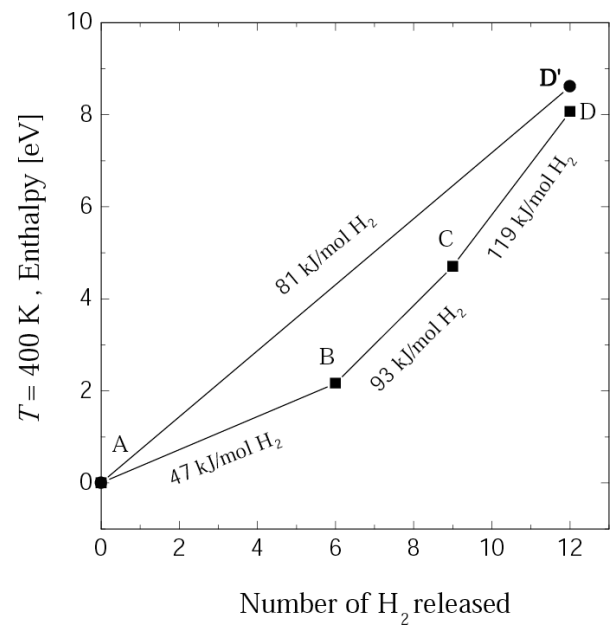

Figure 3. Decomposition sequence corresponding to the 1:4 mixture of $\mathrm{Mg}\left(\mathrm{NH}_{2}\right)_{2}$ and $\mathrm{LiH}$.

and is given by reaction (vi) in Table 2 . The final decomposition step (from $\mathrm{C}$ to $\mathrm{D}$ in Fig. 3) is given by rxn. (vii) from Table 2 , and occurs at $T=1077 \mathrm{~K}$. These three steps are summarized as follows:

$\mathrm{Mg}\left(\mathrm{NH}_{2}\right)_{2}+4 \mathrm{LiH} \rightarrow \mathrm{Li}_{2} \mathrm{Mg}(\mathrm{NH})_{2}+2 \mathrm{LiH}+\mathrm{H}_{2}(A \rightarrow B)$

$\rightarrow \mathrm{Li}_{2} \mathrm{NH}+\mathrm{LiMgN}+\mathrm{LiH}+2 \mathrm{H}_{2}(B \rightarrow C)$

$\rightarrow \mathrm{LiMgN}+\mathrm{Li}_{3} \mathrm{~N}+3 \mathrm{H}_{2}(C \rightarrow D)$

Note that contrary to Equation 2, $\mathrm{Mg}_{3} \mathrm{~N}_{2}$ never appears in the thermodynamically predicted sequence! Therefore, we find that a 1:4 mixture of magnesium amide and lithium hydride decomposes in three steps with sequentially increasing enthalpies. Of these, only the first reaction is suitable for on-board storage, since the 2 nd and the 3 rd step have reaction enthalpies of 93 and $119 \mathrm{~kJ} \mathrm{~mol}^{-1} \mathrm{H}_{2}$, respectively, and release hydrogen at very high temperatures. Finally, we predict that the end product is a $1: 1$ mixture of $\mathrm{Li}_{3} \mathrm{~N}$ and $\mathrm{LiMgN}$, while Equation 2 has a mixture of binary nitrides (represented by point $\mathrm{D}^{\prime}$ in Fig. 3). Our prediction of the favored nitride is in accord with observations ${ }^{[26]}$ that $\mathrm{LiMgN}$ is formed exothermically above $670 \mathrm{~K}$ according to: $\mathrm{Li}_{3} \mathrm{~N}+\mathrm{Mg}_{3} \mathrm{~N}_{2} \rightarrow 3 \mathrm{LiMgN}$.

An experimental study by Aoki et al. ${ }^{[27]}$ found that the lefthand side of Equation 2 transforms to a 1:2 mixture of
$\mathrm{Li}_{2} \mathrm{Mg}(\mathrm{NH})_{2}$ and $\mathrm{LiH}$ at temperatures between 200 and $250{ }^{\circ} \mathrm{C}$. This is in qualitative agreement with our results, which predict a transformation at a lower temperature of $153^{\circ} \mathrm{C}$; the difference can be attributed to the sluggish kinetics of rxn (ii). However, Aoki et al. also found a plateau region preceding the formation of $\mathrm{Li}_{2} \mathrm{Mg}(\mathrm{NH})_{2}$, which they attributed to the existence of a tetragonal $\mathrm{Li}_{4} \mathrm{Mg}_{3}\left(\mathrm{NH}_{2}\right)_{2}(\mathrm{NH})_{4}$ phase. They proposed that this phase subsequently decomposes into a 1:2 mixture of $\mathrm{Li}_{2} \mathrm{Mg}(\mathrm{NH})_{2}$ and $\mathrm{LiH}$ via intermediate phases of orthorhombic symmetry, corresponding to a sloping region that was seen in the measured pressure-composition isotherms. In our opinion, such a transformation sequence is unlikely to represent thermodynamic equilibrium, since the measured $^{[27]}$ hydriding enthalpy of the tetragonal phase $\left(46 \mathrm{~kJ} / \mathrm{mol} \mathrm{H}_{2}\right)$ is higher than the experimentally measured ${ }^{[2,3]}$ enthalpy of forming $\mathrm{Li}_{2} \mathrm{Mg}(\mathrm{NH})_{2}$ according to rxn (ii) $\left(39 \mathrm{~kJ} / \mathrm{mol} \mathrm{H}_{2}\right)$. This contradicts the general thermodynamic principle that lower-enthalpy hydrogen release reactions should occur at lower temperatures than the higher-enthalpy ones, provided the reaction entropies are similar. Further investigations of the crystal structures and energetics of the tetragonal and orthorhombic phases would be needed to clarify whether they are truly stable thermodynamically or whether Aoki et al. ${ }^{[27]}$ have observed a non-equilibrium decomposition pathway.

Regarding the reaction in Equation 3, our results show that a 1:1 mixture of $\mathrm{LiNH}_{2}$ and $\mathrm{MgH}_{2}$ will decompose as follows:

$$
\begin{aligned}
& \mathrm{LiNH}_{2}+\mathrm{MgH}_{2} \rightarrow \mathrm{LiH}+1 / 2 \mathrm{Mg}\left(\mathrm{NH}_{2}\right)_{2}+1 / 2 \mathrm{MgH}_{2} \\
& \rightarrow \mathrm{LiH}+1 / 4 \mathrm{Mg}\left(\mathrm{NH}_{2}\right)_{2}+1 / 4 \mathrm{Mg}_{3} \mathrm{~N}_{2}+\mathrm{H}_{2} \\
& \rightarrow 1 / 2 \mathrm{LiH}+1 / 4 \mathrm{Mg}_{3} \mathrm{~N}_{2}+1 / 4 \mathrm{Li}_{2} \mathrm{Mg}(\mathrm{NH})_{2}+3 / 2 \mathrm{H}_{2} \\
& \rightarrow \mathrm{LiMgN}+2 \mathrm{H}_{2}
\end{aligned}
$$

The scenario of these sequential reactions can be described as follows. First, magnesium amide will form exothermically via Equation 7. In the next step half of the $\mathrm{MgH}_{2}$ and half of the $\mathrm{Mg}$-amide will form $\mathrm{Mg}_{3} \mathrm{~N}_{2}$ via the endothermic reaction in Equation 8, which releases $\mathrm{H}_{2}$ with an enthalpy of $15 \mathrm{~kJ} / \mathrm{mol} \mathrm{H}_{2}$; this is in fact rxn. (i) in Table 2. The third step is the well-known reaction producing a mixed $\mathrm{Li}-\mathrm{Mg}$ imide, i.e., Equation 9, which again is predicted in Table 2 as rxn. (ii). Finally, a ternary nitride is formed according to Equation 10, which is the predicted rxn. (v) in Table 2. The enthalpies of the $3 \mathrm{rd}$ and 4 th steps are 47 and $80 \mathrm{~kJ} / \mathrm{mol} \mathrm{H}_{2}$ at $T=500 \mathrm{~K}$, respectively, given in Table 2 . We conclude that only the third step (Eq. 9) is thermodynamically suitable for on-board storage, and it corresponds to the well-known reaction suggested in Refs. [2,3,10,28].

Both the afore-mentioned examples demonstrate that it is not always easy to "intuit" the preferred decomposition pathway, and that what seems like a plausible reaction with "good" thermodynamics (e.g., Eq. 2), may actually prove to be a multi-step reaction sequence and only some of the steps 
may exhibit favorable thermodynamics. An automated method, such as ours, is crucial for predicting the preferred pathway, as opposed to the currently popular practice of simply guessing the likely reactions.

Finally, we comment on the energetics of ammonia release, which must be avoided in practical storage systems since it poisons PEM fuel cells and destroys the reversible storage capacity of the material. Using the calculated thermodynamic properties from Table 1 we find that the reaction enthalpies for the direct decomposition of $\mathrm{Li}$ amide, $2 \mathrm{LiNH}_{2} \rightarrow$ $\mathrm{Li}_{2} \mathrm{NH}+\mathrm{NH}_{3}$ and $3 \mathrm{LiNH}_{2} \rightarrow \mathrm{Li}_{3} \mathrm{~N}+2 \mathrm{NH}_{3}$, are 94 and $119 \mathrm{~kJ} / \mathrm{mol} \mathrm{NH} \mathrm{NH}_{3}$ at $T=300 \mathrm{~K}$. Using the standard state entropy of $\mathrm{NH}_{3}$ gas, $192.77 \mathrm{~J} / \mathrm{mol} \mathrm{K}$, we estimate that release of ammonia becomes possible at $T=487 \mathrm{~K}$ via the amide-to-imide pathway. Similarly, the direct decomposition of $\mathrm{Mg}$ amide, $3 \mathrm{Mg}\left(\mathrm{NH}_{2}\right)_{2} \rightarrow \mathrm{Mg}_{3} \mathrm{~N}_{2}+4 \mathrm{NH}_{3}$, is predicted to have a room temperature enthalpy of $109 \mathrm{~kJ} / \mathrm{mol} \mathrm{N_{3 }}$, which enables ammonia release at $T=565 \mathrm{~K}$. The calculated phase diagrams in Figure 1 represent a useful thermodynamic guide for avoiding the release of ammonia, as one should avoid compositions that contain $\mathrm{Li}$ and $\mathrm{Mg}$ amides above the threshold temperatures given above.

In conclusion, we have developed a practical formalism for studying phase diagrams of multicomponent systems within the framework of first-principles density-functional theory calculations. Our method can predict all thermodynamically favored hydrogen storage reactions for a given multicomponent system without having to explicitly enumerate possible reaction pathways, and can be used to optimize storage capacity within a given window of temperatures and pressures. The developed formalism has been applied to investigate the thermodynamic properties of the $\mathrm{Li}-\mathrm{Mg}-\mathrm{N}-\mathrm{H}$ system. Our analysis indicates that rxn (ii) in Table 2 is the only hydrogen storage reaction that is near the desired window of temperatures and pressures for reversible on-board storage. We predict two new high-temperature decomposition reactions which involve the mixed $\mathrm{Li}_{2} \mathrm{Mg}(\mathrm{NH})_{2}$ phase and lead to the formation of the ternary nitride $\mathrm{LiMgN}$. Our results also indicate that the mixed imide is thermodynamically very stable and hydrogen extraction from this compound is possible only at temperature above $700 \mathrm{~K}$. The entropies of reactions are between 109 and $137 \mathrm{~J} \mathrm{~mol}^{-1} \mathrm{~K}^{-1}$, which significantly deviate from the standard entropy of $\mathrm{H}_{2}$ gas, indicating that vibrational entropies play an important and often overlooked role in reaction thermodynamics. These results lend support to the idea that entropy modification offers a new route towards obtaining hydrogen storage materials with favorable thermodynamics.

\footnotetext{
Received: April 7, 2007

Revised: July 23, 2007
}

Published online: September 21, 2007
[1] S. V. Alapati, J. K. Johnson, D. S. Sholl, J. Phys. Chem. B 2006, 110, 8769.

[2] W. Luo, J. Alloys Compd. 2004, 381, 284.

[3] W. Luo, J. Alloys Compd. 2004, 385, 316.

[4] Y. Nakamori, G. Kitahara, K. Miwa, N. Ohba, T. Noritake, S. Towata, S. Orimo, J. Alloys Compd. 2005, 404-406, 396.

[5] D. J. Siegel, C. Wolverton, V. Ozolinšs, Phys. Rev. B 2007, 75, 014101.

[6] J. F. Herbst, J. L. G. Hector, Phys. Rev. B 2005, 72, 125120.

[7] P. Chen, Z. Xiong, J. Luo, J. Lin, K. L. Tan, Nature 2002, 420, 302.

[8] Y. Kojima, Y. Kawai, J. Alloys Compd. 2005, 395, 236.

[9] H. Y. Leng, T. Ichikawa, S. Hino, N. Hanada, S. Isobe, H. Fujii, J. Phys. Chem. B 2004, 108, 8763.

[10] W. Luo, S. Sickafoose, J. Alloys Compd. 2006, 407, 274.

[11] V. H. Jacobs, Z. Juza, Z. Anorg. Allg. Chem. 1969, 370, 254

[12] P. E. Blöchl, Phys. Rev. B 1994, 50, 17953.

[13] G. Kresse, J. Furthmüller, Phys. Rev. B 1996, 54, 11169.

[14] G. Kresse, J. Furthmüller, Comput. Mater. Sci. 1996, 6, 15.

[15] G. Kresse, J. Hafner, Phys. Rev. B 1993, 47, 558.

[16] G. Kresse, J. Hafner, J. Phys. Condens. Matter 1994, 6, 8245.

[17] G. Kresse, J. Hafner, Phys. Rev. B 1994, 49, 14251.

[18] G. Kresse, D. Joubert, Phys. Rev. B 1999, 59, 1758.

[19] J. P. Perdew, Y. Wang, Phys. Rev. B 1992, 45, 13244.

[20] H. J. Monkhorst, J. D. Pack. Phys. Rev. B 1976, 13, 5188.

[21] C. Wolverton, V. Ozolinš, M. Asta, Phys. Rev. B 2004, 69, 144109.

[22] We note here that, had we been able to include the MgNH phase in our calculations, the decomposition of $\mathrm{Mg}$ amide could have proceeded via an intermediate $\mathrm{Mg}$ imide step: $\mathrm{Mg}\left(\mathrm{NH}_{2}\right)_{2}+\mathrm{MgH}_{2} \leftrightarrow 2 \mathrm{MgNH}+2 \mathrm{H}_{2}$. It is clear that this reaction would have had a lower enthalpy than rxn (i), and therefore would have occurred at an even lower temperature. Therefore, the inclusion of $\mathrm{MgNH}$ would not change the main conclusion that $\mathrm{Mg}$ amide is practically irreversible, since it binds hydrogen too weakly.

[23] J. Rijssenbeek, Y. Gao, J. Hanson, Q. Huang, C. Jones, B. Toby, J. Alloys Comp. 2007, DOI: 10.1016/j.jallcom.2006.12.008.

[24] F. von Zeppelin, H. Reule, M. Hirscher, J. Alloys Compd. 2002, 330, 723.

[25] In fact, lower reaction enthalpies are often desirable as they alleviate issues of heat management

[26] H. Leng, T. Ichikawa, H. Fujii, J. Phys. Chem. B 2006, 110, 12964.

[27] M. Aoki, T. Noriktake, G. Kitahara, Y. Nakamori, S. Towata, S. Orima, J. Alloys Compd. 2007, 428, 307.

[28] Z. T. Xiong, J. J. Hu, G. T. Wu, P. Chen, W. F. Luo, K. Gross, J. Wang, J. Alloys Compd. 2005, 398, 235.

[29] K. Miwa, N. Ohba, S. Towata, Y. Nakamori, S. Orimo, Phys. Rev. B 2004, 69, 245120.

[30] J. E. Northrup, R. Di Felice, J. Neugebauer, Phys. Rev. B 1997, 56, 4325.

[31] K. Miwa, N. Ohba, S. I. Towata, Y. Nakamori, S. I. Orimo, Phys. Rev. B 2005, 71, 195109.

[32] B. Magyari-Köpe, V. Ozoliň̨s, C. Wolverton, Phys. Rev. B 2006, 73, 220101.

[33] J. Yang, A. Sudik, C. Wolverton, J. Alloys Compd. 2006, 430, 334.

[34] J. F. Stampfer, C. E. Holley, J. F. Suttle, J. Am. Chem. Soc. 1960, 82, 3504. 


\section{APPENDIX G}

Open literature report: a detailed First Principles study of destabilized hydrides

See Section 6.7.2

Physical Review B 2007, 76, 134102-1 - 134102-6. 


\title{
Thermodynamic guidelines for the prediction of hydrogen storage reactions and their application to destabilized hydride mixtures
}

\author{
Donald J. Siegel, ${ }^{1}$ C. Wolverton, ${ }^{1, *}$ and V. Ozolinș ${ }^{2}$ \\ ${ }^{1}$ Ford Motor Company, MD1170/RIC, Dearborn, Michigan 48121, USA \\ ${ }^{2}$ Department of Materials Science and Engineering, University of California, Los Angeles, California 90095, USA
}

(Received 13 October 2006; revised manuscript received 16 September 2007; published 4 October 2007)

\begin{abstract}
We propose a set of thermodynamic guidelines aimed at facilitating more robust screening of hydrogenstorage reactions. The utility of the guidelines is illustrated by reassessing the validity of reactions recently proposed in the literature and through vetting a list of more than 20 candidate reactions based on destabilized $\mathrm{LiBH}_{4}$ and $\mathrm{Ca}\left(\mathrm{BH}_{4}\right)_{2}$ borohydrides. Our analysis reveals several reactions having both favorable thermodynamics and relatively high hydrogen densities (ranging from 5 to $9 \mathrm{wt} \% \mathrm{H}_{2}$ and 85 to $100 \mathrm{~g} \mathrm{H}_{2} / 1$ ), and it demonstrates that chemical intuition alone is not sufficient to identify valid reaction pathways.
\end{abstract}

DOI: 10.1103/PhysRevB.76.134102 PACS number(s): 68.43.Bc, 64.70.Hz, 82.60.Cx, 84.60.-h

\section{INTRODUCTION}

The potential of emerging technologies such as fuel cells (FCs) and photovoltaics for environmentally benign power generation has sparked renewed interest in the development of novel materials for high-density energy storage. For mobile applications such as in the transportation sector, the demands placed upon energy storage media are especially stringent $^{1}$ as the leading candidates to replace fossil-fuelpowered internal combustion engines (ICEs) - proton exchange membrane FCs and hydrogen-powered ICEs ( $\mathrm{H}_{2}$-ICEs) - rely on $\mathrm{H}_{2}$ as a fuel. Although $\mathrm{H}_{2}$ has about three times the energy density of gasoline by weight, its volumetric density, even when pressurized to $10000 \mathrm{psi}$, is roughly six times less than that of gasoline. Consequently, safe and efficient storage of $\mathrm{H}_{2}$ has been identified ${ }^{2}$ as one of the key scientific obstacles to realizing a transition to $\mathrm{H}_{2}$-powered vehicles.

Perhaps the most promising approach to achieving the high $\mathrm{H}_{2}$ densities needed for mobile applications is via absorption in solids. ${ }^{3}$ Metal hydrides such as $\mathrm{LaNi}_{5} \mathrm{H}_{6}$ have long been known to reversibly store hydrogen at volumetric densities surpassing that of liquid $\mathrm{H}_{2}$, but their considerable weight results in gravimetric densities that are too low for lightweight applications. ${ }^{4}$ Accordingly, recent efforts ${ }^{5-9}$ have increasingly focused on low- $Z$ complex hydrides, such as metal borohydrides $M\left(\mathrm{BH}_{4}\right)_{n}$, where $M$ represents a metallic cation, as borohydrides have the potential to store large quantities of hydrogen (up to $18.5 \mathrm{wt} \%$ in $\mathrm{LiBH}_{4}$ ). Nevertheless, the thermodynamics of $\mathrm{H}_{2}$ desorption from known borohydrides are generally not compatible with the temperature-pressure conditions of FC operation; for example, in $\mathrm{LiBH}_{4}$, strong hydrogen-host bonds result in desorption temperatures in excess of $300{ }^{\circ} \mathrm{C} .{ }^{6}$ Thus, the suitability of $\mathrm{LiBH}_{4}$ and other stable hydrides as practical $\mathrm{H}_{2}$-storage media will depend upon the development of effective destabilization schemes.

Building on earlier work by Reilly and Wiswall ${ }^{10}$, Vajo et al. ${ }^{11}$ recently demonstrated that $\mathrm{LiBH}_{4}$ can be destabilized by mixing with $\mathrm{MgH}_{2}$. In isolation, the decomposition of these compounds proceeds according to

$$
\mathrm{LiBH}_{4} \rightarrow \mathrm{LiH}+\mathrm{B}+\frac{3}{2} \mathrm{H}_{2},
$$

$$
\mathrm{MgH}_{2} \rightarrow \mathrm{Mg}+\mathrm{H}_{2},
$$

yielding 13.6 and $7.6 \mathrm{wt} \% \mathrm{H}_{2}$, respectively, at temperatures above $300{ }^{\circ} \mathrm{C}$. The high desorption temperatures are consistent with the relatively high enthalpies of desorption: $\Delta H \sim 67\left(\mathrm{LiBH}_{4}\right)$ and $\sim 70\left(\mathrm{MgH}_{2}\right) \mathrm{kJ} /\left(\mathrm{mol} \mathrm{H}_{2}\right){ }^{11,12}$ By mixing $\mathrm{LiBH}_{4}$ with $\mathrm{MgH}_{2}, \Delta H$ for the combined reaction can be decreased below those of the isolated compounds due to the exothermic formation enthalpy of $\mathrm{MgB}_{2}$,

$$
\mathrm{LiBH}_{4}+\frac{1}{2} \mathrm{MgH}_{2} \rightarrow \mathrm{LiH}+\frac{1}{2} \mathrm{MgB}_{2}+2 \mathrm{H}_{2} .
$$

That is, formation of the $\mathrm{MgB}_{2}$ product stabilizes the dehydrogenated state in Eq. (2) relative to that of Eq. (1), thereby destabilizing both $\mathrm{LiBH}_{4}$ and $\mathrm{MgH}_{2}$. By adopting this strategy, measured isotherms for the $\mathrm{LiBH}_{4}+\frac{1}{2} \mathrm{MgH}_{2}$ mixture over $315-400{ }^{\circ} \mathrm{C}$ exhibited a $25 \mathrm{~kJ} / \mathrm{mol} \mathrm{H}_{2}$ decrease in $\Delta H$ relative $\mathrm{LiBH}_{4}$ alone, with an approximately tenfold increase in equilibrium $\mathrm{H}_{2}$ pressure. ${ }^{11}$ In addition, the hydride mixture was shown to be reversible with a density of $8-10 \mathrm{wt} \%$ $\mathrm{H}_{2} \cdot{ }^{11}$ Nevertheless, the extrapolated temperature $T=225^{\circ} \mathrm{C}$ at which $P_{\mathrm{H}_{2}}=1$ bar is still too high for mobile applications and suggests that additional destabilization is necessary.

The concept of thermodynamic destabilization appears to offer new opportunities for accessing the high $\mathrm{H}_{2}$ content of strongly bound hydrides. However, the large number of known hydrides suggests that experimentally testing all the possible combinations of known compounds would be impractical; thus, a means for rapidly screening for highdensity $\mathrm{H}_{2}$-storage reactions with appropriate thermodynamics ${ }^{13}$ would be of great value. ${ }^{33}$ Toward these ends, here we employ first-principles calculations to identify $\mathrm{H}_{2}$-storage reactions with favorable temperature-pressure characteristics based on destabilizing $\mathrm{LiBH}_{4}$ and $\mathrm{Ca}\left(\mathrm{BH}_{4}\right)_{2}$ (Ref. 9) by mixing with selected metal hydrides. Our goal is to determine whether additional destabilization of $\mathrm{LiBH}_{4}$ and $\mathrm{Ca}\left(\mathrm{BH}_{4}\right)_{2}$-beyond that demonstrated ${ }^{11}$ with $\mathrm{LiBH}_{4} / \mathrm{MgH}_{2}$-is possible by exploiting the exothermic formation enthalpies of the metal borides. We focus specifically on thermodynamic issues since appropriate thermodynamics is a necessary condition for any viable storage material, and thermodynamic properties are not easily altered. While kinet- 
ics must also be considered, catalysts and novel synthesis routes have been shown to be effective at improving reversibility and the rates of $\mathrm{H}_{2}$ uptake or release. ${ }^{14}$ By screening through $\sim 20$ distinct reactions, we identify four destabilized mixtures having favorable Gibbs free energies of desorption in conjunction with high gravimetric $(5-9 \mathrm{wt} \%)$ and volumetric $\left(85-100 \mathrm{~g} \mathrm{H}_{2} / \mathrm{l}\right)$ storage densities. The predicted reactions present new avenues for experimental investigation and illustrate that compounds with low gravimetric densities (i.e., transition metal hydrides) may yield viable $\mathrm{H}_{2}$-storage solutions when mixed with lightweight borohydrides. An advantage of the present approach is that it relies only on known compounds with established synthesis routes, in contrast to other recent studies which have proposed $\mathrm{H}_{2}$-storage reactions based on materials which have yet to be synthesized. ${ }^{15-19}$

An additional distinguishing feature of this study is the development of a set of thermodynamic guidelines aimed at facilitating more robust predictions of hydrogen-storage reactions. The guidelines are used to vet the present set of candiate reactions and to illustrate how other reactions recently reported in the literature ${ }^{13}$ are thermodynamically unrealistic. In total, this exercise reveals some of the common pitfalls that may arise when attempting to simply "guess" at reaction mechanisms.

\section{METHODOLOGY}

Our first-principles calculations were performed using a plane-wave-projector augmented wave method (VASP) ${ }^{20,21}$ based on the generalized gradient approximation ${ }^{22}$ to density functional theory. All calculations employed a plane-wave cutoff energy of $400 \mathrm{eV}$, and $k$-point sampling was performed on a dense grid with an energy convergence of better than $1 \mathrm{meV}$ per supercell. Internal atomic positions and external cell shape/volume were optimized to a tolerance of better than $0.01 \mathrm{eV} / \AA$. Thermodynamic functions were evaluated within the harmonic approximation ${ }^{23}$ and normalmode vibrational frequencies were evaluated using the socalled direct method on expanded supercells. ${ }^{24-27}$ Further information regarding the details and experimental validation of our calculations can be found elsewhere. ${ }^{25-27}$

Our search for high-density $\mathrm{H}_{2}$-storage reactions is based on a series of candidate reactions that are analogous to Eq. (2),

$$
y A\left(\mathrm{BH}_{4}\right)_{n}+M \mathrm{H}_{x} \rightarrow y A \mathrm{H}_{n}+M \mathrm{~B}_{y n}+\frac{3 y n+x}{2} \mathrm{H}_{2},
$$

where $A=\mathrm{Li}$ or $\mathrm{Ca}[n=1$ (2) for $\mathrm{Li}(\mathrm{Ca})], M$ represents a metallic element, and coefficients $x$ and $y$ are selected based on the stoichiometries of known hydrides $M \mathrm{H}_{x}$ and borides $M \mathrm{~B}_{y n}$. To maximize gravimetric density, we limit $M$ to relatively lightweight elements near the top of the Periodic Table. In the case of $A=\mathrm{Li}$, the enthalpy of Eq. (3) per mol $\mathrm{H}_{2}$ can be expressed as

$$
\Delta H=\frac{2}{3 y+x}\left[\frac{3 y}{2} \Delta H^{\mathrm{LiBH}_{4}}+\frac{x}{2} \Delta H^{M \mathrm{H}_{x}}-\Delta H^{M \mathrm{~B}_{y}}\right],
$$

where $\Delta H^{i}$ are the desorption (formation) enthalpies of the respective hydrides (borides) per mol $\mathrm{H}_{2}(M)$. Thus, $\Delta H$ for the destabilized $\mathrm{LiBH}_{4}$ reaction is simply an average of the hydride desorption enthalpies, less the enthalpy of boride formation.

\section{RESULTS}

Table I lists theoretical $\mathrm{H}_{2}$ densities and calculated dehydrogenation enthalpies and entropies for several potential $\mathrm{H}_{2}$-storage reactions. Reactions 1-22 enumerate the candidate reactions, while reactions $23-27$ are included in order to validate the accuracy of our predictions by comparing with experimentally measured enthalpies ${ }^{11,12,29}$ and previous firstprinciples results ${ }^{13}$ (shown in parentheses). Turning first to the reactions from experiment (24-27), it is clear that the calculated $T=300 \mathrm{~K}$ enthalpies are generally in good agreement with the measured data. As mentioned above, reaction 24 was studied by Vajo et al. ${ }^{11}$ [see Eq. (2)]. Our calculated enthalpy of $50.4 \mathrm{~kJ} / \mathrm{mol} \mathrm{H}_{2}$ overestimates the experimental value by $\sim 10 \mathrm{~kJ} / \mathrm{mol}$. However, since the experimental measurements were made at temperatures $\left(T=315-400{ }^{\circ} \mathrm{C}\right)$ above the $\mathrm{LiBH}_{4}$ melting point $\left(T_{m}=268{ }^{\circ} \mathrm{C}\right),{ }^{6}$ and our calculations are with respect to the ground state Pnma crystal structure, ${ }^{6}$ we expect $\Delta H^{\text {calc }}($ Pnma $)>\Delta H^{\text {expt }}($ liquid $)$ due to the higher enthalpy of the liquid state.

We begin our discussion of the candidate reactions by commenting on the vibrational contributions $\left(\Delta S_{\text {vib }}\right)$ of the solid state phases to the total dehydrogenation entropy $\Delta S$. Based on the notion that $\Delta S$ is largely due to the entropy of $\mathrm{H}_{2}\left[\Delta S \simeq S_{0}^{\mathrm{H}_{2}} \simeq 130 \mathrm{~J} /(\mathrm{mol} \mathrm{K})\right.$ at $\left.300 \mathrm{~K}\right]$, a dehydrogenation enthalpy in the approximate range of $20-50 \mathrm{~kJ} / \mathrm{mol} \mathrm{H}_{2}$ would yield desorption pressures/temperatures that are consistent with the operating conditions of a FC. ${ }^{3}$ However, as shown in the last column of Table I, the calculated $\Delta S_{\text {vib }}$ are not negligible (up to $21 \%$ ) in comparison to $S_{0}^{\mathrm{H}_{2}}$, calling into question the assumption $\Delta S \simeq S_{0}^{\mathrm{H}_{2}}$ and the guideline $\Delta H$ $=20-50 \mathrm{~kJ} / \mathrm{mol} \mathrm{H}_{2}$. This suggests that a precise determination of the temperature-pressure characteristics of a given desorption reaction requires an evaluation of the change in Gibbs free energy $[\Delta G(T)]$, accounting explicitly for the effects of temperature and $\Delta S_{\text {vib }}$, as done below.

\section{A. Thermodynamic guidelines}

A key concern when attempting to predict favorable hydrogen-storage reactions is to ensure that the thermodynamically preferred reaction pathway has been identified. This is a nontrivial task, and our experience has shown that intuition alone is not sufficient to correctly identify realistic reactions involving multicomponent systems. ${ }^{26}$ In this regard, several of the reactions in Table I (denoted by $*$ ) are noteworthy as they illustrate the difficulties that may arise when "guessing" at reactions. For example, all of the candidate reactions are written as simple, single-step reactions. 
TABLE I. $\mathrm{H}_{2}$ densities and calculated thermodynamic quantities for candidate $\mathrm{H}_{2}$-storage reactions. Units are $\mathrm{J} / \mathrm{K}$ mol $\mathrm{H}_{2}$ for $\Delta S_{\text {vib }}$ and $\mathrm{kJ} / \mathrm{mol} \mathrm{H}_{2}$ for $\Delta E$ and $\Delta H$; column 7 refers to the temperature at which $P_{\mathrm{H}_{2}}=1$ bar. Reactions denoted with a will not proceed as written (see text). The enthalpies of reactions 24-27 have been measured in prior experiments and are included here (in parentheses) to validate the accuracy of our calculations. For comparison, system-level targets for gravimetric and volumetric densities are cited in the bottom row (Ref. 28).

\begin{tabular}{|c|c|c|c|c|c|c|c|c|}
\hline $\begin{array}{l}\text { Rxn. } \\
\text { No. }\end{array}$ & Reaction & $\begin{array}{c}\text { wt. \% } \\
\left(\mathrm{kg} \mathrm{H} \mathrm{H}_{2} / \mathrm{kg}\right)\end{array}$ & $\begin{array}{l}\text { Vol. density } \\
\quad\left(\mathrm{g} \mathrm{H}_{2} / 1\right)\end{array}$ & $\Delta E$ & $\Delta H^{T=300}$ & & $\begin{array}{c}T, P=1 \text { bar } \\
\left({ }^{\circ} \mathrm{C}\right)\end{array}$ & $\Delta S_{\mathrm{vib}}^{T=300 \mathrm{~K}}$ \\
\hline $1 *$ & $4 \mathrm{LiBH}_{4}+2 \mathrm{AlH}_{3} \rightarrow 2 \mathrm{AlB}_{2}+4 \mathrm{LiH}+9 \mathrm{H}_{2}$ & 12.4 & 106 & 54.8 & 39.6 & & 83 & -18.4 \\
\hline 2 & $2 \mathrm{LiBH}_{4}+\mathrm{Al} \rightarrow \mathrm{AlB}_{2}+2 \mathrm{LiH}+3 \mathrm{H}_{2}$ & 8.6 & 80 & 77.0 & 57.9 & & 277 & -26.9 \\
\hline $3 *$ & $4 \mathrm{LiBH}_{4}+\mathrm{MgH}_{2} \rightarrow \mathrm{MgB}_{4}+4 \mathrm{LiH}+7 \mathrm{H}_{2}$ & 12.4 & 95 & 68.2 & 51.8 & & 206 & -23.3 \\
\hline $4 *$ & $2 \mathrm{LiBH}_{4}+\mathrm{Mg} \rightarrow \mathrm{MgB}_{2}+2 \mathrm{LiH}+3 \mathrm{H}_{2}$ & 8.9 & 76 & 65.9 & 46.4 & & 170 & -29.4 \\
\hline 5 & $2 \mathrm{LiBH}_{4}+\mathrm{TiH}_{2} \rightarrow \mathrm{TiB}_{2}+2 \mathrm{LiH}+4 \mathrm{H}_{2}$ & 8.6 & 103 & 21.4 & 4.5 & & & -23.3 \\
\hline 6 & $2 \mathrm{LiBH}_{4}+\mathrm{VH}_{2} \rightarrow \mathrm{VB}_{2}+2 \mathrm{LiH}+4 \mathrm{H}_{2}$ & 8.4 & 105 & 24.7 & 7.2 & & -238 & -21.7 \\
\hline 7 & $2 \mathrm{LiBH}_{4}+\mathrm{ScH}_{2} \rightarrow \mathrm{ScB}_{2}+2 \mathrm{LiH}+4 \mathrm{H}_{2}$ & 8.9 & 99 & 48.8 & 32.6 & & 26 & -21.4 \\
\hline $8 *$ & $2 \mathrm{LiBH}_{4}+\mathrm{CrH}_{2} \rightarrow \mathrm{CrB}_{2}+2 \mathrm{LiH}+4 \mathrm{H}_{2}$ & 8.3 & 109 & 33.9 & 16.4 & & -135 & -19.2 \\
\hline $9 *$ & $2 \mathrm{LiBH}_{4}+2 \mathrm{Fe} \rightarrow 2 \mathrm{FeB}+2 \mathrm{LiH}+3 \mathrm{H}_{2}$ & 3.9 & 76 & 32.7 & 12.8 & & -163 & -24.6 \\
\hline 10 & $2 \mathrm{LiBH}_{4}+4 \mathrm{Fe} \rightarrow 2 \mathrm{Fe}_{2} \mathrm{~B}+2 \mathrm{LiH}+3 \mathrm{H}_{2}$ & 2.3 & 65 & 21.6 & 1.2 & & & -24.4 \\
\hline 11 & $2 \mathrm{LiBH}_{4}+\mathrm{Cr} \rightarrow \mathrm{CrB}_{2}+2 \mathrm{LiH}+3 \mathrm{H}_{2}$ & 6.3 & 84 & 50.9 & 31.7 & & 25 & -23.8 \\
\hline 12 & $\mathrm{Ca}\left(\mathrm{BH}_{4}\right)_{2} \rightarrow \frac{2}{3} \mathrm{CaH}_{2}+\frac{1}{3} \mathrm{CaB}_{6}+\frac{10}{3} \mathrm{H}_{2}$ & 9.6 & 107 & 57.1 & 41.4 & & 88 & -16.0 \\
\hline $13 *$ & $\mathrm{Ca}\left(\mathrm{BH}_{4}\right)_{2}+\mathrm{MgH}_{2} \rightarrow \mathrm{CaH}_{2}+\mathrm{MgB}_{2}+4 \mathrm{H}_{2}$ & 8.4 & 99 & 61.6 & 47.0 & & 135 & -16.2 \\
\hline $14 *$ & $2 \mathrm{Ca}\left(\mathrm{BH}_{4}\right)_{2}+\mathrm{MgH}_{2} \rightarrow 2 \mathrm{CaH}_{2}+\mathrm{MgB}_{4}+7 \mathrm{H}_{2}$ & 8.5 & 98 & 63.6 & 47.9 & & 147 & -17.0 \\
\hline $15 *$ & $\mathrm{Ca}\left(\mathrm{BH}_{4}\right)_{2}+\mathrm{Mg} \rightarrow \mathrm{CaH}_{2}+\mathrm{MgB}_{2}+3 \mathrm{H}_{2}$ & 6.4 & 79 & 60.6 & 41.9 & & 111 & -22.0 \\
\hline $16 *$ & $\mathrm{Ca}\left(\mathrm{BH}_{4}\right)_{2}+\mathrm{Al} \rightarrow \mathrm{CaH}_{2}+\mathrm{AlB}_{2}+3 \mathrm{H}_{2}$ & 6.3 & 83 & 71.7 & 53.4 & & 200 & -19.5 \\
\hline $17 *$ & $\mathrm{Ca}\left(\mathrm{BH}_{4}\right)_{2}+\mathrm{AlH}_{3} \rightarrow \mathrm{CaH}_{2}+\mathrm{AlB}_{2}+\frac{9}{2} \mathrm{H}_{2}$ & 9.1 & 109 & 51.2 & 36.6 & & 39 & -13.5 \\
\hline 18 & $\mathrm{Ca}\left(\mathrm{BH}_{4}\right)_{2}+\mathrm{ScH}_{2} \rightarrow \mathrm{CaH}_{2}+\mathrm{ScB}_{2}+4 \mathrm{H}_{2}$ & 6.9 & 102 & 44.8 & 29.2 & & -20 & -15.9 \\
\hline 19 & $\mathrm{Ca}\left(\mathrm{BH}_{4}\right)_{2}+\mathrm{TiH}_{2} \rightarrow \mathrm{CaH}_{2}+\mathrm{TiB}_{2}+4 \mathrm{H}_{2}$ & 6.7 & 106 & 17.4 & 1.1 & & & -17.7 \\
\hline 20 & $\mathrm{Ca}\left(\mathrm{BH}_{4}\right)_{2}+\mathrm{VH}_{2} \rightarrow \mathrm{CaH}_{2}+\mathrm{VB}_{2}+4 \mathrm{H}_{2}$ & 6.6 & 108 & 20.8 & 3.8 & & & -16.2 \\
\hline $21 *$ & $\mathrm{Ca}\left(\mathrm{BH}_{4}\right)_{2}+\mathrm{CrH}_{2} \rightarrow \mathrm{CaH}_{2}+\mathrm{CrB}_{2}+4 \mathrm{H}_{2}$ & 6.5 & 113 & 29.9 & 13.1 & & -180 & -13.6 \\
\hline 22 & $\mathrm{Ca}\left(\mathrm{BH}_{4}\right)_{2}+\mathrm{Cr} \rightarrow \mathrm{CaH}_{2}+\mathrm{CrB}_{2}+3 \mathrm{H}_{2}$ & 5.0 & 86 & 45.6 & 27.2 & & -38 & -16.4 \\
\hline 23 & $6 \mathrm{LiBH}_{4}+\mathrm{CaH}_{2} \rightarrow \mathrm{CaB}_{6}+6 \mathrm{LiH}+10 \mathrm{H}_{2}$ & 11.7 & 93 & $61.9(63)^{\mathrm{a}}$ & 45.4 & & 146 & -22.7 \\
\hline 24 & $2 \mathrm{LiBH}_{4}+\mathrm{MgH}_{2} \rightarrow \mathrm{MgB}_{2}+2 \mathrm{LiH}+4 \mathrm{H}_{2}$ & 11.6 & 96 & 65.6 & 50.4 & $(41)^{\mathrm{b}}$ & 186 & -21.7 \\
\hline 25 & $2 \mathrm{LiBH}_{4} \rightarrow 2 \mathrm{LiH}+2 \mathrm{~B}+3 \mathrm{H}_{2}$ & 13.9 & 93 & 81.4 & 62.8 & $(67)^{\mathrm{b}}$ & 322 & -27.1 \\
\hline 26 & $\mathrm{LiBH}_{4} \rightarrow \mathrm{Li}+\mathrm{B}+2 \mathrm{H}_{2}$ & 18.5 & 124 & 103.5 & 89.7 & $(95)^{\mathrm{c}}$ & 485 & -15.3 \\
\hline \multirow[t]{2}{*}{27} & $\mathrm{MgH}_{2} \rightarrow \mathrm{Mg}+\mathrm{H}_{2}$ & 7.7 & 109 & 64.5 & $\begin{array}{l}62.3 \\
(65.8-75.2)\end{array}$ & & 195 & 1.3 \\
\hline & U.S. DOE system-level targets $(2010 / 2015)$ & $6 / 9$ & $45 / 81$ & & & & & \\
\hline
\end{tabular}

${ }^{\mathrm{a}}$ Reference 13 .

${ }^{\mathrm{b}}$ Reference 11 .

${ }^{\mathrm{c}}$ Reference 29 .

${ }^{\mathrm{d}}$ Reference 12 .

While this may seem reasonable given the mechanism proposed in Ref. 11 [Eq. (2)] and its generalization in Eq. (3), as we discuss below, some of these reactions should proceed via multiple-step pathways, with each step having thermodynamic properties that are distinct from the presumed singlestep pathway.

We group the examples of how chemical intuition might fail into three categories, and for each class, give a general guideline describing the thermodynamic restriction:

(1) Reactant mixtures involving "weakly bound" compounds. We refer here to systems where the enthalpy to decompose one (or more) of the reactant phases is less than the enthalpy of the proposed destabilized reaction; thus, the weakly bound phase(s) will decompose before (i.e., at a temperature below that which) the destabilized reaction can proceed. Two examples of this behavior can be found in Table I. The first case pertains to reactions 13-16, which, based on their larger enthalpies relative to reaction 12, would appear to "stabilize" $\mathrm{Ca}\left(\mathrm{BH}_{4}\right)_{2}$. In reality, $\mathrm{Ca}\left(\mathrm{BH}_{4}\right)_{2}$ will decompose before (with $P_{\mathrm{H}_{2}}=1$ bar at $T=88^{\circ} \mathrm{C}$ ) any of the higher temperature reactions $13-16$ will occur $\left(T>110^{\circ} \mathrm{C}\right)$, indicating that it is impossible to stabilize a reaction in this manner. Additional examples of this scenario occur in reactions 1, 8, 17, and 21, which involve the metastable $\mathrm{AlH}_{3}$ and $\mathrm{CrH}_{2}$ phases. In the case of reaction $1, \mathrm{AlH}_{3}$ will decompose first (yielding $\mathrm{Al}$ and $\frac{3}{2} \mathrm{H}_{2}$ ), followed by reaction of $\mathrm{Al}$ with 


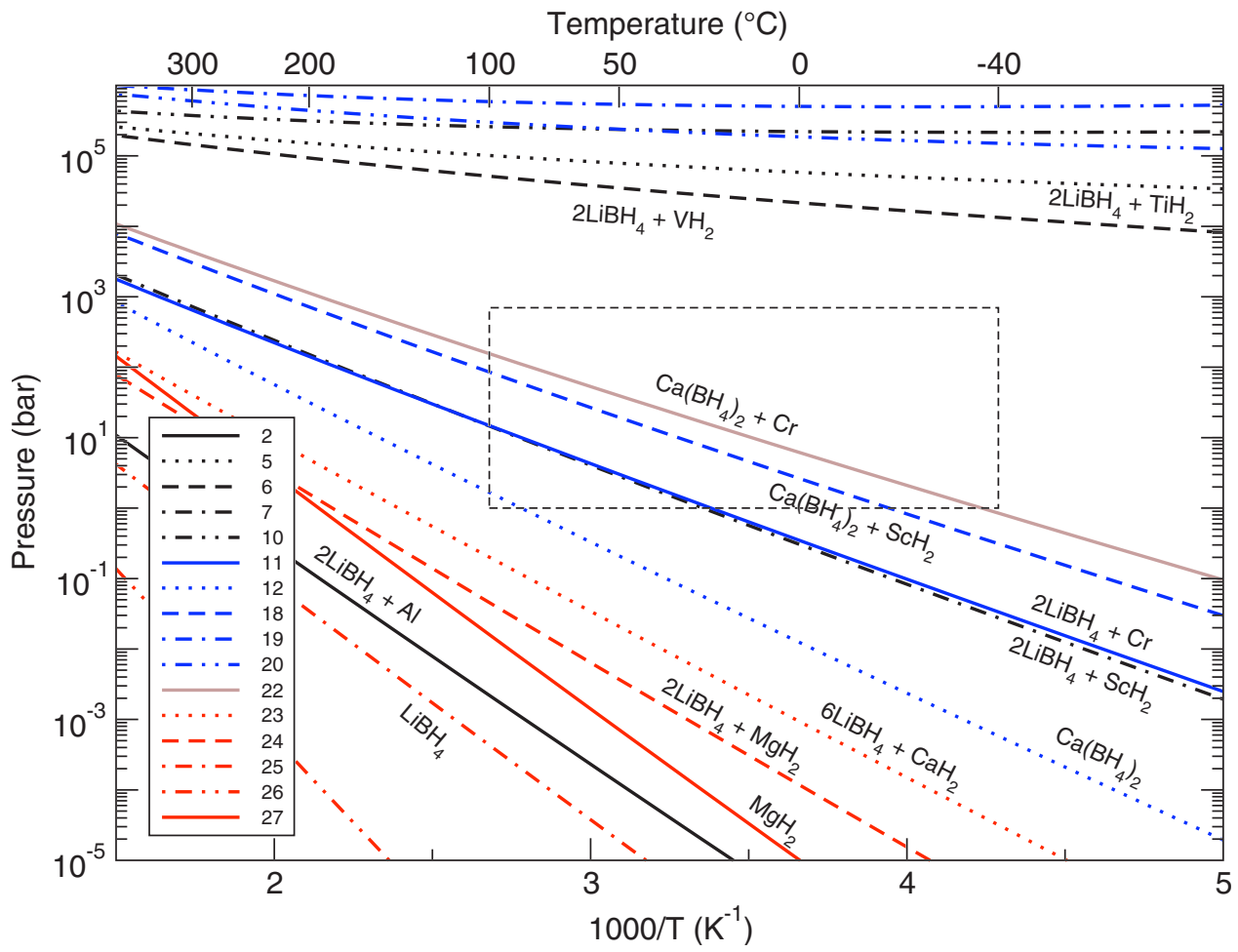

FIG. 1. (Color online) Calculated van't Hoff plot for reactions listed in Table I. The region within the dashed box corresponds to desirable temperatures and pressures for on-board hydrogen storage: $P_{\mathrm{H}_{2}}=1-700$ bar $T=-40-100{ }^{\circ} \mathrm{C}$.
$\mathrm{LiBH}_{4}$ (reaction 2). The consequences of this behavior are significant, since although the intended reaction 1 has an enthalpy $\left(\sim 40 \mathrm{~kJ} / \mathrm{mol} \mathrm{H}_{2}\right)$ in the targeted range, in reality, the reaction will consist of two steps, the first of which has an enthalpy below the targeted range $\left(\mathrm{AlH}_{3}\right.$ decomposition), while the second (reaction 2) has an enthalpy above this range. Guideline 1: The enthalpy of the proposed destabilized reaction must be less than the decomposition enthalpies of the individual reactant phases.

(2) Unstable combinations of product or reactant phases. Reaction 4 illustrates how the seemingly straightforward process of identifying stable reactant and product phases can become unexpectedly complex. Here, the starting mixture of $\mathrm{LiBH}_{4}$ and $\mathrm{Mg}$ is unstable and will undergo the exothermic transformation,

$$
2 \mathrm{LiBH}_{4}+\mathrm{Mg} \rightarrow \frac{3}{2} \mathrm{LiBH}_{4}+\frac{3}{4} \mathrm{MgH}_{2}+\frac{1}{4} \mathrm{MgB}_{2}+\frac{1}{2} \mathrm{LiH},
$$

which will consume the available $\mathrm{Mg}$ and form $\mathrm{MgH}_{2}$. $\mathrm{MgH}_{2}$ will react endothermically with the remaining $\mathrm{LiBH}_{4}$ according to reaction 24. The exothermic nature of Eq. (5) can be understood by noting that the enthalpy of reaction 4 ( $46.4 \mathrm{~kJ} / \mathrm{mol} \mathrm{H}_{2}$ ) is lower than the decomposition enthalpy of $\mathrm{MgH}_{2}$, given by reaction $27\left(62.3 \mathrm{~kJ} / \mathrm{mol} \mathrm{H}_{2}\right)$. Therefore, the total energy can be lowered by transferring hydrogen to the more strongly bound $\mathrm{MgH}_{2}$ compound. Guideline 2: If the proposed reaction involves a reactant that can absorb hydrogen (such as an elemental metal), the formation enthalpy of the corresponding hydride cannot be greater in magnitude than the enthalpy of the destabilized reaction.

(3) Lower-energy reaction pathways. Reaction 3, involving a 4:1 mixture of $\mathrm{LiBH}_{4}: \mathrm{MgH}_{2}$, as well as the related reaction involving a 7:1 stoichiometry, $7 \mathrm{LiBH}_{4}+\mathrm{MgH}_{2}$ $\rightarrow \mathrm{MgB}_{7}+7 \mathrm{LiH}+11.5 \mathrm{H}_{2}$, were recently suggested in Ref. 13 , which considered only a single-step mechanism resulting in the formation of $\mathrm{MgB}_{4}$ and $\mathrm{MgB}_{7}$, respectively. Here, we demonstrate that these reactions will not proceed as suggested there due to the presence of intermediate stages with lower energies. In fact, both hypothetical reactions have larger enthalpies $\left[\Delta E=69(4: 1)\right.$ and $74(7: 1) \mathrm{kJ} / \mathrm{mol} \mathrm{H}_{2}$ (Ref. 13)] than the 2:1 mixture (reaction 24), suggesting that, upon increasing temperature, the 4:1 and 7:1 mixtures will follow a pathway whose initial reaction step is the $2: 1$ reaction (reaction 24), which will consume all available $\mathrm{MgH}_{2}$. Subsequent reactions between unreacted $\mathrm{LiBH}_{4}$ and newly formed $\mathrm{MgB}_{2}$ will become thermodynamically feasible at temperatures above that of reaction 24 since their enthalpies exceed $50 \mathrm{~kJ} / \mathrm{mol} \mathrm{H}_{2}$. [Similar behavior is expected for reactions 9 and 10, as the 1:1 mixture of $\mathrm{LiBH}_{4}: \mathrm{Fe}$ (reaction 9) will initially react in a 1:2 ratio (reaction 10 ), which has a lower enthalpy.] Guideline 3: In general, it is not possible to tune the thermodynamics of destabilized reactions by adjusting the molar fractions of the reactants. There is only one stoichiometry corresponding to a single-step reaction with the lowest possible enthalpy; all other stoichiometries will release $\mathrm{H}_{2}$ in multistep reactions, where the initial reaction is given by the lowest-enthalpy reaction. ${ }^{34}$

\section{B. Destabilized reactions}

In total, the preceding examples reveal that great care must be taken in predicting hydrogen-storage reactions. Having ruled out the specious reactions, we now discuss the thermodynamics of the remaining reactions. Using the calculated thermodynamic data (Table I) as input to the van't Hoff 
equation, $P_{\mathrm{H}_{2}}=P_{0} \exp \left(-\frac{\Delta G}{R T}\right)$, where $P_{0}=1$ bar, Fig. 1 plots the equilibrium $\mathrm{H}_{2}$ desorption pressures of these reactions as a function of temperature. ${ }^{35}$ Included in the plot is a rectangle delineating desirable temperature and pressure ranges for $\mathrm{H}_{2}$ storage: $-40-100{ }^{\circ} \mathrm{C}$ and $1-700$ bar.

As expected, our van't Hoff plot confirms that the experimental reactions having large dehydrogenation enthalpies (reactions 24-27) yield pressures $P \ll 1$ bar even at elevated temperatures. On the other hand, some of the candidate reactions, for example, 5 and 19 , readily evolve $\mathrm{H}_{2}$ at very low temperatures (consistent with their low enthalpies) and are therefore too weakly bound for practical, reversible on-board storage. However, the candidate reactions involving mixtures with $\mathrm{ScH}_{2}$ (Ref. 36) [reactions 7 (Ref. 37) and 18] and $\mathrm{Cr}$ (reactions 11 and 22) desorb $\mathrm{H}_{2}$ in $P-T$ regimes that strongly intersect the window of desirable operating conditions. These reactions have room-temperature enthalpies in the range of $27-33 \mathrm{~kJ} / \mathrm{mol} \mathrm{H}_{2}$, relatively high $\mathrm{H}_{2}$ densities $(5-8.9$ wt $\%$ $\mathrm{H}_{2}$ and 85-100 $\mathrm{g} \mathrm{H}_{2} / 1$ ), and achieve $P_{\mathrm{H}_{2}}=1$ bar at moderate temperatures ranging from -38 to $26^{\circ} \mathrm{C}$. Thus, via a firstprinciples approach of rapid screening through a large number of candidate reactions, and the careful use of thermodynamic considerations to eliminate unstable or multistep reactions, we predict here several reactions with attributes that surpass the state-of-the-art for reversible, lowtemperature storage materials.

\section{CONCLUSION}

In conclusion, using first-principles free energy calculations, we have demonstrated that further significant destabilization of the strongly bound $\mathrm{LiBH}_{4}$ and $\mathrm{Ca}\left(\mathrm{BH}_{4}\right)_{2}$ borohydrides is possible, and we identify several high $\mathrm{H}_{2}$-density reactions having thermodynamics compatible with the operating conditions of mobile $\mathrm{H}_{2}$-storage applications. Unlike other recent predictions, the proposed reactions utilize only known compounds with established synthesis routes and can therefore be subjected to immediate experimental testing. In addition, we provide guidance to subsequent efforts aimed at predicting $\mathrm{H}_{2}$-storage materials by illustrating common pitfalls that arise when attempting to guess at reaction mechanisms, and by suggesting a set of thermodynamic guidelines to facilitate more robust predictions.

\section{ACKNOWLEDGMENTS}

V.O. thanks the U.S. DOE for financial support under Grants No. DE-FG02-05ER46253 and No. DE-FC36-04GO14013.
*Present address: Department of Materials Science and Engineering, Northwestern University, Evanston, IL 60208.

${ }^{1}$ F. E. Pinkerton and B. G. Wicke, Ind. Phys. 10, 20 (2004).

${ }^{2}$ G. W. Crabtree, M. S. Dresselhaus, and M. V. Buchanan, Phys. Today 57(12), 39 (2004).

${ }^{3}$ L. Schlapbach and A. Züttel, Nature (London) 414, 353 (2001).

${ }^{4}$ G. Sandrock, J. Alloys Compd. 293-295, 877 (1999).

${ }^{5}$ J.-P. Soulie, G. Renaudin, R. Cerny, and K. Yvon, J. Alloys Compd. 346, 200 (2002).

${ }^{6}$ A. Zuttel, S. Rentsch, P. Fischer, P. Wenger, P. Sudan, P. Mauron, and C. Emmenegger, J. Alloys Compd. 356-357, 515 (2003).

${ }^{7}$ Y. Nakamori, K. Miwa, A. Ninomiya, H. Li, N. Ohba, S. Towata, A. Zuttel, and S. Orimo, Phys. Rev. B 74, 045126 (2006).

${ }^{8}$ Z. Łodziana and T. Vegge, Phys. Rev. Lett. 93, 145501 (2004).

${ }^{9}$ K. Miwa, M. Aoki, T. Noritake, N. Ohba, Y. Nakamori, S. I. Towata, A. Zuttel, and S. I. Orimo, Phys. Rev. B 74, 155122 (2006).

${ }^{10}$ J. J. Reilly and R. H. Wiswall, Inorg. Chem. 7, 2254 (1968).

${ }^{11}$ J. J. Vajo, S. L. Skeith, and F. Mertens, J. Phys. Chem. B 109, 3719 (2005).

${ }^{12}$ Phase Diagrams of Binary Hydrogen Alloys, edited by F. D. Manchester (ASM, Materials Park, OH, 2000).

${ }^{13}$ S. V. Alapati, J. K. Johnson, and D. S. Sholl, J. Phys. Chem. B 110, 8769 (2006).

${ }^{14}$ B. Bogdanović and M. Schwickardi, J. Alloys Compd. 253-254, 1 (1997).

${ }^{15}$ W.-Q. Deng, X. Xu, and W. A. Goddard, Phys. Rev. Lett. 92, 166103 (2004).

${ }^{16}$ Y. Zhao, Y.-H. Kim, A. C. Dillon, M. J. Heben, and S. B. Zhang, Phys. Rev. Lett. 94, 155504 (2005).
${ }^{17}$ T. Yildirim and S. Ciraci, Phys. Rev. Lett. 94, 175501 (2005).

${ }^{18}$ H. Lee, W. I. Choi, and J. Ihm, Phys. Rev. Lett. 97, 056104 (2006).

${ }^{19}$ Q. Sun, P. Jena, Q. Wang, and M. Marquez, J. Am. Chem. Soc. 128, 9741 (2006).

${ }^{20}$ G. Kresse and J. Furthmüller, Phys. Rev. B 54, 11169 (1996).

${ }^{21}$ P. E. Blöchl, Phys. Rev. B 50, 17953 (1994).

${ }^{22}$ J. P. Perdew, J. A. Chevary, S. H. Vosko, K. A. Jackson, M. R. Pederson, D. J. Singh, and C. Fiolhais, Phys. Rev. B 46, 6671 (1992).

${ }^{23}$ D. C. Wallace, Thermodynamics of Crystals (Wiley, New York, 1972).

${ }^{24}$ S. Wei and M. Y. Chou, Phys. Rev. Lett. 69, 2799 (1992).

${ }^{25}$ C. Wolverton, V. Ozoliņš, and M. Asta, Phys. Rev. B 69, 144109 (2004).

${ }^{26}$ D. J. Siegel, C. Wolverton, and V. Ozoliņš, Phys. Rev. B 75, 014101 (2007).

${ }^{27}$ C. Wolverton and V. Ozolins, Phys. Rev. B 75, 064101 (2007).

${ }^{28}$ S. Satyapal, J. Petrovic, C. Read, G. Thomas, and G. Ordaz, Catal. Today 120, 246 (2007).

${ }^{29}$ M. W. Chase, Jr., NIST-JANAF Thermochemical Tables, 4th ed. (American Chemical Society, Washington, DC 1998).

${ }^{30}$ A. Sudik (private communication).

${ }^{31}$ D. J. Siegel, V. Ozolins, and C. Wolverton, Phys. Rev. B (unpublished).

${ }^{32}$ S. V. Alapati, J. K. Johnson, and D. S. Sholl, Phys. Chem. Chem. Phys. 9, 1438 (2007).

${ }^{33}$ Experimental testing of hydrogen-storage materials-many of which are air sensitive_can be a slow, painstaking process. For example, an equilibrium measurement of the extent of hydrogen 
desorption or uptake at a single temperature may require several months to complete in kinetically hindered materials (Ref. 30). In contrast, the first-principles thermodynamic calculations presented here (encompassing more than 20 unique reactions) were completed in 2-3 weeks.

${ }^{34}$ This discussion assumes that the entropies of all competing reaction pathways are similar. Our results in Table I show that this is generally not the case; generalization of the above guidelines to the free energies is straightforward and will be presented elsewhere (Ref. 31).

${ }^{35}$ We neglect the $\mathrm{LiBH}_{4}$ structural transition at $T_{s} \sim 108{ }^{\circ} \mathrm{C}^{5}$, which should reduce the slope of the data in Fig. 1 for $T>T_{s}$.

${ }^{36}$ It should be noted that the high cost of Sc may preclude its use in practical applications.

${ }^{37}$ This reaction was also reported in Ref. 32 . 